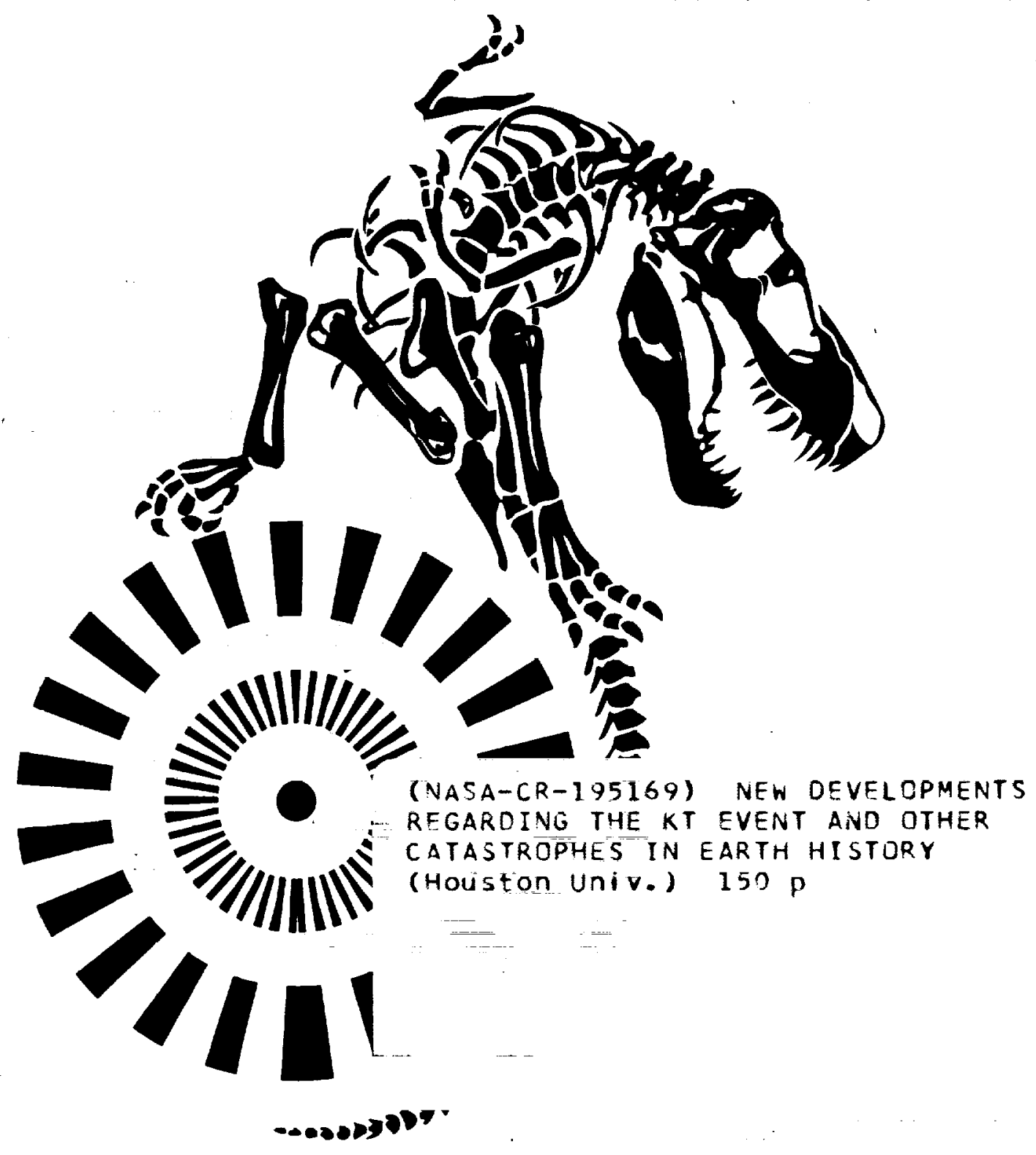

N94-28294

- THRU--

N94-28314

Unclas

$63 / 46$

0208810

PAPERS PRESENTED to

New Developments Regarding the KT Event and Other Catastrophes in Earth History

FEBRUARY 9-12, $1994 \cdot$ HoUSTON, TEXAS 
PAPERS PRESENTED TO

\title{
NEW DEVELOPMENTS REGARDING THE KT EVENT AND OTHER CATASTROPHES IN EARTH HISTORY
}

\author{
February 9-12, 1994
}

Houston, Texas
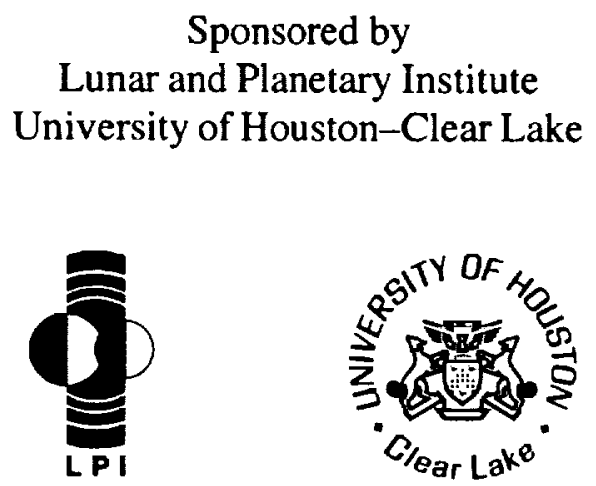

LPI Contribution No. 825 


\section{Compiled in 1994 by LUNAR AND PLANETARY INSTITUTE}

The Institute is operated by the University Space Research Association under Contract No. NASW-4574 with the National Aeronautics and Space Administration.

Material in this volume may be copied without restraint for library, abstract service, education, or personal research purposes; however, republication of any paper or portion thereof requires the written permission of the authors as well as the appropriate acknowledgment of this publication.

This report may be cited as

Author A. B. (1994) Title of abstract. In New Developments Regarding the KT Event and Other Catastrophes in Earth Hisiory. LPI Contribution No. 825, Lunar and Planetary Institute, Houston. 138 pp.

This report is distributed by

ORDER DEPARTMENT

Lunar and Planetary Institute 3600 Bay Area Boulevard

Houston TX 77058-1113

Mail order requestors will be invoiced for the cost of shipping and handling. 


\section{Preface}

This volume contains papers that have been accepted for presentation at the conference on New Developments Regarding the KT Event and Other Catastrophes in Earth History, February 9-12, 1994, in Houston, Texas. The Program Committee consisted of W. Alvarez (University of California, Berkeley), D. Black (Lunar and Planetary Institute), J. Bourgeois (National Science Foundation), K. Burke (University of Houston), R. Ginsburg (University of Miami), G. Keller (Princeton University), C. Koeberl (University of Vienna), J. Longoria (Florida International University), G. Ryder (Lunar and Planetary Institute), V. Sharpton, convener (Lunar and Planetary Institute), H. Sigurdsson (University of Rhode Island), R. Turco (University of California, Los Angeles), and P. Ward (University of Washington). The Scientific Organizing Committee consisted of W. Alvarez (University of California, Berkeley), D. Black (Lunar and Planetary Institute), K. Burke (University of Houston), R. Ginsburg (University of Miami), L. Hunt (National Academy of Sciences), G. Keller (Princeton University), L. Marín (UNAM, cd. Universitaria), D. Raup (University of Chicago), V. Sharpton (Lunar and Planetary Institute), E. Shoemaker (U.S. Geological Survey, Flagstaff), and G. Suarez (UNAM, cd. Universitaria).

Logistics and administrative and publications support were provided by the Publications and Program Services Department staff at the Lunar and Planetary Institute. 


\section{Contents}

Mineralogical Correlations of Near-KT-Boundary Deposits in Northeastern Mexico:

Evidence for Long-Term Deposition and Volcanoclastic Influence

T. Adatte, W. Stinnesbeck, and G. Keller 1

Trajectories of Ballistic Impact Ejecta on a Rotating Earth

W. Alvarez

Developments in the KT Impact Theory Since Snowbird II

W. Alvarez, F. Asaro, P. Claeys, J. M. Grajales-N., A. Montanari, and J. Smit

Impact Materials Recovered by Research Core Drilling in the Manson Impact

Structure, Iowa

R. R. Anderson, B. J. Witzke, and J. B. Hartung.

Testing KT Extinction Hypotheses Using the Vertebrate Fossil Record

J. D. Archibald

Seymour Island: A Southern High-Latitude Record Across the KT Boundary

R. A. Askin, D. H. Elliot, S. R. Jacobson, F. T. Kyte, X. Li, and W. J. Zinsmeister

Stable Carbon Isotopic Evidence for Cretaceous Planktic Species Survivorship and Reworking

E. Barrera and B. T. Huber 8

The KT Boundary Along the Brazos River, Falls County, Texas: Multidisciplinary

Stratigraphy and Depositional Environment

D. Beeson, S. Gartner, G. Keller, N. MacLeod, J. Medus, R. Rocchia,

and E. Robin

KT Boundary in Deccan Intertrappeans: Chemical Anomalies and Their Implications

N. Bhandari, P. N. Shukla, Z. G. Ghevaria, and S. M. Sundaram

Geochemical Constraints on the Composition of Volatiles Released During

the Formation of KT Impact Melts: Implications for Extinction Mechanisms

J. D. Blum and C. P. Chamberlain.

Debris Flow/Turbidite Clastic Units at the KT Boundary, Northeastern Mexico

B. F. Bohor and W. J. Betterton

Axial Focusing of Impact Energy in the Earth's Interior: Proof-of-Principle Tests of a New Hypothesis

M. B. Boslough, E. P. Chael, T. G. Trucano, M. E. Kipp, and D. A. Crawford 14 
Tsunami Deposits and the KT Boundary: A Sedimentologist's Perspective

New Evidence for Terrestrial Ecosystem Collapse at the KT and Permian/Triassic Boundaries

H. Brinkhuis and H. Visscher

Rift-flooding Episodes Around $65 \mathrm{Ma}$ as Causes of Abrupt Sea-Level Falls: Did the KT Impact Happen During a Time of Frequent Catastrophes?

K. Burke

In Search of Nemesis

S. Carlson, T. Culler, R. A. Muller, M. Tetreault, and S. Perlmutter

New Mineralogical and Chemical Constraints on the Nature of Target Rocks at the Chicxulub Crater

E. Cedillo P., P. Claeys, J. M. Grajales-N., and W. Alvarez

Sulfur Isotope Study of High-Calcium Impact Glasses from the KT Boundary M. Chaussidon, H. Sigurdsson, and N. Metrich

Frasnian-Famennian Boundary: Mass Extinctions, Anoxic Oceans, Microtektite

Layers, But Not Much Iridium?

P. Claeys, F. T. Kyte, and J.-G. Casier

The KT Boundary Extinction: A Geologically Instantaneous or Gradual Event?

Evidence from Deep-Sea Benthic Foraminifera

R. Coccioni and S. Galeotti

The KT Boundary in the Southeastern Pyrenees, Ager Basin, Northeast Spain

(Lleida Province)

F. Colombo

The Influence of Large Igneous Provinces on Mass Extinctions: Where Do We Stand?

V. Courtillot, J. J. Jaeger, and G. Féraud

Bone Beds at the Boundary: Are They a Realistic Expectation?

A. H. Cutler and A. K. Behrensmeyer

Impacts, Extinctions, Volcanism, Glaciations, and Tectonics: Matches and Mismatches

I. W. D. Dalziel

Sulfate Volatilization, Surface-Water Acidification, and Extinction at the KT Boundary

S. D' Hondt, H. Sigurdsson, A. Hanson, S. Carey, and M. Pilson 
Biological Changes at the KT Stratotype of El Kef (Tunisia)

P. Donze, H. Méon, R. Rocchia, E. Robin, and L. Froget

Shallow Benthic Fauna: Their Extinction and Survival on the KT Boundary, Adriatic Platform, Slovenia

K. Drobne, B. Ogorelec, W. Lowrie, and E. Marton

The End-Permian Mass Extinction: A Complex, Multicausal Extinction

D. H. Erwin 33

New Evidence for Primary Fractionation of Ruthenium and Iridium in the Chicxulub Ejecta Cloud

N. J. Evans, T. J. Ahrens, B. I. A. McInnes, and D. C. Gregoire

Habitat vs. Asteroid Fragmentation in Vertebrate Extinctions at the KT Boundary:

The Good, the Bad, and the Untested

D. E. Fastovsky and P. M. Sheehan 36

A 74.5-m.y. Stress Schedule and Its Reflection in the Stratigraphic Periods

A. G. Fischer and N. Kitz

Biozonation of the Beloc Formation and Its Relation to the Chronology

of the KT Boundary Event

J.-M. Florentin, R. Maurrasse, and L. J. Geier 38

Organic Matter Changes Across Nonmarine KT Boundary Sections

A. F. Gardner, I. P. Wright, and I. Gilmour 38

Coccolithophore Extinction at the KT Boundary: Gradual or Abrupt

S. Gartner, J. Alcala, and E. Grossman

Preliminary Results Regarding the Formation Conditions of Meteoric Spinels

J. Gayraud, E. Robin, R. Rocchia, and L. Froget

Diamonds, Soot, and Molecules: The Geochemistry of Carbon at the KT Boundary

I. Gilmour and W. S. Wolbach

Results of Blind Tests to Resolve Controversies: Iridium at Gubbio; Extinctions at El Kef

R. N. Ginsburg, F. Asaro, M. Attrep Jr., J. I. Canudo, J. H. Crocket, U. Krähenbühl, B. Masters, H. T. Millard Jr., R. K. Olsson, C. J. Orth, $X$. Orue-etxebarria, L. R. Quintana, and R. Rocchia

Science Observed: The Mass-Extinction Debates

W. Glen 
Biostratigraphic Evidence of the KT Boundary in the Eastern Gulf Coastal Plain, North of the Chicxulub Crater

D. Habib

Elementary Carbon Associated with Volcanic Eruptions: Relevance for the KT Boundary Problem

H. J. Hansen

Cyclochronologic Approaches to KT Events

T. D. Herbert, A. G. Fischer, and S. L. D'Hondt

Search for Extractable Fullerenes in Clays from the KT Boundary of the Woodside

Creek and Flaxboume River Sites, New Zealand

D. Heymann, W. S. Wolbach, L. P. F. Chibante, and R. E. Smalley

The Chicxulub Crater and Its Relation to the KT Boundary Ejecta and Impact-Wave Deposits

A. R. Hildebrand, F. Asaro, M. Attrep Jr., J. C. Bermúdez-Santana, S. Bonis,

E. Cedillo-Pardo, P. Claeys, V. Gonzalez-Casildo, J. M. Grajales-Nishimura,

D. C. Grégoire, C. Ortiz-Aleman, M. Pilkington, M. A. Sánchez-Rios, J. Smit,

and J. A. Stansberry

Consequences of Impacts of Small Asteroids and Comets with Earth

J. G. Hills.

Estimation of the Measures of the Chicxulub Cratering Event

K. A. Holsapple

Carbonate-derived Gases in Haitian KT Boundary Glass Spherules

R. M. Hough, H. Sigurdsson, I. A. Franchi, I. P. Wright, C. T. Pillinger,

and I. Gilmour

Gaia, Cambrian Explosion, and KT Catastrophe

K. J. Hsü, G. Shields, and D. Hollander

Shock Degassing of Sedimentary Rocks Due to the Chicxulub Impact:

Hydrocode Simulation

B. A. Ivanov, D. D. Badukov, and O. I. Yakovlev

Eocene Age of the Kamensk Buried Crater of Russia

G. A. Izett, V. L. Masaitis, E. M. Shoemaker, G. B. Dalrymple,

and $M$. B. Steiner

Mass Extinctions: Persistent Problems and New Directions

D. Jablonski 
Global Biotic Effects of the KT Boundary Event: Mass Extinction Restricted

to Low Latitudes?

G. Keller

The KT Boundary Stratotype Section at El Kef, Tunisia: How Catastrophic

Was the Mass Extinction?

G. Keller, L. Li, and N. MacLeod

On Source and Origin of Haitian KT Boundary Impact Glasses

C. Koeberl

Re-Os Isotope Systematics as a Diagnostic Tool for the Study of Impact Craters

C. Koeberl, S. B. Shirey, and W. U. Reimold

Characterization of Organic Material in KT Boundary Strata, Arroyo

El Mimbral, Mexico

M. A. Kruge, J. C. Crelling, A. Montanari, B. A. Stankiewicz,

and D. F. Bensley .

The KT Boundary on the Pacific Plate

F. T. Kyte, J. A. Bostwick, and L. Zhou.

A Short Normal Magnetic Interval at the KT Boundary: A Measure of Continuity

of Record Across the Boundary and Synchroneity of Boundary Events

J. F. Lerbekmo and A. R. Sweet

The Pliensbachian/Toarcian (Lower Jurassic) Extinction Event

C. Little

Patterns of Planktonic Foraminifer Extinction at the End of Cretaceous: Stepwise,

Gradual, Foreshadowed/Extended, Latitudinal Controlled, or Instantaneous?

C. Liu and R. K. Olsson

KT Phenomena in the Context of Tectonic Seafloor Rearrangements

Y.-G. Liu and R. A. Schmitt

Biotic Effects of the KT Boundary Event in Northeastern Mexico

J. G. Lopez-Olivia and G. Keller.

The Biostratigraphy and Paleogeography of Maastrichtian Inoceramids

K. G. MacLeod, B. T. Huber, and P. D. Ward

An Evaluation of Criteria that May be Used to Identify Species Surviving

a Mass Extinction

N. MacLeod 
The "Upper Cretaceous Unit" in the Chicxulub Multiring Basin: New Age Based on Planktic Foraminiferal Assemblage

L. E. Marín, V. L. Sharpton, J. Urrutia-Fucugauchi, P. Sikora, and C. Carney 77

Modulating Terrestrial Impacts from Oort Cloud Comets by the Adiabatically Changing Galactic Tides

J. J. Matese, P. G. Whitman, K. A. Innanen, and M. J. Valtonen 78

A Search for Tektite-Related Impact Structures in Northeastern Thailand: An Examination of SPOT Satellite Images

J. F. McHone Jr., K. Pitakpaivan, S. Bunopas, P. Angsuwathana, T. Supajanya, and J. T. Wasson.

Some Implications of Large Impact Craters and Basins on Venus for Terrestrial Ringed Craters and Planetary Evolution

W. B. McKinnon and J. S. Alexopoulos

Proposed Law of Nature Linking Impacts, Plume Volcanism, and Milankovitch Cycles to Terrestrial Vertebrate Mass Extinctions Via Greenhouse-Embryo Death Coupling

D. M. McLean

Preliminary Stratigraphy and Iridium and Other Geochemical Anomalies Across the KT Boundary in the Bochil Section (Chiapas, Southeastern Mexico)

A. Montanari, P. Claeys, F. Asaro, J. Bermudez, and J. Smit

Extraterrestrial Accretion and Glacial Cycles

R. A. Muller 85

A KT Boundary Section from Northern Belize

A. C. Ocampo and K. O. Pope

On the Reality of the KT Boundary

$R$. K. Olsson and C. Liu.

An Extraterrestrial Event at the Tertiary-Quaternary Boundary

H. Peng 88

Footprints in the Rocks-New Evidence from the Raton Basin that Dinosaurs

Flourished on Land Until the Terminal Cretaceous Impact Event C. L. Pillmore, M. G. Lockley, R. F. Fleming, and K. r. Johnson 89

Calcareous Nannofossils and the KT Boundary Crisis: An Update J. J. Pospichal 
Cyclostratigraphy of the KT Boundary Section on the Coast of the Black Sea Near Bjala(Bulgaria)

Event-, Bio-, and Magnetostratigraphy of the KT Boundary Sections

in the East Balkan Area, Bulgaria

A. Preisinger and S. Aslanian....

A General Theory of Impacts and Mass Extinctions, and the Consequences

of Large-Body Impact on the Earth

M. R. Rampino

Hydrothermal Witwatersrand Gold Mineralization Caused by the Vredefort

Mega-Impact Event?

W. U. Reimold.

Can an Extraterrestrial Impact Event Explain the Pattern of Biotic Crisis Near the KT Boundary?

J. K. Rigby Jr., G. P. Landis, and R. A. Hengst

Characteristics and Origin of Spinel-bearing Spheroids at the KT Boundary

E. Robin, J. Froget, J. Gayraud, R. Rocchia, and L. Turpin

On the Origin of Regional Variations in Spinel Compositions at the KT Boundary

E. Robin, J. Gayraud, L. Froget, and R. Rocchia

Stratigraphical Distributions of Cosmic Markers at the KT Boundary in the Caribbean Area

R. Rocchia, L. Froget, E. Robin, and J. Gayraud

Ni-rich Spinels (Meteoric Spinels) as Indicators of the KT Event Timing

R. Rocchia, E. Robin, L. Froget, and J. Gayraud

Dinosaurs Within the History of Multicellular Organisms

D. A. Russell

KT Boundary: Historical Context, Counter-Revolutions, and Strawmen

G. Ryder.

Geochemical Record of the KT Event in Dinosaurian Remains from Mongolia

V. S. Samoylov and Ch. Benjamini

Visualizing the Nature and Consequences of the Chicxulub Impactor: Clues

from Venus

P. H. Schultz 
Siderophile-Element Distribution in Chicxulub Melt Rocks: Forensic Chemistry on the KT Smoking Gun

B. C. Schuraytz and V. L. Sharpton 106

The Chicxulub Multiring Basin: Evaluation of Geophysical Data, Well Logs, and Drill Core Samples

V.L. Sharpton, L. E. Marín, and B. C. Schuraytz 108

Were all Extinction Events Caused by Impacts?

P. M. Sheehan and P. J. Coorough

Ozone Control of Biological Activity During Earth's History, Including the KT Catastrophe

$W$. R. Sheldon

The Crash of P/Shoemaker-Levy 9 Into Jupiter and Its Implications for Comet Bombardment on Earth

E. M. Shoemaker and C.S. Shoemaker

Crystals, Lithics, and Glassy Ejecta at the KT Boundary: Implications for Lithology of the Crust at the Impact Site

H. Sigurdsson, S. Smith, S. D'Hondt, S. Carey, and J.-M. Espindola

Misunderstandings Regarding the KT Boundary Deposits in the Gulf of Mexico

J. Smit, W. Alvarez, P. Claeys, S. Montanari, and Th. B. Roep

Impact-Tsunami-generated Clastic Beds at the KT Boundary of the Gulf Coastal

Plain: A Synthesis of Old and New Outcrops

J. Smit, Th. B. Roep, W. Alvarez, P. Claeys, S. Montanari, and M. Grajales

Stratigraphy and Sedimentology of KT Clastic Beds in the Moscow Landing (Alabama)

Outcrop: Evidence for Impact Related Earthquakes and Tsunamis

J. Smit, Th. B. Roep, W. Alvarez, S. Montanari, and P. Claeys

KT Boundary Sections in Southern Mexico (Chiapas): Implications

for the Proposed Chicxulub Impact Site

W. Stinnesbeck, T. Adatte, and G. Keller

KT Boundary Deposits in Northeastern Mexico: Bolide Impact or Sea-Level

Lowstand?

W. Stinnesbeck, G. Keller, and T. Adatte

Northern Meteoritic Impacts and Southern Volcanic Mantle Plumes: Their Roles in Generating Some Differential KT Boundary Extinction Environments

F. L. Sutherland 
Numerical Simulation of Impact Cratering at Chicxulub and the Possible Causes of KT Catastrophe

T. Takata and T. J. Ahrens

Reverse-Polarity Magnetized Melt Rocks from the KT Chicxulub Structure, Yucatan Peninsula, Mexico

J. Urrutia-Fucugauchi, L. Marín, and V. L. Sharpton

Supernovae and Mass Extinctions

$S$. van den Bergh

Dissecting the KT Extinction: Components and Comparisons with the Permo-Triassic and "Modern" Mass Extinctions

P. D. Ward

Catastrophic Alamo Breccia, Upper Devonian, Southeastern Nevada

J. E. Warme

Where are the Chicxulub Coarse-grained, Igneously Layered Impact Melt Rocks

Analogous to Those at Sudbury?

P. H. Warren, P. Claeys, and E. Cedillo-Pardo

A Search for Shocked Grains in the KT Boundary at Braggs, Alabama

S. Y. Wdowiak, T. J. Wdowiak, D. C. Gillis, and M. Dudley.

The Frasnian-Famennian Extinction Event: Dominance of Extrinsic Over Intrinsic

Factors in the Recovery of Reef Communities

G. E. Webb

The Permian-Triassic of the Gartnerkofel-1 Core (Carnic Alps, Austria): Organic

Carbon Isotope Variation

W. S. Wolbach, D. R. Roegge, and I. Gilmour

Antarctica, the Forgotten Stepchild: A View of KT Extinction from

the High Southem Latitudes

W. J. Zinsmeister and R. M. Feldmann

Author Index 


\section{Abstracts}

\begin{abstract}
anit
MINERALOGICAL CORRELATIONS OF NEAR-KT. BOUNDARY DEPOSITS IN NORTHEASTERN MEXICO: EVIDENCE FOR LONG-TERM DEPOSITION AND VOLCANOCLASTIC INFLUENCE. T. Adatte ${ }^{1}$, W. Stinnesbeck ${ }^{2}$, and G. Keller ${ }^{3}$, 'Institut de Géologie, II rue Emile Argand, 2007 Neuchâtel, Switzerland, 'Facultad de Ciencias de la Tierra, Universidad Autónoma de Nuevo León, Ap. Postal 104, 67700 Linares, N.L. Mexico, ${ }^{3}$ Department of Geological and Geophysical Sciences, Princeton University, Princeton NJ 08544, USA.
\end{abstract}

Whole-rock and clay-mineral analyses of five near-KT-boundary clastic deposits in NE Mexico indicate three lithologically and mineralogically distinct and correlatable units similar to those outlined based on lithological correlations [1,2]. The examined sections span a north-northwest to south-southeast transect and include: La Sierrita, EI Peñon, El Mulato, La Lajilla, and El Mimbral (Fig. 1). Two sections have been analyzed at Mimbral: in the channel center and at its edge. Whole-sock and clay-mineral compositions have been determined by XRD, using the methods of Kubler [3].

Unit 1, which disconformably overlies the Mendez Formation is lithologically defined as a poorly cemented, spherule-rich layer characterized by high calcite (50-70\%, Fig. 2) and low phyllosilicate contents $(<20 \%)$, quartz, and plagioclase (albite, $5 \%)$. However, the composition of the sandy limestone layer (SLL) of unit 1 is significantly different with lower calcite, higher quartz, and plagioclase. This change in whole-rock content indicates a different detrital influx during deposition of these spherule-rich sediments $[1,2]$. The massive laminated sandstone of unit 2 is characterized by low calcite $(20-40 \%)$ and phyllosilicate contents and a significant increase in quartz (up to 40\%) and plagioclase (albite, 15-25\%). Whole-rock composition of unit 3 reflects the lithological variations within this unit (including sandstone, sandy limestone, silts, and

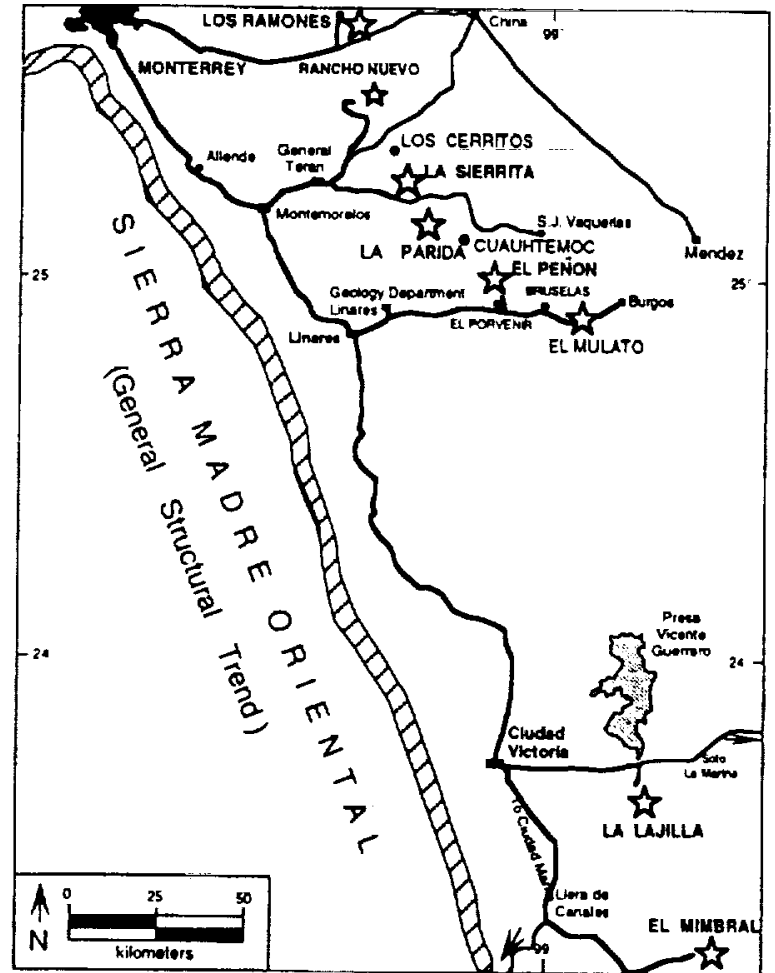

Fig. 1. Location of sections studied

marly intervals) with high variations in calcite (generally higher than in unit 2), quartz, plagioclase, and phyllosilicates.

Zeolites (clinoptilolite) have been recognized near the base and the top (below the rippled sandy limestone) of unit 3 in all sections

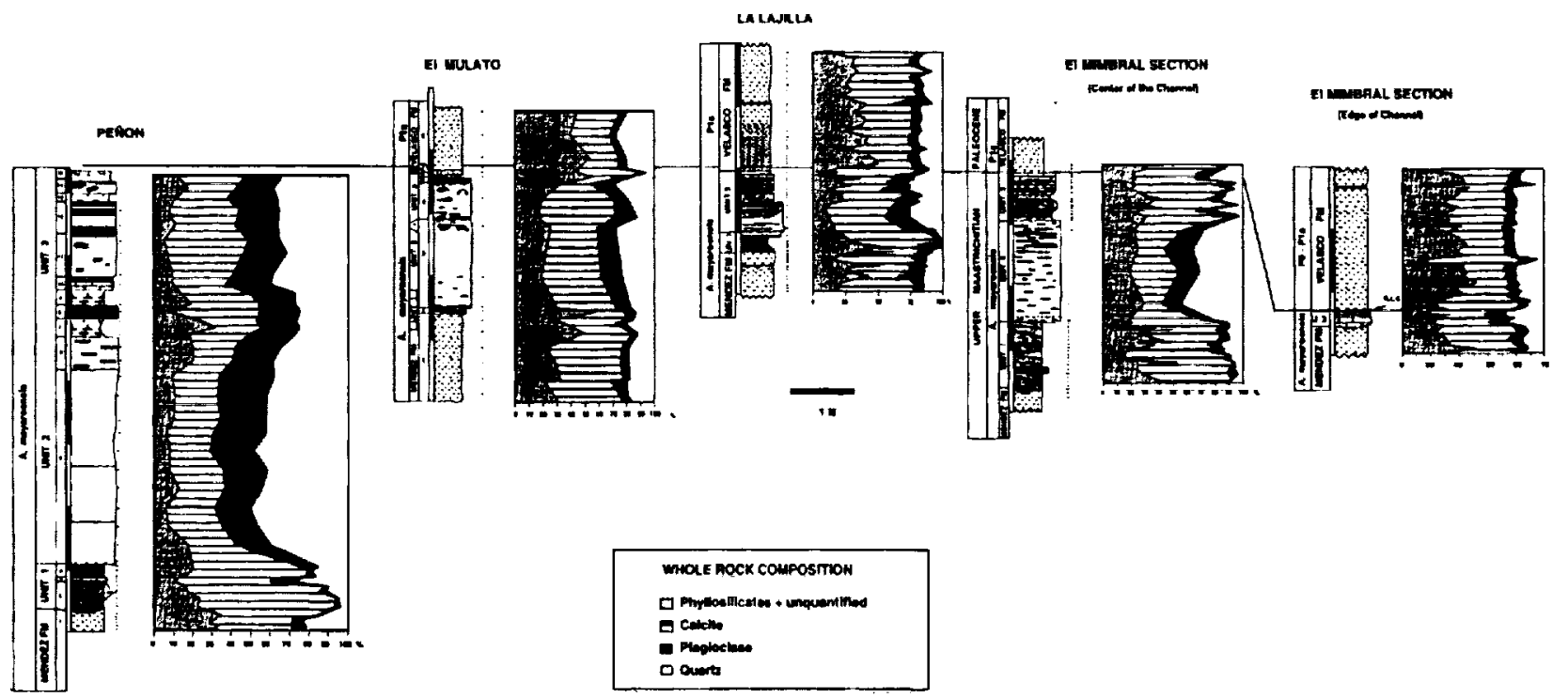

Fig. 2. Whole-rock compositions and correlation of KT boundary sections studied. 


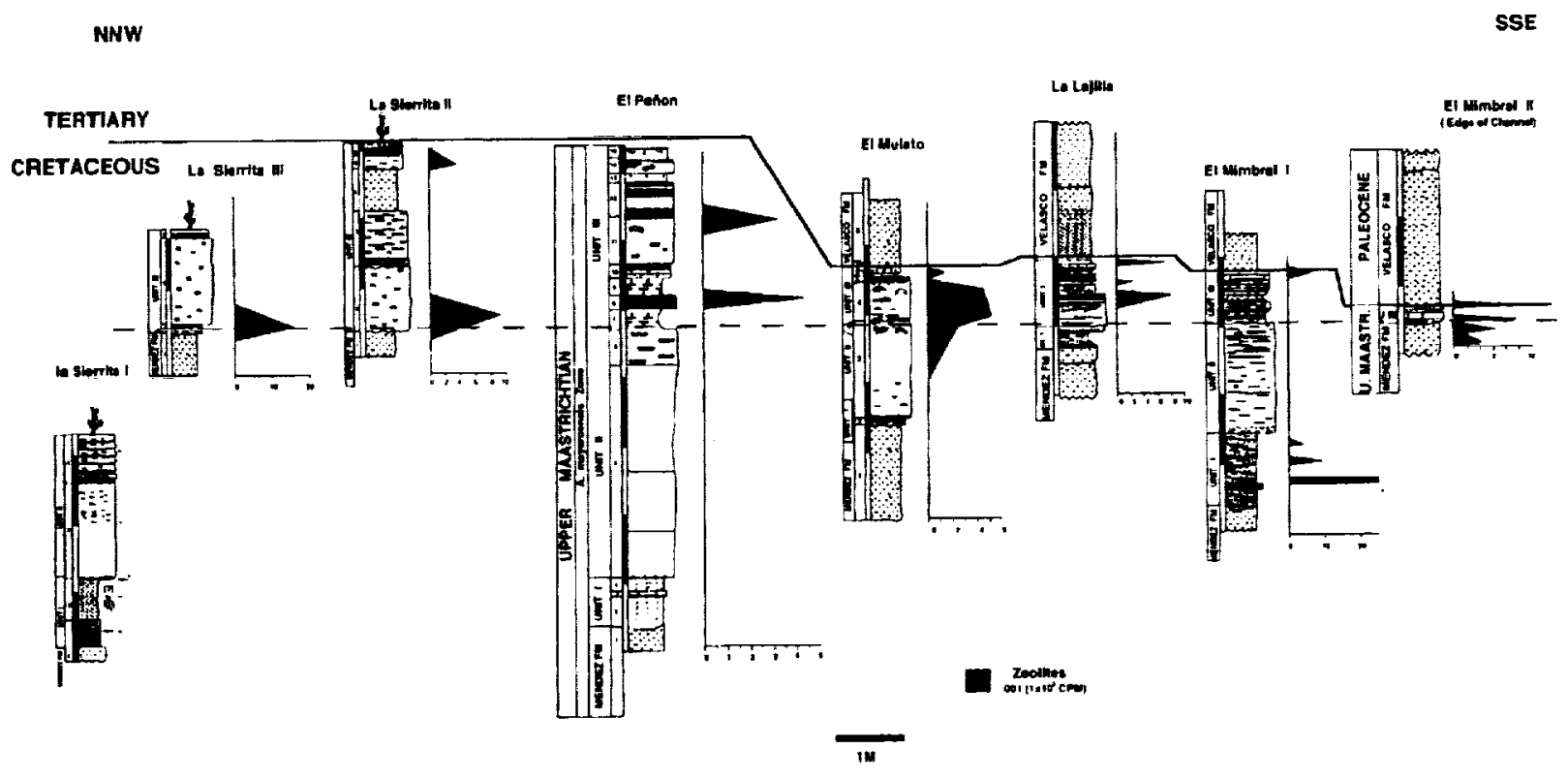

Fig.3. Zeolite-enriched layers and their stratigraphic correlation in north-eastem Mexico.

(Fig. 3). These zeolite occurrences are of detrital origin and mainly present in the size fraction 2-16 $\mu \mathrm{m}$. Zeolites, as well as $\mathrm{Mg}$ smectites, are generally considered an alteration product of volcanic terranes and become abundant from Campanian to Eocene times [4]. In the southeastem sections of El Mimbral, significant enrichment in zeolites is also observed in the boundary clay, the spherule-rich layer of unit 1 , as well as in the underlying marls of the Mendez Formation $[1,2]$. These additional layers, enriched in zeolites compared to the northwestern sections, imply an increase of volcanoclastic influx toward the south-southeast, prior to and across the KT boundary.

Illite-smectite mixed layers characterized by low contents of smectite $(<30 \%)$, are present in all lithologies in the La Sierrita, El Peñon, and ElMulato sections; however, they increase in the Mendez Formation, Velasco Formation, and in the silt-marl intervals of unit 3. Random chlorite-smectite mixed layers, characterized by higher contents in smectite layers ( $>40 \%$ ), are common in the sphenle-rich unit 1 and in the silt-marl intervals of unit 3 ; similar layers with lower values are present in unit 2 . The increase of mixed layers in units $I$ and 3 is similar to mixed layers in the Mendez and Velasco Formations and reflect periods of normal pelagic sedimentation. Chlorite and mica increase in the massive sandstone of unit 2 , relative to units $I$ and 2 , indicating an increase in detrital influx and probably more rapid deposition. Chlorite and mica contents are variable in unit 3 , but also increase in the sandstone layers. As al ready implied by the mixed-layer distribution, unit 3 represents a depositional environment that alternates between increased detrital influx and rapid deposition (silt-sandstone layers) and hemipelagic deposition (shale-marl layers). Based on these observations we conclude

1. Mineralogically and lithologically distincts units, which are correlatable over $300 \mathrm{~km}$ and represent variable detrital influx alternating with normal hemipelagic sedimentation, are incompatible with a Chicxulub impact-generated tsunami deposit.

2. The presence of distinct and correlatable layers enriched in zeolites in the channel-fill clastic deposits as well as the Mendez
Formation and Velasco Formation indicates significant volcanoclastic influx during these times.

3. Dominant mixed/layer chlorite-mica assemblages, which derive from direct and mechanical erosion of bedrock, reflect tectonic instability and/or a sea-level lowstand that increased active erosion of local bedrock.

4. There is no important change in clay-mineral compositions across the KT boundary in the northeastern Mexico sections. Kaolinite, which is abundant in the Mendez Formation (but absent in the KT boundary deposits) suggests a change during the middle to Late Maastrichtian or active erosion due to tectonic instability preventing the development of soils enriched in kaolinite.

References: [1] Stinnesbeck W. et al. (1993) Geology, 2l, 797-800. [2] Stinnesbeck W. et al., this volume. [3] Kubler B. (1987) Cahiers Inst. Geol. Neuchatel, Suisse Série AX, 13. [4] Roben C. (1982) Ph.D. Thesis, Fac. Science, Univ. Marseille, France, 136.

\section{S.-46 ABS. OWLY}

N94- 28295

\section{TRAJECTORIES OF BALLISTIC IMPACT EJECTA ON A}

ROTATING EARTH. W. Alvarez, Department of Geology and Geophysics, University of California, Berkeley CA 94720, USA.

On an airless, slowly rotating planetary body like the Moon, ejecta particles from an impact follow simple ballistic trajectories. If we ignore gaseous interactions in the fireball, ejecta particles follow elliptical orbits with the center of the planetary body at one focus until they encounter the surface at the point of reimpact. The partial elliptical orbit of the ejecta particle lies in a plane in inertial (galactic) coordinates. Because of the slow rotation rate (for example, $360^{\circ} / 28$ days for the Moon), the intersection of the orbital plane and the surface remains nearly a great circle during the flight time of the ejecta. For this reason, Iunar rays, representing concentrations of ejecta with the same azimuth but different velocities and or ejection angles, lie essentially along great circles. 
Ejecta from airless but more rapidly rotating bodies will follow more complicated, curving trajectories when plotted in the coordinate frame of the rotating planet or viewed as rays on the planetary surface. The curvature of trajectories of ejecta particles can be treated as a manifestation of the Coriolis effect, with the particles being accelerated by Coriolis pseudoforces. However, it is more straightforward to calculate the elliptical orbit in inertial space and then determine how far the planet rotates beneath the orbiting ejecta particle before reimpact.

The Earth's eastward rotation affects ballistic ejecta in two ways: (1) the eastward velocity component increases the velocity of eastbound ejecta and reduces the velocity of westbound ejecta; and (2) the Earth tums undemeath inflight ejecta, so that although the latitude of reimpact is not changed, the longitude is displaced westward, with the displacement increasing as a function of the time the ejecta remains aloft.

Low-velocity ejecta reimpacts so quickly that the second effect is small. However, at ejection velocities above about $9 \mathrm{~km} / \mathrm{s}$ and approaching escape velocity $(11.2 \mathrm{~km} / \mathrm{s})$, the semimajor axis and the related height of apogee increase rapidly, and the time aloft may be measured in hours. In such cases, effect (2) becomes important. For example, ejecta particles sent eastward at an elevation angle of $45^{\circ}$ from an equatorial impact at a velocity of about $10 \mathrm{~km} / \mathrm{s}$ reach an apogee of $>6$ Earth radii and stay aloft for about $8 \mathrm{hr}$, during which time the Earth turns far enough for the ejecta to reimpact close to the site from which they were launched. Under similar conditions, but at a velocity of $10.5 \mathrm{~km} / \mathrm{s}$, the ejecta reach an apogee of 16 Earth radii and stay aloft for $34 \mathrm{hr}$. During that time the ejecta, seen from the Earth, make a complete rotation around the Earth, backward! At still higher velocities (but below escape velocity), the ejecta make multiple retrograde rotations.

Calculations still in progress suggest that because of this effect there may be a forbidden zone beyond about $90^{\circ}$ east of the impact site, which cannot be directly reached by eastbound ejecta. If so, this will make a prediction that can be tested by mapping the size and column density of ejecta (spherules and shocked quanz) in the KT boundary layer.

Interactions between the atmospheric density gradient and the expanding fireball of a large impact can accelerate ejecta to velocities approaching and probably exceeding escape velocity. Thus the effects described above are relevant. The time-aloft difference between low- and high-velocity ejecta may explain the double KT layer in the westem interior U.S. (a layer of altered melt ejecta overlain by a layer of shocked quartz, both of which appear to derive from Chicxulub). However, there are serious problems in explaining the failure of the shocked quartz (1) to melt and (2) to disperse, if it is interpreted as fast, high-trajectory ejecta.

The Earth's atmosphere complicates the calculation of ejecta trajectories in at least four ways: (1) At early stages in the evolution of the fireball, temperatures are sufficient to form a plasma, and electromagnetic interactions within the plasma distor the simple inertial trajectories that ejecta would otherwise follow. (2) Even after expansion of the fireball cools it to below plasma temperatures, thermal encounters in the fireball gases continue to distor the ballistic trajectories. (3) Low-velocity portions of the fireball may fall back close to the impact site, forming a base surge that expands radially on top of the normal atmosphere. (4) As ejecta particles settle through the atmosphere they will be carried laterally by winds for distances inversely related to the particle size.
The calculation of ballistic trajectories is an essential step in understanding ejecta distributions, but must be augmented by a fuller understanding of fireball-atmosphere dynamics under conditions that are difficult to calculate and have not been observed. The observational limitation may be partially overcome when the fragments of Comet Shoemaker-Levy impact Jupiter in July 1994. $\div$

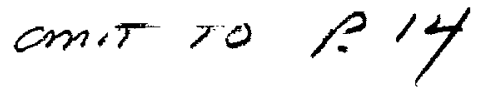

DEVELOPMENTS IN THE KT IMPACT THEORY SINCE SNOWBIRD II. W. Alvarez', F. Asaro', P. Claeys', J. M. Grajales-N. ${ }^{3}$, A. Montanari ${ }^{4}$, and J. Smit ${ }^{5}$, ${ }^{1}$ Department of Geology and Geophysics, University of Califomia, Berkeley CA 94720, USA, 'Lawrence Berkeley Laboratory, University of Califomia, Berkeley CA 94720, USA, ${ }^{3}$ Instituto Mexicanodel Petroleo, Apartado Postal 14-805, 07730 DF, Mexico, 4sservatorio Geologico di Coldigioco, 62020 Frontale di A piro (MC), Italy, ${ }^{5}$ Institute of Earth Sciences, Vrije Universiteit, de Boelelaan 1085, 1081 HV Amsterdam, The Netherlands.

At the second Snowbird conference, entitled "Global Catastrophes in Earth History: An Interdisciplinary Conference on Impacts, Volcanism, and Mass Mortality," held in October 1988, much of the discussion focused on criteria for choosing between the competing explanations-impact or volcanism-to account for the KT boundary mass extinction. Other participants argued that the paleontological record does nol support a rapid mass extinction, and that neither impact nor volcanism was needed to explain the biostratigraphic observations.

At Snowbird II, the proponents of volcanism struggled to explain the physical characteristics of the KT boundary stratum (shocked quartz, spherules, anomalous Ir), but pointed with confidence to the Deccan Traps as the volcanic center responsible for the extinction. In contrast, the proponents of impact could reasonably explain the physical features, but had no candidate crater of anywhere near sufficient size.

As members of the proimpact group, we present the following account of our perception of developments since Snowbird II, well aware that supporters of volcanism will see the matter differently.

Back at the time of the first Snowbird conference, Signor and Lipps [1] showed that an abrupt extinction studied with insufficient sampling of the fossils would appear gradual. Two major animal groups previously said to have died out gradually have recently been studied with heavy sampling and careful statistics (ammonites [2] and dinosaurs [3]) and their disappearences at the KT boundary are now seen to be indistinguishable from a sudden extinction. These cases are clear examples of the Signor-Lipps effect, and weaken the case for a gradual KT extinction.

The strongest improvement in the volcanist position has come from isotopic dating of the Deccan Traps, which yielded an age of $64.96 \pm 0.11 \mathrm{Ma}$ [4]. However, this date comes from a late intrusion cross-cutting the lavas, and earlier ages of $68.53 \pm 0.16 \mathrm{Ma}$ and $68.57 \pm 0.08 \mathrm{Ma}$ were measured on early volcanic alkalic complexes. Although the main pulse of volcanism may have occurred close to the KT boundary at $65 \mathrm{Ma}$, the Deccan Traps seem to have begun erupting well before the extinction, making a causal relationship less likely. Nevertheless, the near coincidence in timing is striking, keeping alive the possibility of some connection between the Deccan volcanism and the KT boundary event. 
It is probably fair to say that the case for explaining the physical characteristics of the KT stratum by volcanic processes is no stronger than it was in 1987. Around the time of Snowbird II, volcanists were reporting the occurrence of anomalous Ir, spherules, and shocked quartz in more than one horizon across the KT boundary at Gubbio which, if true, would falsify the derivation of these features from a single large impact, and better permit their attribution to volcanic sources. A blind sample investigation was organized to test whether these features are confined to the KT boundary bed alone. Although the results of the blind experiment have not yet been published, the results seem less critical now because of the recognition, in the interim, of a strong candidate crater in the subsurface of the Yucatan Peninsula, larger than any other impact crater known on Earth, and apparently dating precisely from the time of the KT boundary.

About the time of Snowbird II, the unusual clastic beds at the KT boundary of the Brazos River in Texas began to be interpreted as tsunami deposits [5], suggesting that the KT impact site might be located in the Gulf of Mexico-Caribbean region. Persistent searching [6] yielded various candidate sites, one of which-Chicxulubis now widely favored as the KT impact crater.

The Chicxulub crater was located by PEMEX geophysicists in the 1950s [7], drilled as a petroleum prospect, and abandoned when it was found to contain melt rocks that were interpreted as andesites. Penfield and Camargo [8] proposed in 1981 that it was an impact crater, but the suggestion lay dormant for 10 years, until Hildebrand et al. [9] proposed that Chicxulub was the long-sought KT impact site.

Recently located samples from the old PEMEX wells include breccias and crystalline rocks compatible with an impact origin but very difficult to explain by volcanic processes [10]. Single-crystal ${ }^{40} \mathrm{Ar} /{ }^{39} \mathrm{Ar}$ dating places the melt rock at $65.0 \mathrm{Ma}[11,12]$.

If Chic xulub is indeed a very large impact crater dating from KT boundary time, it should be surrounded by extensive deposits of impact ejecta and tsunami deposits. This is indeed the case, and the expected deposits have been located in many outcrops from the southem U.S. states of Alabama, Mississippi, and Texas, through the eastern Mexican states of Nuevo Leon, Tamaulipas, and Vera Cruz, and the State of Chiapas in southeastern Mexico, as well as in Haiti and in DSDP Leg 77 sites 536 and 540, between Yucatan, Cuba, and Florida. Many of these outcrops contain bubble-rich spherules with tektitelike morphology in a basal layer, overlain by a clastic bed with sedimentological characteristics strongly indicative of deposition by a large, complex tsunami event [13]. They are constrained by biostratigraphy to lie precisely at the KT boundary (unless the boundary is defined so as to force them to be slightly older [14]).

Many of the tsunami outcrops discussed above contain intense enrichments of the element Ir above background, a characteristic found worldwide at the KT boundary in more than 100 sites. The Ir distribution al Arroyo el Mimbral in Tamaulipas [15] shows several maxima near the top of the 3.2-m-thick tsunami deposit, in contrast to marine sections elsewhere that have a main Ir peak near the bottom of a typically $1-\mathrm{cm}$ KT boundary clay bed. Multiple peaking of the Ir and interlayering of different sized sediment fractions like sandstone and siltstone suggest that tidal-wave seiche activity was not over at the time the Ir peaks were being deposited, and so the latter may have occurred within a few days after the impact. This does not mean, a priori, that the Ir could not have been deposited somewhat earlier, since it could have been remobilized by the tsunami action. Calculations have shown, however, that a bolide large enough to cause the Chicxulub Crater would contain enough Ir to supply that found worldwide at the KT boundary, and that impact dynamics would distribute it worldwide. Although other sources for the KT Ir are possible, the Chicxulub impact is sufficient to produce all that has been observed, and to explain its stratigraphic distribution.

Glass has been recovered from the Beloc outcrop in Haiti [1618] and the Mimbral outcrop in Tamaulipas [15]. Two varieties are common: a black glass of roughly continental crust (or andesitic) composition, and a yellow glass rich in $\mathrm{Ca}$. The Haiti and Mimbral glasses give single-crystal ${ }^{41} \mathrm{Ar} /{ }^{39} \mathrm{Ar}$ ages of $65.0 \mathrm{Ma}$, exactly the same value as found for the Chicxulub melt rock. Isotopic studies by Blum and Chamberlain [19] demonstrated that the Haiti glass (1) has a strong variation in $\mathrm{O}$ isolopic composition that rules out a volcanic origin, and (2) has an isotopic and major-element composition that can be explained by melting of silicate basement and carbonate cover. In a follow-up study, Blum et al. [20] found an essentially perfect isotopic match between the Haiti glass and the Chicxulub melt rock.

Developments since Snowbird II have thus strengthened the case for the impact explanation for the KT boundary. An impact crater as large as [9] or larger than [21] any other on Earth has been discovered in the Yucatan Peninsula and radiometrically dated as of exactly KT boundary age. Ringing the Chicxulub Crater are clastic deposits apparently due to a giant tsunami and rich in tektite-shaped objects, some still containing glass. The glass has the isotopic characteristics of impact melt, matches the chemistry of Chicxulub, and gives radiometric dates of KT boundary age, and the clastic deposits lie at the biostratigraphic KT boundary. It would be hard to imagine a more dramatic confirmation of the essential prediction of the KT impact theory, that an appropriate crater should be found. Nevertheless, some recent authors totally reject this view [22-25]. These last papers represent the skepticism required for testing any scientific interpretation, but even though the testing is not yet complete, the impact theory must be considered to have been notably strengthened since Snowbird II. It is now essential to explore the Chicxulub Crater with the drill.

Dedication: This review is dedicated to the memory of S. V. Margolis. Stan contributed greatly to the developments described here, and we all miss him.

References: [1] Signor P. W. and Lipps J. H. (1982) GSA Spec. Paper 190, 291-296. [2] Ward P. D. et al. (1991) Geology, 19. 118]-1184. [3] Sheehan P. M. et al. (1991) Science, 254, 835-839. [4] Basu A. R. et al. (1993) Science, 261, 902-906. [5] Bourgeois J. et al. (1988) Science, 241, 567-570. [6] Hildebrand A. R. and Boynton W. V. (1989) GSA Abstr. with Prog., 21, A371; Hildebrand A. R. and Boynton W. V. (1990) LPS XXI, 512-513; Hildebrand A. R. and Boynton W. V. (1990) GSA Abstr. with Prog., 22, A280; Hildebrand A. R. and Boynton W. V. (1990) Eos, 71, 1424-1425; Hildebrand A.R. andPenfield G. T. (1990) Eos, 71, 1425. [7] Cornejo A. and Hemandez A. (1950) Bol. Asoc. Mex. Geol. Petroleros, 2 , 453-460. [8] Penfield G. T. and Camargo Z. A. (1981) Soc. Expl. Geophys. Tech. Prog., Abstr., Biogr., 51, 37. [9] Hildebrand A. R. et al. (1991) Geology, 19,867-871. [10] Cedillo E. et al., this volume. [11] Swisher C. C. III et al. (1992) Science, 257, 954-958. [12] Sharpton V. L. et al. (1992) Nature, 359, 819-822. [13] Smit J. et al., this volume. [14] Smit J. et al., this volume. [15] Smit J. 
et al. (1992) Geology, 20,99-103. [16] Izett G. A. et al. (1990) U.S. Geol. Surv. Open-File Rept. 90-635, 1-31. [17] Sigurdsson H. et al. (1991) Nalure, 349, 482-487. [18] Maurrasse F. J.-M. R. and Sen G. (1991) Science, 252, 1690-1693. [19] Blum J. D. and Chamberlain C. P. (1992) Science, 257, 1104-1107. [20] Blum J. D. et al. (1993) Nature, 364, 325-327. [21] Sharpton V. L. et al. (1993) Science, 26I, 1564-1567. [22] Lyons J. B. and Officer C. B. (1992) EPSL, 109, 205-224. [23] Jéhanno C. et al. (1992) EPSL, 109, 229 241. [24] Keller G. et al. (1993) Geology, 21, 776-780. [25] Stinnesbeck W. et al. (1993) Geology, 21, 797-800.

IMPACT MATERIALS RECOVERED BY RESEARCH CORE DRILLING IN THE MANSON IMPACT STRUCTURE, IOWA. R. R. Anderson ', B.J. Witzke', and J. B. Hartung', Ilowa Department of Natural Resources, Geological Survey Bureau, 109 Trowbridge Hall, Iowa City IA 52242-1319, USA, ${ }^{2}$ Iowa Center for Impact Studies, P.O. Box 181, Oakdale IA 52319, USA.

In 1992 the Iowa Department of Natural Resources Geological Survey Bureau and U.S. Geological Survey Branch of Astrogeology completed the last of 12 research cores drilled in the Late Cretaceous Manson impact structure. In excess of $1200 \mathrm{~m}$ of drill core was recovered from the three major crater terranes, the terrace terrane, crater moat, and central peak. Almost all of the cored rocks were impact materials (materials emplaced as a direct result of the impact). The six primary impact materials encountered include(1) crystalline basement blocks: Large blocks of crystalline basement materials cut by pseudotachylite veins; (2) Crystalline clast breccia with sandy matrix: Clasts of brecciated crystalline rocks in a matrix of disaggregated crystalline rock and mineral and rare melt-rock fragments; (3) Crystalline clast breccia with melt-rock matrix: Clasts of brecciated crystalline rocks, melt-rock clasts, and mineral grains (dominantly quartz) in a melt-rock matrix; (4) Keweenawan clast breccia: Clasts of brecciated dark gray to black Keweenawan (Middle Proterozoic) shales, siltstones, and sandstones mixed with light gray-green, devitrified melt rocks in a dark gray argillaceous matrix; (5) Phanerozoic clast breccia: A matrix-dominated breccia composed primarily of clasts of Cretaceous marine shale with lesser numbers of Paleozoic carbonate clasts, rare clasts of Proterozoic Keweenawan clastic rocks, and very rare clasts of crystalline rock and melt rock in a medium-gray calcareous sandy shale matrix; and (6) Impact ejecta: An overtumed flap of Proterozoic Keweenawan Red Clastics and Paleozoic strata.

The crystalline basement blocks (CBB) that form the core of the central peak were encountered in four cores. They are dominated by Proterozoic gneisses and granites, but also include minor occurrences of other igneous and metamorphic lithologies. All blocks display abundant parallel deformation features (pdf's) and other impact deformation features. Pseudotachylite dikes of melt rock and crystalline rock breccia intrude these blocks. The crystalline clast breccia with sandy matrix (SM) lies above the CBB on the central peak and was encountered in five cores. Although this unit is dominated by crystalline rock clasts, rare clasts of melt rock and siltstone reflect minor mixing with overlying units. Pdf's and other impact deformation features are pervasive. The $S M$ is interpreted as impact-brecciated rocks from below the transient crater floor. The SM grades upward into the crystalline clast breccia with melt rock matrix (MRM), recovered in five cores. Melt-rock clasts and re- gions of apparent melt flow banding are common. The abundant matrix in this unit is mostly isotropic, suggestive of melt material; however, apparent zones of solid-state diffusion [1] suggest that very fine-grained unmelted material may also be present. The central portion of the MRM was apparently the hottest, displaying the maximum melv/clast ratio, sanidine and recrystallized quartz, and zones of solid-state diffusion. The MRM also displays rare siltstone clasts and crystalline rock clasts with melt-rock mantles (probable airbome accretion) suggesting minor mixing of overlying materials. All nonrecrystallized material displays pdf's and other impact deformation features. The MRM is interpreted as having originated in a hotter area neared the transient floor than the SM; however, a fallback origin for this unit has also been suggested [2]. A mixture of SM and MRM was encountered in two cores, possibly by slumping or sliding during formation of the central peak. The uppernost of the central peak impact units is the Keweenawan clast breccia (KCB), encountered in four cores. The KCB is a mixture of unmelted and partially melted dark gray to black shale-dominated Proterozoic clastic rocks mixed with melt rock. Only very rare grains with pdf's have been observed in Keweenawan sandstone clasts. This relatively thin unit is interpreted as having been at the crater floor when the transient crater growth stopped. The Keweenawan clastic rocks were apparently displaced downward during transient crater formation, then lifted up on the crest of the central peak.

On the terrace terrane an overtumed flap of late-stage crater ejecta (CE) was encountered in one core. This unit included an inverted sequence of Keweenawan red clastics overlying Cambrian, Ordovician, and Devonian marine carbonate and clastic rocks. While all stratigraphic units in this interval appear to be present, they are represented by only about $20 \%$ of their normal thicknesses. This core reached the maximum depth attainable by the drill rig that was used. The possibility of encountering the structurally preserved Upper Cretaceous ground surface only about $100 \mathrm{~m}$ lower $(-500 \mathrm{~m}$ below land surface) presents a tempting target for future drilling.

Among the most interesting materials encountered in the Manson core drilling was the Phanerozoic clast breccia (PCB). The dominance of rock clasts from the shallowest preimpact stratigraphic units (clast abundance is inversely proportional to preimpact depth) and the scarcity of shock-melted or-deformed minerals is similar to Ries Crater Bunte breccia $[3,4]$. Bunte breccia is, by definition, primary crater ejecta formed by the combined effects of ground

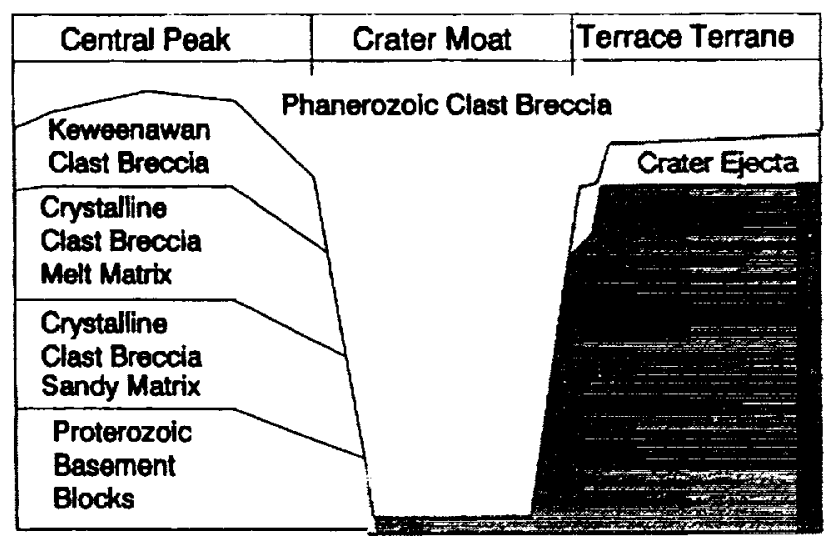

Fig. I. Impact rocks in the Manson structure. 
surge and secondary cratering, and as such is restricted to regions outside the transient crater. However, PCB in the Manson Crater was encountered in eight cores, within all regions of the crater (Fig. 1), implying that if this material had a Bunte breccialike origin, it must have been transported back into the crater by some unknown dynamic process. One possible medium for such transport is water, displaced by the bolide impacting into a shallow marine environment, rushing back into the evacuated crater region. The presence of marine conditions in the Manson area does not preclude a late Cretaceous impact, since erosion has left an equivocal record of conditions at that time. Recovery of the structurally preserved impact surface by core drilling in the crater terrace would resolve the questions of impact environment and age.

References: [1] Reagan M. K. et al. (1993) Eos, 74. [2] Bell M. S. et al. (1993) GSA Absir., 25. [3] Hörz F. (198I) GSA Spec. Paper 190, 39-56. [4] Newsom H. E. et al. (1990) GSA Spec. Paper 247, 195-206.

TESTING KT EXTINCTION HYPOTHESES USING THE VERTEBRATE FOSSIL RECORD. J. D. Archibald, Department of Biology, San Diego State University, San Diego CA 92182 , USA.

Although we do not have geographically extensive data for KT vertebrate tumover, available data from the westem interior of Norh America can be used to examine proposed extinction scenarios. The most recently published compilation [1] included 111 species of vertebrates within the uppermost Cretaceous Hell Creek Formation of Montana and found that species survival at the KT boundary was between $53 \%$ and $64 \%$ when three artifacts were considered. These artifacts were as follows: (1) When a species survived elsewhere but disappeared locally in eastern Montana, this obviously was a survival rather than an extinction. Clearly, when one is attempting to ask global questions of extinction, one must not count local disappearances as true extinctions. (2) Pseudoextinction occurred when a species disappeared in the process of forming a new species through cladogenesis or anagenesis, and thus its disappearance is not true extinction. If pseudoextinction is not recognized, extinction rates can be greatly exaggerated. In a study of early Tertiary mammals it was found that in about $25 \%$ of the cases, species disappearances were the result of speciation events not extinction events [2]. We do not have detailed phylogenetic analyses for most latest Cretaceous mammals, but common sense tells us that their apparent $97 \%$ disappearance is not all true extinction. There is no question that mammals were beginning a tremendous radiation that occurred after the disappearance of nonavian dinosaurs. Such pseudoextinction is undoubtedly masking as true extinction in other vertebrate groups. (3) Finally, the third artifact is rarity of taxa. Archibald and Bryant [1] found a much higher level of disappearance of rare species ( $91 \%$ for rare vs. $54 \%$ for common), suggesting an artifact of preservation.

When all three artifacts were considered, including the exclusion of rare disappearances, a $64 \%$ species survival was calculated. The 28 rare species in this study were more fully examined to estimate if rarity is an issue in estimating survival. Eight rare species that were either extremely poorly known or were based on extremely questionable taxonomy were excluded, leaving a revised data set of 104 species (including 20 rare species). Including all 104 species or species lineages, a $51 \%$ (53 of 104 species) survival was found for vertebrates across the KT boundary in the westem interior. If all of the extinctions of the rare species are actually artifactual, survival would rise to $70 \%$ (73 of 104). This gives a range of $51-$ $70 \%$ species survival. The lower estimate is probably more accurate, but some of the extinctions of very rare species are certainly artifactual. For vertebrates the highest percent extinctions are among sharks and relatives, lizards, bird- and reptile-hipped dinosaurs, and marsupials. These five groups account for $75 \%$ of all extinctions of vertebrates at the KT boundary in the westem interior. In comparison to other intervals in the Late Cretaceous and early Paleocene, the KT vertebrate tumover is only about $10 \%$ higher at the generic level [1]. These tabulations are useful in examining the validity of various extinction scenarios.

Starting with the bolide impact theory, the basic premise is that on a global scale a dust cloud shrouded the Sun, culting off photosynthesis, killing herbivores, finally killing camivores. This scenario is so broad spectrum in its implications because it tries to explain everything, and thus explains nothing. Major extinctions $(>50 \%)$ in only 5 of 12 major taxa are correctly predicted by this hypothesis.

There are some interesting corollaries to the bolide impact: a short, sharp decrease in temperature, highly acidic rains, and a global wildfire. Based on what we know of extant vertebrates, if a short, sharp decrease in temperature occurred, the vertebrates most likely to be affected are ectothermic tetrapods, that is, reptiles and

TABLE 1. Late Cretaceous venebrale species from eastern Montana compared to survival across the KT boundary.

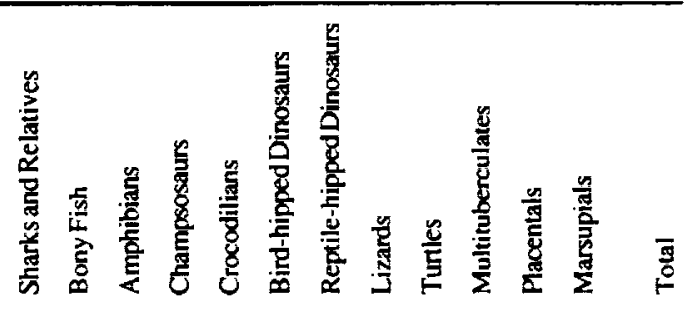

No. LK

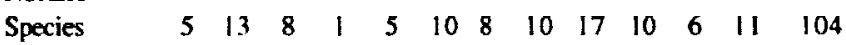

No. KT

$\begin{array}{llllllllllllll}\text { Survivals } & 1 & 9 & 8 & 1 & 4 & 0 & 0 & 3 & 15 & 5 & 6 & 1 & 5.3\end{array}$

Extinct. Observed

$\begin{array}{lllllllllllllll}>50 \% & \mathrm{Y} & \mathrm{N} & \mathrm{N} & \mathrm{N} & \mathrm{N} & \mathrm{Y} & \mathrm{Y} & \mathrm{Y} & \mathrm{N} & \mathrm{N} & \mathrm{N} & \mathrm{Y} & \end{array}$

Bolide

$\begin{array}{llllllllllllll}\text { Impacl } & \mathrm{Y} & \mathbf{y} & \mathrm{y} & \mathrm{y} & \text { y } & \mathrm{Y} & \mathrm{Y} & \mathrm{Y} & \text { y } & \text { y } & \text { y } & \mathrm{Y} & 5\end{array}$

Temp.

$\begin{array}{llllllllllllll}\text { Decrease } & n & N & y & y & y & n & n & Y & n & N & N & n & 4\end{array}$

$\begin{array}{llllllllllllll}\text { AcidRain } & Y & y & y & y & y & n & n & n & y & N & N & n & 3\end{array}$

Global

$\begin{array}{llllllllllllll}\text { Wildfire } & Y & \text { y } & \text { y } & \text { y } & \text { y } & \text { Y } & \text { Y } & \text { Y } & \text { y } & \text { y } & \text { y } & Y & 5\end{array}$

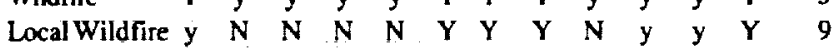
Regress.

$\begin{array}{llllllllllllll}\text { andFrag. } & \mathrm{Y} & \mathrm{N} & \mathrm{N} & \mathrm{N} & \mathrm{N} & \mathrm{Y} & \mathrm{Y} & \mathrm{y} & \mathrm{N} & \mathrm{N} & \mathrm{N} & \mathrm{Y} & \|\end{array}$

Levels of observedextinction $(>50 \%=\mathrm{Y} ;<50 \%-\mathrm{N})$ vs. predicted for various extinction scenarios. Capital letter indicates agreement with observed and small case indicates disagreement. Numbers on right indicate for how many of 12 major taxa predicted agree with observed. See text for discussion. 
amphibians. Endotherms such as birds and mammals and ectotherms such fish would be much less severely affected. Some amphibians and reptiles inhabiting areas with low winter temperatures or of severe drought, evolved methods of torpor to survive. Most Late Cretaceous ectothermic tetrapods in subtropical to tropical climates probably did not have such methods of torpor. Further, torpor is most often preceded by decreases in ambient temperature, changes in light regimes, and decreases in food supply. Ectotherms could not have anticipated a short, sharp decrease in temperature. Except for a decline in lizards, the idea of temperature decrease does not accord well with the vertebrate data at the KT boundary because only 4 of 12 major taxa show extinction or survival pattems in agreeement with this scenario.

Related to this, Clemens and Nelms [3] discussed the lack of ectothermic tetrapods at Late Cretaceous sites in northern Alaska. Endothermic tetrapods, dinosaurs and mammals, and fishes could deal with the lower temperatures and thus are present. If lowered temperatures were a factor for ectothemnic tetrapods in Alaska, then a severe drop in temperature would devastate such animals at midlatitudes at the KT boundary. This is clearly not the case.

The next corollary of a bolide impact is acid rain. Today in regions of decreased $\mathrm{pH}$ rainfall lakes are basically stripped of life and some plants succumb to changes in soil chemistry. Also, we see diminished amphibian, especially frog, populations. We thus have a very clear picture of how modem vertebrate biotas react to acid rain. When we compare these modern patterns to those observed at the KT boundary, we find almost no correlation. Only 3 of 12 major taxa have extinction/survival patterns matching this corollary of bolide impact.

The final corollary of bolide impact is global wildfire. During a global wildfire, terrestrial vertebrates would be baked or fried and the aquatic environment choked with debris, killing most life. Like the global bolide impact scenario, the global wildfire is so broad in its killing effects that it explains everything and nothing. Localized wildfires, however, agree better with extinction pattems for both vertebrates and lower-latitude plants. Local wildfires agree with 9 of 12 extinction/survival patterns for major taxa, while global wildfire only agrees in 5 of 12 cases.

Next I tum to global marine regression and habitat fragmentation. Near the end of the Cretaceous, maximum transgression divided North America into two continents. As regression began and continued across the KT boundary, coastal plains decreased in size and became fragmented, stream systems multiplied and lengthened, and as sea level fell, land connections were established or reestablished. The largest land vertebrates, the nonavian dinosaurs, were most affected by loss and fragmentation of habitats. This is similar to what we see happening today as various habitats are fragmented, especially in modem rainforests. As the stream systems increased in size, freshwater vertebrates did well except for those with close marine ties such as sharks and some bony fishes. Although one cannot predict in general which species experienced increased competition through the establishment of land bridges, the appearance of archaic ungulates in North America as marsupials declined, fits this pattem well. In total, the above scenario agrees with 11 of 12 extinction/survival patterns seen for major vertebrate taxa.

In general, regression was hardest on terrestrial species, especially of larger size, while aquatic forms fared better by comparison. Would the opposite be true during a transgressive phase? We know of four major transgressive-regressive cycles in North America during the Late Cretaceous into the earliest Tertiary. Unfortunately, we currently only have decent vertebrate records near the KT boundary. There are, however, two examples that bear further scrutiny.

Homer and colleagues [4] documented anagenetic appearances within four separate lineages of dinosaurs during the last transgressive phase of the Late Cretaceous. During the deposition of the preceding Judith River Formation that extended for five million years, much of which was during a lowered sea-level still stand, they argue little change occurred in dinosaurian and mammalian lineages.

Eaton and Kirkland $[5,6]$ reported that across the CenomanianTuronian boundary in southern Utah, which encompasses the first maximum transgression in the Late Cretaceous of North America, the riverine-riparian vertebrate fauna shows notable extinction, while groups of terrestrial vertebrates continued to radiate.

These two earlier transgressions, combined with the KT marine regression, suggest that regressions are hardest on terrestrial species, but favor freshwater forms, while transgressions are hardest on freshwater species but favor terrestrial forms. Thus, within the cycles of transgression and regression we may have processes that more completely explain the patterns of vertebrate turnover at the KT boundary. Single-cause theories of extinction, such as a bolide impact and its corollaries, fail to explain the pattern of vertebrate extinction at the KT boundary [1].

References: [1] Archibald J. D. and Bryant L. (1990) GSA Spec. Paper 247, 549-562. [2] Archibald J. D. (1993)Paleobiology. 19, 1-27. [3] Clemens W. A. and Nelms L. G. (1993) Geology, 2l, 503-506. [4] Horner J. et al. (1992) Nature, 358, 59-61. [5] Eaton J. and Kirkland J. (1993) GSA Abst., 25. [6] Kirkland J. (1987) Hunteria, 2, 1-16.

SEYMOUR ISLAND: A SOUTHERN HIGH-LATITUDE RECORD ACROSS THE KT BOUNDARY. R. A. Askin', D. H. Elliot ${ }^{2}$, S. R. Jacobson ${ }^{3}$, F. T. Kyte ${ }^{4}, \mathrm{X} . \mathrm{Li}^{\mathrm{I}}$, and W. J. Zinsmeister ${ }^{5}$, 'Department of Earth Sciences, University of California, Riverside CA 92521, USA, 'BByrd Polar Research Center, Ohio State University, Columbus $\mathrm{OH} 43210$, USA, ${ }^{3} \mathrm{Chevron}$ Petroleum Technology Company, La Habra CA 90633, USA, ${ }^{4}$ Institute of Geophysics and Planetary Physics, University of California, Los Angeles CA 90024 , USA, '5epartment of Earth and Atmospheric Sciences, Purdue University, West Lafayette IN 47097, USA.

Exposures on Seymour Island, Antarctica, provide an apparently continuous, shallow marine, siliciclastic record across the Cretaceous Tertiary (KT) boundary. At the end of the Cretaceous, Seymour Island was located at nearly the same latitude as today $\left(64^{\circ} \mathrm{S}\right)$, and thus at a mid to high southem latitude for this geologically important interval. Exposures of Campanian to Tertiary rocks on this island form part of the James Ross Basin [1,2], a back-arc basin of Early Cretaceous (Barremian) through Eocene age lying east of the northem Antarctic Peninsula. The KT boundary occurs near the top of the López de Bertodano Formation, a monotonous, richly fossiliferous, mud-to-silty sand unit deposited under low-energy, shallow marine conditions. Ten members are recognized in the López de Bertodano Formation; the KT boundary is in a several-meters-thick glauconitic interval at the base of member 10 . 
The glauconitic interval crops out for $5.5 \mathrm{~km}$ along strike on southern Seymour Island. The highest ammonites are found within the lower par of the glauconitic interval, which is above the level of the highest preserved Cretaceous planktonic foraminifera. Invertebrate faunas [3] exhibit a long-term, gradual turnover from upper member 9 into member 10 . The glauconitic interval is only sparsely fossiliferous, except for dinoflagellate cyst assemblages, spores and pollen, and particulate organic material (kerogen). Calcareous nannofossils and planktonic foraminifera are not preserved in the glauconitic interval; only non-age diagnostic benthonic forms remain [4]. The absence of the more-fragile calcareous microfossils may be caused by dissolution during diagenesis, by depositional chemistry, or by modem weathering processes. Siliceous microfossils [5] are too sparse over the KT transition to be stratigraphically useful.

Environmental conditions and dinoflagellate cyst assemblages remained relatively stable throughout most of the Maastrichtian on the Seymour shelf, with dinocyst assemblage change beginning in the latest Maastrichtian (in member 9) and continuing into the Danian [6]. Spread over several tens of centimeters, there is a major compositional change from Manumiella-dominated assemblages to Senegalinium obscurum-dominated asssemblages [7] that are followed by more varied Paleocene assemblages. However, palynomorph remnants of the adjacent land vegetation show no evidence of major environmental upheaval. Dominant constituents of the terrestrial palynoflora (spores and pollen) continue unchanged from upper Maastrichtian into Danian sediments [8]. Minor elements of the terrestrial flora change gradually from the upper Maastrichtian to lower Danian, possibly in response to climate shifts.

No single studied horizon exhibits evidence of sudden catastropic change at or near the KT boundary on Seymour Island. Furthermore, the gradual floral and faunal tumover makes it difficult to pinpoint the boundary. The ubiquitous dinoflagellate cyst assemblages indicate a narrow KT boundary transitional zone $(-30 \mathrm{~cm}$ at "Filo Negro" section). A sharp Ir anomaly within this narrow stratigraphic interval at two separate sites identifies the best candidate horizon for the KT boundary.

Following reconnaisance analysis of a stratigraphic section collected at $0.5 \mathrm{~m}$ intervals [e.g., 3,7], a shor (16-m), well-exposed section (Filo Negro) was collected at $10-\mathrm{cm}$ intervals for more detailed analysis [9]. This section comprises unconsolidated, glauconitic silty sands, with a richer glauconitic interval between $7.7 \mathrm{~m}$ and $10.9 \mathrm{~m}$. There is no observable lithologic expression of the $\mathrm{KT}$ boundary, which occurs in the middle of this glauconite-rich unit. Sedimentation is believed to have been continuous, albeit slow, through this interval. Total organic carbon (TOC) values remain low (most below $0.4 \mathrm{wt} \%$ ) throughout the glauconite unit and exhibit no major perturbations in trend. Kerogen analyses indicate the organic assemblages are dominated by inerinite (oxidized, inert matter), with lesser amounts of woody material (some degraded), and relalively small proportions of palynomorphs and plant cuticle. The depositional environment for the KT transition on Seymour Island was below wave base, in low-energy, somewhat oxidizing conditions, on a very wide (tens of kilometers?) shallow shelf.

"Typically Paleocene" dinocyst species show gradual first appearances, from strata of definite Maastrichtian age beneath the glauconite unit, to within the glauconite unit. Some of these species also appear first in uppermost Maastrichtian strata in the New Zealand KT section at Waipara [10]. Their first appearances else- where in the world are in Danian beds. However, one species, Danea californica, is not currently known below the KT boundary anywhere. It is found at levels 9.6 and $9.7 \mathrm{~m}$ in the Seymour Filo Negro section. The $9.7 \mathrm{~m}$ horizon is notable because it is the level of highest marine dinocyst diversity, lowest "marine dominance" (an offshore indicator [11]), and highest relative abundances of offshore chorate dinocysts. This horizon, with its diagnostic palynomorph suite, is found at several localities along strike and is believed to record a marine transgressive pulse. We consider it a valuable, easily identified chronostratigraphic marker, and correlate it with the flooding event found in earliest Danian sections elsewhere [e.g., 12].

A single peak in Ir concentration was found [9] at the 9.4-m level ( $1.6 \mathrm{ppb}$ Ir, $40 \times$ background). This sharp peak, which occurs $30 \mathrm{~cm}$ below the earliest Danian flooding horizon and in the uppermost Manumiella dinocyst zone, is presumed to represent the main KT "Ir event." We consider it a chronostratigraphic horizon marking the KT boundary. Although the Ir peak is commonly assumed to reflect a bolide impact, there is no discemible direct effect on the floras and faunas at this location. The processes responsible for the systematic changes in latest Maastriçhtian-earliest Danian Seymour Island floras and faunas may be related to one or more noninstantaneous changes in sea level, in water chemistry, and in climate.

References: [1] Elliot D. H. (1988) GSA Memoir, 169, 541555. [2] Del Valle R. A. et al. (1992) Ansarct. Sci., 4, 477-478. [3] Zinsmeister W. J. et al. (1989) J. Paleont., 63, 731-738. [4] Huber B. T. (1988) GSA Memoir, 169, 163-252. [5] Harwood D. M. (1988) GSA Memoir, 169, 55-129. [6] Askin R. A. (1988) GSA Memoir, 169, 131-153. [7] Askin R. A. (1988) GSA Memoir, 169, 155-162. [8] Askin R. A. (1990) Rev. Palaeobot. Palyn., 65, 105-113. [9] Elliot D. H. et al,, Geology, in preparation. [10] Wilson G. J. (1987) NZGS Record, 20, 8-15. [11] Goodman D. K. (1979) Palyn., 3, 169-190. [12] Brinkhuis H. and Zachariasse W. J. (1988) Mar. Micropal., I3, 153-190.

STABLE CARBON ISOTOPIC EVIDENCE FOR CRETACEOUS PLANKTIC SPECIES SURVIVORSHIP AND REWORKING. E. Bartera' and B. T. Huber' ${ }^{2}$, 'Department of Geology, 1006 C. C. Litile Building, University of Michigan, Ann Arbor MI 48109-1063, USA, 2Department of Paleobiology, NHB121, Smithsonian Institution, Washington DC 20560, USA.

The pronounced tumover in planktic foraminiferal faunas at the time of the KT boundary is well documented [e.g., 1,2]. Large and complex forms such as the globotruncanids, which are abundant in sediments deposited in the last several million years of the Cretaceous, were replaced by relatively small and primitive forms in the early Paleocene. Yet the sedimentary record of the lowermost Danian shows the presence of several Cretaceous taxa, mostly cosmopolitan species, suggesting that their extinction may have been gradual (lasting up to several hundreds of thousand years) rather than abrupt or instantaneous as a consequence of the KT boundary event [3-5]. Analysis of the $\delta^{13} \mathrm{C}$ composition of the tests of these species provides the opportunity of testing their survivorship. This is because the KT boundary event is characterized in low and mid latitudes by a pronounced decline in near-surface water carbonate 
$\delta^{13} \mathrm{C}$ values of up to several permil with a virtual elimination of the surface to bottom $\delta^{13} \mathrm{C}$ gradient, reflecting a decrease in productivity in the lowermost Danian [6-8]. In the high latitudes the KT boundary event appears to have had a less pronounced environmental effect since near-surface water carbonate $\delta^{13} \mathrm{C}$ appears to remain constant at the KT boundary. However, there is a significant $\delta^{13} \mathrm{C}$ decrease in the upper portion of Nannofossil zone NPI (lower portion of magnetochron $(29 \mathrm{~N}$ ), which is then followed by an increase in $\delta^{13} \mathrm{C}$ values in lowermost zone NP2 [9].

In the low latitudes (Brazos River, Texas), stable $\mathrm{C}$ isotopic evidence has been used to demonstrate survivorship of the Cretaceous planktic foraminiferal species Heterohelix globulosa and Guembelitria cretacea up to the top of magnetochron C29R and in C28R, respectively [8]. This was established by $\delta^{13} \mathrm{C}$ values that are 2.5\%o higher in tests recovered from Cretaceous sediments than tests from the Danian sequence (125-200- $\mu \mathrm{m}$ size fraction). In contrast, $\delta^{13} \mathrm{C}$ values of these taxa from the northem boreal section in Nye Kløv, Denmark [9] (63-120- $\mathrm{mm}$ size fraction) exhibit no significant change across the $K T$ boundary, and have similar values in uppermost Maastrichtian and lowermost Danian sediments. In southern high-latitude deep-sea hole $738 \mathrm{C}, \delta^{13} \mathrm{C}$ values of the Cretaceous survivor planktic species Zeauvigerina waiparaensis also remain constant at the boundary and decrease subsequently at the top of zone NP1. A similar pattem is observed at this site in the $\delta^{13} \mathrm{C}$ record of the Tertiary planktic species Eoglobigerina eobulloides and Subbotina pseudobulloides, indicating that the NP2 negative $\delta^{13} \mathrm{C}$ excursion is not an artifact of sediment reworking across the $\mathrm{KT}$ boundary at this site.

No isotopic record of a surviving surface-dwelling taxa is yet available to document Danian surface-water conditions. The $\delta^{13} \mathrm{C}$ values of these surviving species in Maastrichtian sediments indicate a deep habitat within the water column. For example, the similarity in $8^{13} \mathrm{C}$ values of the Cretaceous species Globigerinelloides multispina in uppermost Maastrichtian and Danian sediments through the base of NP2 at site 738 (this study), site 750 [10], and site 690 [11] suggests that this surface-dwelling species did not survive the KT boundary event. Stable isotopic analyses of additional Cretaceous planktonic foraminiferal species that occur in Danian sediments at site should reveal whether these survived the terminal Cretaceous extinction event or were reworked.

References: [1] Luterbacher H. P. and Premoli Silva I. (1964) Riv. Ital. Paleont., 70, 67-128. [2] Smit J. (1982) GSA Spec. Paper 190, 329-352. [3] Keller G. (1988) Mar. Micropaleontol., 13, 239263. [4] Keller G. (1989) Paleoceaongr., 4, 287-332. [5] Huber B. T. (1991) in Proc. ODP Sci. Res., $/ 19$ (J. Barron et al., eds.), 451-466. [6] Zachos J. C. and Arthur M. A. (1986) Paleoceanogr., 1, 5-26. [7] Hsu K. J. et al. (1982) GSA Spec. Paper 190, 317-328. [8] Barrera E. and Keller G. (1990) Paleoceanogr., 5, 867-890. [9] Barrera E. and Keller G. (1994) Bull. SA, in press. [10] Zachos J. C. et al. (1992) in Proc. ODP Sci. Res., I20, R. Schlich et al., eds.), 961-977. [1 1] Stott L. D. and Kennett J. P. (1990) inProc. ODP Sci. Res., I/3 (P. F. Baker et al., eds.), 829-848.
THE KT BOUNDARY ALONG THE BRAZOS RIVER, FALLS COUNTY, TEXAS: MULTIDISCIPLINARY STRATIGRAPHY AND DEPOSITIONAL ENVIRONMENT. D. Beeson', S. Gartner ${ }^{2}$, G. Keller ${ }^{3}$, N. MacLeod ${ }^{3.6}$, J. Medus ${ }^{4}$, R. Rocchia ${ }^{5}$, and E. Robin ${ }^{5}$, 'Chevron, 935 Gravier Street, New Orleans, LA 70112, USA, '2Department of Oceanography. Texas A \& M University, College Station TX 77843, USA, ${ }^{3}$ Department of Geological and Geophysical Sciences, Princeton University, Princeton NJ 08544, USA, ${ }^{4}$ Laboratoire de Botanique et Palynologie, Rue Henri Poincaré, 13397 Marseille Cedex 13, France, 'Sentre des Faibles Radioactivités, Laboratoire Mixte CEA-CNRS, Ave de la Terrasse, 91198, Gif Sur Yvette Cedex, France, 6Present address: Department of Palaeontology, The Natural History Museum, Cromwell Road, London SW7 5BD, England.

The recent suggestion that impact-generated megawave deposits, turbidites, or gravity flows are present in the Gulf of Mexico and northeastern Mexico [1-3] has renewed interest in the Cretaceous: Tertiary (KT) boundary sections along the Brazos River in Falls County, Texas. These sections contain the best-preserved marine and terrestrial microfossil assemblages within the region. These fossils also reside within what some workers believe to be a nearly continuous temporal record of the KT transition [4]. Therefore, it is important that the stratigraphic controversies presently surrounding these Texas boundary sections be fully addressed so that the data recorded at Brazos River can be applied to regional KT boundary problems.

Prior to this study placement of the KT boundary and interpretation of the complex coarse clastic unit (herein termed the "event deposit") within these sections has been a subject of disagreement. For instance, in the principle Brazos section (Brazos 1), the boundary has been alternatively placed at the uncomformable base of the event deposit $[5,6]$, within the limestone at the top of the event deposit [7], and 17-22 cm above the event deposit [8-13; Fig. 1]. In addition, several researchers have argued that no uppermost Maastrichtian and lowermost Danian sediments are present in these sequences [14-16]. The event deposit itself has also been variously

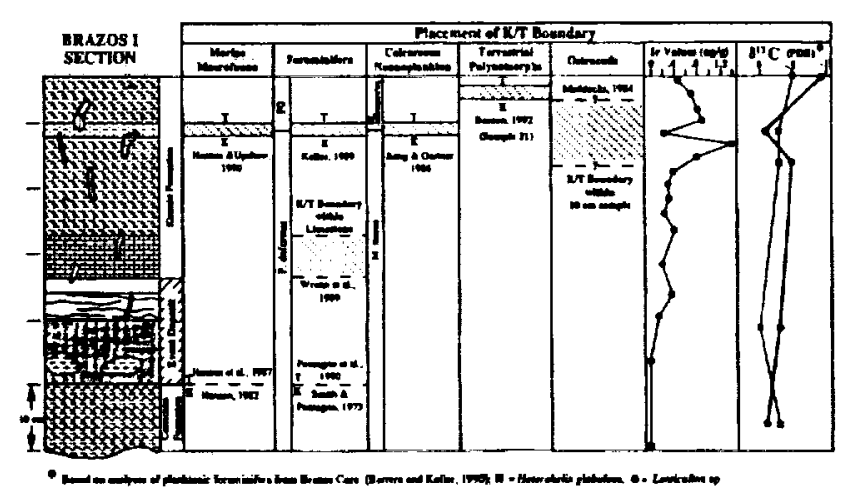

Fig. 1. Placement of the KT boundary in the Brazos I section showing lithostratigraphic and chemostratigraphic data along with biostratigraphic interpretations of various authors. Hachured segments represent degree of biostratigraphic uncertainty due to discontinuous sampling. Dashed "boundary" interpretations are coincident with the unconformity at the base of the event deposit. 
interpreted as an impact-generated tsunami deposit [2,17], an earlier storm or sea-level lowstand deposit [10], and multiple storm events [18].

Integrated biostratigraphic (planktic foraminifera, nannofossils, and palynomorphs) and chemostratigraphic (Ir, stable isotopes) studies of over 550 samples from the Brazos River sections and cores place the KT boundary less than $22 \mathrm{~cm}$ above the top of the event deposit; in agreement with the earlier studies of Maddocks [8], Jiang and Gartner [9], and Keller [10]. A well-defined zone of Ir enrichment is coincident with decreases in $8^{13} \mathrm{C}$ values and with the first appearance of Tertiary planktic foraminifera at these localities, thus confirming their correlation with the boundary stratotype at El Kef, Tunisia. Graphic correlation of Brazos River micropaleontological data with corresponding data from the El Kef stratotype section, and with a KT composite standard reference section [4] suggests that sediment accumulation was, within the present limits of sampling, continuous across the boundary in these sequences.

These microfossil data provide no evidence that could temporally link the underlying clastic event deposit with the KT boundary bioevent. Distinct faunal and floral changes suggest that this coarse clastic deposit represents an independent Maastrichtian event. Benthic foraminiferal and palynomorph data indicate that, during the latest Maastrichtian and earliest Danian, deposition occurred in a shallow, inner neritic environment. Palynomorph data indicate that during the latest Maastrichtian sea-level lowstand, water depths may have been as little as $10 \mathrm{~m}$ in this area. This latest Maastrichtian lowstand is followed by a rapidly rising sea-level across the KT boundary, with water depths becoming no greater than $70 \mathrm{~m}$ by the earliest Danian.

If the Brazos River event deposit is interpreted to be impact related [see $1,2,17]$ then the $17-22-\mathrm{cm}$ claystone interval between the top of this deposit and the KT boundary must be regarded as part of this short-term event (e.g., fine fraction sediments settling out of the water column). But neither paleontological nor sedimentological data support this interpretation. There is no evidence of upward fining of these sediments or of the foraminifera or palynomorphs that they enclose. Moreover, the major planktic foraminiferal and calcareous nannoplankton changes do not occur until well after the KT boundary, whereas changes in the benthic foraminiferal fauna occur in preboundary Cretaceous sediments. Based on the palynomorph evidence, terrestrial floras do exhibit some periods of moderately rapid compositional change across the KT boundary. But the most punitive change in palynomorph composition occurs above the boundary, coeval with marine plankton extinctions.

These data do not support a causal link between the local KT boundary (defined by multiple criteria) and the underlying event deposit. In addition, the Brazos River event deposit contains no shocked quartz, microtektitelike glass spherules, Ir, or Ni-rich spinels that would indicate a genetic relationship between it and a bolide impactevent. The Ir enrichment that does suggest such a connection coincides with the KT boundary which lies $17-22 \mathrm{~cm}$ above this clastic event deposit. The most likely explanation for the event deposit in the Brazos River sequences is that its deposition is related to the uppermost Maastrichtian sea-level lowstand [19,20], with either local or regional storm systems representing the generative mechanism for the emplacement of coarse sediment. A local sequence of hummocky cross-strata overlain by wave ripples is repeated in some outcrops of the event deposit. Given the independently confirmed shallow water depth present in this area during the uppermost Maastrichtian, such features are much more readily compatible with storm-related depositional patterns than with tsunami or megawave mechanisms that would be expected to result in net erosion, rather than deposition, in such nearshore settings.

References: [I] Alvarez et al. (1992) Geology, 20, 697-700. [2] Hildebrand A. R. (1992) Ph.D. thesis, Univ. of Arizona, 358. [3] Stinnesbeck W. et al. (1993)Geology, 21, 797-800. [4] MacLeod N. and Keller G. (1991) Bull. SA, 103, 1439-1457. [5] Hansen T.A. (1984) AAPG-SEPM Annual Meeting Field Trip Guide, 21-36. [6] Hansen T. A. (1987) Cretaceous Res., 8, 229-252. [7] Wrenn J. H. et al. (1989) Palynol., 13, 288-289. [8] Maddocks R. F. (1984) GSA, I6, A 106. [9] Jiang M. J. and Garner S. (1986)Micropaleontol., 32, 232-255. [10] Keller G. (1989) Paleoceanogr., 4, 282-332. [11] Hansen T. A. and Upshaw B. (1990) Extinction Events in Earth History, 402-409. [12] Medus J. (1992) Archs. Sci. Geneve, 45, 127-133. [13] Beeson D. (1992) Ph.D. thesis, Penn. State Univ., 341. [14] Smith C. A. and Pessagno E. A. Jr. (1973) Cushman Found. Foram. Res. Special Pub., 12, 68. [15] Pessagno E. A. Jr. et al. (1990) GSA, 22, A627. [16] Montgomery H. et al. (1992) EPSL, 109, 593-600. [17] Bourgeois J. et al. (1990) Science, 24I, 567-570. [18] Hansen T. A. and Kauffman E. G. (1986) GSA, 18, A627. [19] Donovan et al. (1988) in SEPM Spec. Pub. 42 (C. K. Wilgus et al., eds.), 299-307. [20] Habib et al. (1992) Geology. 20 , $165-168$.

KT BOUNDARY IN DECCAN INTERTRAPPEANS: CHEMICAL ANOMALIES AND THEIR IMPLICATIONS. N. Bhandari', P. N. Shukla', Z, G. Ghevaria ${ }^{2}$, and S. M. Sundaram², 'Physical Research Laboratory, Navrangpura, Ahmedabad 380009 , India, ${ }^{2}$ Geological Survey of India, Gandhinagar 382043, India.

We have identified the KT boundary layer in Deccan intertrappean sediments based on anomalously high concentrations of Os and Ir. Concentration of Os $(\sim 1.5 \mathrm{ng} / \mathrm{g})$, about $20 \times$ more than in the adjacent sediments, have been found in a $\sim 1-\mathrm{cm}$-thick chocolate band within white shale in the third intertrappean sediments (I-III) at Anjar.

The Anjar trap sequence consists of seven alkaline basalt flows with five intertrappean sediments, which appear to be brackish water, shallow continental deposits and one red bole horizon. The site is located south of Anjar in Kutch, which forms the westem periphery of the Deccan plateau. Two of these traps (FII and FIII) have been dated by $\mathrm{Pande}$ et al. [ 1$]$ in our laboratory by the ${ }^{34} \mathrm{Ar} /{ }^{40} \mathrm{Ar}$ method to be $65.5 \pm 0.7 \mathrm{Ma}$ and $65.4 \pm 0.7 \mathrm{Ma}$ respectively, coincident with the KT boundary event (65 Ma [2]). Dinosaur bones and upper Cretaceous fossils have been found in intertrappeans I-II and I-III. The I-III contains the uppermost horizon containing in situ dinosaur fossils [3]. The intertrappean sediments I-III consist of a shale-limestone-chert-clay sequence that contains this Ir-rich thin and compacted chocolate layer within the white shale.

Osmium, Ir, and about 25 other elements were measured by RNAA and INAA following the procedure described by Bhandari et al. [4]. High Os and Ir in sample 27B, representing the chocolate layer, is accompanied by high $\mathrm{Fe}, \mathrm{Co}, \mathrm{Sb}, \mathrm{Zn}, \mathrm{Se}, \mathrm{As}$, and relatively low Th, Hf, and $\mathrm{Sc}$ compared to the adjacent shales and the underlying basalt F-III. Silver is found to be $36 \mathrm{ng} / \mathrm{g}$ in the sample $27 \mathrm{~B}$ and 


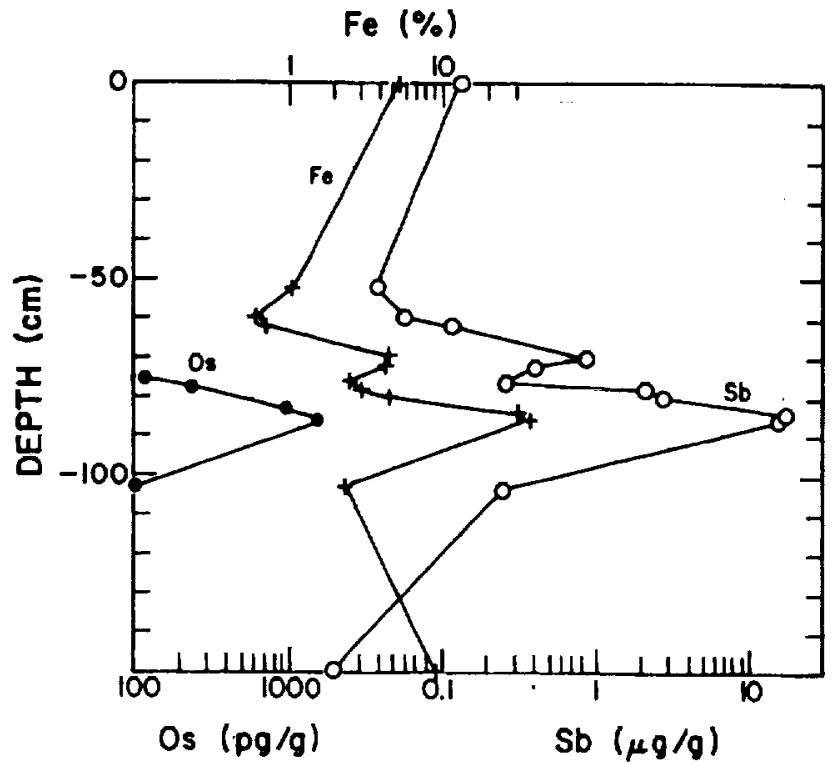

Fig. 1. Os, $\mathrm{Fe}$, and Sb profiles in Anjar intertrappeans. Some data points are displaced along the depth for sake of clarity. The peak concentrations occur in sample 27B. The upper small peak occurs in sample 24. The lowest sample is basalt F-III

has the highest concentration in sample $24 \mathrm{~A}$, located just above $27 \mathrm{~B}$. The enrichment factors for various elements, compared to their concentrations in basalt F-III, are $\mathrm{Sb}$ (795), $\mathrm{Se}$ (14.5), $\mathrm{Fe}(4.1)$, Co (2.6), $\mathrm{Zn}$ (1.9), $\mathrm{Ni}$ ( 1.8 ), and $\mathrm{Zr}$ (1.2). Samarium, $\mathrm{Hf}, \mathrm{Th}, \mathrm{Ta}$, and $\mathrm{Na}$ are all relatively depleted (by factors of 5 or more) and so are rare Earth elements (by factors of $\sim 1.5-6$ ). Depth profiles of $\mathrm{Os}, \mathrm{Fe}$, and $\mathrm{Sb}$ are shown in Fig. 1. The Co profile closely follows the Fe profile, whereas the $\mathrm{Zn}$ and Se profiles are similar to the Sb profile. The $\mathrm{Ch}$ profile, on the other hand, is not similar to that of Fe or Co. Based on these chemical anomalies, some of which (Ir, Os) are diagnostic of the KT boundary, we identify this layer as the KTB horizon.

Two possible scenarios, one envisaging bolide impact (comet or asteroid) and the other involving Deccan volcanism, have been proposed based on the discovery of anomalously high Ir (and other platinum-group elements) concentrations in KT boundary in marine sediments [5]. Our search for similar chemical anomalies within the Deccan is based on the realization that identification and chemical characterization of the KTB layer within the Deccan may help us to resolve this debate between a volcanic and an extraterrestrial origin of high PGE concentration.

The concentration of Ir in Anjar I-III (sample 27B) is not only the highest among Anjar intertrappeans but also 10 to 20 times higher compared to many Deccan intertrappean sediments [6] from the eastern periphery of the Deccan plateau i.e., from Nagpur and Jabalpur [7].

The question arises whether this chocolate layer represents the fallout resulting from the bolide impact or a volcanic deposit resulting from the Deccan eruptions. Furthermore, whether this layer represents the primary concentration of elements or has undergone some secondary processes of alteration after its deposition has to be established before its implications to the source of KTB anomalies can be understood.
The high concentration of $\mathrm{Zn}$ and $\mathrm{Sb}$ in marine sediments at the KTB was considered by Gilmour and Anders [8] to be of oceanic origin. The continental sections, such as Anjar, have the advantage that there is little oceanic interference and the material deposits in a short period of time. Therefore, the presence of high $\mathrm{Zn}$ and $\mathrm{Sb}$, together with Se, etc., in I-III indicates that their enrichment at the KTB may be due to their high concentration in the source material of the dust rather than any oceanic processes.

Several of these elements for which an enhancement is seen are chalcophile and volatile. The Fe abundance is also very high $(-39 \%)$. The element pattem is not consistent with any meteorite composition and therefore also with the asteroidal impact. Comets, on the other hand, are believed to be rich in volatile and possibly chalcophile elements [9]. Many of the elements ( $\mathrm{Sb}, \mathrm{Se}, \mathrm{Zn}$, and $\mathrm{As}$ ) for which enhancements are seen are known to be enriched in volcanic emissions [10] as well, but our earlier study of these chalcophile elements in other Deccan intertrappean sediments [6], as well as of samples other than 27 in the Anjar section, does not show anomalously high concentration of these elements. A complete mineralogical, chemical, and isotopic characterization of this sample, which is now in progress, should enable us to distinguish between various source materials for the KT boundary layer.

References: [1] Pande K. et al. (1988) Mem. Geol. Soc. India, 10, 145. [2] Izett G. A. et al. (1991) Science, 252, 1539. [3] Ghevaria Z. G. (1988) Curr. Sci., 57, 248. [4] Bhandari N. et al. (1993) Chem. Geol., in press. [5] Alvarez L. W. et al. (1980) Science, 208, 1095. [6] Bhandari N. et al. (1993) Chem. Geol., I03, 129. [7] Bhandari N. et al. (1993) PALEO, in press. [8] Gilmour I. and Anders E. (1989) GCA, 53, 503. [9] Clube S. V. M. and Napier W. M. (1986) in The Galaxy and the Solar System (R. Smoluchowski et al., eds.), 260-285. [10] Zoller W. H. et al. (1983) Science, 222, 1118-1123.

\section{GEOCHEMICAL CONSTRAINTS ON THE COMPOSITION OF VOLATILES RELEASED DURING THE FORMATION OF KT IMPACT MELTS: IMPLICATIONS FOR EX.} TINCTIONMECHANISMS. J.D. Blum and C.P.Chamberlain, Earth Sciences Department, Dartmouth College, Hanover NH03755, USA.

It has now been firmly established that an asteroid or comet struck the Yucatan Peninsula $65 \mathrm{Ma}$ ago forming the $\sim 300-\mathrm{km}$ diameter Chicxulub impact structure [1-6]. Major-element and Nd, $\mathrm{Sr}, \mathrm{Pb}$, and $\mathrm{O}$ isotopic studies have shown that impact-induced mixing and melting of the target rocks produced both the melt ejecta found in KT boundary sediments and melts encountered in several drillholes into the Chicxulub structure [5-7]. Major element variation among the melts indicates that they formed by mixing of a silicate end member (of granodiorite/dacite composition) with a high-CaO end member [ $8-10]$, which is easily understood because the preimpact target stratigraphy included a $\sim 2-\mathrm{km}$ platform of limestone, marl (i.e., limestone + shale), dolomite, and sulfate evaporite overlying crystalline silicate basement $[11,12]$. Thus, the high- $\mathrm{CaO}$ end member is likely to be a mixture of devolatized calcite $\left(\mathrm{CaCO}_{3}\right)$, dolomite $\left(\mathrm{MgCO}_{3}\right)$, and anhydrite $\left(\mathrm{CaSO}_{4}\right)$ with minor shale. The relative proportion of carbonate to anhydrite excavated by the impact is obscured by the cratering event, but a drillhole ( $\mathrm{Y}$. 4) that is $50 \mathrm{~km}$ outside of the outer ring structure encountered 
$\sim 1.25 \mathrm{~km}$ of Cretaceous limestone, marl, and dolomite overlying $-0.30 \mathrm{~km}$ of anhydrite, which overlies crystalline basement [12]. Determination of the relative proportion of the minerals that devolatilized during impact is an essential factor in assessing the influence of the impact on the chemistry of the Earth's atmosphere and in turn the potential climatic and environmental changes induced by the impact.

On Fig. I we have plotted $\mathrm{SiO}_{2}+\mathrm{Al}_{2} \mathrm{O}_{3}$ vs. $\mathrm{CaO}+\mathrm{MgO}$ (these four components account for $\geq 90 \%$ of the rock compositions) for (1) KT impact glasses from Haiti [10], (2) melt clasts, melt matrix, and melt rock from the Y-6 and C- 1 drillholes into the Chicxulub structure [3,5], (3) a high-CaO end member calculated in [10] that accounts for all the major-element variability in the Haitian glasses, and (4) average values for platform carbonates [13] and sulfate evaporites [14] from the literature. The covariation between the Haitian glasses, Chicxulubmelts, and calculated end member strongly support a common origin by mixing of two end members. However, the most important question at hand is the relative proportion of carbonate (calcite + dolomite) to sulfate in the high-CaO end member, which can only be addressed with the aid of $O$ isotope studies because they provide a sensitive measure of the relative contribution of $O$ from carbonate vs. sulfate.

The $O$ isotopic composition $\left(\delta^{18} \mathrm{O}_{\mathrm{SMOw}}\right.$ ) of calcite (and dolomite) precipitated from seawater is $28-30 \%$ and global compilations of $\delta^{18} \mathrm{O}$ values of Cretaceous carbonates display a range of 26-29\% [15]. In contrast, the $\delta^{11} \mathrm{O}$ value of sulfate precipitated from seawater is $12-15 \%$ and global compilations of $\delta^{18} \mathrm{O}$ values of Cretaceous sulfates show a range of $13-15 \%$ [17]. The average $\delta^{18} \mathrm{O}$ values and major-element compositions of anhydrite, carbonate, granodiorite, and shale are plotted on Figs. $2 \mathrm{a}, \mathrm{b}$ along with analyses of impact glasses from Haiti. Also plotted are thick horizontal lines that indicate average compositions of platform carbonates and sulfate evaporites. The arrows indicate that mixing pure carbonate with shale (toproduce marl) explains the difference between the carbonate and platform carbonate fields. On Figs. $2 a$ and $2 b$ lines are drawn

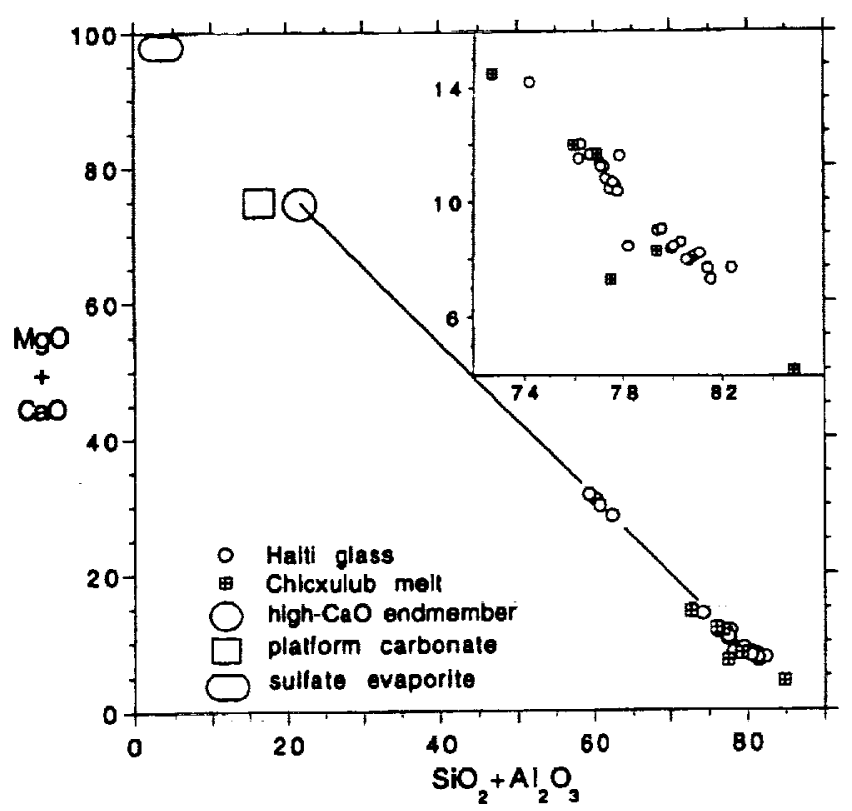

Fig. 1.
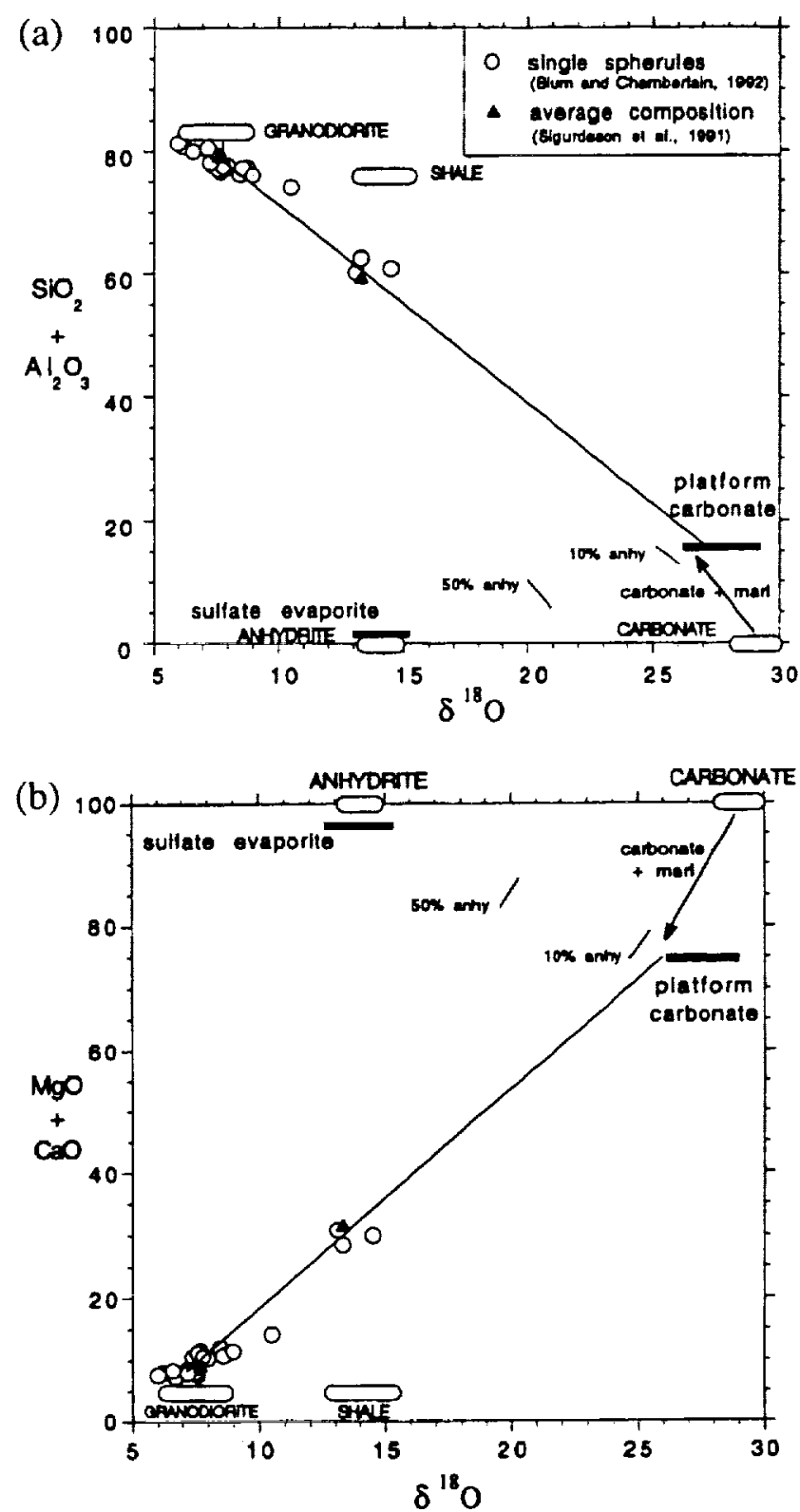

Fig. 2.

following the variation trend of the impact glasses and extending out toward the high- $\mathrm{CaO}$ end member. The most plausible interpretation of these data is that virtually all the $\mathrm{CaO}$ in the impact glasses was contributed by devolatilization of platform carbonate. Short line segments are shown for mixtures of $10 \%$ and $50 \%$ anhydrite with platform carbonate. If the high- $\mathrm{CaO}$ end member contained these amounts of anhydrite, the chemical variation trend of the impact glasses would trend toward these line segments. Based on these data we conclude that the anhydrite contribution to the high$\mathrm{CaO}$ end member was $10 \%$ or less, a conclusion consistent with trace element mixing calculations [18].

The concentration and isotopic composition of $\mathrm{S}$ in the high- $\mathrm{CaO}$ Haitian glasses require the involvement of some oxidized $S$ (i.e., anhydrite) in the target material, and thus there is no question that some sulfate aerosol was released to the atmosphere by the impact 
[17]. However, the $\mathrm{SO}_{3}$ content of $\leq 1 \%$ in the Haitian glasses requires the high- $\mathrm{CaO}$ end member to contain only $\sim 2 \% \mathrm{CaSO}_{4}$, not $100 \%$ as has been recently suggested $[17,19]$. Therefore, we suggest that estimates of the amount of sulfate aerosol released, which are based on the assumption that the high- $\mathrm{CaO}$ end member in the target material was mostly anhydrite, are overestimates by a factor of 10 or more. In addition to devolatilization by melting, sulfate and carbonate devolatization is also assumed to have taken place in unmelted target rocks due to the impact shock pressure $[17,19,20]$. Recent experiments on the shock devolatilization of sulfate minerals, however, find that sulfate devolatilization reactions occur to a far lower degree under shock conditions than previous calculations have assumed, and suggest that the amount of $\mathbf{S}$ devolatilized is several orders of magnitude lower than previous estimales [21].

The amount of $\mathrm{SO}_{3}$ and $\mathrm{CO}_{2}$ released during the $\mathrm{KT}$ impact relates directly to several of the proposed extinction mechanisms including ( $\mathrm{I}$ ) cooling of the Earth's surface on a $~ 1-y$ r timescale due to increased $\mathrm{H}_{2} \mathrm{SO}_{4}$ aerosol in the stratosphere, (2) increased precipitation acidity on land and lowering of the $\mathrm{pH}$ of surface ocean water due to $\mathrm{H}_{2} \mathrm{SO}_{4}$ rainout, and (3) an enhanced greenhouse effect for $10^{4}$ to $10^{5} \mathrm{yr}$ due to release of $\mathrm{CO}_{2}$ into the atmosphere from melting and shock devolatilization of carbonates. Our results and those of [21] suggest that the volume of $\mathrm{SO}_{3}$ released by the KT impact has been overestimated by at least $\mathrm{I}$ and possible 2 orders of magnitude, implying that inputs of $\mathrm{SO}_{3}$ to the atmosphere may not have been as lethal as previously proposed.

References: [1] Hildebrand A. R. et al. (1991) Geology, 19, 867-871. [2] Swisher C. C. et al. (1992) Science, 257, 954-958. [3] Sharpton V. L. et al. (1992) Nature, 359, 819-821. [4] Sharpton V. L. et al. (1993) Science, 26I, 1564-1567. [5] Kring D. A. and Boynton W. V. (1992) Nature, 358, 141-[44. [6] Blum J. D. et al. (1993) Nature, 364, 325-327. [7] Premo W. R. and Izett G. A. (1992) Meteoritics, 27, 413-423. [8] Sigurdsson H. et al. (1991) Nature, 349, 482-487. [9] Sigurdsson H. et al. (1991) Nature, 353, 839-842. [10] Blum J. D. and Chamberlain C. P. (1992) Science, 257. 1 104-1107. [11] López-Ramos E. (1983) Geología de México, 259-282. [12] Sharpton V. L. et al., this volume. [13] Wedepohl K. H. (1969) Handbook of Geochemistry, I, 250-269. [14] Stewart F. H. (1963) USGS Prof. Pap., 440Y, Y1. [15] Veizer J. and Hoefs J. (1976) GCA, 40, 1387-1395. [16] Claypool G. E. et al. (1980) Chem. Geol., 28, 199-260. [17] Sigurdsson H. et al. (1992) EPSL, 109, 543-559. [18] Koeberl C. (1993)Geology, 2I, 211-214. [19] Brett R. (1992) GCA, 56, 3603-3606. [20] O'Keefe J. D. and Ahrens T. J. (1989) Nature, 338, 247-249. [21] Chen G. et al. (1993) Nature, submitted.

\section{DEBRIS FLOW/TURBIDITE CLASTIC UNITS AT THE KT BOUNDARY, NORTHEASTERN MEXICO. B. F. Bohor and W. J. Betterton, U.S. Geological Survey, Box 25046, Mail Stop 972,} Denver CO 80225, USA.

Ten sites that contain clastic units enclosed in marine calcareous rocks at the KT boundary have been discovered in northeastem Mexico [1]; we visited two of these: Arroyo el Mimbral [2,3] and La Lajilla [3]. The clastic sequences at these sites consist of two distinct units; we interpret the lower spherule-bearing bed as a debris flow, and the upper sandstone unit as a turbidite. Both units are interpreted as being caused by disturbances associated with the $K T$ impact.
The lower spherule-bearing unit attains $\sim 1 \mathrm{~m}$ in maximum thickness and disconformably overlies Maastrichtian marls of the Mendez Formation. It consists of poorly sorted and poorly graded clayey spherules up to $3 \mathrm{~mm}$ in diameter in a calcite matrix. Spherule-rich layers altemate with spherule-poor, calcite-rich layers in almost horizontal bedding. Numerous marl clasts of Mendez age [3] occur throughout this bed. The basal surface of the spherule bed marks a disconformity with the underlying Mendez marl.

Most of the clayey spherules consist of hollow chlorite-smectite shells, representing alteration products of palagonite rims that were observed on similar spherules in Haiti [4]. Most of the original glass cores have been dissolved and the central voids filled with secondary calcite. We separated rare relict glass cores and fragments from the spherule unit, at both Mimbral and La Lajilla, that have compositions and colors similar to those from the Haiti spherule beds, except that the Mexican sites also contain a greenish-colored, hydrated glass [5]. Shocked quartz had been reported previously from the Mimbral spherule bed [2], but we did not find any. These beds contain pure albite grains that are probably authigenic.

Disconformably overlying the spherule bed at Mimbral is a massive-to-laminated, siliceous, calcite-cemented sandstone unit that is $-2 \mathrm{~m}$ thick. The lowest part of this unit is massive and normally graded, but it becomes horizontally laminated upward. Wood fragments and other plant debris, along with large mudstone rip-up clasts of Turonian age [3], flute casts, and sole markings, are present at the base of the massive sandstone. The laminated zone is suc. ceeded by wavy, rippled, and crossbedded strata; this zone is capped by thin, parallel lamellae of siltstone and, finally, by silty claystone (Fig. Ia). An Ir anomaly of $-0.8-0.9 \mathrm{ppb}$ has been reported from the top of the sandstone unit at the Mimbral site $[2,3]$. We searched for shocked quartz in several thousand grains from this zone at both sites, but did not identify any. However, these quartz grains are heavily overgrown with authigenic quartz, making recognition of PDF difficult. We did find a single $\sim 5-\mu \mathrm{m}$ crystal of high- $\mathrm{Ni}$ magnesioferrite spinel in the uppermost layer from Mimbral. This sample also contains numerous grains of pure albite.

Based on field and laboratory studies, we interpret the clastic sequence at Mimbral and La Lajilla as a debris flow/turbidite. The

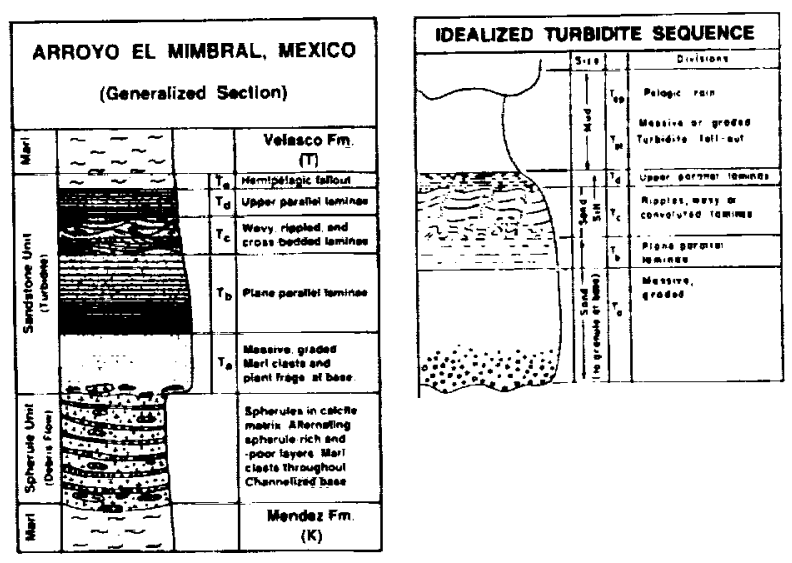

Fig. 1. (Left) Generalized stratigraphic section of the Arroyo el Mimbral outcrop. Bouma $\mathrm{T}_{\mathrm{a}-\mathrm{c}}$ divisions of idealized turbidite sequence added. (Right) Idealized complete Bouma sequence with modified $T_{c}$ division, modified from [10]. Compare with Mimbral sandstone unit on left. 
spherule bed was originally composed of impact-glass spherules ejected from the putative KT impact crater on the Yucatan peninsula. The impact nature of the spherule bed was confirmed by the previous identification of shocked quartz and relict impact glass. These melt-glass spherules were deposited on a shallow shelf, probably located north-northwest of the present sites in the Mendez basin [3]. Thick, unstable deposits of these spherules were mobilized as debris flows at the mouths of canyons in the shelf/slope by either tsunamis, earthquakes, or storms (associated with the KT impact).

The debris flows either generated their own turbidity currents involving unconsolidated shelf sands, as has been calculated theoretically and observed experimentally [6], or these sands were mobilized into turbulent flow simultaneously with the spherules, unmixing from the latter by a sieve mechanism operating on relative particle sizes and flow densities. An alternative to this singlepulse hypothesis is that of two separate episodes, wherein the spherule-laden debris flows were separate events that preceded the turbidity-flow units slightly in time. Arguing against the latter dual-pulse hypothesis is the lack of significant amounts of spherule-bearing material incorporated in the base of the sandstone unit, which should occur if this unit originated later as a separate turbidity flow that scoured the top of the previously deposited debris flow.

Either process resulted in debris flows consisting of glass spherules that scoured and filled shallow channels in basinal Mendez marls, followed closely by sand in turbid suspension that was deposited on top of the spherule beds in the neoformed channels. This model resembles the modem example of upper Pleistocene chaotic silt beds transported by debris flows (analogous to the spherule beds) and directly overlain by turbidite sand beds in distal, channelized, outer-fan lobes of the Mississippi delta in the Gulf of Mexico [7]. As in this example, the presence of relatively undeformed clasts in the Mexican spherule beds suggests deposition in a nonturbulent, debris-flow regime.

Channel scouring by the debris flow is exemplified by the rip-up clasts of underlying Mendez marl contained in this bed. Also, the bed is deposited in a typical shallow-channel profile with clearly defined edges. Both the spherule unit and the sandstone unit contain benthic foraminifers of late Maastrichtian age from a shallow neritic environment, whereas benthic taxa are rare in the underlying, deepwater, Mendez marl $[3,8]$. This strongly suggests that these clastic units are allochthonous, having been transported from shallow water to their present basinal setting.

The sandstone unit at Mimbral displays sedimentary features similar to those that define a turbidite. For comparison, these features have been marked as divisions of the Mimbral sandstone unit in Fig. Ia, using the same nomenclature $\left(T_{a-c}\right)$ that subdivides a classic turbidite sequence (Fig. Ib).

The final, fine-grained phase of turbidite deposition and recommencement of the hemipelagic rain coincided with the arrival of the last portion of the fireball layer at the seafloor; components identifying this partial fireball layer are an Ir anomaly and magnesioferrite spinel crystals [9]. The presence of a capping fireball layer limits the time of formation of this clastic unit to a period of up to several months following impact, according to our single-impact KT model [9].

The almost instantaneous loading of a thick deposit of glass spherules (up to $3 \mathrm{~mm}$ in diameter) onto a shallow shelf constitutes a rather rare event that may, when mobilized, produce unique deposits. For the reasons stated above, we interpret the clastic sequences at Mimbral and La Lajilla as spherule-bearing, debris-flow units overlain by sandstone turbidite units. Furthermore, both of these clastic units were mobilized on a distant shelf/slope soon after impact by the effects of seismic or oceanic disturbances associated with the KT impact event.

References: [I] Alvarez W. et al. (1992) GSA Absis., 24, 7, A331. [2] Smit J. et al. (1992) Geology, 20, 99-103. [3] Stinnesbeck W. et al. (1993) Geology, 21, 797-800. [4] Bohor B. F. et al. (1993) LPS XXIV, 145-1 46. [5] Bohor B. F. and Betterton W. J. (1993) LPS XXIV, 143-144. [6] Hampton M. A. (1972) J. Sed. Petrol., 42, 775793. [7] Nelson C. H. et al. (1992) Geology, 20, 693-696. [8] Keller G. et al. (1992) GSA Absis., 24, A332. [9] Pollastro R. M. and Bohor B. F. (1993) Clays, Clay Minerals, 4I, 7-25. [10] Howell D. G. and Normark W. R. (1982) in Sandstone Depositional Environments (P. Scholle and D. Spearing. eds.). AAPG, 365-404.

N94- 28296

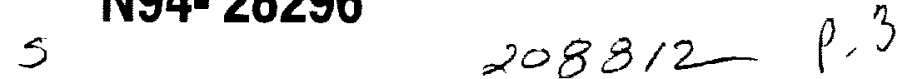

AXIAL FOCUSING OF IMPACT ENERGY IN THE EARTH'S INTERIOR: PROOF-OF-PRINCIPLE TESTS OF A NEW HYPOTHESIS. M. B. Boslough, E. P. Chael, T. G. Trucano, M. E. Kipp, and D. A. Crawford, Sandia National Laboratories, Albuquerque NM 87185, USA.

Along with the appreciation of the importance of impact events on the Earth's evolution, there has been increasing speculation that energetic collisions have been responsible for processes as varied as continental flood basalt eruptions, mantle plumes, continental rifting, and geomagnetic pole reversals. The link between impacts and such geophysical processes was first discussed by Seyfert and Sirkin [I], who suggested that impact-induced mantle plumes could be a mechanism for initiating the breakup of plates. Burek and Wänke [2] listed correlations between known Cenozoic impacts and geomagnetic field reversals, unconformity ages, shifts in paleotemperatures, and tectonic episodes. They suggested that major impacts could generate shock-induced phase transitions in the upper mantle, disnupting a delicately balanced stability down to the core-mantle boundary. Rampino and Strothers [3] proposed a quasiperiodic correlation between mass extinctions and major continental flood basalt volcanism over the last $250 \mathrm{~m} . \mathrm{y}$. and attempted to explain it in terms of episodic showers of impacting comets. Connections between impacts and the intemal workings of the Earth are supported by correlations of the ages of tektites from strewn fields with geomagnetic field reversals [4], and by a reversal associated with sediments deposited immediately after the impact that formed the Ries Crater [5].

A causal link between major impact events and global processes would probably require a significant change in the thermal state of the Earth's interior, presumably brought about by coupling of impact energy. One possible mechanism for such energy coupling from the surface to the deep interior would be through focusing due to axial symmetry. Antipodal focusing of surface and body waves from earthquakes is a well-known phenomenon [6], which has previously been exploited by seismologists in studies of the Earth's deep interior [7,8]. Antipodal focusing from impacts on the Moon, Mercury, and icy satellites has also been invoked by planetary scientists to explain unusual surface features opposite some of the large impact structures on these bodies [9, 10]. For example, "disrupted" terrains have been observed antipodal to the Caloris impact basin on 
Mercury and Imbrium Basin on the Moon. Very recently there have been speculations that antipodal focusing of impact energy within the mantle may lead to flood basalt and hotspot activity $[11,12]$, but there has not yet been an attempt at a rigorous model.

We have proposed a new hypothesis and performed preliminary proof-of-principle tests for the coupling of energy from major impacts to the mantle by axial focusing of seismic waves. Because of the axial symmetry of the explosive source, the phases and amplitudes are dependent only on ray parameter (or takeoff angle) and are independent of azimuthal angle. For a symmetric and homogeneous Earth, all the seismic energy radiated by the impact at a given takeoff angle will be refocused (minus attenuation) on the axis of symmetry, regardless of the number of reflections and refractions it has experienced. Mantle material near the axis of symmetry will experience more strain cycles with much greater amplitude than elsewhere and. will therefore experience more irreversible heating. The situation is:very different than for a giant earthquake, which in addition $10^{-}$ having less energy, has an asymmetric focal mechanism and a larger ${ }^{-}$ area. It should be noted that our hypothesis is fundamentally differ-? ent than those proposed by many others [e.g., 13-16], which involve melting and excavation at the impact location. Problems with models of this type have been pointed out by Loper [17].

We are using two independent proof-of-principle approaches. The first makes use of seismic simulations, which are being performed with a realistic Earth model to determine the degree of focusing along the axis and to estimate the volume of material, if any, that experiences significant irreversible heating. The second involves two-dimensional hydrodynamic code simulations to determine the stress history, intemal energy, and temperature rise as a function of radius along the axis,

For the preliminary seismic modeling the impact was represented as a vertical point force applied at the Earth's surface as a delta function in time. The impactor was assumed to yield an impulse of approximately $3 \times 10^{24} \mathrm{dyne}$ sec, as an estimate of a KTsized impact. Synthetic displacement and strain records were generated for such a source by summing the normal modes of the elastic Earth model 1066A of Gilbert and Dziewonski [18]. We used the attenuation profile of the model PREM [19] to determine $Q$ values for the $1066 \mathrm{~A}$ modes. We assumed a vertically directed point source so we included only spheroidal modes in the synthetic seismogram

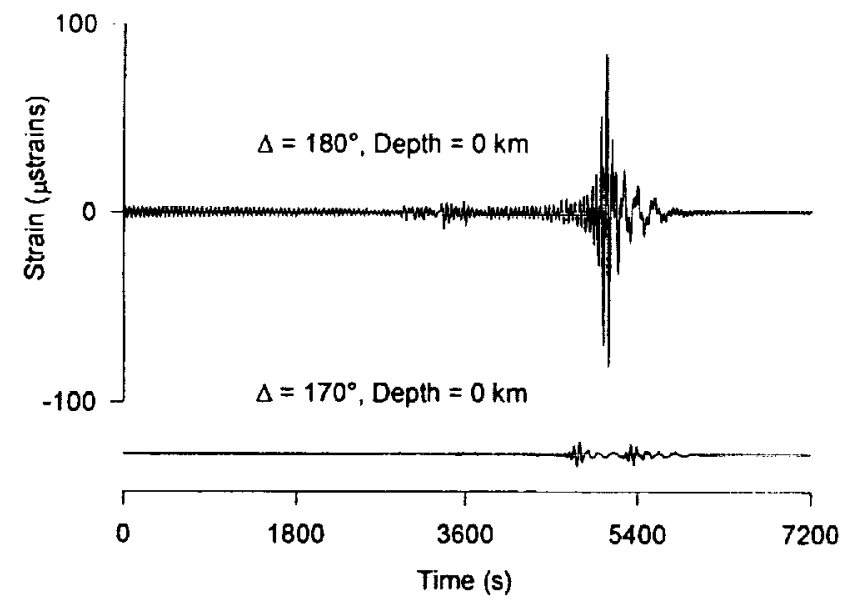

Fig. 1. Synthetic strain histories at and near impact antipode. plotted on same scale. calculations. Toroidal modes are not excited by a vertical point force. All spheroidal modes with periods greater that $45 \mathrm{~s}$ were summed for the synthetics.

The synthetic signals yield estimates of the peak strains at any location in or on the Earth. Figure I shows the difference in strain histories on the Earth's surface at two different angular distances from the source. This figure demonstrates the gross effects of antipodal focusing. Strains at the surface near the antipode (angular distance $=180^{\circ}$ ) are orders of magnitude higher than those over most of the rest of the Earth's surface. Figure 2 plots the peak strains as a function of depth beneath the antipode of the impact, from the surface to the core-mantle boundary. It can be seen that peak strain amplitude varies by 2 orders of magnitude and is largest at the top. This would imply that most of the energy is focused at shallow depths; however, it may be an artifact of ignoring shorter-period modes. This issue will be resolved by adding more modes, and by doing body wave calculations. Figure 3 demonstrates that focused arrivals have much greater amplitudes than direct arrivals at the core-mantle boundary. At the beginning of Fig. $3 \mathrm{a}$, the direct arrival is shown for a point directly beneath the impact, followed by a long high-amplitude focused trace. For comparison, the strain history at the same level on the antipodal axis is shown in Fig. 3b. It can be seen to have a larger peak amplitude.

In addition to seismic modeling, we are in the process of performing detailed calculations of a hypothetical impact and subsequent wave propagation through the Earth with the CTH [20] strong-shock hydrodynamics code. CTH is a one-, two-, and three-dimensional multimaterial elastic-plastic Eulerian hydrodynamics code. CTH accurately computes the very large material deformations, material ejection, and strong-shock generation created by the initial KT impact. For these calculations we model the Earth as a central, gravitationally stable, stratified body, with a variety of interior structure, including inner and outer core and mantle. The materials are treated as elastic-plastic. Also, the equations of state associated

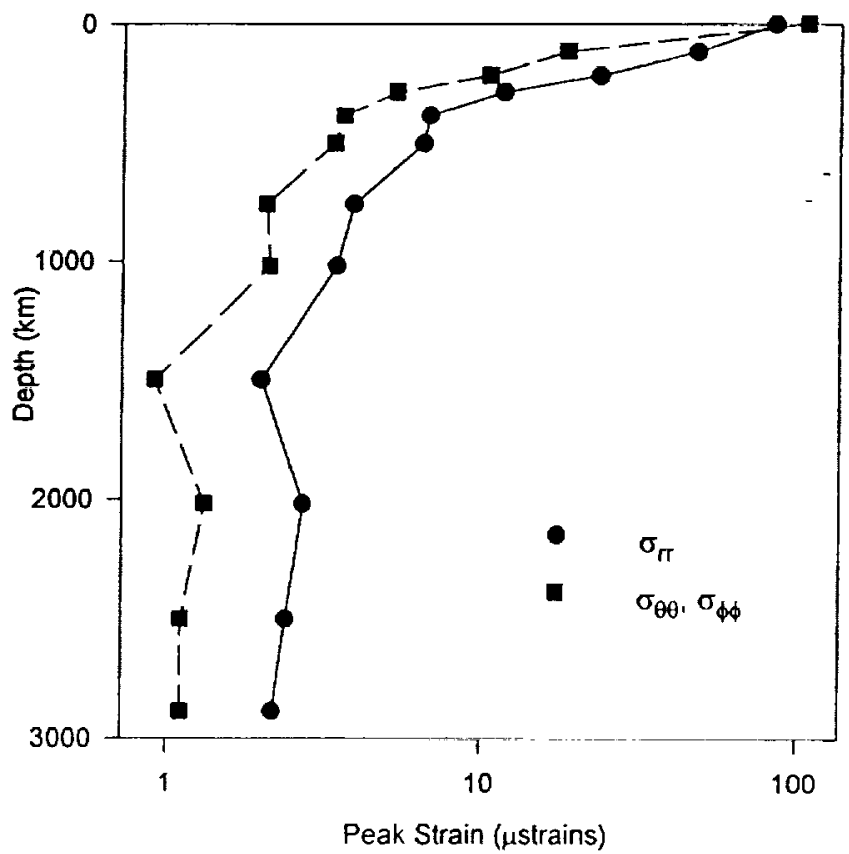

Fig. 2. Peak strain vs. depth along antipodal axis. 

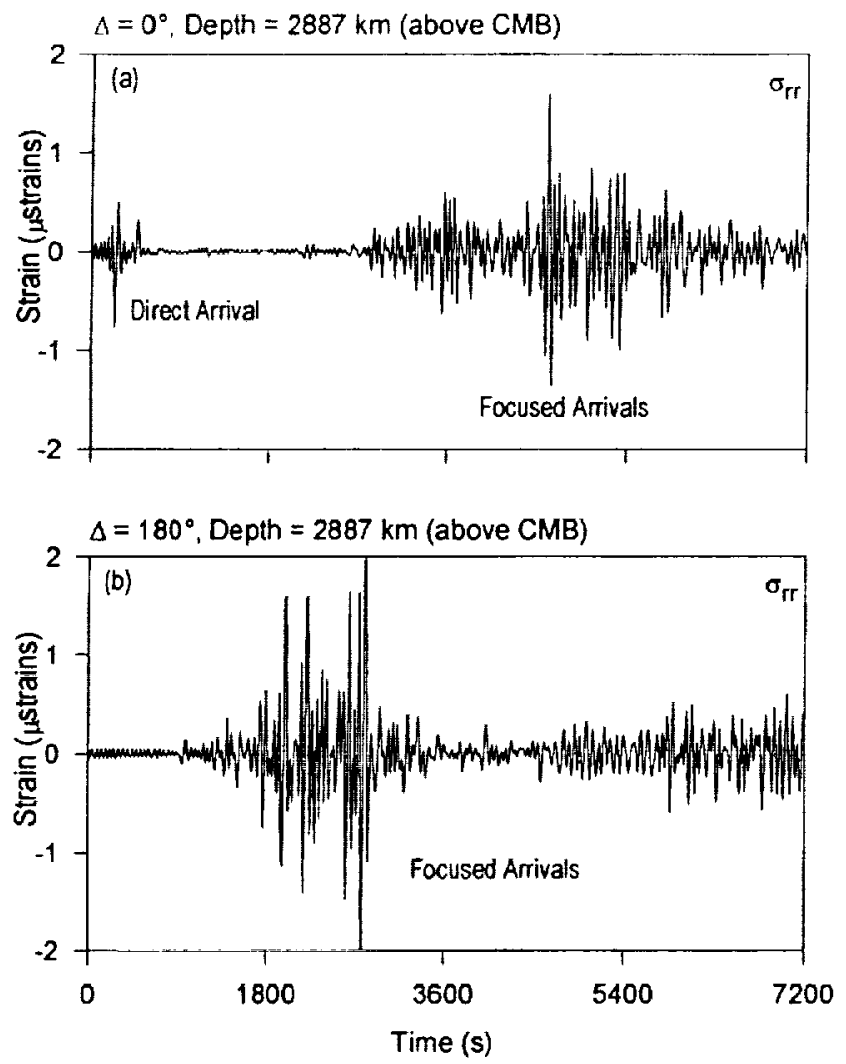

Fig.3. Synthetic strain histories just above the core-mantle boundary (CMB) on the impact ax is (a) beneath the impact and (b) antipodal to the impact.

with CTH allow thermodynamically consistent phase transitions, so that vaporization at the initial impact site can be properly modeled, as well as shock-wave modification in the Earth's interior due to solid-solid phase transitions. Alternatively, we have also modeled the initial impact site as a general energy source, similar in strategy to the seismic model and to the work of Watts et al. [10].

CTH can be used to study the long-term evolution of the resulting wave structures through the interior of the Earth, with some caveats related to accuracy. CTH is an artificial viscosity code, and numerically widen s shock discontinuities. Generally speaking, at very long ranges and times the numerical dissipation in the code will cause inaccuracies in the almost linear wave propagation that is expected to occur. In particular, the numerical dissipation will attenuate stress waves at great propagation distances. In addition, resolution of these low amplitude waves as they propagate through regions of large hydrostatic compression in the Earth's interior must be maintained. While we have still studied the overall response of the antipodal region to the KT impact, the resulting amplitudes and strain due to the long-term wave interactions can be in error. Nonetheless, this approach has also been pursued by Watts et al. [10], and has led to useful investigation of the response of the antipodal region. Our numerical resolution is significantly finer than that of Watts et al. [10]. Ultimately, we will improve the accuracy of our numerical modeling by linking earlier time CTH results to the more accurate seismological analyses described earlier.

Acknowledgments: This work was performed at Sandia National Laboratories supported by the U.S. Department of Energy under contract DE-AC04-76DP00789 with funding under the LDRD program.

References: [1] Seyfert C. K. and Sirkin L. A. (1979) Earth History and Plate Tectonics. [2] Burek P. J. and Wänke H. (1988) Phys. Earth Planet. Inter., 50, 183-194. [3] Rampino M. R. and Sirothers R. B. (1988) Science, 24I, 663-668. [4] Glass B. P. et al. (1979) Proc. LPSC 10th, 25-37. [5] Pohl J. (1977) Geol. Bavarica. 75, 329-348. [6] Gutenberg B. and Richter C. (1934) Gerlands Beitr. Geophys., 43, 56, [7] Rial J. A. (1979) Ph.D. Thesis, Caltech. [8] Chael (1983) Ph.D. Thesis, Caltech. [9] Schultz P. H. and Gault D. E. (1975) Moon, 12, 159-177. [10] Watts A. W. et al. (1991) Icarus, 93, 159-168. [11] Hagstrum J. T. and Turrin B. D. (1991) Eos, 72, 44, 516. [12] Rampino M. R. and Caldeira K. (1992) GRL. 19, 2011-2014. [13] Green D. H. (1972) EPSL, 15, 263-270. [14] Alt D. et al. (1988) J. Geol., 96, 647-662. [15] Oberbeck V. R. et al. (1992) J. Geol., I0I, 1-19. [16] Negi J. G. et al. (1993) Phys. Earth Planet. Int., 76, 189-197. [17] Loper D. E. (1991) Tectonophys.,187, 373-384. [18] Gilbert F. and Dziewonski A. M. (1975) Phil.Trans. R. Soc. London, A278, 187-269. [19] Dziewonski A. M. and Anderson D. L. (1981) Phys. Earth Planet. Inter., 25, 297-356. [20] McGlaun J. M. et al. (1989) Sandia National Laboratories Report SAND89-0607.

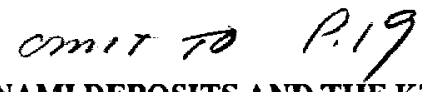

TSUNAMI DEPOSITS AND THE KT BOUNDARY: A SEDIMENTOLOGIST'S PERSPECTIVE. J. Bourgeois ${ }^{1.2}$, 'Department of Geological Sciences, University of Washington, Seattle WA 98195, 2Present address: at National Science Foundation, EAR Room 785, 4201 Wilson Boulevard, Arlington VA 22230, USA.

Tsunamis are impulse-generated waves and can be generated by any event that displaces a significant amount of water in a short period of time, on the scale of seconds to minutes. The most typical source of tsunamis are subduction zone earthquakes, when deformation associated with low-angle thrusting displaces water during the event. Tsunamis are also generated by volcanic events and subaqueous landslides; bolide impacts in water will produce the largest tsunamis in Earth history. Tsunamis are wave trains, rather than single waves, and they may be locally damped, focused, amplified, and reflected.

Our knowledge of typical (seismogenic) tsunamis and their deposits has increased significantly since Snowbird II. These tsunamis typically generate near field run-ups on the scale of meters, to tens of meters in rare cases. Recent tsunamis in Nicaragua (1992), Indonesia (1992), and Japan (1983, 1993) have allowed workers to generate detailed information about the nature of these tsunamis, their erosional and other destructive effects, and their deposits. Paleotsunami deposits from subduction-zone earthquakes have been documented from Chile (1960), Alaska (1964), the Pacific Northwest U.S. (late $1600 \mathrm{~s}$ ), and elsewhere. I will present a brief summary of the Nicaraguan, Chilean, and Pacific Northwest examples.

Tsunamis generated by bolide impacts ("megatsunamis") are at the other end of the tsunami scale, potentially generating isunamis several orders of magnitude more energetic than seismogenic cases. Our understanding of these kinds of events is much more theoretical because there are no historic cases. We can expect that an impact in deep water could propagate a wave equal to the water depth, and thus megatsunamis may affect the floor of the ocean at depths much greater than seismogenic tsunamis, which only have an effect in the coastal zone. Certainly shelf environments (depths of $\sim 30,200 \mathrm{~m}$ ) 
would be affected by megatsunamis and, in proximal regions, the continental slope would also be subject to the effects of such a wave or set of waves.

Coarse-grained KT boundary deposits around the Gulf of Mexico and Caribbean have been variously interpreted as (mega)tsunami deposits, transgressive sequence boundaries, and lowstand fan or delta deposits. The first published examples of each of these interpretations preceded the identification of a likely impact structure of possible KT boundary age in the Yucatan (Chicxulub). The postulate that Chicxulub is a KT boundary impact structure has generated even more interest in these coarse-grained beds. One interesting aspect of the possibility of this event is that the impact would have occurred in shallow water, and thus the tsunami or tsunamis generated would have been smaller (than for a deep-water impact) and more complex, possibly related to platform collapse or large subaqueous landslides. Locally, slide-generated tsunamis can generate catastrophic run-ups, of hundreds of meters, as documented in Lituya Bay, Alaska, and in prehistoric examples in the Hawaiian islands. Other phenomena such as the blast wave and fallout of the ejecta blanket would also create disturbances. In the complex geometry of the Gulf and Caribbean, such waves would have been locally damped, focused, amplified, and reflected; seiches (sloshing effects) would have been set up. The waves themselves could generate destabilization, e.g., of delta fronts, generating large turbidity currents.

A number of talks and posters at this meeting will address the sedimentological interpretation of coarse-grained deposits of KT age around the Gulf of Mexico and Caribbean, presenting diverse points of view. While biostratigraphers may still and forever disagree with regard to the "precise" placement of these beds biostratigraphically, it is up to sedimentologists to produce physically plausible explanations for these beds, irrespective of their age. Careful examination, description, and analysis will elucidate the sedimentary processes responsible for generating these beds, and will help us to determine, for example, the water depths at the time of deposition (and during bracketing times), and the amount of time represented by the beds. My examination of the KT boundary unit in Texas (Brazos) and my preliminary study of outcrops in northeastern Mexico lead me to conclude, as have a number of others, that the nature these beds is compatible with a megatsunami scenario. Many exciting details in the reconstruction of this scenario are yet to be worked out!

NEW EVIDENCE FOR TERRESTRIAL ECOSYSTEM COLLAPSE AT THE KT AND PERMIAN/RIASSIC BOUNDARIES. H. Brinkhuis and $\mathrm{H}$. Visscher, Laboratory of Palaeobotany and Palynology, University of Utrecht, Heidelberglaan 2, 3584 CS Utrecht, The Netherlands.

A new Cretaceous/Teriary (KT) boundary site was recently discovered in ancient man-made caves at Geulhem, in the vicinity of the Maastrichtian type-section in The Netherlands. Micropaleontological and palynological evidence indicates that this section includes an extraordinarily well-developed earliest Danian succession. At the locality, the earliest Danian "boundary clay" interval is represented by several individual clay layers separated by more calcareous units and totals some $125 \mathrm{~cm}$.

The section can be confidently assigned to the latest Maastrichtian and earliest Danian. The KT transition is complete in terms of its micropaleontological and palynological record. In the latest Maastrichtian portion of the section, the uppermost part of the Thalassiphora pelagica subzone of the Palynodinium grallator (dinoflagellate cyst) zone can be recognized. The earliest Danian interval is represented by the NPI (pars; nannoplankton; A. J. T. Romein, personal communication), P0 (planktonic foraminifer; J. Smit, W. J. Zachariasse, personal communication) and Carpatella cornuta (dinoflagellate cyst) zones. Preliminary evidence from other disciplines (studies in progress) confirms the completeness of this newly found $K T$ boundary site.

In addition to rich dinoflagellate cyst assemblages, which cross the KT boundary without any evidence of extinction, the boundary clay layers yield unparalleled abundances of bryophyte spores. This phenomenon is interpreted to reflect a conquest and domination of the terrestrial domain by bryophytes following a major terrestrial ecosystem collapse. Bryophytes are well known to be resistant to adverse environmental conditions, and are the first to colonize spaces where higher land plants have disappeared. Since the pattem is consistent over $125 \mathrm{~cm}$ of sediment following the KT boundary, it is suggested that this phase lasted at least $5000 \mathrm{yr}$ prior to recovery of the terrestrial ecosystem and reestablishment of stable vegetations.

Reinterpretation of palynological successions reponed earlier from sequences straddling the Permian/Triassic (P/Tr) boundary in southem Europe now suggests great similarity with the KT succession discussed above. It was already demonstrated that at the $\mathrm{P} / \mathrm{Tr}$ junction a reflection of a worldwide collapse of terrestrial ecosys tems with concomitant loss of standing biomass is indicated by unprecedented abundances of fungal remains. Directly succeeding this "fungal event," one may frequently note high abundances of palynomorphs generally interpreted as marine phytoplankton of unknown affinity (so-called acritarchs). However, restudy of these palynomorphs now suggests that many of these elements may, in fact, be assigned to bryophyte spores.

Thus, both the Paleozoic/Mesozoic and Mesozoic/Cenozoic transitions appear to be marked by an overall similar array of events, both reflecting severe disruption of the terrestrial ecosystem, followed by gradual recovery. It is proposed that these biotic crises in terrestrial ecosystems could have been triggered by the effects of acidifying pollution of the atmosphere. Volcanic emissions or ejecta effects of meteorite impact(s) may be taken into consideration as the underlying mechanisms.

\section{RIFT-FLOODING EPISODES AROUND 65 Ma AS CAUSES OF ABRUPT SEA-LEVEL FALLS: DID THE KT IMPACT HAPPEN DURING A TIME OF FREQUENT CATASTRO-} PHES? K. Burke, Department of Geosciences, University of Houston, Houston TX 77204-5503, USA.

Catastrophic filling of the kind of subaerial, sub-sea-level depression commonly formed during the opening and the closing of ocean basins is the only known mechanism, other than glacial eustasy, capable of lowering global sea level by tens of meters within a few thousand years [1].

At present there is no evidence of the existence of large continental ice sheets that could have induced significant glacial eustatic changes during the Late Cretaceous. But several continental rift systems were evolving toward ocean basin formation during the $85 \mathrm{Ma}$ to $50 \mathrm{Ma}$ interval (Table I and Fig. 1). Episodes of the sudden 
spilling of ocean waters into deep subaerial depressions in some of these rifts could have lowered sea level in discrete, rapid, and substantial steps and may in that way have contributed to the exposure of continental shelf areas, to the destruction of reefs, and to the extinction of some life forms.

Ocean spill events are recognized in closing ocean basins where evaporites have formed during low-stands as happened in the Mediterranean at $6 \mathrm{Ma}$ during Messinian time [2] and in the North Caspian depression during the Late Permian [3]. Spill events are also recognizable from rifts with evaporites that are linked to ocean opening such as those of the South Atlantic, formed during Aptian time at about $115 \mathrm{Ma}[1]$ and those of the Gulf of Mexico, formed during the late Jurassic at about $155 \mathrm{Ma}$ [4]. Three of these spills have been estimated to have lowered global sea level by about $10 \mathrm{~m}$ [1] and the Permian spill was probably larger. The Arctic Ocean was tectonically isolated during the Late Cretaceous and Early Cenozoic (Fig. I and [5]). Its waters may also have been isolated from the world ocean for pan of that time. Ocean spills into an Arctic basin, which then had an area in excess of one million square kilometers, would have reduced global sea level considerably.

A 10-m lowering of sea level is sufficient to have catastrophic effects on shallow-water life forms especially when, as during the Late Cretaceous, large areas of the continents are flooded. Catastrophic changes in the area of continent flooded are also likely to modify the chemistry of the linked ocean and atmosphere system by rapidly inducing changes in $\mathrm{CO}_{2}$ concentration. Where a deep continental rift was filled to the brim by a lake, as the Lake Baikal and Lake Tanganyika rifts are today, the transition to ocean would have had no effect on global sea level. If the rift was partly filled by a lake, the transition would have reduced sea level by less. In temperate latitudes and near the equator lake-filled rifts are probable, although rift shoulders are likely to reduce drainage into the rifts. At high latitudes and in desert latitudes dry rifts are more likely. Most of the rifts in Table I lay in high latitudes at the critical time and there is a strong possibility that they were not occupied by deep lakes. Erwin [6] characterizes the late Pernian as involving successive, rapid, sea-level-lowering events. Flooding the North

TABLE 1. Late Cretaceous and Paleocene Rift transitions to oceans and possible associated global sea level falls.

\begin{tabular}{|c|c|c|c|c|}
\hline Rift & $\begin{array}{l}\text { Paleolatitude } \\
\text { (degrees) }\end{array}$ & $\begin{array}{l}\text { Approximate } \\
\text { Oldest Ocean } \\
\text { FloorAge } \\
\text { (Ma) }\end{array}$ & $\begin{array}{l}\text { Approximate } \\
\text { Length } \\
(\mathbf{k m})\end{array}$ & $\begin{array}{c}\text { Estimated } \\
\text { Maximum } \\
\text { Global Sea } \\
\text { Level Drop } \\
\text { (m) }\end{array}$ \\
\hline Labrador Sea & 55 & 80 & 1000 & 3 \\
\hline Baffin Bay & 65 & 60 & 1000 & 3 \\
\hline North Atlantic* & 55 & 53 & 3000 & 10 \\
\hline $\begin{array}{l}\text { South Coast } \\
\text { of Australia }\end{array}$ & 65 & 80 & 2000 & 7 \\
\hline Arctic Americar & & & & \\
\hline Basin & 70 & 53 & 1500 & 5 \\
\hline South Caspian & 35 & 70 & 1000 & 3 \\
\hline Black Sea & 35 & 70 & 1000 & 3 \\
\hline
\end{tabular}

Sea level is likely to have fallen abruptly at a time within a few million years of the age of formation of the oldest ocean floor.

"North Atlanic effect likely to have been reduced because of Icelandic plume volcanism.

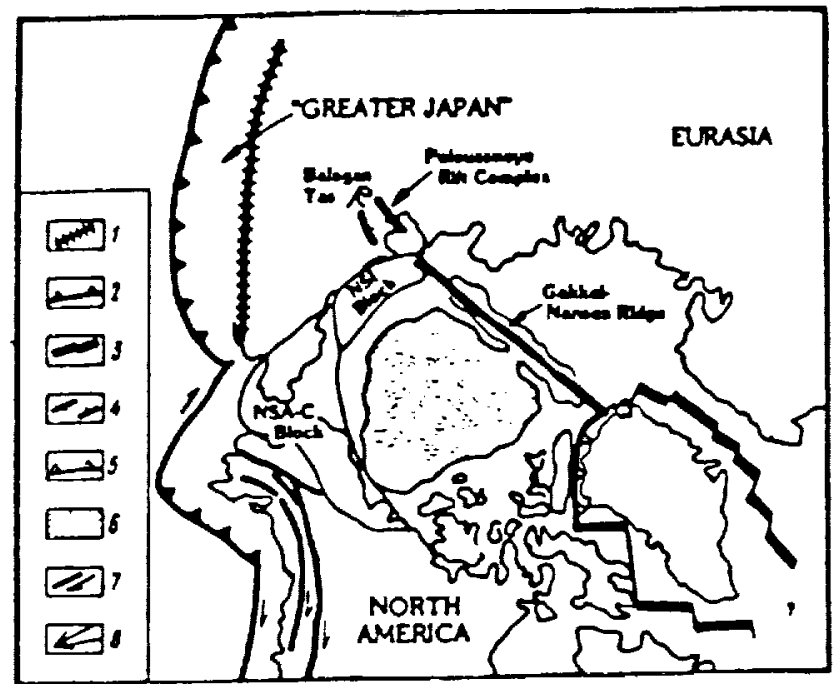

The Arctic in the Mid-Cenozoic (60 to $40 \mathrm{Ma}$ B.P.)

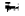

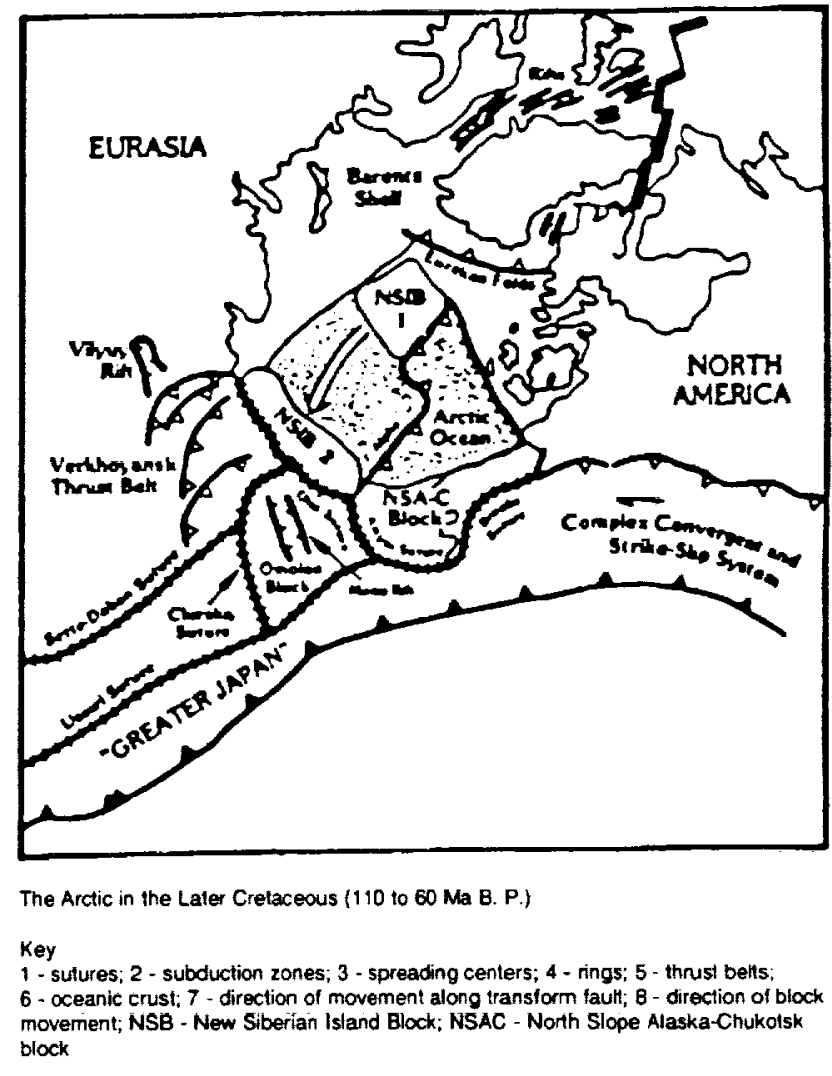

Fig. 1. Isolation of the Arctic Ocean basin.

Caspian depression, a closing ocean basin at the time $[1,3]$, and flooding possible sub-sea-level foreland basins in the Zechstein and West Texas may have contributed to these changes.

The long-term effects of spill episodes on sea level are small because they are dwarfed by changes in spreading center volume and changes in mass distribution in the shallow mantle. It is the sudden nature of the spills that warrants the use of the term catastrophic and it is the same suddenness that may have led to catastrophic effects on life forms and the environment. 
Conclusions: Because of an unusual likelihood of ocean spills associated with an unusually large number of rift to ocean basin transitions and also because of possible spills into a then-isolated Arctic Ocean basin, the $20 \mathrm{~m}$.y. interval bracketing 65 Ma may have been a time of unusually frequent episodes of sudden sea-level fall and for that reason an interval of episodic, rapid, environmental change.

Discriminating the effects of the great Chicxulub impact from this background of repeated catastrophe represents a challenge that is likely to require the collaborative efforts of a variety of specialists including geochemists, paleobiologists, stratigraphers, and tectonicians. The two different kinds of catastrophe should have had recognizably different effects on sea level, on the environment, and on biota. Extinction of some life forms would be a feature common to both kinds of catastrophe.

Possible effects on sea level from rift initiation have been analyzed by Cathles and Hallam [6]. The model presented here is somewhat different and indicates some specific examples as research targets. Testing the model, especially by studying the sequence stratigraphy of the deeply buried sediments deposited during rift to ocean transitions, may prove feasible.

References: [1] Burke K. and Sengor A. M. C. (1988) Marine Geol., 83, 309-312. [2] Hsu K. J. et al. (1973) Nature, 242, 240244. [3] Burke K. (1977) Ann. Rev. EPSL, 5, 371-398. [4] Burke K. (1975) Geology, 3, 613-616. [5] Burke K. (1984) Geology, 27, 4, 189-198. [6] Erwin P., this volume. [7] Cathles L. and Hallam A. (1991) Tecto$$
\text { N94- } 28297
$$

ᄀ IN SEARCH UF NEMESIS. S. Carison, 1. Culler, R. A. Muller, M. Tetreault, and S. Perlmutter, Lawrence Berkeley Laboratory, Berkeley CA 94720 , USA.

The Nemesis model [1] was proposed in 1984 to account for a reported periodicity in mass extinctions [2]. In this model a companion star (probably a red dwarf) orbiting the Sun at a distance of about 3 light years triggers a comet shower once per orbit. This theory contained the first proposal that apparently extended extinctions could in fact be a series of stepwise events in a comet shower [see 3].

Since the original proposal, both the periodicity and self-consistency of the Nemesis theory has been strongly debated. In detailed Monte Carlo simulations, Hut [4] concluded that the orbit was stable for about 1 g.y., consistent with the original model [i] ]. However, others argued that the orbit was unstable. Clube and Napier [5] argued that the effects of giant molecular clouds (GMCs) dominate and decrease the lifetime to about 0.1 g.y. However, Morris and Muller [6] pointed out that most GMCs are too diffuse to have such an effect and that gravitational scattering from randomly passing stars dominates. Other authors assumed that a 1-g.y. lifetime was too short to be compatible with the nearly 5-g.y. lifetime of the solar system; however, the original paper [1] argued that the lifetime at formation was approximately 5 g.y., and has been decreasing linearly ever since; see, for example, Hut [4]. For more details on this debate, see Perlmutter et al. [7].

What to Look For-Red Dwarfs: The parallax of all stars of visual magnitude greater than about 6.5 has already been measured. If Nemesis is a main-sequence star 1 parsec away, this requires Nemesis's mass to be less than about 0.4 solar masses. If it were less than about 0.05 solar masses it's gravity would be too weak to trigger a comet storm [1,3]. If Nemesis is on the main sequence, this mass range requires it to be a red dwarf.

A red dwarf companion would probably have been missed by standard astronomical surveys [8]. Nearby stars are usually found because they are bright or have high proper motion. However, Nemesis's proper motion would now be $0.0 \mathrm{I}$ arcsec/yr, and if it is a red dwarf its magnitude is about 10 - $100 \mathrm{dim}$ to attract attention.

Unfortunately, standard four-color photometry does not distinguish between red dwarfs and giants. So although surveys such as the Dearborn Red Star Catalogue list stars by magnitude and spectral type, they do not identify the dwarfs. We therefore must scrutinize every star of the correct spectral type and magnitude.

Our candidate list is a hybrid; candidate red stars are identified in the astrometrically poor Dearborn Red Star Catalogue and their positions are corrected using the Hubble Guide Star Catalogue. When errors in the Dearborn catalogue make it impossible to identify the corresponding Hubble star we split the fields so that we have one centering on each possible candidate. We are currently scruti-
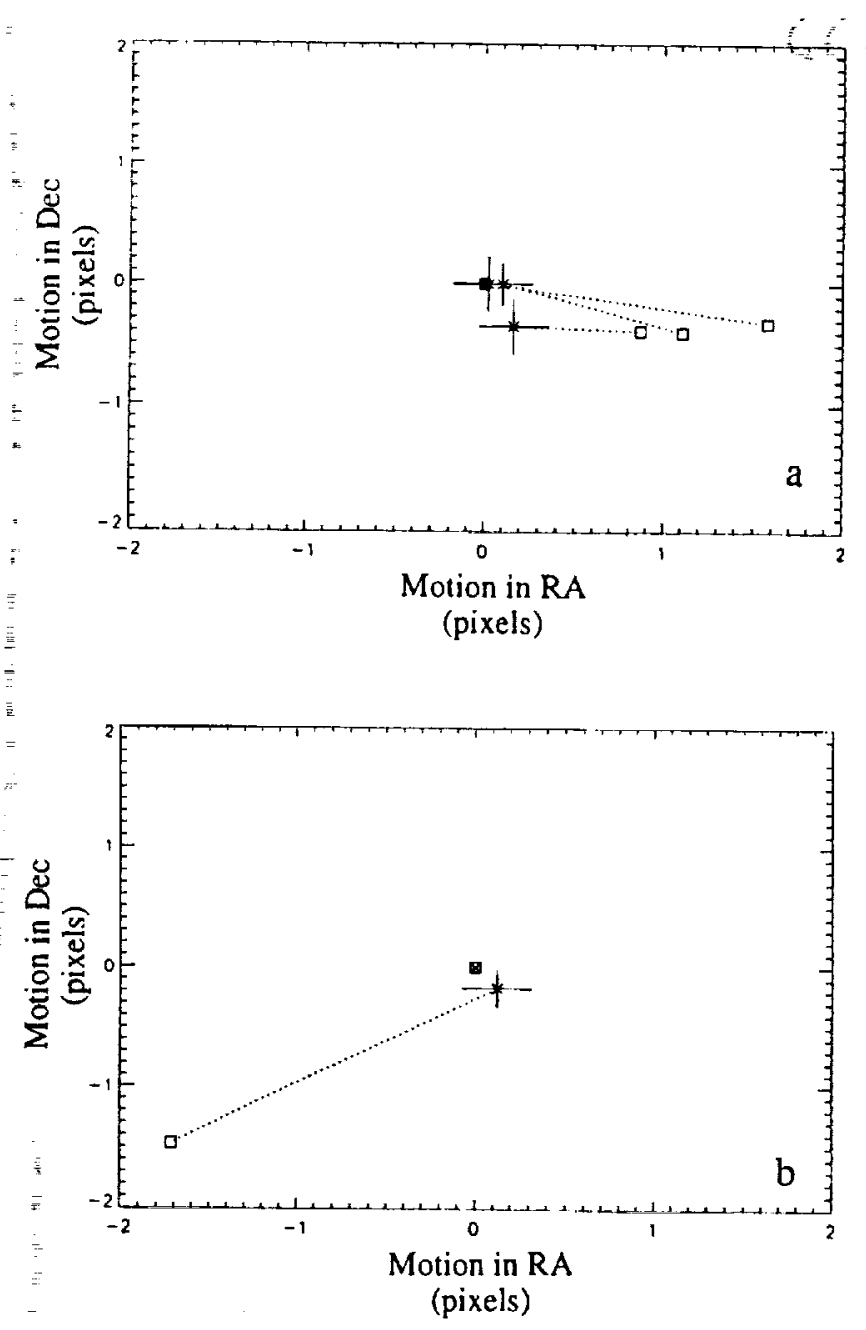

Fig 1. (a) Shows the relative positions measured for one candidate on four different nights. Squares show the expected locations of a star at I parsec on the same night. Dashed lines match data to expectations. Data is consistent with a distant star, not with Nemesis. (b) Shows a star that can be rejected with only twoobservations. 

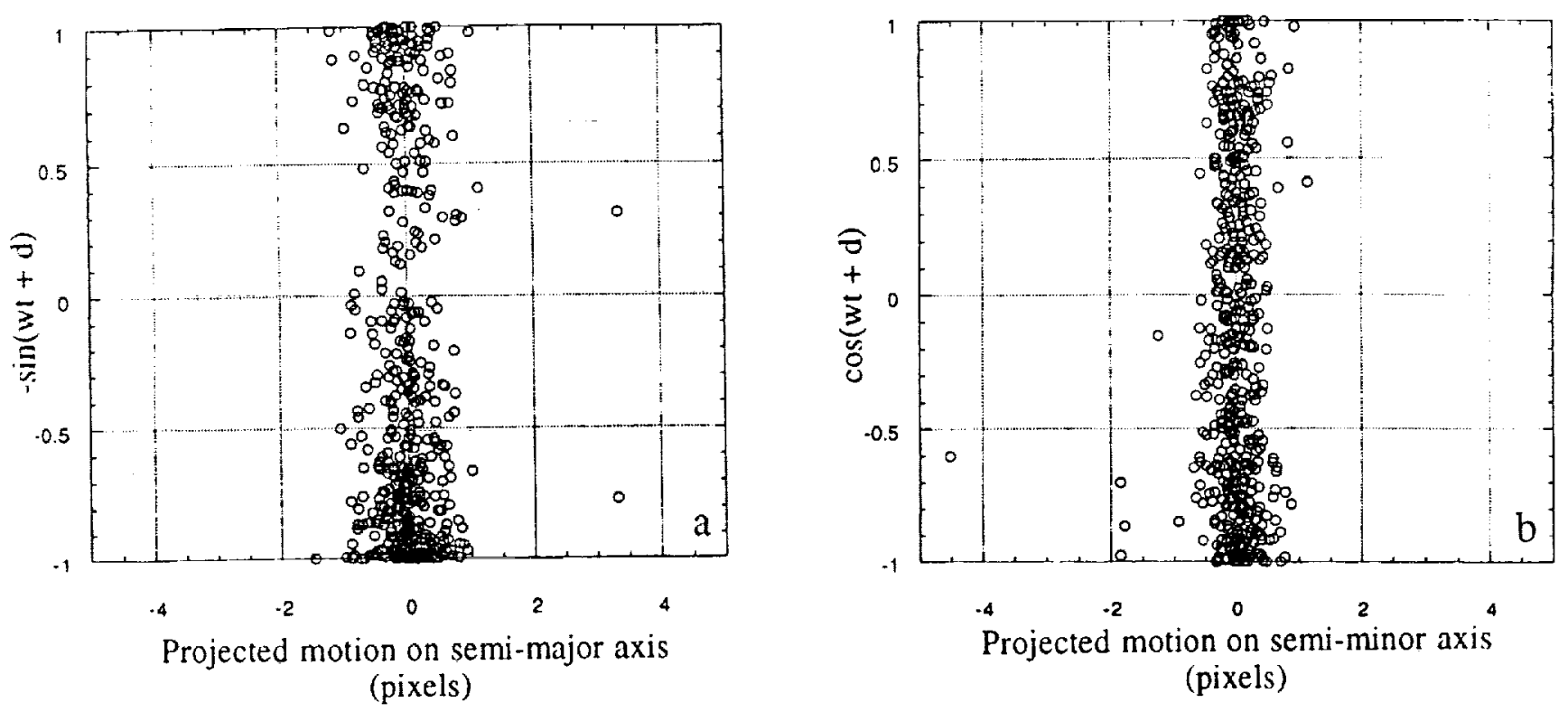

Fig. 2. Summarizes the data as of October 1993.(a) Shows the projected motion of all candidates along the semimajor axis of their parallax ellipse and(b) shows the motion along the semiminor axis vs. the relevant trigonometric factors. Nemesis should fall on a straight line in both plots.

nizing 3098 fields, which we believe contain all possible red dwarf candidates in the northern hemisphere.

Since our last repor [ 7$]^{\text {the }}$ analysis and database software has been completely rebuilt to take advantage of updated hardware, to make the data more accessible, and to implement improved methods of data analysis. The software is now completed and we are eliminating stars every clear night.

Finding Nemesis: A star at 3 light years would display a parallactic motion of 2.5 arcsec over 6 months. We are collecting digitized images of $6 \times 6$ arcmin fields centered on each of the candidate stars. Images of each star are taken several months apart and aligned using the field stars. The candidate's apparent motion is then measured. The plate scale of our CCD is 0.7 arcsec per pixel and we can routinely locate the centriod of a candidate to within 0.2 pixels. Thus, Nemesis's peak-to-peak displacement should be discemible at about the $18 \sigma$ level.

Figure I shows two candidates that have been eliminated. The data mark the candidate's motion in pixels (zero is defined as the location at which it was first observed) on different nights. Also plotted (squares) are the locations at which a star at I parsec would be expected to be on the same nights. The dashed lines show which measurements go with which squares. Figure la summarizes four measurements. Figure $1 b$ shows that we can easily eliminate candidates with only two observations.

Figure 2 summarizes the data taken as of October 1993. Measured along the semimajor axis a star executes a motion given by $P_{\text {major }}=-(1 / d) \sin (w t+d)$, where $d$ is the distance to the object in parsec, $w=2 \pi / 365$ days, $t$ is the time between observations in days. The phase angle $d$ is set by the date of the first observation. The motion along the semiminor axis is given by $P_{\text {minor }}=[(1 / d)$ $|\sin (L)|] \cos (w t+d)$ where $L$ is the heliocentric latitude of the candidate. The plots show the observed motion for all the candidates projected along the semimajor and semiminor axes of their respective parallax ellipses vs. the relevant trigonometric factors. Observations of a nearby star should fall on a straight line through the origin. For Fig. 2a the slope will be equal to the distance in parsec. For Fig. $2 b$ it is the distance in parsec divided by $\sin (\mathrm{L})$.

At present we are limited only by available observing time. When this abstract was written we were eliminating typically 10 candidates every clear night.

References: [1] Davis M. et al. (1984) Nature, 308, 715-717. [2] Raup D. M. and Sepkoski J. J. (1984) Proc. Nat. Acad. Sci., 8I, 801-805. [3] Muller R. A. (1985) The Search for Extraterrestrial Life; Recent Developments, 233-243. [4] Hut P. (1984)Nature, 3II, 638-640. [5] Clube S. V. M. and Napier W. M. (1984) Nature, 3II, 635-636. [6] Morris D. E. and Muller R. A. (1986) Icarus, 65, I12. [7] Perlmutter S. el. al. (1990) GSA Spec. Paper 247, 87-9]. [8] van de Kamp P. (1982) Binary and Multiple Stars as Tracers of Stellar Evolution, 81-103.

$$
\text { c.s.t T.28 P.9 }
$$

NEW MINERALOGICAL AND CHEMICALCONSTRAINTS ON THE NATURE OF TARGET ROCKS AT THE CHICXULUB CRATER. E. Cedillo P.', P. Claeys'2, J. M. Grajales-N.', and W. Alvarez ${ }^{2}$, Instituto Mexicano del Petroleo, Apartado Postal 14-805, 07730 DF, Mexico, ${ }^{2}$ Department of Geology and Geophysics, University of Califomia, Berkeley CA. 94720 , USA.

The Chicxulub Crater melt rocks are being found to display striking mineralogical and chemical features. The most important mineralogical and textural features are related to (1) partial melting of the rock and the preexisting minerals (quartz, plagioclase, and anhydrite), and (2) textural features developed in pyroxenes, feldspars, and magnetite that provide clues to the crystallization behav- 
ior of the melts. Chemical analyses of minerals and whole rocks display a wide range of compositions. Core samples used for the present study come from the Yucatan-6(Y-6) and Chicxulub- $1(\mathrm{CH}-$ 1) wells.

Preexisting minerals exhibit numerous features indicative of partial melting. In some shocked quartz grains, this process has destroyed lamellar features, while in others the lamellae were only partially destroyed. Quartz xenoclasts show a rim of melted and recrystallized quarz surrounded by a reaction corona of pyroxenes, similar to those found in the Manicouagan impact melts [1]. Plagioclase crystals show sievelike melting textures consisting of a network of glassy material following crystallographic directions. Textural evidence also supports parial melting of anhydrite; the physical-chemical conditions under which this process took place are not completely understood.

Skeletal crystals of pyroxene, feldspar, and ilmenite provide clues to the crystallization behavior of the melts. The pyroxene is found as small crystals $(10 \mu \mathrm{m})$, some only partially crystallized, which indicates supercooling. It is also common to find larger crystals of pyroxene $(70 \mu \mathrm{m})$ as reaction coronas around quartz. This texture shows competition for silica in the melt. The chemical composition of pyroxenes is characterized by high $\mathrm{Ca}$ content; the analyses plot outside the normal pyroxene quadrilateral, to the calcic side of normal diopside. Although X-ray diffraction lines of melt pyroxene are similar to those of diopside, its composition is closer to fassaite. The abundance of $\mathrm{Ca}$-rich pyroxenes in the melt rocks is strong evidence for the participation of platform carbonate sediments in the genesis of melts at Chicxulub.

Feldspars were formed from glass derived from the melting of basement rocks. The chemical composition ranges from albite to andesine, supporting a variety of sources for the glass, as pointed out earlier [2-6]. Chemical analyses of glasses show the same variation in composition as their associated plagioclases, indicating that they have a common origin.

The basement rocks were the source of silica for the pyroxenes and plagioclases, as shown by xenoclasts found in the melts of $\mathrm{Y}$ $6[4]$ and by the abundance of shocked quartz grains of igneous and metamorphic origin found in KT boundary sediments [7]. The ilmenite shows skeletal growth indicative of supercooling, which is also supported by the absence of exsolution.

In summary, the mineralogy indicates that two groups of rocks (platform carbonates and basement) were involved in the genesis of melt rocks at Chicxulub. The relative contribution of the two sources determines the final composition of melt rocks. On the other hand, the abundance of xenoclasts in the melt rocks played an important role in the thermal behavior of the melts, favoring a greater cooling rate. This is the case of melts found in the samples of $Y-6$, in contrast to those of Chicxulub-1. Work in progress is focused on the chemical composition of glasses in order to constrain the importance of target rocks as source for melt rocks, vaporization products, and tektites of the KT boundary.

Acknowledgments: The authors wish to thank the permanent suppon of PEMEX and the Instituto Mexicano del Petroleo. We also express our gratitude to the late Dr. S. V. Margolis, who participated in the microprobe analytical work at the beginning of the investigation.

References: [1] Floran R. J. et al. (1978)JGR, 83, 2737-2759. [2] Swisher C. C. Ill et al. (1992)Science, 257, 954-958. [3] CedilloPardo. E. et al. (1992) GSA Abstr. with Prog.. 24, A333. [4] Quezada J. M. et al. (1992) LPS XXIII, 1121-1122. [5] Sharpton V. L. et al.
(1992) Nature, 359.819-821. [6] B lum J. D. and Chamberlain C. P. (1992) Science, 257, 1104-1107. [7] Owen M. R. et al. (1990) GSA Spec. Paper 247, 343-347.

SULFUR ISOTOPE STUDY OF HIGH-CALCIUM IMPACT GLASSES FROM THE KT BOUNDARY. M. Chaussidon ${ }^{1}, \mathrm{H}$. Sigurdsson', and N. Metrich', 'CRPG/CNRS, 54501 Vandoeuvre, France, ${ }^{2}$ Graduate School of Oceanography, University of Rhode Island, Narragansett RI 02882, USA, 'Laboratoire Pierre Sue, CE/ Saclay, 91191 Gif sur Yvette, France.

High-Ca yellow glasses form a volumetrically minor component of the impact spherules found in the KT boundary deposit in Haiti, but these glasses contain valuable information about lithology of the geologic terrane at the impact site. The high- $\mathrm{Ca}$ glasses define a mixing trend with abundant high-Si glasses, which led to the hypothesis that they are derived from fusion of $\mathrm{Ca}$-rich sediment in presence of silicate melt [1]. Two different sources of $\mathrm{Ca}$ have been proposed for the yellow glasses, either anhydrite-rich evaporitic terrane, as suggested by their high $S$ content and elevated $\delta^{34} S$ (13.2 $\pm 4 \%$, one sample) [2], or plat form carbonates as suggested by their high $\delta^{1 \times} O$ values ( $13.6 \pm 0.8 \%$, three samples) [3]. These two hypotheses have important and radically different implications for atmospheric and other environmental effects following bolide impact: either global cooling due to sulfate aerosol formation [4] or greenhouse effect because of increased $\mathrm{CO}_{2}$ concentration in the atmosphere. Because of the correlations observed between $S$ and $\mathrm{CaO}$ in the yellow glasses [2], we conducted a detailed $\mathrm{S}$ isotopic study of 20 high-Ca yellow glass particles in order to constrain sources of $\mathrm{S}$ and $\mathrm{Ca}$.

Sulfur isotopes were determined with ims $3 f$ ion microprobe, using an $\mathrm{O}^{-}$primary beam and analyzing secondary $\mathrm{S}^{-}$ions at a mass resolution of $\sim 3500[5,6]$. Instrumental mass fractionation was determined $\left(\alpha_{\text {insir }}=0.9547 \pm 2.8 \%\right.$ ) on high-Ca synthetic glass standards with $0.8-1.2 \mathrm{wt} \% \mathrm{SO}_{3}$, dissolved mainly as sulfate and having $\delta^{34} S$ of $24.4 \%$. Analytical uncertainty of the $\delta^{34} S$ values is

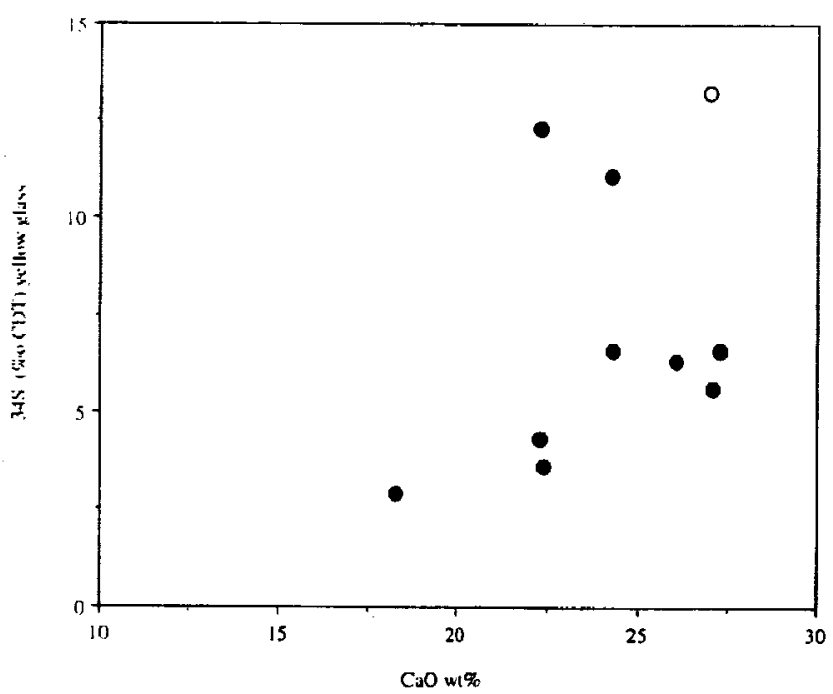

Fig. I. Mean $\mathrm{CaO}$ content vs. $\delta^{14} \mathrm{~S}(\%, \mathrm{CDT})$ in high- $\mathrm{Ca}$ and high- $\mathrm{S}$ yellow impact glass particles from the $K T$ boundary in Haiti. Open circle shows re sults from an earlier study [2]. 
between $1.5 \%$ and $5 \%$, depending mainly on $\mathrm{S}$ content. The yellow glasses are heterogenous in terms of both $S$ and $\delta^{34} S$ values. Their $\mathrm{S}$ contents range from 0.3 to $1.25 \mathrm{w} 1 \% \mathrm{SO}_{3}$. The spectral position of the $\mathrm{S} \mathrm{K \alpha}$ line in the electron microprobe shows that $\mathrm{S}$ speciation is $\sim 94.5 \%$ sulfate in the high-Ca glass (sulfate/sulfide $=17.2$ ), in agreement with high $O$ fugacity inferred from Mössbauer spectra [7]. Melting experiments with gypsum and andesite have reproduced the high-Ca glass trend, both for major oxides and $S$ content [2]. A S geothermometer, calibrated by melting experiments, indicates that the crystal-free glasses were quenched in the range $1257^{\circ}-$ $1360^{\circ} \mathrm{C}$.

The $8^{34} \mathrm{~S}$ values range between $2.9 \%$ and $14.5 \%$, confirming earlier results [2]. A strong isotopic heterogeneity is observed at all scales, between $2.5 \pm 5.1 \%$ and $10.9 \pm 1.9 \%$ within a single glass particle, and between $2.9 \pm 6.8 \%$ and $12.3 \pm 3 \%$ between different particles. This degree of isotopic heterogeneity is not known in any terrestrial volcanic glasses [8] and was not observed in melting experiments [2], which produced glasses with homogenous $\delta^{34} \mathrm{~S}$ values, within analytical uncertainty $\left(2.8 \%\right.$ ). The variations of $\delta^{34} \mathrm{~S}$ are not clearly correlated to other parameters, however, all the samples show a general tendency of increase of $8^{34} \mathrm{~S}$ values with increase of $S$ and $C$ a content (Fig. 1). The only previous yellow glass measured for $8^{34} \mathrm{~S}[2]$ follows the same trend.

The $\delta^{34} S$ values of the yellow glasses can be used to constrain the origin of S. Clearly, sedimentary rocks are the only ones that have high enough $S$ contents to account for the high $S$ content of the yellow glass. The hypothesis of an anhydrite-rich evaporitic source was tested by modeling, on the basis of mass fraction of $\mathrm{S}$ degassing calculated from known quenching temperatures of the glasses, isotopic fractionation of $S$, and the observed $\delta^{34} S$ of the yellow glasses. Assuming mixing between anhydrite $\left(41 \% \mathrm{CaO}\right.$ and $\left.59 \% \mathrm{SO}_{3}\right)$ and a silicate melt from a crustal component with roughly andesitic composition $\left(5 \% \mathrm{CaO}, 0.3 \mathrm{wt} \% \mathrm{SO}_{3}\right)$, the fraction of anhydrite re-

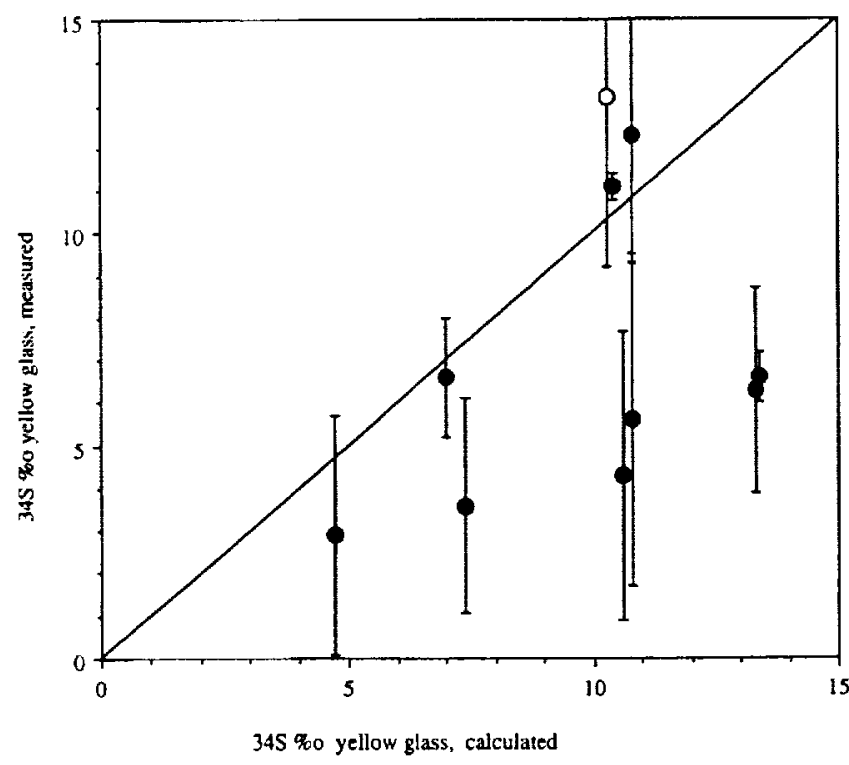

Fig. 2. Isotopic fractionation model of $\delta^{34} \mathrm{~S}$ evolution in high-Ca yellow impact glasses. Calculated $\delta^{34} S$ is based on fractionation factors from [9], quench temperature determined from $S$ geothermometry and measured sulfate/sulfide ratio in the glass. Open circle shows results from previous study [2]. quired to account for the $\mathrm{CaO}$ in the yellow glass was calculated from mass balance, ranging from 0.3 to 0.6 . This would have produced a silicate melt plus anhydrite mixture with $\sim 20-36$ wt\% $\mathrm{SO}_{3}$. The initial $\delta^{34} S$ value of this mixture, before $S$ degassing, is assumed to be that of the anhydrite. Loss of $S$ from the melt during degassing/volatilization lowered its $\mathrm{S}$ content to $0.3-1.25 \mathrm{wt} \% \mathrm{SO}_{3}$, causing isotopic fractionation. We have calculated the degree of fractionation on the basis of quench temperature (from the S geothermometer) and from dependence of the isotopic fractionation on temperature at a dissolved sulfate/sulfide ratio of 17.2 in the glasses [9]. The results shown in Fig. 2 are for a $\delta^{34} \mathrm{~S}$ of $12 \%$ (the minimum value for Cretaceous evaporite [10]). It is clear from Fig. 2 that some of the glasses have $\delta^{34} \mathrm{~S}$ values in agreement with the hypothesis of isotopic fractionation during anhydrite volatilization, while others have too low $\delta^{34} \mathrm{~S}$ values. This might be related to the different trends observed in Fig. 1. It is clear that a high-S source such as anhydrite is required, but these initial results indicate that in addition to anhydrite, other high-Ca sediments, such as carbonates, may have participated in the formation of the yellow glasses, contributing to the large $\delta^{34} \mathrm{~S}$ range. As discussed previously [4] the geology of the Chicxulub region of the Yucatan peninsula in Mexico is consistent with the above scenario, with interbedded Cretaceous evaporites and carbonates. Further $S$ and $O$ isotope measurements are in progress in order to quantify the role of these two components in the genesis of the yellow high-Ca impact glasses.

References: [1] Sigurdsson H. et al. (1991) Nature, 349, 482487. [2] Sigurdsson H. et al. (1991) Nature, 353, 839-842. [3] Blum J. D. and Chamberlain C. P. (1992) Science, 257, 1104-1107. [4] Sigurdsson H. et al. (1992) EPSL, 109, 543-560. [5] Chaussidon M. and Lorand J.-P. (1990) GCA, 54, 2835-2846. [6] Deloule E. et al. (1992) Chem. Geol., 101, 187-192. [7] Oskarsson N. et al. (1991) LPS XXII, 1009. [8] Taylor B. E. (1986) Rev. Mineral., 16. [9] Zheng Y.-F. (1990) Terra Nova, 2, 74-78. [10] Claypool G. E. et al. (1980) Chem. Geol., 28, 199-260.

FRASNIAN-FAMENNIAN BOUNDARY: MASS EXTINC. TIONS, ANOXIC OCEANS, MICROTEKTITE LAYERS, BUT NOT MUCH IRIDIUM? P. Claeys ${ }^{1.3}$, F. T. Kyte', and J.-G. Casier ${ }^{2}$, Institute of Geophysics and Planetary Physics, University of Califomia, Los Angeles CA 90024 , USA, ${ }^{2}$ Paleontology Department, Belgian Royal Institute of Natural Sciences, 29 rue Vautier, B-1040, Brussels, Belgium, ${ }^{3}$ Presently at Department of Geology and Geophysics, University of California, Berkeley CA 94720 , USA.

The Cretaceous-Tertiary boundary (KTB) debate has triggered intense search for other possible impact-induced mass extinction events in Earth history. So far, of the five major mass extinctions of organisms in the last $600 \mathrm{~m} . y$. [1], only the most recent one, the KTB $65 \mathrm{Ma}$ ago, presents abundant evidence for a major impact associated with the faunal disappearance.

The Frasnian-Famennian boundary (FFB) mass extinction took place approximately $365 \mathrm{Ma}$ ago in the Late Devonian. The International Subcommission on Devonian Stratigraphy recently defined the FFB at the base of the Famennian lower triangularis conodont zone (Fig. 1). This boundary is marked by a drastic reduction in marine biomass and ecosystem diversity. The highly productive coral-stromatoporoid reefs of the Frasnian disappeared; many bra- 


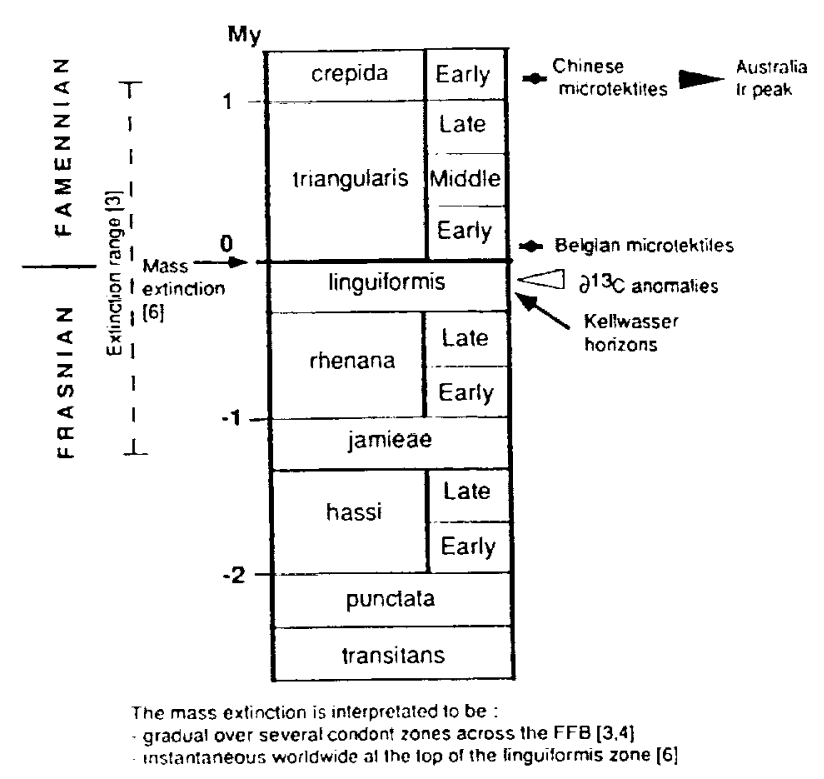

Fig. 1. Late Devonian stratigraphy, conodont zones [II], and stratigraphic position of major events. The mass extinction is interpreted to be (a) gradual over several conodont zones across the FFB $[3,4]$ or (b) instantaneous worldwide at the top of the linguiformis zone [6].

chiopods and trilobites, and all tentaculitids were wiped out; and conodonts, goniatites, ammonoids, cricoconarids, and ostracods were severely affected [2]. McGhee [3] estimates that 20\% of all families and approximately $50 \%$ of all genera disappeared. The time frame of the extinction varies according to different authors: stepwise process within the last conodont zones of the Frasnian [4], extinction of various species ranging over six conodont zones [3], an instantaneous worldwide extinction event occurning precisely at the FFB $[2,5,6]$.

Glassy spherules displaying morphological and chemical similarities to microtektites have been found near the FFB in two Late Devonian sections: Hony and Senzeille located in the Dinant Basin in Belgium [7,8]. These spherules range in size from 100 to $500 \mu \mathrm{m}$, have smooth or etched surfaces, and rounded or teardrop shapes. Their chemical composition is variable with mainly $\mathrm{Ca}$ - and $\mathrm{K}$-rich end members. The spherules have a water content of $0.001 \mathrm{wt} \%$, comparable to that of tektites from the Cenozoic strewnfields [8]. Lechatelierite and partially melted quartz grains may be present in the glass matrix [8]. In Hony the spherules are found at the very base of the Famennian lower triangularis conodont zone, only 2 to $3 \mathrm{~cm}$ above where Sandberg et al. [9] placed the FFB. In Senzeille the exact location of the spherule layer is unclear because of poor conodont biostratigraphy. Similar glassy spherules have been described in the Early Famennian crepida conodont zone in south China [10]. According to the conodont zonation timescale [11] the Chinese spherules are approximately $1.5-2 \mathrm{~m} . y$. younger than the ones recovered in Belgium (Fig. 1). They are stratigraphically associated with a $300 \mathrm{pg} / \mathrm{g}$ Ir anomaly in the Caning Basin (Australia) [12].

The Hony section was investigated to determine if a positive Ir anomaly coincided with the spherule-bearing layer. A succession of 42 samples distributed across the FFB were analyzed by radiochemical neutron activation. Near the spherule layer the samples were collected approximately every 2 to $3 \mathrm{~cm}$. The results are presented in Fig. 2. No significant positive Ir anomaly was detected in the $2 \mathrm{~m}$ of section investigated. The one-point Ir increase up to $83 \mathrm{pg} / \mathrm{g}$ over a background of $\approx 40 \mathrm{pg} / \mathrm{g}$ right at the spherule layer is inconclusive. Two similar spot increases occur in basal Famennian shales above the spherule layer. The Hony Ir result demonstrates that there is no Ir anomaly comparable in magnitude to that observed at the KTB. As in the Cenozoic, microtektite events are generally not associated with major Ir anomalies [13].

Trace-element analyses in the Hony section reveal that the chalcophile elements $\mathrm{Zn}, \mathrm{As}$, and $\mathrm{Sb}$ are correlated and increase near the FFB (Fig. 3). An increase in these elements may be linked to suboxic conditions. During the Late Paleozoic the Paleotethys ocean was probably $O$ stratified [14]. Ostracod fauna assemblages associated with the FFB are indicative of dysaerobic conditions [15]. Joachimski and Buggish [16] describe positive $\delta^{13} \mathrm{C}$ anomalies just below the FFB in sections in France and Germany. These anomalies coincide with the deposition in the uppermost Frasnian of black limestones and shales known as the lower and upper Kellewasser horizons [16]. These Kellewasser horizons are not identifiable in the Hony section based on lithology alone. However, the increase in $\mathrm{Zn}$, As, and Sb suggests that perhaps in Hony there

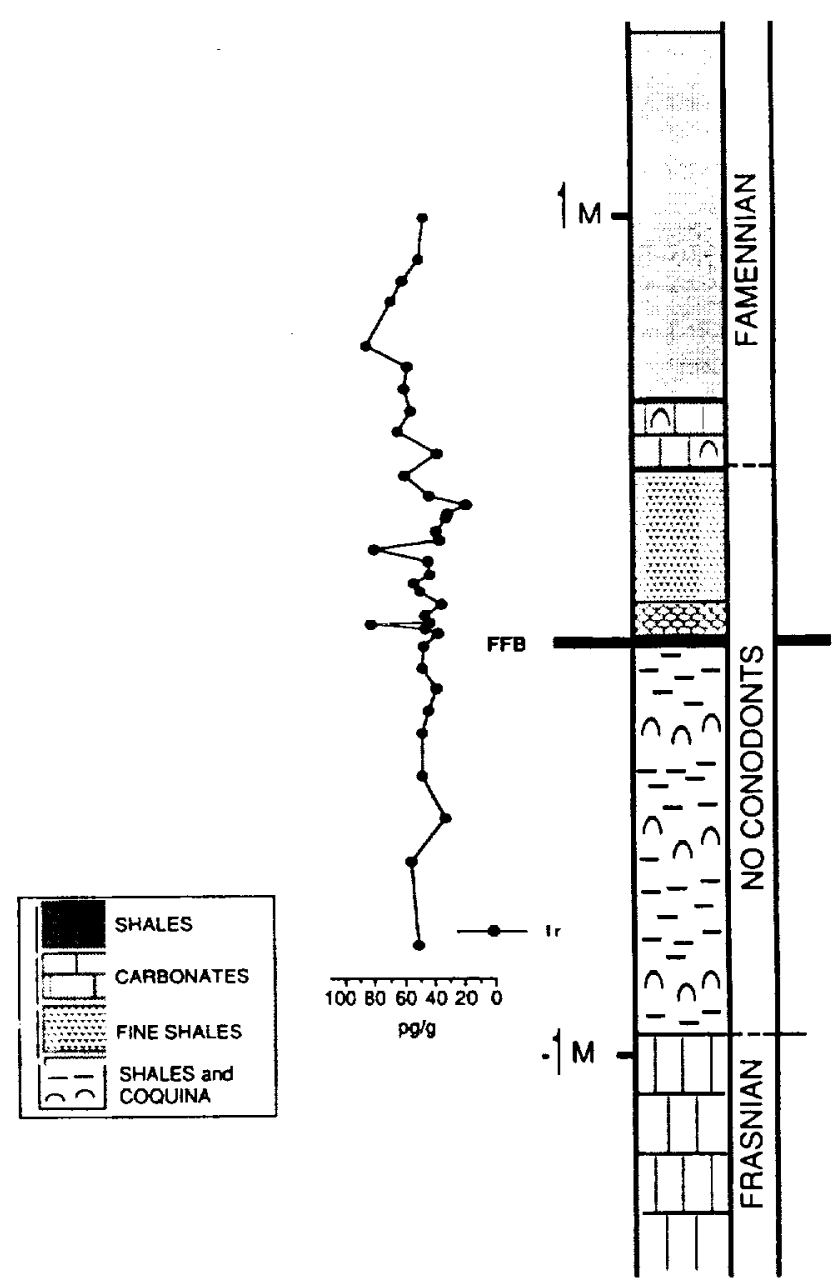

Fig. 2. Iridium profile in the Hony section (Belgium). No significant anomaly is present at the spherule layer. 


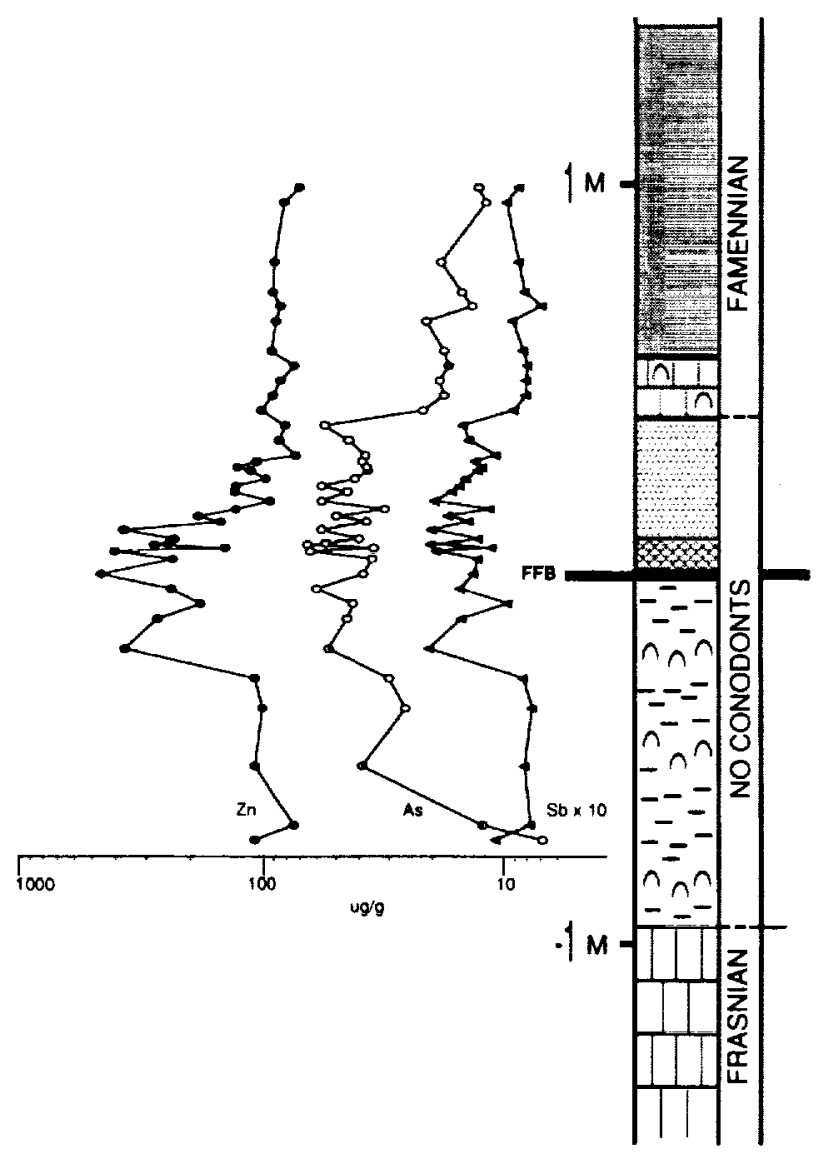

Fig.3. Chalcophile element profiles across the FFB in Hony (Belgium). The increase in $\mathrm{Zn}, \mathrm{As}$, and $\mathrm{Sb}$ may indicate the influx of suboxic water on the shelf at the FFB.

was also an input of disaerobic water into shallow marine environments at the FFB.

The FFB is marked by a succession of major events including overflow of O-depleted water on the shelf in Western Europe, impact evidence in Belgium and China, and worldwide extinction of shallow marine species (Fig. 1). These events are spread over three to four condont zones or roughly $2 \mathrm{~m}$.y. [11]. At this point the relationships between these events and thus the cause(s) of the mass extinction are unclear. Part of this problem may be due to the old age ( $365 \mathrm{Ma}$ ) of the event, the biostratigraphic resolution available, the difficulties in worldwide correlations, and too few well-preserved FFB sections.

It has been proposed that the influx of low-O water on the shelf could be responsible for the FFB mass extinction [16]. In the Dinant Basin during the entire Frasnian the coral-stromatoporoid reefs are repeatedly buried by shale deposited under $\mathrm{O}$-depleted conditions [15] and each time the reefs reappear when conditions retum to more oxygenated. Only at the FFB do they finally disappear to be replaced in the Famennian by cyanobacterial reefs [2].

The impact hypothesis also poses problems. The stratigraphic relationships between the Belgian and Chinese glassy spherules is puzzling. Do these two occurrences correspond to one global impact event or to two smaller events separated by $\approx 1.5 \mathrm{~m}$.y.? The occurrence of microtektitelike glass in two Belgian sections lends support to a possible impact closely associated with the FFB. The lack of a positive Ir anomaly in Hony indicates that the FFB impact differs, perhaps in magnitude or type of bolide, from the KTB event. It appears more similar to the four tektite-producing impacts that took place in the Cenozoic.

References: [I] Raup D. M. and Sepkoski J. J. Jr. (1982) Science, 2I5, 1501-1503. [2] McLaren D. J. (1970) J. Paleont., 44, 801-815. [3] McGhee G. R. (1989) in Mass Extinctions: Processes and Evidences (S. K. Donavan, ed.), 133-151. [4] Becker T. R. et al. (1991) Hist. Biol., 5, 183-196. [5] McLaren D. J. (1985) Geology, 13, 170-172. [6] McLaren D. J. and Goodfellow W. D. (1990) Annu. Rev. EPSL, I8, 123-171. [7] Claeys P. et al. (1992) Science, 257, 1102-1104. [8] Claeys P. and Casier J.-G. (1993) EPSL, submitted. [9] Sandberg C. A. et al. (1988) Cour. Forsch-Inst. Senckenberg, 102, 267-307. [10] Wang K. (1992) Science, 256, 1546-1549. [11] Ziegler W, and C. A. Sandberg (1990) Cour. Forsch-Inst. Senckenberg, I2I, 1-115. [12] Nicoll R. S. and P. E. Playford (1988) Geol. Soc. Austral. Abstr., 291, 296. [13] Glass B. P. (1990) Tectonophys., 171, 393-404. [14] Kammer T. et al. (1986) Lethaia, 19, 109-121. [15] Casier J.-G. (1987) Rev. Paleobiol., 6, 193-204. [16] Joachimski M. M. and Buggisch W. (1993) Geology, 21, 675-678.

THE KT BOUNDARY EXTINCTION: A GEOLOGICALLY INSTANTANEOUS OR GRADUAL EVENT? EVIDENCE FROM DEEP-SEA BENTHIC FORAMINIFERA. R.Coccioni and S. Galeotti, Istituto di Geologia, 61029 Urbino, Italy.

The Cretaceous/Tertiary (KT) boundary event, which 65 Ma ago led to a well-known global mass extinction, is one of the most discussed subjects in earth sciences. A lively debate developed in the past decade between those who favor a gradual disappearance of late Cretaceous fauna and flora [1] and those who argue for a catastrophic extinction event [2]. The changes in the benthic foraminiferal community structure across the KT boundary have been intepreted differently including multiple mechanisms. According to previous studies, the deep-sea benthic foraminifera were not severely affected by the KT boundary event [3]. However, most data on the rate of benthic foraminiferal extinction and distribution across the KT boundary cannot be compared because different methods and taxonomic concepts were followed by different authors $[4,5]$. In particular, conceming the methods, a very highresolution (millimeter-scale) study on the benthic foraminiferal record at the KT boundary transition had not been done. The present study is therefore concerned with the development of such a very high-resolution investigation on deep-sea benthic foraminiferal distribution across the KT boundary at Caravaca (Southeast Spain)(Fig. 1). Thirty-nine samples were collected from $80 \mathrm{~cm}$ below to $120 \mathrm{~cm}$ above the KT boundary clay layer, encompassing the last $20 \mathrm{k} . \mathrm{y}$. of the Cretaceous and the early $60 \mathrm{k} . \mathrm{y}$. of the Paleocene. The 7-cm-thick KT boundary clay layer, which spans $5-6$ k.y. [6] was sliced up, every $7 \mathrm{~mm}$ to obtain II samples. All the specimens from the fraction greater than $125 \mu \mathrm{m}$ were picked, classified at generic level, and counted. More than 100 species were identified belonging to 59 genera, among which 32 are calcareous-hyaline genera and 27 are agglutinated genera. Based on benthic foraminifera, the terminal Maastrichtian-basal Danian sediments at Caravaca were deposited in a middle bathyal environment (paleodepth $600-1000 \mathrm{~m}$ ). 


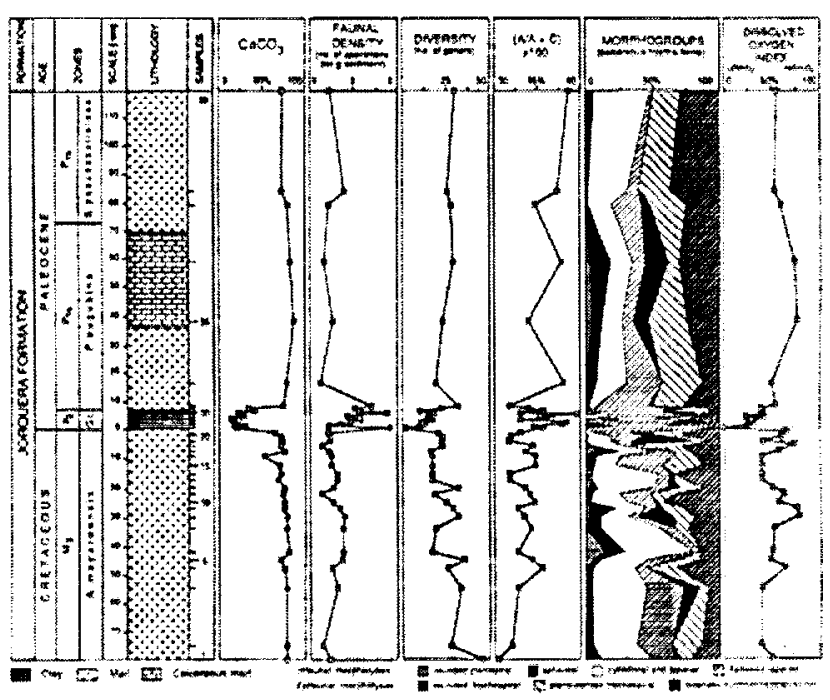

Fig.1. Faunal parameter changes in benthic foraminiferal assemblages across the KT boundary at Caravaca. In order to document changes in benthic foraminiferal assemblages across the KT boundary and to determine how the deep-sea benthic foraminifera responded to the $K T$ boundary event, the faunal density expressed as number of specimens per gram of sediment, the diversity expressed as number of genera, and the agglutinated-to-agglutinated and calcareous-hyaline ratio percent have been taken into consideration. Moreover, all the calcareous-hyaline taxa were allocaled into seven morphogroups [7] and assessed as aerobic, intermediate, and anaerobic forms [8]. All these parameters, together with the calcareous-hyaline morphogroup distribution and the record of the dissolved oxygen index (DOI), expressed as the aerobic-toaerobic and anaerobic forms ratio percent, have been plotted against the chronostratigraphy, lithostratigraphy, planktonic foraminiferal biostratigraphy [9]. and carbonate content. Note the marked fluctuation of all the parameters at the KT boundary.

Our data show a complex history of deepwater benthic foraminiferal decimation, survivorship, and recovery, and a close coupling between the surface- and deepwater ecosystems, the collapse of the planktonic environment deeply disturbing the deep-oceanic biota. In terms of biotic decimation, survivorship, and recovery, a distinct four-step pattern was recognized (Fig. 2). The influence of the KT boundary event on deepwater benthic foraminifera was dramatic, consisting of a sudden and marked decrease in diversity that is equivalent to a taxonomic decimation associated with a concurrent bloom of infaunal-deposit-feeder, low-O-tolerant forms. Such a dramatic faunal change points to an exceptionally large nutrient influx, which suddenly reached the sea floor as a consequence of the rapid accumulation of the "nutrient soup" resulting from the mass mortality at the KT boundary. The stepped pattem recognized in the recolonization fauna is here regarded as the response to a return to (1) more oxygenated boltom-water conditions, (2) a wider spectrum of utilizable nutrient resources on and in the sediment, and (3) a larger environmental stability. The complete recovery of the benthic foraminiferal ecosystem was much faster than that of the planktonic foraminiferal ecosystem, the adverse environmental conditions lasting for about $7 \mathrm{k} . \mathrm{y}$. on a so-called "stressed sea floor." During the $20 \mathrm{k} . y$. before and the $50 \mathrm{k} . \mathrm{y}$. after this time interval the sea floor was characterized by environmental stability and normal conditions of oxygenation and food supply.

The sudden and dramatic collapse on the sea floor at the end of the Cretaceous as evidenced by the deepwater benthic foraminiferal

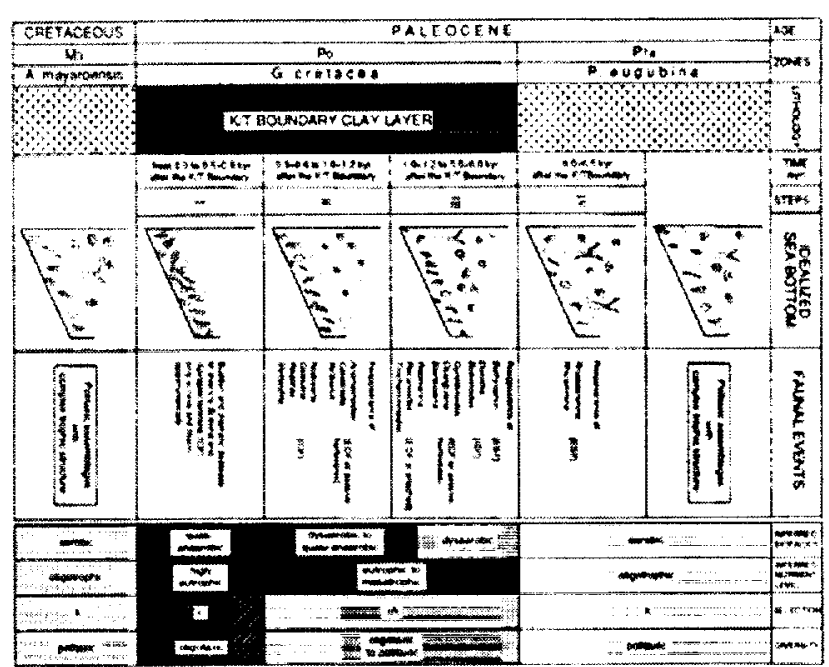

Fig. 2. Idealized paleoenvironmental reconstructions of the sea bottom across the KT boundary at Caravaca. The roman numbers indicate the different steps (not in scale) of decimation, survivorship. and recovery of deepwater benthic foraminifera. IDF = infaunal deposit feeder. EDF - epifaunal deposit feeder, ESF - epifaunal suspension feeder. Both the nutrient levels and the biofacies were inferred through the calcareous-hyaline morphotype distribution together with the faunal densily and diversity records.

record can only be explained by a geologically instantaneous, catastrophic event.

Acknowledgments: This study was supported by the Italian Ministery of University, Scientific Research and Technology (M.U.R.S.T. 60\% to R.C.).

References: [1] Clemens W. A. et al. (1981) Paleobiol., 7, 293-298. [2] Alvarez L. W. et al. (1980) Science, 208, 1095-1108. [3] Thomas E. (1990) GSA Spec. Paper 247, 481-495. [4] Coccioni R. et al. (1993) Terra Abstr., 5, 694. [5] Coccioni R. et al. (1994) Paleopelagos., in press. [6] Smit J. (1990) Geologie en Mijnbouw, 69, 187-204. [7] Corliss B. H. and Chen C. (1988) Geology, 16, 716-719. [8] Kahio K.(1991)Palaeogeogr.,Palaeoclimatol., Palaeoecol., 83, 65-85. [9] Smit J. and Hertogen A. J. T. (1985) Nature, $285,198-200$.

\section{THE KT BOUNDARY IN THE SOUTHEASTERN PY- RENEES, AGER BASIN, NORTHEAST SPAIN (LLEIDA PROVINCE). F. Colombo, Department de Geologia Dinámica, Geofisica y Paleontologia, Fac. de Geologia, Universitat de Barcelona. E-0807! Barcelona, Spain.}

Introduction: The materials that constitute the transition between the Mesozoic and the Cenozoic in the area studied were accumulated in different depositional environments in continental areas as evidenced by the abundant nonmarine fossils.

The aim of this paper is to describe the exact limits between the Mesozoic and the Tertiary in the Ager Basin, northeast Spain. It has been confirmed that in the KT transition the limits are not coincidental with respect to the different fossil groups considered $[1,2]$.

The KT Boundary: A number of studies have been carried out to determine the location of this boundary (Fig. 1). The results 


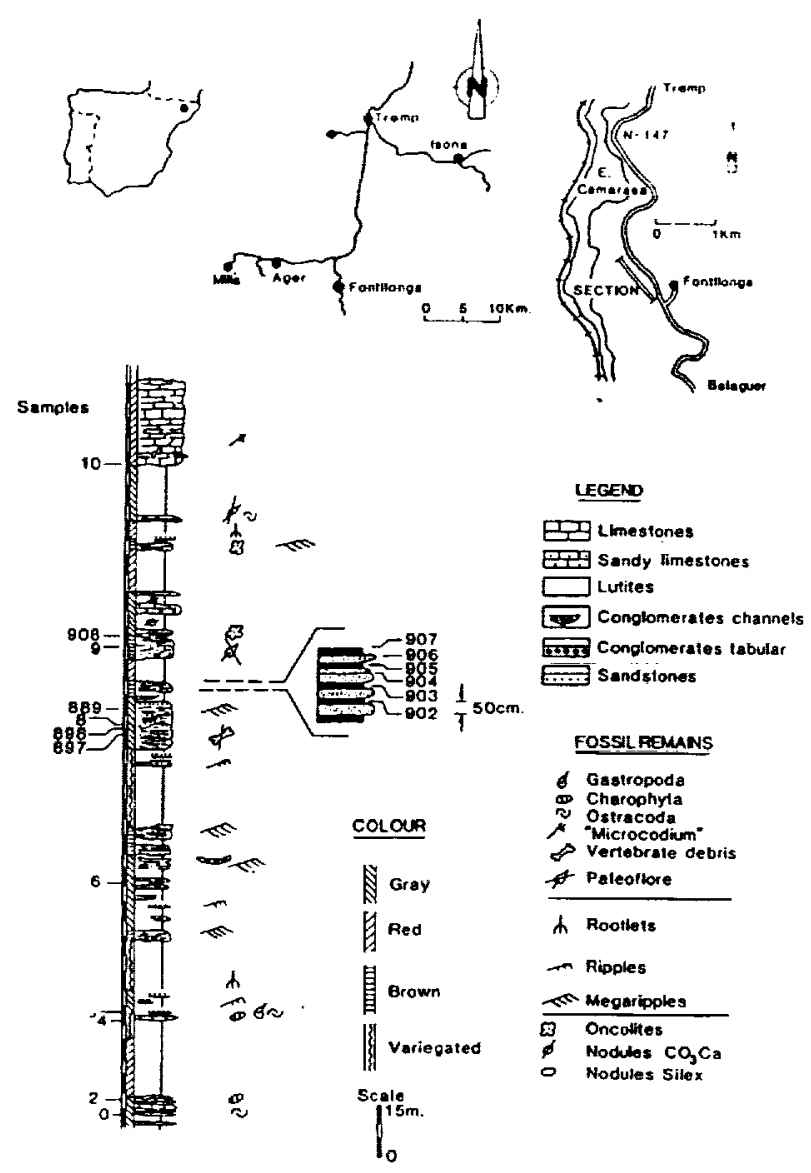

Fig. 1. A studied stratigraphic log in the Fontllonga section.

have enabled us to confirm a lack of unanimity on the location of this boundary. Thus, there is still a lack of precision conceming the vertical palynoflora distribution [3-5]. However, it seems that some forms considered typical of the Tertiary have been found in the Maastrichtian levels, whereas characteristic forms from the Cretaceous have been found in materials that could be attributed to the base of the Tertiary. The present palynofloristic associations do not allow us to distinguish the floras of the upper part of the Mastrichiian from the ones at the base of the Tertiary (Thanetian).

The charophyta group poses the problem that the KT boundary does not appear to be exactly related to any type of specific association. Thus, there was an interval between the upper Cretaceous and the lower Paleocene that could correspond approximately to $5 \mathrm{~m}$.y. and is comprised between the latest cretaceous floras (upper Maastrichtian) and the upper part of the Danian or Danian-Montian [6]. Although we have managed to define five (Fig. 2) overimposed biozones that include the KT boundary, this could be located within one local zone [7]. For this reason, forms clearly from the upper Maastrichtian coexist with forms that correspond to the Thanetian ancestors. Thus, current knowledge of the paleontological type does not allow us to know with sufficient exactitude, the position of the KT boundary in the Ager area.

As for the Ir layer, many samples were systematically collected in the lithostratigraphic intervals where, from the paleontological point of view, the possible location of the KT boundary is known.
The samples were treated by means of neutronic bombardment with instrumentation that permitted the detection of a smaller concentration than that ranging between 50 and $100 \mathrm{pg} / \mathrm{g}$. Thirty-five samples were treated and no significant concentrations greater than $100 \mathrm{pg} / \mathrm{g}$ were found. It could therefore be concluded that there is no layer with an Ir enrichment in the Fontllonga section.

Finally, a paleomagnetic study of the same levels was carried out. We collected 99 samples by means of a manual perforator, which was treated in a cryogenic magnetometer [7]. When the paleomagnetic data were incorporated into the stratigraphic log (Fig. 2), it was possible to propose a general sequence of magnetic polarity.

Discussion and Conclusions: From paleomagnetic studies we know that the KT boundary is placed within the chron $29 \mathrm{R}$ [8-10], but its precise position cannot be determined since a sedimentary uniformity in the studied outcrops does not exist. Thus, the standard magnetic sequences that are very well correlated with marine biozonations on a global scale [11] are utilized.

Data from the study of different groups of fossil organisms, together with the paleomagnetic data of the Fontllonga section, allow correlation with the standard paleomagnetic sequence. The section includes chrons $32 R$ to $26 R$, from the lower Maastrichtian to the lower Thanetian. Despite some discontinuities in the data, the

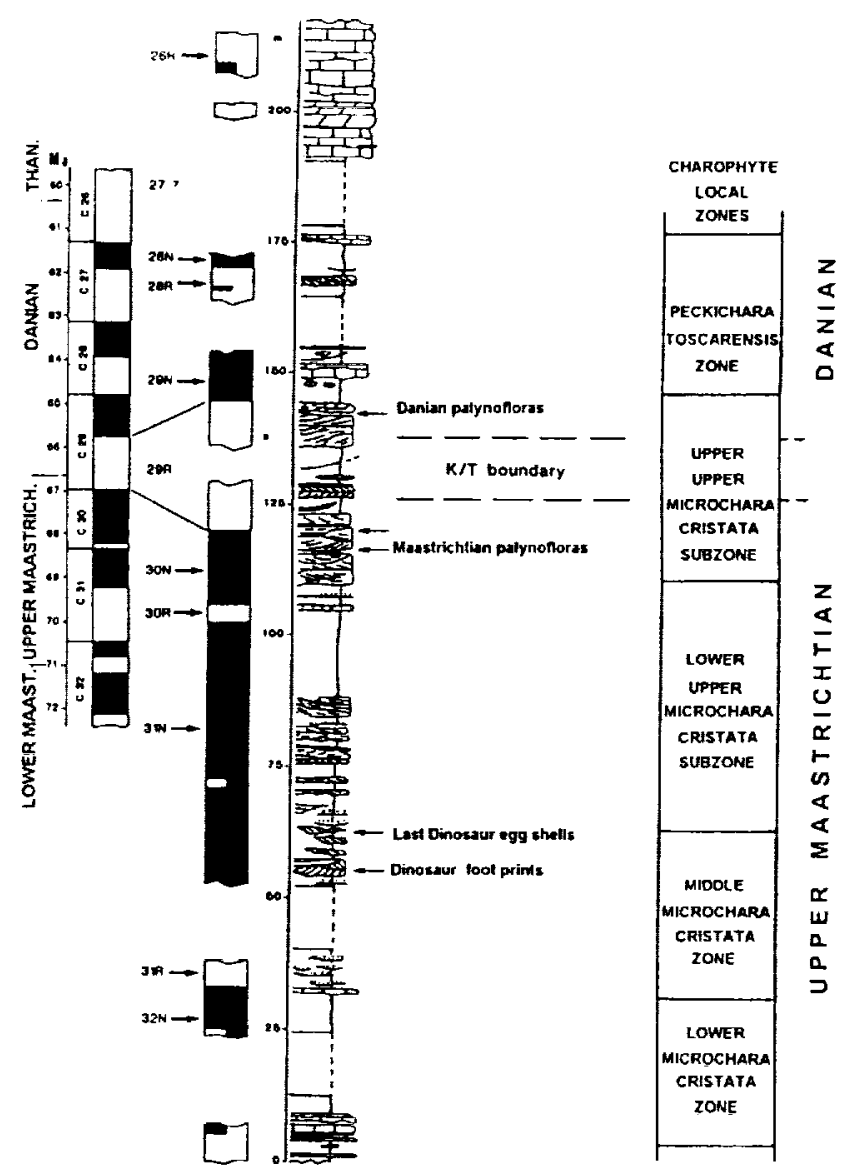

Fig. 2. A Fontlonga stratigraphic log. The magnetic polarity log is referred to as the Haq et al. [II] standard. The charophyte local biozones and the imprecision tract, located between the Upper Maastrichtian and the Danian (modified after [7]), are noteworthy. 
most continuous succession ranges from chrons $31 \mathrm{~N}$ to $28 \mathrm{R}$. Thus, chron 29R, where the KT boundary exists has been clearly identified in the USA [12] but not so clearly in southeast France $[13,14]$ this being one of our most significant findings.

The extinction in this area of the cretaceous charophytes and dinosaurs (last appearance of egg remains, footprints, etc.) seems to have occurred some $2 \mathrm{~m} . \mathrm{y}$, before the beginning of the Tertiary. Thus, these extinctions would have taken place before and independently of the crisis associated with the KT boundary, as a consequence of considerable decrease in climatic temperature during the Campanian and the Maastrichtian.

As for the absence of the Ir anomaly, despite its interest it is not advisable to use this as an important argument in favor of the worldwide presence of the catastrophic effects related to the crisis associated with the KT boundary [15]. In the Fontllonga section all chron $29 \mathrm{R}$ is contained in some lutitic and sandy materials deposited in a fluvial depositional environment of the braided type. Its sedimentologic characteristics suggest elevated ratios of synsedimentary reworking of the materials by means of autocyclic processes. Therefore, the possibilities of the preservation of the KT boundary ( $\mathrm{Ir}, \mathrm{Ni}$ rich spinels, impact minerals, etc.) markers that yield evidence of a calastrophic event on a global scale are very scarce.

Acknowledgments: This work was partially supported by the DIGICYT Project PB91-0805.

References: [1] Feist M. and Colombo F. (1983)Géol. Médit., 20, 303-326. [2] Ashraf A. R. and Erben H. K. (1986) Palaeontogr., 200, 111-163. [3] Medus J. et al. (1988) Newsl. Statigr., 18, 123138. [4] Medus J. and Colombo F. (1991) S. Acta. Geol. Hisp., 26 27-35. [5] Medus J.et al. (1992)Cret.Res., 13, 119-132. [6] Riveline J. (1986)Cah.Paléont., 1-227. [7] Galbrun B. et al.(1993)Paleogeo. Paleoclim. Paleoec., 102, 41-52. [8] Alvarez W. et al. (1977) GSA Bull., 88, 367-389. [9] Chave A. D. (1984) Deep Sea Drilling Project Leg 74, Init. Rep. DSDP, 74, 525-531.[10] Petersen N. P. et al. (1984) Rep. DSDP, 73, 657-661. [11] Haq B. U. et al. (1987) Science, 235, 1156-1 167. [12] Wolbach W. S. et al. (1985) Science, 230, 167-170. [13] Westphal M. and Durand J. P. (1990) Bull. Soc. Géol. Fr., 6, 609-620. [14] Galbrun B. et al. (1991) C. R. Acad. Sci. Paris, 3/2, 1467-1473. [15] Alvarez W. et al. (1982) GSA Spec. Paper 190, 305-315.

THE INFLUENCE OF LARGE IGNEOUS PROVINCES ON MASS EXTINCTIONS: WHERE DO WE STAND? V. Courtillot', J. J. Jaeger'2, and G. Firaud ${ }^{3}$, 'Institut de Physique du Globe, 75252 Paris Cedex 05, France, Institut des Sciences de I'Evolution, 34095 Montpellier Cedex 05, France, ${ }^{3}$ Laboratoire de Giodynamique, 06108 Nice Cedex 02, France.

As proponents in the late 1980 s of the volcanic scenario for the KTB mass extinctions, and not having worked on the subject for the last few years, we find this conference an opportunity to critically evaluate the ever-expanding literature and to attempt to summarize where we stand now.

A number of publications have reported results from sections that were later found to be incomplete, underlining the need for careful interdisciplinary basic field geology. For instance, early interpretation of the Mimbral section as an instantaneous deposit, or of the Chixculub structure as a KTB impact crater, have been challenged on simple geological grounds $[1,2]$. Sedimentary features such as glasses or spherules previously attributed to an impact have been shown to give an ambiguous message, to say the least $[3,4]$. The most complete sections (e.g., El Kef) apparently record a prolonged period of ecological disruption beginning some $200,000 \mathrm{yr}$ prior to the KTB (as defined by the Ir anomaly) and lasting hundreds of thousands of years afterward [5].

Dating of continental flood basalts has reinforced the correlation between them and mass extinctions [e.g., 6]. The coincidence of the age of the Permo-Triassic boundary and the Siberian traps, which had been predicted by several authors including ourselves [7], has subsequently been verified [8]. A claim by Venkatesan et al. [9] that the Deccan traps predate the KTB by at least 1 m.y. has been shown ill-founded on Iwo counts [10]: The Ar plateaus have suffered recoil effects leading to age overestimates and the magnetostratigraphic interpretation contains an internal contradiction. Given the few estimates of absolute age of the KTB [1]], the coincidence of Deccan volcanism and KTB remains tenable.

Claims that impacts could generate flood basalts, however interesting, do not seem founded [12]. Observations such as time constraints, lack of Ir for boundaries other than KT [13], and probable involvement of the lower mantle [14], seem to argue against such a view. For instance, had the Deccan traps been triggered by impact, this would place the timing of impact within chron $30 \mathrm{~N}$, several hundred thousand years before the Ir anomaly.

We believe that extensive work on large igneous provinces $[14,15]$ has emphasized their major geodynamical role and potential environmental impact. More harmful flood basalts may result from a combination of large size, rapid emplacement, detrimental chemical composition, and subaerial emplacement, all variable parameters. They remain very strong candidates as causes of most mass extinction events.

On the other hand, the Ir anomaly (which remains a rather unique feature in the geological record [13]) and the shocked quartz [e.g., 16] are strong evidence for an impact, with no appropriate explanation in terms of volcanism as yet. Many other lines of evidence cited in the last decade as unambiguous proofs of impact have subsequently been shown ambiguous (e.g., spherules, spinels, etc. [17]). There is no doubt that large impacts have occurred on Earth fairly recently, but their biological consequences remain to be assessed. Large (40- to 80-km-diameter) craters such as Montagnais or Kara and Ust Kara are dated from some $10 \mathrm{Ma}$ after and before the KTB, respectively, and have had no significant effect on extinction rates.

It may well be that an unusual impact did coincide with the KTB and accelerated the extinction of some $30 \%$ of the species that dissappeared in the crisis. But the extinction event, probably due to volcanism, was well on by that time and the role of impacts seems to have been largely overstated in this last decade. We expect further insights from detailed analysis both of the Narsapur (off the Deccan traps and the Bombay coast) and of the projected Chicxulub drill cores.

References: [1] Keller G. (1993) Marine Micropaleontology, 2I, 1-45; Keller G. et al. (1993) GSA Bull., 105, 979-997; Keller G. et al. (1993) Geology, 21, 776-780. [2] Meyerhoff A. A. et al. (1993) Geology, submitted. [3] Jéhanno C. et al. (1992) EPSL, J09, 229-241. [4] Officer C. B. and Lyons J. B. (1993) EPSL., I/8, 349351. [5] Keller G. and Barrera E. (1990) GSA Spec. Paper 247, 563 575. [6] Stothers R.B. (1993) GRL, 20, 1399-1 402. [7] Courtillot V. (1990) Sci. Am., 263, 85-92. [8] Renne P. R. and Basu A. R. (1991) Science, 253, 176-179. [9] Venkatesan T. R. et al. (1993) EPSL, 119, 181-189. [10] Féraud G. and Courtillot V. (1993) EPSL, submitted. [1I] Baadsgaard H. et al. (1988) Can. J. Earth Sci., 25, 
1088-1097; Gillot P. Y. et al. (1991) C. R. Acad. Sci. Paris, 3/3, 193-199; Odin G. S. (1989) Bull. Soc. Giol. France, 8, 145-152; Izett G. A. et al. (1991) Science, 252, 1539-1542; Swisher C. C. et al. (1992) Science, 257, 954-958. [12] White R. (1989) Eos, 70. 1490-1491. [13] Orth C. J. et al. (1990) GSA Spec. Paper 247, 4559. [14] Coffin M. F. and Eldholm O. (1993) Rev. Geophys., in press. [15] Richards M. A. el al. (1989) Science, 246, 103-107. [16] Goltrant O. et al. (1992) Terra Nova, 4, 405-412; Goltrant et al. (1991) EPSL, 106, 103-115. [17] Swinbume N. C. et al. (1993); Robin E. et al. (1992) EPSL, 108, 181-190.

\section{$m / 7$}

BONE BEDS AT THE BOUNDARY: ARE THEY A REALISTIC EXPECTATION? A.H. Cutler and A. K. Behrensmeyer, Department of Paleobiology, NHB MRC-121, Smithsonian Institution, Washington DC 20560, USA.

Over the past decade and a half an impressive array of evidence has been amassed to support the hypothesis that the Mesozoic Era was brought to a close by the impact of one or more extraterrestrial bodies on the Earth [1-3]. The most convincing lines of evidence have been mineralogic, geologic, and geochemical rather than paleontologic. Indeed, the fossil record remains ambiguous, and paleontologists disagree as to whether the putative impact was in fact responsible for abrupt and widespread extinction of species [4]. The problem is especially acute for the terrestrial record where KT boundary sections are not extensive and the fossil record tends to be fragmentary and facies-dependent [5].

One source of confusion is the absence of a clear picture of what the fossil record of a global catastrophe should look like. Signor and Lipps [6] made an early contribution along these lines by pointing out that the vagaries of preservation would tend to truncate species' apparent ranges below their true level of extinction, with the result that truly abrupt extinction events would appear gradual in the fossil record. In their analysis, however, Signor and Lipps assumed that taphonomic processes remained constant up to and across the extinction boundary, and at least one author [7] has suggested that the scale of mortality implied by an impact should be reflected in the record by widespread bone beds and mass mortality horizons.

Mass mortality horizons associated with local or regional events such as droughts [8], fires [9], and volcanic ashfalls [10] can be documented in the vertebrate fossil record. Is it reasonable to expect that mass mortality of large vertebrates on a global scale would leave a recognizable signal in the record? It is obviously too much to expect to find vast horizons of dinosaur carcasses in their final death postures dusted with a layer of Ir, but it is less obvious whether such an event would produce a detectable elevation in the frequency or scale of bone concentrations (a "bone spike") at the extinction horizon.

Based on calculations of mortality (lumover) rates of dinosaurs from known relationships of body size to life span [11,12], estimates of the dinosaur-carrying capacity of the late Cretaceous ecosystems (animals $/ \mathrm{km}^{2}$ ) and faunal lists indicating the number of coexisting species of animals $>20 \mathrm{~kg}$ [13] we infer a range of probable densities of live animals and carcasses on the landscape of the latest Cretaceous. From this we infer the differences between a bone assemblage formed under normal tumover (attritional input of bones) and from a catastrophe that wiped out all large tetrapods over a period of hours to days. In addition to the issue of attritional vs. single-pulse availability of carcasses, longer-term effects of burial and preservation of bone-bearing strata must be taken into account in assessing whether a mass die-off of dinosaurs would leave a detectable signal in the fossil record at the KT Boundary. We conclude that it is unlikely that a single event such as a bolide impact would leave dense, multispecies dinosaur bone beds in the area of greatest mass mortality.

It is possible that ecological stress farther from the impact site, which allowed some species time to congregate around specific areas prior to death (waterholes, remaining patches of forage), would have created more concentrated bone assemblages for particular taxa. Whether any of these were preserved in the long run would depend on whether such zones of variable, "less catastrophic" mortality intersected active areas of deposition at the time. Recovery of a fossil record from these same areas would depend also on later tectonic processes that created outcrops, which we can search today. The complexity of the combined requirements for there to be a record of any major mass morality event for land animals at the KT boundary makes it unlikely that this will be detectable. The absence of bone beds at the boundary should not be used for or against hypotheses regarding causes of the extinction event.

References: [i] Sharpton V. L. and Ward P. D. (1990) GSA Spec. Paper 247, 631. [2] Hildebrand A. R. et al. (1991) Geology, 19. 867-871. [3] Swisher C. C. (1992) Science, 257, 954-958. [4] Flessa K. W. (1990) GSA Spec. Paper 247, 1-7. [5] Fastovsky D. E. (1990) GSA Spec. Paper 247, 541-548. [6] Signor P. W. and Lipps J. H. (1982) GSA Spec. Paper 190, 29I-296. [7] Carpenter K. (1988) LPI Contrib. 673, 24-25. [8] Rogers R. R. (1990) Palaios., 5, 394-413. [9] Sander P. M. (1987) Palaeogeogr. Palaeoclimatol. Palaeoecol., 6l, 221-236. [10] Voorhies M. R. (1985) Nall. Geog. Soc. Res. Rep., 19,671-688. [11] Farlow J. O. (1976) Ecology, 57, 841-857. [12] Westem D. (1980) in Fossils in the Making (A. K. Behrensmeyer and A. P. Hill, eds.), 41-54. [13] Beland P. and Russell D. A. (1978) Can. J. Earth Sci., 15, 1012-1024.

\section{N94- 28298}

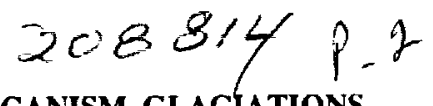

IMPACIS, EXTINCTIONS, VOLCANISM, GLACIATIONS, AND TECTONICS: MATCHES AND MISMATCHES. I. W. D. Dalziel, Institute for Geophysics, University of Texas, 8701 N. Mopac Expressway, Austin TX 78759-8397, USA.

The debate concerning possible relations between impacts, extinction events, and volcanism has recently taken a new turn. Diamictites and associated sedimentary deposits long regarded by geologists as glaciogenic, have been reinterpreted as impact-related. Going further, the Permo-Carboniferous diamictites that are widespread in the southem continents and India are now put forward as evidence that fragmentation of the Gondwana supercontinent in the Mesozoic was a direct result of meteorite impact. In an abstract at a meeting of the American Geophysical Union, and in an article in the popular press, one member of the earth science community has made a specific claim to identify the site of the supercontinentdestroying bolide on the Falkland/Malvinas Plateau. It is claimed by this scientist that the Cape fold belt in Africa represents a "breaking wave" of deformation resulting from this impact, and that fractures in the clasts of the Dwyka diamictite in southem Africa represent impact-induced cataclasis of the target rock. These hypotheses fly in the face of the well-established tectonic history of the Gondwana supercontinent in several respects. 


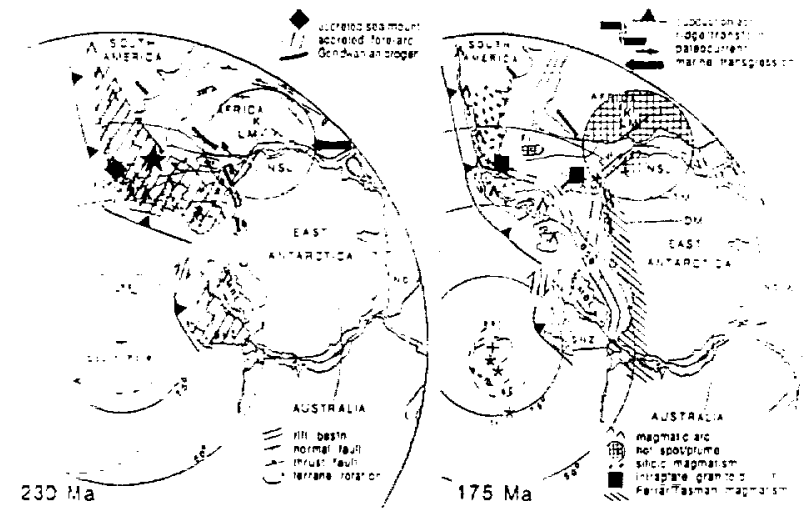

Fig. 1. (a)Gondwana during the Late Triassic (230 Ma) after the Gondwanide orogeny, based on the reconstruction of Grunow et al. (1991), intraplate deformation in Africa, after Daly et al. (1991), and reconstruction of the Gondwanide orogen, afier Dalziel and Gnunow (1991). Arc magmatism from Pankhurst (1990). The positioning of the incipient Karoo/Bouvet plume (circle) follows that of Whate and McKenzie (1989). AP - Antarctic Peninsula block; EWM Ellsworth. Whitmore Mountains block; Fl - Falkland Islands terrane (shape schematic): K - Karoo Basin; LM - Lebombo monocline; MBL - Marie Byrd Land; NSL - Neuschwabenland; SNZ - south New Zealand (South Island, Campbell Plateau, and Chatham Rise); TI - Thurston Island block. Dashed circles are confidence circles about paleomagnetic poles (asterisks and crosses) of Gnunow et al. (1992) and are identified by letters as above. Reconstructions are polar stereographic projections centered on the paleomagnitic South Pole (cross) determined for East Antarclica(eat). (b)Gondwana in the Middle Jurassic $(175 \mathrm{Ma})$ after the rotation of the Falkland Island and Ellsworth-Whitmore Mountains blocks, based on the reconstruction of Grunow et al. (1991). The location of the magmatic provinces follows Cox (1978), Dalziel et al. (1987) While and McKenzie (1989), and Storey and Alabaster (1991). Additional abbreviations: BSB - Byrd Subglacial Basin (including Bentley Subglacial Trough); DM - Dufek Massif; EW - Explora wedge; TM - Theron Mountains.

1. The suggested site of impact is the Lafonian (Falkland Malvinas) microplate that was displaced relative to both South America and Africa after the time of the proposed impact and before opening of the South Atlantic Ocean basin. Hence the suggested geometric relationship of this site to surrounding features such as the Cape Fold Belt is incorrect (see Fig. 1).

2. Gondwana reconstructions based on sea-floor spreading and paleomagnetic data show that the Gondwanide fold belt is almost rectilinear from Argentina, through southem Africa, to the Pensacola Mountains of Antarctica. It is not circular in plan view (see Fig. 1).

3. The Gondwana diamictites and associated deposits are dia chronous and track the paleomagnetically determined position of the South Pole across the supercontinent in the Devonian, Carboniferous, and Permian.

4. Gondwanide deformation is also diachronous: Even within the Cape fold belt it extended from ca. 278-230 Ma. It took place behind an active subducting margin of the Pacific Ocean.

5. The fracturing of the clasts in the diamictites can be directly related to strain during a mid-to-Late Permian or Triassic phase of deformation in the Gondwanide fold belt. Glossopteris-bearing Permian strata overlie the diamictites everywhere, and were deformed with them during the Gondwanide folding.

Leaving aside the issue of obvious distinctions (textural, metamorphic, etc.) between modern tillites and deposits such as the
Onaping Formation of the Sudbury basin that are widely accepted as being impact related, it is unfortunate that the largest extinction event in Earth history should have been related in such a cavalier fashion to geologic features spanning several tens of millions of years (indeed even hundreds of millions of years to judge by maps shown at AGU and published, with attribution, in the popular press). Geologists clearly need to consider impact of extraterrestrial bodies as a major agent of tectonic as well as environmental change. But as students of impact and its effect on our planet reach back in time from the KT boundary, it is all the more important for them to look carefully at its complex tectonic history in relation to the geologically instantaneous events that they invoke.

\section{omir 70 P 3}

SULFATE VOLATILIZATION, SURFACE-WATER ACIDIFICATION, AND EXTINCTION AT THE KT BOUNDARY. S. D'Hondt, H. Sigurdsson, A. Hanson, S. Carey, and M. Pilson, Graduate School of Oceanography, University of Rhiode Island, Narragansett RI 02882, USA.

It appears that the severity of environmental effects related to the KT boundary impact may have been largely due to the unusual geochemistry of an evaporite-rich impacted terrane. KT tektite composition, experimental results, and comparison to Yucatan stratigraphy all indicate the presence of gypsum or anhydrite at the tektite source (Chicxulub crater). Thick $(\sim 1-\mathrm{km})$ Late Cretaceous evaporite sequences occur in the region of the Chicxulub KT impact structure [1]. Calcium-rich KT tektites contain high $\mathrm{SO}_{3}$ concentrations $(0.83 \%$ [2]; $0.53 \%$ [3]; range $=0.20-1.0 \%)$. They also exhibit $\delta^{34} S$ values typical of evaporites $(13.2 \% 0[2,4])$. Experimental results have duplicated the high-Ca tektite composition by hightemperature melting of evaporite + andesite $[2,5]$.

Several studies have estimated the amount of $\mathrm{SO}_{2}$ volatilized from target evaporites by the KT impact. An estimate of $1.3 \times 10^{16}$ was based on the proportion of unaltered high-Ca glass in Haiti and the global thickness of the KT boundary clay. This assumed that $1000 \mathrm{~km}^{3}$ of impact glass was created and $2 \%$ was high-S glass derived from evaporite source $[2,5]$. This represents a minimum estimate, since it is limited to $\mathrm{SO}_{2}$ released by tektite formation and does not include $\mathrm{SO}_{2}$ released from solid rock by shock, or $\mathrm{SO}_{2}$ released by initial volatilization of the target. More comprehensive estimates have been derived from reconstruction of Chicxulub geology and assumed shock pressures required for sulfate release. These rely on variable estimates of transient crater diameter (80 to $146 \mathrm{~km})$, stratigraphy of Chicxulub region ( $0.5101 .5 \mathrm{~km}$ anhydrite), and shock pressure of sulfate release (20 to $40 \mathrm{Gpa})$. Based on such criteria, Sigurdsson et al. [5] estimated that $2.4 \times 10^{18}$ to $8.4 \times 10^{18} \mathrm{~g}$ $\mathrm{SO}_{2}$ was released, Brett [6] estimated that $4 \times 10^{17} \mathrm{~g} \mathrm{SO}_{2}$ was released, and Pope et al. [7] estimated that $5.4 \times 10^{17}$ to $1.6 \times 10^{18} \mathrm{~g}$ $\mathrm{SO}_{2}$ was released.

Combined with the great optical depth loading previously estimated to result from the KT impact "dust" cloud, the resultant stratospheric $\mathbf{S}$ aerosols may have contibuted to a rapid decline in global surface temperatures to near-freezing in about one week [5]. Time-dependent conversion of stratospheric $\mathrm{SO}_{2}$ to $\mathrm{H}_{2} \mathrm{SO}_{4}$ would have prolonged this cooling for several years [5]. These stratospheric sulfate aerosols may also have caused global "blackout," preventing photosynthesis for months and disrupting it for years [7]. These relatively long-lived effects of the estimated $\mathrm{SO}_{2}$ release 
(global cooling and global darkness) appear likely to have been major causes of the global KT extinctions.

The estimated mass of $\mathrm{H}_{2} \mathrm{SO}_{4}$ generated by this event is equal to or greater than the most tightly constrained estimates of $\mathrm{HNO}_{3}$ formed by the same event ( $\mathrm{HNO}_{3}$ yields corresponding to $10^{15}$ moles $\mathrm{NO}_{x}$ - perhaps higher if the impact was oblique (8]). Depending on the stratospheric conversion rate of $\mathrm{SO}_{2}$ to $\mathrm{H}_{2} \mathrm{SO}_{4}$ and the rate of transport to surface waters, these combined sulfuric and nitric acids may have led to varying levels of acidification in surface marine and freshwater systems. Instantaneous and uniform global rainout of maximum $\mathrm{KT} \mathrm{H}_{2} \mathrm{SO}_{4}$ estimates $\left(10^{17}\right.$ moles $\left.\mathrm{H}_{2} \mathrm{SO}_{4}\right)$ would have temporarily destroyed the buffering capacity of surface marine waters (the upper $100 \mathrm{~m}$ of the water column) and driven the $\mathrm{pH}$ of near-surface marine and fresh waters below 3. Assuming complete atmospheric conversion of $\mathrm{SO}_{2}$, most estimates of $\mathrm{KT} \mathrm{SO}_{2}$ release would create $\sim 10^{16}$ moles of atmospheric $\mathrm{H}_{2} \mathrm{SO}_{4}$. Instantaneous and uniform global rainout of this mass would have driven marine $\mathrm{pH}$ below 6 in the upper $25 \mathrm{~m}$ of the water column. Its mixing throughour a 100-m water column would have depressed marine $\mathrm{pH}$ below 7 and unbuffered freshwater values below 3. Similar rainout of $10^{15}$ moles of $\mathrm{H}_{2} \mathrm{SO}_{4}$ would have depressed surface marine $\mathrm{pH}$ from 8.2107 only in the upper $10 \mathrm{~m}$ of the water column, but would have depressed the $\mathrm{pH}$ of unbuffered fresh waters to about 4.5 throughout a 100-m water column. Similar rainout of $10^{15}$ moles of $\mathrm{HNO}_{3}$ would have had a still smaller effect on water-mass acidification. In all cases, sea-surface $\mathrm{pH}$ would have subsequently increased by varying amounts as the $\mathrm{pCO}_{2}$ of the atmosphere and surface oceans reequilibrated (on timescales of a few months to a few years). On slightly longer timescales, sea-surface $\mathrm{pH}$ would closely approach preimpact values as surface and deep waters exchanged.

Possible environmental effects of KT surface ocean and freshwater acidification include ( 1 ) increased availability of free metal ions in surface waters, (2) loss of $\mathrm{CO}_{3}{ }^{2-}$ and $\mathrm{HCO}_{3}$ - from surface marine waters, and (3) selective extinction in surface-water environments $[9,10]$. Nontheless, acidification of the marine and freshwater photic zone may not have been a primary cause of global KT extinctions. Even assuming maximum estimates of $\mathrm{KT} \mathrm{SO}_{2}$ volatilization, our maximum estimates of global KT water-mass acidification are probably unrealistic since the time-dependent conversion of $\mathrm{SO}_{2}$ to $\mathrm{H}_{2} \mathrm{SO}_{4}$ may preclude instantaneous global injection of the total $\mathrm{H}_{2} \mathrm{SO}_{4}$ mass into surface waters. Furthermore, analysis of vertebrate fossil records indicates that freshwater organisms of the westem interior U.S. exhibited much higher KT survivorship than terrestrial organisms [11], suggesting that extinction in that region primarily resulted from factors other than freshwater acidification. Finally, extant carbonate-secreting marine phytoplankton and planktic foraminifera have respectively survived $\mathrm{pH}$ values of less than 7.6 [12] and less than 7.2 [13] in culture experiments. This probably precludes rapid global and uniform rainout of $10^{15}$ moles of $\mathrm{H}_{2} \mathrm{SO}_{4}$ and/or $\mathrm{HNO}_{3}$ from consideration as a primary cause of global extinction of carbonate-secreting marine plankton. However, it allows the possibility of regional or depth-related extinctions resulting from acidification of marine or freshwater photic environments if rapid nonuniform acid rain occurred. Furthermore, photic zone acidification remains a possible cause of global carbonatesecreting plankton extinction in the case of instantaneous and uniform global rainout of more than $10^{16}$ moles of $\mathrm{H}_{2} \mathrm{SO}_{4}$ and/or $\mathrm{HNO}_{3}$.

References: [1] Lopez Ramos E. (1979) Geologia de Mexico. Tomo III, 2nd ed. [2] Sigurdsson H. et al. (1991) Nature, 353, 839 842. [3] Koeberl C. and Sigurdsson H. (1992) GCA, 56, 2113-2129.
[4] Chaussidon et al,, this volume. [5] Sigurdsson H. et al. (1992) EPSL, I09, 543-559. [6] Brett R. (1992) GCA, 56, 3603. [7] Pope K. O. et al. (1993) LPS XXIV, 1165-1166. [8] Zahnle K. (1990)GSA Spec. Paper 247, 271-288. [9] Lewis J. et al. (1982) GSA Spec. Paper 190. 215-221. [10] Prinn R. and Fegley B. Jr. (1987) EPSL, 83, 1-15. [11] Sheehan P. and Fastovsky D. (1992) Geology, 20, 6, 1992. [12] Griffis K. and Chapman D. (1990) Leshaia, 23, 379-383. [13] Spero (1993) personal communication.

\section{BIOLOGICAL CHANGES AT THE KT STRATOTYPE OF} EL KEF (TUNISIA). P. Donze', H. Méon', R. Rocchia², E. Robin ${ }^{2}$ L. Froget ${ }^{2}$, 'Centre de Paléontologie Stratigraphique et Paléoécologie, UA II CNRS, 29 Bd du 11 Novembre 1918,69622 Villeurbanne Cedex, France, ${ }^{2}$ Centre des Faibles Radioactivités, Laboratoire Mixte CEA-CNRS, A venue de la Terrasse, 91198, Gifsur-Yvette Cedex, France.

Introduction: KT boundary sediments are characterized by a strong enrichment in platinum group elements (PGEs) and the presence of exotic minerals (shocked quartz and meleoric spinels). A cosmic collisional origin for all these markers is now widely accepted. However, the biological consequences of this event are still a subject of debate. The site of El Kef (Tunisia) offers exceptional conditions permitting the precise stratigraphical study of the development of the biological crisis.

Site Description: The paleontological boundary is exceptionally well defined by a sharp lithological discontinuity. The top of the A. Mayaroensis zone is marked by a thin millimetric brown-reddish layer containing Ir and meteoric spinels, the signature of the cosmic event $[1,2]$. Above that layer there is a $10-12-\mathrm{cm}$ bed of dark grey marl overlain by $5 \mathrm{~cm}$ of nearly pure and azoic black clay. Above that, we observe a slow increase of the carbonate fraction indicating the recovery of the biological activity. Stable sedimentation conditions are found again about $2 \mathrm{~m}$ above the boundary.

Floral and Faunal Populations: The upper Maastrichtian is extremely rich in pelagic and benthic microorganisms: foraminiferas, ostracods, coccoliths, dinoflagellates, etc. It also contains pollens and spores from the nearby continent (Kasserine lsland).

Evolution of the marine environment. In the upper Maastrichtian one can identify at least 30 species of foraminifera, I5 species of calcareous nannofossils [2], 30 species of dinoflagellates, and 15 species of ostracods [3]. No significant change is observed until the appearance of meteoric spinels in the stratigraphic column. Immediately above the millimeter-thick layer containing spinels and maximum Ir concentration, we note that $90-95 \%$ of the populations disappear. The surviving specimens of foraminifera, coccoliths, and ostracods are characterized by reduced sizes, unhealthy aspect, and badly calcified and fragile tests. In the $10-12 \mathrm{~cm}$ of marls above, the plankton gets progressively extinct. Some species seem more resistant (Gumbelesria cresacea). The reaction of benthos is different: only simple and resisting organism survived (Lenticulina sp.). This progressive degradation ends in the black clay layer where we have found only small benthic arenaceous tests.

As far as dinoflagellates and other palynomorphs are concemed they do not exhibit such a dramatic extinction pattern. Counting reveals (after correction for the variations of the sedimentation rate) a reduction by only a factor of 2 of the number of specimens [4]. This moderate decrease is strikingly different from the collapse of pro- 
ductivity characterizing microorganisms with calcareous tests. Dinoflagellates are known to survive in water with low nutrient concentrations. This is a possible explanation for their survival in an environment that could not be accepted by other species.

Evolution of the terrestrial environment. Because of the proximity of emerged lands (Kasserine Island) the site of El Kef is extremely rich in land plant remains, pollen grains, and spores. We do not observe at El Kef any sharp change in continental plant populations. Early extinctions of species are observed well inside the Maastrichtian and continue across the KT boundary and the Danian. These gradual extinctions appear to be related to longduration climatic changes and not to the cosmic boundary event.

Conclusion: The coincidence, now well established, of a cosmic material infall with the sharp decrease of marine productivity implies a causal link between the two phenomena. The occurrence of extinctions is obvious, but the way the extinctions occurred is far from being understood. Some points, however, appear rather clear. Faunal and geochemical analyses show that the environment became suddenly highly reducing right at the time of the cosmic event. This change is probably due to the phytoplankton whose development is strongly modulated by the intensity of solar radiations. It has been proposed that the dust blanket produced by the alleged KT impact might have resulted in a strong reduction of the solar radiation income and, consequently, in a drastic reduction of photosynthesis [5]. This hypothesis is attractive and widely accepted. However, at El Kef it raises some difficulties. First, the decrease of solar light should have affected not only plankionic species but also land plants. This is not what we observe: sporomorph populations do not significantly change across the boundary. Second, it does not explain the very different behavior of calcareous planktonic species and dinoflagellates, which have chitinous tests. Planktonic species neared total extinction when most dinoflagellates, which also need light for their photosynthesis, survived. In fact, in most sections (with the possible exception of the sections in the Caribbean area) we have analyzed so far, the observed amount of ejecta is always very low. In El Kef, for instance, the total ejected material is represented by the $1-2 \mathrm{~m}$-thick layer containing spinels. This is far below the amount predicted by models $(10-100 \times$ the impactor mass).

The cause of this difference could be, instead of a decrease of the solar flux, a disturbance of chemical conditions in the ocean. A significant infall of some elements ( $\mathrm{Ni}$ for instance) could have prevented or reduced the action of usual oligoelements ( $\mathrm{Fe}, \mathrm{Cu}, \mathrm{Mn}$ ) that are involved in life processes and, in particular, in the fixation of carbonates. This could explain the extinction of calcareous planktonic species and, as a consequence, the decrease of $O$, which is mainly provided by these species in warm oceanic waters.

The survival of dinoflagellates, which at high latitudes are efficient $O$ providers, could explain why the biological crisis was less severe in northem seas than in tropical regions [6].

References: [1] Robin E. et al. (1991) EPSL, 107, 715-721. [2] Perch-Nielsen K. (1981) Cahiers de Micropaleontologie, 3, 2536. [3] Donze P. (1992) Inı. Workshop on K-T Transitions (El Kef section), April 1992 Tunis (abstract), 2-3. [4] Mion H. (1991) Palaeontographica, Abt. B, 223, 107-168. [5] Alvarez et al. (1980) Science, 208, 1095-1 108. [6] Keller G. et al. (1993) GSA, 105, 979997.
SHALLOW BENTHIC FAUNA: THEIR EXTINCTION AND SURVIVAL ON THE KT BOUNDARY, ADRIATIC PLATFORM, SLOVENIA. K. Drobne', B. Ogorelec ${ }^{2}$, W. Lowrie ${ }^{3}$, and E. Marton', 'Paleontological Institute ZRC SAZU, 61000 Ljubljana, P.O.B. 323, Slovenia, ${ }^{2}$ Geological Survey, Dimiceva 14, 61000 Ljubljana, Slovenia, 'Institute of Geophysics, ETH, Honggerberg, 8093 Zurich, Switzerland, ${ }^{4}$ E. L. Geophysical Institute of Hungary, Kolumbusz u. 17-23, 1145 Budapest, Hungary.

Introduction: Southwest Slovenia, with outcropping Paleogene beds, lies in the northwestem part of the Adriatic platform. Already G. Stache [1] and M. Hamrla [2] conjectured the possibility of gradual transition in the Libumian Formation at the KT boundary. Later studies did not confirm this hypothesis $[3,4]$. The presence of the terminal part of Maastrichtian with foraminifer Rhapydionina liburnica was, however, beyond all doubt. The problem arises in continuation of deposition in the lowermost Paleocene beds. Discoveries of KT transitions at the Adriatic carbonate platform in the Gubbio section [5], in the north at Gosau [6], and in the west at Caravaca $[7,8]$ with increased concentrations of rare elements and Ir stimulated the search for transition in the territory of Slovenia as well.

In the Dolenja vas section (northem margin of the Adriatic platform) transition from limestones with rhapydionina into Tertiary limestones was recognized [9]. Lithology of beds at the boundary showed marks of intertidal environment. Faunal characteristics of these sediments promised the smallest possible gap, if not a continuous passage at the KT boundary.

Material, Sections: For detailed examination of the KT boundary the sections Dolenja vas-west and Sopada in a separate syncline ( $4.5 \mathrm{~km}$ south of Dolenja vas) were selected. The column considered is $2.5-3.0 \mathrm{~m}$ thick. In each section 16 samples were collected for microfacial and micropaleontologic analyses (B. Ogorelec, $\mathrm{K}$. Drobne). Ten samples in each zone at the KT boundary were collected for paleomagnetic investigations (W. Lowrie, E. Marton).

Microfacies: Sopada section. On the basis of lithologic characteristics Unit A (Sop 65-64/3, $55 \mathrm{~cm}$ ), Unit B (Sop 64/2-63/0, $95 \mathrm{~cm}$ ), and Unit $C$ (Sop 62/1-59,130 cm) can be distinguished.

Unit A. This light-grey limestone Sop 65 with a typical Cretaceous fossil assemblage is structurally a weakly washed pelbiomicrite or intrabiomicrite (W-P). Limestone was deposited in a shallow, relatively well aerated part of restricted shelf with EI 1-2.Valves of pachyodont pelecypods are mostly fragmented and show marks of heavy corrosion.

Unit $B(1+2)$. Sediment in this unit gets somewhat darker. Structurally it is biomicrite and partly pelbiomicrite (M-P). Deposition in a lagoonal quiet environment is indicated by the occurrence of ostracods and characean oogonia. Framboids appear in the upper zone of unit $B(1)$. The bed in unit $B(2)($ Sop $63 / 1,0), 15 \mathrm{~cm}$, is dark biomicrite (M-W) deposited in a quiet lagoonal environment. Characteristic are intense bioturbation, stylolite seams, frequent framboids and organic matter. Cretaceous and Paleocene microfauna, as well as rare remains of broken and corroded valves of larger pelecypods, also occur here.

Unit C. Limestone is dark grey biomicrite from a very quiet lagoonal environment. Temporary inter-, upper inter-, and supratidal conditions are indicated by desiccation pores, geods, and stromatolite laminae. In spite of the lagoon environment and shallows a 
variable but significant presence of pelagic organisms is observable in all beds.

Section Dolenjavas-nest: Lithologically Unit A (Dvas-5a/5- f, $145 \mathrm{~cm}$ ), Unit B (Dvas-5g/5-j, $65 \mathrm{~cm}$ ), and Unit C (Dvas-5k/.4 5 , $35-40 \mathrm{~cm})$ were distinguished.

Unit $A(1+2)$. In the lower $120 \mathrm{~cm}$ limestone is homogeneous, light grey intrabiomicrite and biopelmicrite (W-P). The rock contains frequent microfauna, in places with accumulated pachyodontid pelecypod valves. Rims of valves are clearly corroded. Intraclasts measure up to several millimeters, and they have the character of plasticlasts. In the upper part of unit A(2), 20-30 cm thick, plasticlasts are very frequent. Marks of intense biolurbation and temporary drying occur in the supratidal. Carbonate mud was deposited in smaller restricted ponds. Micrite in bioturbation pockets contain numerous framboids and organic material coatings in this part of the section.

Unit B. Limestone is dark grey to dark brown biomicrite or biopelmicrite $(W)$. Bioturbation structures are rare. This sediment was deposited in a very calm lagoon environment. Traces of stromatolite laminae and fragments of microcodia indicate a rather shallow sea. Organic matter and framboids are rare.

Unit C. Contact with lower unit at a thickness of about $10 \mathrm{~cm}$ is not clear. Above that follows dark grey to black limestone. By its structure the rock is biomicrite and intrabiomicrite with signs of intense bioturbation. Locally bioturbation pockets are filled with plankton, mostly globigerinas. This is indicative of a connection between the lagoon and the open shelf. Episodically higher energy conditions are indicated by biomicritic layers with numerous bioclasts of larger forams, corals, and dasycladaceas.

Micropaleontological Association: The microfacial characteristics in both sections are illustrated by biostratigraphic subdivision of beds $2.5-3.0 \mathrm{~m}$ thick. Both units $\mathrm{A}$ are characterized by typical Cretaceous fossils, the units B by Cretaceous, Paleocene, and undefined common fossils, and unit $C$ by Paleocene and undefined fossils.

In Unit A forms and taxa were established that indicate a slow and gradual retreat from the association. EXTINCT genera and species include Gyroconulina sp., Bolivinopsis sp. 2, Cuneolina cylindrica, ex Moncharmontia, Cuneolina ketini, Minouxia, Pullenoides, "Dargenioella," Bigenerina, planktonic Gublerina sp. and pachyodontid pelecypods, among them Gyropleura, Bournoni and Radiolites.

Cretaceous species with longer life span should extend to Unit B, e.g., as Rhapydionina liburnica, Ophthalmidium sp. $\overline{2}$, and the longest Bolivinopsis sp. 1. They are often accompanied by Cretaceous miliolids with large tests, such as Spirolina sp. 1, Nummoloculina sp. 1, Sigmoilina sp. 1, Massilina, Ophthalmidium sp. 2, and others of smaller dimensions, such as Sigmoilina sp. 2. The forms listed at the end of Unit B disappear from the association. Among the SURVIVING genera and species from Unit A to Unit B, and higher, to Unit C, belong Anomalinoides sp., Ophthalmidium sp. 1, Triloculina sp. div., Nummoloculina sp. 2, and ostracods with small smooth tests less than $0.4 \mathrm{~mm}$ long. Numerous are already conical tests with agglutinated wall. Globigerinas appear in corresponding facies. Cretaceous and surviving forms are in Unit B accompanied by genera and species with constant occurrence in Paleocene. They are Protelphydium, "Pseudochrysalidina," Globorotalia sp. div., Globorotalia compressa, and ostracods with smooth tests up to $0.8 \mathrm{~mm}$ long.
Unit $\mathrm{C}$ is characterized by the above-mentioned Paleocene and surviving species and genera, and by newly appearing Globorotalia uncinata, Biloculina sp., and coral Dendrophyllia.

Algae. Numerous algal remains occur throughout all layers. According to facies Thaumatoporella sp., oogonia of characeas, Aeolisaccus barartoloi, and planktonic forms appear. Dasycladacaea with genus Cymopolia sp. does not appear after the Paleocene.

For the time being, with respect to the aforementioned assemblage, a sharp KT boundary cannot be defined. We defend the existence of a gradual transition and a broader boundary zone, as shown by the diagram prepared using the Biograph program [12].

The fossil inventory was established exclusively from thin sections without isolated forms up to the species of genus level, or only to the group level. At this stage of the sludy the new systematics from Loeblich and Tappan [8] have not been taken into consideration either.

Abiotic Analysis: Preliminary geochemical analysis of 10 samples in the section from Dolenja vas (Dvas $-5 \mathrm{a} /-5 \mathrm{j}$ ) show an increased concentration of rare elements (Dvas $-5 f$ ) about $60 \mathrm{~cm}$ below the supposed KT boundary. Two- to threefold increase of concentration with respect to samples below and above this zone can be seen for $\mathrm{Co}, \mathrm{Ga}, \mathrm{Ni}, \mathrm{Sm}$, and $\mathrm{Zr}$. Vanadium is almost $10 \times$ higher. The concentration of Ir is less than $10 \mathrm{ppb}$ in all samples. Paleomagnetic examination from the same zone shows feeble $R$ magnetization.

The series of limestone samples from the KT boundary in the Sopada section did not yield satisfactory results, according to Lowrie's analysis. This collection of samples was unfortunately inapplicable for magnetostratigraphy.

Discussion: For the time being, no similar development was encountered on the Adriatic platform or beyond it. On the basis of correlation of the for $i$ l association the terminal part of Maastrichtian [11] could be idr Geochemical analyses also revealed evidence of the " $\quad$ beds [5,12], and with planktonic and benthic for basal part of Paleocene beds. Currently sar 'nalysis and in repeated geochemical ar eboth sections. New samples we" Infortunately, samples for . Icropaleontological analyses 1 evelopment of the upper part of $0^{5}+$ astrichtian beds below KT indicate $\mathrm{de}_{\mathrm{r}} \quad$.nd shallow lagoon. At Sopada no traces of cat. the KT boundary can be observed in the internalp. - on. Lithologically and micropaleontologically there is a g. transition from Cretaceous into Paleocene. A sharp boundary between the two systems cannot be localized. At Dolenja vas the definition of the boundary is equally dim, if increased concentrations of rare elements are the criterion. This zone still contains the Cretaceous, SURVIVING, and already the Paleocene representatives of the fossil association. The gap in deposition is observable below the limestone with characteristic Paleocene association. (3) EXTINCT Cretaceous forms belong mainly to epifaunal macro- and micropopulation. Characteristic are size reduction and more frequent aberrant phenomena, especially in foraminifers. The surviving forms are mainly simple miliolids, tender forms Ophthalmidium sp. 1, benthic forms Anomalinoides sp., and tiny smooth ostracods. Among the algae all detected forms 
belong to the surviving ones with the exception of large dasycladaceae or genus Cymopolia sp. (4) Biostratigraphic determination of Lower Danian beds is confirmed by the species Globorotalia compressa and Proselphidium sp. in the Sopada section. By this the carbonate complex of beds can be compared for the first time with deeper marine beds on the basis of planktonic zonation. (5) By further biotic and abiotic studies the shallow marine carbonates of the Adriatic platform will have to be more successfully documented and linked with the global sequence of events at the KT boundary.

References: [1] Stache G. (1889) Abh. geol. Reichants, 13, 1-170. [2] Hamrla M. (1960)RMZ, 3, 203-216. [3] Loeblich A. R. Jr. et al. (1987) Foraminiferal Genera and Their Classification. [4] Bignot G. (1972) Trav. Lab. Micropaleont., 2. [5] Alvarez L. W. et al. (1980) Nature, 208, 1095-1108. [6] Premoli-Silva I. et al. (1966) Riv. Ital. Pal. Strat. 72, 1183-1267. [7] Lindinger M. (1988) Mitt. Geol. Inst. ETH, 272, 253. [8] Keller G.,Benthos' 90, in print. [9] Drobne K. et al. (1988) Razprave SAZU, 4, razr., 29, 147-224. [10] Guex J. (1991) Bichronological Correlations. [11] Fleury J. J. (1980) Soc. Geol. du Nord, 4. I121 Preisinger A. et al. (1986) Nature, 3: N94- 28299

$$
55
$$

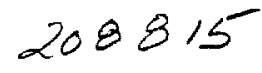

THE END-PERMIAN MASS EXTIŃCTION: A COMPLEX, MULTICAUSAL EXTINCTION. D. H. Erwin, Department of Paleobiology, NHB-121, National Museum of Natural History, Washington DC 20560, USA.

The end-Permian mass extinction was the most extensive in the history of life and remains one of the most complex. Understanding its causes is particularly important because it anchors the putative 26-m.y. pattern of periodic extinction. However, there is no good evidence for an impact and this extinction appears to be more complex than others, involving at least three phases $[1,2]$. The first began with the onset of a marine regression during the Late Permian and resulting elimination of most marine basins, reduction in habitat area, and increased climatic instability; the first pulse of tetrapod extinctions occurred in South Africa at this time. The second phase involved increased regression in many areas (although apparently not in South China) and heightened climatic instability and environmental degradation. Release of gas hydrates, oxidation of marine carbon, and the eruption of the Siberian flood basalts occurred during this phase. The final phase of the extinction, episode began with the earliest Triassic marine regression and destruction of nearshore continental habitats. Some evidence suggests oceanic anoxia may have developed during the final phase of the extinction, although it appears to have been insufficient to be the sole cause of the extinction.

Some $50 \%$ of marine families and perhaps over $90 \%$ of marine species were eliminated during the last few million years of the Permian [1,3]. Preservational problems and geochemical evidence suggest the extinction may have persisted into the earliest Triassic. Extinction patterns were highly selective: conodonts, nonfusulinid foraminifera, mosi bivalves, nautiloid cephalopods, and bellerophontid gastropods were largely unaffected, while blastoids, camerate crinoids, and tabulate corals had been declining well before the end of the period and disappeared entirely by the latest Permian. The last trilobites, stenolaemate bryozoans, rugose corals, and crinoids persisted at low diversity into the final, Changxingian stage. The extinction primarily affected the fusulinid foraminifera, several groups of articulate brachiopods, and ammonoid cephalopods; cidaroid echinoids, other gastropods, sponges, and some brachiopod groups declined in the latest Permian, but rebounded fairly quickly during the Early Triassic.

Late Permian faunas are highly provincial, however, and the biogeographic component of the extinction is only now being assessed. The best data for rapid extinction come from South China [4-6], an isolated tectonic block during the late Permian. It remains unclear to what extent the data from South China are representative of global diversity patterns. Biogeographic, taphonomic, and other problems continue to plague analysis of extinction data, obscuring important information on the rate and pattern of extinction. Recently developed conodont biostratigraphic correlations hold the promise of answering such questions [7]. It does seem fairly clear that sessile, epifaunal filter-feeders, and nearshore taxa suffered higher extinction rates than other taxa.

On land, 21 of $27(75 \%)$ tetrapod families disappeared [8]. In the Karoo Basin of South Africa two extinction peaks have been described from the Late Permian [9] although sampling problems raise important questions. Of the 27 orders of insect recorded from the Permian, eight disappeared and an additional seven suffered considerable reductions; four of the latter recovered during the Triassic. This was the most extensive ordinal extinction in insect history [10]. Plants show little evidence for mass extinction, although both pollen and fungal spores show significant changes at the Permo-Triassic boundary $[1,11]$. These changes may be associated with the destruction of nearshore communities during the rapid Early Triassic transgression.

Determining the cause of the extinction is complicated by the multitude of Late Permian geological changes. Although the supercontinent of Pangea had formed tens of millions of years earlier, a widespread regression during the terminal Permian exposed most of Pangea [12] leading to widespread climatic instability [13]. The rapid eruption of the Siberian flood basalts [14], significant shifts in $\mathrm{C}, \mathrm{O}, \mathrm{S}$, and $\mathrm{Sr}$ isotopes $[1,12,15,16]$, and increasing evidence for some marine anoxia $[17]$ complicate the picture. The $\delta^{13} \mathrm{C}$ evidence has received considerable attention, but appears to be equally consistent with erosion and oxidation of marine carbonates $[12,15]$, formation of anoxic bottom waters [17-20], and release of methane gas hydrates during regression [1].

Recently proposed causes for the end-Permian extinction include volcanism-induced cooling, extraterrestrial impact, and global anoxia (reviewed in [1]). Although no Ir anomaly has been identified at the P/Tr boundary [21], microspherules, apparently of volcanic origin, are widespread [e.g., 4]. However, despite the apparent force of the eruption of the Siberian traps, the eruption appears to have begun after the extinction. Additionally, the eruption appears to have been insufficient to trigger an extinction this large. Anoxia hypotheses have a related problem: calculations suggest that the observed $\delta^{13} \mathrm{C}$ shift may have been insufficient to reduce atmospheric $O$ levels sufficiently to induce extinction $[1,2]$.

The most plausible current explanation of the end-Permian mass extinction appears to involve multiple elements in a complex extinction, as outlined above. Testing this scenario, and the others proposed, requires high-resolution, global analyses of survival and extinction with particular attention to various biases (taphonomic, taxonomic, etc.), which may bias the data. Recent biostratigraphic advances [7] now make this possible and such studies are currently underway in the U.S. and China. 
The end-Permian mass extinction differs sharply from the endCretaceous in length, the pattern of extinction, and in the complexity of associated geological events. Additionally, there is little evidence for extraterrestrial impact at the close of the Permian and $C, O, S$, and $\mathrm{Sr}$ isotopic patterns are significantly different [22]. These sharp differences pose important problems for attempts to link these two extinctions to a common cause.

References: [1] Erwin D. H. (1993) The Great Paleozoic Crisis, 327. [2] Erwin D. H. (1993) Nalure, in press. [3] Raup D. M. (1979) Science, 206, 217-218. [4] Yang Z. Y. el al. (1993) PermoTriassic Events of South China, 153. [5] Yang Z. Y. et al. (1987) Geological Memoir, Ser., 2, 1-379. [6] Yang Z. Y. and Li Z. S. (1992) in Permo-Triassic Events in the Eastern Tethys (W. C. Sweet et al., eds.), 9-20. [7] Sweet W. C. (1992) in Permo-Triassic Events in the Eastern Tethys (W. C. Sweet et al., eds.), 120-133. [8] Maxwell W. D. (1992) Palaeontology, 35, 571-584. [9] King G. M. (1991) Hist. Biol., 5, 239-255. [10] Labandiera C. C. and Sepkoski J. J. (1993) Science, 261, 310-315. [11] Visscher H. and Brugman W. A. (1988) Mem. Soc. Geol. Ilal. 34, 121-128. [12] Holser W. T. and Magaritz M. (1987) Mod. Geol., 11, 155-180. [13] Parrish J. M. et al. (1986) The Ecology and Biology of Mammal-Like Reptiles $(\mathbf{N}$. Hotton, ed), 109-131. [14] Campbell I. H. et al. (1992) Science, 258. 1760-1763. [15] Holser W. T. et al. (1991) Abh. Geolog. Bund., 45, 213-232. [16] Baud A. el al. (1989) Geologische Rundschau., 78, 649-677. [17] Wignall P. B. and Hallam A. (1992) Palaeogeog. Palaeoclimat. Palaeoecol., 93, 21-46. [18] Wignall P. B. and Hallam A. (1993) Palaeogeog. Palaeoclimat. Palaeoecol., 102, 215-237. [19] Hoffman A. et al. (1990) Mod. Geol., 14, 211-221. [20] Malkowski K. et al. (1989) Nature, 337,64-68. [21] Clark D. L. et al. (1986) Science, 233, 984-986. [22] Holser W. T. and Magaritz M. (1992) GCA, 56, 3297-3309.

\section{OmT 0 P.4}

NEW EVIDENCE FOR PRIMARY FRACTIONATION OF RUTHENIUM AND IRIDIUM IN THE CHICXULUB EJECTA CLOUD. N. J. Evans', T. J. Ahrens ${ }^{1}$, B. I. A. McInnes ${ }^{2}$, and D. C. Gregoire ${ }^{3}$, 'Lindhurst Laboratory of Experimental Geophysics, Seismological Laboratory 252-21, California Institute of Technology, Pasadena CA 91125 , USA, ${ }^{2}$ Division of Geological and Planetary Sciences 170-25, California Institute of Technology, Pasadena CA 91125, USA, '3eological Survey of Canada, 601 Booth St., Ottawa Ontario KIA OE8, Canada.

Introduction: Platinum-group element (PGE; Ru, Ir, Pt, Pd, Ir, plus Au, included in the term PGE for the sake of brevity) analysis of the KT boundary fireball layer (terminology of [1]) has revealed that the mean $\mathrm{Ru} / \mathrm{Ir}$ ratio of the many marine sites studied $(1.67 \pm$ 0.38 ) is close to the chondrite ratio $(1.48 ;[2])$, whereas the value for nonmarine sites $(0.76 \pm 0.26)$ is not $[3,4]$. A positive correlation between the Ru/Ir ratio of globally distributed $\mathrm{KT}$ sites and $65-\mathrm{Ma}$ paleodistance from the Chicxulub structure was also observed [4]. This trend suggested that temperature-dependant, primary fractionation of PGE occurred in the ejecta cloud during condensation of vaporized projectile material. However, this previous work could not negate the dependence of the paleodistance- $R \mathrm{u} / \mathrm{Ir}$ ratio correlation on environment of deposition because all the marine sites studied were far from Chicxulub (Europe and New Zealand) and all the nonmarine sites were in North America. This work presents additional Ru and Ir analysis of the fireball layer from marine KT sites proximal to the impact structure at Chicxulub, Yucutan, other North American nonmarine KT sites, and DSDP cores. With this new data we assess the dependence of the previously observed trend on depositional environment and suggest a simple mechanism for primary fractionation of PGE, prior to their deposition in the fireball layer.

Methods and Results: Ruthenium and Ir in KT boundary samples were measured by isotope dilution inductively coupled mass spectrometry (ICP-MS), and a complete description of the digestion and analytical procedures have been published elsewhere $[3,4]$. Precision for the technique as percent standard deviation for multiplicate analysis of USGS diabase standard $\mathrm{W}-1$ are $6 \%(\mathrm{Ru})$ and $0.7 \%$ (Ir).

The abundances of Ru and Ir for all KT sites is given in Table 1. The Ru/Ir ratio and nature of the fireball layer samples analyzed from the following sites have been previously published [4]; Petriccio, Italy; Knappengraben and Elendgraben, Austria; Stevns Klint, Denmark; Agost, Spain; Woodside Creek, New Zealand; Raton Basin, Colorado; Red Deer Valley, Alberta; Morgan Creek, Saskatchewan and Lance Creek, Wyoming. New data is presented here for DSDP 577, DSDP 596, Brazos River, Texas, and Beloc, Haiti.

TABLE I. Paleodistance to Chic xulub and $\mathrm{Ru} / \mathrm{Ir}$ ratio for the fireball layer at the KT boundary sites studied.

\begin{tabular}{lcccc}
\hline & $\begin{array}{c}65 \mathrm{Ma} \\
\text { Paleodistance } \\
\text { to Chicxulub }\end{array}$ & Rulr & $\begin{array}{c}\text { Ru } \\
\text { (ppb) }\end{array}$ & $\begin{array}{c}\text { Ir } \\
\text { (ppb) }\end{array}$ \\
\hline Rite & & & & \\
\hline \multicolumn{1}{c}{ Berwind Canyon } & 52 & 0.89 & 50.9 & 56.9 \\
\multicolumn{1}{c}{ Starkvilie South } & 52 & 0.97 & 53.0 & 54.5 \\
Clear Creek North & 52 & 0.59 & 8.4 & 14.2 \\
Lance Creek & 2635 & 1.1 & 2.7 & 2.4 \\
Morgan Creek & 3440 & 0.43 & 7.8 & 18.0 \\
Frenchman River & 3532 & 0.49 & 1.4 & 2.9 \\
HellCreek & 3299 & 0.60 & 0.83 & 1.4 \\
Red Deer Valley & 3711 & 0.57 & 2.4 & 4.2 \\
Stevns Klint & 7363 & 1.6 & 69.4 & 42.9 \\
Agost & 6838 & 1.9 & 44.1 & 23.9 \\
Petriccio & 8318 & 1.2 & 4.6 & 3.7 \\
Knappengraben & 7730 & 2.0 & 4.9 & 2.5 \\
Elendgraben & 7642 & 2.2 & 18.7 & 8.4 \\
Woodside Creek & 12019 & 1.4 & 36.8 & 25.9 \\
Brazos River & 1338 & 0.87 & 0.76 & 0.85 \\
Beloc, Haiti & 688 & 0.72 & 4.1 & 5.7 \\
DSDP 577 & 9621 & 1.7 & 0.47 & 0.27 \\
DSDP 596 & 9378 & 0.8 & 8.0 & 9.7 \\
Chancet Rocks* & 12019 & 2.4 & 11 & 4.6 \\
Needles Point* & 12019 & 2.9 & 19 & 6.4 \\
\hline
\end{tabular}

nd - no data; All analyses are on a carbonate-free basis. Stevns Klint sample is of the lower layer III of [16]; spheroid-rich red clay, $0-1 \mathrm{~cm}$ above the lop of the Maastrichtian. DSDP 577 sample is from Leg 86, core 12, section 5, $115-$ $116 \mathrm{~cm}$. DSDP 596 value is a mean of eight $1-\mathrm{cm}$ continuous samples over the boundary interval; leg 91 , core 32 , section $4,47-55 \mathrm{~cm}$. Paleoreconstruction is courtesy of the PLATES PROJECT, Institute for Geophysics. The University of Texas at Austin.

*Data from [11]. Petriccio sample is of the middle $0.5 \mathrm{~cm}$ of the boundary clay (redlayer). 


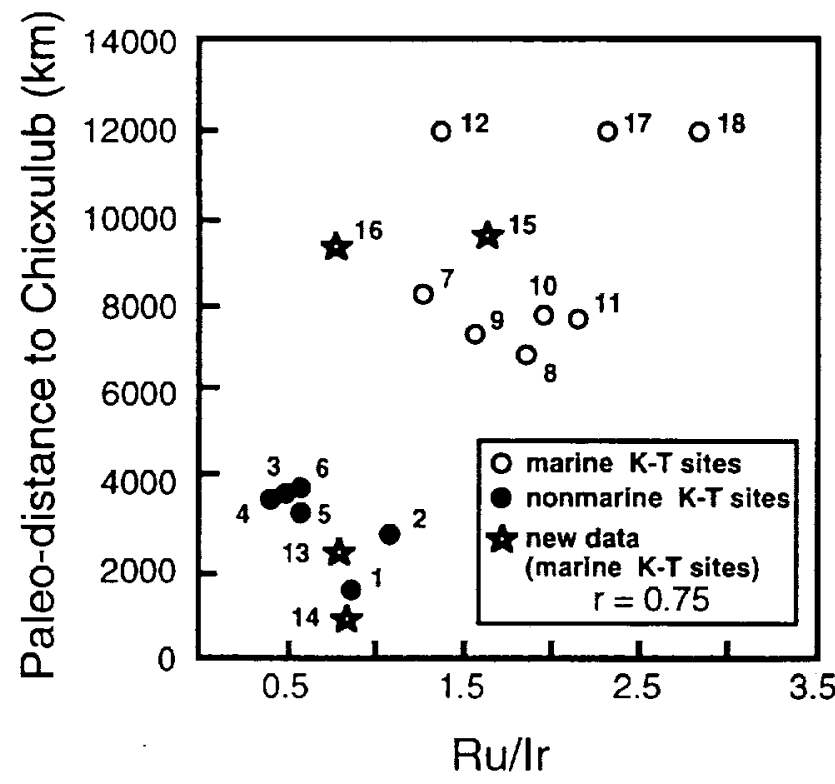

Fig. 1. Paleodistance $(\mathrm{km})$ from KT sample siles studied to Chicxulub, Yucatan, vs. Ru/Ir ratio. I. Raton Basin, Colorado; 2. Lance Creek, Wyoming (not included in regression coefficient calculation); 3. Morgan Creek. Saskatchewan; 4. Frenchman River, Saskatchewan; 5. Hell Creek, Montana; 6. Red Deer Valley, Albena; 7.Stevns Klint, Denmark; 8. Agost, Spain; 9. Petriccio, ltaly; 10. Knappengraben, Austria; 11 . Elendgraben, Austria; 12. Woodside Creek, New Zealand; 13. Brazos River, Texas; 14. Beloc, Haiti; 15. DSDP 577; 16. DSDP 596; 17. Chancet Rocks, New Zealand; 18. Needles Point, New Zealand. Sites 17 and 18 are data of [11].

DSDP Samples: Typical Ir contents for the boundary in DSDP 577 are $5 \mathrm{ppb}$ [5], over an order of magnitude higher than the value obtained here. A possible explanation for this discrepancy may be that the boundary sample analyzed is at the upper limit of the boundary interval, which is smeared out by bioturbation over $10 \mathrm{~cm}$ in this core [5,6]. Since no Ru values have previously been presented for this section, there is no basis for comparison of the present Ru data and no way to estimate how sampling the outer region of the boundary interval might affect the $\mathrm{Ru} / \mathrm{Ir}$ ratio. However, we have both $\mathrm{Ru}$ and Ir data for the entire 10-cm boundary interval in DSDP 596 and the $R u / I r$ ratio only varies by \pm 0.06 throughout (unpublished data).

The PGE-rich KT section in DSDP 596 is smeared over at leası $10 \mathrm{~cm}$ by bioturbation [7] and the values in Table 1 represent a mean for this interval. The physical mixing of the sediment does not seem to have affected the $R u / I r$ ratio since, as noted above, it varies little over the 10-cm interval.

Brazos River, Texas, and Beloc, Haiti: There is significant controversy over the location of the KT boundary at the extensively studied Brazos River site [8-10]; however, the observed Ru and Ir data indicate that the degree of fractionation of $\mathrm{Ru}$ from Ir during physical reworking processes is insignificant and we conclude that the Brazos River $\mathrm{Ru} / \mathrm{Ir}$ ratio reflects as primary a value as that for the other sites analyzed. The fireball layer sample from Beloc, Haiti (HKB92-56, oblained from A. Hildebrand) is a medium-gray claystone $1.5 \mathrm{~cm}$ thick.

There is some uncertainty regarding the composition of the boun- dary sample we analyzed for Lance Creek (collected by others) in that it might include both the underlying kaolinitic claystone and the fireball layer. This would have the effect of raising the $\mathrm{Ru} / \mathrm{Ir}$ ratio because the ratio in the kaolinitic claystone is always higher than that of the associated fireball layer for any given site [4]. For this reason, the Lance Creek value has been excluded from the calculation of regression coefficients (Fig. 1).

Table 1 gives the paleodistances $(65 \mathrm{Ma})$ from each site to the Chicxulub impact structure and the corresponding $\mathrm{Ru} / \mathrm{Ir}$ ratios. In Fig. I we have plotted all the Ru/Ir ratios for the fireball layer worldwide against the paleodistance from Chicxulub. In addition to sites analyzed in our laboratory, data for Chancet Rocks and Needles Point, New Zealand from [11] have been included.

Discussion: Previous work has shown that although all the PGE in the KT fireball layer are somewhat redistributed laterally and vertically by postdepositional processes [11-13], Ir and Ru are not significantly fractionated from each other during redistribution and are the most immobile PGE in the sedimentary environment $[14,4]$. The $R u / I_{r}$ ratio is therefore the most useful PGE interelement parameter for providing insight into primary fractionation processes. The Ru/Ir ratio of marine and nonmarine KT fireball layer samples are statistically distinct and nonmarine sites have nonchondritic ratios. In addition, the fact that all the marine sites previously analyzed were far from the Chicxulub impact site and all nonmarine sites were located in North America resulted in a positive correlation between $\mathrm{Ru} / \mathrm{Ir}$ ratio and paleodistance to Chicxulub. This trend cannot be explained by input of mantle-derived PGE or addition of PGE from a simultaneous impact event [3]. A primary mechanism for fractionation, which operates to change the $\mathbf{R u} / \mathbf{I r}$ ratio of nonmarine, North American KT sites from chondrite prior to their deposition in the fireball layer, is therefore indicated. However, more data were needed to definitively eliminate the possible dependance of the correlation on factors related to environment of deposition. The addition of data from the marine sites, Brazos River and Beloc, which both plot in the region dominated by nonmarine sites (Fig. 1), negates the dependance of the trend on differential remobilization associated with differences in the depositional environment. In addition, samples of DSDP cores from the Pacific represent an environment not previously investigated for $\mathrm{Ru} / \mathrm{Ir}$ ratios and provide convincing evidence that the environment of deposition is independent of the observed trend.

The greater than $1000^{\circ} \mathrm{C}$ difference in the condensation temperatures of $\operatorname{Ir}\left(5017^{\circ} \mathrm{C}\right)$ and $\operatorname{Ru}\left(3900^{\circ} \mathrm{C}\right)$ [15] leads us to propose that fractionation of Ir from Ru during condensation of the projectile-rich component of the ejecta may have occurred in the cooling ejecta cloud. The first condensates would have a low $\mathrm{Ru} / \mathrm{Ir}$ ratio because Ir condensed from the cloud while Ru remained in the vapor. Settling of early-formed condensates close to the impact site could explain the low $\mathrm{Ru} / \mathrm{Ir}$ ratios of North American nonmarine $\mathrm{KT}$ sites (Table 1, Fig. 1). Early fractionation of Ir from the ejecta cloud, combined with later incorporation of $\mathrm{Ru}$, results in later condensates having higher $\mathrm{Ru} / \mathrm{Ir}$ ratios [4].

Chemical analysis of ejecta collected after a $6.4-\mathrm{km} / \mathrm{s}$ experimental hypervelocity impact of a Fe-Ni-PGE alloy projectile into a Mo target indicates that temperature-dependent fractionation of PGE occurs in the ejecta during an impact event (Evans and Ahrens, unipublished data). Further study of these experimental results will determine whether this fractionation occurred during melting-quenching or vaporization-condensation processes. 
References: [1] Hildebrand A. R. and Boynton W. V. (1990) Science, 248, 843-847. [2] Anders E. and Grevesse N. (1989) GCA, 53, 2363-2380. [3] Evans N. J. et al. (1993) GCA, 57, 3737-3748. [4] Evans N. J. et al. (1993) GCA, 57, 3149-3158. [5] Michel H. V. et al. (1985) Init. Reports DSDP, 86 (G. R. Heath et al., eds.), 533538. [6] Smit J. and Romein A. J. T. (1985) EPSL, 74, 155-170. [7] Zhou L. et al. (1991) Geology, 19, 694-697. [8] Bourgeois J. et al. (1988) Science, 24l, 567-570. [9] Keller G. (1989) GSA Bull., 101, 1408-1419. [10] Montgomery H. et al. (1992) EPSL, 109,593600. [11] Tredoux M.et al. (1989) J. Geol.,97,585-605. [12] Schmitz B. (1988) Geology, 16, 1068-1072. [13] Izett G. A. (1990) GSA Spec. Paper 249,100. [14] Cousins C. A. and Vermaak C. F. (1976) Econ. Geol., 71, 287-305. [15] Weast R. C. (1989) CRC Handbook of Chemistry and Physics, 69th ed. [16] Schmitz B. (1985) GCA, 49, 2361-2370.

HABITAT VS. ASTEROID FRAGMENTATION IN VERTEBRATE EXTINCTIONS AT THE KT BOUNDARY: THE GOOD, THE BAD, AND THE UNTESTED. D. E. Fastovsky' and P. M. Sheehan'2, 'Department of Geology, University of Rhode Island, Kingston RI 02881, USA, 2Department of Geology, Milwaukee Public Museum, 800 W. Wells Street, Milwaukee WI 53233, USA.

The vertebrate fossil record is a touchstone in popular and scientific perceptions of KT events. However, the record actually is limited largely to the upper Great Plains of the United States. With in these confines, nevertheless, sufficient data are available to test vertebrate extinction scenarios in a limited way. Among competing theories, extinction by asteroid impact has been contrasted with extinction due to marine regression and concomitant habitat fragmentation. Here we address the evidence for these competing hypotheses, considering first the sedimentary environments represented by the relevant stratigraphic units, then the timing of the marine regression, and finally the evidence for habitat fragmentation and partitioning. It is our contention that (1) the marine regression maximum probably preceded KT boundary, (2) geological evidence for habitat fragmentation is completely lacking, and (3) pattems of vertebrate survivorship are fully concordant with extinction by asteroid impact.

The KT boundary in the upper Great Plains of the United States is represented by a conformable sequence spanning the last $2.2-$ $3.5 \mathrm{~m}$.y. of the Cretaceous (Lancian) through early Paleocene (Puercan). The Cretaceous is represented by the Hell Creek Formation; the Tertiary is represented by the Tullock Formation. These units are part of a clastic wedge that developed as the Laramide pulse of the Cordilleran orogeny began. The progradation of the wedge was approximately concurrent with the latest Cretaceous marine regression, whose timing we consider below.

The Hell Creek Formation represents an aggradational meandering fluvial depositional system along a coastal plain. It is composed largely of sandstones and mudstones, representing, respectively, river channel and floodplain deposits [1]. Because of the nature of the depositional system and the presence of successive stacked paleosols, the Hell Creek is riddled with hiatuses, each probably measured in hundreds to thousands of years [2]. By contrast, the base of the Tullock Formation primarily consists of widespread suspension-settling deposits interbedded with coals and some river channel deposits, representing a broadly flooded landscape during earliest Paleocene time $[1,3]$. The KT boundary itself is commonly-although not exclusively-represented by a coal, and a hiatus is indicated during which time peat deposition took place. The KT boundary in this region is thus marked by a facies change; however, in the context of local, shor-duration hiatuses, sedimentation was continuous to a first-order approximation.

Although it is widely known that the KT boundary in the Great Plains was associated with a marine regression, the precise timing of the boundary vis-a-vis the regression remains unclear. What is clear is that the Hell Creek clastic wedge is temporally sandwiched between the Campanian-Maastrichtian retreat of the Bearpaw Sea and the early Paleocene transgression of the Cannonball Sea, represented by the Cannonball Formation. In Montana, the Cannonball Formation is stratigraphically approximately $20 \mathrm{~m}$ above the KT boundary; in Alberta the unit is stratigraphically less than $3 \mathrm{~m}$ above the boundary [4]. This is reflective of the fact that during KT time, Alberta was closer than Montana to the marine strand line, which must have been located in northern Canada. Transgression, when it took place, would be expected to raise riverine base levels, and subsequently impede Cordilleran drainages. This is in fact what is observed at and above the Hell Creek/Tullock lithostratigraphic contact, suggesting that by the time of this lithostratigraphic feature (approximately coincident with the KT chronostratigraphic boundary), the Cannonball transgression had proceeded sufficiently to modify stream base levels.

J. D. Archibald and colleagues [5-10], have repeatedly linked the KT extinctions and the marine regression, suggesting that the retreating seaway caused habitat fragmentation that led to the extinctions:

Although total area increased during marine regression, the size and variety of low coastal plain habitats ... declined drastically. Shallow coastal marine habitats showed a similar decline. Not only did habitat size in these two realms decrease, but habitat fragmentation ... further stressed living populations [6].

As discussed earlier, the regression resulted in the loss of tens of thousands of square miles of coastal habitats in which these dinosaurs lived [7].

As the seaways bisecting North America receded some 65 m.y. ago, it [sic] reduced and fragmented the low coastal plains where the dinosaurs lived [8] ... and dinosaurs disappeared as habitats in low coastal plains were severely reduced and fragmented during regression [9].

Neither geomorphology, nor the sedimentary geology of the Hell Creek and Tullock, nor the patterns of extinction of the biota provides any support for this premise. It is counterintuitive to posit that an increase in land surface area (as occurs by definition as the result of a marine regression) will be accompanied by habitat fragmentation; why should the terrestrial realm be "fragmented" by increasing the habitable area? An increase in land should provide opportunities and space previously not available to land-dwelling organisms.

Hell Creek sedimentation appears to have been constant through time, and there is no evidence for fragmentation or deteriorating habitats. Channel size, shape, and lateral relations with flood-plain sediments do not change through the thickness of the formation. It is conceivable that a lowering of base level could increase incision by stream channels. This should not be equated with habitat frag- 
mentation; the system was clearly aggradational and not erosional (as the preservation of sediments recording the KT time interval attests). Moreover, the KT interval in Montana (the source of the vertebrate faunas) is stratigraphically, and thus by inference geographically, quite distant from the shore line. This means that the faunas from which $\mathrm{KT}$ events are being reconstructed were living in a setting hundreds of kilometers from marine influences. It is significant that the two previous great transgressive and regressive pulses of the westem interior seas failed to cause anything close to the magnitude of the KT extinction.

It is generally agreed that in the terrestrial realm pattems of survivorship across the $\mathrm{KT}$ boundary strongly favored land-dwelling vertebrates over aquatic ones $[6,11]$. This provides clues to the nature of the causal agent in the KT extinction. Land-dwelling vertebrates underwent an $88 \%$ extinction; aquatic vertebrates underwent only a 10\% extinction. Sheehan and Fastovsky [11] explained this disparity by differences in trophic structures: aquatic vertebrates exist within detritus-based or detritus-enhanced food chains, while land-dwelling vertebrates are directly dependent upon primary productivity. A hypothesis that calls for a cessation in primary productivity, such as via the loss of sunlight due to an asteroid impact, can explain this marked pattern of survivorship and extinction.

The pattern of vertebrate survivorship in eastem Montana takes its place among the mounting evidence that global primary productivity was severely but temporarily curtailed at the KT boundary [12-14]. This should be contrasted with the idea of habitat fragmentation, for which there is no geological evidence, and which has no context or relevance beyond the terrestrial ventebrates of the upper Great Plains of the United States. In this sense, habitat fragmentation is no hypothesis at all; it is only an ad hoc explanation for a local pattern of survivorship and extinction. It does not take into account the wealth of geochemical, geological, and biological events that are known to have characterized the KT boundary around the world. The asteroid impact hypothesis provides a global context in which to consider the extinctions in eastem Montana. Considered thus, the eastern Montana record is fully concordant with virtually all that is known of KT events.

References: [1] Fastovsky D. E. (1987) Palaios., 2, 282-295. [2] Fastovsky D. E. (1990) GSA Spec. Paper 247, 541-548. [3] Belt E. S. et al. (1984) SEPM Spec. Publ. 7, 317-335. [4] Lerbekmo J. F. and Coulter K. C. (1984) Can. Soc. Pel. Geol. Mem., 9, 313-317. [5] Archibald J. D. (1991) GSA Abstr. with Prog., 23, A-359. [6] Archibald J. D. (1993) Geology, 21, 90-92. [7] Archibald J. D. (1993) in The Ultimate Dinosaur, (B. Preiss et al., eds.), 276-288. [8] Archibald J. D. (1993)New Scientist 13/2/93, 24-27. [9] Archibald J. D. (1993) GSA Abstr. with Prog., 24, A-297. [10] Archibald J. D. and Bryant L. J. (1990)GSA Spec. Paper 247,549-562. [11] Sheehan P.M. and Fastovsky D. E. (1992)Geology, 20, 556-560. [12] Sheehan P. M. and Hansen T. A. (1986) Geology, 14, 868-870. [13] Wolfe J. A. and Upchurch G. A. (1986) Nature, 324, 148-151. [14] Arthur M. A. et al. (1987) Cretaceous. Res., 8, 43-54.
A 74.5-M.Y. STRESS SCHEDULE AND ITS REFLECTION IN THE STRATIGRAPHIC PERIODS. A. G. Fischer ${ }^{l}$ and N. Kitz'2, 'Department of Earth Sciences, University of Southem Califomia, University Park, Los Angeles CA 90089-0740, USA, ${ }^{2}$ Wedgwood House, Pains Hill, Cobham, Surrey KTII ID3, UK.

Sepkoski's and Raup and Sepkoski's work on biotic crises (various papers) and improvement of radiometric geochronology provide the basis for a new evaluation of periodic biospheric stress. Plotting the six strongest biotic crises in terms of age shows a remarkable regularity (Table 1): With exception of the greatest of them (the unique first-order Permo-Triassic crisis) they define successive steps in a 74.5 m.y. schedule. These coincide (or very nearly coincide) with period boundaries end Cambrian, end Ordovician, end Devonian, end Triassic, and end Cretaceous. Two stops on this schedule are not marked by severe (second-order) crises, but match the third-order crises at end Carboniferous and end Jurassic. The Siluro-Devonian boundary falls off the 74.5 m.y. schedule, and has no associated crisis: it reflects regional bias on the part of the founding fathers of stratigraphy. The Permo-Triassic boundary and crisis fall off the schedule, and we attribute them to unidentified complications. No crisis marks the Tertiary-Quatemary boundary: rather, the 74.5-m.y. stop lies $8 \mathrm{~m} . \mathrm{y}$. in the future.

Thus Phanerozoic time was segmented by biotic stresses recurring at 74.5-m.y. intervals. Third-order crises seem to have bisected these segments in Paleozoic time and to have trisected them in the Mesozoic and Cenozoic. The cause of these stresses remains uncertain, but we incline to interactions with galactic forces: The period of the solar system's oscillation transverse to the midgalactic plane has been estimated at between 67 (Oor, 1960, 1965) and $80 \mathrm{Ma}$ (Tumpler and Weaver, 1968).

TABLE 1. Scheduled nature of period boundaries and crises.

\begin{tabular}{|c|c|c|c|c|}
\hline \multirow{2}{*}{$\frac{74.5 \mathrm{Ma}}{\text { Schedule }}$} & \multirow[t]{2}{*}{ Periods } & \multirow[t]{2}{*}{ Ages } & \multicolumn{2}{|c|}{ Crisis Magnitude } \\
\hline & & & & \\
\hline \multicolumn{5}{|l|}{+8} \\
\hline \multicolumn{5}{|c|}{$\begin{array}{l}\text { Quatemary } \\
\text { Tertiary }\end{array}$} \\
\hline \multicolumn{5}{|c|}{ Cretaceous } \\
\hline$-140 \ldots .$. & Jurassic & $-141^{*}$ & Jurassic & (3) \\
\hline \multicolumn{5}{|c|}{$\begin{array}{l}\text { Triássic } \\
\text { Permian }\end{array}$} \\
\hline$-289 \ldots .$. & \multicolumn{4}{|c|}{ Carboniferous } \\
\hline \multicolumn{5}{|c|}{$\begin{array}{c}\text { Devonian } \\
\text { Silurian }\end{array}$} \\
\hline \multicolumn{5}{|c|}{ Ordovician } \\
\hline$-512 \ldots .$. & Cambrian & -513 & & (2?) \\
\hline
\end{tabular}

Permo-Triassic crisis omitted. Ages rounded to Ma, according to Harland et al. (1989) (best fit numbers), except Bralower et al. (1990) (marked with asterisk). 
BIOZONATION OF THE BELOC FORMATION AND ITS RELATION TO THE CHRONOLOGY OF THE KT BOUNDARY EVENT. J.-M. Florentin, R. Maurrasse, and L. J. Geier, Department of Geology, Florida International University, Tamiami Trail, Miami FL 33199, USA.

Biostratigraphy of the Beloc Formation from the Southem Peninsula of Haiti compared to various locations worldwide indicates that, in addition to problems related to taxonomic identification, discrepancies associated with the biostratigraphic succession that characterizes the KT boundary are related to various superimposing regional and local factors: (1) faunal provincialism controlled by global ecological constraints such as temperature gradient; (2) local exclusions influenced by paleogeographic factors; and (3) physical disturbance of varying magnitude coeval with a major impact event, which occurred toward the close of the Maastrichtian. This event left a distinct horizon in the circum-Caribbean area, where it includes splash ejecta melt (tektites) and other cosmically derived residues.

The biostratigraphy across the marker horizon implies that the initial impact event occurred toward the close of the Maastrichtian, in the foraminiferal biozone that can be correlated with the Trinitella scotti zone. This zone, suggested by Masters [2], is a viable concurrent altemative zone to the traditional Abathomphalus mayaroensis zone, whose specimens are often missing.

An apparent second major physical disturbance affected the ocean in the early Teriary and caused further mixing of early Danian and Cretaceous taxa.

Thus, the main discrepancies that exist worldwide conceming the biostratigraphic continuity, or the exact biostratigraphic age of the KT boundary, are seen as related to complex interacting factors further intensified by reworking caused by deepwater megawaves during the impact(s), as postulated by [3] and [1], not by turbidites. Subsequent subaqueous flow events also enhanced mixing with more local characteristics.

Despite the fact that the same physical evidence (tektite layer, subaqueous flow deposits, etc.) will be synchronous every where, the actual biochronologic continuity at different KT sites is often very different, an artifact due to physical disturbances.

References: [1] Gault D. E. and Sonett C.P. (1982)GSA Spec. Paper 190, 69-92. [2] Masters B. A. (1977) in Oceanic Micropaleontology (A. T. S. Ramsay, ed.), 301-731, Academic. [3] Sonett C. P. et al. (1991) Adv. Space Res., II, 77-86.

ORGANIC MATTER CHANGES ACROSS NONMARINE KT BOUNDARY SECTIONS. A. F. Gardner, I. P. Wright, and 1. Gilmour, Department of Earth Sciences, The Open University, Milton Keynes, UK.

Previous work on $\mathrm{C}$ and N in KT boundary clays at marine sites has revea led enrichments for both elements, as well as corresponding changes in isotopic compositions [1-3]. The enrichment in $\mathrm{N}$ has been attributed to either acid rain [4] or an anoxic environment [2]. The $N$ enrichment at marine sites, while being a worldwide phenomenon, is apparently not universal. For instance, no enrichment was nored at Gubbio, Italy, or Stevns Klint, Denmark [3]. We have examined both $\mathrm{C}$ and $\mathrm{N}$ abundance and isotopic compositions from two nonmarine KT sequences in the USA (Brownie Butte, Montana, and Raton Pass, New Mexico).
At Brownie Butte the fireball layer is separated from an overlying coal seam by a thin shale band, which is characterized by a fem spore abundance anomaly and is thought to represent a resurgence in biological productivity above the boundary. It has been termed the recovery layer [5]. A series of 12 samples spanning the boundary, along with pure samples of the ejecta and fireball layers from Brownie Butte, were treated with $\mathrm{HF} / \mathrm{HCl}$ to leave a residue (total $\mathrm{C}$ fraction) containing kerogen, elemental $\mathrm{C}$, and soot. In a similar fashion 16 samples from across the boundary at Raton Pass were also prepared. All samples were then analyzed for $C$ and $N$. Carbon isotope measurements were made on a VG SIRA 24 mass spectrometer using sealed-tube combustion and $\mathrm{N}$ isotope measurements were made using the method of Boyd et al. [6,7] on a static vacuum mass spectrometer.

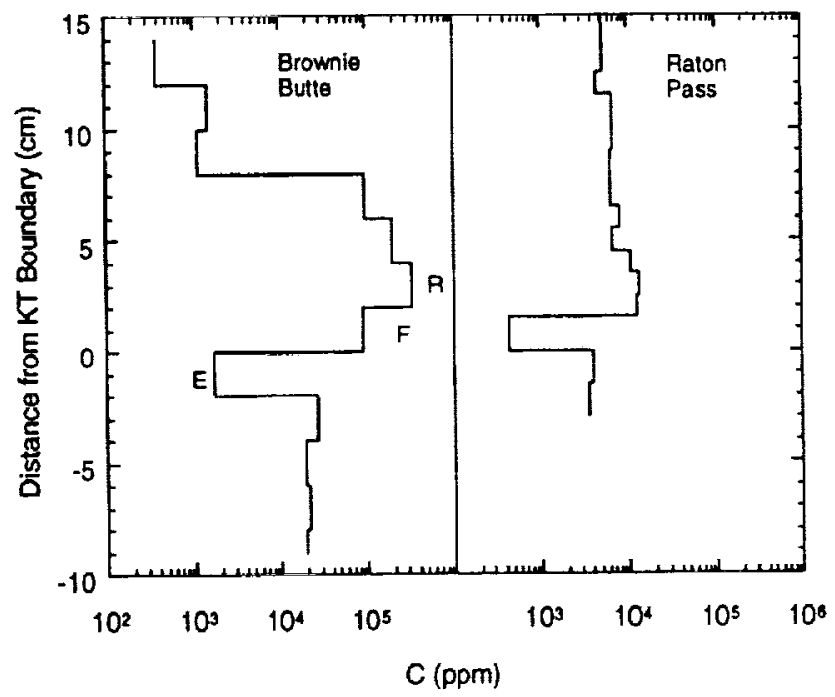

Fig. 1. Organic $C$ abundance at Brownie Butte and Raton Pass. E - ejecta layer, F - fireball layer, $\mathrm{R}$ - recovery layer.

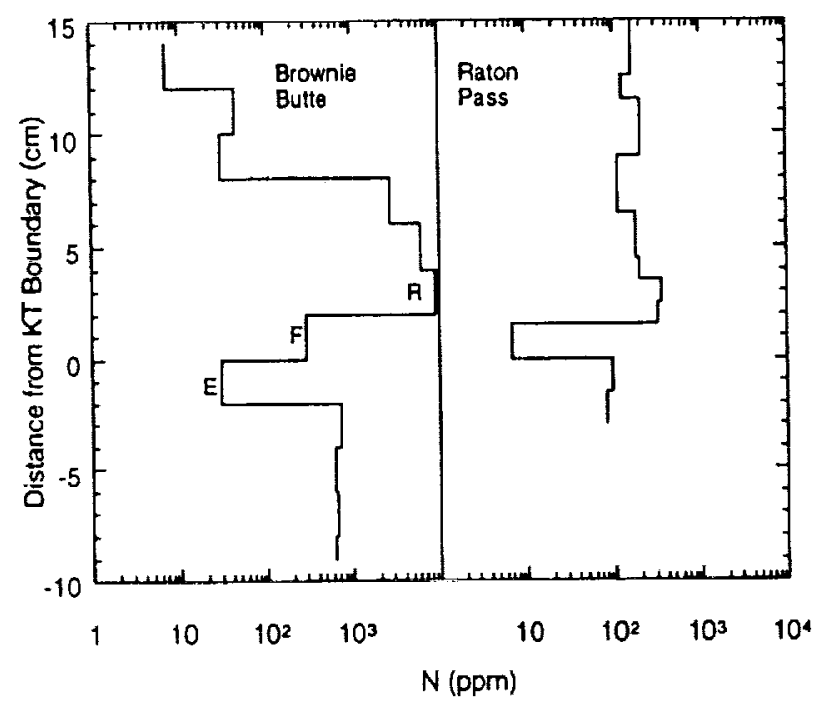

Fig. 2. Organic $\mathrm{N}$ abundance at Brownie Butte and Raton Pass. $\mathrm{E}=$ ejecta layer, $\mathrm{F}$ - fireball layer, $\mathrm{R}$ - recovery layer. 
Results from Brownie Butte (Figs. 1 and 2) show $C$ concentration to decrease 26-fold in the ejecta layer, compared to late Cretaceous values, before increasing 18 -fold in the fireball layer, followed by a further 4-fold increase in the layer above. Nitrogen concentration reflects this pattem, with a 25 -fold decrease in the ejecta layer, followed by a 10 -fold increase. The recovery layer further increases in $\mathrm{N}$ by 31 -fold. The results from Raton Pass (Figs. 1 and 2) parallel those of Brownie Butte, showing a 9-fold decrease in $C$ concentration at the boundary and 28 -fold increase in the layer above, while $N$ concentration decreased 13-fold at the boundary followed by 44 -fold increase immediately above. Elemental $\mathrm{C}$ and soot are concentrated in the fireball layer at the Raton section [8], though soot does not comprise the bulk of the $C$ remaining after acid etching.

The $\mathrm{C}$ isotopic composition of the total $\mathrm{C}$ at both sites (Fig. 3) shows a marked shift in $\delta^{13} \mathrm{C}$ across the boundary. At Raton Pass, values shift from $-24.5 \%$ immediately below the boundary to $-27.3 \%$ immediately above, becoming progressively heavier at $-26.3 \%$ to $-25.6 \%$ in the overlying coal. The values reported are similar to those of Hildebrand and Wolbach [8], who also observed a $-2 \%$ shift in total $\mathrm{C}$ isotope compositions at the boundary. The Brownie Butte samples also show a shift in their $\delta^{13} \mathrm{C}$ values, changing from $-26.2 \%$ o below the boundary to $-28.3 \%$ in the thin shale band, again a shift of some $-2 \%$. A similar trend toward heavier isotopic compositions is observed in the overlying coal, as is seen at Raton Pass.

Organic $\mathrm{N}$ isotope composition at Raton Pass (Fig. 4) averages $\sim 1 \%$ below and above the boundary, though there is an apparent shift of $\sim 1.5 \%$ in the lowest Tertiary before returning to Cretaceous values. At Brownie Butte (Fig. 4), Cretaceous and Tertiary $\delta^{15} \mathrm{~N}$ values similarly range from $2-3 \%$ with a small $(<1 \% 0)$ shift toward heavier values in the lowermost Tertiary samples. At both sites the fireball layer is isotopically lighter at around $0-0.5 \%$; however, the amount of $\mathrm{N}$ in these layers is comparatively low (295 ppm at Brownie Butte and 7 ppm at Raton Pass).

The enrichments in $\mathrm{N}$ abundance observed at marine sites [2-4] occur in the basal layer and continue throughout the boundary clay,

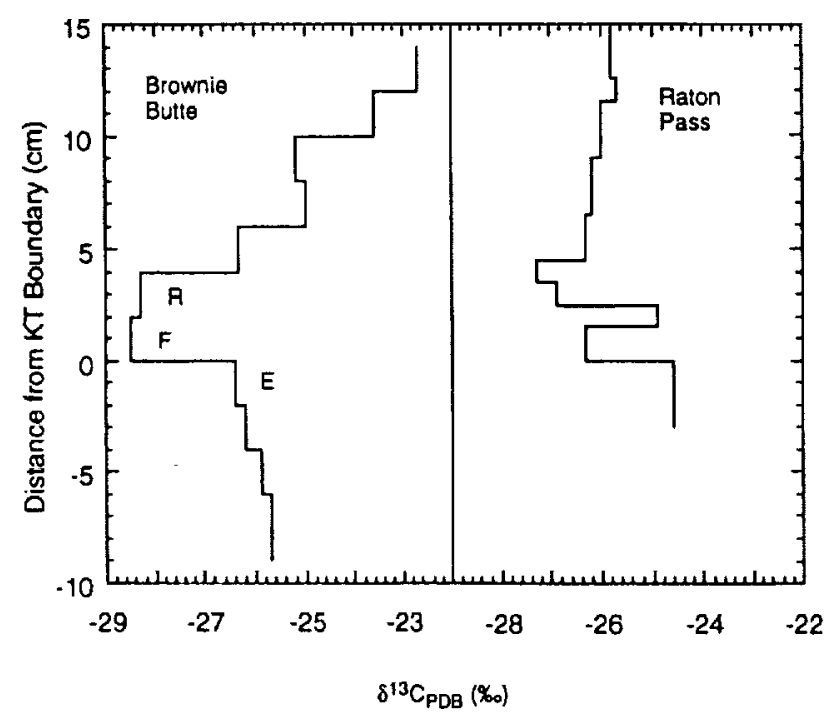

Fig. 3. Carbon isotope composition of organic matter at Brownie Butte and Raton Pass. E - ejecta layer, F = fireball layer, R - recovery layer.

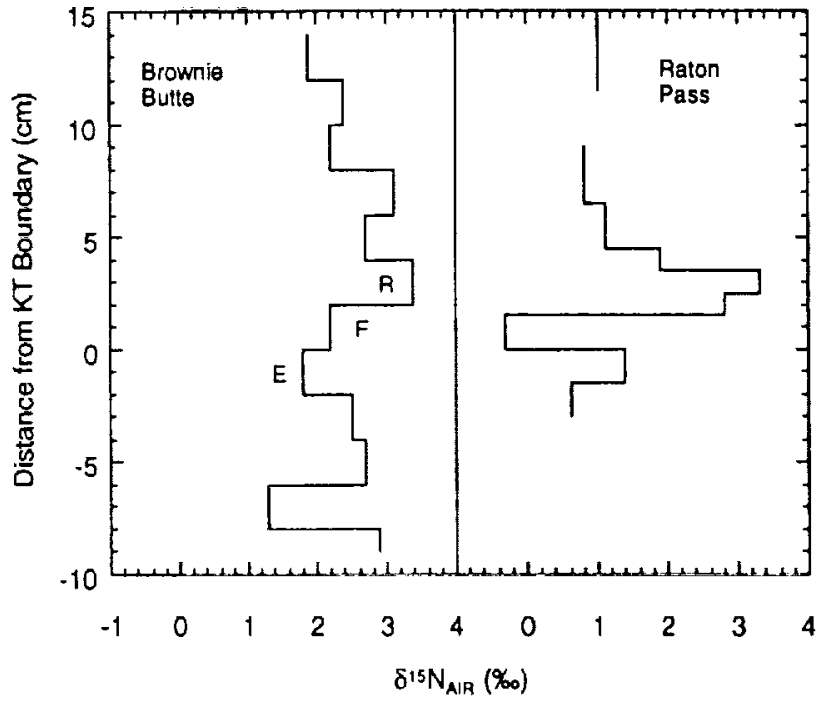

Fig. 4. Nitrogen isotope composition of organic matter at Brownie Butle and Raton Pass. E - ejecta layer. F - fireball layer. R - recovery layer.

representing a substantial accumulation of isotopically anomalous $\mathrm{N}$ over very short timescales. The basal layer is thought to be stratigraphically equivalent to the fireball layer observed in North American sections. However, the fireball layer itself does not show any enrichment in $\mathrm{N}$ abundance; in fact, it is generally depleted in both organic $\mathrm{C}$ and $\mathrm{N}$ as might be expected for a layer that essentially represents atmospheric fallout. An enrichment in $\mathrm{N}$ does occur in the overlying recovery layer and persists into the coal. However, there is no substantial change in $\mathrm{C} / \mathrm{N}$ ratio at either Brownie Butte $(\mathrm{C} / \mathrm{N}=$ 30-35) or Raton ( $\mathrm{C} / \mathrm{N}=40-50)$ between Cretaceous and Tertiary samples, implying no additional input of $\mathrm{N}$ at or immediately above the boundary as might be expected had the shock combination of $\mathrm{N}_{2}$ and $\mathrm{O}_{2}$ in the atmosphere led to the production of nitric acid rain that had subsequently been fixed as organic $\mathrm{N}$. Carbon/nitrogen ratios are slightly higher in the fireball layers at both sites (Raton, $\mathrm{C} / \mathrm{N}=$ 62; Brownie Butte, $\mathrm{C} / \mathrm{N}=61$ ), presumably reflecting the input of elemental $\mathrm{C}$ and soot to this layer.

The increase in both organic $\mathrm{C}$ and $\mathrm{N}$ above the boundary, however, reflects a significant environmental change from conditions preceding the KT boundary. The $0-3-\mathrm{cm}$ layer coincides with a fem spore abundance anomaly and its palynology is thought to reflect the first resurgence of biological productivity immediately following the KT event [5]. The isotopic changes seen in this layer at both sites may therefore be a record of environmental change immediately following the impact. Interestingly, the $\mathrm{C}$ isotopic changes observed in the Raton Pass samples studied here are similar to those reported by Hildebrand and Wolbach [8] for a separate set of samples from the Raton Basin, where the boundary clay was not overlain by a coal seam. They are also similar to those from Brownie Butte, where the coal is separated from the fireball layer by a narrow band of shale. This would imply that the isotopic compositions reflect large-scale changes in the environmental conditions, independent of local effects. It has recently been suggested that the negative shift in $\mathrm{C}$ isotopes observed in carbonates at many marine $\mathrm{KT}$ sequences may be the result of isotopically light $\mathrm{CO}_{2}$ entering the atmosphere as a result of widespread fires [9]. A similar effect might also be expected in organic $\mathrm{C}$ at nonmarine sites, had the isotopic 
composition of atmospheric $\mathrm{CO}_{2}$ significantly differed from the late Cretaceous value, as this would be reflected in more negative $\delta^{13} \mathrm{C}$ values for photosynthetically produced $C$. Such a change is apparent at both the sites studied here; however, such changes in the $\delta^{13} \mathrm{C}$ of organic $\mathrm{C}$ are not unusual across stratigraphic boundaries, and more detailed work, specifically on the isotopic compositions of individual organic compounds, is required to see whether the changes observed are indeed due to such a drastic change in the Earth's environment.

References: [1] Wolbach W. S. et al. (1990) GSA Spec. Paper 247, 391-400. [2] Gilmour I. et al. (1990) GSA Spec. Paper 247, 383-390. [3] Robert F. et al. (1990) Meteoritics, 25, 401. [4] Prinn R. G. and Fegley B. (1987) EPSL, 83, 1-15. [5] Tschundy R. H. et al. (1984) Science, 225, 1030-1032. [6] Boyd S. R. et al. (1988) J. Phys. E: Sci. Instrum., 2l, 876-885. [7] Wright I. P. et al. (1988) J. Phys. E: Sci. Instrum., 21, 865-875. [8] Hilderbrand A. R. and Wolbach W. S. (1989) LPS XX, 414-415. [9] Ivany and Salawitch (1993) Geology, 21, 487-490.

COCCOLITHOPHORE EXTINCTION AT THE KT BOUNDARY: GRADUAL OR A BRUPT. S. Garner, J. Alcala, and E. Grossman, Texas A\&M University, College Station TX 77843, USA.

The past 15 years have witnessed a staggering expenditure of effort in an attempt to understand the events that surround the KT boundary. Yet with all that effort some very fundamental issues remain unresolved, issues that go to the heart of the problem. One unanswered question remaining is what precisely was the pattern of the extinction of the various groups of organisms, the very issue that first defined the problem and, indeed, continues to frame it to this day. Few deny that an extensive faunal and floral turnover occurred near the KT boundary. But even the closest scrutiny of the record has failed to yield unambiguous evidence that the demise of a particular group of organisms was massive and near instantaneous, as would be expected, indeed required, from a catastrophe such as a large impact. No group of organisms, it seems, has left a record that does not lend itself to contradictory interpretations. The principal problem is the inherent lack of resolution to allow discrimination of events that may have occurred over a time span of perhaps less than a decade to a century, but certainly not more than a millennium. The problem is complicated further by ubiquitous redeposition, which seems to be more prevalent at the KT boundary than in any other interval of the geological record (except perhaps the Pleistocene).

One of the first groups to have its remarkable turnover at the KT boundary documented in detail were the coccoliths (calcareous nannofossils), a group of marine planktonic algae that, like terrestrial reptiles, thrived during the Cretaceous as never before and probably not ever thereafter. When catastrophic extinction mechanisms were proposed the coccolith record was again scrutinized, this time more closely than before. It became clear that the species abundance pattem alone could not demonstrate conclusively whether extinction of Cretaceousspecies was geologically instantaneous (on a timescale of decades to centuries), which would require that all of the many Cretaceous species occurring in Danian sediments were redeposited, or whether some Cretaceous species actually survived into earliest Danian time. Al some boundary sections stable $C$ isotope ratios in the abundant calcite of the sediments seem to indicate survival of some Cretaceous coccolithophores into Danian time: $\delta^{13} \mathrm{C}$ values obtained from early Danian samples in which presumed redeposited Cretaceous species dominated, were so different from a $\delta^{13} \mathrm{C}$ values of average latest Maastrichtian (latest Cretaceous) samples from immediately below the boundary at the same location as to require unrealistic values for the indigenous Danian species that contributed only a small proportion of the biogenic carbonate and, hence, of the $\delta^{13} \mathrm{C}$ signal in the early Danian sample [1].

It is important to note that coccoliths constitute much of the fine fraction of the carbonate in these sediments, and because it is very difficult to isolate coccoliths from other fine sediments, all $\mathrm{C}$ isotope determinations were made on whole-rock samples. The assumption made in these interpretations is that $\delta^{13} \mathrm{C}$ values of the whole-rock samples are in all cases an adequate approximation of the $\delta^{13} \mathrm{C}$ values of the coccoliths in the samples. A further assumption is that the whole-rock $\delta^{13} \mathrm{C}$ value is a composite of the contribution from the "Cretaceous" coccolith and Danian coccolith $\delta^{13} \mathrm{C}$ values, with each contributing to the $\mathrm{C}$ isotope signal in the proportion in which the coccolith calcite occurs in the sample. Thus the $\delta^{13} \mathrm{C}$ data lead to the conclusion that some Cretaceous coccolithophores survived into early Danian time and actually formed coccoliths with a typical Danian $\delta^{13} \mathrm{C}$ signature.

In order to test this conclusion a study was undertaken on two deep-sea KT boundary sections, one at DSDP Site 527, the other at DSDP Site 529, both from Walvis Ridge in the eastern South Atlantic. For this study $C$ isotope determinations were not made on wholerock samples. Instead the samples were repeatedly processed by settling from suspension in a water column, thereby incrementally removing all particles that were larger or smaller than coccoliths. Slides were prepared at each successive step and compared to slides prepared from the previous step, to make certain that no undue number of coccoliths was lost from either end of the size range of the various species. In nocase was it possible to remove all non-coccolith debris from a sample, but the final concentrate of coccoliths contained significantly less noncoccolith particles than did the initial unprocessed material. The residue remaining at the end of the processing was used to determine $\mathrm{O}$ and $\mathrm{C}$ isotope ratios for that sample.

From the measured $C$ isotopic composition of the sample the $\delta^{13} \mathrm{C}$ of the earliest Danian indigenous coccoliths was calculated, using the same mathematical expression used by Perch-Nielsen [1]

$$
\delta^{13} C_{m}=f_{K}\left(\delta^{13} C_{K}\right)+f_{T}\left(\delta^{13} C_{T}\right)
$$

where $\delta^{13} C_{m}$ is the measured $C$ isotope ratio of the sample, $\delta^{13} C_{K}$ is the average $C$ isotope ratio of the latest Maastrichtian samples (coccoliths) immediately below the KT boundary, and $\delta^{13} \mathrm{C}_{\mathrm{T}}$ is the (calculated) $\mathrm{C}$ isotope ratio of earliest Danian coccoliths. The two values $f_{K}$ and $f_{T}$ represent the proportion of Cretaceous and Tertiary coccoliths, determined for each sample from the proportion of area covered by Cretaceous and Danian coccoliths in a representative number of fields in the light microscope. (For the purpose of the calculations it is assumed that all Cretaceous coccoliths occurring above the KT boundary have been redeposited.) The resulting data are plotted on Fig. 1. The largest excursion of the calculated $\delta^{13} C_{T}$ from the measured $\delta^{13} \mathrm{C}_{\mathrm{m}}$ at both sites is from the sample at or closest to, but above, the boundary; at Site 527 the excursion is $-3.63 \%$, at Site 529 it is $-0.85 \%$. At both sites there is a distinct shift of the $\mathrm{C}$ isotope ratios in the negative direction but at neither site do the calculated Danian values seem so unreasonable as to require that the Cretaceous species that dilute the signal must have lived in Danian seas. Our preferred interpretation, therefore, is that Maastrichtian 


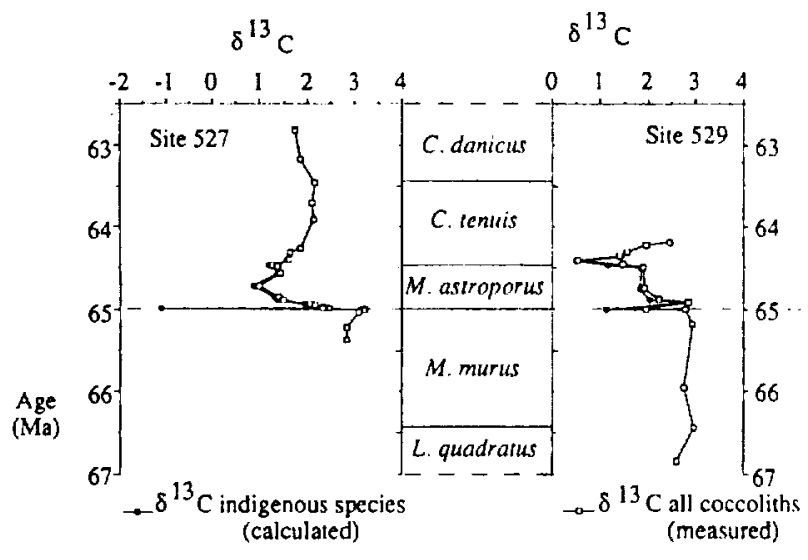

Fig. 1. Carbon isotope ratios in latest Maastrichtian and earliest Danian calcareous nannofossil concentrates at DSDP sites 527 and 529. Walvis Ridge, eastem South Atlantic.

species probably did not survive into early Danian time, and, where they occur within earliest Danian sediments, their occurrence should be ascribed to redeposition.

If this conclusion is correct, it raises two other difficult questions. The first is that if the epiplanktonic Cretaceous coccolithophores became extinct essentially in a single event at the boundary, then why were some Cretaceous planktonic foraminifera living in the same environment able to survive into early Danian time? There seems little doubt that some planktonic foraminifera did indeed survive. The second question is what component of unprocessed early Danian sediment contributes the intensely negative isolope signal that other investigators have found, but that clearly does not seem to be associated with the calcareous nannoplankton. It seems there are still more questions than there are answers.

References: [1] Perch-Nielsen K. et al. (1982) GSA Spec. Paper 190, 353-371.

PRELIMINARY RESULTS REGARDING THE FORMATION CONDITIONS OF METEORIC SPINELS. J. Gayraud, E. Robin, R. Rocchia, and L. Froget, Centre des Faibles Radioactiv* ités CEA/CNRS, 91198 Gif-sur-Yvelte, France.

Introduction: Meteoric spinels, which previously have been termed cosmic spinels [1], are magnetic minerals formed when a piece of extraterrestrial matter is melted and oxidized in the Earth's atmosphere. Such minerals have no analog in terrestrial rocks but are systematically found in cosmic spherules $[1,2]$, in the fusion crusts of meteorites [1,2], and in various cosmic debris such as meteoroid ablation droplets [3] and oceanic impact products [4]. We adopt here the term "meteoric" rather than "cosmic" for two reasons: (1) to avoid any confusion with spinels originally present in meteoritic matter and (2) because their formation is associated with the occurrence of meteors. The importance of meteoric spinels in the geological record is twofold: They are specific markers of meteoritic material and they contain information regarding the mode of accretion of this material [1]. In order to interpret this information it is essential to understand the formation condition of these minerals. In terrestrial magmas, spinel formation is controlled by the $O$ fugacity, temperature, and initial composition of the crystallizing material
$[5,6]$. In the case of meteoric spinels, the kinetics of the reaction (duration of the heating and cooling phases) may also play an important role. The study of the effect of the $O$ fugacity on the composition of meteoric spinels is of particular interest as it provides information about the altitudes of deceleration and oxidation of cosmic bodies in the atmosphere and, hence, of their size. Here we report on the

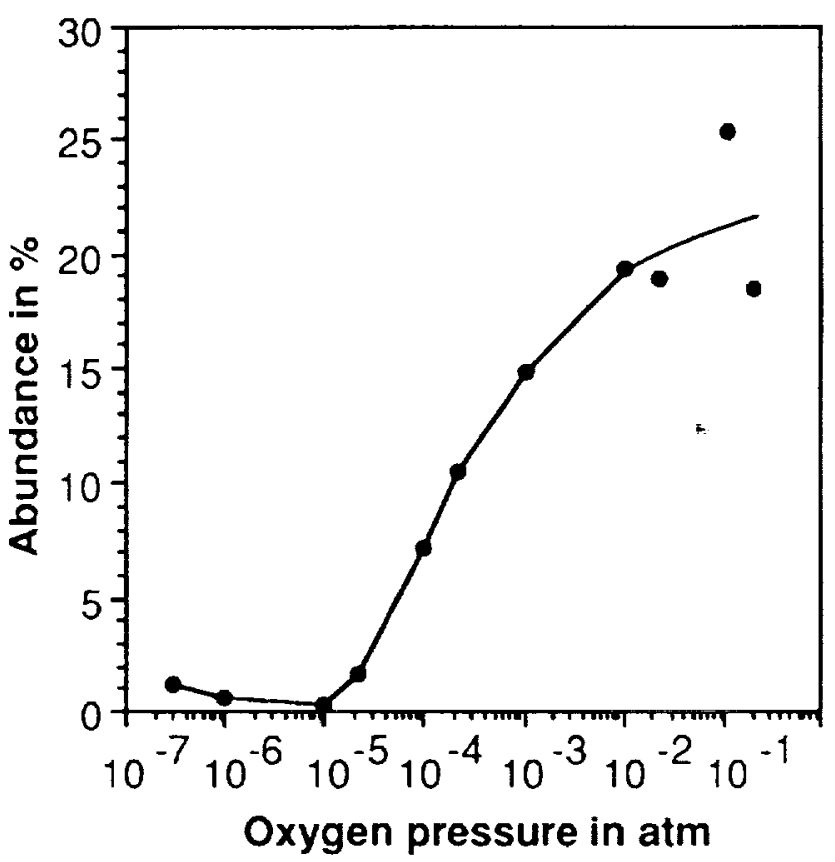

Fig. 1. Variation of the number of meteoric spinels with $O$ pressure.

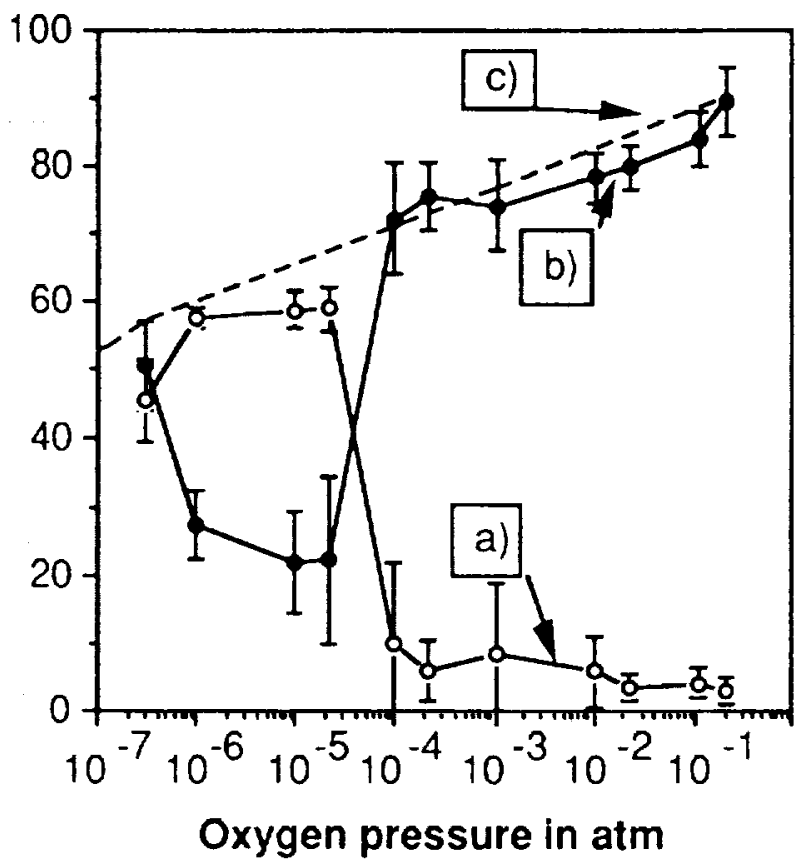

Fig. 2. Variation with the oxygen pressuren of (a) the $\mathrm{Cr}_{2} \mathrm{O}_{3}$ content, (b) the $\mathrm{Fe}^{3+} / \mathrm{Fe}_{\text {total }}$ ratio of meteoric spinels, and (c) the $\mathrm{Fe}^{3+} / \mathrm{Fe}_{\text {potal }}$ ration of spinels in basalts (from [6]). 
TABLE 1. Average composition of meteoric spinels.

\begin{tabular}{|c|c|c|c|c|c|c|c|c|c|c|c|}
\hline $\begin{array}{l}\text { Number of } \\
\text { Spinel Analyses: }\end{array}$ & {$[106]$} & {$[137]$} & {$[87]$} & [201] & {$[130]$} & {$[100]$} & [85] & {$[7]$} & [9] & [7] & {$[15]$} \\
\hline $\begin{array}{l}\text { Oxygen Pressures } \\
\text { in alm: }\end{array}$ & $210^{-1}$ & $10^{-1}$ & $210^{-2}$ & $10^{-2}$ & $10^{-3}$ & $210^{-4}$ & $10^{-4}$ & $210^{-3}$ & $10^{-5}$ & $10^{-6}$ & $310^{-7}$ \\
\hline $\mathrm{MgO}$ & 11.9 & 10.9 & 8.4 & 8.4 & 6.5 & 6.8 & 6.4 & 8.8 & 9.0 & 8.5 & 7.8 \\
\hline $\mathrm{Al}_{2} \mathrm{O}_{3}$ & 0.9 & 1.0 & 1.0 & 1.1 & 1.5 & 1.3 & 1.6 & 4.1 & 4.3 & 3.4 & 2.7 \\
\hline $\mathrm{TiO}_{2}$ & $<0.1$ & $<0.1$ & $<0.1$ & $<0.1$ & 0.2 & 0.1 & 0.3 & 1.1 & 1.2 & 1.1 & 0.5 \\
\hline $\mathrm{Cr}_{2} \mathrm{O}_{3}$ & 3.1 & 4.2 & 3.6 & 5.8 & 8.7 & 5.9 & 10.1 & 58.7 & 58.6 & 57.5 & 45.6 \\
\hline $\mathrm{MnO}$ & 0.4 & 0.5 & 0.4 & 0.4 & 0.3 & 0.3 & 0.3 & 0.6 & 0.4 & 0.6 & 0.4 \\
\hline $\mathrm{FeO}^{*}$ & 7.4 & 11.7 & 15.3 & 16.1 & 18.3 & 18.6 & 19.4 & 18.9 & 18.9 & 19.2 & 19.4 \\
\hline $\mathrm{Fe}_{2} \mathrm{O}_{3}$ & 70.1 & 68.3 & 67.3 & 64.8 & 59.9 & 63.1 & 58.1 & 6.2 & 6.1 & 8.0 & 22.5 \\
\hline $\mathrm{NiO}$ & 4.9 & 1.9 & 2.1 & 1.4 & 2.2 & 1.4 & 1.4 & 0.1 & 0.2 & 0.3 & 0.8 \\
\hline Total & 98.7 & 98.5 & 98.1 & 98.0 & 97.6 & 97.4 & 97.5 & 98.7 & 98.7 & 98.5 & 99.3 \\
\hline D..$^{+}$ & 89.7 & 84.1 & 79.9 & 78.3 & 74.1 & 75.4 & 72.2 & 22.4 & 22.1 & 27.3 & 50.3 \\
\hline
\end{tabular}

* $\mathrm{FeO}$ and $\mathrm{Fe}_{2} \mathrm{O}_{3}$ are calculated assuming the spinels are stoichiometric.

'D.O.: Fe oxidation state $\left(\mathrm{Fe}^{3+/} / \mathrm{Fe}_{\text {twoul }}\right.$ in atom\%).

variation of $\mathrm{O}$ fugacities of the elemental content and of the $\mathrm{Fe}^{3+1}$ $\mathrm{Fe}_{\text {toral }}$ ratio of spinels synthetized from meteoritic material. Applications of this study to spinels found in Cretaceous-Tertiary boundary samples are discussed in a companion abstract in this volume [7].

Experimental Technique: Synthetic spinels were obtained by melting a few milligrams of chondritic material in a platinum crucible enclosed in a quartz cell and placed in the coil of a highfrequency generator. The $O$ pressure was stabilized in a dynamic way by using a vacuum pump combined with a leakage-controlled system. The total air pressure was measured with a nanometer at high pressures $\left(>10^{-3} \mathrm{~atm}\right)$ and a Pirani gauge at low pressures (down to $\left.3 \times 10^{-7} \mathrm{~atm}\right)$. The $O$ pressure measurements are accurate $10 \pm 10 \%$. The temperature was measured with an optical pyrometer calibrated at the melting points of $\mathrm{Au}, \mathrm{Pd}$, and $\mathrm{Pt}$. The absolute temperature measurements are estimated to be accurate to $\pm 10^{\circ} \mathrm{C}$ at temperatures below $1400^{\circ} \mathrm{C}$ and $\pm 20^{\circ} \mathrm{C}$ at higher temperatures. The starting materials for the runs were powders prepared from $50 \mathrm{~g}$ of St. Severin LL-type chondrite that was crushed and well homo-geneized in an agate mortar. Each experiment was run for 1-2 min in order to simulate a pulselike heating event except for the lowest $O$ pressure $\left(3 \times 10^{-7} \mathrm{~atm}\right)$, which was run for $60 \mathrm{~min}$. The peak temperature reached during the runs was fixed at $1335^{\circ} \mathrm{C}$, close to the melting point of chondrite. After fusion, samples were mounted in epoxy and polished for detailed scanning electron microscopy and electron microprobe analysis. Spinels larger than $2 \mu \mathrm{m}$ are analyzed using an automatic routine. The elemental contribution from the matrix was corrected from the $\mathrm{Ca}$ and $\mathrm{Si}$ contents assuming that these elements are absent from the spinel.

Results and Discussion: Analytical results for 11 runs are given in Table 1 and plotted in Figs. 1 and 2 as a function of $O$ fugacities. As a result, we observed a marked change in the number, chemical composition, and $\mathrm{Fe}^{3+} / \mathrm{Fe}_{\text {total }}$ ratio of spinels between $2 \times$ $10^{-5}$ and $10^{-4} \mathrm{~atm}$. At $O$ fugacities $<2 \times 10^{-5}$, few but large reduced chromites are formed $\left(\mathrm{Cr}_{2} \mathrm{O}_{3} \approx 45-60 \%, \mathrm{Fe}^{3+} / \mathrm{Fe}_{\text {10tal }}=20-50 \%\right)$, whereas at $O$ fugacities $>10^{-4}$ atm, numerous oxidized spinels of various morphologies (dendritic, octahedral, cruciform. . .) and compositions are observed $\left(\mathrm{Cr}_{2} \mathrm{O}_{3}=3-10 \%, \mathrm{Fe}^{3+} / \mathrm{Fe}_{\text {total }}=70-90 \%\right)$. This change in the crystallization or stability of spinel at low pressures may be caused by a reaction between spinel, any other crystallizing mineral (pyroxene), and liquid. It may also be due to nonequilibrium conditions at low $O$ fugacities as the duration of the heating phase is short $(1-2 \mathrm{~min})$. The maximum $\mathrm{Fe}^{3+} / \mathrm{Fe}_{\text {|olal }}$ ratio of spinel at $0.21 \mathrm{~atm}$ of $O$ fugacity (corresponding to $1 \mathrm{~atm}$ total pressure) is $\approx 90 \%$. At this pressure a maximum number of spinels is observed with a minimum $\mathrm{Cr}_{2} \mathrm{O}_{3}$ content. As the $\mathrm{O}$ fugacity decreases, the number of spinels falls together with their $\mathrm{Fe}^{3+} / \mathrm{Fe}_{\text {total }}$ ratio, whereas their $\mathrm{Cr}_{2} \mathrm{O}_{3}, \mathrm{Al}_{2} \mathrm{O}_{3}$, and $\mathrm{TiO}_{2}$ contents slightly increase. Note that the $\mathrm{NiO}$ content of the spinel decreases with the $\mathrm{O}$ fugacity from $\approx 5 \%$ at 0.21 atm to $<1 \%$ at $O$ pressure $<2 \times$ $10^{-5}$ atm. Globally, the $\mathrm{Fe}^{3+} / \mathrm{Fe}_{\text {total }}$ and $\mathrm{Cr}_{2} \mathrm{O}_{3}$ variations at $\mathrm{O}$ fugacities $>10^{-4} \mathrm{~atm}$ are consistent with previous results obtained by Hill and Roeder [6] on spinel crystallizing from basaltic liquid (see Fig. 3). Unfortunately, these authors have no available data for $\mathbf{O}$ fugacities ranging from $10^{-3}$ to $10^{-6}$ atm and no direct comparison can be done.

Preliminary Conclusions: (1) Formation of meteoric spinels $\left(\mathrm{Fe}^{3+} / \mathrm{Fe}_{\text {total }}>60 \%\right.$; $\mathrm{NiO}>1 \%$; see reference [1]) requires $\mathrm{O}$ fugacities $>2 \times 10^{-5} \mathrm{~atm}$. Therefore, meteoric spinels cannot be formed in terrestrial magmas that evolve under lower $O$ fugacities $\left(<10^{-6} \mathrm{~atm}\right)$ and are strongly depleted in $\mathrm{Ni}$. Even for magmas slightly enriched in $\mathrm{Ni}$ ( $\approx 0.2 \%$ in ultramafic rocks), the low $\mathrm{O}$ fugacity would prevent the formation of $\mathrm{Ni}$-rich spinels. (2) $\mathrm{Fe}^{3+} / \mathrm{Fe}_{\text {total }}$ ratio (and to a lesser extent the $\mathrm{Cr}_{2} \mathrm{O}_{3}, \mathrm{Al}_{2} \mathrm{O}_{3}$, and $\mathrm{TiO}_{2}$ content of spinels) are relatively good indicators of the $\mathrm{O}$ fugacity. It is possible to differentiate meteoric spinels that derive from micrometeors that are decelerated at $40-80 \mathrm{~km}$ corresponding to 0 pressures of $2 \times 10^{-6}-10^{-4} \mathrm{~atm}$ from spinels that derive from large meteors that are decelerated deeper in the atmosphere corresponding to higher $O$ pressures. (3) Meteoric spinels with $\mathrm{Fe}^{3+} / \mathrm{Fe}_{\text {total }}>90 \%$ were not reproduced in our experiments. It seems that $O$ pressures higher than the one existing at sea level $(0.21 \mathrm{~atm})$ is required to form spinels with higher $\mathrm{Fe}^{3+/ \mathrm{Fe}_{\text {tolal }}}$ ratio.

References: [1] Robin E. et al. (1992) EPSL, 108, 181-190. [2] Robin E. et al. (1992) LPS XXIII, 1159-1160. [3] Jéhanno C. et al. (1988) Proc. LPSC 18th, 623-630. [4] Margolis S. V, et al. (1991) Science, 25I, 1594-1597. [5] Haggerty S. E. (1976) Oxide Minerals, 3 (D. Rumble ed.), 101-300, Mineral. Soc. Am. [6] Hil] R. and Roeder P. (1974) J. Geol., 82, 709-729. [7] Robin E. et al., this volume. 
DIAMONDS, SOOT, AND MOLECULES: THE GEOCHEMISTRY OF CARBON AT THE KT BOUNDARY. I. Gilmour' and W. S. Wolbach'2, 'Department of Earth Sciences, The Open University, Milion Keynes, MK7 6AA, UK, 2Department of Chemistry, Illinois Wesleyan University, Bloomington IL 61702 , USA.

The C geochemistry of the KT boundary, in particular the iso-tope systematics, have provided clues to both the nature of the postulated impact and its associated effects. To date five $\mathrm{C}$ compo-nents have been identified that are associated with the fireball and ejecta layers: (1) soot/elemental $C[1,2],(2)$ diamonds occurring as nanometer-sized cubic crystals [3,4], (3) C released from impact melt glasses primarily as $\mathrm{CO}_{2}$ inclusions [5], (4) organic $\mathrm{C}$ in the form of insoluble kerogen and extractable organic molecules [6-8], and (5) amorphous $C$ particles [9]. Marine KT boundary sequences also display carbonate $\mathrm{C}$ and $\mathrm{O}$ isotope shifts [10].

Soot and Elemental Carbon: A total of $12 \mathrm{KT}$ boundary sites worldwide that were examined for $\mathrm{C}$ were found to be enriched in soot and charcoal $[1,2,11,12]$. The enrichment parallels that for Ir and apparently comes from major fires triggered by the impact. Evidence that at least part of the fuel source was biomass comes from the occumence of polycyclic aromatic hydrocarbons [6] and the remarkably uniform $\delta^{13} \mathrm{C}$ values for the soot and charcoal of $-25.8 \pm$ $0.6 \%$ [13]. The total amount of charcoal and soot $\left(0.11 \mathrm{~g} / \mathrm{cm}^{2}\right)$ is surprisingly large and implies that either a substantial proportion of biomass bumed or that a major part of the fuel was fossil C. Altematively, such large-scale fires may result in a higher soot yield. Several ignition mechanisms have been envisaged for such fires; immediate blast effects that would ignite dry biomass within a $1200-\mathrm{km}$ radius, charge separation during settling of ejecta that could result in lightning in volcanic ash clouds, or radiated heat from impact ejecta fallout [14].

Diamonds: The discovery of nanometer-sized diamonds in a KT boundary clay from Knudsen's farm, Canada [3], led to the suggestion that they may be derived from an interstellar diamond component in the impacting asteroid. Nanometer-sized diamonds (Cס) found in carbonaceous, ordinary, and enstatite chondrites have a number of very characteristic properties: the presence of the exotic noble gas component $\mathrm{Xe}(\mathrm{HL})$, an extremely negative $\delta^{15} \mathrm{~N}$ value of $\sim-343 \pm 16 \%$ with typical $N$ concentrations of $2000-15,000 \mathrm{ppm}$, a cubic structure, and $\delta^{13} \mathrm{C}$ values of -32 to $-40 \%$. Gilmour et al. [4] undertook a systematic study of acid-resistant residues from three boundary sites in North America (Brownie Butte and Berwind Canyon) and Europe (Petriccio) using six independent criteria: diamond size distribution, $C$ isotopic composition, $N$ isotopic composition, $N$ abundance, $C$ release profiles obtained in stepped heating experiments, and $\mathrm{N}$ release profiles.

The presence of approximately 6-nm cubic diamonds at the two North American sites was confirmed by transmission electron microscopy. The combustion temperature of the majority of the $\mathrm{C}$ in both fireball residues is similar to $\mathrm{C} \delta$ diamonds, but the $\mathrm{C}$ and in particular $\mathrm{N}$ isotopic compositions $\left(\delta^{13} \mathrm{C}=-19 \%\right.$ to $-12 \%, \delta^{15} \mathrm{~N} \sim$ $5 \%$ ) were clearly inconsistent with them being an interstellar diamond component derived from the impacting asteroid or comet. It would seem therefore that the diamonds were formed as a result of the impact, and there are several possible mechanisms. The most likely would be either production by shock alteration of $\mathrm{C}$ from the target rock and/or asteroid or by a mechanism such as chemical vapor deposition (CVD) producing diamonds in the fireball. The $\mathrm{C}$ isotopic compositions do not match any major crustal reservoir of $\mathrm{C}$ such as carbonate or organic $\mathrm{C}$, though they could clearly be obtained by mixing. Indeed, the variations in $\delta^{13} \mathrm{C}$ are indicative of the presence of more than one component and may suggest the existence of two populations of diamonds, perhaps reflecting several formation processes.

Impact Glass Fluid Inclusions: Glass spherules thought to be tektites from Haiti have previously been analyzed for mineralogy and chemical composition to identify their origin and mode of formation [15]. They occur in various colors, depending upon the original target rock, and contain bubbles. To investigate these spherules and the nature of any gas phase, several dark brown glasses were analyzed by Hough et al. [5] for $\mathrm{C}$ content and isotope composition using stepped combustion analysis and static mass spectromelry. Optical examination of the glasses showed that they contained bubbles of gas at pressures slightly above atmospheric. Individual spherule frag. ments were found to yield a total of $0.2 \mathrm{wt} \% \mathrm{C}$ in two components of different isotopic composition. One of these components, with an isotopic composition of $-19 \%$, is apparently common to all the brown glass spherules. The second more abundant component had a maximum isolopic composition of $-3 \%$ o but is apparently heterogeneous in its distribution, suggesting that it represents the trapped bubbles.

Organic C: Organic $\mathrm{C}$ remains one of the least studied and poorly understood aspects of the stratigraphy of the KT boundary event. The boundary clay in marine sequences is often substantially enriched in organic matter over background values but there are considerable differences between sites, suggesting strong local environmental controls [8]. In contrast, the greater stratigraphic resolution possible for North American terrestrial sites reveals an ejecta and fireball layer depleted in organic $C$ but with a sharp increase in abundance, with concomitant changes in isotope composition, in the so-called recovery layer immediately above $[16,17]$. The isotopic shifts observed seem to be independent of local environmental conditions with the same isotopic shift of around $-2 \%$ o being apparent at sites where the boundary is overlain by coal or shale. Such an effect might be expected in organic $\mathrm{C}$ at nonmarine sites had the isotopic composition of atmospheric $\mathrm{CO}_{2}$ significantly differed from the late Cretaceous value. This might have been caused by an input of combustion-produced $\mathrm{CO}_{2}$ from wildfire, which would be reflected in more negative $\delta^{13} \mathrm{C}$ values for photosynthetically produced $\mathrm{C}$.

Relationships Between Components: Comparison of the data for the components outlined above may impose constraints on their origins. For instance, the $\mathrm{C}$ isotopic composition of the gaseous components in the glasses from Haiti are indicative of a carbonate origin for the $\mathrm{C}$ with $\delta^{13} \mathrm{C}$ values of around $-2 \%$ to $-4 \%$. If these glasses were indeed formed in an impact fireball then this isotopic composition presumably represents that of a substantial proportion of the $\mathrm{C}$ present. However, the nanometer-sized diamonds have $\delta^{13} \mathrm{C}$ values of $\sim-12 \%$ to $-16 \%$; it is difficult to see how these two components can have the same $\mathrm{C}$ source if both are synthesized in an impact fireball unless the fireball itself was heterogeneous. The $\mathrm{C}$ source for the diamonds is problematic, it would seem unlikely from their isotopic compositions that they have a relationship with the soot produced in the fires, although it is not inconceivable that nanodiamonds may be produced in such fires. Similarly if the diamonds were synthesized in the impact fireball then their isotopic composition is distinct from that of any fossil $\mathrm{C}$ component that may have contributed to the soot. 


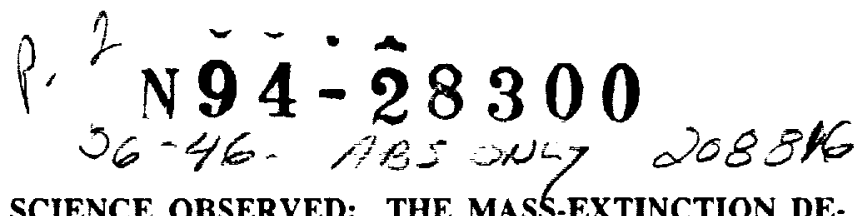

References: [1] Wolbach W. S. et al. (1985) Science, 230 , 167-170. [2] Wolbach W. S. et al. (1988) Nalure, 334, 665-669. [3] Carlisle D. B. and Bramman D. R. (1991) Nature, 352, 708-709. [4] Gilmour I. et al. (1992) Science, 258, 1624-1626. [5] Hough R. M. et al. (1993) Meteoritics, 28, 364-365. [6] Venkatesan M. I. and Dahl J. (1989) Nature, 338, 57-60. [7] Gilmour I. et al. (1990) GSA Spec. Paper 247,383-390. [8] Meyers P. A. and Simoneit B. R. T. (1990) Org. Geochem., 16,641-648. [10] Perch-Nielsen K. et al. (1982) GSA Spec. Paper 190, 353-371. [11] Wolbach W.S. and Anders E. (1989) GCA, 53, 1637-1647. [12] Wolbach W, S. et al. (1990) GCA, 54, 1133-1146. [13] Wolbach W. S. et al. (1990) GSA Spec. Paper 247, 391-400. [14] Melosh H. J. et al. (1990) Nature, 343, 251-254. [15] Koeberl C. and Sigurdsson H. (1992) GCA , 56, 2113-2129. [16] Gardner A. F. et al., this volume. [17] Hildebrand A. R. and Wolbach W.S. (1989)LPSXX, 414-415.

\section{$\ln , 7$}

RESULTS OF BLIND TESTS TO RESOLVE CONTROVERSIES: IRIDIUM AT GUBBIO; EXTINCTIONS AT EL KEF. Compiled by R. N. Ginsburgl from analyses of F. Asaro ${ }^{2}, M$. Attrep Jr. ${ }^{3}$, J. I. Canudo ${ }^{4}$, J. H. Crocket ${ }^{5}$, U. Krähenbühl ${ }^{6}$, B. Masters', H. T. Millard Jr. ${ }^{8}$, R. K. Olsson', C. J. Orth ${ }^{3}$, X. Orueetxebarria ${ }^{1 !}$, L. R. Quintana ${ }^{3}$, and R. Rocchia ${ }^{1 !}$, 'University of Miami, Miami FL 33149, USA, ${ }^{2}$ Lawrence Berkeley Laboratory, Berkeley CA 94720, USA, 'Los Alamos National Laboratory, Los Alamos NM 87545, US A, ${ }^{4}$ Universidad de Zaragoza, Zaragoza 50009, Spain, 5 McMaster University, Hamilton, Ontario L8S 4K I, Canada, 6Universität Bem, Bem CH-3000, Switzerland,' Sapolpa OK 74066, USA, ${ }^{8}$ U.S. Geological Survey, Denver CO 80225, USA, " Rutgers University, New Brunswick NJ 08903, USA, "Universidad del Pais Vasco, Bilbao E-48060, Spain, "CNRS Laboratoire, Gif-sur-Yvette 91198 , France.

Two of the many controversies about KT events are based on differing results of analyses of samples from the same outcrops between two or more workers. One concems the distribution of Ir across the boundary in the much-studied sections at Gubbio, Italy; the other involves the patterns of disappearance of planktonic Formanifera in the boundary section at El Kef, Tunisia. At the 1988 Snowbird Conference it was proposed that proponents of the differing interpretations join in collecting comprehensive samples for a blind test to resolve the differences.

For the sections near Gubbio, 16 samples were selected for analysis, including those that could settle the controversy and placebos from other localities. The samples were ground in a ball mill and splits were distributed blind for analysis of Ir to six analysts: Asaro, Crocket, Krähenbühl, Millard, Orth, and Rocchia. The results to be presented have settled the controversy.

For the El Kef sections, closely spaced samples were collected across the boundary under the supervision of the two proponents of differing interpretations. The samples were split and distributed blind to four micropaleontologists: Masters, Canudo, Olson, and Orue-etxebarria. The results to be presented indicate the status of the controversy.
SCIENCE OBSERVED: THE MASS-EXTINCTION DE2235, USA, and c/o Mail Stop 930, U.S. Geological Survey, 345 Middlefield Road, Menlo Park CA 94025, USA. impact hypothesis transformed the literature of mass extinctions from an unfocused, sporadic collection of papers that virtually ignored extraterrestrial causes and treated endogenous ones only sparingly better to an integrated, diverse body of literature. Research programs organized seemingly ovemight spawned collaborative teams whose members (often from distant, isolated disciplines) redirected their careers in order to address the captivating, high-stakes issues.

The initial, generally skeptical cool reception of the impact hypothesis might have been predicted for any of a number of reasons: Such an instantaneous catastrophe contravened Earth science's reigning philosophy of uniformitarianism; it was formulated from a form of evidence (siderophile element anomalies) alien to the community charged with its appraisal; it advanced a causal mechanism that was improbable in terms of canonical knowledge; and it was proffered mainly by specialists alien to Earth and biological science, especially paleobiology.

Early on it became clear that irrespective of which causal hypothesis was chosen, the chosen one would be the strongest predictor of how the chooser would select and apply standards in assessing evidence bearing on all such hypotheses. Less strong correlation also appeared between disciplinary specialty and choice of hypothesis, and between disciplinary specialty and the assessment of evidence. Such correlations varied with the level of specialization; the most robust correlations appeared in the most restricted subspecialtiesthe weakest in the broadest areas of science practice. The gestalt (mindset) seemingly engendered by the embrace of an extinction hypothesis overrode, or was stronger than, the intellectual predispositions attributable to disciplinary specialty.

The great majority of paleontologists rejected outright or eschewed impact theory at its advent, and most who later came to believe in an impact event(s) at the KT boundary still deny impact(s) as the main extinction cause. Many paleontologists regarded the duration, severity, and other aspects of the KT mass extinction in terms of the fate of their own fossil taxa at the extinction boundary; specialists in severely affected fossil groups were most often among those who spoke of a connection between impact and the mass extinction. Certain subspecialty communities within paleontology differed markedly in their opinions on the cause of mass extinction: For example, vertebrate paleontologists were almost unanimously opposed to impact-as-extinction-cause; in contrast, micropaleontologists-especially those treating planktonic calcareous formswere most often oppositely inclined.

Most cosmo- and geochemists, planetary geologists, impacting specialists, and students of Earth-crossing comets and asteroids were immediately sympathetic to impact theory in its entirety. Study of impacting and closely related topics appeared to foster sympathy for the impact hypothesis; however, most volcanologists (volcanic specialists) did not accept the volcanist hypothesis-which was not conceived by volcanologists-but no unusual proportion of volcanologists favored the alternative impact hypothesis.

Published authors and published supporters of altematives to the impact hypothesis of mass extinction, examined in all cases save one, were opposed to the impact hypothesis at its advent. Irrespective of
The upheaval triggered in 1980 by the Alvarez-Berkeley group 
their discipline, or however poorly informed, scientists rarely failed to embrace one of the mass extinction hypotheses.

The use of obsolete data and/or the omission of contrary evidence almost always punctuated published and oral arguments, and opposing views were never treated at equal length. The gestalts or cognitive frames of members of the opposing theoretical camps seemingly precluded mutually congruent viewpoints on any of the important debated issues or the assessment of evidence. The widely held view that such adversaries suffer an "incommensurability of viewpoint" seemed understated.

Impactors (proponents of impact as extinction cause) and volcanists (proponents of volcanism as extinction cause) commonly used different standards of appraisal and weighted the same evidence differently. Application of standards and weighting of evidence varied widely even among those in the same theoretical camp. The impactors argued mainly from canonical standards and claimed that their hypothesis - backed by empirical evidence-facilitated clear predictions with implicit directions for testing. The prediction of impact-generated, global, ballistic transport of impact products raised expectations for many that impact evidence in addition to Ir would be found at KT boundary sites - this provided important impetus for the rapid formation of diversely comprised research teams. Almost always, the members of the same collaborative team subscribed to the same extinction hypothesis.

Impact's opponents focused on the great range of variation in the character of the boundary interval around the world, emphasizing that the geographic variations indicated a cause that was neither global nor instantaneous. It was a prime mission of impact's opponents to demonstrate a lack of the ubiquitous, globally uniform effects claimed for an impact. Unlike the orthodox evidence that was advanced for the radical impact hypothesis, impact's active opponents - mainly the volcanists - sought to undermine a wide range of suppositions and vagaries that lay long hidden in established principles and methods; the volcanists searched for the weaknesses in the orthodox standards and thus prompted much research at unprecedented levels of refinement. The call for higher resolution and greater detail required the development of new, or the acquisition of theretofore unused, methods, techniques, and instruments in a number of disciplines; such needs were often fulfilled through the formation of appropriately composed collaborative teams.

In the mid 1980s the postulate of stepped or multiple extinctions near the KT boundary evolved through a series of recognizable stages. The evidence for extinction steps was initially viewed as an anomaly in terms of the single-impact hypothesis and, as such, was more or less dismissed early on by the impactors. But it then became an increasingly serious problem as supporting data accrued and stepped extinctions approached the status of a normative assumption. Ultimately, with further affirmative evidence, the steppedextinction idea, and all it came to imply in terms of impugning singleimpact theory, evolved into a standard of appraisal that drove the reassessment of the nature of extinctions at the KT boundary. At that point the newly born standard of multiple extinction steps - which had begun life as an anomaly in terms of the single-impact hypothesis-evolved into the primary forcing function that forced the reformulation of the single-impact hypothesis into a hypothesis of multiple impacts spanning enough time to accommodate the extinction steps.

Leadership of the various factions engaged in the debates was, in all cases, clearly in the hands of only one or very few senior leaders who exercised magisterial authority. Such doyens were most frequently sought for their opinions on debated issues by both their own communities and the media; that was reflected in both the publications of science and the public. The rapid pace of the mass extinction debates, with which only few could keep abreast, seemed to add to general reliance on the magister. Such two-step communication, from the world to the magister and then from the magister to the world, has been documented in other studies of conflicted ideas.

Closure has not been reached on any of the many issues reticulated in these debates, but most Earth scientists are now convinced of at least one impact at the KT boundary and many are inclined to think in terms of multiple impacts, either instantaneous or spread over I$3 \mathrm{~m} . y$.; however, far from all who subscribe to impact(s)-especially among paleontologists-view impact(s) as the chief cause of the mass extinction(s).

Research programs organized in the past decade to address the many issues that have arisen in the course of this upheaval continue to generate new publications at a surprising rate (more than 2500 have already appeared). Modeling of impacts and mantle plumes and their effects on a number of internal, crustal, and biospheric processes grow increasingly sophisticated with different research approaches showing promising convergence in their conclusions. The search for impact sites, which includes the reexamination of many long-enigmatic structures, and the remapping and dating of great flood basalt bodies are being actively pursued. Mass extinction horizons throughout the Phanerozoic are being scrutinized with methods, techniques, and instruments that did not exist just a decade ago, and the broad character of the debates has forced unprecedented interpenetrations of long isolated subdisciplines. The debates continue, sustaining the opportunity to study the workings of science during a time of conflict over several related theories that span multiple disciplines. The intensity, fast pace, and disciplinary diversity of this upheaval has opened windows on the workings of science where only peepholes had been expected. These conclusions and others, and a historical overview of the debates are detailed by me and a dozen other scientists and social studies of science scholars in [1].

References: [1] (1994) The Mass-Exfinction Debates: How Science Works in a Crisis, Stanford Univ., in press.

\section{0,270 P.50 \\ BIOSTRATIGRAPHIC EVIDENCE OF THE KT BOUND- ARY IN THE EASTERN GULF COASTAL PLAIN, NORTH OF THE CHICXULUB CRATER. D. Habib, Geology Depart- ment, Queens College and Graduate School, The City University of New York, Flushing NY 11367-1597, USA.}

The KT boundary in Alabama is currently being restudied in light of the proximity of this area to the Chicxulub impact crater in the Yucatan Peninsula of Mexico [1,2]. Previous studies have suggested that there is an apparent discordance between the position of the KT boundary and the stratigraphy based on the Ir anomaly pattem [3], paleomagnetic reversals [4], and the major biotic extinction event [5]. The purpose of this paper is to present the biostratigraphic evidence from dinoflagellate cysts [6], calcareous nannofossils [7], and planktonic foraminifera [8] to show that the mass extinction datum is situated precisely at the KT boundary in Alabama and that the low values of Ir peaks in the sediments directly above the bound- 
ary resulted from the effects of the rise of the Ir-enriched ocean in the earliest Danian. The biostratigraphic evidence indicates further that the hiatus at the boundary was of short duration and could have resulted from asteroid impact. The presence of the Micula prinsii nannofossil zone in the paleomagnetically unstable interval directly beneath the KT boundary indicates an equivalence with the earliest part of Polarity Chron C29R. The contact between C29R and the well-developed $\mathrm{C} 30 \mathrm{~N}$ at this level supports the latest Maestrichtian age assignment adjacent to the KT boundary.

In central and westem Alabama, the latest Maestrichtian is represented by a prograding succession of carbonaceous marls and sandy mudstones. This interval is succeeded by a minor disconformity at the KT boundary, cut by shallow channels containing parallellaminated crossbedded sand deposits approximately $0.8 \mathrm{~m}$ thick at Mussel Creek to pebbles and boulders of reworked Maestrichtian marls in deposits approximately $1.9 \mathrm{~m}$ thick at Moscow Landing. The channel sands contain nannofossils in the NPI zone, foraminifera in the P0 zone, and dinocysts in the Senoniasphaera inornata and Danea californica dinoflagellate zones, which collectively pre-sent convincing evidence of the earliest Tertiary age directly above the disconformity. The top of the sandy muds of latest Maestrichtian age represents the severe and abrupt extinction of nannoplankton, foraminifera, gastropods, bivalves, and cephalods, many of which revealed high diversity of taxa with widespread and long-ranging clades in the Maestrichtian [5,6]. Paleoshelf deposits lie directly on the channels. In the Braggs area, the first shelf deposit is a highly argillaceous limestone, which contains a rubble zone at its base, suggesting a higher-energy depositional environment.

The Ir anomaly pattern [3] resulted from depositional processes associated with the Ir-enriched ocean that covered the area during the first Tertiary episode of sea level rise [6]. Figure 1 illustrates the correlation between dinoflagellate species richness, amorphous organic matter of fecal origin, and Ir peaks. The Ir peaks occur in the tops of limestone beds $[3,5,9]$. They are restricted to the retrograding transgressive interval of the Transgressive Systems Tract. The over-
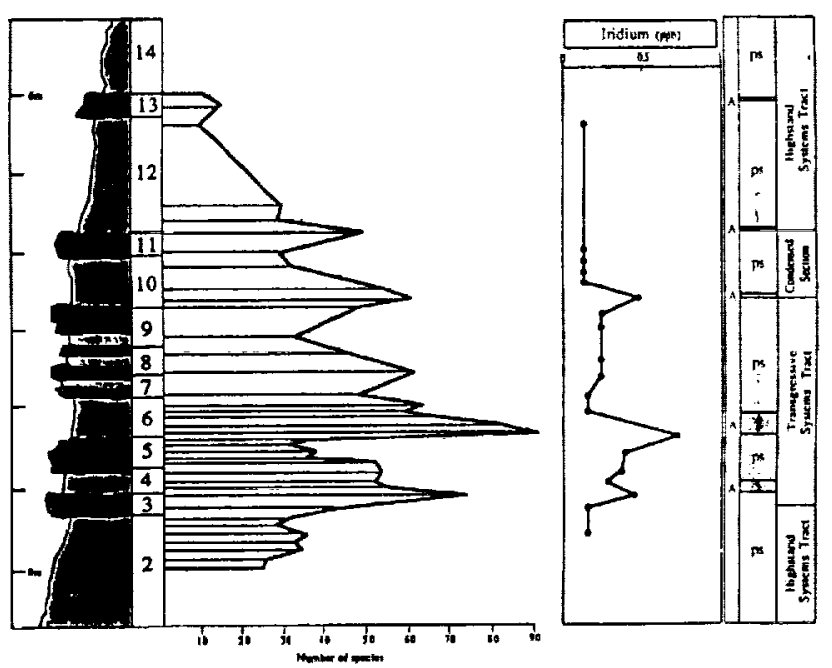

Fig. 1. Correlation between dinoflagellate species richness peaks, Ir peaks, and amorphous debris (A) in the Braggs roadcut section. Amorphous debris concentrated at the base of each parasequence (ps). Iridium peaks restricted to the interval of beds 3-9 within the Transgressive Systems Tract. lying condensed section and prograding Highstand Systems Tract show no anomalous occurrence of Ir. Dinoflagellate species peak in the amorphous debris-rich mudstones directly above the Ir-enriched limestones in the transgressive interval. This organic matter may have played a role in concentrating the Ir [9]. The shallow channel deposits may represent a short episode of rapid erosion related to asteroid impact. The enrichment of Ir in the world ocean at the KT boundary could have deposited this material in neritic sediments during the earliest Tertiary rise of sea level.

References: [1] Hildebrand A. et al. (1991)Geology, 19, 867871. [2] Sharpton V. L. et al. (1993) Science, 26J, I564-1567. [3] Donovan A. D. et al. (1988) SEPM, Spec. Publ. 42, 299-307. [4] Channel J. E. T. and Dobson J. P. (1989) Palaeogeogr. Palaeoclimatol. Palaeoecol., 69, 267-277. [5] Bryan J. R. and Jones D. S. (1989) Palaeogeogr. Palaeoclimatol. Palaeoecol., 69, 279301. [6] Habib D. et al. (1992)Geology, 20, 165-168. [7] Moshkovitz S. and Habib D. (1993) Micropaleontol., 39, 167-191. [8] Olsson R. K. and Liu C. (1993)Palaios., 8, 127-139. [9] Schmitz B. (1988) Geology, 16, 1068-1072.

ELEMENTARYCARBON ASSOCIATEDWITH VOLCANIC ERUPTIONS: RELEVANCE FOR THE KT BOUNDARY PROBLEM. H. J. Hansen, Geological Institute, University of Copenhagen, Øster Voldgade 10, DK-1350, Denmark.

Volcanic glass particles from 24 different Icelandic eruptions (basaltic and intermediate composition) were analyzed for their $\mathrm{C}$ content. The values range from 400 to $1100 \mathrm{ppm}$. Volcanic glass dissolved in HF shows the presence of hollow spheres of graphite with diameters in the range of $1-15 \mu \mathrm{m}$. The hollow spheres are interpreted as coatings of the walls of the gas vesicles in the glass. Glass grains of basaltic composition from the Paleocene Fur Formation, Denmark, showed bulk $\delta^{13} \mathrm{C}$ value of -16 while the solid $C$ alone showed almost -28 .

The eruption of Hekla, Iceland, on January 19, 1991, took place during a snow period resulting in a sandwiched complete ash layer in the snow. The fraction of the ash layer smaller than $125 \mu \mathrm{m}$ had a $C$ content of $400 \mathrm{ppm}$. After cleaning by ultrasonic vibrations the fine fraction showed only 100 ppm of $C$.

From these observations it can be concluded that volcanos produce elementary $\mathrm{C}$ as part of the eruptional products. Some of the $\mathrm{C}$ is contained in gas vesicles in the glass, while other $C$ is part of the ash. Hollow $C$ spheres are thus indicators of volcanism and they stand a good chance of surviving later diagenetic alteration of the glass. The smallest spheres (1-2 $\mu \mathrm{m}$ in diameter) survive sediment compaction.

Samples from the gray chalk underlying the KT boundary clay at Stevns Klint and the boundary clay itself contain $C$ spheres, indicating that a volcanic component is present. The isotopic value of the solid $\mathrm{C}$ is in good agreement with the values from the gray chalk.

Whitish spheres from the "altered iektite layer" at Beloc, Haiti, after dissolution showed the presence of $\mathrm{C}$ spheres, pointing to a volcanic rather than a tektite origin. Various tektites dissolved in HF did not show any $\mathrm{C}$ residue. 
CYCLOCHRONOLOGIC APPROACHES TO KT EVENTS. T. D. Herbert', A. G. Fischer ${ }^{2}$, and S. L. D'Hondt', 'Geological Research Division, A-015, Scripps Institution of Oceanography, La Jolla CA 92093, USA, ${ }^{2}$ Department of Earth Sciences, University of Southem Califormia, University Park, Los Angeles CA 90089-0740, USA, ${ }^{3}$ Graduate School of Oceanography, University of Rhode Island, Narragansett RI 02882, USA.

The KT boundary crisis and associated events occurred within Polarity Chron 29R, occupying only a small fraction of that interval. Milankovitch-band cyclicity recorded in pelagic sediments promises to provide time-resolution of events within this Chron, down to the $\sim 20,000-y r$ level. As yet only a few of many sedimentary sequences have been analyzed, but we present consonant data from the South Atlantic (Rio Grande Rise, Walvis Ridge, Herbert and D'Hondt) and from Spain (Kate and Sprenger). All sequences show precessional signals (low-carbonate/high-carbonate couplets), and some show a bundling of these into $\sim 100$-ka eccentricity cycles, some of which show grouping into $400-\mathrm{ka}$ eccentricity cycles.

Unless the "boundary clay" represents a full 100,000-yr eccentricity cycle, Polarity Chron $29 \mathrm{R}$, beginning after the second or third precession in an eccentricity cycle, lasted for about $600,000 \mathrm{yr}$. The Ir event and main extinction occurred after the third or fourth precession in the third succeeding eccentricity cycle, about $320,000 \mathrm{yr}$ after the magnetic reversal. The main boundary event thus falls near the middle of the polarity chron; its seemingly up-ward displacement in stratigraphic plots of pelagic carbonates results from a drastic (factor of 2-3) diminution of sedimentation rates, owing to a crisis-induced drop in carbonate production.

Cyclostratigraphic analysis of more KT boundary sections is required to check and refine these results. A cyclostratigraphic answer to the duration of the "boundary clay" requires sites at which the 400-ka cyclicity is developed above as well as below the boundary. A general cyclochronology of the KT episode should provide timing of associated isotope excursions (preceding positive and succeeding negative ${ }^{13} \mathrm{C}$ anomalies) and biotic events (first and last occurrences of species, recurrences of disaster forms).

SEARCH FOR EXTRACTABLE FULLERENES IN CLAYS FROM THE KT BOUNDARY OF THE WOODSIDE CREEK AND FLAXBOURNE RIVER SITES, NEW ZEALAND. D. Heymann $^{1}$, W. S. Wolbach ${ }^{2}$, L. P. F. Chibante ${ }^{3}$, and R. E. Smalley ${ }^{3}$, IDepartment of Geology and Geophysics, Rice University, Houston TX 77251-1892, USA, ${ }^{2}$ Department of Chemistry, Illinois Wesleyan University, Bloomington IL 61702-2900, USA, 3Department of Chemistry, Rice University, Houston TX 77251-1892, USA.

Fullerenes were first discovered in a geologic environment by Buseck et al. [1]. The occurrence of significantly increased concentrations of C, mostly soot, and of Ir at the KT boundaries of at least 11 sites worldwide has been interpreted as evidence for the raging of major wildfires in the aftermath of the "Terminal Cretaceous Impact" [2-4]. The recent discovery that soot generated by the free buming of toluene and candle wax contains some $50-100 \mathrm{ppm}$ extractable fullerenes [5] suggested a chance that fullerenes are associated with the soot at KT boundaries. A search for extractable $C_{60}$ and $C_{70}$ fullerenes in soot-rich materials from a $\mathrm{KT}$ boundary was undertaken
TABLE 1 . The boundary samples, the ir weights, and corresponding $\mathrm{cm}^{2}$ of surface area.

\begin{tabular}{lccc}
\hline Sample & $\begin{array}{c}\text { Weight of Rock } \\
(\mathrm{g})\end{array}$ & $\begin{array}{c}\text { Weight of Residue } \\
(\mathrm{mg})\end{array}$ & $\begin{array}{c}\text { Surface } \\
\left(\mathrm{cm}^{2}\right)\end{array}$ \\
\hline $\begin{array}{l}\text { Woodside Creek }(W C) \\
\text { KTBa }\end{array}$ & 4.2085 & & \\
KTBa $^{*}$ & $3.4967^{4}$ & 37.23 & 3.2 \\
KTBb* $^{*}$ & 3.3231 & 5.10 & 2.65 \\
Flaxbourne River $(F R)$ & & & \\
KTBa* $^{*}$ & 1.9798 & 12.81 & 0.45 \\
\hline
\end{tabular}

* Demineralized samples.

+ Only 3.4967 of the original $4.2085 \mathrm{~g}$ (WC)KTBa were demineralized. For this, a correction was made in the final calculations for sample (WC)KTBa.

to establish fullerenes as markers for fires of wood, oil, or gas. We are grateful to Dr. R. R. Brooks of Massey University, Palmerston North, New Zealand for having donated these samples for our study.

Table 1 describes the samples. (WC)KTBa and (WC)KTBb were splits from a homogenized boundary clay from the Woodside Creek site. (WC)KTBa was first extracted prior to, then extracted again after, demineralization. (WC)KTBb and (FR)KTBa were only extracted after demineralization. Also available from Woodside Creek, but not shown in the table, were two samples from a shale located at some $32 \mathrm{~cm}$ above the KT boundary. These were named (WC) KTa and (WC)KTb after demineralization.

All glassware was new and was heated in an oven in air at $500^{\circ} \mathrm{C}$. The samples were digested with toluene at room temperature for $30 \mathrm{~min}$. Solutions and solids were separated by centrifugation. The solution was evaporated to dry at reduced pressure and $45^{\circ} \mathrm{C}$. Then the flasks of the (WC) samples were rinsed with $0.5 \mathrm{ml}$ and the flask of the (FR) sample with $0.1 \mathrm{ml}$ toluene. Procedural blanks were always performed.

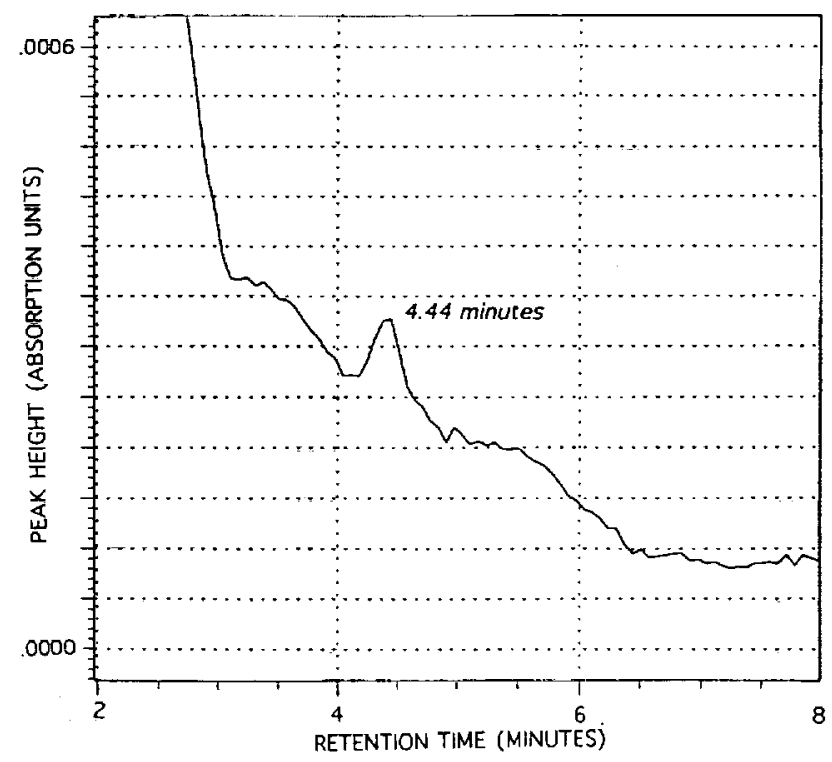

Fig. 1. 
Twenty-five microliters of solution was injected with a dedicated pipelte into the high-pressure liquid chromatograph. UVvisible spectra were taken in the range $310-430 \mathrm{~nm}$ every $4 \mathrm{~s}$, but the processing of the chromatograms was done at $330 \mathrm{~nm}$. Prior to a series of analyses, "instrumental blanks" were analyzed by the repeated injections of fresh toluene. The retention times of the $C_{60}$ and $C_{70}$ are 4.44 and $6.91 \mathrm{~min}$ respectively. At the end of a series of blanks and samples, the instrument was calibrated by the injection of only $4.8 \mathrm{ng} \mathrm{C}_{60)}$ and $5.3 \mathrm{ng} \mathrm{C}_{7()}$. The limit of detection was about $0.2 \mathrm{ng} \mathrm{C}_{60}$ injected, i.e., $1.7 \times 10^{11}$ molecules.

Figure 1 shows the enlarged chromatogram for the injection of $25 \mu \mathrm{l}$ from (WC)KTBb\#. The chromatogram has a clear-cut peak at the expected retention time of $\mathrm{C}_{\theta 1}$, riding on the "tail" of a strong "oil" peak. Unfortunately, even the combined solutions of all (WC) extractions contained too little $\mathrm{C}_{60}$ for the acquisition of an acceptable UV-VIS spectrum. No signal significantly above noise at the retention time of $\mathrm{C}_{70}$ was found in any of the samples.
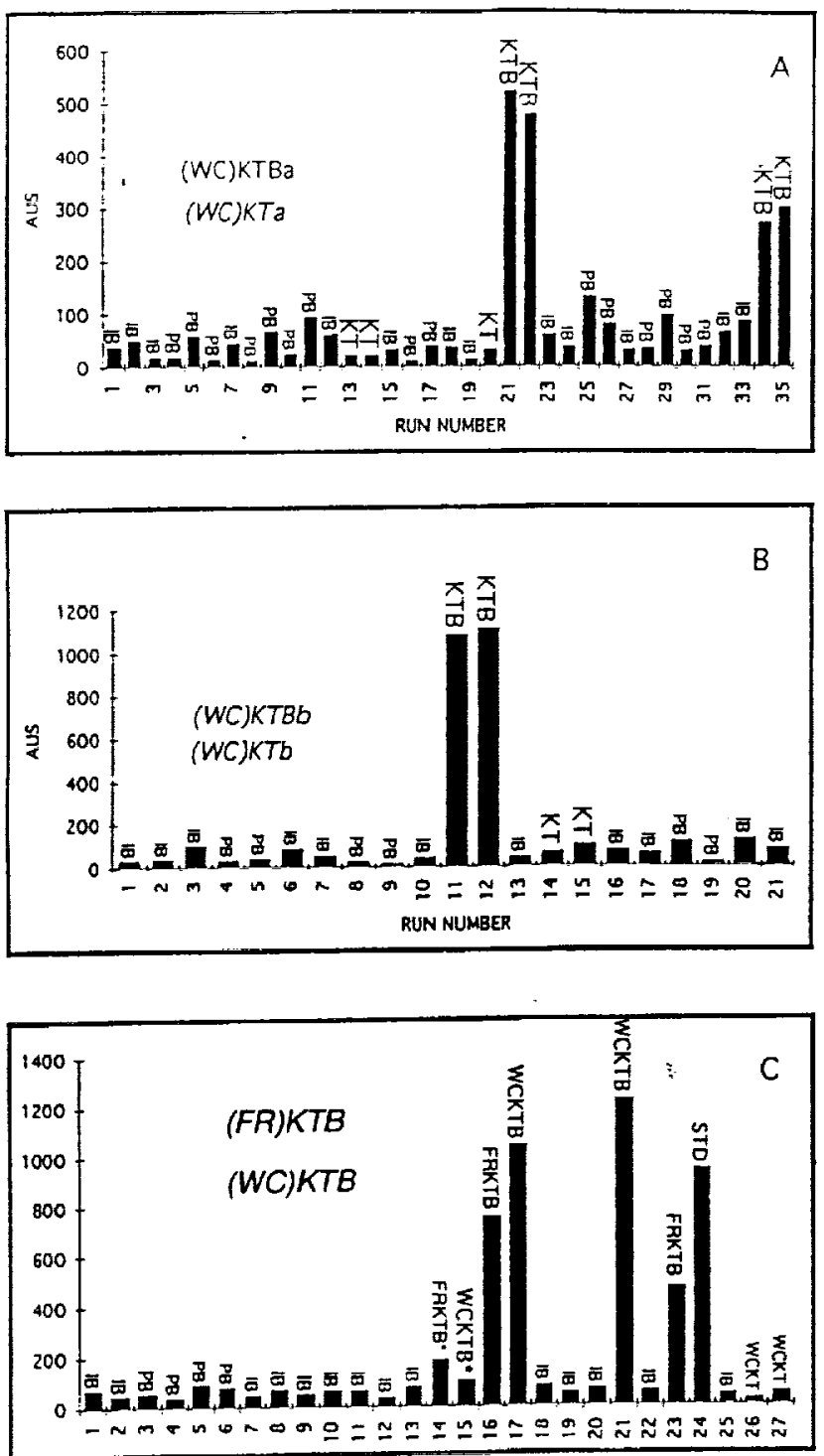

TABLE 2. Results.

\begin{tabular}{lccc}
\hline Sample & $\begin{array}{c}\mathrm{C}_{(*)} \text { Weight } \\
(\mathrm{ng})\end{array}$ & $\begin{array}{c}\mathrm{C}_{\mathrm{n}} \\
(\mathrm{ppm}) *\end{array}$ & $\mathrm{ng} / \mathrm{cm}^{2}$ \\
\hline $\begin{array}{l}\text { Woodside Creek }(W C) \\
\text { (WC)KTBa }\end{array}$ & $7.6 \pm 1.0^{+}$ & $0.17 \pm 0.03^{+}$ & $2.4 \pm 0.3^{+}$ \\
(WC)KTBb & $9.1 \pm 1.5$ & $0.17 \pm 0.03$ & $3.6 \pm 0.5$ \\
& & & \\
Flaxbourne River (FR) & & & \\
(FR)KTBa & $1.1 \pm 0.3$ & $0.10 \pm 0.03$ & $2.5 \pm 0.8$ \\
\hline
\end{tabular}

* Based on the weight of the residue after demineralization.

" These results are sums of (WC)KTBa and(WC)KTBa\#. The first extraction yielded $3.8 \mathrm{ng} \mathrm{C}_{(x)}$, the second $3.8 \mathrm{ng}$.

Figure 2 summarizes the analyses of extracts from (WC)KTBa, (WC)KTBa\#, (WC)KTBb\#, and (FR)KTBa\#. In every subfigure, the numbers on the $X$ coordinate represent the sequence of injections of samples and blanks. The $\mathrm{Y}$ coordinate represents the integrated peak areas at $4.44 \mathrm{~min}$. It is seen that only injections from extracts of boundary samples yield peak areas significantly above the blank values. We adopted $75 \pm 50$ AUS for corrections. We surmise that the boundary samples contain $\mathrm{C}_{6(t)}$.

Table 2 presents the numerical results. In addition to the error from blank corrections, there is a substantial stochastic error of $\pm 8 \%$ from the injected volumes as deduced from repeated injections of standard solution.

The results show that the amounts of $C_{(x)}$ per unit surface are in the nanogram range, and that the "concentration" in the residue, mostly soot, is in the 0.1-0.2 ppm range. There may be several reasons why these amounts are so much smaller than those found in soot from the free buming of toluene and candle wax [5]. The buming of wood may not produce as much fullerene as the burning of toluene and wax. The fullerenes produced by the KT wildfires, regardless of what was buming then, were exposed to the "perils of waters, winds, and the rocks," and fullerenes are especially sensitive to ozone [6]. Since wildfires occur frequently, albeit usually on much smaller scales, it seems possible that lignites and coals contain small amounts of fullerenes.

The failure to find $\mathrm{C}_{70}$ is not disturbing when one considers that the predicted $C_{7}$, peak area for an assumed $70 / 60$ ratio of 0.2 would have been barely above background.

References: [1] Buseck P. R. et al. (1992) Science, 257, 215217. [2] Alvarez L. el al. (1980) Science, 208, 1095-1108. [3] Wolbach W. S. et al. (1985) Science, 230, 167-170. [4] Anders E. et al. (1991) in Global Biomass Burning (J. S. Levine, ed.), 485492 , MIT (this is only a selection of many more papers on the subject of wildfires). [5] Chibante L. P. F. et al. (1993) Science, submitted. [6] Chibante L. P. F. and Heymann D. (1993) GCA. 57, 1879-1881.

Fig. 2. 
THE CHICXULUB CRATER AND ITS RELATION TO THE KT BOUNDARY EJECTA AND IMPACT-WAVE DEPOSITS. A. R. Hildebrand ', F. Asaro ${ }^{2}$, M. Attrep Jr. ${ }^{3}$, J. C. Bermúdez-Santana ${ }^{4}$, S. Bonis ${ }^{5}$, E. Cedillo-Pardo ${ }^{4}$, P. Claeys ${ }^{6}$, V. Gonzalez-Casildo ${ }^{4}$, J. M. Grajales-Nishimura4, D. C. Grégoire', C. Ortiz-Alemann, M. Pilkington', M. A. Sánchez-Rios ${ }^{4}$, J. Smit ${ }^{8}$, and J. A. Stansberry', 'Geological Survey of Canada, 'Observatory Crescent, Building 3, Ottawa ON, Canada KIA OY3, 'Lawrence Berkeley Laboratory, I Cyclotron Road, University of Califomia, Berkeley CA 94720, USA, ${ }^{3}$ Los Alamos National Laboratory, Los Alamos NM 87545, USA, Instituto Mexicano del Petroleo, Eje Central Lazaro Carderas 152, Codigo 07730, Mexico, D.F., Mexico, ${ }^{5}$ Department of Earth Sciences, Dartmouth College, Hanover NH 03755, USA, ${ }^{6}$ Department of Geology and Geophysics, University of California at Berkeley, Berkeley CA 94720, USA, 'Instituto de Geofisica, Ciudad Universitaria, Delgacion de Coyoacan, Codigo 045 10, Mexico, D.F., Mexico, ${ }^{,}$Department of Sedimentary Geology, Free University, P.O. Box 7161, 1007 MC Amsterdam, Netherlands, "Department of Planetary Sciences, University of Arizona, Tucson AZ 85721, USA.

Introduction: The Chicxulub Crater is the largest known Phanerozoic terrestrial impact crater and the environmental degradation associated with its formation was probably the cause of the mass extinction associated with the end of the Cretaceous Period [1-3]. The Chicxulub projectile impacted a shallowly submerged pedestal of continental crust located between the proto-Caribbean and the Gulf of Mexico. The resulting crater was immediately flooded and eventually buried, leading to apparently complete preservation of its intracrater deposits subsequent to the effects associated with the backwash. Because the crater is well preserved and because its ejecta blanket is known from hundreds of globally distributed localities, this impact affords an unprecedented opportunity for impact studies, including the effects of large impacts on the terrestrial environment.

Chicxulub Crater: The Chicxulub Crater is a $165-180-\mathrm{km}-$ diameter peak-ring crater based on drill-hole data, magnetic- and gravity-field data, seismic reflection profiles, and surface fracture patterns; $170 \mathrm{~km}$ diameter is the most likely size, slightly smaller than that originally proposed by [1]. A preliminary structural cross section produced based on these constraints [4] has the features expected for a large complex crater analogous to other examples such as Popigai, Manicouagan, and Manson (Fig. 1). The three main structural elements are an inner zone of brecciated and melted target material
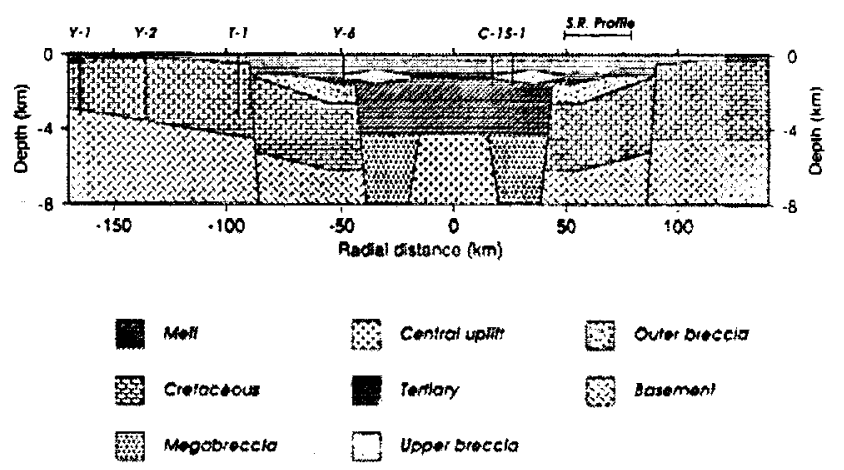

Fig. 1. roughly corresponding to the transient cavity ( $\sim 90 \mathrm{~km}$ diameter), a central uplift $(\sim 40 \mathrm{~km}$ diameter) resulting from inward and upward movement of material following rebound of the transient cavity floor, and an outer faulted, inwardly slumped zone $(\sim 170 \mathrm{~km}$ diameter) formed during collapse of the transient cavity. None of the observations support suggestions of larger crater diameters [e.g., 5].

Impact Angle and Projectile Type: The angle of impact is constrained $t o>10^{\circ}$ by the circularity of the crater and to $>45^{\circ}$ by the azimuthal symmetry of the crater's ballistically distributed ejecta [6]. Additional discoveries of proximal KT ejecta yield thicknesses consistent with azimuthal symmetry. The independent constraints of the global nuence of Ir (250,000 tonnes) and the energy required to excavate the $90-\mathrm{km}$-diameter transient cavity (based on energy scaling relationships) are best satisfied by a cometary projectile [7,8]. An asteroidal projectile is allowed if most of the projectiles' Ir escaped the Earth in high-energy ejecta or was sequestered in the crater's melt rocks as reported by [3]. However, analysis of a sample of the Y $6 \mathrm{NI} 7$ melt rock yielded only $29 \mathrm{ppt}$ of $\mathrm{lr}$, indicating that not all the melt rocks carry anomalous Ir. Assuming a melt volume of $20,000 \mathrm{~km}^{3}$ requires an average concentration of $5 \mathrm{ppb}$ in the melt rocks if they are to hold an amount equivalent to that found in the global fireball layer. Further analyses will clarify Ir melt-rock concentrations, but, as a total amount of Ir several times greater than the current fireballlayer inventory is required for an asteroidal impact, a cometary projectile is indicated.

Proximal Deposits: Discoveries of proximal deposits of ballistic ejecta and impact-wave disturbances continue at an accelerating pace. The ballistic ejecta deposits (exposed at the surface only $>500 \mathrm{~km}$ from the crater) are comprised almost entirely of tektites (now generally pseudomorphed) with a minor component of relatively fine-grained shocked and unshocked debris. Ejecta thicknesses observed both at newly discovered and previously described localities (Fig. 2) are consistent with thicknesses predicted by the power-law relation of [9]. Near the crater the ballistic ejecta have been stripped and/or diluted by impact waves in shallow-water environments. In conirast, the fireball layer appears to maintain its uniform thickness of $\sim 3 \mathrm{~mm}$. Deep-water environments appear to offer the best chance for preservation of minimally disturbed ejecta near the crater.

Sequences of sedimentary breccias (and other clastics) up to $>100 \mathrm{~m}$ thick occur at numerous KT localities surrounding the Chicxulub Crater. These deposits are interpreted as the result of erosion and transport by giant impact waves and submarine slumps triggered by the seismic energy deposited by the impact. This class of deposits is volumetrically probably several times larger $\left(>100,000 \mathrm{~km}^{3}\right)$ than that of the ballistic ejecta. These deposits invariably show transport of material to deeper water and may provide "snapshots" of life at KT time. Across the Chiapas Basin, Mexico, these deposits show significant variation in clast lithologies controlled by varying source terranes on the margins of the basin. In the Peten Basin, Guatemala, a dramatic deepening (order of $100 \mathrm{~m}$ ) occurs across the boundary breccias, possibly indicating large-scale slumping at the platform margin at KT time. These deposits are a record of the dramatic erosional effects near the point of impact and serve as a model for proximal deposits produced by other marine impacts.

Extinction Mechanisms: The Chicxulub impact is a 1-in-100. million-year event based on observed crater and impactor populations. The impact released approximately $10^{31}$ ergs of energy in a 


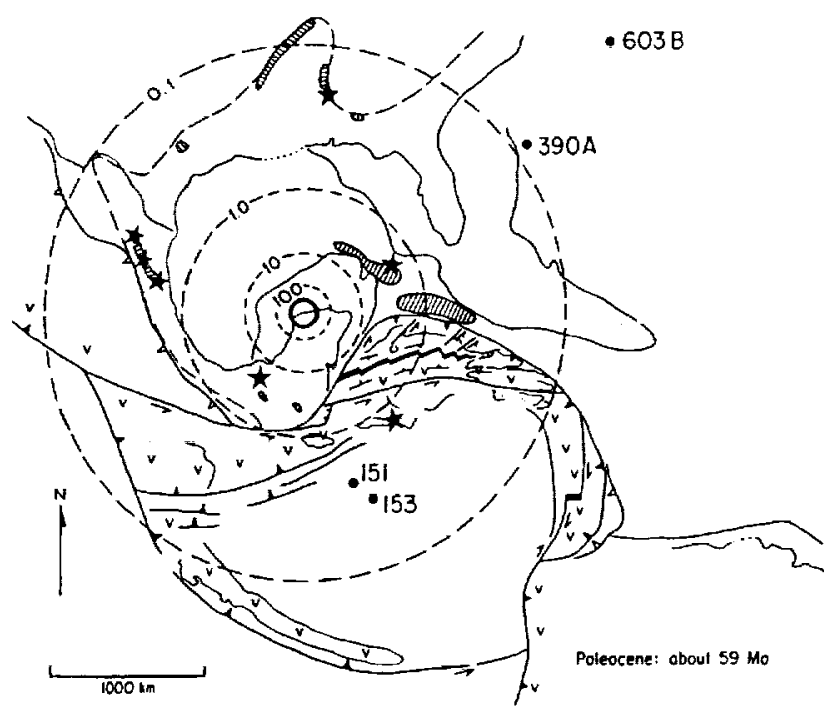

Fig. 2. Isopachs of Chicxulub crater ejecta in meters.

fraction of an hour. Deposition of this amount of energy allowed lethal changes in oceanic and atmospheric systems. Release of devolatized $C$ and sulfur dioxides from the impacted rocks of the Yucatan Platform probably made the Chicxulub impact particularly deadly for its size. Understanding the contributions of different mechanisms to the extinction of species will be more difficult than establishing the location and size of the impact, but having the latter information constrains modeling of the impact's effects.

References: [1] Hildebrand A. R. et al. (1991) Geology, 19, 867-871. [2] Swisher C. C. et al. (1992) Science, 257, 954-958. [3] Sharpton V. L. et al. (1992)Nature, 359, 819-821. [4] Pilkington M. et al. (1993) JGR, submitted. [5] Sharpion V. L. et al. (1993) Science, 261, 1564-1567. [6] Hildebrand A. R. and Stansberry J. A. (1992) LPSC XXIII, 537-538. [7] Sigurdsson H. et al. (1992) EPSL, 109, 543-559. [8] Hildebrand A. R. (1992) Ph.D. dissertation, Univ. of Ari N94. 28301 1973)EPSL, 20,226-236. $5 ; \quad 2088 \% 7$ CONSEQUENCES OF IMPACTS OF SMALL ASTEROIDS ANDCOMETS WITHEARTH. J.G. Hills, Theoretical Division, Los Alamos National Laboratory, Los Alamos NM 87545, USA.

The fragmentation of a small asteroid in the atmosphere greatly increases its cross sections for aerodynamic braking and energy dissipation. At atypical impact velocity of $22 \mathrm{~km} / \mathrm{s}$, the atmosphere absorbs more than half the kinetic energy of stony meteoroids with diameters, $D_{M}<220 \mathrm{~m}$ and iron meteoroids with $D_{M}<80 \mathrm{~m}$. The corresponding diameter for comets with impact velocity $50 \mathrm{~km} / \mathrm{s}$ is $D_{M}<1600 \mathrm{~m}$. Most of the atmospheric energy dissipation occurs in a fraction of a scale height, so large meteors appear to "explode" or "flare" at the end of their visible paths. This dissipation of energy in the atmosphere protects the Earth from direct impact damage (e.g., craters), but it produces a blast wave that can do considerable damage. The area of destruction around the impact point in which the over-pressure in the blast wave exceeds $4 \mathrm{lb} / \mathrm{in}^{2}=2.8 \times 10^{5}$ dynes $\mathrm{cm}^{3}$, which is enough to knock over trees and destroy buildings, increases rapidly from zero for chondritic meteoroids less than $56 \mathrm{~m}$ in diameter (15 megatons) to about $2000 \mathrm{~km}^{2}$ for those $80 \mathrm{~m}$ in diameter (48 megatons). (The probable diameter of the Tunguska impactor of 1908 is about $80 \mathrm{~m}$.)

Crater formation and earthquakes are not significant in land impacts by stony asteroids less than about $200 \mathrm{~m}$ in diameter because of the air protection. A tsunami is probably the most devastating type of damage for asteroids $200 \mathrm{~m}$ to $\mathrm{l} \mathrm{km}$ in diameter. An impact by an asteroid this size anywhere in the Atlantic would devastate coastal areas on both sides of the ocean. An asteroid a few kilometers across would produce a tsunami that would reach the foothills of the Appalachian Mountains in the upper half of the East Coast of the United States. Most of Florida is protected from a tsunami by the gradual slope of the ocean off its coast, which causes most of the tsunami energy to be reflected back into the Atlantic. The atmosphere plume produced by asteroids with diameters exceeding about $120 \mathrm{~m}$ cannot be contained by the atmosphere, so this bubble of high-temperature gas forms a new layer on top of the atmosphere. The dust entrapped in this hot gas is likely to have optical depths exceeding $\tau=10$ for asteroids with diameters exceeding about 0.5 $1 \mathrm{~km}$. The optical flux from asteroids $60 \mathrm{~m}$ or more in diameter is enough to ignite pine forests. However, the blast wave from an impacting asteroid goes beyond the radius in which the fire starts.

The blast wave tends to blow out the fire, so it is likely that the impact will char the forest (as at Tunguska), but the impact will not produce a sustained fire. Because comets dissipate the ir energy much higher in the atmosphere than asteroids, they illuminate a much larger region and their blast wave is weaker, so they are much more effective in producing large fires. This suggests that the KT impactor was a comet rather than an asteroid.

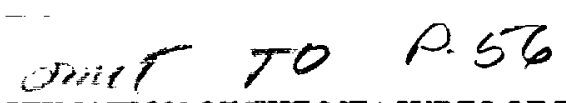

ESTIMATION OF THE MEASURES OF THE CHICXULUB CRATERING EVENT. K. A. Holsapple, Mail Stop FS-10, University of Washington, Seattle WA 98195, USA.

Introduction: The impact of a large asteroid or comet into the Earth sets in motion a very complex event with severe consequences. The energy from the impact of a $10-\mathrm{km}$ body at $20 \mathrm{~km} / \mathrm{s}$ velocity is $10,000 \times$ greater than the sum of the energy from the simultaneous detonation of all nuclear devices in the world [1]. That energy is deposited into what is, compared to the range of the effects, a single spot in the lithosphere. The consequences of such an impact are well outside any known experience, and require extreme extrapolations of limited data to estimate.

The most important link to the estimation of the other aspects of the crater formation is the remaining final crater. Here we review the existing methods of estimating the relations between the conditions of the impact: the impactor composition, size, and velocity; and the resulting effects: crater size, ejecta deposition, dynamic flow fields, melt volumes, etc.

Database: The quantification of cratering phenomena is based on results of four types. Those types and some comments on their importance and limitations follow.

Experiments in the laboratory. Since the 1960 s experimenters have formed centimeter-sized craters in a variety of materials at velocities up to about $6 \mathrm{~km} / \mathrm{s}$. In the $1980 \mathrm{~s}$, experiments were also performed at high gravity on a centrifuge [2]. Primarily from these data, two distinct physical regimes for cratering have been identified, depending on the relative magnitudes of material strength $\mathrm{c}$ com- 
pared to gravitational stresses $\rho g h$ at a crater depth $\mathrm{h}$. The ratio $\mathrm{c} /$ $\rho g h$ is large when the crater depth $h$ is small. For even very weak materials such as a dry alluvial soil, $c$ is on the order of $10^{5}-10^{6}$ (cgs units). Thus, a crater must be meter sized before gravity becomes significant. On the other hand, for craters tens to hundreds of meters diameter in soils, and kilometers in size in rocks, the material strength plays little role.

That is the primary limitation of laboratory experiments. With the exception of a dry sand with zero cohesion, the testing of a geological material in laboratory experiments is by necessity in the strength regime, and govemed by different physics than events in the gravity regime. Even with the centrifuge methods testing into the gravity regime is barely possible, and only for the weakest materials. However, the entirety of data does convincingly support the concepts of the existence of the two distinct regimes, and makes clear that all significant planetary events are well into the gravity regime. Since the data for the dry sand materials are always in the gravity regime they are thought to furnish good estimates for cratering phenomena for other materials including rocks in the gravity regime [3].

Field experiments with conventional and nuclear explosive cra. ters. The field experiments for cratering are a consequence of interest in nuclear cratering over the decades since the 1950s. The majority are limited to explosives with no more than a few hundred pounds of conventional explosives, while the threshold of the gravity regime requires on the order of a couple of tons of explosives for nearsurface events. Many were buried much deeper than meaningful for impact cratering. Only a handful of the larger nuclear events were conducted for cratering on the Earth's surface in meaningful geologies, due to the nuclear test-ban treaty. As a consequence, the use of explosive cratering results for estimates of large impact structures is very uncertain. Corrections must be made for burial depth effects, for the vast differences in specific energy between conventional exlosives, impact events, and nuclear events, for differences in the geologies, and for the differences between strength- and gravitydominated events. An overview and summary of size estimates for the entirety of explosive cratering has been given in [2].

Code calculations. It is plausible that meaningful calculations of the entire history of an event could be made from "first principles" using computers. That hope must be tempered with some caution. The difficulties arise from our lack of knowledge of meaningful models for the behavior of geological materials over the vast ranges of physical regimes involved in a cratering event. Therefore, the calculation of an entire cratering event from the basic principles cannot be considered very precise. There is little hope of correctly tracing all the earlier parts of an event to correctly predict the latter and final stages. Even when the models might be complete, there is a dearth of data to calibrate them for the range of regimes where they are exercised. Code calculations are useful primarily for the more qualitative features of impact events.

Observations of planetary craters. The variety of craters on the planetary bodies is well documented in the literature. It is clear that cratering on the size scale common on planets must involve physical processes not involved in the data discussed above. The craters exhibit morphologies of multiple rings, central depressions, and uplifts, and others that have never been reproduced in normal geological materials in the lab, in the field, or in code calculations. The transformation of craters from bowl-shaped, "simple" craters into the morphologies of the observed large craters and basins requires additional guesses about the relevant physics and estimates of its quantitative aspects.
Interpretations: Simple craters. The "magnitude" of a cratering event must be determined by the impactor size, mass, and velocity, and perhaps to a lesser extent on other conditions such as impact angle and composition. It has become accepted that all firstorder estimates should be based on a single scalar measure of the impactor mass, diameter, and velocity. Such a measure can be derived from a melding of the theoretical considerations of "pointsource" solutions with results of the laboratory experiments, field events, and code calculations [see 1,4]. All are consistent with a single scalar measure of the power-law form $\mathrm{aU}^{u} \delta^{v}$ involving the impactor radius a, velocity $U$, and mass density $\delta$. For impacts into relatively nonporous materials, $\mu \sim 0.55$.

If the dominant measure of the impact conditions is this single parameter, all subsequent effects are determined by this same parameter. Its use in a dimensional analysis for any aspect of the event will yield a so-called scaling law, some restricted form for the functional dependence of one aspect of the cratering event on the initial conditions. For example, in the gravity regime the crater volume must depend on the impactor according to the specific power-law form

$$
V \propto \frac{m}{\rho}\left[\frac{g a}{U^{2}}\right]^{\frac{-3 \mu}{2+\mu}}\left(\frac{\rho}{\delta}\right)^{\frac{2+\mu-6 v}{2+\mu}}
$$

using the impactor mass $m$, mass density $\delta$, gravity $g$, and planetary mass density r. Many other specific scaling laws are given in a recent review [1]. Figure 6 of [1] is reproduced here as Fig. 1. Unfolding the dimensionless forms given in this figure gives for the crater volume in soft rock geologies the specific equation

$$
V=0.48 \mathrm{~m}^{0.78} G^{-0.65} \mathrm{U}^{1.3}
$$

(using units of $\mathrm{kg}$ for mass, $\mathrm{km} / \mathrm{s}$ for velocity, gravity $G$ in Earth multiples, and $\mathrm{m}^{3}$ for volume). This is for the gravity regime only, for impactors with a diameter above a few tens of meters. The crater diameter at the original ground surface for a simple crater can be estimated from $D=2.4 \mathrm{~V}^{1 / 3}$ to give

$$
\mathrm{D}=1.9 \mathrm{~m}^{0.26} G^{-0.22} \mathrm{U}^{0.43}
$$

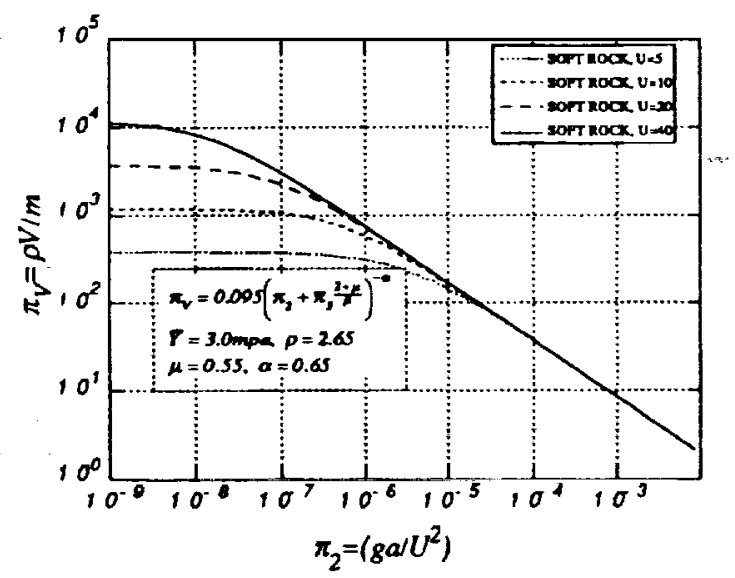

Fig. 1. Volume scaling relations for simple craters showing the strength regime on the left (constant $\Pi_{V}$ for each impact velocity) and the gravity regime on the right. 
The diameter at the top of the resulting lip is a factor of $1.3 \times$ greater.

Complex craters. Terrestrial craters larger than $\sim 3 \mathrm{~km}$ (and lunar craters larger than $\sim 15 \mathrm{~km}$ ) in diameter undergo additional processes, presumably gravity-driven, "late-stage" collapse that modify an initial transient bowl-shaped "simple" crater into the flatfloored complex craters and basins observed. Thus, in addition to strength scaling for small craters, and gravity scaling for larger, there is a final complex crater regime for very large craters. The complete scaling relations are as shown schematically in Fig. 2 . The relations for crater depth and radius need significant corrections compared to those for simple craters. This complex crater regime has not been successfully calculated with codes, and requires much larger combinations of gravity-scaled size than possible for experiments. It is commonly assumed that such a gravitational-driven collapse of a transient bowl-shaped crater is a process that preserves volume. Based on this, the relation between the final complex crater diameter $D$, the earlier transient diameter $D_{1}$ and the threshold diameter $\mathrm{D}$, at the onset of complex crater morphologies can be put into the form [1]

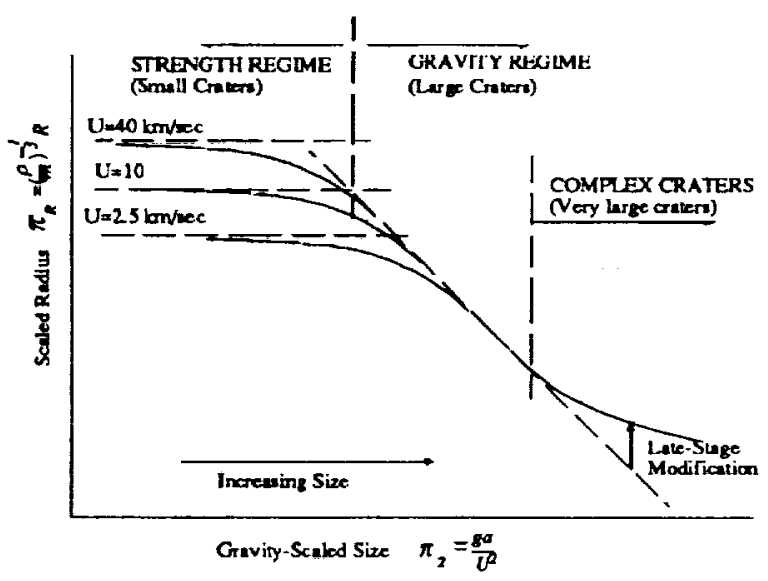

Fig. 2. Schematic of crater radius scaling relation showing the complex crater regime for very large craters.

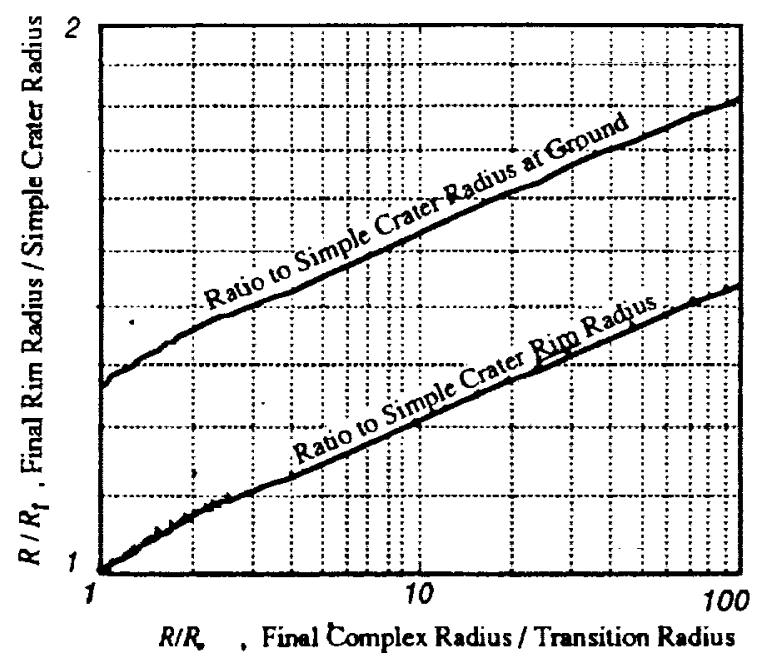

Fig. 3. Diameter enhancement for the transformation from a transient simple to a final complex crater.
TABLE I. The results of the application of the scaling methods to an impact basin of $300 \mathrm{~km}$ diameter created by a $20-\mathrm{km} / \mathrm{s}$ rocky asteroid impacting the Earth.

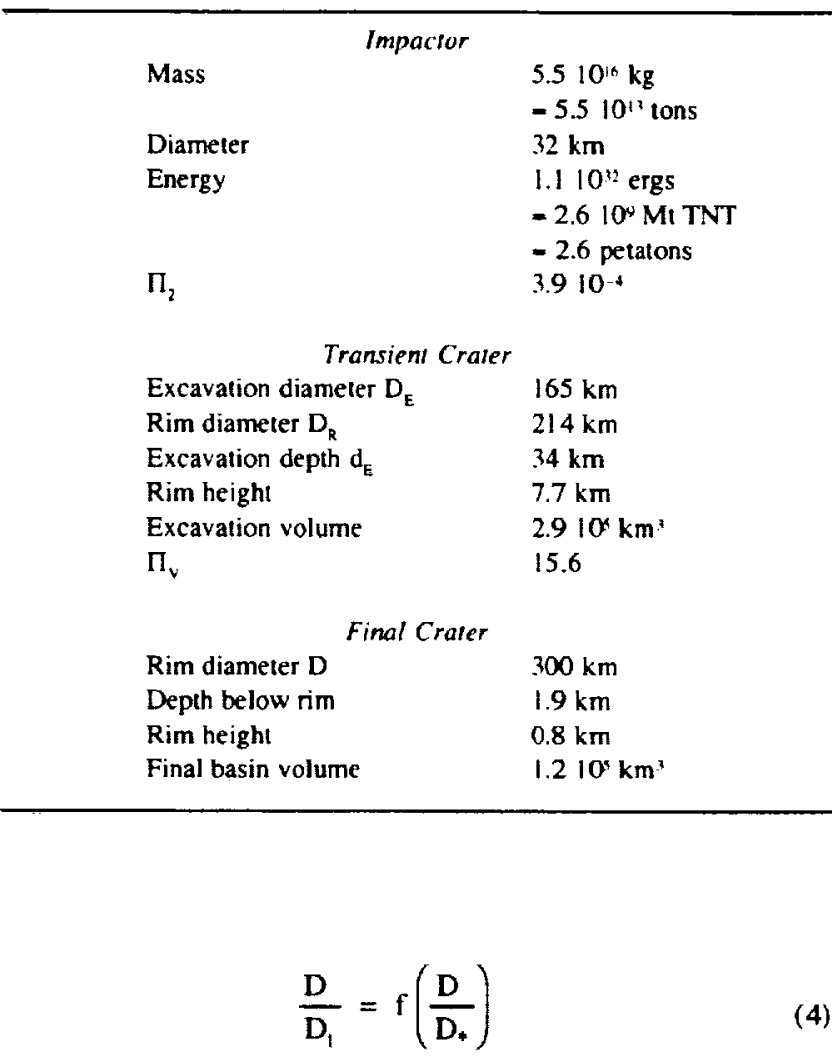

The function has been explicitly determined from a comparison of the measured crater shapes for simple craters to those observed for the complex craters on the Moon [5]. The final results of this analysis are as shown in Fig. 3, Over most of the domain of interest the result is given by

$$
\frac{D}{D_{e}}=1.3\left(\frac{D}{D_{e}}\right)^{0.073}
$$

Using equation (3) for the excavation diameter and equation (5) one can get

$$
D=1.41 \mathrm{~m}^{0.2 \times} \mathrm{U}^{0.47}
$$

using the units as before.

Chicxulub Application: For the Chicxulub basin, assuming $\mathrm{D}=30010^{3}$, one can use this relation and others [ 1$]$ with an assumed normal velocity of $20 \mathrm{~km} / \mathrm{s}$ for a rocky impactor to determine the entries in Table 1. Other possibilities in assumed size, velocity, or impactor composition will modify these values.

References: [1] Holsapple K. A. (1993) Annu. Rev. Earth Planet. Sci., 21, 333-373. [2] Schmidt R. M. et al. (1986) Defense Nuclear Agency Report DNA-TR-86-I82. [3] Schmidt R. M. and Housen K. R. (1987)Intl. J. Impact Eng., 5, 543-560. [4] Holsapple K. A, and Schmidt R. M. (1987) JGR, 92,6350-6376. [5] Holsapple K. A. (1993) LPS XXIV. 
CARBONATE-DERIVED GASES IN HAITIAN KT BOUNDARY GLASS SPHERULES. R. M. Hough', H. Sigurdsson'2, I. A. Franchi', I. P. Wright', C. T. Pillinger', and I. Gilmour', IPlanetary Sciences Unit, The Open University, Milton Keynes, MK7 6AA, UK, ${ }^{2}$ Graduate School of Oceanography, University of Rhode Island, Narragansett RI 02882, USA.

Glass spherules, thought to be tektites from Haiti, have been analyzed previously for their mineralogy and chemical composition to identify their origin and mode of formation [1].

They occur in various colors, dependent upon the composition of the original target rock, and in many cases are seen to contain bubbles. To investigate these spherules and the nature of any gas phase present in the bubbles, several dark brown glasses have been analyzed for their $\mathrm{C}$ content and isotope composition, using stepped combustion analysis and static mass spectrometry [2]. Furthermore, brown and yellow spherules were analyzed for $O$ isotope composition using laser fluorination and conventional dynamic gas source mass spectrometry.

Petrographic analysis using a standard microscope illustrated the presence of "bubbles" within the dark brown glass spherules. By simply submerging a fragment in refractive-index oil, placing a glass slide above it, and applying pressure, it was possible to release the gas in the bubbles. Since on no occasion did the oil move to fill the void left when the gas was released it can be concluded that the bubbles were at greater than atmospheric pressure and may represent a volatile component such as $\mathrm{CO}_{2}$ or hydrocarbon. Bubbles were also released simply through fracturing glass fragments that didn't display any signs of bubbles.

In most cases spherules analyzed for $\mathrm{C}$ were treated as whole entities, but one was broken into fragments for the purpose of replication. Individual fragments were found to contain $0.2 \mathrm{wt} \% \mathrm{C}$ in two components of different isotopic compositions. The first component had a release temperature of $350^{\circ}-400^{\circ} \mathrm{C}$ with a $\delta^{13} \mathrm{C}$ of $-22 \%$, and the second component was released at higher temperatures, $500^{\circ}-$ $600^{\circ} \mathrm{C}$ and had $\mathrm{a} \delta^{13} \mathrm{C}$ value of $-6.3 \%$. The isotopic composition and release temperature of the first component strongly suggest that it is organic and probably represents surface contamination of the sample. To try and reduce contamination, other spherule fragments were

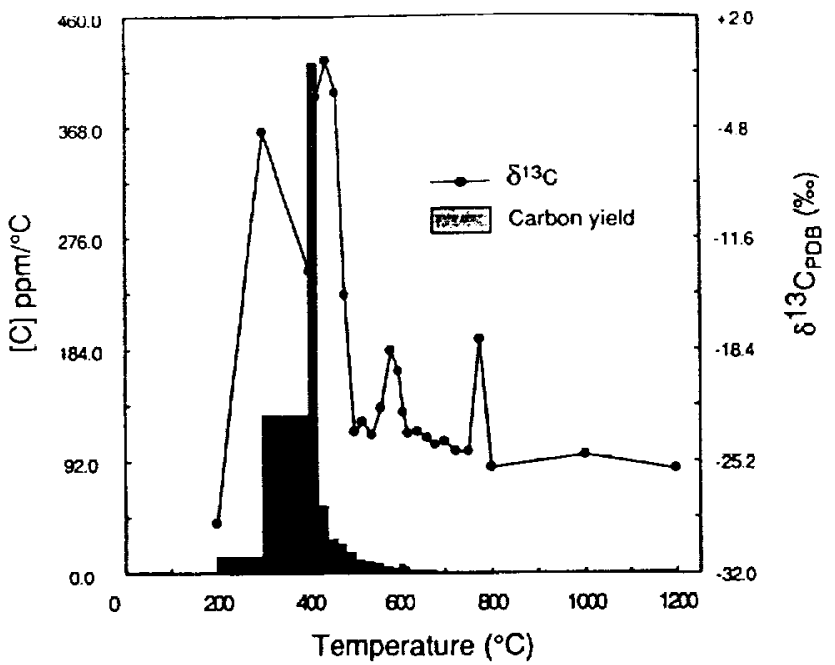

Fig. 1. Stepped combustion profile of a dark brown glass spherule from Haiti. pretreated with $0.1 \mathrm{M}$ chromic acid to remove organic and carbonate components. Analyses of cleaned fragments indicated a variable $\mathrm{C}$ content from 0.005 to $2.6 \mathrm{wt} \% \mathrm{C}$, but again with two isotopically different components. The first with a peak $\delta^{13} \mathrm{C}$ of $-0.8 \%$ released between $420^{\circ}$ and $460^{\circ} \mathrm{C}$ and the second, a $\delta^{13} \mathrm{C}$ of $-19.0 \%$ released between $550^{\circ}$ and $600^{\circ} \mathrm{C}$ (Fig. 1). Levels of low-temperature organic contamination were greatly reduced in the cleaned spherules.

The component with a $\delta^{13} \mathrm{C}$ of $-19 \%$ is present in most of the spherule fragments. A component with a similar combustion temperature and $\delta^{13} \mathrm{C}$ has been encountered in KT residues containing nanodiamonds [3]. There is currently no information available confirming its identity, but it does not appear to be surficial or an oxidizable organic.

The $\mathrm{C}$ released between $420^{\circ}$ and $460^{\circ} \mathrm{C}$ is present in most spherule fragments and has a consistently heavy isotopic composition (maximum $\delta^{13} \mathrm{C}$ of $-0.8 \%$ ). This isotopic composition is remarkably similar to those of marine carbonates [4], but isotopically heavier than present-day atmospheric $\mathrm{CO}_{2}(-7 \%)$.

If the bubbles are indeed $\mathrm{CO}_{2}$ then one likely origin is that they represent $\mathrm{CO}_{2}$ released from target rock carbonates by the impact [5]. Identification of these $\mathrm{C}$ components by future work may reveal a possible source and mode of formation for the spherules and will also clarify the effect of the internal bubbles upon the compositions.

Dark brown spherules selected for $\mathrm{O}$ isotope measurements were broken into fragments to allow repeat analyses on the same spherule. Due to the smaller size of the yellow spherules they were analyzed whole. The dark brown spherules have $\delta^{18} \mathrm{O}$ values between $7.1 \%$ and $9.5 \% \circ$ and $\delta^{17} \mathrm{O}$ between $3.7 \%$ and $5.0 \%$. The yellow spherules have a $\delta^{18} \mathrm{O}$ of $13.0 \%$ and a $\delta^{17} \mathrm{O}$ of $6.8 \%$.

Both types of spherule fall on the terrestrial fractionation line (TFL) on a plot of $\delta^{17} \mathrm{O}$ vs. $\delta^{18} \mathrm{O}$ (Fig. 2). The $\mathrm{O}$ isotope data suggest no obvious input from an extraterrestrial impactor into the glasses, but it should be noted that only a small number of spherules have been analyzed.

Heterogeneities seen in the $\mathrm{C}$ data for the dark brown spherules seem to be reflected in the $\mathrm{O}$ data with variations between fragments of the same spherule and between whole spherules.

References: [1] Koeberl C. and Sigurdsson H. (1992) GCA, 56, 2113-2119. [2] Yates P. D. et al. (1992) Chem. Geol., 101, 81-

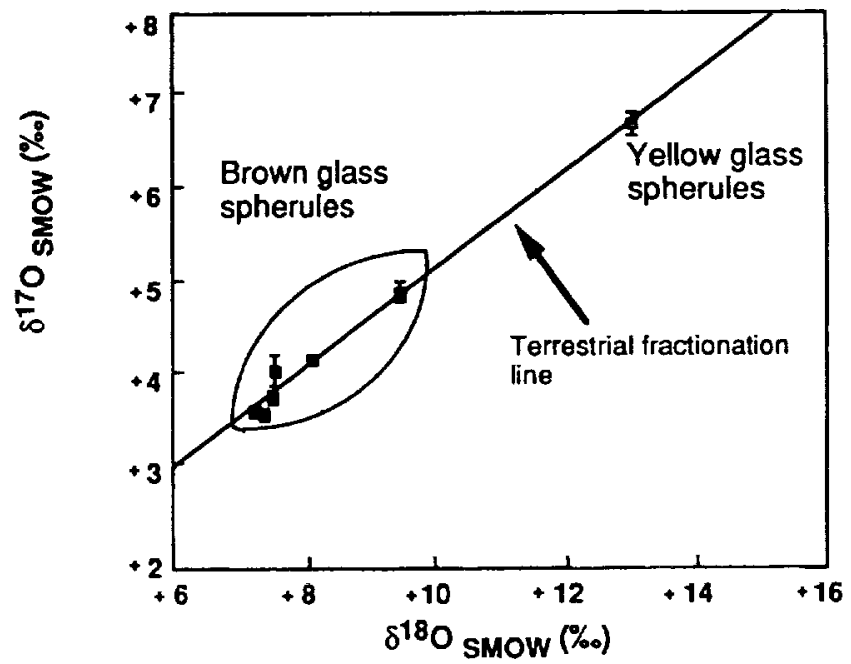

Fig. 2. Oxygen isotopic composition of glass spherules. 
91. [3] Gilmour I. et al. (1992) Science, 258, 1624-1625. [4] Faure G. (1986) Wiley, New York, 496-499. [5] Sigurdsson H. et al. (1991) Nalure, 353, 839.

GAIA, CAMBRIAN EXPLOSION, AND KT CATASTROPHE. K. J. Hsu', G. Shields', and D. Hollander ${ }^{2}$, 'ETH Zurich, Switzerland, ${ }^{2}$ Northwestem University, Evanston IL, USA.

In a previous paper ("Is Gaia Endothermic?"), Hsu suggested that the Earth's climate cooled down considerablv during the Proterozoic, when atmospheric $\mathrm{CO}_{2}$ was increasingly tied up in stromatolitic carbonates. The consequence was the late Proterozoic glaciation. Two bigs steps forward in biologic evolution took place at that time. First the metazoans appeared and flourished. The Ediacaran faunas had no hard parts, and decreased the efficiency of biological communities in storing $C$ as inorganic $C$ in sediments. Then the first skeletal organisms appeared, and their skeletons were mainly phosphatic. Both of those seemed to have successfully competed against cyanobacteria for living space. A prediction was made that a reduction in the biomass of the cyanobacteria biocoenoses subsequent to the evolution of the Ediacaran and small shelly faunas should have increased the atmospheric partial pressure of $\mathrm{CO}_{2}$. At the same time, more terrestrial $\mathrm{Ca}$ should have been released from the tidal flat environment to the open ocean. The termination of the Precambrian glaciation and the Cambrian explosion were the consequences of this evolutionary change of life.

Recent data by de Marais and other showed a reduction of the carbonate-C/organic-C reduction by a factor of more than half from $2.0-0.5 \mathrm{Ga}$ before present, reaching a minimum at about $0.8 \mathrm{Ga}$ (Nature, March, 1993). According to the relation obtained by Hollander and McKenzie, this corresponds to a reduction of $\mathrm{CO}_{2}$ partial pressure. This trend supports the postulate that the onset and retreat of Precambrian glaciation and deglaciation were related to the atmospheric greenhouse. Studies of $\mathrm{Sr}$ isotope values have also indicated that the ${ }^{87} \mathrm{Sr} /{ }^{86} \mathrm{Sr}$ ratio reaches a maximum at the beginning of the Cambrian. Terrestrial $\mathrm{Sr}$ should have been preferentially stored with $\mathrm{Ca}$ in stromatolites. With the destruction of the cyanobacteria biocoenosis the terrestrial $\mathrm{Ca} \mathrm{Sr}$ should have preferentially been released. The increased flux could support the postulate that the Precambrian seawater that was undersaturated with respect to calcite became suptersaturated at the beginning of the Cambrian. The increased flux of $\mathrm{Ca}$ and $\mathrm{Sr}$ to the open ocean is indicated by the maximum value of the ${ }^{87} \mathrm{Sr} /{ }^{86} \mathrm{Sr}$ ratio at the time of the Precambrian/Cambrian transition.

The hypothesis that the interaction of geosphere and biosphere has influenced terrestrial climate postulates that the early Tertiary warming was a long-term consequence of the KT boundary event. The living biomass of marine plankton is a sink of atmospheric $\mathrm{CO}_{2}$ and the Quatemary record indicates reduced $\mathrm{CO}_{2}$ pressure and warmer climate during interglacial epochs of reduced plankton production. Using the same argument, we conclude that the early Tertiary waming was related to a reduction of plankton biomass after the KT boundary event. The cooling trend that started with the evolution of marine planktons was interrupted at the KT boundary and reversed during Paleocene and Eocene. Global cooling resumed in the Late Eocene when plankton fertility, as indicated by $\mathrm{C}$ isotope data, had recovered sufficiently to reduce atmospheric $\mathrm{CO}_{2}$ pressure, leading ultimately to Quatemary glaciations.
SHOCK DEGASSING OF SEDIMENTARY ROCKS DUE TO THE CHICXULUB IMPACT: HYDROCODE SIMULATION. B. A. Ivanov' , D. D. Badukov², and O. I. Yakovlev?, 'Institute for Dynamics of Geospheres, Moscow, Russia, ${ }^{2}$ Vernadsky Institute, Moscow, Russia.

We present the progress report of the work conceming the scenario of the Chicxulub impact event. The work includes the twodimensional hydrocode simulation of the impact and study of geochemistry of shocked rocks.

The specific feature of the target geology at the Chicxulub site is the presence of a 2-3-km-thick layer of sedimentary rocks over the crystalline basement. High contents of anhydrite $\left(\mathrm{CaSO}_{4}\right)$ may cause the production of $\mathrm{SO}_{2}$ gases due to shock heating of rocks [ I]; $\mathrm{CO}_{2}$ production from carbonates also may impact the terrestrial environment at the KT boundary [2].

Our computer simulation, briefly reported earlier [3], is now in progress to model various stages of the Chic xulub event. All simulations use the supposed rim diameter of the crater of $180-300 \mathrm{~km}$. To create such a crater the silicate asteroid with a diameter of $10-20$ $\mathrm{km}$ would strike Earth at the most probable impact velocity for asteroids of $20 \mathrm{~km} / \mathrm{s}$ [4]. Variations of the asteroid's size, composition, and impact velocity give an intrinsic uncertainty for all estimates of a single event. An oblique impact may result in additional complex phenomena [5].

First we make simple estimates for the future geochemical modeling by calculating the vertical impact of a cylindrical asteroid into the double-layer target. Such a geometry allows us to use the relatively simple SALE code [6]. The problem in using this code for the Chicxulub event is to calculate the shock wave propagation in the target with a top $3-\mathrm{km}$ layer, which is thin in comparison to a projectile diameter $(10-20 \mathrm{~km})$. To resolve the shock front in the hydrocode with an artificial viscosity we need to have al least 10 rows of cells to describe the sedimentary layers, so the cell dimension is limited to a few hundreds of meters. In this case we need to cover the projectile with several tens of cells. This means that the shape of the projectile may play an important role close to projec-tile zones.

We run several variants of the code varying the equation of state of target layers. Tillotson EOS has been used with a minor modification in the expansion range. To model the dynamic properties of the sedimentary layer we used constants for wet tuff and limestone, and aluminum and granite constants for the crystalline basement cited by Melosh [7]. The first output of the simulation is the estimate of sedimentary rock volumes compressed above a given shock pressure. The geometry of isobars has been also mapped. For all our calculations the volume of sedimentary material shocked up to pressures $30-60 \mathrm{GPa}$ (the typical for the postshock thermal decomposilion of carbonates) and higher vary in the range $500-1500 \mathrm{~km}^{3}$. These values may be used as an upper limit for all scenarios of the consequent effect of impact-produced gases on the terrestrial environment.

It is important to note that more than half of this volume is the "plug" of sediments compressed by a projectile. This material will be released to the atmosphere relatively late mixed with projectile material and maybe with crystalline material. The other part of highly shocked sediments may be involved in the early high-speed ejecta, so the scenario of impact-produced gas transport to the atmosphere and stratosphere may have several consequent stages, which should be investigated separately. 
The number of gaseous phases formed by impact devolatilization of S-bearing minerals such as anhydrite and gypsum should depend on two causes, which act in opposite ways: (1) shock-induced heating and (2) reverse reactions after decompression and devolatilization. The degree of thermochemical decomposition can be obtained as a function of the amount of postshock specific intemal energy provided that ( 1 ) the reaction of the decomposition takes place only after decompression, (2) the system is thermodynamically closed at the ambient pressure of $1 \mathrm{bar}$, and (3) all processes in the system are in equilibrium. According to our calculation incipient outgassing of anhydrite starts by $90 \mathrm{GPa}$ and is completed by $155 \mathrm{GPa}$. Violation of equilibrium, for example, due to fast expansion, may change simple equilibrium estimates.

One must consider this estimation as a maximum one because of the high ability of newly formed $\mathrm{CaO}$ for reaction with $\mathrm{SO}_{3}$. This reverse reaction can take place in cooling ejecta plumes. On the other hand, the completeness of the reverse reaction can be restric-ted due to the removal of the gas from plumes and the slow rate of this heterogeneous reaction. Laboratory shock experiments by high parameters can constrain the suggestion. This work is now in progress.

The next stage of this work will be to use the calculated evolution of various elements of shocked materials to estimate the possible kinetics of chemical reactions for the better constraint of the residual composition of impact-produced gases.

References: [1] Brett R. (1992) GCA, 56, 3603-3606. [2] O'Keefe J. D. and Ahrens T. J. (1989) Nature, 338, 247-249. [3] Pope K. O. et al. (1993) LPS XXIV, 1 165-1 166. [4] Roddy D. J. et al. (1987) Intl. J. Impact Eng., 5, 525-541. [5] Schultz P. H. and Gault D. E. (1990) In GSA Spec. Paper 247, 239-262. [6] Amsden A. A. et al. (1980) LA-8095, 100, Los Alamos, New Mexico. [7] Melosh H. J. (1989) Impact Cratering, Oxford, 245 pp.

EOCENE AGE OF THE KAMENSK BURIED CRATER OF RUSSIA. G. A. Izett ${ }^{1}$, V. L. Masaitis ${ }^{2}$, E. M. Shoemaker ${ }^{3}$, G. B. Dalrymple $^{4}$, and M. B. Steiner ${ }^{5}$, 'U.S. Geological Survey, P.O. Box 80225, Denver CO, USA, ${ }^{2}$ Karpinsky Geological Research Institute, Sredny prospekt 74, St. Petersburg, 199026, Russia, ${ }^{3}$ Lowell Observatory, 1400 West Mars Hill Road, Flagstaff AZ 86001, USA, ${ }^{4}$ U.S. Geological Survey, 345 Middlefield Road, Menlo Park CA 94025 , USA, ${ }^{5}$ Department of Geology, University of Wyoming, Laramie WY 82070, USA.

The 25-km-diameter Kamensk buried impact crater of southem Russia $\left(48^{\circ} 20^{\prime} \mathrm{N}, 40^{\circ} 15^{\prime} \mathrm{E}\right.$ ) was long considered to have an age close to that of the Cretaceous-Tertiary (KT) boundary [1,2]. This age assignment seemingly rested on secure biostratigraphic evidence.
The uppermost precrater rocks on the crater rim were reported to be Upper Cretaceous marine marl, sandstone, claystone, and chalk, ranging in age from Cenomanian to Maastrichtian [1]. These rocks also occur as clasts in the allogenic breccia underlying the crater floor. The crater is filled with marl with small reworked fragments of Upper Cretaceous and carboniferous rocks. The crater-filling marl was assigned to the lower Paleocene on the basis of foraminifera considered to be of early Paleocene age [1]. With this biostratigraphic evidence in hand, it seemed possible that the Kamensk impact might be related to the great Chicxulub impact event in Mexico and possibly other impacts at KT boundary time. Microstratigraphic evidence at the KT boundary in western North America suggests that multiple impacts took place [3-5]. If multiple large impacts did indeed occur at or near the time of the KT boundary, the impacting bodies most likely would have been derived either from the breakup of a very large periodic comet or from a comet shower produced by perturbation of the Oort cloud [4-9].

Impact glass recovered from a drill core in the Kamensk impact structure provided the opportunity to refine its age and to determine if it could be of KT boundary age. A centimeter-sized specimen of the Kamensk core was first demagnetized to test whether the orientation could be recovered from viscous remanent magnetization and whether the polarity of a characteristic remanent magnetization could be determined. The sample was then crushed, and shards of clear, yellowish-brown glass that looked promising for ${ }^{41} \mathrm{Ar}-{ }^{34} \mathrm{Ar}$ dating were hand picked.

To isotopically date the glass we used a state-of-the-art ${ }^{40} \mathrm{Ar}$ ${ }^{39} \mathrm{Ar}$ laser-fusion analytical system in the U.S.G.S. laboratories in Menlo Park, Califomia. Although this technique has important advantages relative to the conventional $\mathrm{K}$ - $\mathrm{Ar}$ method, ages of unknown samples are relative to ages of neutron fluence-monitor minerals. We calculated the age of the Kamensk glass using the age of an intralaboratory neutron fluence-monitor mineral [sanidine from the Taylor Creek Rhyolite (Oligocene) of New Mexico]. This sanidine has a ${ }^{41} \mathrm{Ar}-{ }^{-39} \mathrm{Ar}$ age of $27.92 \mathrm{Ma}$ relative to a $\mathrm{K}-\mathrm{Ar}$ age of $162.9 \pm$ $0.8 \mathrm{Ma}$ for a primary fluence-monitor standard SB-3 biotite or of $513.9 \mathrm{Ma}$ for an international hornblende standard MMhb-1.

The ${ }^{40} \mathrm{Ar}-{ }^{39} \mathrm{Ar}$ analytical data for the Kamensk glass shards are shown in Table 1 , and the weighted-mean total-fusion ${ }^{40} \mathrm{Ar}-{ }^{39} \mathrm{Ar}$ age of six glass shards is $49.15 \pm 0.18 \mathrm{Ma}$. We believe this age accurately reflects the time of origin of the Kamensk structure, but final confirmation awaits ${ }^{40} \mathrm{Ar}-{ }^{39} \mathrm{Ar}$ incremental-heating ages for the glass now in progress. In view of the reported early Paleocene age of foraminifera from postcrater-fill marl, the ${ }^{41} \mathrm{Ar}-{ }^{39} \mathrm{Ar}$ apparent age of the glass was a surprise. The tight clustering of ages, however, gives us confidence in the isotopic ages and indicates either that the reported age of Paleocene foraminifera from the crater fill should be reevalu-

TABLE 1. "Ar"/ ${ }^{* 4} \mathrm{Ar}$ analytical data for impact glass fragments from the Kamensk impact structure (analyst G. A. lzett).

\begin{tabular}{|c|c|c|c|c|c|c|c|}
\hline Exp. No. & ${ }^{37} \mathrm{Ar} / 14 \mathrm{Ar}$ & ${ }^{3} \mathrm{Ar} /{ }^{3 y} \mathrm{Ar}$ & ${ }^{*} \mathrm{Ar}{ }^{*} /{ }^{9} \mathrm{Ar}$ & $\% \mathrm{Ar}^{*}$ & $\begin{array}{c}4 \mathrm{Ar}^{*} \\
\times 10^{-14} \text { moles }\end{array}$ & Age (Ma) & Error (1) \\
\hline $93 Z 0382$ & 0.7960 & $5.11 E-04$ & 4.4809 & 97.91 & 2.936 & 49.20 & 0.56 \\
\hline $93 Z 0383$ & 0.7821 & $2.05 \mathrm{E}-04$ & 4.4920 & 99.81 & 10.5007 & 49.32 & 0.32 \\
\hline $93 Z 0384$ & 0.7921 & $3.18 \mathrm{E}-04$ & 4.4742 & 99.11 & 12.5073 & 49.13 & 0.31 \\
\hline $93 Z 0385$ & 0.7834 & $4.03 \mathrm{E}-04$ & 4.4904 & 98.61 & 7.0590 & 49.30 & 0.35 \\
\hline $93 Z 0386$ & 0.8344 & $3.30 \mathrm{E}-04$ & 4.4501 & 99.11 & 8.7525 & 48.86 & 0.33 \\
\hline $93 \mathrm{Z} 0387$ & 0.7794 & $2.11 \mathrm{E}-04$ & 4.4757 & 99.81 & 11.1172 & 49.14 & 0.31 \\
\hline
\end{tabular}

* Radiogenic. 
ated or that the se forams have been reworked from Paleocene beds on the crater rim that were previously thought to postdate the crater.

Our ${ }^{4} \mathrm{Ar}-{ }^{39} \mathrm{Ar}$ age of $49.15 \pm 0.18 \mathrm{Ma}$ implies that the Kamensk structure is early Eocene, not Paleocene or KT boundary age. This isotopic age, recalculated using a reference age of $520.4 \mathrm{Ma}$ for MMhb- 1, is $49.84 \pm 0.18 \mathrm{Ma}$, which is identical (within experimental error) to the $50.5 \pm 0.8 \mathrm{Ma}$ age reported by Bottomley and York [10] for the $50-\mathrm{km}$-diameter Montagnais impact structure on the continental shelf off Nova Scotia. This close match in age for the two impact structures may only be fortuitous, but altematively, it might indicate that both impact structures formed during nearly simultaneous impacts of large fragments of a single disrupted comet.

It is also of interest to try to place Kamensk on the standard paleontologic and magnetostratigraphic timescales. If one uses the Harland et al. [11] or DNAG timescales, an age of $49.84 \mathrm{Ma}$ would fall in chron $21 \mathrm{~N}$, and fossil plankıon zones P10, CP12, and NP14. However, recent recalibration of the Eocene timescale by Montanari et al. [12] suggests that the standard timescale is off by several million years through most of the Eocene. On the Montanari et al. timescale, the age of the Kamensk structure falls in chron $22 \mathrm{R}$ and zones $\mathrm{P9}$, CP11, and NP13. From stepwise alternating field demagnetization measurements of the single specimen of core, we believe that we have recovered the orientation of the specimen and tentatively conclude that the characteristic magnetization is reversed and consistent with an age assignment to chron $22 \mathrm{R}$.

References: [1] Masaitis V. L. et al. (1980) The Geology of Astroblemes, 231, Nedra, Leningrad. [2] Grieve R. A. F. (1982) in GSA Spec. Paper 190, 25-37. [3] Izett G. A. (1991) Eos, 72, 278. [4] Shoemaker E. M. and Izetl G. A. (1992) LPS XXIII, 12931294. [5] Shoemaker E. M. and Izett G. A. (1992) International Conference on Large Meteorite Impacts and Planetary Evolution, 66-68, LPI Contrib. No. 790. [6] Hut P. K. et al. (1987) Nature, 329, 118-126. [7] Hut P. et al. (1991) LPS XXII, 603-604. [8] Hut P. et al. (1991) International Conference on Near-Earth Asteroids, 16 , San Juan Capistrano Research Inst. [9] Shoemaker E. M. (1991) $A C M$ '91, 199. [10] Bottomley R. and York D. (1988) GRL, 15, 1409-1412. II I1 Harland W. B.et al. (1982) A Geologic Time Scale, C N94. 28302 ari A. et al., unpublished. N94-28302

MÁSS EXTINCTIONS: PERSISTENT PROBLEMS AND NEW DIRECTIONS. D. Jablonski, Department of the Geophysical Sciences, University of Chicago, 5734 South Ellis Avenue, Chicago IL 60637, USA.

Few contest that mass extinctions have punctuated the history of life, or that those events were so pervasive environmentally, taxonomically, and geographically that physical forcing factors were probably involved. However, consensus remains elusive on the nature of those factors, and on how a given perturbation (impact, volcanism, sea-level change, oceanic anoxic event) could actually generate the observed intensity and selectivity of biotic losses. At least two basic problems underlie these long-standing disagreements: (1) difficulties in resolving the fine details of taxon ranges and abundances immediately prior to and after an extinction boundary and (2) the scarcity of simple, unitary cause-and-effect relations in complex biological systems.

Detailed Stratigraphic Patterns: Local outcrops and cores are the ultimate source of the data used to analyze mass extinctions, but the pitfalls to taking local data at face value are still little appreciated, resulting in massive overinterpretation of paleontological pattems. The accumulation of sediments and fossils is discontinuous and environmental change is the rule, so that temporal gaps and stepped extinctions are inevitable on some scale in any local sequence. Further, reworking and time-averaging mix fossils from successive intervals; radiocarbon dates on shells collected from surface sediments and forams in core tops indicate a timeaveraging window of $10^{3}-10^{4} \mathrm{yr}$ in marine shelf and deep-sea sediments alike [1]. Statistical protocols are available to test for artificial extinction steps and to place confidence limits on stratigraphic ranges [2,3], but to date these have seen little use in the mass extinction literature: nearly all workers wants to take their data at face value and as virtually devoid of local overprint. Clearly, the answer to this problem is to test patterns against an appropriate null hypothesis.

Inferring Cause from Effect: One fundamental obstacle in linking extinction patterns and hypothesized forcing factors resides in the nature of complex systems: nonlinearities, thresholds, and elaborate feedbacks often rule out the reconstruction of simple catuseand-effect cascades. The same forcing factor might have radically different effects depending on the state of the system at the time of perturbation, and several alternative forcing factors might produce the same biolic response. The survival of an evolutionary lineage during a mass extinction, for example, could be because it (1) lived in a habitat that was not stressed, (2) possessed a physiology or life habit that allowed it to survive in a stressed habitat, (3) was so widespread that its range includes a locality that provided a refuge, and so on. Urgently needed is not another catalog of potential reasons for survival or extinction, but the development of protocols for testing the alternatives. This is partly a matter of constructing large, robust databases amenable to statistical analysis, and coming to grips with the need to integrate local and synoptic databases. With sufficient tuning, the long list of potential KT killing mechanisms can indeed account for virually any conceivable extinction pattem; therefore, while the mere fact of observed selectivity clearly is no argument against impacts, neither is it an argument in their favor. The time for consistency arguments is past: hypothesized extinction mechanisms need to generate unique predictions on the timing, selectivity (taxonomic, biogeographic, ecologic), or other biotic pattems to advance beyond the status of plausible alternatives.

Selectivity is still a neglected area of study for mass extinctions, and even negative results will be important here. Selectivity is played out, if at all, at lower taxonomic levels (families and genera), biogeographically, or ecologically, and the relevant parameters are largely absent from the synoptic databases [4]. Consider the problem of multiple causation for one general pattern: the apparently higher extinction intensities in the tropics. The question is whether the greater losses of shallow-water late Devonian corals relative to deepwater genera, or of symbiont-bearing KT corals and rudist bivalves relative to nonsymbiotic corals and nonrudist bivalves, occur because (1) tropical biotas in general are fragile, perhaps because the ir species are adapted to a narrow range of climatic and other conditions; (2) reef communities in particular are such a tightly woven network of biological interactions that the initial removal of the same proportion of species as were lost at high latitudes could be more disruptive; (3) tropical biotas contain a large proportion of extinction-prone endemics, so that losses are high here owing to biogeographic structure; or (4) the favored habitat of reef communities, low-sedimentation, and low-nutrient shallow-water platforms or ramps, is itself easily disrupted $[5,6]$. Some support exists for 
(3) and (4). First, among-province variation in mass extinction intensities within latitudinal belts tends to be positively related to the proportion of endemic genera in the preextinction biota [7]. Second, a global analysis of end-Cretaceous extinction in marine bivalves found that tropical settings outside the carbonate platforms suffered no greater losses than did extratropical faunas [8]; the reported latitudinal gradient in plankton extinction intensities may have a similar basis. The statistical dissection of altemative mechanisms offers considerable promise for improving our understanding of extinction mechanisms and biological consequences, both for the Big Five mass extinctions and for the smaller extinction maxima that occur throughout the Phanerozoic.

The initial physical and biological conditions must play a role in the biotic response to a perturbation. Perhaps, for example, impacts or volcanism at times of low relative sea level yield greater taxonomic losses than the same event at times of high sea level when the thermal inertia and other ameliorating effects of shallow seas are prominent. This frequent suggestion has yet to be modeled rigorously, let alone tested empirically, but may help to explain why some geologically detectable impacts evidently had negligible biotic effects. The global biota or even individual taxa may vary in relative extinction vulnerability through time. For example, it may take time to accumulate a new crop of extinction-prone taxa after a major extinction event has removed all but the hardiest lineages. Conversely, lineages may evolve in directions that make them less vulnerable to successive perturbations. Such biotic lags and longterm shifts might explain waiting times between extinction events [9. but see 10], and the differential responses of individual taxa to successive extinctions [7].

The evolutionary impact of mass extinctions is another active area of research. Many of the biotic replacements once thought to represent competitive victories over inferior lineages now appear to have been mediated by major extinction events, even though most species extinctions in the fossil record, probably $>90 \%$, occur outside the five major extinction events [11]. Mass extinctions have such profound biological consequences because they bite deep into standing diversity and disrupt background selection regimes, not because they account for most species terminations. Traits that favor survival during mass extinctions need have little correlation with those that enhance survival and diversification during background times, so mass extinctions can have unpredictable and lasting evolutionary effects $[5,7]$. Not only do mass extinctions remove taxa and adaptations well-suited to the background regimes that represent the great bulk of geologic time, they create ecological and evolutionary opportunities by removing incumbent, dominant taxa and enabling other taxa to diversify in the aftermath of the extinction event. On the other hand, mass extinctions do not completely reset the evolutionary clock: many major evolutionary and ecological trends transcend even the Big Five events (e.g., the modemization of marine communities, the rise of flowering plants, and of predatory neogastropods). We need to understand survivors and rebounds as well as victims and ecosystem collapse.

References: [1] Kidwell S. M. and Behrensmeyer A. K. (1993) Paleont. Soc., Short Courses in Paleontology, 6,Univ. of Tennessee, Knoxville. [2] Gilinsky N. L. and Signor P. W. (1991)Paleont. Soc., Short Courses in Paleonsology, 4, Univ. of Tennessee, Knoxville, [3] Sepkoski J. J. Jr. and Koch C. F (1994) in Global Bio-Events and Event-Stratigraphy (O. H. Walliser, ed.), Springer, Berlin. [4] Sepkoski J. J. Jr. (1990) GSA Spec. Paper 247, 33-44. [5] Jablonski D. (1986) in Patterns and Processes in the History of
Life (D. M. Raup and D. Jablonski, ed.), 313-329, Springer, Berlin. [6] Jablonski D. (1994) Phil. Trans. R. Soc. London, in press. [7] Jablonski D. (1989) Phil. Trans. R. Soc. London, B325, 357368. [8] Raup D. M. and Jablonski D. (1993) Science, 260, 971-973. [9] Stanley S. M. (1990) Paleobiology, 401-414. [10] Sepkoski J. J. Jr. (1989) J. Geol. Soc. London, J46, 7-19. [11] Raup D. M. (1991) Paleobiology, 17, 37-48.

$$
0 \times 17,0 \% 24
$$

GLOBAL BIOTIC EFFECTS OF THE KT BOUNDARY EVENT: MASS EXTINCTION RESTRICTED TO LOW LATITUDES? G. Keller, Department of Geological and Geophysical Sciences, Princeton University, Princeton NJ 08544, USA.

One of the most important recent developments in KT boundary studies is the growing awareness that ( 1 ) the mass extinction associated with this event is not the result of a single catastrophe, (2) that extinctions occurred over an extended time period and were selective rather than random within organismal groups as well as between different groups, and (3) that the biotic effects were most severe and sometimes limited to tropical-subtropical regions while high-latitude faunas and floras escaped virtually unscathed. The growing global body of high-resolution faunal and floral data upon which these observations are based now provides the empirical database and the opportunity to test various KT catastrophe scenarios whether volcanic or bolide-impact based. Moreover, specific details of these scenarios can now be tested, including the dust cloud-darkness and shutoff of photosynthesis, acid rain, nuclear winter, and global greenhouse scenarios all presumably leading to global mass extinctions. Unfortunately, there has been no serious test of these scenarios based on empirical data, largely because (1) many catastrophists ignore paleontologists' data and interpretations that widely disagree with their theories, (2) many paleontologists ridicule catastrophists' theories for which they see no basis in the fossil record, and (3) experts disagree among themselves depending on which side of this scientific chasm their sympathies lie. Despite these seemingly insurmountable differences, there is hope for a growing interdisciplinary discourse as both sides accumulate and synthesize more observational data. All scientists agree that a major environmental change occurred across the KT boundary; they disagree on the cause, whether impact or volcanism, and on the biotic effects of this environmental change. Here I will address the latter. Ultimately it is the biotic data that must determine how significant a bolide impact or massive volcanism at KT boundary time was for life on Earth.

The planktic foraminiferal record has played a unique role in the KT boundary controversy. Near the base of the food chain, these single-celled marine plankton are both sensitive to environmental changes and a critical food source for higher, more complex organisms. Moreover, they have long been known to undergo a virtually complete faunal turnover between the end of the Cretaceous and early Tertiary with deep-sea studies documenting a sudden mass extinction at the boundary [1-3]. This prior interpretation cannot be supported by subsequent studies for three major reasons. First, this conclusion was originally based on deep-sea sections that have been subsequently shown to contain major hiatuses spanning from $60 \mathrm{k} . \mathrm{y}$. to $500 \mathrm{k} . \mathrm{y}$. of the basal Tertiary [4,5]. In these sections extinctions and originations, spanning as much as $0.5 \mathrm{~m}$.y. across the KT transition, are artificially concentrated at one horizon giving the appearance of a sudden catastrophic mass extinciion. In contrast, shallow 
continental shelf sections are generally more temporally complete and show a more gradual transition. These sections are more complete primarily due to the sea-level transgression that characterizes the KT boundary and early Danian that shifted the locus of sedimentation to continental shelf areas, leading to sediment starvation, nondeposition, and/or erosion in the deep sea [4,5].

Second, the presence of many Cretaceous taxa in lowermost Tertiary sediments has been routinely ignored based on the assumption that all Cretaceous species (except one) must have become extinct at the KT boundary. Their presence in Danian sediments is therefore assumed to be due to reworking. However, about one-third of the Cretaceous fauna has been observed to range well into the Tertiary world wide and isotopic measurements of their shell calcite provide unequivocal evidence of their residence in Tertiary environments [5-8].

Third, species extinctions are often assumed to have occurred instantaneously due to a bolide impact. However, to date, no sudden extinction horizon of all, or nearly all, Cretaceous planktic foraminifera has been documented in any chronostratigraphically complete KT boundary section [5,9-13], although such an extinction horizon is sometimes inferred $[1,2,12]$.

Comparison of species extinction and evolution patterns of planktic foraminifera across the KT boundary in the most complete high- and low-latitude sections (El Kef, Agost, Caravaca, Brazos River, El Mimbral, Nye Kløv, and ODP Site 738) reveal major differences in extinction pattems. No significant species extinction or major faunal abundance changes coincide with the KT boundary in high latitudes, and nearly all Cretaceous species survive and thrive well into the early Tertiary $[5,11]$. The same lack of species extinctions has been observed in siliceous microfossils, palyno-morphs, and invertebrate faunas $[14,15]$. In contrast, major species extinctions occurred in low latitudes where two-thirds of the Cretaceous taxa disappeared at or below the KT boundary. But, only tropical and subtropical, large, complex, and omamented taxa disappeared. Stable isotopic data indicate that these taxa were predom-inantly deeper water dwellers living at or below the thermocline. Only surface dwellers survived. All the disappearing taxa were already rare endangered species in the late Maastrichtian ocean, comprising only between $5 \%$ and $17 \%$ of the planktic foraminiferal population [5-11,13]. Extinction of these rare taxa could have been caused by relatively minor environmental perturbations in temperature, salinity, $O$, or nutrients. Although it is possible that the extinction of some or all of these taxa was related to the climatic changes associated with a KT boundary bolide impact, a direct cause-and-effect relationship cannot be demonstrated.

In the KT boundary stratotype section of El Kef, all major microfossil groups have been analyzed and their species richness data are illustrated in Fig. 1. At this most complete low-latitude section, the biotic effects are highly variable across the spectrum of microfossils. Planktic foraminifera appear to be most severely affected with gradual species extinctions across the KT boundary. Benthic foraminifera and nannofossils also show pronounced biotic effects beginning at the KT boundary [16,17]. But curiously, ostracods and plants (pollen and spores) show little or no effect $[18,19]$, whereas dinoflagellates increase in diversity [20]. Similar patterns in extinctions, or lack thereof, have been observed in other low- latitude sections, whereas in high latitudes no major species extinctions are documented in any microfossil or macrofossil groups. These variable extinction patterns across latitudes and between fossil groups are difficult to explain by either volcanism or bolide impact theories. Stable-isotope data suggest that the major difference between high and low latitudes across

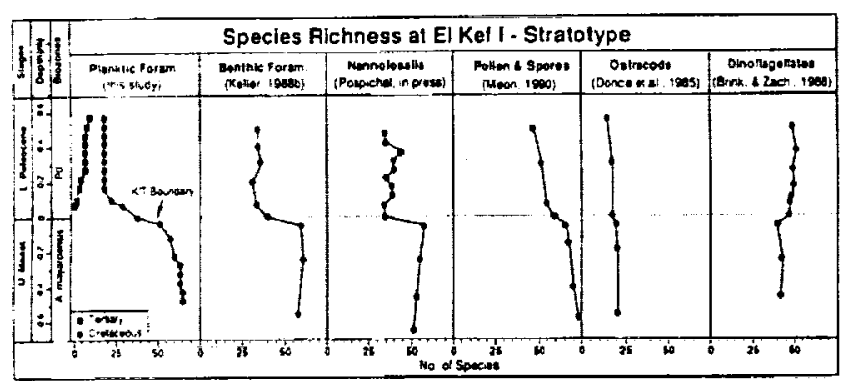

Fig. 1. Species richness pattems in six microfossil groups across the KT boundary at the El Kef KT boundary stratotype section.

the KT boundary is in surface water productivity. In low latitudes, surface water productivity dropped significantly beginning at the $\mathrm{KT}$ boundary and did not recover until about $300-500 \mathrm{k}$.y. later, whereas in high latitudes surface productivity remained nearly constant [5,11]. The cause of this high-vs. low-latitude difference in surface productivity remains an enigma.

None of the current impact, volcanism, or gradual environmental change scenarios currently proposed can explain these variable species extinction and isotope records. Any successful scenario, however, will have to account for the following low- and high-latitude differences.

Low Latitudes: (1) Mass extinctions limited to low latitudes with only tropical-subtropical rare species extinct, (2) selectivity in the extinction record within species groups (extinction of deeper dwelling plankton), (3) gradual extinction pattem beginning below and ending well above the KT boundary, (4) survivorship of cosmopolitan (generalist) taxa, (5) survivorship of surface-dwelling plankton (implies no shut-off of photosynthesis or acid rain), (6) absence of extinctions in some low-latitude faunal and floral groups, (7) negative $\delta^{13} \mathrm{C}$ shift beginning at the KT boundary and gradually declining through Zone PO $(\sim 40 \mathrm{k}, \mathrm{y}$.) (only in temporally incomplete KT sections is the $\delta^{13} \mathrm{C}$ shift sudden), (8) decreased surface productivity.

High Latitudes: (1) Absence of mass extinctions in any fossil group, microfossils, invertebrates, or vertebrates, (2) absence of $\delta^{13} \mathrm{C}$ shift, (3) stable or increased productivity.

These varied and complex extinction and survival pattems do not support a single catastrophe as the sole causal agent, but rather suggest a multicausal scenario that has yet to be defined.

References: [1] Premoli-Silva I. and McNulty C. L. (1984) DSDP, 77, 547-584. [2] Smit J. (1982) GSA Spec. Paper 190, 329352. [3] Smit J. (1990) Geol. Mijnbouw, 69, 178-204. [4] Macleod N. and Keller G. (1991) Geology, 19, 497-501. [5] Keller G. et al. (1993) GSA Bull., 105, 979-997. [6] MacLeod N. and Keller G. (1993) Paleobiology, in press. [7] MacLeod N., this volume. [8] Barrera E. and Keller G. (1990) Paleoceanography, 5, 867-890. [9] Canudo J. I. et al. (1991) Mar. Micropaleo., 17, 319-341. [10] Keller G. (1988a) Mar. Micropaleo., 13, 239-263. [11] Keller G. (1993) Mar. Micropaleo., 21, 1-45. [12] Liu C. and Olsson R. K. (1992) JGR, 4, 328-346. [13] Keller G. et al. (1993) Palaios., in press; Lopez-Oliva J. G. and Keller G., this volume. [14] Askin R. et al., this volume. [15] Zinsmeister W.J.et al., this volume. [16] Keller G. (1988b) Paleo., 3, 153-171. [17] Pospichal J. (1993) Geology, in press. [18] Donce P. et al. (1985)Acles du Premiere Congrès Nationale des Sciences de la Terre, Tunis, 161-169. [19] Méon H. (1990)Rev. Paleobotany and Palynology, 65, 85-94. [20] Brinkhuis H. and Zachariasse W. J. (1988) Mar. Micropaleo., 13, 153-191. 
THE KT BOUNDARY STRATOTYPE SECTION AT EL KEF, TUNISIA: HOW CATASTROPHIC WAS THE MASS EXTINCTION? G. Keller', L. Li', and N. MacLeod', 'Department of Geological and Geophysical Sciences, Princeton University, Princeton NJ, 08544, USA, ${ }^{2}$ Department of Paleontology, The Natural History Museum, Cromwell Road, London, SW7 5BD, UK.

The El Kef section of Tunisia was officially designated the Cretaceous-Tertiary (KT) boundary global stratotype section and point (GSSP) at the XXVIII Intemational Geological Congress in Washington in 1989. Chosen for its apparently continuous and expanded sedimentary record, excellent preservation of microfossils, and geochemical and mineralogical marker horizons, the stratotype provides an ideal sequence by which other sections can be compared and correlated worldwide. As such the El Kef stratolype has become the single most important KT boundary section and the standard by which the completeness of the faunal, floral, and sedimentary records are judged worldwide. Such a comparison was recently published by MacLeod and Keller [1] based on graphic correlation of over $30 \mathrm{KT}$ boundary sections worldwide. Results show that the El Kef section indeed represents the most expanded and stratigraphically complete KT boundary transition known to date. Similar nearly complete sections also occur at Brazos River (Texas), Agost and Caravaca (Spain), Nye Kløv (Denmark), Mimbral (Mexico), and ODP Site 738C.

Placement of the KT Boundary: The KT boundary is easily identified in the El Kef stratotype or elsewhere based on the following criteria: (1) A lithologic break from chalk or marl deposition of the Cretaceous to a thin layer of dark organic-rich and $\mathrm{CaCO}_{3}$ poor clay, known as the boundary clay. At El Kef this layer is $55 \mathrm{~cm}$ thick and represents the most expanded boundary clay observed to date in any $\mathrm{KT}$ boundary sections. More frequently, the boundary clay is only 4-6 cm thick (e.g., Agost, Caravaca, Stevns Klint, Nye Kløv, El Mimbral [3,4]). (2) A 2-3-mm oxidized red layer at the base of the boundary clay. This red layer is present at El Kef as well as in all complete KT boundary sections. (3) Maximum Ir concentrations generally concentrated in the red layer and boundary clay although they may trail several tens of centimeters above the boundary clay. At El Kef maximum Ir concentrations are found in the red layer and values decrease through the boundary clay [5]. (4) Nickel-rich spinels frequently present in the red clay or base of the boundary clay as also observed in El Kef [5]. (5) A negative $\delta^{13} \mathrm{C}$ shift in marine plankton of low and middle latitudes as also present at El Kef [6]. (6) The first appearance of Tertiary planktic foraminifera at the base or within a few centimeters of the boundary clay, red layer, Ir anomaly, and Ni-rich spinels. At El Kef, the first Tertiary species ( $G$. conusa) appears at the base of the boundary clay and three other new species appear within the basal $15 \mathrm{~cm}$ of the boundary clay $[10,17]$.

In the stratotype section at El Kef all these criteria are met and most of them are present in all the best and most complete KT boundary sequences (e.g. Agost, Caravaca, Nye Kløv, Brazos River, El Mimbral, ODP Site 738C). The coincidence of these lithological, geochemical, and paleontogical criteria is unique in the geological record and virually ensures that the stratigraphic placement of the KT boundary is uniform and coeval in marine sequences across latitudes. Any of these criteria used in isolation, however, diminish the stratigraphic resolution of the KT boundary.

Selectivity and Gradual Mass Extinction Pattern at El Kef: The El Kef stratotype has been extensively studied based on planktic foraminifera [7-10], benthic foraminifera [9], ostracods [11], nan- noplankton [12], dinoflagellates [8], palynoflora [13], isolope geochemistry [6], and Ir and $\mathrm{Ni}$-rich spinels [5]. With the exception of Smit's [7] report, none of these microfossil studies record a catastrophic mass extinction horizon at the KT boundary. Instead, some microfossil groups record gradual species extinctions across the KT boundary whereas others show no significant species extinctions. For instance, Méon [13] reports that there is "no drastic modification at the KT boundary and hence no phenomenon of catastrophic dimension." Similar observations have been made in palynofloral studies from northem and southem high latitudes [14] and from Brazos River, Texas [15]. Only in the U.S. westem interior (Raton Basin) are sharp floral changes, including a fem spore spike, observed coincident with KT boundary [16]. Dinoflagellates have long been known to have survived the KT boundary event virtually unscathed and studies at El Kef confirm this observation. Brinkhuis and Leereveld [8] report "No sharp qualitative changes in dinoflagellate cysts associations coincide with that boundary." Nannofossil diversity (Shannon-Wiener diversity index) shows a gradual decline into the earliest Teniary (Danian) with most Cretaceous species present well into the early Tertiary [12]. This record has proved difficult to interpret because nannofossils are easily reworked due to their small size and there is no unequivocal criterion that can be used to distinguish reworked from in situ specimens.

Planktic foraminifera have been considered as the microplankton group that suffered virtually total extinction due to a bolide impact at KT boundary time at El Kef and elsewhere [3,7]. This interpretation could not be supported by subsequent studies for three reasons. First, this conclusion was originally based on deep-sea sections, all of which have been subsequently shown to contain major hiatuses. MacLeod and Keller [1] demonstrated that boundary hiatuses spanning from 50 k.y. $10500 \mathrm{k}$.y. of the basal Tertiary are present in nearly all deep-sea sections deposited at depths below $1000 \mathrm{~m}$. In these sections extinctions and originations, spanning as much as 0.5 m.y. across the KT transition, are artificially concentrated at one horizon, giving the appearance of a sudden catastrophic mass extinction. In contrast, shallow continental shelf sections, such as El Kef, are generally more complete and show a more gradual transition.

Second, the presence of many Cretaceous taxa in lowermost Tertiary sediments has been routinely ignored based on the assumption that all Cretaceous species (except one) must have become extinct at the KT boundary. Their presence in Danian sediments is therefore assumed to be due to reworking. For instance, at El Kef Smit [7] reported that "The mass extinction event at the KT boundary... exterminated all but one species of the planktonic foraminifera (Guembelitria cretacea Cushman)." In contrast, Keller $[2,17]$ found that about one-third of the Cretaceous taxa are consistently present in early Tertiary sediments at El Kef and elsewhere and their presence could not be considered due to reworking, but indicated survivorship. Moreover, the simple morphology and small size of survivor taxa imply that these species were generalists able to tolerate a wide range of environmental conditions. Although Smit $[3,7]$ also observed these Cretaceous species in early Tertiary sediments at El Kef as well as Agost and Caravaca, he chose to ignore them (no indication of their presence in range charts) in the belief that they were reworked. Survivorship of cosmopolitan taxa has since been documented in KT boundary sections worldwide with isotopic measurements of shell calcite of several taxa providing unequivocal evidence of their residence in Tertiary environments [4].

Third, species extinctions are often assumed to have occurred instantaneously due to a bolide impact. Smit [7] stated that "the mass 


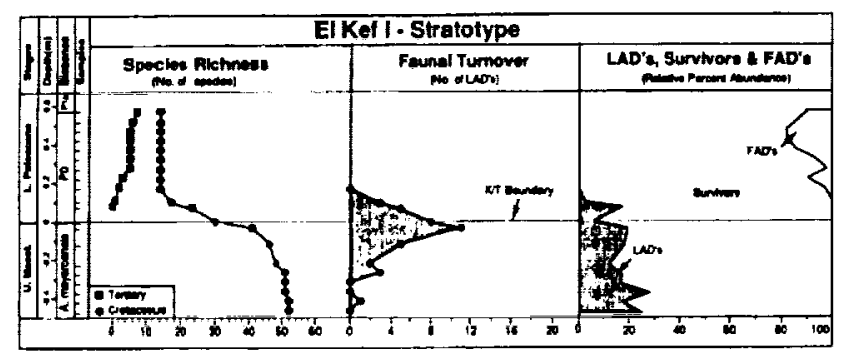

Fig. 1. Planktic foraminiferal species richness, species extinctions (last appearance datums, LADs), and the combined relative abundance of all species extinct (LADs), Cretaceous survivors, and first appearances of Tertiary species (FADs). Note that a total of $72 \%$ of all Cretaceous species disappeared across the KT boundary, but their combined relative abundance averages $<20 \%$ of the total population. In contrast, the relative abundance of Cretaceous survivors averages $>80 \%$ of the population.

extinction is inferred to have occurred within 50 years and a new stable planktonic fauna re-established within 35,000 years." Biostratigraphic data from El Kef and Agost provided by Smit $[3,7]$ in support of this interpretation show the extinction of all Cretaceous taxa (except $G$. cretacea) precisely at the KT boundary even though many of these same species are commonly present in overlying Danian sediments $[2,4,10,17]$. Moreover, Smit's El Kef study identified only about a dozen Cretaceous taxa and most of these are not identified to species level. In contrast, Keller $[2,17]$ and Liu and Olsson [18] identified 48 and 54 Cretaceous species respectively in the same samples of the same section. We have also observed that species extinctions began before the KT boundary and continued well into the Tertiary. Moreover, species extinctions appear sequential with complex, large, omate deep water dwelling forms disappearing first and smaller, less omate forms surviving longer. All deep dwelling species disappeared by KT boundary time and only surface dwellers survived into the Tertiary.

How calastrophic was the mass extinction at El Kef? The severity of a mass extinction is generally measured by the number of species extinct, giving equal weight to extinction of species that are very rare as to those that dominate the assemblage while ignoring dramatic changes in relative abundances of species that survived. A more reliable measure of the catastrophic nature of mass extinctions would include measurement of the relative abundance of species extinct and the relative abundance changes of survivors because the extinction of rare taxa may be caused by minor environmental perturbations. By using this measure, the combined relative abundances of all $72 \%$ species of planktic foraminifera extinct between $50 \mathrm{~cm}$ below 10 $10 \mathrm{~cm}$ above the KT boundary at $\mathrm{El} \mathrm{Kef}$ account for an average of less than $20 \%$ of the planktic foraminiferal population (Fig. 1). While this certainly represents a major mass extinction in low latitudes, it is not of the magnitude generally quoted. If we also consider the fact that no significant species extinctions occurred in high latitudes [4], we must seriously consider a killing mechanism that was not only selective across organismal groups and species selective within organismal groups, but also restricted to low latitudes.

References: [1] MacLeod N. and Keller G. (1991) Geology. 19, 497-501; MacLeod N. and Keller G. (1991) GSA Bull., I03, 1439-1457. [2] Keller G. (1988) Mar. Micropaleo., 13, 239-263.
[3] Smit J. (1990) Geol. Mijnbouw, 69, 187-204; Smit J. (1992) personal communication. [4] Canudo J. I. et al. (1991) Mar. Micropaleo., 17, 319-341; Keller G. (1989) Paleoceanography, 4, 287332; Keller G. (1993) Mar. Micropaleo., 21, 1-45; Keller G. et al. (1994) Palaios, in press; MacLeod N. and Keller G. (1994) Paleobiology, in press. [5] Robin E. et al. (1991) EPSL, 107, 715-721. [6] Smit J. et al. (1982) Cret. Res., 3, 307-332; Kuslys M. and Krähenbühl U. (1983) Radiochim. Acta., 34, 139-141; Keller G. and Lindinger M. (1989) Paleo., 3, 73, 243-265. [7] Smit J. (1982) GSA Spec. Paper 190, 291-296. [8] Brinkhuis H. and Leereveld H. (1988) Rev. Paleobot. Palynol., 56, 5-19; Brinkhuis H. and Zachariasse W. J. (1988) Mar. Micropaleo., J3, 153-191. [9] Keller G. (1988b) Paleo., 3, 66, 153-171; Keller G. (1992) Tokai Univ. Press, Tokyo, 77-91. [10] Ben Abdelkader O. B. (1992) Geol. Survey Tunisia, 9-10. [11] Donce P. et al. (1982) Bull. Cent., Rech, Explor. Prod, Elf-Aquirane, 6, 307-335; Peypouquet J. P. et al. (1986) Geol. Rundschan, 75/1, 159-174. [12] Perch Nielsen K. (1981) Cah. Micropaléont., 3, 7-23; Jiang and Gartner (1986) Micropaleo., 32, 232-255; Pospichal J. (1994) Geology. in press. [13] Meon H. (1990)Rev. Paleobot. Palynol., 65,85-94. [14] Sweet A. R. et al. (1992) GSA Spec. Paper 190, 457-470; Askin R. A. (1988) GSA Mem., 169, 131-156; Askin R. A. (1992) Antarct. J. U.S., 25, 42-44. [15] Beeson D. et al. (1994) Palaios, in press. [16] Tschudy R. H. et al (1984)Science, 225, 1030-1032.[17] Keller G. et al. (1994) Paleo., 3, submitted. [18] Liu C. and Oisson R. K. (1992) J. Foram. Res., 22, 328-346.

ON SOURCE AND ORIGIN OF HAITIAN KT BOUNDARY IMPACT GLASSES. C. Koeberl, Institute of Geochemistry, University of Vienna, A-1010 Vienna, Austria.

Haitian KT Boundary Glasses are not Tektites: There has been an unfortunate tendency to designate any newly discovered glass that is suspected to be of impact origin as a tektite, or glassy spherule as microtektite, even if these glasses do not fulfill several of the criteria that designate tektites [e.g., 1]. The "definition" of a tektite has a somewhat historic aspect; there are obvious differences between normal impact glasses and tektites [see, e.g., 1]. Tektites are of course impact glasses, but the reverse is not true: Not all impact glasses are tektites.

Glasses found in Haiti that have been shown to be associated with the KT boundary are among the glasses that have been termed "tektites." These glasses are, beyond doubt, of impact origin. However, considering the size of the $\approx 300-\mathrm{km}$-diameter Chicxulub structure, and the distance of Haiti at the time of the impact, these glasses have been deposited at only about 1-2 crater diameters' distance from the crater-much closer to the source crater than any splash-form tektites. A number of arguments have been cited that indicate that tektites are shock melts of surface rocks (e.g., the high contents of ${ }^{1 /} \mathrm{Be}$ coupled with very low ${ }^{26} \mathrm{Al}$ abundances in tektites are evidence for a derivation of tektites from terrestrial surface rocks, and preclude an origin from greater depth in the crater).

Blum et al. [2] have shown that the Haitian glasses have isotopic characteristics that are indistinguishable from those of impact melt rock from the Chicxulub Crater. The Haitian glasses have therefore originated from much deeper in the crater, analogous to some other impact glasses (e.g., at the Ries Crater), and not from the surface as tektites. The descriptive term "impact glasses" should thus be used 
for these glasses and the term "tektites" reserved for those glasses that fall in the proper definition of tektites.

Evaporite was not Involved in Making Yellow Haitian Glasses: Sigurdsson et al. [3-5] suggested that the rare yellow Haiti glasses formed by mixing carbonates and evaporites with rocks of andesitic composition. No andesites have been recovered so far from the Chicxulub Crater, as rocks initially thought to be andesites seem to be impact melts. The black Haiti glasses seem to be representative of the target rock composition and are thus used for comparison. Blum and Chamberlain [6] and Koeberl [7] have presented data that are not in agreement with a major evaporite component in the yellow glasses. An argument for the incorporation of evaporites is the high $\mathrm{Ca}$ and $\mathrm{S}$ content of the yellow glasses; however, no mixture between evaporites from Chicxulub and black glass that yields a good fit for $\mathrm{Ca}$ gives values for $\mathrm{S}$ and most other elements that are similar to those of the yellow glasses [7].

Some mixing studies have been performed for evaporites and pure anhydrite from the Chicxulub Crater ([7] and Koeberl, unpublished data). Resulting discrepancies are illustrated by the REE patterns shown in Fig. 1, and by the comparison of trace-element abundances between mixtures of evaporites and anhydrites with a target rock composition and yellow glasses (Fig. 2). The REE pattern for average yellow glass is very similar to and only slightly lower than that for average black glass [8], while the pattem for evaporitic rocks from Chicxulub is very different [7]. Thus, a mixture of a rock with a composition similar to the black glass with a significant amount of evaporites, as proposed by Sigurdsson et al. [3-5], yields REE patterns that are different from, as well as REE abundances that are far lower than, those of the yellow glasses. In addition, other trace elements show no consistent pattern at all. Evaporites did not contribute significantly to the chemical composition of the yellow glasses.

The $B$ isotope ratio provides another argument against a large evaporite component in yellow glass. The $\delta^{\prime \prime} \mathrm{B}$ of the yellow Haiti glass is $-2.1 \%$ [4], compatible with normal terrestrial sediments (e.g., shales). However, evaporitic rocks (elsewhere) are known to have very high $\delta^{11} \mathrm{~B}$ values $(20-60 \%$ ) because of the seawater signature [e.g., 9]. The B isotopic composition of the yellow glasses is thus not consistent with an evaporitic source.

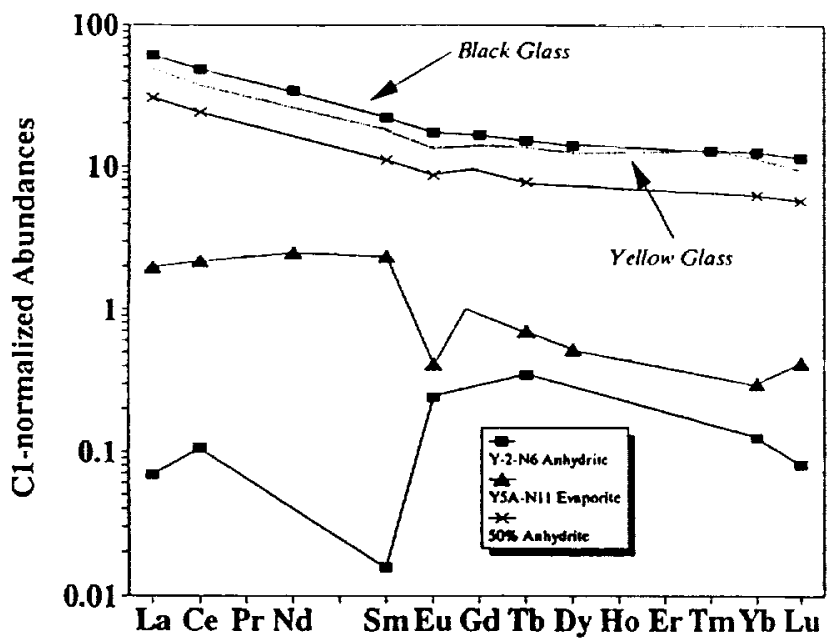

Fig. 1. REE patterns of Haitian black and yellow impact glass [8], evaporite [7], and anhydrite (this work) from Chicxulub, and resulting mixture.

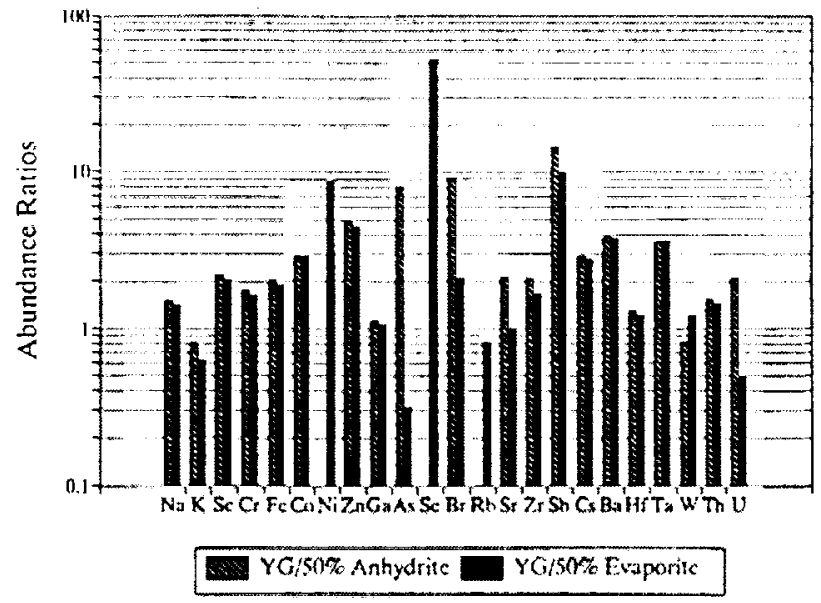

Fig. 2. Comparison of the composition of yellow impact glass from Haiti with that of mixtures between evaporite or pure anhydrite from Chicxulub with "average" target composition as shown by the composition of black Haitian impact glass.

Trace-element data, $\mathrm{O}$ and $\mathrm{Sr}$ isotopic composition [6], and $\mathrm{B}$ isotopic composition [4] all argue against a major anhydrite component in the yellow impact glasses from Haiti. This is in agreement with observations of Chen and Ahrens [10], who found that anhydrite devolatilizes much less than carbonate. The $\mathrm{Ca}$ and $\mathrm{S}$ abundances in the yellow glasses can be explained consistently by admixture of limestone and sandstone, instead of anhydrite.

Acknowledgments: This contribution was supported by the Austrian FWF, Project P8794-GEO.

References: [1] Koeberl C. (1994) in Large Meteorite Impacts and Planetary Evolution (B. O. Dressler et al. eds.), GSA Spec. Paper, in press. [2] Blum J. D. et al. (1993) Nature, 364, 325-327. [3] Sigurdsson H. et al. (1991) Nalure, 349,482-487. [4] Si-gurdsson H. et al. (1991) Nature, 353,839-842. [5] Sigurdsson H. et al. (1992) EPSL, 109, 543-559. [6] Blum J. D. and Chamberlain C. P. (1992) Science, 257, 1104-1 107. [7] Koeberl C. (1993) Geology, 21, 211214. [8] KoeberlC. and Sigurdsson H. (1992) GCA, 56, 2113-2129. [9] Vengosh A.et al. (1992)Geology, 20,799-802. [10] Chen G. and Ahrens T. J. (1993) LPS XXIV, 273-274.

Re-OS ISOTOPE SYSTEMATICS AS A DIAGNOSTIC TOOL IN THE STUDY OF IMPACT CRATERS. C. Koeberl', S. B. Shirey ${ }^{2}$, and W. U. Reimold ${ }^{3}$, 'Institute of Geochemistry, University of Vienna, A-1010 Vienna, Austria, '2Department of Terrestrial Magnetism, Camegie Institution, 5241 Broad Branch Road, N.W., Washington DC 20015, USA, 'Economic Geology Research Unit, Department of Geology, University of the Witwatersrand, Johannesburg 2050, South Africa.

Basics of Re-Os Isotopes for Impact Studies: The Re-Os isotopic system is based on the $\beta$ decay of ${ }^{1 k 7} \mathrm{Re}$ to ${ }^{187} \mathrm{Os}$ (half-life = $42.3 \pm 1.3 \mathrm{Ga}$ ). Rhenium and $\mathrm{Os}$ behave differently during partial melting of mantle rocks. Osmium is highly compatible and remains in the residue, but $\operatorname{Re}$ is moderately incompatible and is therefore enriched in the melt. Crustal rocks therefore have high $\mathrm{Re}$, but low 
Os concentrations. As a result of the high Re concentrations, the abundance of ${ }^{187}$ Os in crustal rocks increases significantly with time. The growth of ${ }^{187} \mathrm{Os}$ from the decay of ${ }^{187} \mathrm{Re}$ can be described by nomalizing to an nonradiogenic Os isotope

$$
{ }^{187} \mathrm{Os} /{ }^{18 \mathrm{R}} \mathrm{Os}=\left({ }^{187} \mathrm{Os} /{ }^{18 \times} \mathrm{Os}\right)_{\mathrm{i}}+{ }^{187} \operatorname{Re} /{ }^{188} \mathrm{Os}\left(\mathrm{e}^{\lambda i_{-}}\right)
$$

Present-day mantle has a low ${ }^{187} \mathrm{Os} / 18 \times$ Os ratio of about 0.13 , and meteorites also have low ${ }^{187} \mathrm{Os} /{ }^{188} \mathrm{Os}$ ratios of about $0.11-0.18$ $\left({ }^{187} \mathrm{Os} /{ }^{186} \mathrm{Os}=0.95-1.5\right)[1-3]$. Because in meteorites (and in the mantle) Os is much more abundant than $\mathrm{Re}$, the ${ }^{187} \mathrm{Os} / 188 \mathrm{Os}$ ratio changes only very slowly with time. However, the crustal ${ }^{187} \mathrm{Os} /$ ${ }^{188} \mathrm{OS}$ ratio increases rapidly with time because $\mathrm{Re}$ abundances are several orders of magnitude higher than Os abundances. Isotopic ratios of crustal rocks depend on age and elemental abundances. ${ }^{187} \mathrm{Os} /{ }^{18 x} \mathrm{Os}$ ratios of about $0.67-1.61$ (with an average of about 1.2) are thought to be representative of currently eroding upper continental crust $[4,5]$.

The fact that the absolute abundances of $O$ s as well as the ${ }^{187} \mathrm{Re} /$ ${ }^{188} \mathrm{Os}$ and ${ }^{187} \mathrm{Os} /{ }^{188} \mathrm{Os}$ ratios in meteorites are distinctly different from those in old crustal target rocks is of potential use for the study of impact craters. Impact melts, glasses, or breccias consist usually of predominantly terrestrial target rocks, mixed with usually a very small $(<1 \%)$ meteoritic component. However, the difference in $a b$ solute Os abundances between meteorites and crustal target rocks favors detection of small amounts of a meteoritic component. This concept has been proposed by Turekian [6] for distinguishing between a cosmic and a terrestrial component in KT boundary clays. Despite the potential importance of such studies, a surprisingly small number of studies has followed [7-12], probably in part because of analytical difficulties. The first application of the Os isotopic system to impact craters was attempted by [13], who used AMS and found evidence for a meteoritic component in melt rocks from the East Clearwater Crater. Their method, however, did not allow the measurement of all relevant $O$ s isotopes (or $\mathrm{Re}$ ), required large amounts of sample, and yielded relatively low precision.

Wider application for impact crater studies was made possible by the recent development of the negative thermal ionization technique [e.g., 14]. This method allows the determination of abundances and isotopic ratios of Os and $\operatorname{Re}$ at the low abundance levels found in target rocks and in impact-derived rocks while using relatively small amounts of material. Limited sample quantity is a factor for many impact glasses or impact melt rocks. The feasibility of the method was recently show in studies of material from various impact craters, as summarized below.

Examples from Different Craters: Kalkkop Crater, South Africa. The Kalkkop Crater is a recently identified 640 - $\mathrm{m}$-diameter impact crater [15]. A drill core became available in late 1992, yielding breccia and target rock samples. We measured abundances and isotopic compositions of $\mathrm{Re}$ and $\mathrm{Os}$ in two target rock samples (sandstone and shale) as well as in four suevite breccia samples ([22], Table 1). Osmium abundances and isotopic ratios in the tar-get rocks are typical for old continental crust. Two of the suevite samples have Os contents about $10 \times$ higher than values obtained for the target rocks. These samples show low ${ }^{187} \mathrm{Os} /{ }^{188} \mathrm{Os}$ ratios of 0.215 and 0.333 respectively. Such values are distinctly different from the target rock ratios and incompatible with old continental crustal values. The elevated Os content together with the near-meteoritic ${ }_{187} \mathrm{Os} /{ }^{18 k} \mathrm{Os}$ ratio demonstrate that the suevite contains about up to $0.05 \%$ of an extraterrestrial component. Figure 1 shows the mixing relationship between target rocks and a meteoritic component.

Saltpan Crater, South Africa. The Saltpan Crater is a $220,000-$ yr-old, $1.13-\mathrm{km}$-diameter impact crater that was formed in $2.05-\mathrm{Ga}$ granites from the Bushveld Complex. The crater was drilled in 1988/ 1989 to a depth of $200 \mathrm{~m}$, revealing the existence of a suevitic breccia with evidence for shock metamorphism [16]. The Re-Os isotope characteristics of basement granites and suevitic breccias from the Saltpan Crater were measured ([17], Table 1). The granitic target rocks have Os abundances of about $7.0 \mathrm{ppt}$ and a high ${ }^{187} \mathrm{Os} \mathrm{s}^{18 x} \mathrm{Os}$ ratio of 0.713 . The breccias have $10 \times$ higher Os abundances and lower ${ }^{167} \mathrm{Os} /{ }^{1 \times 8} \mathrm{Os}$ ratios of about 0.205 . The composition of the breccias is consistent with derivation by mixing of a meteoritic component with basement granites. Correction for indigenous concentrations yields about 72 ppt Os, corresponding to about $0.015 \%$ of a chondritic component in the bulk breccia.

Bosumwi Crater, Ghana. This II-km-diameter, I. I-Ma-oldcrater is exposed in $\sim 2$-Ga-old ( $\mathrm{Sm}-\mathrm{Nd}$ ) metasediments, and is the most likely source crater for the Ivory Coast tektites, which are of the same

TABLE 1. Re-Os isotopic data for impact breccias, melts, glasses, and target rocks.

\begin{tabular}{|c|c|c|c|c|c|}
\hline & Os (ppb) & $\operatorname{Re}(p p b)$ & ${ }^{1} \mathrm{Os}(\%)$ & ${ }^{1 \times 7} \mathrm{Os} /{ }^{14 x} \mathrm{Os}$ & ${ }^{1 \mathrm{k} / \mathrm{Re}} /{ }^{\prime k *} \mathrm{Os}$ \\
\hline \multicolumn{6}{|l|}{ Kalkkop Crater, South Africa } \\
\hline Suevitic breccia & 0.189 & 0.062 & 2.82 & 0.215 & 1.613 \\
\hline Target sandstone & 0.019 & 0.033 & 11.0 & 0.920 & 8.939 \\
\hline Target shale & 0.021 & 0.053 & 7.64 & 0.613 & 12.77 \\
\hline \multicolumn{6}{|l|}{ Salipan Crater, South Africa } \\
\hline Suevitic breccia (average) & 0.078 & 0.140 & 2.7 & 0.205 & 8.94 \\
\hline Target granite & 0.0070 & 0.054 & 8.73 & 0.713 & 44.91 \\
\hline \multicolumn{6}{|l|}{ Bosumtwi Crater, Ghana } \\
\hline Ivory Coast tektite (2069) & 0.129 & 0.0155 & 2,0 & 0.153 & 0.584 \\
\hline Impact glass (BI 9201) & 0.125 & 0.0727 & 10.8 & 0.901 & 3.099 \\
\hline Target rocks & $0.021-0.327$ & $0.015-0.218$ & $16.7-40.2$ & $1.48-4.98$ & $1.10-30.2$ \\
\hline \multicolumn{6}{|l|}{ Chicxulub Crater, Mexico } \\
\hline Impact melt rock $(\mathrm{Cl}-\mathrm{N} \mid 0)$ & 25.2 & 1.599 & 1.5 & 0.113 & 0.305 \\
\hline Melt rock (background) & 0.056 & 0.952 & 6.3 & 0.505 & 87.71 \\
\hline
\end{tabular}




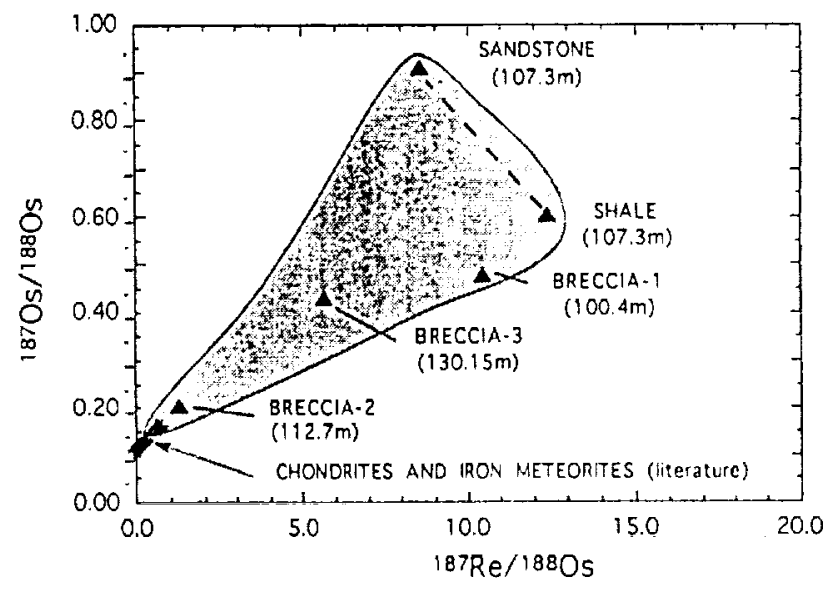

Fig. 1. Re-Os isolope diagram for rocks from the Kalkkop crater, showing that the breccias plot into a mixing field defined by meteoritic and target rock compositions (after [22]).

age and have appropriate chemical and isotopic characteristics. The Re-Os isotopic characteristics of tektites, impact glasses, and target rocks were studied [18]. The tektites have isotopic characteristics very similar to meteorites, while the target rocks show typical crustal values. A meteoritic component of up to $0.6 \%$ was calculated for tektites [18].

Chicxulub Crater, Mexico. This $>200-\mathrm{km}$-diameter multiring impact structure is the best candidate for the KT boundary impact crater [19]. Crystalline impact melt rocks and breccias have been recovered from drill cores within the crater. A melt rock contained $25.2 \mathrm{ppb}$ Os, and very low ${ }^{1{ }^{17}} \mathrm{Os} /{ }^{18 R} \mathrm{Os}$ and ${ }^{187} \mathrm{Re} /{ }^{188} \mathrm{Os}$ ratios, which are inconsistent with those of old continental crust [23]. Another melt rock has only $0.056 \mathrm{ppb}$ Os and high ratios, similar to continental crustal values. The terrestrial mantle is an unlikely source for abundance and isotopic signature of Os in the Chicxulub melt rock, which has all chemical and isotopic characteristics of a continental crustal rock [23]. An extraterrestrial source is the most likely explanation for the observed values. We estimate a maximum of $3 \%$ chondritic contribution, which is within the range of meteoritic components reported for large craters [20].

We also measured Re-Os isotopic characteristics of Haitian KT boundary impact glass, which is indistinguishable from Chicxulub melt rock in $\mathrm{Rb}-\mathrm{Sr}$ and $\mathrm{Sm}-\mathrm{Nd}$ isotopic characteristics [21]. The glass contains $0.095 \mathrm{ppb} \mathrm{Os}$, and has a ${ }^{187} \mathrm{Os} /{ }^{188} \mathrm{Os}$ ratio of 0.251 , which is lower than the average crustal ratio and indicates contamination with meteoritic material (CCC).

Work in Progress: Materials from a number of other structures are currently being studied. Preliminary results show the existence of meteoritic components for the Manson, Gardnos, Aouelloul, and Vredefort structures.

Re-Os Isotopes asan Impact-Diagnostic Criterion: The study of the Re-Os isotope characteristics is of considerable importance for the investigation of impact structures. It allows the determination and quantification of a meteoritic component in impact-derived materials (in comparison to target rocks) and may help to understand the mixing between the bolide and target rocks. Furthermore, such studies allow the confirmation of an impact origin for doubtful structures. If properly applied, Os isotopes may be almost as diagnos- tic a tool for the establishment of an impact origin as shock metamorphism.

Acknowledgments: Supported by the Austrian FWF, Project P9026-GEO (to C.K.) and NSF, Project EAR-9218847 (to S.B.S).

References: [1] Walker R. J. and Morgan J. W. (1989)Science, 243, 519-522. [2] Morgan J. W. et al. (1992) EPSL, 108, 191-202. [3] Horan M. F. et al. (1992) Science, 255, 1118-1121. [4] Esser B. K. (1991) Ph.D. thesis, Yale. [5] Esser B. K. and Turekian K. K. (1993) GCA, 57, 3093-3104. [6] Turekian K. K. (1982) GSA Spec. Paper 190, 243-249. [7] Luck J. M. and Turekian K. K. (1983) Science, 222, 613-615. [8] Lichte F. E. et al. (1986) Nature, 322, 816-817. [9] Krähenbühl U. et al. (1988) Meteoritics, 23, 282. [10] Esser B. K. and Turekian K. K. (1989)Eos, 70, 717. [11] Schmitt R. A. (1990) LPS XXI, 1085-1086. [12] Meisel T. et al. (1993) Meteoritics, 28, 396-397. [13] Fehn U. et al. (1986) Nalure, 323, 707-710. [14] Creaser R. A. et al. (1991) GCA, 55,397-401. [15] Reimold W. U.et al. (1993) LPSXXN, 1197-1198. [16] ReimoldW. U. et al. (1992) Geology, 20, 1079-1082. [17] Koeberl C. et al. (1993) $G C A$, in press. [18] Koeberl C. and Shirey S. B. (1993) Science, 26], 595-598. [19] Sharpton V. L. et al. (1993) Science, 261. [20] Palme H. (1982) GSA Spec. Paper 190, 223-233. [21] Blum J. D. et al. (1993) Nature, 364, 325-327. [22] Koeberl C. et al. (1993) GCA, in press. [23] Koeberl C. et al. (1993) GCA, in press.

CHARACTERIZATION OF ORGANIC MATERIAL IN KT BOUNDARY STRATA, ARROYO EL MIMBRAL, MEXICO. M. A. Kruge', J. C. Crelling', A. Montanari2, B. A. Stankiewicz', and D. F. Bensley' ' 'Department of Geology, Southem Illinois University, Carbondale IL 62901, USA, 2Osservatorio Geologico di Coldigioco, 62020 Frontale di Apiro (MC), Italy.

If the Cretaceous Period closed with a bolide impact [1], evidence of the resulting catastrophic effect on standing terrestrial vegetation should be detectable in the sedimentary record. Around $25 \%$ of terrestrial biomass was consumed in the conflagration, according to a recent estimate [2], and indeed soot has been detected at KT boundary sites throughout the world $[3,4]$. With the Chicxulub site in northem Yucatan now recognized as the likely point of impact $[5,6]$ and the discovery of megawave deposits in the vicinity [7-9], the search for evidence of the impact aftermath in organic sediments can be intensified. One site in particular (Arroyo el Mimbral, Taumalipas, Mexico) is of special interest, as its KT sequence contains apparent megascopic plant remains [10]. The Mimbral KT deposit consists of $3 \mathrm{~m}$ of coarse clastics, interrupting a pelagic marl sequence [10]. Organic material $(\mathrm{OM})$ was isolated by acid digestion (HCl/HF) and floatation from 6 Mimbral samples. While most samples yielded only traces of $\mathrm{OM}$, one sample contained $0.2 \%$ by weight, which was sufficient for organic petrologic and geochemical analyses.

Petrographic examination in reflected white light revealed an unusual organic assemblage containing $90 \%$ inertinite (fossil charcoal). The inertinite particles are large, approaching a millimeter in size in some cases, and show extraordinary preservation of fine botanical detail. The remaining $10 \%$ is vitrinite (diagenetically altered, but uncharred terrestrial plant remains). Flash pyrolysis-gas chromatography/mass spectrometry of the $O M$ concentrate indicates a predominance of polyaromatic structures, often unmethylated. These chemical features are indicative of severe ther- 
mal alteration due to partial combustion and therefore consistent with the petrographic recognition of fossil charcoal.

While most sedimentary $O M$ assemblages contain a few percent of inertinite, it is most unusual to see inertinite as the predominant component. It is even more unusual to find such an occurrence within a pelagic sequence, as inertinite originates from charring of land plant material. (Instead, fossil marine algal or bacterial remains would be expected.) Thus the inertinite is "out of place," as are the coarse clastic sediments. A case can be made for the transport of the clastics by a tsunami of large magnitude, perhaps seismically induced. However, when the additional evidence of the fossil charcoal (and the paucity of noncharred plant remains) is considered, then a coincident firestorm must also be evoked. A nearby bolide impact would provide the mechanism to explain the origin of the Mimbral deposit.

References: [1] Alvarez L. W. et al. (1980) Science, 208, 1095-1108. [2] Ivany L. C. and Salawitch R. J. (1993) Geology, 21, 487-490. [3] Wolbach W. S. et al. (1990) GSA Spec. Paper 247, 391-400. [4] Venkatesan M. I. and Dahl J. (1989) Nature, 338, 57 60. [5] Pope K. O. et al. (1991) Nature, 35I, 105. [6] Hildebrand A. R. et al. (1991) Geology, 19, 867-871. [7] Bourgeois J. et al. (1988) Science, 241, 567-570. [8] Hildebrand A. R. and Boynton W. V. (1990) Science, 248, 843-846. [9] Alvarez W, et al. (1992) Geology, 20, 697-700. [10] Smit J. et al. (1992) Geology, 20, 99-103.

THE KT BOUNDARY ONTHE PACIFICPLATE. F.T.Kyte, J. A. Bostwick, and L. Zhou, Institute of Geophysics and Planetary Physics, University of California, Los Angeles CA 90024, USA.

We will review our results to date on the geochemistry and impact mineralogy of the KT boundary on the Pacific Plate. Over the past several years we have been relatively successful at locating the KT boundary at Pacific sites. In addition to the two KT boundaries in calcareous sequences at DSDP Sites 465 and 577 , the boundary is now confirmed in three pelagic clay cores-LL44-GPC3, DSDP 576, and DSDP 596-and in the relatively barren boundary sequence at ODP Site 803 . At each locality the KT boundary is characterized by an Ir anomaly, spherules, and shocked quartz. We have extracted and analyzed magnesioferrite spinel from each site except DSDP 465.

These six sites encompass a region of $20 \times 10^{6} \mathrm{~km}^{2}$ ( $4 \%$ of the Earth's surface), but they must be used as representative of a region at least five times larger. The pre-Cenozoic portion of the Pacific Plate was situated generally southwest of the Yucatan Peninsula at $65 \mathrm{Ma}$ and these sites were $\sim 6500$ (GPC3) to $\sim 10,000 \mathrm{~km}$ (DSDP 596) distant from the Chicxulub impact structure. Of the six sites, all except DSDP 465 are bioturbated and sediments from this site were severely disturbed by drilling. Thus it is nearly impossible to perform detailed analyses of fine-scale stratigraphic units in this portion of the world.

In DSDP Hole $465 \mathrm{~A}$ we were fortunate to recover a clast containing $1.3 \mathrm{~cm}$ of stratigraphy including the KT boundary. In this sample, a distinct boundary clay $\sim 2-3 \mathrm{~mm}$ thick was recovered. Detailed geochemical analyses were performed on four layers from this clast in conjunction with leaching experiments and isotopic analyses [1]. Siderophile-element abundances are quite variable across the clast (e.g., Ir/Au varies by a factor of 65). However, as at other sites [2], integration of the samples results in siderophile element abundances approaching chondritic values with element/Ir ratios for $\mathrm{Ni}$, $\mathrm{Pd}, \mathrm{Os}, \mathrm{Pt}$, and $\mathrm{Au}$ within a factor of 2 of chondritic ratios. These data are consistent with a chondritic source for the siderophiles, but require fractionation by impact or terrestrial processes, such as diagenetic mobilization.

The KT boundary at each site is characterized by a large Ir anomaly. Iridium fluences range from $61 \mathrm{ng} \mathrm{cm}^{-2}$ in DSDP Hole 577B [3] to $320 \mathrm{ng} \mathrm{cm}^{-2}$ in DSDP Hole 596 [4]. At each of the three pelagic clay sites (GPC3, 576, and 596) Ir concentrations have been measured across the entire Cenozoic. These Ir profiles are sufficient to rule out the existence of global Ir anomalies comparable to the KT signal at any time since $65 \mathrm{Ma}$. These data confirm earlier results [5] and cast serious doubt on hypotheses of periodic comet showers as a cause of mass extinctions.

These sediments are particularly amenable to trace-mineral analyses. Sediment samples (typically $0.5 \mathrm{~g}$ ) are disaggregated and dispersed, the fine-fraction pipetted off, and biogenic and hydrogenous components dissolved by sequential leaching. This procedure should quantitatively retain trace-mineral fractions $>30 \mu \mathrm{m}$ in size. Residues typically consist principally of quarz and magnesioferrite spinel. Quartz is defined as shocked if planar deformation features (PDF) are observed during SEM analyses. Approximately $40 \%$ of the quartz grains do not have PDF, but these are also apparently derived from

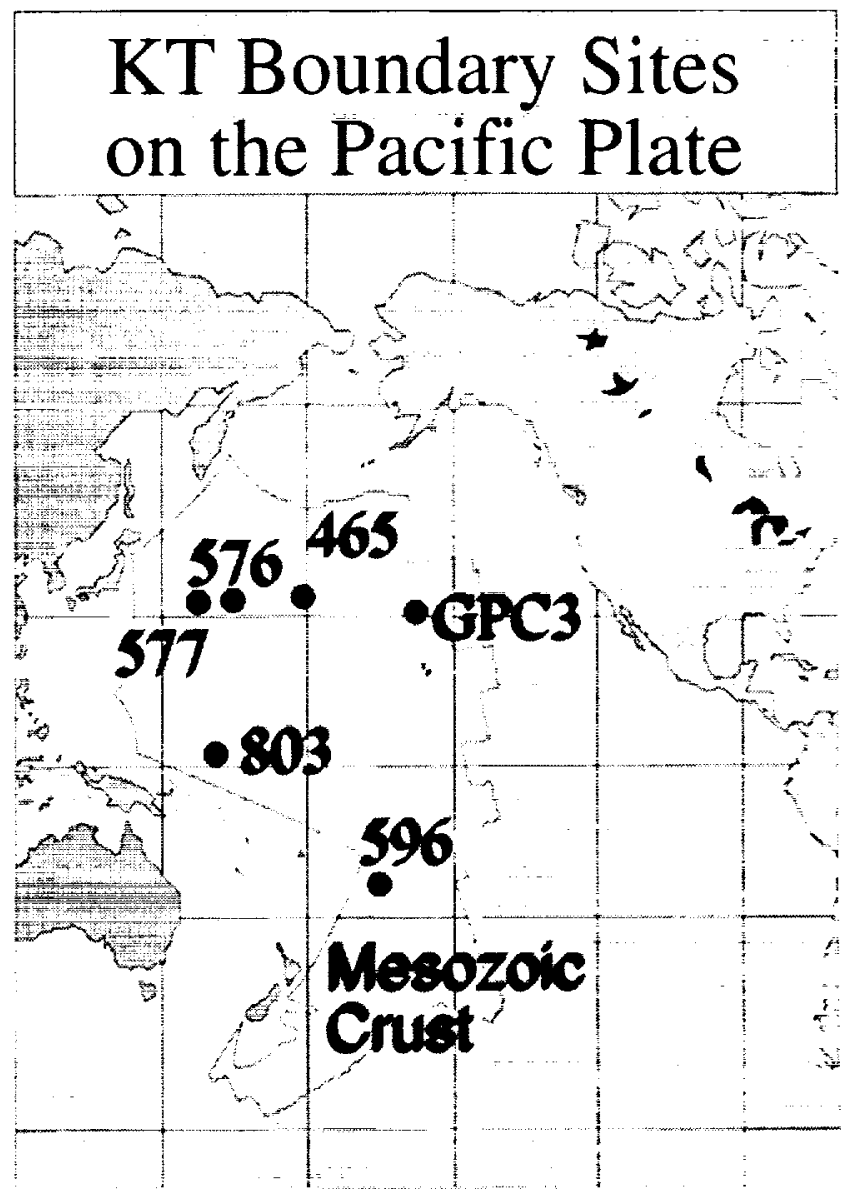

Fig. 1. 


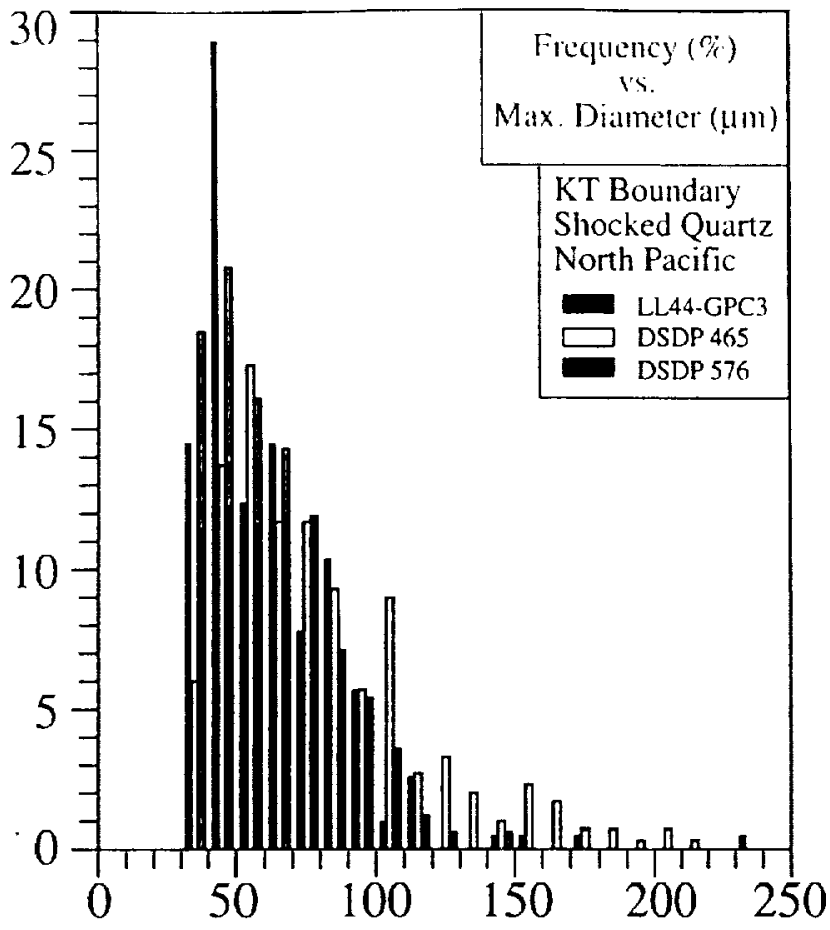

Fig. 2.

the KT impact event. Large grains of unshocked and shocked quartz from DSDP 596 [4] and DSDP 576 [6] are restricted to the Ifenriched interval. Terrigenous eolian components apparently do not contribute to the $>30-\mu \mathrm{m}$ fraction at these deep-sea sites.

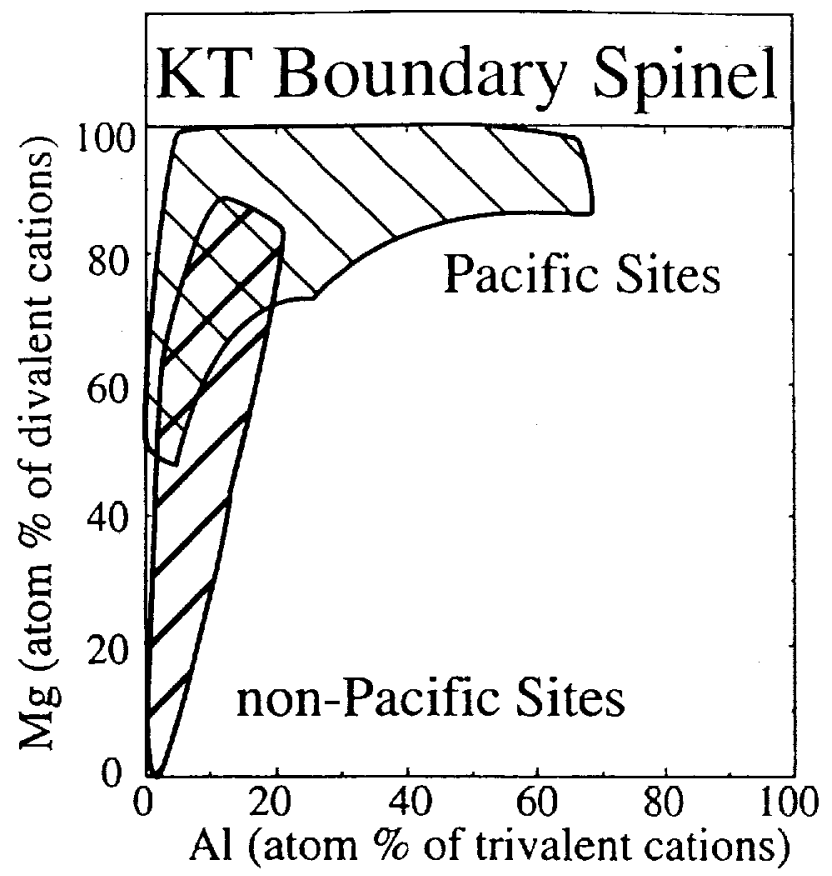

The largest shocked quartz grain recovered was from GPC 3 with a maximum diameter of $230 \mu \mathrm{m}$. We assume that larger grains have been deposited on the Pacific Plate, but our ability to define a maximum size is inhibited by small sediment sample sizes. Size distributions of shocked quartz at three North Pacific sites are similar, with mean maximum diameters of 58,61 , and $76 \mu \mathrm{m}$ (for the $>30-\mu \mathrm{m}$ fraction) at DSDP 576, GPC3, and DSDP 465 respectively. This is considerably less than the mean maximum diameters (typically $\sim 200 \mu \mathrm{m}$ ) reported for North American sites [7], but consistent with the $\sim 70 \mu \mathrm{m}$ reported for DSDP 596 [4]. We estimate a total fluence of 1200 grains $\mathrm{cm}^{-2}$ of shocked quartz $>30 \mu \mathrm{m}$ at DSDP 576, comparable to the 1800 grains $\mathrm{cm}^{-2}$ at South Pacific DSDP site 596. Our data are not yet sufficient to quantify the fluence of grains at other sites, but we expect similar results.

Electron microprobe analyses of magnesioferrite spinel confirm previous results that indicated regional variations in KT boundary spinel compositions [8]. Our extensive data (349-point analyses) from all Pacific sites except DSDP 465 show that spinel on the Pacific Plate is compositionally distinct from non-Pacific sites (Furlo, 127 points; Caravaca, 19 points; DSDP 524, 7 points; ODP 761,13 points). The most striking differences are higher ratios of $\mathrm{Fe}_{2} \mathrm{O}_{3} / \mathrm{FeO}$ and $\mathrm{Al}_{2} \mathrm{O}_{3} / \mathrm{Fe}_{2} \mathrm{O}_{3}$ at the Pacific sites with the most extreme values observed at northwestern DSDP sites 576 and 577. These data indicate a clear compositional asymmetry of KT impact debris relative to the proposed impact site in the Yucatan. Models to explain these variations could include asymmetric ejection from Chicxulub resulting from processes such as low-angle impact or heterogeneous target materials, or heterogeneous accretion of multiple projectiles $[9,10]$. The compositions of Pacific spinel indicate crystallization at high $\mathbf{O}$ fugacities and high temperatures. We suspect that these compositions, in part, reflect chemical fractionation during vapor condensation.

Mineral and chemical data from the KT boundary on the Pacific Plate must be accounted for by models that are used to explain KT boundary phenomena. Key constraints imposed by data from this and earlier studies include ( 1 ) significant amounts of shocked debris and spherules thousands of kilometers from any continental source, (2) chemical asymmetry of high-temperature mineral phases, and (3) absence of global Ir anomalies during the Cenozoic. The Mesozoic portion of the Pacific Plate is now only a small remnant of a vast region of the Earth's surface, most of which was lost by subduction. However, the KT boundary appears to be very well preserved over most of the plate, commonly buried by only $20-60 \mathrm{~m}$ of clay, and readily accessible by ocean-drilling or long-piston coring.

Acknowledgments: Supported by NSF EAR-9118701.

References: [1] DePaolo D. J. and Kyte F. T. (1984) LPS XV. 220-221. [2] Kyte F. T, et al. (1985) EPSL, 73, 183-195. [3] Michel H. V. et al. (1985) Init. Rept. DSDP, 86, 533-538. [4] Zhou L. et al. (1991) Geology, 19, 694-697. [5] Kyte F. T. and Wasson J. T. (1986) Science, 232, 1225-1229. [6] Bostwick J. A. and Kyte F. T. (1993) LPS XXIV, 157-158. [7] Izett G. A. (1990) GSA Spec. Paper 249, 100. [8] Kyte F. T. and Smit J. (1986) Geology, 14. 485-487. [9] Kyte F. T. et al. (1980) Nature, 288, 651-656. [10] Robin E. et al. (1993) Nature, 363, 615-617.

Fig. 3. 


\begin{abstract}
A SHORT NORMAL MAGNETIC INTERVAL AT THE KT BOUNDARY: A MEASURE OF CONTINUITY OF RECORD ACROSS THE BOUNDARY AND SYNCHRONEITY OF BOUNDARY EVENTS. J. F. Lerbekmo' and A. R. Sweet ${ }^{2}$, 1 University of Alberta, Edmonton AB T6G 2E3, Canada, ${ }^{2}$ Geological Survey of Canada, Calgary AB T2L 2A7, Canada.
\end{abstract}

Intensive detailed study of the KT boundary interval during the last decade or so has led to stratigraphic arguments over extinctions and catastrophic events that hinge on exceptionally fine-tuned chronostratigraphy. The science progressed rapidly from determining that the KT boundary occurred in the upper half of chron $29 \mathrm{r}$ to recognizing that a global Ir anomaly associated with shocked quartz. probably represents the time of impact of a large extraterrestrial body. Such an impact could be expected to be responsible for some or all of the multiple widespread extinctions that collectively had come to be recognized as the end of the Mesozoic Era. The Ir anomaly has provided a stratigraphic pinpoint against which to measure the synchroneity of the extinctions. Paleontologists have since argued that some of these extinctions occurred before the Ir event, some considerably later, and some extinctions that appear to be synchronous with the Ir horizon are only apparently so because of a hiatus at the boundary $[1,2]$. Therefore an independent method of measuring sedimentary continuity across the border is required in order to assess the presence or absence of a recognizable hiatus. Magnetostratigraphy might provide such information if there were a short-term magnetic event associated with the boundary interval.

Detailed magnetic sampling across the KT boundary in eight continental sections from the Red Deer Valley in central Alberta southeastward through Saskatchewan to the Hell Creek area of northeastern Montana indicates that the KT boundary occurs within a shor normal polarity interval within reversed magnetozone $29 r$. The KT boundary in these sections is defined by polynomorph extinctions and an Ir anomaly. The boundary clay is also present in four of the sections and occurs locally nearby in the other four. Choice of section was based largely upon character of the outcrop and type of lithology, sandstones being avoided as much as possible. Samples were collected at stratigraphic intervals of $0.1-0.3 \mathrm{~m}$ near the boundary where lithology permitted. Samples were obtained by driving an oriented 1 in-diameter core barrel into the rock and ex-truding the core into a vial of the same diameter [3]. Magnetic measurements were made on a Molspin magnetometer after AF and thermal demagnetization.

The base of the normal polarity interval occurs from $0.7-1.4 \mathrm{~m}$ below the KT boundary (mean $=1.1 \mathrm{~m}, \mathrm{n}=7$ ) and extends to 0.8 to $1.3 \mathrm{~m}$ above (mean $=1.1, \mathrm{n}=5$ ) (sections with sandstones in the boundary interval have not been included). Four sections are illustrated in Fig. 1 . The length of time represented by this normal polarity interval can be estimated from its proportion of magnetozone (a) R.V.

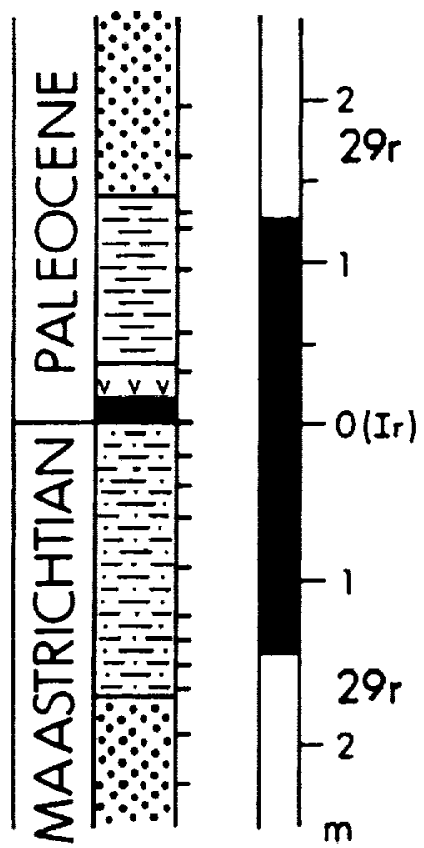

F. R.

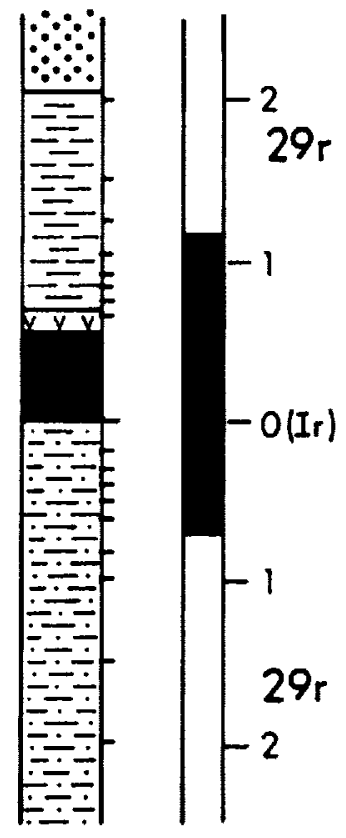

(b) M.C.

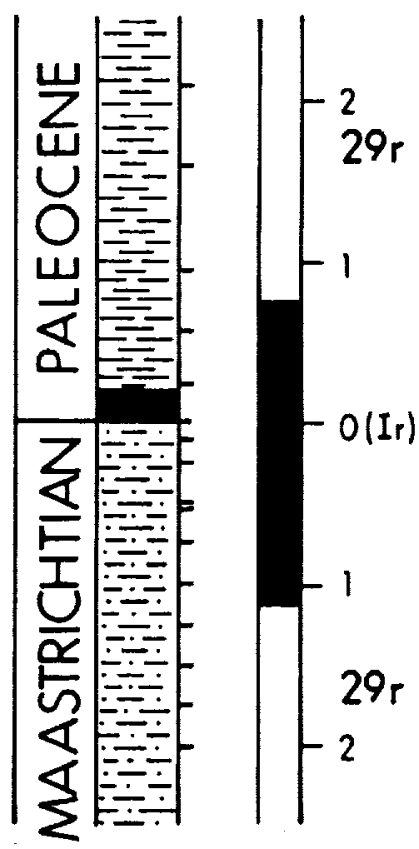

H.C.

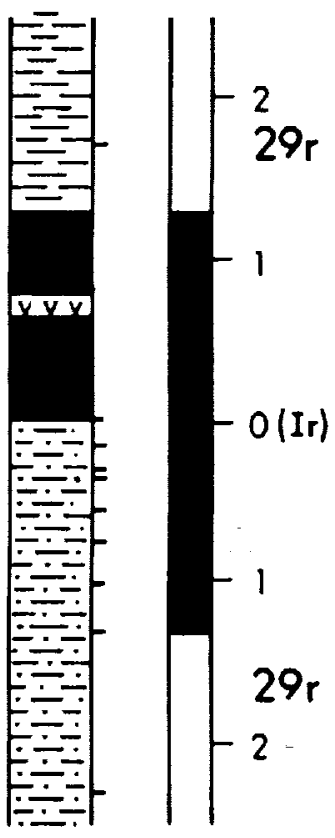

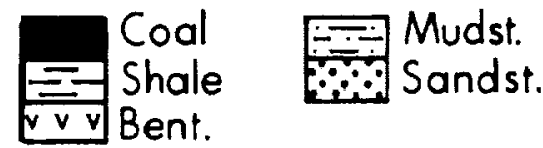

Fig. 1. Magnetostratigraphy of four KT boundary sections. Righthand columns show magnetic polarity: black - normal; white - reversed. (a) R. V. - Red Deer Valley, Alberta; F. R. = Frenchman River, Saskatchewan; (b) M. C. = Morgan (Rock) Creek. Saskatchewan; H. C. - Hell Creek, Montana. 
29r. Magnetochron 29r lasted about 0.6 m.y. [4]. In the Red Deer Valley and Frenchman River section magnetozone $29 \mathrm{r}$ is about $30 \mathrm{~m}$ thick $[5,6]$. Thus the mean rate of sedimentation over this interval in these sections is $\sim 50 \mathrm{~m} / \mathrm{m}$.y. In these two sections the average thickness of the normal interval below the KT boundary is $1.1 \mathrm{~m}$; the average interval above the boundary is $1.2 \mathrm{~m}$. If the rate of sedimentation in the vicinity of the boundary is similar to the mean for $29 \mathrm{r}$, the normal interval began some $21,000 \mathrm{yr}$ before the boundary event that produced the Ir anomaly, and lasted for about $24,000 \mathrm{yr}$ afterward.

Keller and others have argued that most deep marine KT boundary sections show one or more hiatuses at or near the boundary [2]. Early Paleocene foraminiferal zonation is detailed, enabling short hiatuses to be detected. The first Paleocene zone (Po) is estimated to have lasted only about 50,000 yr [1]. However, the latest Maastrichtian zone extends downward through 29r, and therefore a short hiatus below the boundary might be difficult to detect paleontologically.

References: [1] Keller G. (1989) GSA Bull., I0I, 1408-1419. [2] MacLeod N. and Keller G. (1991) GSA Bull., 103, 1439-1457. [3] Lerbekmo J. F. (1990) Sed. Geol., 66, 295-299 [4] Harland W. B. et al. $(1982,1989)$ Cambridge Earth Sci. Ser., Geol. Time Scale. [5] Lerbekmo J. F. and Coulter K. C. (1985) CJES, 22, 567-583. [6] Lerbekmo J. F. (1985) BCPG, 35, 454-459.

THE PLIENSBACHIAN/TOARCIAN (LOWER JURASSIC) EXTINCTION EVENT. C. Little, Department of Geology, University of Bristol BS8 1RJ, UK.

In the fossil record of marine genera during the last $250 \mathrm{Ma}$. Raup and Sepkoski [1] have identified eight events where extinction rates were significantly higher than background rates. These are often called "mass" extinctions. The authors postulate that they were spaced with a 26-Ma periodicity. The Permo-Triassic and KT extinctions were the largest of the eight, and are the best documented. One of the smaller-scale events is at the Pliensbachian-Toarcian boundary (Lower Jurassic, $186 \mathrm{Ma}$ ), a peak implied by the 26-Ma periodicity hypothesis. The periodicity itself suggests a single causative mechanism, such as bolide impacts or terrestrial processes such as volcanism or sea-level change. Hallam [2] has suggested the later as a cause of the Pliensbachian-Toarcian event and claims it does not have global distribution.

I have studied various Pliensbachian-Toarcian sections in northwest Europe to gain an understanding of the timing and magnitude of the event. An excellent ammonite biostratigraphic scheme, first developed by Quenstedt and others over $130 \mathrm{yr}$ ago, allows detailed correlation between sections, with a resolution of perhaps $250 \mathrm{ka}$. The section on the Yorkshire coast in Northern England is one of the thickest and most complete in Europe, consisting of $110 \mathrm{~m}$ of siliciclastic and oolitic iron-rich marine sediments ranging in age from the Upper Pliensbachian margaritatus zone to the mid Toarcian bifrons zone (Fig. 1). Macrofaunal species diversity and abundance were recorded at $\leq 1-m$ intervals from this section. A careful sampling procedure was employed to assess the role of collecting effort in diversity/abundance counts.

During the late Pliensbachian, there was a diverse range of benthic species, including infaunal and epifaunal bivalves, brachiopods, and crinoids. The equally diverse nekton included belemnites and am-

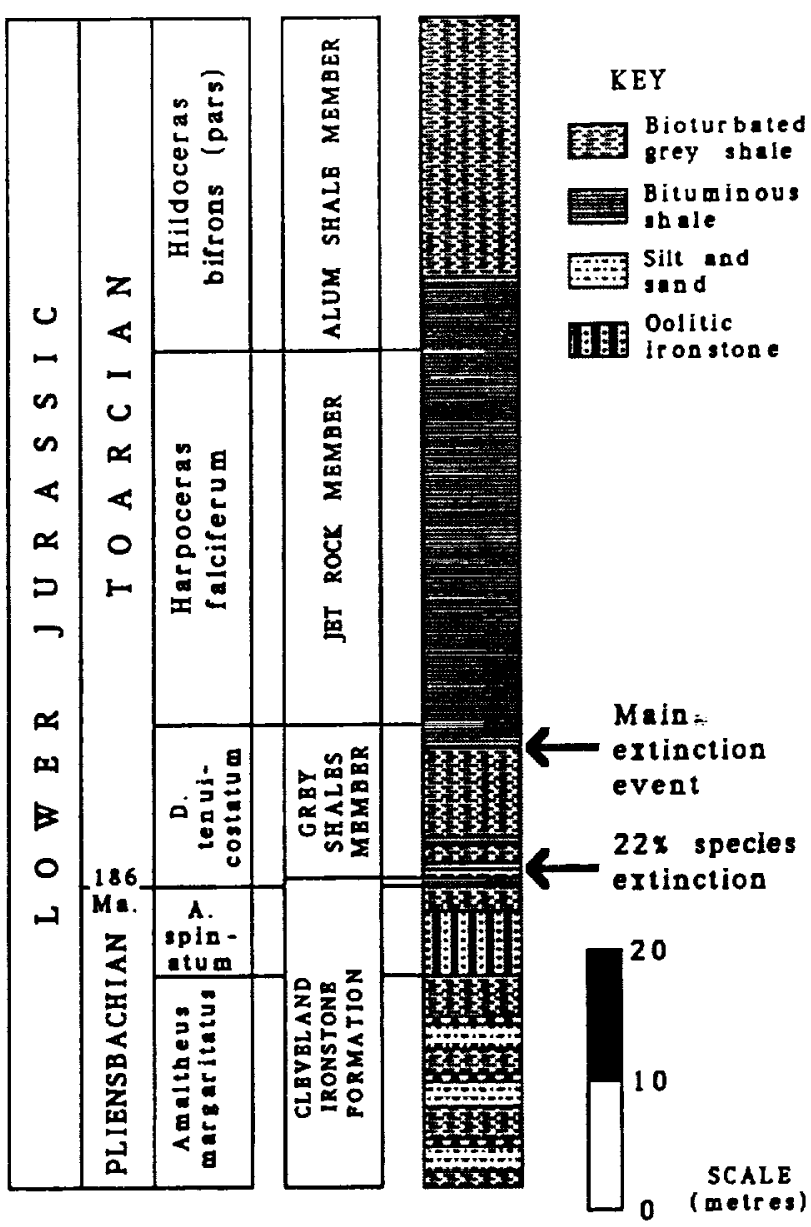

Fig. 1. Yorkshire coast lithology, lithostratigraphy, and ammonite biostratigraphy.

monites. These faunas cross the Pliensbachian-Toarcian boundary without showing any significant extinctions. There was a $22 \%$ reduction in diversity $50 \mathrm{~cm}$ above the boundary beneath a decimeter-scale layer of laminated bituminous shale, a lithology indicative of sediment anoxia/dysaerobia. The typical Pliensbachian faunas continued into the lowest zone (tenuicostatum) of the Toarcian until the last subzone (semicelatum). Here there was a $77 \%$ ( 17 from 22 species) reduction in diversity. This event is intimately associated with the onset of bituminous shale deposition, which formed a thick unit, the Jet Rock member (falciferum zone), in the basin. The benthos was the most severely affected ( $87 \%$ diversity reduction), the two surviving species being epifaunal bivalves. Among the nekton, the belemnites (two species) became extinct, while the rapid tumover of ammonite species, characteristic of the group, continued unchanged. The othertwo surviving species were pseudoplanktonic crinoids, which attached to floating logs [3]. Thus there was a gradient of extinction from infaunal benthos to epifaunal benthos to nektic belemnites, ammonites, and pseudoplanktonic crinoids. This pattem is consistent with that expected from a long period of sediment anoxia/dysaerobia.

The Jet Rock member contains an impoverished benthic fauna of two or three species of epifaunal bivalves, often extremely abundant, scattered fish debris and, especially in the top half (falciferum 
subzone), an increasing diversity of immigrant nektic ammonites and belemnite species. Benthic diversity does not increase again until the resumption of grey shale deposition, with nomal sediment $O$ concentrations, in the mid Toarcian Alum Shale member (bifrons zone). These species are different from those of the lowest Toarcian. However, at generic level, a certain amount of pseudo-extinction occurs, as shown by shared genera in sediments below and above the Jet Rock member.

The extinction event recorded in the Yorkshire PliensbachianToarcian section lasts slightly Tonger than one ammonite biozone, a time interval of perhaps $1 \mathrm{Ma}$.

The sections in Baden-Württemburg, southwest Germany, show very similar faunal and facies changes to the Yorkshire section, although they are thinner [4]. Faunas pass relatively unchanged across the Pliensbachian-Toarcian boundary into the lowest zone (tenuicostatum) of the Toarcian. As in Yorkshire, there is a decimeter-scale bituminous shale layer (Tafelfleins) in the first subzone (paltum) of the tenuicostatum zone. The main extinction event occurs at the start of the Jet Rock equivalent, the Posidonienscheifer (falciferum zone). The bituminous shales of this unit again contain very low-diversity, high-abundance benthic faunas, diverse nekton, and pseudoplanktonic crinoids. Benthic diversity does not increase until the top of the bifrons zone.

This pattern of extinction, linked to falciferum zone-age bituminous shales, is cornmon in Pliensbachian-Toarcian sections in northwest Europe. Indeed, contemporaneous facies are developed in sections in Italy, Austria, Hungary, and Greece [5], and are expected to show similar faunal trends. Outside Europe, lower Toarcian age bituminous shales are found in the Canadian Arctic, Western Canada, Madagascar, of fshore Westem Australia, and Japan. However, sections in Chile show neither bituminous shale development nor an associated extinction event [6]. This implies that the event does not have a global distribution, nor is it independent of facies change from normal marine to $\mathrm{O}$-deficient conditions.

The Toarcian is generally agreed to be a time of maximum marine transgression in northwest Europe. One model suggests that these bituminous shales on epicontinental margins are characteristic of sediments deposited during the early stages of a rapid transgression [7].

In summary: (1) The Pliensbachian-Toarcian event actually occurs one ammonite biozone higher in the lower Toarcian, perhaps 1 Ma later, than at the boundary between the two stages. (2) The event is not global as it is not found in Chilean sections. (3) The event is intimately associated with bituminous shale deposition and is therefore facies dependent.

As yet, no signatures of bolide impact (Ir anomalies, tektites, shocked quartz, etc.) have been found. The early Toarcian event thus seems to be a poor candidate for an impact-related extinction. It can more easily be explained by widespread continental-margin sediment anoxia lasting on the order of I Ma perhaps related to the rapid early stages of eustatic transgression.

References: [1] Raup D. M. and Sepkoski J. J. (1986) Science, 231,833-836. [2] Hallam A. (1986) Nature, 319, 765-768. [3] Simms M. J. (1986) Palaeoniology, 29, 475-493. [4] Riegraf W. et al. (1980) Der Posidonienschiefer. Biosiratigraphie, Fauna und Fazies des sudwestdeutschen Untertoarciums (Liase). Enke, Stuttgart, 195. [5] Aberhan M. (1992)Beringeria, Würzbuger geowissenschafilische Mitteilungen, 5, 1-174. [6] Jenkyns H. C. (1988) Am. J. Sci., 288, 101-151. [7] Wignall P. B. (1991) Geology, 19, 167-170.
PATTERNS OF PLANKTONIC FORAMINIFER EXTINCTION AT THE END OF CRETACEOUS: STEPWISE, GRADUAL, FORESHADOWED/EXTENDED, LATITUDINAL CONTROLLED, OR INSTANTANEOUS? C. LIU and R. K. Olsson, Department of Geological Sciences, Rutgers University, New Brunswick NJ 08855, USA.

Various gradual pattems including intensified background, foreshadowed followed by prolonged [1], gradual and stepwise [2-3], and variations with climatic belts [4-5], have been proposed for the KT extinction of planktonic foraminifer in contrast to the observation of a single instantaneous global event [6-8]. Despite the conIrasting hypotheses, the datasets of various workers are fairly compatible. A large part of the dispute must come from contrasting interpretations on the observed fossil record. These include equivocal placement of the KT boundary, differential treatment of Cretaceous taxa occurring in the basal Danian, taxonomic inconsistencies, and the logic used in separating local events from a global change.

Placement of the KT Boundary: The placement of the KT boundary above the KT GSSP at El Kef led workers to propose a foreshadowed extinction pattem [1]. Application of different criteria for defining the KT boundary in individual sections may result in correlating the $\mathrm{KT}$ event in a different temporal framework and viewing a single global event as several local events. For instance, the KT boundary in the sections at El Kef (Tunisia) and Agost, Caravaca (Spain), are placed at the mass disappearance of Cretaceous taxa by Smit [6], Keller, and co-workers [2-5,9]. However, in other sections, Keller and co-authors $[2-5,9]$ defined the KT boundary as the FO (first occurrence) of Tertiary species. This change in criterion obviously leads to correlation of diachronous layers as the geochronologic boundary because Tertiary taxa have never been found in the basalmost Danian in the stratotype and in other sections where the boundary is unequivocally placed. It is the mass disappearance of Late Cretaceous taxa marked by an abrupt decline in abundance that coincides with the KT boundary. Because diversity measurement alone may cause a problem in the accurate placement of the $\mathrm{KT}$ boundary due to reworking of Cretaceous taxa into the Danian, the initial abundance increase of the survivor species Guembelitria cretacea, which is the direct result of the mass disappearance of Cretaceous taxa, was used to define the KT boundary in shelf margin sections [8].

Obviously only the magnitude, but not the time, of this relative abundance increase is affected by reworking of Cretaceous taxa. However, Keller and co-authors [4-5] recently defended the use of the FO of Tertiary taxa and misinterpreted the initial increase in relative abundance as the peak abundance of $G$. cretacea. They explain the absence of Tertiary taxa in some KT boundary layer as due to dissolution of Tertiary species. This ad hominem explanation misses the fact that the more fragile $G$. cretacea occurs abundantly in the basal Danian while Tertiary species are absent. The explanation of selective dissolution of Tertiary taxa without supportive taphonomic data is subjective.

Reworking: Reworking of microfossils may significantly distort the KT boundary fossil record. Paleoenvironment is one of the major factors affecting the magnitude of reworking of Cretaceous taxa. Reworking of Late Cretaceous planktonic foraminifera into Zone P3b and $45 \mathrm{~m}$ above the KT boundary in São Paulo Plateau off the Brazilian coast due to downslope transportation in the paleoslope is an example. Unfortunately, there is no satisfactory means 
for separating reworked specimens from indigenous species although up to nine criteria have been utilized [10]. Stable isotope and phylogeny are perhaps the most reliable and positive methods. Stable isotopic comparisons show that reworked Cretaceous specimens have significantly lower $\delta^{18} \mathrm{O}$ and higher $\delta^{13} \mathrm{C}$ signature than indigenous survivor species and evolving Paleocene taxa [11]. However, stable isotopic analysis can only be applied to well-preserved specimens. Both Tertiary and Cretaceous taxa may display similar stable isotope signatures due to diagenetic replacement of elements in the tests.

A comparison of diversity vs. abundance change is indicative of the origin of Cretaceous taxa in the basal Danian because abundance will sharply decline while reworking may still bring specimens of extinct species up. The result is that diversity drops less abruptly than abundance. The abrupt abundance decline in contrast to slower diversity change at El Kef and Millers Ferry obviously indicates a reworked origin of the Cretaceous taxa in basal Danian. Since reworked specimens of extinct taxa gradually diminish following the abrupt decline at the KT boundary, with smaller-sized and more abundant Cretaceous taxa reworked higher than the larger-sized and rarer species, the apparent diversity (the number of reworked taxa) will decrease sample by sample. If these reworked taxa are regarded as surviving indigenous species [2-5], a gradual or stepwise extinction pattern would be concluded.

Application of phylogenetic criterion led us $[7-8,10-11]$ to recognize three species from two separate stocks as survivors. However, phylogenetic criterion will not recognize survivorship of species without descendants (if they did indeed survive). The exact number of survivor species is also affected by taxonomy. For instance, we [7-8] recognize three survivor species with Guembelitria cretacea as the only triserial species. When Keller and co-authors [2-5] split Guembelitria into four species (irregularis, trifolia, danica, and cretacea), survivorship of this triserial morphotype quadrupled by this taxonomic treatment.

Local Events and Global Change: To solve the problem of whether the KT mass extinction is an accumulation of a series of events or a single event, one important aspect to investigate is the diversity change across the KT boundary in a variety of environments. Recent studies by Keller [3-4] concluded that gradual environmental perturbations for $\sim 200,000-300,000$ yr before and after the KT led to "gradual mass extinction." They also suggested that the KT extinction is mainly a low-latitude phenomenon while no major extinction coincides with the KT boundary in high latitudes.

In order to separate local environmental perturbations from a global event, we compare the Late Cretaceous diversity change of planktonic foraminifera in various paleoenvironments in high and low latitudes. The data are from tropical site El Kef, low-latitude Gulf Coast of Mexico, southem high-latitude ODP Site 738C, and northem high-latitude Danish section (Nye Kløv) [2-8]. The diversity in four of the five sections are nearly constant, although they show contrasting background diversity in the Upper Cretaceous. The only section that displays significant decline in diversity in the Upper Cretaceous is at Braggs, Alabama. The number of species declined from 28 at $50 \mathrm{~cm}$ to 21 at $20 \mathrm{~cm}, 22$ at $10 \mathrm{~cm}$, and further to $17-18$ species at $2-5 \mathrm{~cm}$ below the KT boundary. These changes cannot be due to gradual global extinctions because during the same interval the diversity basically remains constant $(40-43)$ at Millers Ferry, which is only 34 miles west of Braggs. The reason for the diversity decline at Braggs is a change in paleodepth. In the sampled interval, the planktonic-benthic foraminifer ratio (higher $\mathrm{P} / \mathrm{B}$ ratio indicates deeper paleodepth) also drops from $53 \%$ to less than $8 \%$, i.e., from an outer-shelf to an inner-shelf environment. The Nye Kløv section, as at Braggs, was deposited in a marginal marine environment characterized by a low-diversity planktonic fauna ( $5-10$ species) if all triserial guembelitriids are regarded as Guembeli-tria cretacea. The two "stepwise" declines (16-14 species and 14-12 species at 103 and $4 \mathrm{~cm}$ below the KT boundary respectively) at ODP Site $738 \mathrm{C}$ are not compatible with either the stepwise or the gradual extinction hypotheses if the quality of preservation and poor core recovery (8-10\%) are considered. To the contrary, no matter what the diversity was in the Cretaceous, an abrupt decline to approximately three species occurred right at the KT boundary in all sections regardless of the latitudinal position or paleoenviron-ment of the section. This dramatic change occurred in an interval of less than -3000 yr and therefore is considered a geologically instantaneous event [11].

In conclusion, an equivocal temporal framework, an illogical interpretation of the observed data, and taking local events for global phenomenon are three major sources of artifacts in KT- related studies. If the change in planktonic foraminifer biota is viewed globally, in the evolutionary as well as stratigraphic context, and geologic processes are fully understood, one would conclude that extinction of planktonic foraminifera at the end of the Cretaceous is a single, instantaneous, global event.

References: [1] Brinkhuis H. and Zachariasse W. J. (1988) Marine Micropal., 13, 153-191. [2] Keller G. (1988) Marine Micropal., 13,239-263. [3] KellerG. (1989) Paleocean., 4, 287-332. [4] Keller G. (1993) Marine Micropal., 21, 1-45. [5] Keller G. el al. (1993) GSA Bull., I05, 979-997. [6] Smit J. (1982)GSA Spec. Paper 190,329-352. [7] Liu C. and Olsson R. K. (1992)JFR, 22, 328-346. [8] Olsson R. K. and Liu C. (1993) Palaois, 8, 127-139. [9] Canudo J. I. et al. (1991) Marine Micropal., 17, 319-341. [10] Liu C. and Olsson R. K. (1992) GSA, A29. [11] Liu C. (1993) Ph.D. thesis, 189, Rutgers.

KT PHENOMENA IN THE CONTEXT OF TECTONIC SEAFLOOR REARRANGEMENTS. Y. G. Liu 1.2 and R. A. Schmitt 1-4, 'The Radiation Center and Departments of ${ }^{2}$ Chemistry and ${ }^{3}$ Geosciences, ${ }^{4}$ College of Oceanography, Oregon State University, Corvallis OR 97331, USA.

Various processes have been proposed for mass extinctions in the Earth's history. Rampino and Caldeira [1] showed that major geologic events over the past $250 \mathrm{Ma}$ were periodic and interrelated and seem to involve jumps in sea-floor spreading associated with continental rifting, volcanism, enhanced orogeny, global sea-level changes, and fluctuations in climate. Lyle et al. [2] and Owen and Rea [3] found that sea-floor hydrothermal activities fluctuate by as much as an order of magnitude and that episodes of greatest hydrothermal flux correspond to times of major tectonic sea-floor arrangements (TSR). The ridge jumps and changes in ridge orientation may significantly increase hydrothermal activities by fracturing oceanic crust and providing seawater access to deep-seated crustal heat sources. Enhanced leaching of $\mathrm{Ca}^{2+}$ ion into the hydrothermal solutions reacts with oceanic bicarbonate to yield $\mathrm{CO}_{2}$ [3]. Rea et al. [4] noted that $20 \%$ of the preindustrial atmospheric $\mathrm{CO}_{2}$ may be attributed to the present midoceanic ridge hydrothermal activities. It was estimated 
from geochemical evidences that one or two orders of magnitude of hydrothermal activity occurred at the Paleocene/Eocene boundary. The $\mathrm{CO}_{2}$-induced climate change may be the cause of the extinction and evolution at the Paleocene/Eocene boundary.

We [5] found $\mathrm{P}_{\mathrm{CO}_{2}} / \mathrm{P}_{\mathrm{CO}_{2}^{\circ}}$ peaks at $\sim 17, \sim 53$, and $\sim 63 \mathrm{Ma}$, where $\mathrm{P}_{\mathrm{CO}_{2}}$ values relative to the present $\mathrm{PCO}_{2}^{\circ}$ were calculated from $\mathrm{Ce}^{A} \mathrm{~s}$ (Ce anomalies) of Pacific seawater recorded by $\mathrm{Ce}^{A^{*}} \mathrm{~s}$ recorded in deep-sea carbonate sediments. The correspondence between our calculated $\mathrm{P}_{\mathrm{CO}_{2}}$ enhancements and the TSR-HA (hydrothermal activities) associated with major TSRs [1] strongly support the hypothesis that the $\mathrm{pH}$ of the deep ( $>600 \mathrm{~m}$ ) Pacific Ocean was lowered by the $\mathrm{CO}_{2}$ generated by enhanced TSR-HA at these times.

Hydrothermal solutions are strongly enriched in $\mathrm{Mn}$ and $\mathrm{Fe}$ by $\sim 10^{6} \times$, in Co by $\sim 3000 \times$, in $\mathrm{Zn}$ by $\sim 8000 \times$ [6], and in REEs by $10-10^{4} \times$ (avg. $\sim 10^{3} \times$ ) [7]. Therefore, in addition to $\mathrm{Ce}^{\mathrm{A}}$ changes, which indicate $\mathrm{pH}$ changes, the enrichments of the above elements in sedi-ments signify the enhanced TSR-HA. Because $M n$ at $\sim 0.017 \mu \mathrm{g} / \mathrm{L}$ and $\mathrm{Co}$ at $\sim 0.0015 \mu \mathrm{g} / \mathrm{L}$ are quite low in present seawater [8], their signals should be observable at the postulated TSR-HA events, especially in carbonate sediments with relatively low amounts of detrital clay. As the hydrothermal plumes mix with seawater, $\mathrm{Fe}^{2+}$ is rapidly oxidized to ferric-oxyhydroxides forming particulates while the slow oxidation of Mn serves to keep most of the $\mathrm{Mn}$ in solution for dispersal throughout the oceans [9]. Likewise, Co is dispersed and kept in solution.

However, the REEs are largely coprecipitated and scavenged with the Fe-oxyhydroxides near the vent [10]. We and Michel et al. [1 1] have obtained $(\mathrm{Eu} / \mathrm{Sm})$ ratios of $0.24-0.27$ for $~ 300$ carbonates from Pacific DSDP Holes 316, 317A, 317B, 577, 577A, 577B, and the Laytonville Limestones, and these ratios overlap the present $\mathrm{EW}^{\prime}$ $S m=0.26 \pm 0.01$ ratio in the Pacific [12]. These observations firmly support the contention [10] that the bulk (say, >95\%) of the REEs in the hydrothermal plumes are scavenged by the ferric-oxyhydroxides that precipitate out of the hydrothermal-seawater mixture close to the hydrothermal vents.

Since the REEs, Mn, and Co precipitate out of seawater onto the detritus and ferric-oxyhydroxide coatings and also because the $\mathrm{La}^{*} /$ $\mathrm{Th}, \mathrm{Mn}^{*} / \mathrm{Th}$, and $\mathrm{Co}^{*} / \mathrm{Th}$ (Th is an excellent detritus proxy and is well determined by INAA) indicate a surface/volume effect (i.e., these ratios generally increase with lower Th abundances), we have

TABLE 1. Summary of average $\mathrm{Ce}^{\wedge *}$ and hydrothermal fluid enriched elements $\mathrm{Mn}$ and $\mathrm{Co}$ at $\mathrm{P}_{\mathrm{CO}_{2}}$ peaking during the past $66.2 \mathrm{Ma}$. Pacific Ocean sites.*

\begin{tabular}{|c|c|c|c|c|}
\hline Age $(\mathbf{M a})^{+}$ & $\mathrm{Ce}^{\mathrm{A}^{*}}$ & $\mathrm{Mn}^{*} / \mathrm{La}^{*}$ & $\mathrm{Co}^{*} / \mathrm{La}$ & $\begin{array}{l}\text { Inferred Tectonic Seafloor } \\
\text { Rearrangements }\end{array}$ \\
\hline \multicolumn{5}{|c|}{ Manihiki Plateau, Hole $\overline{3} 17 \mathrm{~B}$} \\
\hline $3.2-15.5$ bkgd. & $0.06 \pm 0.02$ & $48 \pm 94$ & $0.48 \pm 0.15$ & none \\
\hline $15.7-19$ & $0.14 \pm 0.02$ & $65 \pm 18$ & $0.90 \pm 0.18$ & major al $\sim 17 \mathrm{Ma}$ \\
\hline $20-31$ bkgd. & $0.07 \pm 0.02$ & $32 \pm 7$ & $0.57 \pm 0.18$ & none \\
\hline \multicolumn{5}{|c|}{ Shatsky Plateau, Holes 577, 577A, 577B } \\
\hline $50.1-55.0$ & $0.15 \pm 0.04$ & $26.5 \pm 3.7$ & $0.25 \pm 0.07$ & major at $\sim 53 \mathrm{Ma}$ \\
\hline $58-58.9$ bkgd. & $0.08 \pm 0.02$ & $16.9 \pm 3.1$ & $0.19 \pm 0.03$ & none \\
\hline $62.0-64.25$ & $0.20 \pm 0.03$ & $24.6 \pm 2.5$ & $0.28 \pm 0.03$ & major at $\sim 63 \mathrm{Ma}$ \\
\hline $64.45-64.58$ bkgd. & $0.10 \pm 0.01$ & $6.9 \pm 1.1$ & $0.072 \pm 0.014$ & none \\
\hline $64.595-64.80$ & $0.12 \pm 0.02$ & $9.4 \pm 1.3$ & $0.101 \pm 0.016$ & minor at $-64.6 \mathrm{Ma}$ \\
\hline 64.95-65.1I bkgd." & $0.052 \pm 0.010$ & $6.9 \pm 1.6$ & 1 & none \\
\hline \multirow[t]{2}{*}{$65.15-65.24$} & $0.10 \pm 0.02$ & $16.2 \pm 4.5^{\circ "}$ & $0.15 \pm 0.05^{\circ}$ & minor at $\sim 65.2 \mathrm{Ma}$ \\
\hline & $0.12 \pm 0.01^{t+}$ & $21.9 \pm 1.6^{+4}$ & $0.23 \pm 0.03^{+1}$ & \\
\hline 65.25-65.27 bkgd. & $0.06 \pm 0.01$ & $9.5 \pm 1.7$ & $0.088 \pm 0.016$ & none \\
\hline $65.28-65.30$ & $0.08 \pm 0.01$ & $13.5 \pm 1.7$ & $0.136 \pm 0.010$ & very minor at $\sim 65.3 \mathrm{Ma}$ \\
\hline $65.30-65.31$ bkgd. & $0.06 \pm 0.01$ & $8.9 \pm 0.6$ & $0.088 \pm 0.008$ & none \\
\hline $65.34-65.46$ & $0.08 \pm 0.04$ & $13.1 \pm 4.0$ & $0.118 \pm 0.028$ & very minor at $-65.4 \mathrm{Ma}$ \\
\hline $65.46-66.24$ bkgd. & $0.05 \pm 0.01$ & $7.8 \pm 1.0$ & $0.076 \pm 0.018$ & none \\
\hline
\end{tabular}

* $\mathrm{Ce}^{\wedge *}, \mathrm{Mn}^{*}, \mathrm{Co}^{*}$, and $\mathrm{La}^{*}$ represent abundances precipitated out of seawater onto carbonate sediments; i.e., REEs, Mn, and Co in NASC-like detritus were subtracted from total abundances. Differences in seawater depths and chemical environmënts over the Manihiki and Shatsky Plateaus are expected to yield different $\mathrm{Mn}^{*} / \mathrm{La}^{*}$ and $\mathrm{Co}^{*} / \mathrm{La}^{*}$ ratios.

+ bkgd a background values of parameters before or after peaks.

$\ddagger$ The higher $\mathrm{Mn}^{*} / \mathrm{La}^{*}$ and $\mathrm{Co}^{*} / \mathrm{La}^{*}$ at $11.0 \mathrm{Ma}$ were not included in the averages. A lower $\mathrm{La}^{*}$ for this sample is probably the cause for higher abnormal ratios.

\$ This interval covers largely the KT-Ir boundary samples (Ir peaking at $\equiv 65.0 \mathrm{Ma}\left(13\right.$ ]). $\mathrm{Mn}^{*} / \mathrm{La}$ * data from [11] for 64.98$65.01 \mathrm{Ma}$ were used. Inclusion of our $\mathrm{Mn}^{*} / \mathrm{La}^{*}$ data from Hole 577 for this interval yields the same average $\mathrm{Mn}^{*} / \mathrm{La}^{*}$ ratio.

1 We have found that the ratios of $(\mathrm{CO} / \mathrm{Ir})_{\mathrm{KT}}-1140 \pm 90$ by using [ 11$]$ data for Hole $577 \mathrm{~B}$ and $-930 \pm 50$ by our data for Hole 577. These ratios overlap the $\mathrm{Co} / \mathrm{Ir}-1050 \pm 90$ ratio in $\mathrm{C}$ I chondrites by [16]. The normal $\mathrm{Mn}^{*} / \mathrm{La}^{*}$ ratios for this interval indicate no hydrothermal activities slightly before, during, and slighily after the KT-Ir event. Therefore, the higher $\mathrm{Co}^{*} / \mathrm{La}^{*}$ ratios are definitely attributed to global dispersion of vaporized bolide (Alvarez-asteroid or Urey-comet) ejecta.

* For 65.15-65.24-Ma broad inierval.

"For 65.216-65.222-Ma peak interval. 


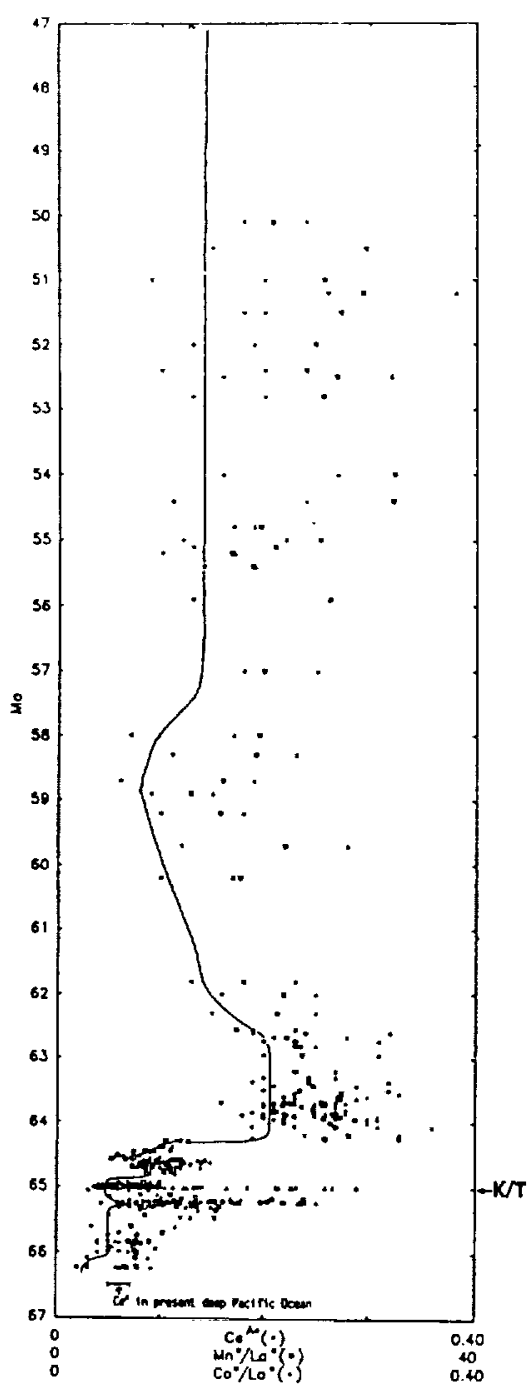

Fig. 1.

eliminated the surface/volume effect of the detritus by correlating $\mathrm{Mn}^{*} / \mathrm{La}^{*}$ and $\mathrm{Co}^{*} / \mathrm{La}^{*}$ ratios. $\mathrm{Mn}^{*}, \mathrm{Co}^{*}$, and $\mathrm{La}^{*}$ values are seawaterprecipitated abundances and are corrected for $\mathrm{Mn}, \mathrm{Co}$, and $\mathrm{La}$ in the NASC-like detritus.

From Table 1, we clearly observe enhanced $\mathrm{Mn}^{\top} / \mathrm{La}^{*}$ and $\mathrm{Co}^{*} / \mathrm{La}^{*}$ ratios in the 15.7-19-Ma interval, with a maximum at $\sim 17 \mathrm{Ma}$. This corresponds to the enhanced $\mathrm{Mn}$ abundances of $\sim 10-40 \times$ re-ported [2] in 17-18.5-Ma metalliferous sediments from DSDP Leg 92, East Pacific Rise, and attributed to TSR-HA.

The Shatsky Plateau (SP) data indicate a number of interesting observations. There is a hiatus in SP cores between 6-50 Ma and no older samples than $66.24 \mathrm{Ma}$ were cored. The background levels of $\mathrm{Ce}^{\mathrm{A}^{*}}$ in the time intervals of $65.46-66.24,65.30-65.31,65.25-65.27$, $64.95-65.11$ (the KT-Ir event), 58-58.9, 20-31, and 3.2-15.5 Ma are the same within error and equal to the $\mathrm{Ce}^{\mathrm{A}^{*}}$ in present deep Pacific seawater of $0.06 \pm 0.01$ [12]. Since $\mathrm{Ce}^{\mathrm{A}^{*}}$ is controlled by the $\mathrm{P}_{\mathrm{CO}_{2}}$ [5], $\mathrm{P}_{\mathrm{CO}_{2}}$ during those intervals was the same as the present

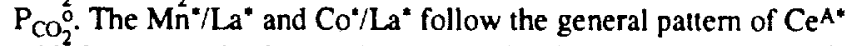
with the average background values of $\mathrm{Mn}^{*} / \mathrm{La}^{*}=8.3 \pm 1.1$ and $\mathrm{Co}^{*} /$
$\mathrm{La}^{*}=0.084 \pm 0.007$. Relative to the above background levels, $\mathrm{Ce}^{\mathrm{A}^{*}}$, $\mathrm{Mn}^{*} / \mathrm{La}^{*}$, and $\mathrm{Co}^{*} / \mathrm{La}^{*}$ in the $62.0-64.25$ and $50.1-55.0 \mathrm{Ma}$ intervals are quite high and indicate major TSR-HA. We also note minor enhancements of $\mathrm{Ce}^{\mathrm{A}^{*}}$ at intervals of 64.59-64.80 and 65.15-65.24 $\mathrm{Ma}$ and very minor enhancements of $\mathrm{Ce}^{\mathrm{A}^{*}}$ at 65.28-65.30 and 65.34-65.46 Ma but relatively pronounced enhancements of $\mathrm{Mn}^{2}$ / $\mathrm{La}^{*}$ and $\mathrm{Co}^{*} / \mathrm{La}^{*}$ during these intervals. They are designated as minor or very minor TSR-HA.

The inferred major TSR at $\sim 53 \mathrm{Ma}$ corresponds to the broad $\delta^{14} \mathrm{O}$ minimum between $24 \mathrm{~N}$ and $22 \mathrm{~N}$ chron and to a rising $\delta^{13} \mathrm{C}$ signal for the same chron intervals [4]. These parameters coupled with our observations are consistent with a greenhouse effect induced by higher $P_{\mathrm{CO}_{2}}$ due to TSR. The major TSR-HA event at $\sim 63 \mathrm{Ma}$ started $0.75 \mathrm{Ma}$ after the KT-Ir event at $65.0 \mathrm{Ma}$ [13] and lasted for $2.3 \mathrm{Ma}$ from 64.25-62.0 Ma. An average high $\mathrm{Ce}^{\mathrm{A}^{*}}$ corresponds to a $\mathrm{P}_{\mathrm{CO}_{2}}$ $\sim 1.9 \times$ the present $\mathrm{P}_{\mathrm{CO}_{2}}$. At that time, seafloor spreading in an eastwest direction about the Gakkel Ridge resulted in the opening of the Eurasian Basin. The extensive islandic plume was activated at that time. The high $\mathrm{Mn}^{*} / \mathrm{La}^{*}$ and $\mathrm{Co}^{*} / \mathrm{La}^{*}$ ratios suggest that hydrothermal activities were very extensive in the world's oceans.

As proposed by [2,3], TSR-HA would lower the oceans' pH. Some trace-element poisoning would have occurred if a significant fraction of elements like $\mathrm{As}, \mathrm{Sb}, \mathrm{Pb}, \mathrm{Bi}$, etc., remained in the hydrothermal plume and dispersed throughout the oceans. Therefore, some of the extinctions before the KT-Ir boundary [14] may be attributed to either $\mathrm{pH}$ or poisoning effects or to a combination of both effects. The absence of TSR-HA and a normal pH like that present in the deep $(>600-\mathrm{m})$ oceans at the KT-Ir boundary negates poisoning and $\mathrm{pH}$ effects. Of course, the $\mathrm{pH}$ of the mixed oceanic layer was probably lowered from the acidic rain caused by the atmospheric effects of bolide transit [15], thereby resulting in extensive planktonic extinctions at KT time, $65.0 \mathrm{Ma}$.

References: [1] Rampino M. R. and Caldeira K. (1993)EPSL, 114. 215-227. [2] Lyle M. et al. (1987) GRL, 14,595-598. [3] Owen R. M. and Rea D. K. (1985) Science, 227, 166-169. [4] Rea D. K. et al. (1990)Palaeogeo. Palaeoclim. Palaeoecol., 79, 117-128. [5] Liu Y.-G. and Schmitt R. A. (1993) LPS XXIV, 883-884. [6] Von Damm K. L. et al. (1985) GCA, 49, 2197-2220. [7] Michard A. et al. (1983) Nature, 303, 795-797. [8] Martin J. H. and Gordon R. M. (1988) Deep Sea Res., 35, 177-196; Nature, 314, 524-525. [9] Klinkhammer G. and Hudson A. (1986) EPSL, 79, 241-249. [10] German C. R. et al. (1990) Nature, 345, 516-518. [11] Michel H. et al. (1985) Init. Repts. DSDP, 86, 533-538. [12] Piepgras D. J. and Jacobsen S. B. (1992) GCA, 56, 1851-1862. [13] McWilliams M. O. et al. (1992) Eos, 363; Sharpton V. L. et al. (1992) Nature, 359, 819-821; Swisher C. C. et al. (1992) Science, 257, 954-958. [14] Keller G. (1989) GSA Bull., 101, 1408-1419. [15] Prinn R. G. and Fegley B. Jr. (1987) EPSL, 83, 1-15. [16] Anders E. and Grev-esse N. (1989) GCA, 53, 197-214. 
BIOTIC EFFECTS OF THE KT BOUNDARY EVENT IN NORTHEASTERN MEXICO. J.G. Lopez-Oliva and G. Keller, Department of Geological and Geophysical Sciences, Princeton University, Princeton NJ 08544, USA.

A large K Tboundary bolide impact near Chicxulubon the Yucatan Peninsula is predicted to have produced catastrophic destruction of marine and terrestrial organisms. These catastrophic biotic effects should be evident in nearby areas of the Gulf of Mexico and northeastem Mexico. Here we evaluate the biotic effects in planktic foraminifera in eight KT boundary sections spanning over $300 \mathrm{~km}$ in northeastem Mexico (Fig. 1). Planktic foraminifera are the group of marine microplankton long believed to have suffered most severely as a result of a bolide impact at KT boundary time.

Alleight sections examined reveal similar depositional sequences, although of variable thickness, spanning from the Maastrichtian Mendez Formation to a $0.2-7-\mathrm{m}$-thick clastic deposit and to the overlying Tertiary Velasco Formation. We interpret the clastic deposits to represent channelized sediments that thin out toward the channel edges and may locally disappear [1]. In sections where the clastic deposit is very thin $(10-20 \mathrm{~cm})$ or absent, the Mendez marls grade into the shales and marls of the Velasco Formation.

Stratigraphically, the upper Mendez Formation is of late Maastrichtian Abathomphalus mayaroensis-zone age and the lower Velasco Formation is of earliest Tertiary (Danian) age. The clastic deposit is also of A. mayaroensis-zone age as indicated by the presence of the A. mayaroensis-zone fauna, including the index taxon, and absence of Tertiary species. Four of the eight sections examined (El Mimbral, La Lajilla, El Mulato, and La Parida) span Cretaceous to

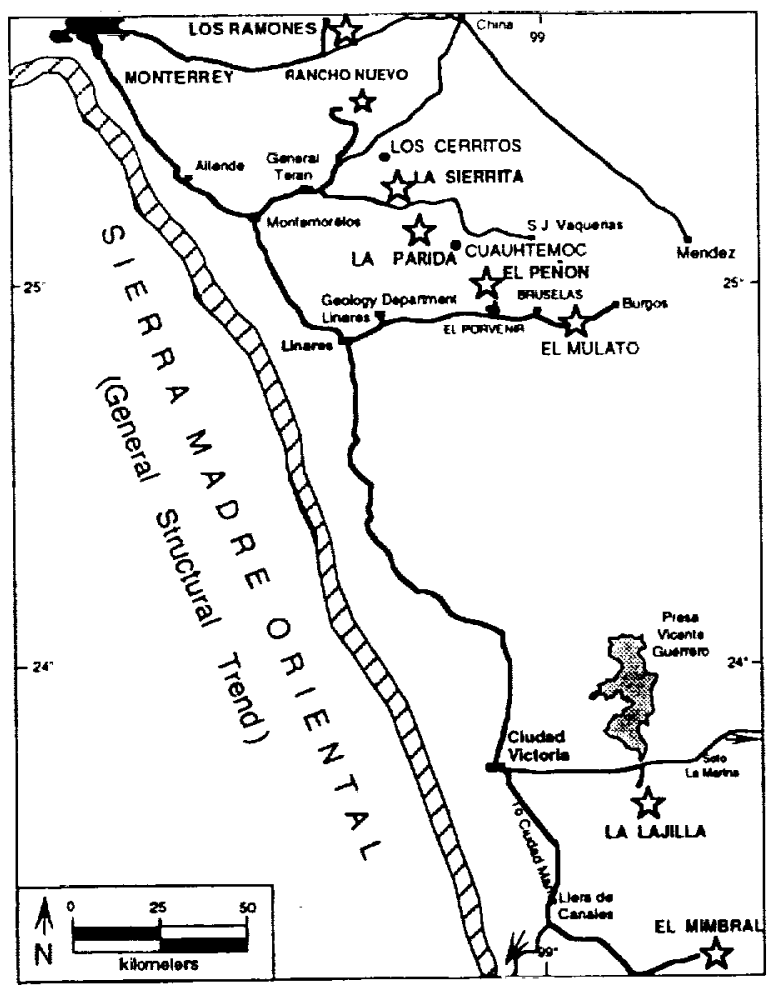

Fig. 1. Location map of northeastem Mexico sections studied.
Tertiary sediments. In four of the sections (EI Peñon, La Sierrita, Rancho Nuevo, and Los Ramones) Tertiary sediments are eroded. At La Lajilla and El Mulato a thin layer of A. mayaroensis-zone age marl overlies the top of the clastic deposits, clearly marking clastic deposition as of Maastrichtian age. In addition, abundant Chondrites, Zoophycos, and Y-shaped Thalassinoides burrow networks present in the top of the clastic deposit are infilled with Maastrichtian sediments that also indicates that deposition occurred in the Maastrichtian. The basal Tertiary Zone PO has only been recognized at El Mimbral near the edge of the channel fill in a 4-cm-thick dark gray clay layer $[1,2]$. In all other sections, Zone $\mathrm{P} 0$ is missing as well as part of the overlying Zone Pla ( $P$. eugeubina). The absence of the lowermost Tertiary sediments in these sections is due either to nondeposition or erosion.

In order to observe the biotic effects of the KT boundary event in these northeastern Mexico sections, we have qualitatively analyzed the upper Cretaceous to lower Tertiary planktic foraminiferal faunas of each section in closely spaced (5- $\mathrm{cm}$ intervals) samples. Planktic foraminifera, although recrystallized, are abundantly present in the Mendez and Velasco Formations. In the channel-fill deposits they are common in the spherule-rich layer of unit $I$, the mudclasts of unit I and unit 2 , in hemipelagic layers of unit 3 , and in the rippled sandy limestone at the top of unit 3 . Since much of the channel fill represents transponed sediments, an evaluation of the biotic effects must be based upon faunas from the Mendez and Velasco Formations. Thus, the faunal data from the channel-fill deposits must be disre-

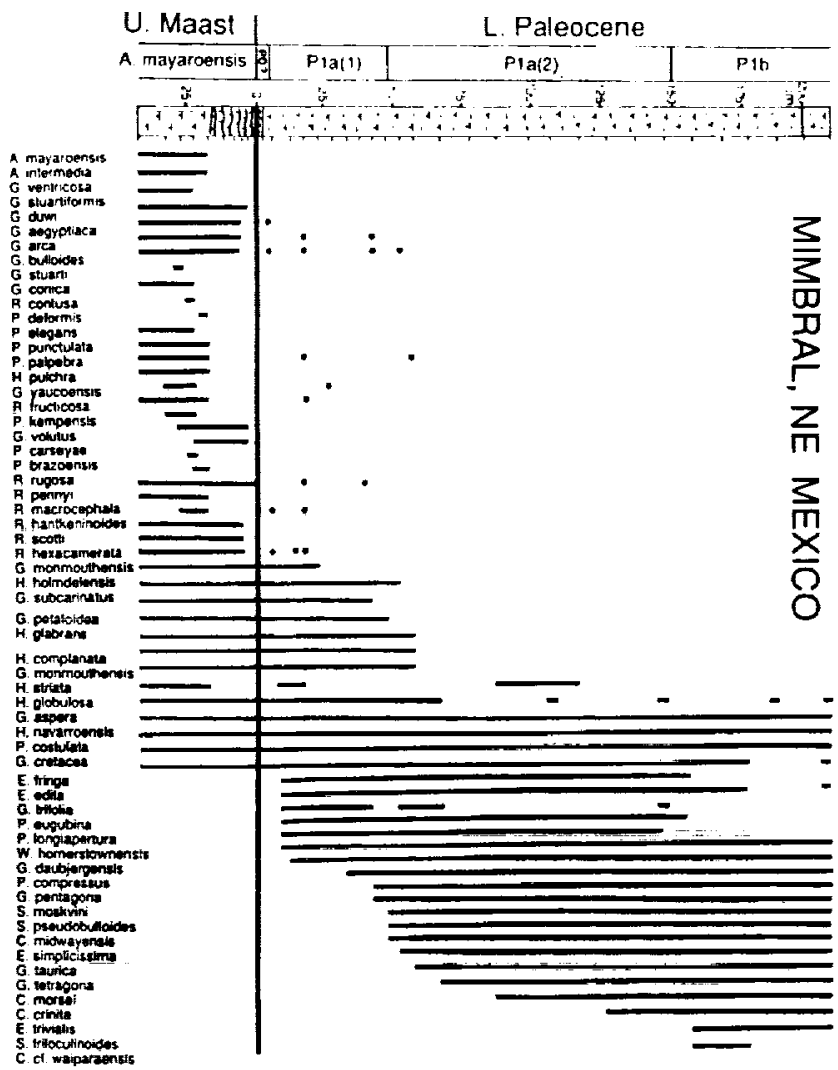

Fig. 2. Planktic foraminiferal species ranges across the KT boundary at EI Mimbral (edge of channel). 


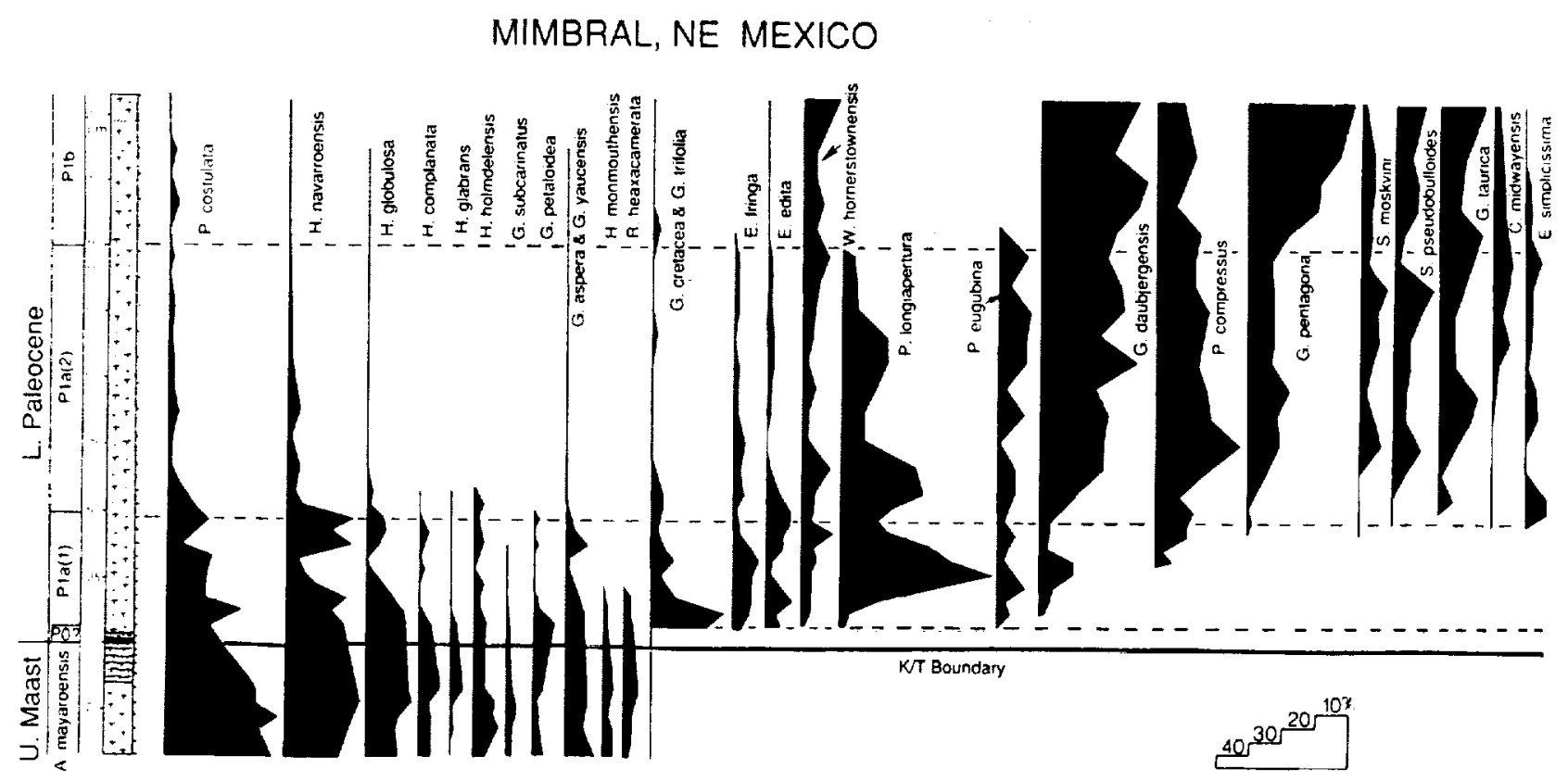

Fig. 3. Relative abundances of Cretaceous survivor species and evolving Tertiary species at El Mimbral (edge of channel).

garded or, ideally, a trans-KT boundary sequence without the clastic deposit must be used. At El Mimbral at the edge of the channel, a nearly continuous Mendez to Velasco marl-shale sequence is present, interrupted only by the top $20 \mathrm{~cm}$ (rippled sandy limestone) of the clastic deposit. A similar sequence has been found at La Parida. In all sections that contain the clastic channel fill, an undulating erosional surface marks the contact between the Mendez Formation and the base of the clastic deposit. This indi-cates that the topmost Maastrichtian sediment has been eroded within the channel. Despite this erosional disconformity all trans-KT boundary sections show similar faunal turnovers as illustrated here for El Mimbral.

Figure 2 shows that about two-thirds ( 28 species) of all Cretaceous taxa disappeared at the base or top of the rippled sandy limestone (RSL, top of clastic deposit). Isolated specimens of some of these taxa are also found in the lower Tertiary and are assumed to be reworked (dots). Since preservation in the RSL is poor, we tentatively assume that all 28 species disappeared at the KT boundary. About one-third (13 species) of the Cretaceous species are continuously present well into the Tertiary Velasco Formation, and these are considered as survivors for the reasons outlined in several studies [3-5]. The relative species abundances of survivor taxa and early Tertiary evolving species are illustrated in Fig. 3. It is notable that Cretaceous survivors are all small surface dwellers, of simple morphology, little omamented, and cosmopolitan taxa. They dominate the late Maastrichtian assemblage and show little or no adverse effects at the KT boundary. Their relative abundances decline in Zone Pla ( $P$. eugubina) about 100 k.y. after the KT boundary, coincident with the evolutionary diversification and increased competition of the early Teriary fauna. The decline and eventual extinction of the Cretaceous survivor fauna in Zone Pla thus seems to be a direct consequence of increased competition, rather than the belated effects of a KT boundary bolide impact.
In contrast to the survivor fauna, the two-thirds of the Cretaceous species that disappeared at or below the KT boundary are tropical-subtropical large, deep dwellers (living at or below the thermocline) of complex morphology and well omamented. They are generally rare with a combined relative abundance of less than $17 \%$ of the population. Thus, their disappearance had little effect on the overall foraminiferal population. Similar high rates of species extinctions, but low combined relative abundance in the foraminiferal population, were observed earlier at El Kef, Tunisia (KT boundary stratotype), and Agost and Caravaca in southem Spain $[6,7]$.

Our study indicates that the biotic effects of the KT boundary event on planktic foraminifera in the northeastern Mexico sections were not as catastrophic as predicted from a large bolide impact on Yucatan, Although two-thirds of the Cretaceous species disappeared at or below the KT boundary, the effect on the overall foraminiferal population was small $(<17 \%)$ because only rare, already endangered taxa disappeared. These taxa were specialized tropical and subtropical forms living at or below thermoclinal depth; this group is historically the least tolerant of environmental changes. The limited negative biotic effects observed across the KT boundary in northeastem Mexico are consistent with other low-latitude sections. They indicate that if a bolide impact occurred on Yucatan, the biologic consequences were not as catastrophic as generally assumed even within a radius of 2000 miles.

References: [1] Stinnesbeck W. et al. (1993) Geology, 2l, 797-800. [2] Keller G. et al. (1994) Palaios., in press. [3] MacLeod N. and Keller G. (1994) Paleobiology, in press. [4] Keller G. (1993) Mar. Micropaleo., 21, 1-45. [5] MacLeod N., this volume. [6] Keller G. (1988) Mar. Micropaleo., 13, 239-263. [7] Canudo J. I. et al. (1991) Mar. Micropaleo., 17, 319-341. 


\section{N94- 28303

THE BIOSTRATIGRAPHY AND PALEOGEOGRAPHY OF MAASTRICHTIAN INOCERAMIDS. K. G. MacLeod', B. T. Huber', and P. D. Ward', 'Department of Paleobiology, Smithsonian Institution, MRC: NHB 121, Washington DC 20560, USA, 2Department of Geological Sciences, AJ-20, University of Washington, Seatle WA 98195 , USA.

The global distribution of Maastrichtian inoceramids is now known in enough detail that the patterns of disappearance can be used to place first-order constraints on paleoceanographic changes that may have occurred during that age. The Inoceramidae is an excellent group to focus on in a study of Maastrichtian events because (1) they were globally distributed in the early Maastrichtian, (2) they did not survive the age (i.e., they undergo change during the interval), and (3) they have left a rich microfossil and macrofossil record. Some inoceramids grew to be very large; however, even the largest often passively disaggregated and are preserved as hundreds of millions of characteristic, columnar, polygonal prisms of calcite $\sim 100 \mu \mathrm{m}$ across. This taphonomic process has greatly increased the inoceramid fossil record and provides a means of objectively estimating changes in their standing population [1] In addition, because these prisms commonly occur in Deep Sea Drilling Project (DSDP) and Ocean Drilling Program (ODP) cores, it is relatively easy to generate a truly global database. The existing macrofossil record of inoceramids has less temporal and spacial resolution but greater taxonomic resolution than the microfossil record. In concert the microfossil and macrofossil records of inoceramids demonstrate that important changes occurred during the Maastrichtian. These changes are distinct from the KT boundary catastrophe but are part of the larger KT transition.

One striking aspect of the inoceramid record is how ubiquitous these bivalves were during the early Maastrichtian. Inoceramids are known from all continents and we have documented prism occurrences in early Maastrichtian strata from deep-sea cores collected in the North Atlantic, the South Atlantic, and the Pacific, Indian, and Southern Oceans. In sections containing inoceramids, prisms are found in every sample collected across tens of meters of section. In land-based sections we have studied, inoceramids form virtual shell pavements on some bedding planes, and prism densities $>100,000$ prisms $/ 50 \mathrm{~g}$ samples are typical in high-abundance intervals.

During the mid Maastrichtian, though, there was a concentrated, worldwide pulse of extinction among inoceramids. At the more than 25 sites where we have recorded this event, inoceramids decline gradually but over a relatively short stratigraphic interval. The rate at which the extinction progressed falls between catastrophic [e.g., 2] and gradual [3] scenarios that have previously been proposed for the event. One unusual inoceramid taxon, Tenuipteria, survives after the mid Maastrichtian event and disappears at the KT boundary. We think we have recently found the first known occurrence of Tenuipteria shell fragments in core material (DSDP hole 605 off Delaware).

Although the major pulse of extinction falls in the mid Maastrichtian, this extinction horizon is demonstrably diachronous on a global scale. In high southem latitudes (e.g., ODP holes 698A and $700 \mathrm{~B}$ [4], and 750A) the last occurrence of inoceramid remains is stratigraphically below the first appearance of Abarhomphalus mayaroensis. At lower-latitude sites in southwestern Europe [1] and in Indian Ocean ODP holes $754 \mathrm{~B}$ and $758 \mathrm{~A}$, inoceramid remains are found above that datum. The first appearance of $A$. mayaroensis is itself diachronous, but in a direction that accentuates the diachroneity of the inoceramid extinction. A. mayaroensis appears earliest in high southern latitudes [5.6] where inoceramids disappear first. Therefore, there seems to be a general Antarctic to equator progression in the timing of the pulse of extinction among inoceramids.

A second trend is that the disappearance of inoceramids seems to occur earlier in onshore areas than in nearby offshore areas. This pattern is not yet well constrained, but it has been observed in four regions:

1. In the Basque region of northem Spain, the decline in the abundance of inoceramid macrofossils occurs at a lower level (based on lithostratigraphic correlation) in sections that represent more shoreward areas than it does in more offshore areas.

2. ODP Hole $761 \mathrm{~B}$, located off the northwest coast of Australia, records an early extinction level compared to the other Indian Ocean sites.

3. In the South Allantic, inoceramid prisms disappear earlier in a shoreward site (DSDP Hole 356) than they do in a more offshore site at the same latitude (DSDP Hole 21).

4. Finally, inoceramids disappeared in Campanian strata on Seymour Island [7], while in offshore ODP sites from high southem latitudes inoceramid prisms clearly range into Maastrichtian strata.

Although inoceramid remains are ubiquitous in early Maastrichtian strata, they are not omnipresent. We have found inoceramids to be less common in Pacific Ocean sites than in Atlantic or Indian Ocean sites. Perhaps inoceramid occurrences reflect oceanographic differences between the relatively old, wide Maastrichtian Pacific Ocean and the relatively young, narrow Maastrichtian Atlantic and Indian Oceans. Conversely, the scarcity of inoceramids in Pacific sites may be an artifact of sampling as the recovery of Cretaceous, calcareous sediments is relatively sparse in the Pacific Ocean. More problematic is the absence of inoceramid remains in two ODP sites from Maud Rise (689 and 690). Compared to nearby, inoceramidbearing ODP localities (698, 700, and 750), the Maud Rise sites may represent slightly cooler environments as they were deposited a little further south; however, foraminiferal assemblages indicate no significant environmental differences among the sites. At present we do not have an explanation for the absence of inoceramids on Maud Rise.

In addition to these global patterns, where the stratigraphic distribution of whole inoceramids is well documented, there is an ordered pattem of species extinction $[8,9]$. As already noted, only Tenuipteria ranges through the late Maastrichtian, but there is also structure in the pattem of disappearance of species of Inoceramus within the mid Maastrichtian pulse of extinction. In the Basque region large platyceramids and endocostids disappear first; the youngest Inoceramus taxon found is 1 . (Trochoceramus) morgani, which is a relatively small form [9]. Anecdotal evidence suggest that this morphologic pattem of disappearance is repeated outside the Basque region, and ongoing research is attempting to confirm these reports. If the pattern holds up, it suggests that the more typical, large, flat inoceramids were least tolerant of the changes occurring during the Maastrichtian.

The pattem of disappearance of inoceramids indicates that there was a major event during the mid Maastrichtian, which affected the benthic environment in all the world's oceans. The duration and the diachroneity of the inoceramid extinctions suggests that the forcing mechanism was a gradual change, not a sudden, catastrophic perur- 
bation. If most Maastrichtian inoceramids were adapted to low- $\mathrm{O}$ environments, a reorganization of ocean circulation leading to increasing influence of oxygenated, Antarctic bottom waters fits the constraints imposed by inoceramid biostratigraphy and paleogeography. In this scenario typical inoceramids would be expected to survive longest in somewhat isolated basins in low latitudes. Regardless of the ultimate fate of this hypothesis, though, changes occurring during the mid Maastrichtian provide the opportunity to examine the interplay of ecological variables on a global scale across a geologically resolvable interval of time.

References: [1] MacLeod K. G. and Orr W. N. (1993) Paleobio., 19, 235-250. [2] Kauffman E. G. (1988) Revista Espanola de Paleontologia, 57-71. [3] D'Hondt A. V. (1983) Zitteliana., 10, 689-701. [4] Huber B. T. (1991) in ODP Sci. Res., 1/4 (P. F. Ciesielski et al., eds.), 281-297. [5] Huber B. T. (1992) Palaeo., Palaeo., Palaeo., 92, 325-360. [6] Huber B. T. and Watkins D. K. (1992) in AGU Antarctic Research Series, 56 (J. P. Kennett and D. A. Warnke, eds.), 31-60. [7] Zinsmeister W. J. (1993) GSA Abstr. wish Progr., 25, A-295. [8] Ward P. et al. (1991) Geol., 19,

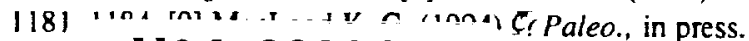

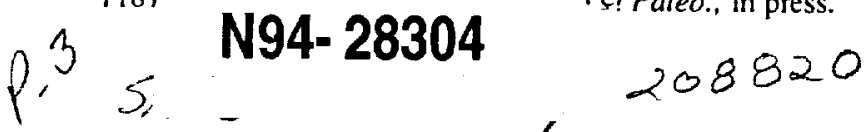

AN EVALUATION OF CRITERIA THAT MAY BE USED TO IDENTIFY SPECIES SURVIVING A MASS EXTINC. TION. N. MacLeod 1.2, 'Department of Geological and Geophysical Sciences, Princeton University, Princeton NJ 08544, USA, 2Present address: Department of Palaeontology, The Natural History Museum, Cromwell Road, London, SW7 5BD, UK.

One of the most difficult obstacles to establishing a causal connection between mass extinctions and large body impacts is the existence of what appear to be many more KT survivor species than previously suspected. Though interpretations of "Cretaceous" faunal elements in lowermost Danian sediments differ, this enigmatic fauna has now been recovered from every biozone-complete boundary section, including the El Kef stratotype. In terms of their potential for providing constraints on scenarios seeking to account for the KT extinction event, the significance of such observations cannot be overstated.

Owing to the consistency with which these observations have been made over the last several years, the possibility of widespread trans-KT biotic survivorship can no longer be dismissed. Rather, the survivorship hypothesis must be tested alongside its altemative (the reworking hypothesis) to detemnine which explains the available data in the most complete yet parsimonious manner. Moreover, valid tests for survivorship cannot be based on negative evidence or on the assumption that only a small cohor of species could have survived the KT boundary event. Several authors have recently proposed various criteria that might be used to test alternative interpretations for this aspect lowermost Danian biotic record (Table 1). These are evaluated below.

Preservational State: The most commonly applied test for survivor identification is based on the principle that physically reworked specimens should exhibit abrasions, breaks, recrystallized surface texture, or other signs of degraded preservation. Although it is possible to collect and quantify evidence bearing on preservational state, all reports of degraded physical condition of Cretaceous species in lowermost Danian sediments offered thus far have been qualitative and anecdotal. Nevertheless, several authors have noted that when specimens of "Cretaceous" species collected from Danian sediments are compared side by side with conspecific uppermost Cretaceous specimens, predicted differences in preservational state often fail to be observed. In addition, recent statistical analyses [1] indicate that the planktic foraminiferal survivor fauna is dominantly composed of species that are susceptible, rather than resistant, to abrasion and diagenesis.

Relative Abundance/Population Ratio: Olsson and Liu [2] explain this test as follows: "If one species survived (the KT boundary) its population size in the lower Paleocene would be composed of both the reworked and indigenous surviving fractions while that of the extinct species consists only of the reworked fraction. As a result, the relative abundance of the survivor taxon to that of the extinct species would significantly increase after the extinction of the other species" (p. 136). Applying the relative abundance/population ratio test to depositional rate-normalized $\mathrm{KT}$ planktic foraminiferal data of [2] and [3] shows that pattems of abrupt relative abundance decline in Danian occurrences of "Cretaceous" planktic foraminiferal species are not consistently observed for either established or putative KT survivor species. Nevertheless, pattems of post-boundary relative abundance variation exhibited by many "Cretaceous" species are indistinguishable from pattems present in widely-accepted survivor species. Overall, these data support recognition of a expanded survivor fauna and a progressive faunal turnover.

Stable Isotope Geochemistry: This test involves determining whether the stable isotopic signature of postboundary populations differs from that of preboundary populations. Recovery of different isotopic signatures from these populations constitutes a direct species-level test of survivorship. However, adequate controls must be maintained to insure that the observed difference cannot be accounted for through diagenetic or species-specific metabolic factors. Comparative analyses of planktic and benthic foraminiferal species from Brazos River (Texas), Nye Klov (Denmark), and ODP Site 738 (South Indian Ocean) suggest that several survivor species are present in these faunas. Changes in the isotopic signatures of these survivor populations also begin in the upper Cretaceous; well below the appearance of any putative impact debris.

Quantitative Morphology: Like the stable isotope test, consistent changes in test size and shape parameters provide another means of identifying survivor species. MacLeod and Keller [4] demonstrated that lowermost Danian samples of Heterohelix globulosa and $H$. navarroensis from Brazos Core undergo statistically significant test size reductions, while at the same time preserving the ontogenetic trajectories of comparably sized uppermost Maastrichtian populations. Once again, this size reduction does not coincide with the KT boundary but rather takes place well below this horizon, within the uppermost Maastrichtian. Since this initial study, similar size/shape patterns have been documented for several other "Cretaceous" survivor species in other boundary sections/ cores.

Comparative Biogeography: Occurrence of Danian populations of "Cretaceous" species in areas in which they were not observed during the upper Cretaceous is consistent with trans-KT survivorship. Also, comparison of changes in the biogeographic structures of survivor and indigenous Danian faunas can be used to determine whether the spatial organization of these faunas are

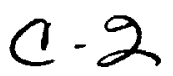


TABLE I. Criteria proposed for identifying survivor microfossil species.

\begin{tabular}{|c|c|c|}
\hline Criterion & Description* & Reference \\
\hline Preservational state & $\begin{array}{l}\text { Survivor species should exhibit a superior preservational } \\
\text { state relative to reworked specimens. }\end{array}$ & [7] \\
\hline $\begin{array}{l}\text { Relative abundance/ } \\
\text { population ratio }\end{array}$ & $\begin{array}{l}\text { Survivor species will include indigenous and reworked } \\
\text { fractions and thus will exhibit a sudden increase in } \\
\text { interspecific relative abundance and intraspecific relative } \\
\text { abundance (-population ratio) across the event horizon. }\end{array}$ & [2] \\
\hline Stable isotope geochèmistry & Survivor species may exhibit unique stable isolopic signatures. & [8] \\
\hline Comparative biogeography & $\begin{array}{l}\text { Survivor species may be found in previously unoccupied } \\
\text { habitats', might exhibit unique patterns of geographic } \\
\text { organization }{ }^{2}\left({ }^{2} \text { relative to underlying conspecific }\right. \\
\text { Cretaceous fauna), should exhibit pattems of geographic } \\
\text { organization similar to that of Danian faunas. }\end{array}$ & $\begin{array}{l}{[9]^{1}} \\
{[1]^{2.3}}\end{array}$ \\
\hline Quantitative morphology & Survivor species may exhibit changes in size or shape. & [4] \\
\hline Association with Ir anomaly & $\begin{array}{l}\text { Survivor species should persist above the level at which } \\
\text { It values (or } \mathrm{Ni} \text {-rich spinel abundances) have retumed } \\
\text { to background levels. }\end{array}$ & $\begin{array}{c}\text { Modified from } \\
{[10]}\end{array}$ \\
\hline $\begin{array}{l}\text { Synchronous last appearance } \\
\text { datums (LADs) }\end{array}$ & $\begin{array}{l}\text { Survivor species should exhibit synchronous LADs throughout } \\
\text { their geographic range. }\end{array}$ & [9] \\
\hline Phylogenetic ancestry & Incoming species should be derived from survivors. & [9] \\
\hline
\end{tabular}

similar (suggesting survivorship) or different (suggesting reworking). MacLeod and Keller [1] and MacLeod [5] have carried out an extensive series of analyses designed to implement this test. Results show that (1) many "Cretaceous" taxa occurring in the Danian portions of various boundary sections are not present in underlying Cretaceous strata, (2) a close and predictive association exists between "Cretaceous" and indigenous Danian species richness values throughout the lower Danian, (3) a close geographic correspondence is present between centers of Danian planktic foraminiferal speciation and the disappearance of "Cretaceous" species from the Danian fossil record, and (4) a pronounced similarity exists between changes in the general biogeographic structures of "Cretaceous" and indigenous Tertiary faunas throughout the lowermost Danian. Furthermore, these data show that the KT planktic foraminiferal extinction event exhibited a marked geographic structure with low- and middlelatitude faunas experiencing differentially high extinction rates in the lowermost Danian zones P0 and Pla and high-latitude survivor faunas persisting relatively unchanged into the overlying Danian.

Association with Elevated Ir Abundances: This test argues that Cretaceous faunas occurring in lower Danian sediments in which elevated ( $=$ nonbackground) levels of Ir also occur should be regarded as reworked. There are several problems with the use of this test. Association of "Cretaceous" morphotypes with elevated abundances of Ir in lowermost Danian sediments is indeterminate with respect to the question of survivorship. Bolide-introduced I can diffuse through undisturbed sediments via interstitial fluids [6] while fossils require physical disruption of the sediment to be reworked. Moreover, many lines of evidence indicate that the KT Ir anomaly reflects input of Ir into the environment from multiple sources over a considerable time interval. Assuming that stratigraphic thickness of the Ir anomaly might place an upper limit on the reworking depth, though, continued occurrence of "Cretaceous" morphotypes above the Ir anomaly constitutes evidence for survivorship. Using this test almost all Danian occurrences of "Cretaceous" taxa, regardless of taxonomic group, are identified as survivors.

Synchronous Last Appearance Datums (LADs): This test suggests that true survivors should have synchronous LADs. Both the Intemational Stratigraphic Guide and the North American Stratigraphic Code agree that the boundaries of most biozones, unlike the boundaries of chronozones, are characteristically and conceptually diachronous. Thus, there is no justification for the idea that synchrony of local LADs, or lack thereof, can play any role in deciding the question of survivorship. This conceptual distinction between biostratigraphic and chronostratigraphic units is also bome out by the large number of high-resolution biostratigraphic studies that routinely document substantial diachrony in paleontological datums.

Phylogenetic Ancestry: This proposed test is based on the principle that incoming species must be derived from survivor species. Of course, the phylogeny test is imelevant to determining the survivorship of Cretaceous species that may have existed in the lower Danian but failed to give rise to any fully Danian descendants. A more serious problem, however, lies in the fact that phylogeny can only provide a relative ordering, rather than the absolute lemporal location, of speciation events. These problems, along with present levels of indeterminacy with respect to the species-level phylog- 
enies of virtually all trans-KT clades, invalidate this application of phylogeny to the question of survivor identification.

The unambiguous identification of KT survivor species is extremely difficult. But, as outlined above, criteria are available to lest the survivorship/reworking altematives at both the individual species and faunal levels, though not all tests that have been proposed are adequate on theoretical or phenomenological grounds. While much more work needs to be done on this question, the data presented above demonstrates that there is a large body of evidence consistent recognition of a greatly expanded survivor fauna that dominated both marine and terrestrial ecosystems during the earliest Tertiary.

References: [1] MacLeod N. and Keller G. (1994) Paleobiology, 20, in press. [2] Olsson R. K. and Liu C. (1993) Palaios, 8, 127-139. [3] Keller G. et al. (1994) Palaios, 9, in press. [4] MacLeod N. and Keller G. (1990) GSA, 22, A 106. [5] MacLeod N. (1994) Historical Biology, 8, in press. [6] Colodner et al. (1992) Nature, 358, 402-404. [7] Keller G. (1988) Mar. Micropaleont., 13, 239-263. [8] Bartera E. and Keller G. (1990) Paleocean., 5, 867-870. [9] Liu C. and Olsson R. K. (1992) GSA, 24, A29. [10] Pospichal J. J. (1993) GSA, 25.

$$
\operatorname{lon} 7 \rightarrow P>8
$$

THE "UPPER CRETACEOUS UNIT' IN THE CHICXULUB MULTIRING BASIN: NEW AGE BASED ON PLANKTIC FORAMINIFERAL ASSEMBLAGE. L. E. Marín', V. L. Sharpton $^{2}$, J. Urtutia-Fucugauchil, P. Sikora ${ }^{3}$, and C. Camey ${ }^{3}$, Instituto de Geofisica, Universidad Nacional Autónoma de México, Cd. Universitaria, Mexico City, 045 10, Mexico, ${ }^{2}$ Lunar and Planetary Institute, 3600 Bay Area Boulevard, Houston TX 77058, USA, ${ }^{3}$ Amoco Production Company, 501 Westlake Park Boulevard, Houston TX 77253, USA.

The Chicxulub structure is now recognized as one of the largest multiring impact basins on Earth with a corresponding age of $65 \mathrm{~m} . \mathrm{y}$. [1]. It has been interpreted as the source of the KT ejecta layer. However, some doubt has been expressed as to the age of the structure because "Upper Cretaceous" fossils were reported $355 \mathrm{~m}$ above what is now known to be the impact melt in the well Yucatan 6 [2]. However, samples recently released by Petroleos Mexicanos (Pemex) to the Universidad Nacional Autónoma de México have allowed us to examine closely the core immediately above the impact rocks in the Yucatan 6 well. The so-called Upper Cretaceous limestone unit is represented by core interval (nucleo) 12 recovered from a depth 1000-1003 $\mathrm{m}$ below sea level. This unit is a finegrained well-indurated white limestone with visible laminations demarcated by dark gray fine-grained material, possibly clay. Original records indicate that a $2-\mathrm{cm}$-thick bentonite layer is located near the top of this core interval. The next core interval down from N12 was recovered from a depth $1100-1103 \mathrm{~m}$ below sea level. N13 was previously listed as a green bentonitic sandstone unit of Upper Cretaceous age, but our analysis indicates that this is a sand-sized impact breccia containing shocked mineral clasts and partially altered glass in a a carbonate-rich matrix.

Thin sections of two N12 samples (part 11 and part 12) near the base of the core interval were examined. The fossil assemblage consists mainly of abundant planktic foraminifera of the genera Globigerina and Globorotalia. The following age-significant spe-

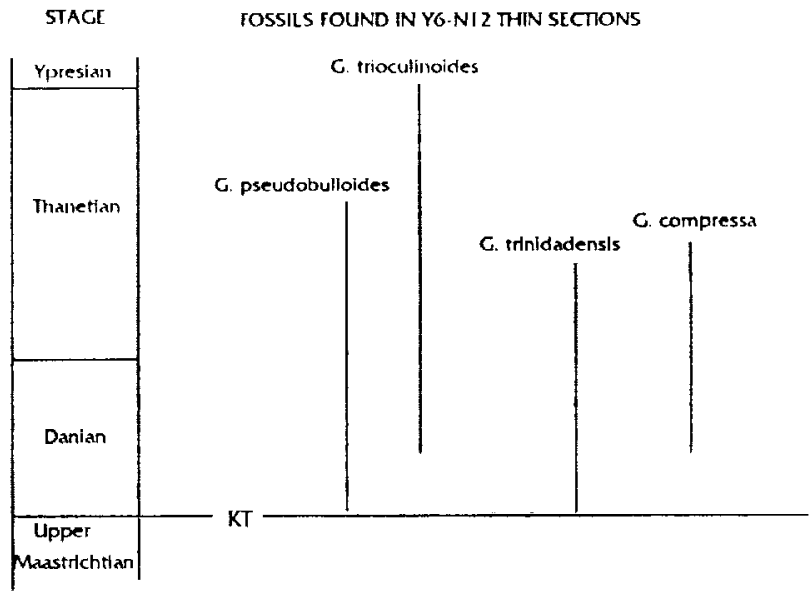

Fig. 1.

cies were identified: Globorotalia pseudobulloides, Globorotalia Irinidadensis (or possibly Globorotalia uncinata), and Globigerina triloculinoides. Each of these forms has the base of its stratigraphic range in the lower Danian; the youngest base is that of $G$. compressa. The tops of their ranges are mostly in the lower Thanetian; the oldest top is that of $G$. trinidadensis in the lowermost Thanetian. Thus, the most likely age for these cores is Middle-Lower Danian to lowermost Thanetian. These age assignments rely on the stratigraphic ranges of these species in Amoco's Corporate Composite Standard Database, but can be referenced to (Blow's) Planktonic Foram Zones [e.g., 3]; either middle P1 through Middle P2 if we have $G$. trinidadensis or Lower $\mathrm{P} 2$ through Lower $\mathrm{P} 3$ if we have $G$. uncinata. Either alternative yields Lower to Lower Middle Paleocene (Fig. 1).

At the time of deposition, the water depth at this spot was at least $100 \mathrm{~m}$. This is based on the abundant occurrences of planktonic forams in general. Frequent occurrences of Globorotalias suggest somewhat deeper water environments, maybe outer neritic-approaching $200 \mathrm{~m}$. We observe a single specimen that appears to be Nuttallides (benthic). If this interpretation is correct, an upper bathyal environment is implied. More work is needed, however, before a positive identification of Nuttallides can be made.

The work presented here shows that the so called "Upper Cretaceous" fossil assemblage found above the impact melt has an age corresponding to the Lower Tertiary. Thus, the age of this unit is consistent with Chicxulub being temporally linked to the KT boundary, as radiometric and paleomagnetic data have indicated.

Acknowledgments: The authors acknowledge Pemex for providing the cores to Unịversidad Nacional Autónoma de México. This work was funded through grants to L. E. Marin by DGAPA (IN I06891). We also thank the Johnson Space Center and Amoco Production Company for providing additional support. This work is part of a cooperative research agreement between the Lunar and Planetary Institute and Universidad Nacional Autónoma de México.

References: [1] Sharpton et al., this volume. [2] Lopez Ramos (1973) Geologia de Mexico. [3] Bolli et al. ( 1985) Plankton Stratigraphy. 
MODULATING TERRESTRIAL IMPACTS FROM OORT CLOUD COMETS BY THE ADIABATICALLY CHANGING GALACTIC TIDES. J. J. Matese', P. G. Whitman', K. A. Innanen', and M. J. Valtonen ${ }^{3}$, 'Department of Physics, The University of Southwestern Loujsiana, Lafayette LA 70504-4210, USA, ${ }^{2}$ Department of Physics, York University, Toronto ON, M3J IP3, Canada, ${ }^{3}$ Tuorla Observatory, SF-21500, Piikkiö, Finland.

Time modulation of the flux of new Jupiter-dominated Oort cloud comets is the subject of interest here. The major perturbation of these comets during the present epoch is due to the tidal field of the relatively smooth distribution of matter in the galactic disk. A secondary source of the near-parabolic comet flux are stars penetrat-: ing the inner Oort cloud and providing impulses that create brief comet showers. Substantial stellar-induced showers occur approximately every 100 m.y. Less frequent (but stronger) impulses due to giant molecular clouds can also perturb comets from the inner cloud. These occur on timescales of $\approx 500$ m.y. In contrast to these infrequent stochastic shower phenomena is the continuously varying tidal-induced flux due to the galaxy. As the Sun orbits the galactic center it undergoes quasiharmonic $\left(T_{z}=64\right.$ m.y.) motion about the galactic midplane, which is superimposed on the small eccentricity, near-Keplerian motion in the plane having epicycle period $=150$ m.y. In the process the galactic tidal field on the Sun/cloud sy stem will vary, causing a modulation of the observable Oort cloud flux. We have created a model of the galactic matter distribution as it affects the solar motion over a time interval ranging from 300 m.y. in the past to $100 \mathrm{~m} . \mathrm{y}$. into the future. As constraints on the disk's compact dark matter component we require consistency with (1) the observed galactic rotation curve, (2) today's flux distribution of new comets, (3) the studies of K-giant distributions, and (4) the periodicity found in the terrestrial cratering record. The adiabatically varying galactic tidal torque is then determined and used to predict the time dependence of the flux. We find that a model in which approximately half the disk matter is compact is consistent with these constraints. Under such circumstances the peak-to-trough flux variation will be $\approx 5: 1$ with a full width of 9 m.y. This variability will manifest in the terrestrial cratering record and is consistent with the observed cratering periodicity, if over half of the impacts on Earth are caused by comets or asteroids that originate in the outer Oort cloud.

Analysis: The galaxy is modeled using a modified CBIP potential with a nucleus, a bulge, a halo, and a disk. The analysis is similar to that described in Innanen et al. [1]. A central issue here is the question of local dark disk matter. Bahcall et al. [2] have analyzed the distribution of $\mathrm{K}$ giants and have concluded that there is "significant but not overwhelming evidence for disk dark matter." We are guided by their ISM-like model. Two of the three disk components of the disk are fixed as having scale heights of $325 \mathrm{pc}$ and $125 \mathrm{pc}$, mass fractions of $4: 1$ respectively, and represent old stellar and atomic gas contributions. The third component is compact and simultaneously includes contributions of young stars, dust, molecular $\mathrm{H}$, and the dark matter. We then vary three disk parameters, the total disk mass, the fraction of disk matter that is compact, and the scale height of the compact component.

The disk mass is tightly constrained by a present solar velocity, which we fix at $\Theta=225 \mathrm{~km} \mathrm{~s}^{-1}$. The scale height and mass fraction of the compact component are primarily limited by the K-giant studies and the period requirement. The equations of molion of the Sun about the galactic center are solved both backward and forward in time. As initial conditions we adopt $Z_{\odot}-10 \mathrm{pc}$ and $R_{\odot}=8 \mathrm{kpc}$ along with a $Z$ component of velocity of $7.5 \mathrm{~km} \mathrm{~s}^{-1}$. The scale height and mass fraction of the compact component is then varied (keeping the total mass fixed) and the solar motion is determined. In Fig. 1 we show the parameter range that reproduces the required planecrossing period. For further illustrations we choose the specific parameter set for the compact disk component to have scale height $50 \mathrm{pc}$ and mass fraction 0.50 . It corresponds to total local disk midplane density of $0.29 \mathrm{M}_{\odot} \mathrm{pc}^{-3}$ and yields a mean plane crossing period of $32 \mathrm{~m} . \mathrm{y}$. This is within the 10 range of values (dark matter mass fraction 0.24-0.74) given in [2] for their ISM model. In Fig. 2 we illustrate the trajectory of the Sun as it orbits the galaxy. The time interval considered is from 100 m.y. in the future to 300 m.y. in the past.

Results: It has been demonstrated that the galactic tidal field dominates random stellar encounters in making Oon cloud comets observable [3-5]. Matese and Whitman describe how the time evolution of all orbital elements can be analytically determined if the disk density $\rho_{\odot}(t)$ can be taken as adiabatically changing. The results are expressible in terms of Jacobi elliptic functions. Of the elements $\omega, \Omega, \mathrm{i}, \mathrm{e}$, and a only the last is taken to be invariant in the

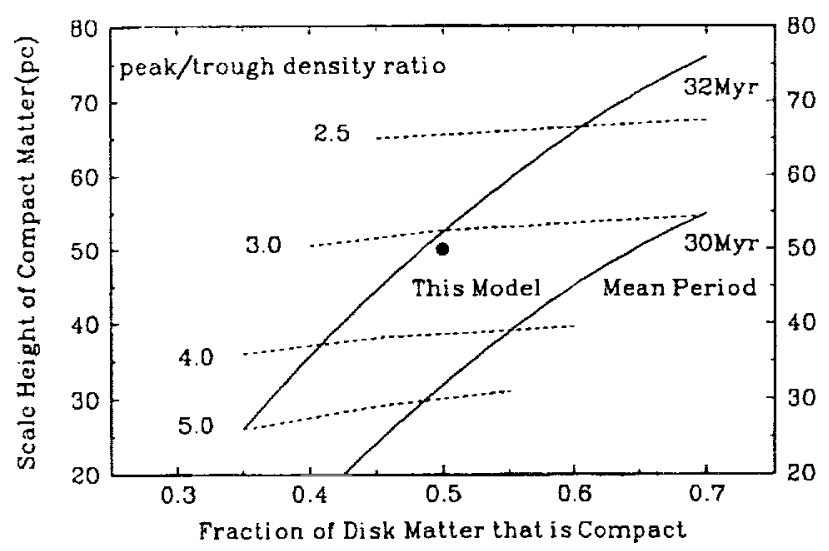

Fig. 1. Parameter range of the disk compact malter. Solid curves border parameters for galactic midplane crossing intervals of 30-32 m.y. Dashed curves illustrate the ratio of maximum to minimum disk density per oscillation cycle.

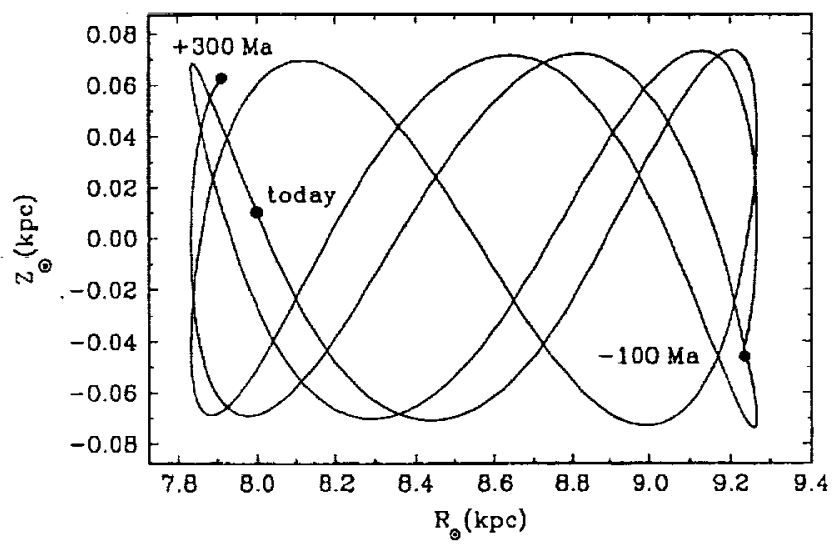

Fig. 2. Solar trajectory from $300 \mathrm{~m} . \mathrm{y}$. in the past to $100 \mathrm{~m} . \mathrm{y}$, in the future. 


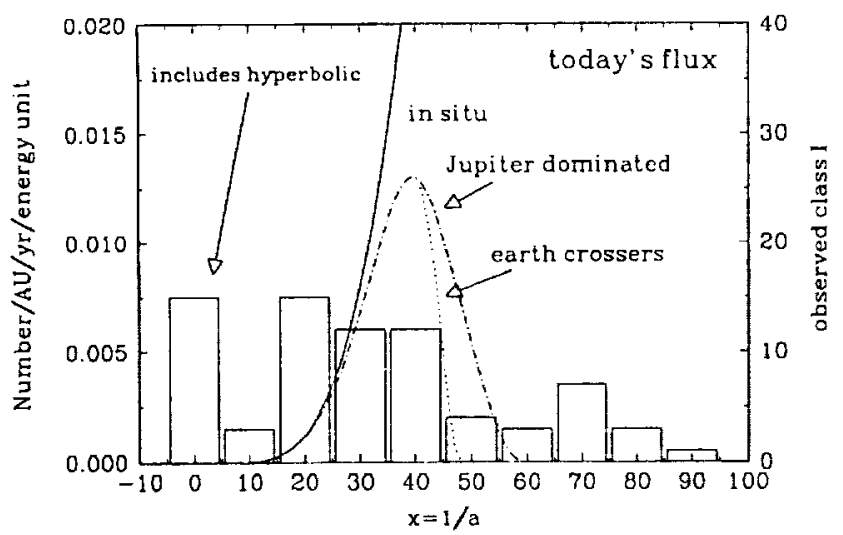

Fig. 3. Theoretical Oort cloud flux for today 's density. The observed flux of new class I comets is shown also.

adiabatic limit. Since a typical Oort comet has a semimajor axis $\mathrm{a} \approx$ $30,000 \mathrm{AU}$ (period $\approx 5$ m.y.) this approximation is adequate here. Our model of the Oor cloud includes the following assumptions.

The distribution of comet angular momenta and perihelia directions is taken to be random. For the in situ comet energy flux (shown in Fig. 3) we adopt the predictions of Bailey [6] where $x \equiv 10^{6} \mathrm{AU} / \mathrm{a}$ is a dimensionless original energy and the nominal cloud boundary is $\mathrm{a}=10^{5} \mathrm{AU}$. A Monte Carlo analysis proceeds in a manner detailed in $[4,5]$ in which trajectories are evolved one period into the future and new orbit parameter values are determined. The notion of a "tidal efficiency," which measures the ability of the galactic tide to overcome the loss cylinder barrier and change the perihelion distance, was described in [5]. We use the tidal efficiency, at a time retarded by half an orbital period, along with in situ flux density to predict the flux of Oort comets whose perihelia leap the loss cylinder barrier ( $15 \mathrm{AU})$ to the zone of Jupiter dominance in a single orbit due to tides.

Figure 3 also shows today's predicted Earth-crossing as well as Jupiter-dominated flux. The results are scaled to the observed flux of new comets today. For comparison we further show the observed distribution [7] of class I comets that are broadened by measurement errors and nongravitational forces. The time-dependent Jupiterdominated current is displayed along with the galactic density at the solar location in Fig. 4. We have subjected the results of Fig. 4 to a conventional regression analysis to determine the width of the current peaks. The standard deviations are 4.0-4.5 m.y.

In Table 1 we list the epochs of peak Oort cloud currently entering the solar system as well as the maximum and minimum rates. One observes that the cycle interval, $\tau$, changes, i.e., the "periodic" oscillations have in fact a variable period. Further, the phase of the nearest cycle peak is $0.6 \mathrm{~m} . \mathrm{y}$. in the future with the adopted parameters. This is consistent with the terrestrial cratering record $[8,9]$. There is ample evidence from the dating of impact structures and impact glass that suggests that the nearest flux maximum may not have occurred as yet. The predictions are in good agreement with the dating of impact glasses, microspherules, and the Ir anomalies that have peaks at I, 35, and 65 m.y. ago [9].

Shoemaker and Wolfe state that the cratering record appears to be periodic but consider it to be a statistical fluke as they can find

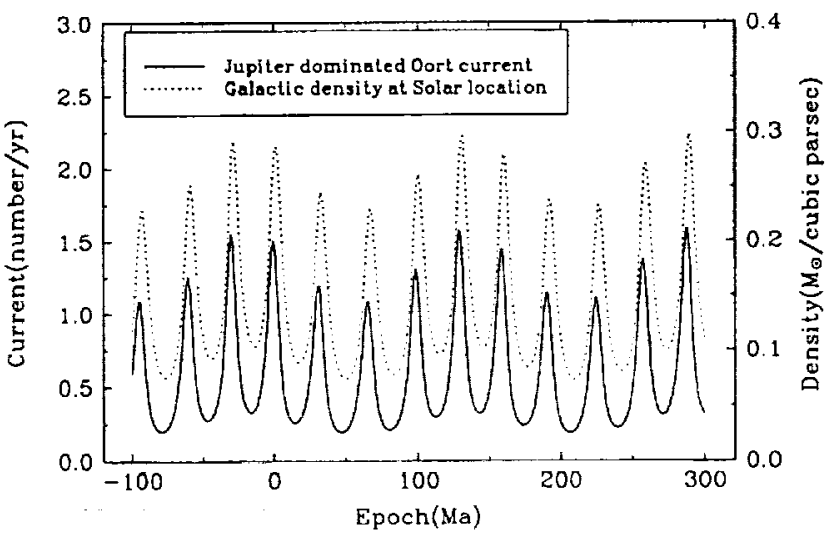

Fig.4. Time dependence of the Jupiter-dominated current of comets from the outer Oort cloud due to the adiabatically changing galactic tides. Note the small retardation between the current and the density.

no mechanism for the periodicity. In particular they reject the galactic oscillations model of Rampino and Stothers [8] since it requires the impulsive perturbation of inner Oort cloud comets by molecular clouds. As the plane-crossing epochs are too close to the crater peak times of $2,32,65$, and 99 m.y. ago to be due to rare stochastic cloud impulses, the Rampino-Stothers mechanism was rejected as a clock for this phenomena. These objections are obviated in the present model since modulation of outer Oort cloud comet flux is the physical mechanism for the periodicity.

In comparing these results with the numerical experiments on impact periodicity, we need to estimate the total dispersion expected from a strictly periodic sequence, i.e., we should convolve the standard error in the mean cycle interval $(\approx 1 \mathrm{~m} . \mathrm{y}$.) with the standard deviation of the modulation about the cycle peak ( $\approx 4 \mathrm{~m} . \mathrm{y}$.) and the dating uncertainties of the most accurately dated craters $\left(\approx 4 \mathrm{~m} . y_{\text {. }}\right.$. If terrestrial cratering impact probabilities were modulated as described here with dating uncertainties of this order, we would expect a net dispersion about a strictly periodic signal to be $\approx 5-6$ m.y. Were such a signal to have a reasonable probability of

TABLE 1. Oort cloud maxim̄um [minimum] currents.*

\begin{tabular}{rccc}
\hline$-t_{\text {max }}{ }^{+}$ & $\left(\tau^{+}\right)$ & Earh & Jupiter \\
\hline-95.0 & $(33.8)$ & $0.146[0.025]$ & $1.088[0.199]$ \\
-61.2 & $(31.1)$ & $0.168[0.035]$ & $1.250[0.275]$ \\
-30.1 & $(29.5)$ & $0.210[0.043]$ & $1.554[0.328]$ \\
-0.6 & $(31.3)$ & $0.202[0.033]$ & $1.501[0.260]$ \\
30.7 & $(34.0)$ & $0.160[0.025]$ & $1.193[0.193]$ \\
64.7 & $(33.4)$ & $0.145[0.027]$ & $1.085[0.210]$ \\
98.1 & $(30.5)$ & $0.176[0.038]$ & $1.306[0.294]$ \\
128.6 & $(29.7)$ & $0.212[0.042]$ & $1.571[0.323]$ \\
158.3 & $(31.9)$ & $0.194[0.031]$ & $1.441[0.241]$ \\
190.2 & $(34.2)$ & $0.153[0.024]$ & $1.143[0.189]$ \\
224.4 & $(32.9)$ & $0.148[0.029]$ & $1.107[0.224]$ \\
257.3 & $(30.0)$ & $0.185[0.040]$ & $1.376[0.311]$ \\
287.3 & & 0.214 & 1.581 \\
\hline
\end{tabular}

* Scaled to 0.2 Earth-crossers/yr today.

+ Epoch of maximum comet current, in Ma.

" Cycle interval to previous maximum, in m.y. 
manifesting itself in the cratering record the steady-state main-belt asteroidal cratering rate would have to be $<50 \%$ of the total.

It is noted that the actual galactic disk matter compactness and the past solar motion are not well known. Should it be verified that (I) over half the disk matter is compact and of scale height $\approx 50 \mathrm{pc}$, and (2) over half of terrestrial cratering is due to active, dormant, or extinct comets having an origin in the outer Oort cloud, then the solar oscillation cycle will manifest itself in the cratering record at the marginally significant level observed. These results do not require the dark matter to be in the form of massive objects capable of impulsing the inner Oort cloud. Detectable modulation will exist even in the absence of infrequent molecular cloud showers. The observed periodicity in terrestrial cratering would then no longer be rejectable as a statistical fluke and we would be approaching a flux maximum from the outer Oort cloud within the next $\approx 1 \mathrm{~m} . \mathrm{y}$. We could then say that today we are at the peak of a continuous cometary drizzle, if not a shower.

References: [1] Innanen K. A. et al. (1978) Astrophys. Space Sci., 57, 511-515. [2] Bahcall J. N. et al. (1992) Astrophys. J., 389, 234-250. [3] Heisler J. and Tremaine S. (1986) Icarus, 65, 13-26. [4] Matese J. J. and Whitman P. G. (1989) Icarus, 82, 389-401. [5] Matese J. J. and Whitman P. G. (1992) Celest. Mech. Dyn. Astron., 54, 13-36. [6] Bailey M. E. (1986) Mon. Not. R. Astron. Soc., 218, 1-30. [7] Marsden B. G. (1989) Catalogue of Comelary Orbits, 6th ed. [8] Rampino M. R. and Stothers R. B. (1986) The Galaxy and the Solar System, 241-260. [9] Shoemaker E. M. and Wolfe R. F. (1986) The Galaxy and the Solar System, 338-386.

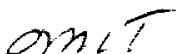

A SEARCH FOR TEKTITE-RELATED STRUCTURES IN NORTHEASTERN THAILAND: AN EXAMINATION OF SPOT SATELLITE IMAGES. J. F. McHone Jr. ${ }^{1}$, K. Pitakpaivan $^{2}$, S. Bunopas ${ }^{2}$, P. Angsuwathana ${ }^{2}$, T. Supajanya ${ }^{3}$, and J. T. Wasson ${ }^{4},{ }^{1}$ Arizona State University, Tempe AZ, USA, ${ }^{2}$ Geological Survey Divjsion, Department of Mineral Resources, Bangkok, Thailand, ${ }^{3}$ Chulalongkorn University, Bangkok, Thailand, ${ }^{4}$ University of California, Los Angeles CA 90024, USA.

The dip of the magnetic remanence indicates that layered (MuongNong-type) Australasian tektites formed as puddles of melt with their layers roughly parallel to the Earth's surface [1,2]. Wasson [3] concluded that, because silicate melt can only retain its heat within the incandescent impact plume, these melis were ejected from nearby small (kilometer-sized) craters. Several deposits of layered Australasian tektites have been found in northeastem Thailand, with the largest in the northeastem comer.

We obtained a set of seven high-resolution, 1:50000-scale, SPOT1 and SPOT-2 satellite images covering parts of the southeastern comer of northeastem Thailand and examined them for possible impact structures. Four adjacent images and corresponding topographic maps provided location and elevation controls for the most promising region comprising more than $3000 \mathrm{~km}^{2}$. Examination of these yielded several sites that may be craters.

Layered tektites are found over a band $1200 \mathrm{~km}$ long extending from Hainan Island in the north-northeast to central Cambodia in the south-south west. Wasson [3] noted that it appears to be impossible for a single large (5-20-km radius) crater to produce puddles of melt over such a large region and suggested that a cometary projectile broke up in deep space with the fragments producing many thou-
TABLE 1. Kilometer-sized circular features near Buntharik and Det Udom, Thailand, recognized on satellite images and topographic maps.

\begin{tabular}{|c|c|c|c|}
\hline Site & ${ }^{\circ} \mathrm{E}$ & ${ }^{\circ} \mathrm{N}$ & Feature \\
\hline 1 & 105.42 & 14.73 & $\begin{array}{l}\text { Shallow } 1.5-\mathrm{km} \text {-diameter basin with annular } \\
\text { ring at } 2.5 \mathrm{~km} \text {. }\end{array}$ \\
\hline 2 & 105.46 & 14.73 & $\begin{array}{l}\text { I-km depression includes reservoir. } \\
\text { Bleached rim indicates grading. Airstrip. }\end{array}$ \\
\hline 3 & 105.15 & 14.77 & $\begin{array}{l}\text { Bull's-eye structure. Radius of outer ring } \\
\text { (with stream) } 2.5 \mathrm{~km} \text {, inner ring } 1 \mathrm{~km} \text {. }\end{array}$ \\
\hline 4 & 105.24 & 14.80 & $\begin{array}{l}\text { Village on central mound. Annular rings at } \\
1-\mathrm{km} \text { and } 4-\mathrm{km} \text { radii. }\end{array}$ \\
\hline 5 & 105.48 & 14.83 & $\begin{array}{l}\text { Annular drainage. May be eviscerated } \\
\text { dome. }\end{array}$ \\
\hline $6 a$ & 105.07 & 14.98 & $\begin{array}{l}\text { Small elliptical feature on topographic high. } \\
\text { Radius } 0.15 \mathrm{~km} \text {. }\end{array}$ \\
\hline $6 b$ & 105.14 & 14.85 & $\begin{array}{l}\text { Several elliptical to subrounded features. } \\
\text { Radii } \leq 0.3 \mathrm{~km} \text {. }\end{array}$ \\
\hline $6 c$ & 105.06 & 14.76 & $\begin{array}{l}\text { Elliptical features, some farmed. Possible } \\
\text { meander scars. }\end{array}$ \\
\hline $6 d$ & 105.17 & 14.85 & $\begin{array}{l}\text { Eliptical feature. Bleached southem mar- } \\
\text { gin. Radius } 0.3 \mathrm{~km} \text {. }\end{array}$ \\
\hline $6 e$ & 105.32 & 14.63 & $\begin{array}{l}\text { Numerous small, vegetated, rounded fea- } \\
\text { tures having radii } \leq 0.3 \mathrm{~km} \text {. }\end{array}$ \\
\hline
\end{tabular}

sands of small craters across the region where layered textiles have been found. The microteklites and the tektites showing atmospheric ablation features were launched from the largest one or more craters whose formation deposited enough energy lo produce a plume that penetrated through the atmosphere.

Much of this $1200-\mathrm{km}$-long field of the layered tektites is mountainous and has experienced appreciable erosion during the $770 \mathrm{ka}$ since the Australasian tektites were formed [4]. Other regions, particularly in the valley of the Mekong and some other major rivers, have been covered by recent sediments. Particularly promising for crater preservation is the flat-lying Khorat Plateau of northeastem Thailand. The southeastem comer of northeastern Thailand is within the layered-tektite band; in fact, large deposits of layered tektites have recently been discovered near the county-seat town of Buntharik. The existence of these tektites demonstrates that erosion in the region has been minimal during the past $770 \mathrm{ka}$. The bedrock is mainly sandstone; there seems to be little salt or limestone in the stratigraphic column, and thus there are no solution features that would mimic small craters.

The locations of the most promising sites are summarized in Table 1. All sites are on the four quadrangles 60381-60384 covering the region $105.0^{\circ}-105.5^{\circ} \mathrm{E}$ and $14.5^{\circ}-15.0^{\circ} \mathrm{N}$. The Thai coordinates listed in Table 1 are kilometers east of Bangkok and north of the equator. The prime search site is the first, which shows up prominently on aerial photos, the SPOT image, and the 1:50000 topographic sheet. All bear investigating; one, site 5 , is only a few kilometers from a region where large layered tektites are being found today.

Site 1: Centered about $5 \mathrm{~km}$ south-southeast of Amphoe Buntharik, this site was the target of a brief reconnaissance visit in February 1989. The site is a topographic depression about $0.7 \mathrm{~km}$ in radius surrounded by a discontinuous, slightly elevated rim to the east. An isolated hill in the west may represent a large ejecta block. A north-south road from Buntharik to Kaeng Sawang traverses the 
slightly elevated westem margin of the depression. Field work in 1989 showed sandstone outcropping on this western margin. Unconsolidated sediments in the center of the structure seem to be lake deposits.

Site 2: We list this site immediately after site 1 because it is geographically near, but the available evidence for impact origin is ambiguous. The center is only $4 \mathrm{~km}$ east of site 1; a small airport, Sua Phra Camp, and the villages of Ban Nan Noi and Ban Nong Saena occupy elevated ground surrounding three sides of the 0.8 radius, amphitheater-like depression that opens westward into a small reservoir. The satellite image of the area is dominated by bleached ground indicating bare soil due possibly 10 grading or agriculture.

Site 3: This site is located $\sim 17 \mathrm{~km}$ southeast of Amphoe Det Udom. The village of Ban Lup Lao is centered within a 3-km-radius partial bull's-eye pattem prominent on both the SPOT image and the topographic map. Outcrops along the annular streams would be suitable initial targets for investigation.

Site 4: This site is geographically near site 3 and also seems to be a multiring structure. About $9 \mathrm{~km}$ east-northeast of Ban Lup Lao, the village of Ban Bua Ngain is situated on a small area of higher ground that may represent the center of a bull's-eye feature nearly $3 \mathrm{~km}$ in radius. Trails radiate from the village several kilometers in all directions indicating generally gentle relief but the drainage pattern weakly suggests possible concentric ring troughs at radial distances of $0.8 \mathrm{~km}$ and $3 \mathrm{~km}$.

Site 5: This 1-km-radius circular feature is centered some $3 \mathrm{~km}$ north of Ban Pa Tia village and $2 \mathrm{~km}$ southeast of Ban Nonk Kop. This area is at the southeast end of the big Lam Dom Noi Reservoir in a region of intense road building east and northeast of Buntharik. The structure is within several kilometers of tektite recovery sites near the village of Huai Sai.

Sites 6a-6e: Scattered in low-lying regions throughout the area are numerous elliptical or subcircular features having radii smaller than $\sim 0.3 \mathrm{~km}$. Most appear to be basins with subdued rims, especially along southem margins. Many are elongated with longer axes running north-northwest 10 south-southeast. Several are located along a 3-km stretch north of the road between Wat Ban Mak Mai and Highway 2182. This is the area between the Ban Lup Lao bull's-eye structure and Amphoe Det Udom. Because these structures are quite small, it would be remarkable if they are craters that have been preserved for $770 \mathrm{ka}$.

A field trip to northeastem Thailand by North American and Thai scientists is planned for January 1994. The prime targets for investigation are the first five listed in Table 1. In addition we will survey the occurrence of layered tektites in the region. A preliminary survey in 1989 indicated that all fragments in the tektite-bearinglaterite marker horizon in this region are layered.

If time permits, we will also survey some circular sites about $200 \mathrm{~km}$ to the north where layered tektites have been found northwest of the city of Mukdahan. SPOT images of this region have been requested.

We expect to receive SIR-C shuttle radar images of these regions in mid 1994; these will allow additional sites to be defined for investigation in subsequent field work.

References: [1] De Gasparis A. A. et al. (1975) Geology, 3, 605-607. [2] Barnes V. E. and Pitakpaivan K. (1962) Proc. Natl. Acad. Sci., 48, 947-955. [3] Wasson J. T. (1991) EPSL, 102, 95109. [4] Izett G. A. and Obradovich J. D. (1992) LPS XXIII, 593594.

Approximately 950 impact craters have been identified on the surface of Venus [e.g., 1], mainly in Magellan radar images. From a combination of Earth-based Arecibo, Venera 15/16, and Magellan radar images, we have interpreted 72 as unequivocal peak-ring craters and four as multiringed basins $[2,3]$. The morphological and structural preservation of these craters is high, owing to the low level of geologic activity on the venusian surface (which is in some ways similar to the terrestrial benthic environment). Thus these craters should prove crucial to understanding the mechanics of ringed crater formation. They are also the most direct analogs for craters formed on the Earth in Phanerozoic time, such as Chicxulub. Below summarize our findings to date $[2,3]$ conceming these structures:

Peak-ring craters are relatively large complex craters whose central structure is a ring of peaks rather than a single central peak or central-peak complex. Otherwise they possess the usual features of complex craters: flat, usually melt-covered floors and a collapsed, terraced rim. For peak-ring craters on Venus, crater-rim to innerpeak-ring diameter, or ring, ratios decrease with increasing crater diameter; the ratios do not follow $\sqrt{2}$ spacing [4]. The onset to the peak-ring form is in the $\sim 30-40-\mathrm{km}$-diameter interval [3]. The morphology of peak-ring craters, the decrease in ring ratios with increasing crater size, and the general size-morphology progression from complex central-peak to peak-ring crater, including some with both an inner ring and a central peak or peaks, on Venus and the other terrestrial planets suggest a similar process of peak-ring formation: hydrodynamic downward and outward collapse of an unstable central peak to form a ring. The overall phenomenology of the peak-to-peak-ring crater transition on the terrestrial planets (morphology, ring ratios, etc.) is also consistent in character with the differential melv/crater volume scaling hypothesis of Grieve and Cintala [5], in which the core of the central uplift is shock melted and weakened so that the final, stable, emergent form of the uplift is a ring.

The four largest ringed structures on Venus-Klenova, Lise Meitner, Isabella, and Mead-are structurally and morphologically more similar to the Orientale Basin on the Moon, and are probably true multiringed basins. Here we refer to multiringed basins as those that have one or more outer rings that are (usually) asymmetric in radial topographic profile and structurally appear to have formed by circumferential normal faulting. While the four venusian structures $(\approx 145-, 150-, 170-$, and $270-\mathrm{km}$ diameter) are smaller than Orientale ( $\approx 930-\mathrm{km}$ diameter), we suggest that based on the megaterrace/ring tectonic model of Melosh and McKinnon [6], the higher gravity and temperature gradients on Venus, compared with that of the Moon when its basins formed, compensate and allow a crustal or mantle asthenosphere to form and inward viscous flow to create sufficient radial extensional stress in the overlying lithosphere. It is this stress that initiates the circumferential normal faulting and outer ring formation.

Tuming our attention to the Earth, given that the geology and surface gravily of the Earth and Venus are similar, we expect that 
fresh terrestrial impacts greater than $-30-40-\mathrm{km}$ diameter should have interior rings. In the tabulation of large terrestrial impacts in, or dominantly in, crystalline rocks [5], the majority above $40 \mathrm{~km}$ diameter have central depressions, offset peaks, or rings, despite the interpretational difficulties posed by erosion. We also expect that terrestrial craters $\geq 150 \mathrm{~km}$ diameter have the potential to be true multiringed basins. The formation of outer, asymmetric-in-profile rings in the megaterrace/ring tectonic model depends on subsurface rheology, which is determined by composition and especially by temperature. Large asteroids striking present-day oceanic lithosphere could create rings by this mechanism, but probably would not within continental cratons because of the low heat flows there [7]. There the peak-ring form should persist to much higher diameters. As an example, we address one of the largest and most significant structures in the terrestrial record, Chicxulub.

Suspected from magnetic data, corroborated by gravity, and finally confirmed as an impact by petrology [8, cf. 9], Chicxulub is probably the KT crater (or the major one). Chicxulub is definitely in the size class to be multiringed. The gravity and magnetic anomalies define a bull's-eye pattem $\sim 180 \mathrm{~km}$ across [8]. Unfortunately it is buried by younger carbonate platform rocks, so structural information on the crater itself is lacking. Reprocessed gravity data over the northem Yucatan by Sharpton and others [10] clearly show a main rim with a diameter of $199 \pm 12 \mathrm{~km}$ and a central ring with a diameter of $105 \pm 10 \mathrm{~km}$. The gravity signature hints at an additional ring between the two others, but it is not nearly as prominent, if it exists. Chicxulub may thus be a very large peak-ring crater. On the other hand, Chicxulub apparently formed within a few hundred kilometers of several active plate margins [8], albeit excavating into early Paleozoic crystalline basement [10], so it is not inconceivable that the heat flow was high enough to, for example, define a crusial asthenosphere during transient crater collapse, leading to outer ring formation and thus to three (or four) rings. We are not claiming that Chicxulub is a true multiringed basin, only that it is a possibility.

The case for Chicxulub being a multiringed basin in the structural sense meant here would be enhanced if it were larger, implying greater driving stresses during collapse and lower deep crustal viscosities. A fourth, outer ring of $278 \pm 22 \mathrm{~km}$ diameter is advocated in [10] on the basis of some very-low-amplitude, discontinuous gravity highs. It is also apparent that the argument for this ring and the intermediate one mentioned above is enhanced in [10] by belief in an invariant $\sqrt{2}$ spacing for impact rings [4]. Our results for Venus [2,3], as well as those of the Magellan team [1], demonstrate that ring spacing is not invariant and alone is an imperfect guide for understanding impact mechanics. Clearly, direct structural information must take precedence (this is partly why the relatively pristine craters on Venus are so valuable). Thus it is interesting that a less than conspicuous feature of the venusian multiringed structures, the inner "peak ring," should be so prominent in the gravity maps interpreted in [10], while a major structural feature, the outer down-faulted rim, hardly shows up in the Chicxulub gravity field (i.e., the outer ring in [10]). Volcanic burial of venusian peak rings and erosion of the original Chicxulub rim can be invoked, but erosion won't erase the offsets of subsurface layers caused by the outer ring fault. Greater attention to this last point, as well as additional gravity and seismic data, should confirm or deny the existence of the $280-\mathrm{km}$ ring of Chicxulub. Modeling Magellan gravity to constrain the subsurface structure beneath the large venusian craters, and well as theoretical models of their formation, will also be important.

Any discussion of Chicxulub naturally brings up the question of the KT mass extinction. It is sobering to contemplate a map of the venusian surface with its impact craters clearly marked (for example, Plate 2 in [11]). Over the same time period $(\sim 500 \mathrm{~m}$.y., or the length of the Phanerozoic) the Earth has accumulated an even greater number of impacts because of the relative thinness of the terrestrial atmospheric shield, but the number of large craters (including those that are ringed) should be very similar. The formation of an Isabella or a Mead on the Earth would surely be a catastrophe for a large portion of our planet.

References: [1] Schaber G. G. et al. (1992) JGR, 97, 13257 13301. [2] Alexopoulos J. S. and McKinnon W. B. (1992) Icarus, 100, 347-363; Erratum: Icarus, 103, 161. [3] Alexopoulos J. S. and McKinnon W. B. (1994) GSA Spec. Paper, in press. [4] Pike R. J. and Spudis P. D. (1987) Earth, Moon, and Planets, 39, 129194. [5] Grieve R. A. F. and Cintala M. J. (1992) Meteoritics, 27, 526-538. [6] Melosh H. J. and McKinnon W. B. (1978) GRL, 5 , 985-988. [7] McKinnon W. B. (1981) Proc. LPS /2A, 259-273. [8] Hildebrand A. R. et al. (1991) Geology, 19, 867-871. [9] McKinnon W. B. (1982) GSA Spec. Paper 190, 129-142. [10] Sharpton V. L. et al. (1993) Science, 261, 1564-1567.

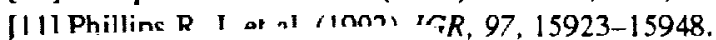

N94- 28307

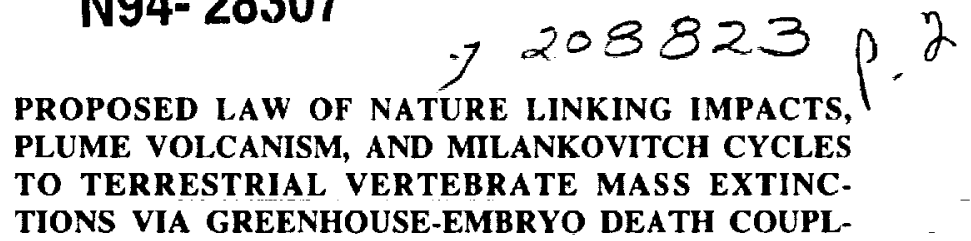

ING. D.M.McLean, Department of Geological Sciences, Virginia Polytechnic Institute, Blacksburg VA 24061, USA.

A greenhouse-physiological coupling killing mechanism active among mammals, birds, and reptiles has been identified. Operating - via environmental thermal effects upon maternal core-skin blood flow critical to survival and development of embryos, it reduces the flow of blood to the uterine tract. Today, during hot summers, this phenomena kills embryos on a vast, global scale. Because of sensitivity of many mammals to modern heat, a major modem greenhouse could reduce population numbers on a global scale, and potentially trigger population collapses in the more vulnerable pans of the world. In the geological past, the killing mechanism has likely been triggered into action by greenhouse warming via impact events, plume volcanism, and Earth orbital variations (Milankovitch cycles).

Earth's biosphere is maintained and molded by the flow of energy from the solar energy source to Earth, and on to the space energy sink (SES) [1]. This SES energy flow maintains Earth's biosphere and its living components, as open, intermediate, dissipative, nonequilibrium systems whose states are dependent upon the rate of energy flowing through them. Greenhouse gases such as $\mathrm{CO}_{2}$ in the atmosphere influence the SES energy flow rate. Steady-state flow is necessary for global ecological stability (autopoiesis).

Natural fluctuations of the $\mathrm{C}$ cycle such as rapid releases of $\mathrm{CO}_{2}$ from the mantle, or oceans, disrupt steady-state SES flow. These fucluations constantly challenge the biosphere; slowdown of SES energy flow drives it toward thermodynamical equilibrium and stagnation. Fluctuations induced by impact events, mantle plume 
volcanism, and Milankovitch cycles can grow into structure-breaking waves, triggering major perturbations of Earth's $\mathrm{C}$ cycle, and mass extinctions.

A major $C$ cycle perturbation involves readjustment of the outer physiochemical spheres of the Earth: the atmosphere, hydrosphere, and lithosphere, and by necessity, the biosphere. A greenhouse, one manifestation of a major $C$ cycle perturbation, is the most dangerous natural phenomenon that life of Earth can experience. Greenhouse conditions existed during the KT mass extinctions of 65 m.y. ago [2], and the Pleistocene-Holocene (P-H) mammalian extinctions of $10,000-12,000$ yr ago. Coupling climatology to reproductive physiology via effects of ambient air temperature upon uterine blood flow to developing embryos accounts for the extinctions via established physiological principles.

The KT extinctions seem a function of both Late Cretaceous climatic cooling and $\mathrm{KT}$ greenhouse warming that began at or about the $\mathrm{KT}$ boundary. A negative $\delta^{13} \mathrm{C}$ excursion indicates a major $\mathrm{C}$ perturbation, and a synchronous negative $\delta^{18} \mathrm{O}$ excursion, climatic warming. The greenhouse lasted 200-300k.y. into the Early Tertiary.

Two natural phenomena are candidates for the KT boundary greenhouse: the Deccan Traps mantle plume volcanism in India, and the Chicxulub structure on Yucatan, which has been attributed to extraterrestrial impact event. Ninety percent of the Deccan Traps' vast volume of tholeiitic lavas erupted $65 \mathrm{~m}$.y. ago [3]. The Chicxulub structure has been dated at about the same age [4]. Massive $\mathrm{KT} \mathrm{CO}_{2}$ release via Deccan Traps eruptions [5], or impact [6], or impactinduced water vapor release [7] would have disrupted SES energy flow, triggering change of state of the biosphere manifested in the $\mathrm{KT}$ transition extinctions.

Other sources of $\mathrm{KT}$ transition $\mathrm{CO}_{2}$-induced greenhouse conditions were failures of the Williams-Riley marine "pump" that removes $\mathrm{CO}_{2}$ from the atmosphere-marine mixed layer and stores it in the deep oceans, and a KT transition marine transgression starting just below the KT boundary and extending through early Paleocene (130-m rise) [8] that flooded highly productive terrestrial plant ecosystems with low productive marine ecosystems [9]. The KT record contains no definitive evidences of an "impact winter" global blackout and refrigeration [10].

A key point in linking climate to embryo survival is that embryo damage and death can occur at environmental temperatures that pose little danger to adults. During hot conditions, adults shunt blood to the skin to transport body heat to the environment. This action reduces blood flow to the core and to the uterine tract. Blood flow to the uterine tract carries damaging melabolic heat away from developing embryos [11], and supplies critical $\mathrm{O}, \mathrm{H}_{2} \mathrm{O}$, nutrients, and hormones [12]. Reduced uterine blood flow causes the uterine tract to overheat, damaging and killing fertilized eggs during the critical first cleavage. During later stages of development, reduced uterine blood flow can produce dwarfing and skeletal abnormalities. For modem pregnant, lactating European-type cattle, air temperature in the range of $70^{\circ}-81^{\circ} \mathrm{F}\left(21^{\circ}-27^{\circ} \mathrm{C}\right)$ causes the core temperature to rise. $A$ rise in uterine temperature of $1.8^{\circ}-2.7^{\circ} \mathrm{F}$ $\left(1.0^{\circ}-1.5^{\circ} \mathrm{C}\right)$ will kill most embryos. Study of air temperature vs. conception rates of 12,000 Florida cattle via arificial inseminations showed that on days when the air temperature following insemination exceeds $86^{\circ} \mathrm{F}\left(30^{\circ} \mathrm{C}\right)$, conception rates fall from $52 \%$ to $32 \%$, and then stay low during the hot summer months [13].

Vertebrate adaptation to climate involves adjusting size and $\mathrm{S} / \mathrm{V}$ ratios, body shape, insulation, and metabolism. Of the five, size is slowest to change in response to sudden climatic warming. Large Pleistocene mammals adapted to a cold ice age climate would have had difficulty getting rid of body heat during rapid warming. The main pulse of the P.H mammalian extinctions coincided with the abrupt warming about $11,700 \mathrm{yr}$ ago that ended the last ice age (indicated in Greenland ice cores). Those extinctions eliminated primarily large "big game" mammals, and produced dwarfing and skeletal abnormalities, reflecting the "signature" of climatic heat effects upon uterine blood flow to developing embryos [14]. Milankovitch cycles drive the Cenozoic ice age cycles and also seem to influence mammalian bioevolution and extinctions.

Among birds, uterine blood flow is reduced by high environmental temperatures. Studies of modem chickens indicate that hyperthermia diminishes blood flow to the ovarian follicles by $40-50 \%$, decreasing shell weight and quality, and reducing egg production [15]. During the P-H climatic warming at the end of the last ice age, large birds experienced more extinctions than any other group except large mammals [16]. In the face of rapid warming, coldadapted large birds would have experienced hyperthermia. Hyperthermia-induced reduction of uterine blood flow to the follicles would have reduced fertility and egg production, triggering collapse of populations.

For moderate to large reptiles (including the dinosaurs), "gigantothermy," a thermoregulatory strategy based on use of large body size, low metabolic rate, peripheral tissues as insulation, and control of blood now between core and skin [17], allows successful response to diumal and seasonal climatic changes. Via such strategy, the modem leatherback turtle, the largest marine turle $(1000 \mathrm{~kg})$, maintains body temperature of $86^{\circ} \mathrm{F}\left(30^{\circ} \mathrm{C}\right)$ in Arctic waters of $50^{\circ} \mathrm{F}$ $\left(10^{\circ} \mathrm{C}\right)$, or less; it has a problem dumping heat in a warm terresirial environment [17]. Dinosaurs that were adapting to Late Cretaceous climatic cooling would have, in the face of KT boundary greenhouse warming, experienced thermal stress, and likely uterine blood flowinduced reproductive problems. Hot summers rather than cold winters likely caused the disappearance of the dinosaurs [18].

Proposed law of nature: Climate control of uterine blood supply to the fertilized egg during first cleavage and later embryo development influence population dynamics, bioevolution, and extinction.

References: [1] Morowitz H. J. (1979) Energy Flow In Biol. ogy, Ox Bow Press. [2] McLean D. M. (1978) Science, 201, 401406. [3] Basu A. R. et al. (1993) Science, 261, 902-906. [4] Sharpton V. L. et al. (1992) Nature, 359, 819-821. [5] McLean D. M. (1985) Cretaceous Research, 6, 235-259. [6] O'Keefe J. D. and Ahrens T. J. (1988) LPS XIV, 885-886. [7] Emiliani C. et al. (1981) EPSL, 55, 317-334. [8] Keller G. et al. (1993) GSA Bull., 105, 979-997. [9] McLean D. M. (1978) Science, 200, 1060-1062. [10] McLean D. M. (1991) in Global Biomass Burning: Aimospheric, Climatic, and Biospheric Implications, 493-503, MIT. [11] Gwazdauskas F. C. et al. (1974) J. Anim. Sci., 39, 87-92. [12] Senger et al. (1967) J. Exp. Zool., 165, 337-344. [13] Badinga L. et al. (1985) J. Dairy Sci., 68, 78-85. [14] McLean D. M. (1981) Am. J. Sci., 28I, 1144 1152; (1991) in Energy and Environment, 93-100, ASHRAE. [15] Wolfenson D. et al. (1979) Br. Poult. Sci., 20, 167-174. [16] Steadman D. W. and Martin P. S. (1984) in Quaternary Exfinctions, 466-477, Univ. Arizona. [17] Spotila J. R. et al. (1993) Mod. Geol., 16, 203-227. [18] Cloudsley-Thompson J. L. and Butt D. K. (1977) Br. J. Herpet., 5, 641-647. 


\section{$32, r$}

PRELIMINARY STRATIGRAPHY AND IRIDIUM AND OTHER GEOCHEMICAL ANOMALIES ACROSS THE KT BOUNDARY IN THE BOCHIL SECTION (CHIAPAS, SOUTHEASTERN MEXICO). A. Montanari', P. Claeys ${ }^{2}$, F. Asaro $^{3}, \mathrm{~J}$. Bermudez ${ }^{4}$, and J. Smit ${ }^{5}$, 'Osservatorio Geologico di Coldigioco, 62020 Frontale di Apiro (MC), Italy, 2Department of Geology, University of California at Berkeley, Berkeley CA 94720 , USA, ${ }^{3}$ Energy and Environment Division, Lawrence Berkeley Laboratory, University of California, Berkeley CA 94720, USA, Instituto Mexicano del Petroleo, Eje Central Lazaro Cardenas 152, 07730 , Mexico, ${ }^{5}$ Department of Sedimentary Geology, Free University of Amsterdam, P.O. Box 716IMC Amsterdam, The Netherlands.

Coarse chaotic Cretaceous-Tertiary (KT) deposits produced by large-scale marine disturbances and megawaves have been found in Texas [1], several localities in norheastem Mexico [2]. Haiti [3,4], and in deep-sea cores in the Gulf of Mexico [5]. All these sites surnound the huge Chicxulub Crater in the State of Yucatan, Mexico. The chaotic deposits, with a tektite-bearing layer at their base, usually interrupt tranquil deep-sea sequences of pelagic and hemipelagic carbonate sediments. They are topped by layers with anomalously high Ir abundances, and immediately underlie undisturbed sediments containing microfossils of earliest Paleocene age and enhanced Ir abundances tailing from the peaks. One of the best preserved of these $\mathrm{KT}$ sequences is exposed in the Arroyo de Mimbral in the state of Tamaulipas, Mexico, and is located about $950 \mathrm{~km}$ west-northwest of the center of the Chicxulub Crater [2].

In the State of Chiapas (southeastem Mexico), a search was made for a KT marine sequence as close as possible to the Chicxulub Crater, which might have preserved a complete, proximal sedimentary record of a giant impact explosion. Such a sequence was found near the town of Bochil, exposed along the road leading to Pemex well "Soyalo IA." This site is located about $550 \mathrm{~km}$ south-southwest from the center of the Chicxulub Crater. As in other localities in the Gulf of Mexico-Caribbean region, the KT sequence is characterized by a thick, fining-up, clastic unit including thick heterogeneous carbonate breccia and sandstone beds, followed by an undisturbed sequence of lowermost Paleocene pelagic and hemipelagic marls. The lithostratigraphy of the Bochil KT sequence is shown in Fig. 1.

The Bochil clastic unit rests on top of a sequence of gray pelagic and hemipelagic marls and limestones, interbedded with pebbly mudstones and turbiditic calcarenites of probable Cretaceous age. The contact between the clastic unit and the underlying sediments is not clear due to poor exposure along the road. It may represent an erosional uncomformity but the possibility of a faulted contact cannot be excluded. No spherule layer or tektites have been found at the base of the clastic unit. The latter consists of approximately $38 \mathrm{~m}$ of calcareous breccia composed of angular poorly sorted clasts (ranging in size from less than $1 \mathrm{~mm}$ to several meters in diameter) of reefal and carbonate platform rocks suspended in a finer calcareous matrix. The clast size decreases upward. The proportion of the matrix varies greatly, and locally the breccia is clast supported. Tests of Murciella sp., an upper Cretaceous miliolid, are the youngest microfossils identified in the calcareous matrix.

The breccia unit is discontinuously exposed along the road, and is overlain by a $\mathrm{l}-\mathrm{m}$-thick fining- and thinning-up sequence of yellowish sandstone, siltstone, and reddish clay layers (Fig. 1). This sequence is topped by an irregular $(10 \pm 5 \mathrm{~cm})$ micritic limestone layer underlying a thin greenish-reddish, clayey arenite, and a whitish, laminated chalk containing abundant Globigerina eugu-

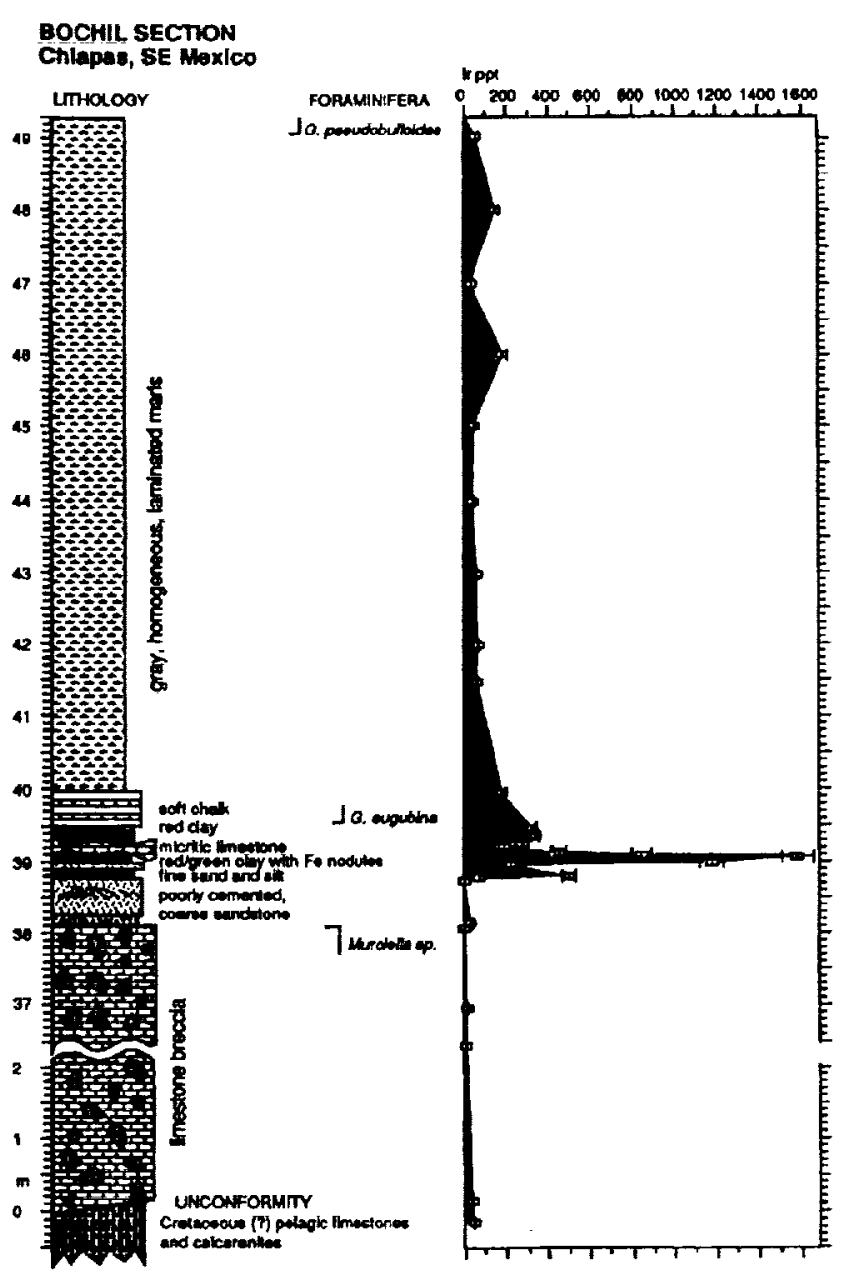

Fig. 1.

bina tests of lowermost Paleocene age (Fig. 1). The rest of the Bochil exposure comprises a 10 -m-lhick sequence of gray, homogeneous, pelagic and hemipelageic marls containing, in the upper part, tests of Globorotalia psendobulloides. A more detailed paleontological analysis of the Bochil section was still in progress at the time this abstract was submitted.

Abundance measurements were made of the elements Ir, $\mathrm{Co}, \mathrm{Cs}$, $\mathrm{Eu}, \mathrm{Fe}, \mathrm{Hf}, \mathrm{Ni}, \mathrm{Sb}, \mathrm{Sc}, \mathrm{Se}$, and $\mathrm{Ta}$ with the Ir coincidence spectrometer, following neutron activation on a suite of samples collected in an expedition to Bochil in March 1992. Data for Is are shown in Fig. I, and selected abundances of $\mathrm{Cs}$ and $\mathrm{Fe}$ in the 2-m interval across the major Ir peaks are shown in Fig. 2.

A sample of limestone immediately underlying the breccia unit contains abundant trace elements (suggesting a clay component) and $36 \pm 10 \mathrm{ppt} \mathrm{Ir}$. This Ir abundance is considerably higher than would be expected from contributions of clay similar to Cretaceous black shales in the Brazos $1 \mathrm{KT}$ section in Texas, but comparable to abundances in Paleocene marls of the same Bochil sequence. Four samples from the breccia limesione are much more barten in Ir with a best value of $5 \pm 2 \mathrm{ppt}$, if the Ir content of the samples is assumed to be constant.

There are 4-7 Ir peaks above background levels in the sediments above the breccia unit. The largest peak has $1580 \pm 72 \mathrm{ppt}$ and is 


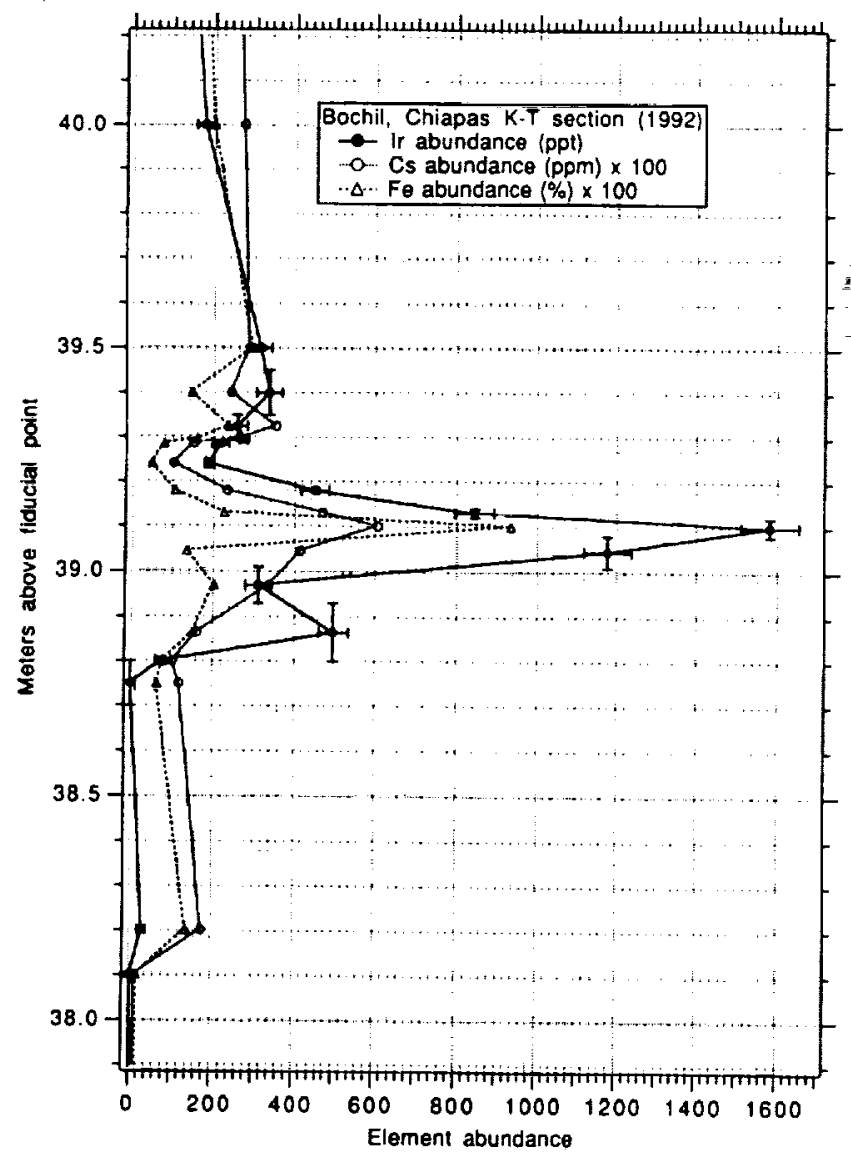

Fig. 2.

found in fine intensely bioturbated silty chalk about $6-10 \mathrm{~cm}$ below an irregular $10 \pm 5-\mathrm{cm}$-thick micritic limestone layer. The upper tail of the Ir peak extends into the micritic limestone (Fig. I). There are other considerably smaller Ir peaks extending as high as $7 \mathrm{~m}$ and possibly $8 \mathrm{~m}$ above the main peak and $0.2 \mathrm{~m}$ and possibly $0.9 \mathrm{~m}$ below. Generally, the more distant the subsidiary peaks are from the main peak, the smaller are their abundances. The Ir abundance in a thin sandstone layer below the main peak, however, was found to be lower than those in underlying and overlying silt layers. If ratios are taken of Ir abundances to those of $\mathrm{Fe}$ or $\mathrm{Cs}$, anomalously high ratios are found where the Ir abundance is anomalously high.

The element abundance patterns, which are similar to those found in other marine KT sections in Haiti, Mexico, and Texas, are consistent with a fining-up debris deposited from a Isunami triggered by a bolide impact on the Yucatan Peninsula. Our preliminary study of the Bochil section indicates the Ir began depositing (or redepositing) immediately before the first appearance of the lowermost Tertiary microfossils. The $38-\mathrm{m}$ breccia unit may have resulted from breakage of reefal sediments triggered by the Chicxulub impact, but other explanations are possible.

References: [1] Bourgeois J. T. et al. (1988) Science, 24l, 567-570. [2] Smit J, et al. (1992) Geology, 20, 99-103. [3] Hildebrand A. R. and Boynton N. V. (1990) Science, 248, 843-846. [4] Maurrasse F. J. M. R. et al. (1991) Science, 252, 1690-1693. [5] Alvarez W. et al. (1985) Geology, 20,697-700.

\section{N94- 28308

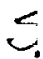 \\ EXTRATERRESTRIAL ACCRETION AND GLACIAL CY-}

CLES. R. A. Muller, Department of Physics and Lawrence Berkeley Laboratory, University of Califomia, Berkeley CA 94720 _ of USA.

We propose that the $\approx 100-k . y$. cycle seen in terrestrial glaciation is due to changes in meteor flux that come from changes in the Earth's orbit. This model can explain a 70-k.y. "anomalous" period in climate data and the apparent discrepancy between present extraterrestrial fluxes and those in oceanic sediments. It can be tested by measuring Ir densities in sediments and ice during glacials and interglacials.

Milankovitch [1] attributed the changes in the Earth's ice coverage to perturbations in the motion of the Earth and the resulting changes in insolation in the northern hemisphere. The strongest effects were expected to come from changes in the Earth's obliquity (the tilt of the Earth's axis with respect to its ecliptic) and from a precessional term that accounts for the delay between solstice and perihelion. The success of this mechanism has been-argued by Imbric et al. [2]. The most compelling evidence is the presence of Earth orbital frequencies in Fourier analysis of proxy climate measurements such as $\mathrm{CO}_{2}$ and $\delta^{1 \times} \mathrm{O}$. In a recent review and reanalysis of available data, MacDonald [3] showed that inclination, obliquity, and precession frequencies account for eight of nine statistically significant $\delta^{18} \mathrm{O}$ frequencies in an eastem Pacific core. The "only anomalous line" in the data with no theoretical counterpart was a $\delta^{18} \mathrm{O}$ peak at $0.014 \pm 0.001 / \mathrm{k}$.y.

However the insolation mechanism proposed by Milankovitch has difficulty accounting for the magnitudes and phases of the climate cycles. The spectrum is dominated by a 100-k.y. period, usually attributed to the oscillation of eccentricity e. However, yearly average insolation varies as $(1 / 2) \mathrm{e}^{2}$, giving changes in insolation of only $10^{-3}$. MacDonald [3] calculated the solar insolation at $60^{\circ} \mathrm{N}$ at the primary frequencies for (obliquity, precession, eccentricity) to be in the ratio $(1,5,0.1)$; in sharp disagreement with the $\delta^{14} \mathrm{O}$ data, which show the climate variations to be in the ratios (1, $0.4,4.4)$.

Milankovitch explained the strong eccentricity dependence by arguing that the insolation effect of obliquity and precession are biggest when the eccentricity is greatest and that the effect is nonlinear. Other suggestions to solve the puzzle postulate resonances and time constants in the geologic system to enhance ice coverage at periods near $100 \mathrm{k} . \mathrm{y}$. and to cause delays without enhancing the 20-k.y. and 40-k.y. periods. However, recent $\delta^{1 \mathrm{x}} \mathrm{O}$ measurements with precise dates show that the warming associated with several glacial terminations begins well before the start of above-average insolation, and this has been interpreted as disproving Milankovitch's mechanism [4,5].

The correspondence of observed climate frequencies with those of the Earth's orbit argue strongly for a causal connection, but the failure to predict the correct amplitudes and phases suggest that the insolation mechanism of Milankovitch may be incorrect, at least for the 100-k.y. period. We suggest that this cycle might be due to a different mechanism: extraterrestrial accretion. This mechanism yields the correct frequencies, can account for the "anomalous line" of MacDonald, gives a new interpretation to recent accretion measurements, and makes predictions that can be tested in the near future. Accretion does not account for the periods near $20 \mathrm{k}$.y. and 40 k.y., and we assume that the Milankovitch solar insolation mechanism correctly accounts for these. 
Mechanism of Extraterrestrial Accretion: As the orbit of the Earth changes, it passes through different parts of the Sun's zodiacal ring, and should encounter different meteor streams. Changes in meteor flux can affect the density of dust and aerosols in the upper atmosphere. The fact that high-altitude dust can affect global climate is generally accepted. The eruption of Krakatoa has been estimated to cause global cooling $>1{ }^{\circ} \mathrm{C}$, and climate changes have been altributed to El Chichon and other eruptions that injected megatons of material into the stratosphere. Measurements of Ir in oceanic sediments [6] show that long-term global average flux from extraterrestrial materials is $60-120 \mathrm{kt} / \mathrm{yr}$ [6], comparable over 10100 yr to that from a large volcanic eruption. The meteors may not come in at a steady rate but in bursts as we cross the meteor streams (with peaks much higher than the $60-120 \mathrm{kt} / \mathrm{yr}$ average) and in cycles as the Earth's orbit oscillates. The shortest variation detectable (the Nyquist period) in the best sediment records [6] $\approx 600 \mathrm{k} . \mathrm{y}$., so a 100-k.y. os-cillation would have been missed. Clube [7] analyzed the possibility of large unobserved meteor streams and argued that the zodiacal ring of the Sun is largely meteoroid in composition rather than dust. He concluded that large unobserved streams exist, and suggested that encounters with them could cause climate excursions and extinction events; however, he did not propose a relationship with the known climate cycles.

A single meteor stream can contain the mass of one comet $=10^{5} \mathrm{Mt}$. The Earth can capture about $10^{-4}$ of the stream with each passage $\approx 10 \mathrm{Mt} \approx 1$ large volcano equivalent/yr, as long as the orbits intersect. The cumulative effect would be very much larger than Krakatoa.

We do not propose that the climate effects are due to a single meteor stream, rather that the solar ring has many, in nearly circular orbits with semimajor axis $\approx 1 \mathrm{AU}$, so that their own orbital perturbation frequencies (but not necessarily their phases) closely match those of the Earth. We do not explain how such rings were formed, but for our model to work, they must have been present for the last million years.

A nother orbital parameter expected to have little effect on climate, because of its negligible effect on insolation, has been the inclination of the Earth's orbital plane. Changes in inclination also cause the Earth to probe different regions of interplanetary debris, so we predict correlations berween inclination and climate. The long-term variation of the inclination was calculated by Berger [8], who showed that the behavior is quasiperiodic with a period of $70 \mathrm{k.y}$., and a fundamental frequency of $0.0144 / \mathrm{k}$.y. Note that this frequency is, within errors, equal to the one unexplained peak in the $\delta^{18} O$ data [3]; thus we explain the one "anomalous" frequency.

We can gain more insight into this effect, and possibly understand the relative intensities of the spectral lines, if we chose coordinates based on the invariable plane of the solar system, perpendicular to the total angular momentum vector of the planets, approximately the plane of Jupiter's orbit. In these coordinates the oscillations of inclination are nearly sinusoidal with peak-to-peak amplitude reduced by two, and period changed to $100 \mathrm{k} . \mathrm{y}$, rather than $70 \mathrm{k} . \mathrm{y}$. (The change simplifies the behavior because the primary perturber, Jupiter, has a nearly stationary orbit in this system.) In this frame the precession of the inclination vector, $\Omega$, now shows a virtually steady advance of one cycle every $70 \mathrm{k} . \mathrm{y}$. In the invariable frame, the inclination i oscillates with a 100 k.y. period, nearly identical to that of the eccentricity e. Changes in $i$ and e both cause the Earth to sweep out new material with a frequency $0.01 /$ k.y., identical to that of the strongest line seen in the climate data. The "anomalous" line [3] at $70 \mathrm{k} . y$. period is $\Omega$, the frequency of precession of the inclination vector (the advance of the line of nodes) measured in the invariable plane.

Accretion Measurements: Our proposed mechanism predicts a substantial reduction in the flux of meteoritic material in the present era compared to the long term average. In fact, just such a reduction is known. In a recent review, Rochia et al. [9] found six of seven published determinations of recent influx measured $\approx 10 \mathrm{kt} / \mathrm{yr}$, yet the long-term flux [6] was $60-120 \mathrm{kv} / \mathrm{yr}$. They speculate that the recent low flux is a fluctuation, due to few large meteoroid impacts recently. Yet the most straightforward measurement, that of Ir in Antarctic snow, gave $10 \mathrm{kVyr}$ despite the presence of the Tunguska event of $1908=0.1-1 \mathrm{Mt}$.

We offer a different interpretation, that the discrepancy is not from the absence of large impacts, but is due to the fact that interglacials (including the present one) are periods of low extraterrestrial meteoroid flux.

References: [1] Milankovitch M. (1941)Royal Serbian Acad. Spec. Publ. 132. [2] Imbrie J. et al. (1984) in Milankovitch and Climate (A. Berger et al. eds.), 269-305, Reidel. [3] MacDonald G. (1990) in Global Climate and Ecosystems Change (G. MacDonald and L. Sertoria, eds.), 1-95, Plenum. [4] Winograd I. et al. (1992) Science, 258, 255-260. [5] Broecker W. and Denton G. (1989) $G C A, 53,2465-2501$. [6] Kyte F. and Wasson J. (1986) Science, 232, 1225-1229. [7] Clube S. (1987) Phil. Trans. R. Soc. London, A323, 421-436. [8] Berger A. (1976) Astron. Astrophys., 51, 127135. [9] Rocchia R. et al. (1990) GSA Spec. Paper 247, 189-193.

\section{Onit $70 \%$}

A KT BOUNDARY SECTION FROM NORTHERN BELIZE. A. C. Ocampo and K. O. Pope ${ }^{2}$, 'Jet Propulsion Laboratory, California Institute of Technology, Pasadena CA 91109 , USA, ${ }^{2}$ Geo Eco Arc Research, 2222 Foothill Boulevard, La Canada CA 91011 , USA.

A KT boundary section recently discovered in northem Belize provides new insights into cratering processes near the rim of the Chicxulub KT crater in northwestern Yucatan. The section is located in a quarry on Albion Island near the Mexican border, which is only $2-3$ crater radii $(-350 \mathrm{~km})$ from the center of Chicxulub. This is the most proximal exposed KT section yet studied from the Chicxulub Crater, excluding material from deep drilling within the crater and on the rim. The Albion Island section provides an example of deposits intermediate between the crater rim and more distal, possible impact-tsunami deposits in the region [1-3].

Quarrying activity on Albion Island has exposed a $45-\mathrm{m}$-thick section in a region where deep weathering and dense vegetation has obscured most bedrock exposures. The regional stratigraphy has been established in two exploratory wells drilled at near by Orange Walk and San Pablo [4]. The Orange Walk I well records place the KT boundary between dolomites of the Sand Hill Formation and undifferentiated Tertiary limestones at a depth of $\sim 1500 \mathrm{~m}$. The KT boundary rises to a depth of $\sim 150 \mathrm{~m}$ in the San Pablo I well located $11 \mathrm{~km}$ north of Orange Walk 1 . The Albion Island quarry is located $15 \mathrm{~km}$ northwest of Orange Walk, near the crest of an anticlinal fold and possible uplifted fault block that has further elevated the KT boundary. A major erosional unconformity separates the hard crystalline Cretaceous dolomites and a chaotic, poorly sonted breccia at a depth of $\sim 15 \mathrm{~m}$ in the quarry. We propose that this unconformity marks the KT boundary. 
The unconformity is exposed for a lateral distance of over $100 \mathrm{~m}$ and is parallel with the bedding planes in the underlying dolomites. It contains at least three erosional troughs that cut into the dolomites, each $\sim 15 \mathrm{~m}$ wide $\times 2 \mathrm{~m}$ deep. The orientation of the troughs could not be determined, but they indicate high-energy scouring. The only sediments filling the scours are the chaotic breccias.

The maximum breccia thickness in the quarry is $15 \mathrm{~m}$; however, the breccias continue to the surface and the total original thickness of the unit is unknown. Tertiary strata are not exposed in the quarry, but are found on the surface in other parts of the island, presumably overlying the breccia. The breccia is weakly indurated and deeply weathered. Clasts range in size from $30 \mathrm{~cm}$ to microscopic grains, and all sizes are abundant. The clasts are angular to subrounded and supponed in a dolomitic matrix. Most clasts, especially the large ones, are dolomite, apparently derived from the underlying beds. Other carbonate clasts, representing lithologies not found in the lower section, are also present. Some of the subrounded clasts are grain-supported, well-indurated, and partially recrystallized carbonate breccias. Highly altered clasts consisting of red, green, and yellow clay are also abundant and give the unit a polychromatic appearance. The original lithology of these clasts is unknown (glass?), but they occur in a variety of shapes, including angular, round, and elongated. Quartz grains are present, but rare.

We propose that the Albion Island breccia is the product of ballistic sedimentation [5] from the Chicxulub impact. Such deposits are created by secondary impacts of ejecta and for large craters are composed mostly of brecciated local rock [6]. Impact models $[5,7]$ predict that ballistic sedimentation would occur within 2-3 crater radii of Chicxulub, consistent with the position of this KT section. The breccia lithology and scoured contact are also consistent with the ballistic model; however, they do not confirm an impact origin. The Albion Island breccia is remarkably similar to the breccia/conglomerate unit found on the rim of the Chicxulub Crater, which we have also interpreted as a product of ballistic sedimentation [8]. Petrographic analyses of the Albion Island breccias are currently underway to determine if Chicxulub ejecta can be recognized, thereby confirming an impact origin.

References: [1] Hildebrand A. R. and Boynton W. V. (1990) Science, 248, 843-847. [2] Alvarez et al. (1992) Geology, 20, 697700. [3] Smit J. et al. (1992) Geology, 20,99-104. [4] Geology and Petroleum Office (1986) Petroleum Prospect and Potential of Concession Block-l in Belize, Central America, Geology and Petroleum Office, Belmopan. [5] Oberbeck V. R. (1975) Rev. Geophys. Space Phys., 13, 337-362. [6] Hörz F. et al. (1983) Rev. Geophys. Space Phys., 21, 1667-1725. [7] Melosh H. J. Impact Cratering, Oxford. [8] Pope K. O. et al. (1994) Earth, Moon, and Planets, in press.

\section{$0 m \geqslant 7$}

ON THE REALITY OF THE KT BOUNDARY. R. K. Olsson and C. Liu, Department of Geological Sciences, Rutgers University, New Brunswick NJ 08903, USA.

From the point of view of impact supporters the KT boundary should contain a glassy spherule layer on top of uppermost Maestrichtian strata followed by a fallout layer containing an Ir anomaly. In the Gulf of Mexico a third unit should be sandwiched between these layers, a tsunami-deposited clastic unit that may contain several layers with various bedding characteristics. Others regard the clastic unit as Maastrichtian in age. However, it is clear that some of the clastic units sandwiched at the boundary are Danian in age and therefore they cannot have been deposited by a tsunami wave. At the stratotype section at El Kef, Tunisia, only the spherule layer and the fallout layer are present. At deep-sea drilling sites in the Caribbean the completeness of the KT boundary is in dispute with many sites apparently containing hiatuses either in the uppermost Maestrichtian or in the Danian. Outside the Caribbean at deepsea drilling and ocean drilling sites it is a fact that recovery of the KT boundary has been disappointing and only a few sites are regarded as containing a continuous section.

Identifying the KT boundary by means of planktonic foraminifera has not been straightforward. If one uses the stratotype section (GSSP) at El Kef as the standard reference, the KT boundary is identified on the basis of the boundary clay layer with the Ir anomaly, which is associated with Zone P0, the Guembelitria cretacea zone. This zone was originally interpreted as containing only the nominate species with other planktonic taxa (i.e., Cretaceous taxa) regarded as reworked. Newly evolved Danian species do not appear until the upper part of this zone. In this view the oceans had been sterilized by the boundary event, which caused a mass extinction of planktonic foraminifera so that, initially, there was only one survivor, Guembelitria cretacea. The second view identifies the KT boundary on the first occurrence of newly evolved Danian species. This view apparently assumes that Danian taxa evolved immediately after the KT event so that evolution must have been instantaneous. The other view allows a short period of geologic time to pass before the first Danian species evolve. This view has been fortified by the recognition of two additional survivors in Zone P0,Hedbergella holmdel-ensis and $H$. monmouthensis. The origins of all evolved Danian species can now be traced to the three survivor species. In any case, the KT boundary cannot be the same as it is applied by these two opposing views.

There is a certain amount of consistency in the various opposing views of the geology and micropaleontology at the KT boundary. There are hiatuses, there are clastic units at the boundary in the Gulf of Mexico, there are spherule layers, there is an Ir anomaly, there are specimens of Cretaceous taxa above the boundary, and there are newly evolved Danian taxa above the KT boundary. But few of these criteria are present at all KT boundary sections. We offer the hypothesis that the KT transition should be taken at face value. A KT section that contains a gap in criteria may, in fact, be complete in the sense that it contains a record of the KT event. The true record of the KT boundary is not at any one section (e.g., there is no clastic unit at E] Kef), nor does it lie with the hunt for biostratigraphically continuous sections. We illustrate this concept with the record at Millers Ferry and its comparison with other well known KT boundary sections.

At Millers Ferry photographs of the excavation pit for the construction of the powerhouse for the Millers Ferry Dam on the Alabama River offer an unusual opportunity to view the top of the latest Maestrichtian Prairie Bluff Chalk. The surface of the Prairie Bluff Chalk is irregular and undulating without any interconnections, which would indicate fluvial erosion during a period of subaerial exposure. Furthermore, there is no evidence of weathering in the photographs nor in two cores taken from the site. On the contrary, the surface is marked by scour features, flute markings, groove markings, and striations that have a north-south orientation. Direction of flow is from south to north. In addition, synthetic 
normal faults with a north-south orientation and offsets of tens of centimeters break the Prairie Bluff surface. They are buried by the overlying Danian Basal Clayton Sands. The faults and the surface markings indicate an instantaneous event for their origin. We interpret these features as having formed as a result of a tsunami wave and earthquakes created by a bolide impact at Chixulub Crater in Yucatan.

The overlying Clayton Basal Sands fill in the topographic lows on the Prairie Bluff Chalk and thin over the topographic highs. As a consequence, the basal Danian Zone PO is found where the Clayton Basal Sands are thickest and is absent where the sands thin on topographic highs. Calcareous microfossil biostratigraphy shows that the Prairie Bluff Chalk lies within the uppermost Maestrichtian calcareous nannofossil Micula prinsii zone, which is equivalent to the upper part of the planktonic foraminiferal Abathomphalus mayaroensis zone. Paleomagnetic data show that the Prairie Bluff Chalk/Clayton Basal Sands (KT) boundary lies in the middle part of paleomagnetic chron 29R in the cores taken at Millers Fenry. The last occurrence (LO) within the Prairie Bluff Chalk of the planktonic foraminifer Gansserina gansseri is a datum from which to measure the degree of topographic irregularity on the top of the Prairie Bluff Chalk. This indicates about a meter or so of relief. The relief could be due entirely to the erosive effect of a tsunami wave or it could represent a modified original depositional surface. In either case, it is clear that the KT boundary at Millers Ferry is biostratigraphically continuous but it is not contained in one section.

We interpret that the abrupt change from the Prairie Bluff Chalk to the Clayton Basal Sands is due to the mass extinction of the Prairie Bluff Chalk biola, which includes planktonic foraminifera, calcareous nannoplankton, and the molluscan megafauna. Benthic foraminifera, which were little affecled by the extinction event indicate that there was little, if any, change in sea level across the boundary. Minor changes in foraminiferal taxon abundances across the boundary are due to substrate change from chalk to sand.

At Brazos River, Texas, the "tsunami bed" has been placed in the Cretaceous [7,3] and in the Danian [8]. A Danian age would indicate a similar origin for this unit as the Clayton Basal Sands. A Cretaceous age does not necessarily exclude a bolide impact-generated tsunami wave origin. At Mimbral, Mexico, the sand unit at the boundary interpreted as a tsunami deposit, whereas an alternate hypothesis regards it as a possible incised valley deposit of Cretaceous age. These different interpretations are not necessarily incompatible since they center around the age of the sand unit and the interpretation of the origin of the spherules at the base of the unit. The use of different biostratigraphic criteria for placing the KT boundary may give a different age assignment to the sand unit [2]. It is difficult to ignore the fact that thin discontinuous sands occur in very close proximity to the KT boundary around the Gulf Coastal Plain for a distance of about $2000 \mathrm{~km}$ in different paleodepth settings (upper bathyal at Mimbral to shallow shelf at Millers Ferry). The origin of these sands could well be different and still be related to a KT terminal event, which dispersed enormous energy. Some of the sands could be tsunami deposits, whereas others must represent a brief period of increased clastic deposition that can be explained by a fireball-denuded, erosion-enhanced landscape. The scoured surface upon which these sands lie can also be regarded as evidence of the passage of a powerful tsunami wave.

At the Caribbean deep-sea drilling sites the apparent record [6] of hiatuses on either side of the KT boundary can be interpreted as evidence for signicant disturbance of the sea bottom. Enormous earthquakes generated by a bolide impact would cause displacement of sediments and would lead to the development of localized hiatuses. At greater distances away from the impact, such as El Kef in a deep margin selting, the KT boundary records the mass extinction event of calcareous marine plankton, the spherule layer, and the Ir anomaly in direct succession.

In our view $\mathrm{KT}$ boundary sections should be taken at face value because they each record various aspects of the KT event. In highly disturbed areas, such as the Gulf of Mexico and the Caribbean, the regional picture of the terminal event needs to be developed in order to appreciate the reality of the KT event.

References: [1] Smit J. et al. (1992) Geology, 20, 99-103. [2] Olsson R. K. and Liu C. (1993) Palaios, 8, 127-139. [3] Keller G. (1989) Paleocean., 4, 287-332. [4] Stinnebeck W. et al. (1993) Geology, 9, 797-800. [5] Smit J. (1990) Geol. Mijnbouw, 69, 187 204. [6] Keller G. et al. (1993) Geology, 9, 776-780. [7] Jiang M. J. and Gartner S. (1986) Micropaleon., 32, 232-255. [8] Montgomery H. el al. (1992) FPS 1 ino $\mathrm{cm}$

\section{N94- 28309$$
\Gamma
$$

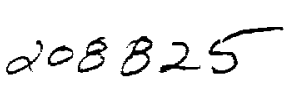

AN EXTRATERRESTRIAL EVENT AT THE TERTIARY QUATERNARY BOUNDARY. H. Peng, First Institute of Oceanography, State Oceanic Administration, Qingdao, 266003, P.R. China.

During the North Pacific Manganese Nodules Investigation in 1983, we collected a large-diameter core M14 $\left(8^{\circ} 00.15^{\prime} \mathrm{N} .176^{\circ}\right.$ $10.65^{\prime} \mathrm{W} ; 3991-\mathrm{m}$ depth of water). This gravity core is $420 \mathrm{~cm}$ long in total. I is composed of calcureous ooze at $0-320 \mathrm{~cm}$ and siliceous ooze at $320-420 \mathrm{~cm}$ of depth. A great number of microtektites were found at $270-300 \mathrm{~cm}$ (average content is 15 microtektites per $100-\mathrm{g}$ sediment). Because abundant microtektites are restricted to. a $30-\mathrm{cm}$-thick zone of deep-sea core, we called this zone the microtektite layer. The age of the sedimentary stratum containing microtektites is $2.14-2.30$ m.y., corresponding to the Pliocene to Pleistocene Periods as indicated by paleomagnetic and paleontologic analysis[1].

Most microtektites appeared as light-yellowish-green, small, glassy spherules and their average size is $137 \mu \mathrm{m}$ in diameter. The individual grain is dumbbell shaped and its size is $652 \times 223 \times$ $151 \mu \mathrm{m}$ (Fig.1). The average refractive index of microtektites determined by the oil immersion method is 1.52 .

The $\mathrm{SiO}_{2}$ contents of five microtektites are $69.13-70.54 \%, \mathrm{Al}_{2} \mathrm{O}_{3}$ is $15.89-18.95 \%, \mathrm{FeO}$ is $3.45-4.96 \%, \mathrm{MgO}$ is $2.33-3.62 \%, \mathrm{CaO}$ is $1.93-2.60 \%$, and $\mathrm{K}_{2} \mathrm{O}$ is $1.24-2.78 \%$. These oxide contents are similar to the North American microtektites. But core M14 microtektites have unique properties, i.e., their $\mathrm{Na}_{2} \mathrm{O}$ contents are only $0.11-0.18 \%$, which is lower than North American microtektites and other microtektites; their $\mathrm{TiO}_{2}$ contents reached $1.08-1.34 \%$, which is higher than North American microtektites and other microtektites.

Core M14 microtektites also have a high siderophile-element content. For example, $\mathrm{Ni}$ content reached $1380 \mathrm{ppm}$, Co reached $21.7 \mathrm{ppm}$, Os reached $22.5 \mathrm{ppm}$, and Ir reached $0.026 \mathrm{ppm}$. This high concentration of siderophile elements indicates that their parent materials come from outside the Earth. We also found that core M1 4 microtektite layer is apparently associated with the beginning of the Reunion geomagnetic event, and is probably associated with 
(a)

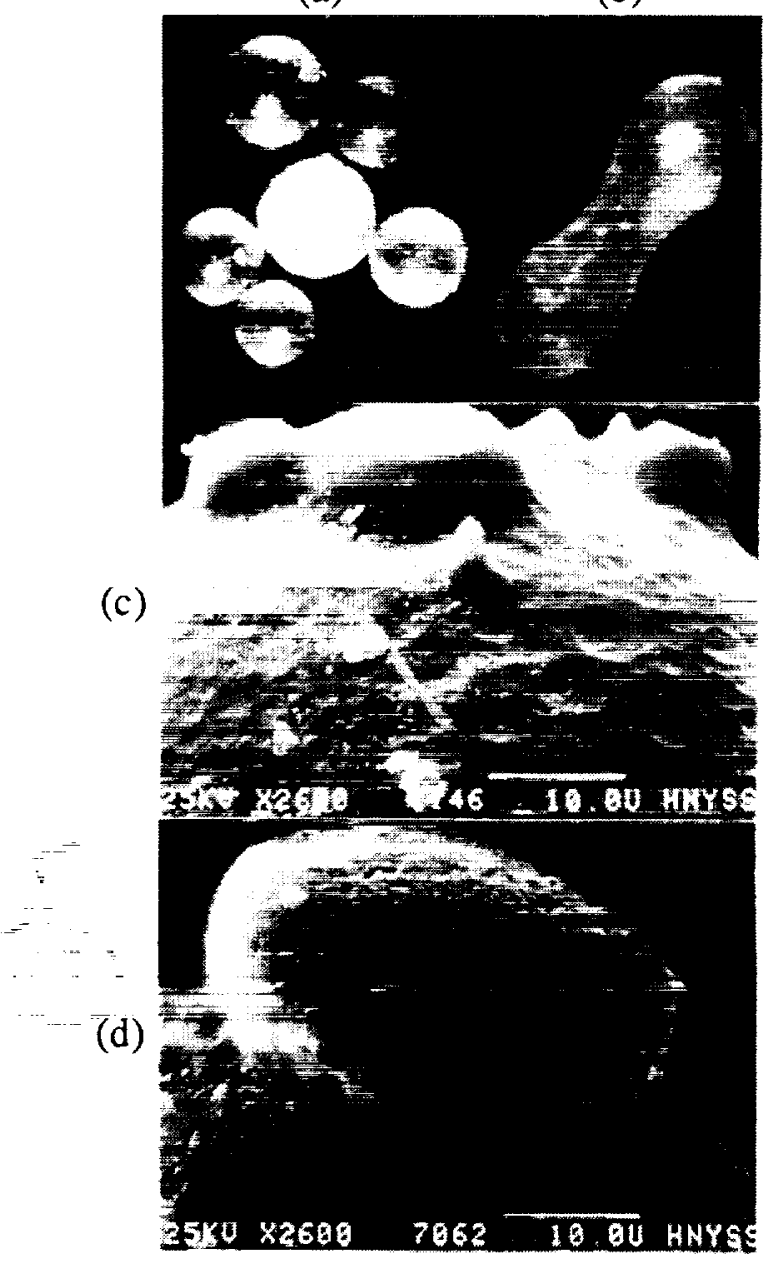

Fig. 1. Microscope and SEM photographs of Microtektites from core M/4. (a) Microscope photograph of spherical microtektites; (b) a large dumbbell microtektite $(652 \times 223 \times 151 \mathrm{\mu m}$ in size); (c) and (d) SEM photographs of microtektites with circular, flat-topped, elevaled area at top.

the Matuyama/Gauss geomagnetic reversal boundary in core M/4 (Fig.2). As you can see, the declination is $\sim 170$ decreasing sharply to 0 and the inclination is $\sim 7$ decreasing sharply to -15 at the 270 $\mathrm{cm}$ depth (corresponding age is $2.14 \mathrm{~m}$.y.). In addition, three specific radiolarians that belong to the Tertiary are extinguished near the microtektite layer. They are Pterocanium prismatium, Ommatarlus antepenultimus, and Lamprocyrtis heteroporos [1].

Based on the above data, we can give the following two primary conclusions: (1) The core $\mathrm{M} 1 \overline{4}$ microtektites are products of a major meteorite or asteroid impact 2.14-2.30 m.y. ago. (2) The age of 2.14-2.30 m.y. is an important geological age; perhaps it is just a correct age for dividing the Tertiary/Quatemary boundary. This result is quite close to previous data. For example, Kyte et al. [2] found that high noble metals and meteoritic particle concentrations

occur in upper Pliocene sediments (2.3 Ma B.P.) from the Antarctic Ocean; Yuan et al. [3] found the microtektite layer in clay between the Wuchen loess and Paleosol (2.4 Ma B.P.) from Luochuan county

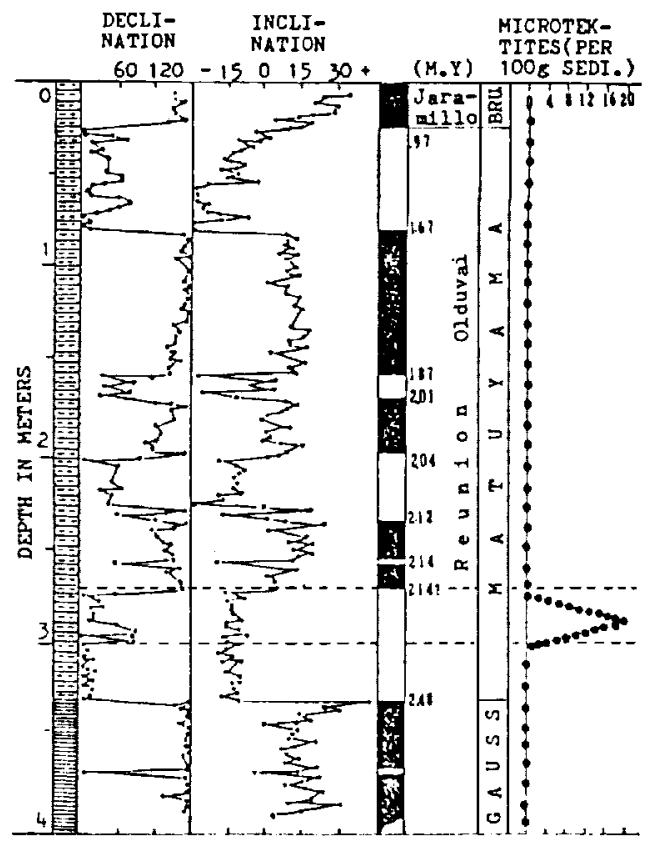

Fig. 2. Correlation between the microtektite layer and paleomagnetic stratigraphy in the core M14 collected from the North Pacific. Note the declination and inclination at the $270-320-\mathrm{cm}$ depth (corresponding age of 2.14 2.48 m.y.) showing extreme variation.

in Shanxi province in China; and Wu et al. [4] found the microspherule layer in the Paleosol, which is associated with the Matuyama/Gauss geomagnetic reversal [4].

References: [1]Wang Y.et al. (1986) inComprehensive Investigation Report on Manganese Nodules in the Northern Central Pacific, 64-69. [2] Kyte F. T. et al. (1981) Nature, 292, 417-420. [3] Yuan B. et al. (1989) Kexue Tongbao, 22, 1725-1728 (in Chinese). [4] Wu X. et al. (1991) Kexue Tongbao, 23, 1799-1802 (in Chinese).

\section{ant $70 \% 9$}

FOOTPRINTS IN THE ROCKS-NEW EVIDENCE FROM THE RATON BASIN THAT DINOSAURS FLOURISHED ON LAND UNTIL THE TERMINAL CRETACEOUS IMPACT EVENT. C. L. Pillmore', M. G. Lockley ', R. F. Fleming', and K. r. Johnson'; 'U.S. Geological Survey, Denver CO 80225, USA, 'University of Colorado, Denver CO 80217, USA, '3Denver Museum of Natural History, Denver CO 80205, USA.

In recent months, we have found convincing evidence that dinosaurs were present and probably flourished in the Raton Basin, southem Colorado and northern New Mexico, possibly until, or only a very shor time before, the asteroid impact at the end of the Cretaceous Period. This evidence is in the form of impressions and natural casts of dinosaur footprints that occur in the lower part of the continental Raton Formation of Late Cretaceous and Paleocene age within $1 \mathrm{~m}$ below the KT boundary claystone layer. Tracks are also present at several other horizons farther below the boundary. Curiously, Raton Basin rocks have never produced dinosaur skeletons. 
Though rare fragmentary remains of fish, crocodiles, and turtles have been identified in samples from the Cretaceous portion of the Raton Formation, only one bone attributed to a dinosaur has ever been found.

In the southem part of the Raton Basin, the KT boundary occurs at the top of the lower coal zone of the Raton Formation. This zone consists of sequences of rocks comprising beds of mudstone, carbonaccous shale, and thin beds of coal with interbeds of sandstone; sandstone beds at the base of the lower coal zone are commonly conglomeratic. The depositional environment is fluvial, consisting of broad flood plains characterized by mudflats and swamps that were periodically flooded by crevasse splays from meandering channelways. Crevasse splays occur when natural levees are breached along river channels and sediment-laden water pours out over the floodplain. Footprints and other impressions in silty muds of the mudflats were quickly buried by sand as crevasse splays prograded across the flood plain. Where the splay sand deposits were not subsequently eroded by crevasse channels and associated meandering rivers, the animal tracks and traces on the buried flood plain surface may be preserved as sand-filled depressions at the base of the deposits. This might be considered analogous to the making of huge plaster-of-Paris casts of the flood plain surface or, in a sense, to "photographing" an instant in time. Traces identified to date include hadrosaurid and ceratopsid tracks; an unidentified trace, possibly a turtle; bird tracks; and a well-preserved tyrannosaur footprint. The tyrannosaur print is the first convincing record ever found.

Natural casts of the hadrosaur footprints are preserved in track ways at several horizons in the lower coal zone. One horizon is only $37 \mathrm{~cm}$ below the KT boundary clay bed about $15 \mathrm{~km}$ northwest of Trinidad, Colorado, at the Berwind locality. Ceratopsid and hadrosaur tracks also occur only a short distance ( $1-2 \mathrm{~m})$ below the boundary at the Clear Creek north site $5 \mathrm{~km}$ south of Trinidad. The tyrannosaur footprint was found about $75 \mathrm{~km}$ to the southwest near Cimarton, New Mexico. This track as well as other traces are preserved as natural casts at the base of loose sandstone blocks derived from a ledge $20 \mathrm{~m}$ below the level of the KT boundary. The position of the track-containing ledge with respect to the boundary was defined recently by palynological analyses. The Cretaceous pollen and spores recovered from a carbonaceous mudstone unit immediately beneath the tyrannosaur track-bearing sandstone ledge suggest that palms and fems typical of a subtropical environment dominated the plant community on the flood plain around the track site.

\section{$\operatorname{lon} T$}

CALCAREOUS NANNOFOSSILS AND THE KT BOUNDARY CRISIS: AN UPDATE. J. J. Pospichal, Antarctic Marine Geology Research Facility, Florida State University, Tallahassee FL 32306, USA.

Calcareous nannofossil assemblages in closely spaced samples, which span the KT boundary of several sections around the globe, were quantitatively analyzed to assess the nature of nannoplankion extinctions. The results of this investigation are summarized:

I. Climate-sensitive nannoplankton populations are relatively stable during the latest Maastrichtian, which indicates that in lowlatitude sections, such as El Kef, Tunisia, and Agost, Spain, no major ecologic stresses such as temperature change foreshadowed the KT boundary event. At midlatitude South Atlantic Site 527, cooling near the end of the Maastrichtian is suggested by a slight drop in abundance of warm-water nannofossil taxa and rise in abundance of cooler water forms. However, no extinctions are associated with these changes and abundance fluctuations are within limits of error.

2. No stepwise or gradual extinctions are noted across the KT boundary at any of the sites examined. Nannoplankton extinctions are abrupt and synchronous, and correlate well with reported shifts in $\mathrm{C}$ isotopes, carbonate sedimentation decline, and anomalous Ir abundance.

3. In the sections examined, no noticeable difference exists between the low-latitude and high-austral-latitude sites in terms of the tempo and mode of nannoplankton extinctions. Cosmopolitan Cretaceous species exhibit the same extinction pattem across latitude.

4. The early Danian is characterized by sequential blooms of surviving and new nannoplankton species. No two localities are the same in terms of the species composition of these blooms. This reflects the unstable conditions around the globe following the KT boundary crisis.

5. There is no unequivocal evidence for the survival of additional Cretaceous species into the Tertiary (other than the traditionally accepted survivor taxa). Cretaceous specimens present in variable amounts above the KT boundary are the result of reworking by bioturbation and/or current activity. This is suggested by overall abundance pattems in each section and correlations with short term sea-level lowstands at El Kef. In addition, correlation of Cretaceous nannofossil abundance and Ir abundance above the KT boundary at Indian Ocean Site 752 strongly suggests reworking of these specjmens.

\section{Ome}

CYCLOSTRATIGRAPHY OF THE KT BOUNDARY SECTION ON THE COAST OF THE BLACK SEA NEAR BJALA (BULGARIA). A. Preisinger, Institute of Mineralogy, Crystallography and Structural Chemistry, Technological University Vienna, 1060 Vienna, Getreidemarkt 9, Austria.

KT boundaries on the coast of the Black Sea near Bjala, $35 \mathrm{~km}$ south of Varna, have been identified by biostratigraphic, mineralogical, geochemical, and magnetostratigraphic methods [1].

In the hemipelagic profile Bjala $2 \mathrm{~b}$ oriented rock cores were drilled for magnetostratigraphic studies. The measurements show the nomal and reversed zones from chron $29 R$ to chron $26 \bar{R}$. Using biostratigraphic investigations, the Tertiary (Dan) could be subdivided into nannofossil zones NP1 to NP4. Since the profile Bjala $2 b$ shows $\mathrm{CaCO}_{3}$ cycles between $40 \mathrm{wt} \%$ and 80 wt\% these precessional cycles in Late Cretaceous-Early Tertiary marine sediments could be used for cyclostratigraphy. The comparison of biostratigraphic, magnetostratigraphic, and cyclostratigraphic data with the KT event allows the determination of a timescale in the range 65$62.5 \mathrm{~m}$.y. Climatic changes could be determined by means of $8^{18} \mathrm{O}$ determinations of the nannofossil from the survivorThoracosphaera operculasa.

References: [1] Preisinger A. et al. (1993) Palaeogeogr., Palaeoclimatol., Palaeoecol., I04. 


\section{$\operatorname{Onn} 17$}

EVENT-, BIO-, AND MAGNETOSTRATIGRAPHY OF THE KT BOUNDARY SECTIONS IN THE EAST BALKAN AREA, BULGARIA. A. Preisinger' and S. Aslanian '.2, 'Institute of Mineralogy, Crystallography and Structural Chemistry, Technological University, Vienna, Austria, 2 Permanent address Institute of Geology, Bulgarian Academy of Science, Sofia, Bulgaria.

KT boundary sections in the East Balkan area, south of the thrust and nappes of the Balkan Mountain, have been identified by biostratigraphic, mineralogical, geochemical, and magnetostratigraphic methods. From these investigations a real-time KT boundary was detected only on the coast at the Black Sea near the village Bjala, 35 $\mathrm{km}$ south of Varna [1]. The hemipelagic sediments of profile Bjala $2 \mathrm{~b}$ and Bjala $2 \mathrm{c}$ show an Ir enrichment in the boundary clay, a minimum of $\mathrm{CaCO}_{3}$ and $\delta^{13} \mathrm{C}$, shocked quartzes, and a mass extinction of Cretaceous nannoplankton species, as well as a bloom of survivors at the KT boundary and the first appearance of new nannoplankton species after the $\mathrm{KT}$ event. Both profiles lie within the reversal paleomagnetic chron $29 \mathrm{R}$. The comparison of biostratigraphic and magnetostratigraphic results provides a timescale for the evolution of these new nannoplankton species [2].

References: [1] Preisinger A. et al. (1993) Palaeogeograph., Palaeoclimasol.. Palmononn 104. [2] Preisinger A. et al. (1993) N94- 28310$$
\text { orty } 0 \text { क } 826
$$ \\ $\checkmark$ A GENERAL THEORY OF IMPACTS AND MASS EX- TINCTIONS, AND THE CONSEQUENCES OF LARGE- BODY IMPACT ON THE EARTH. M. R. Rampino, Depart- ment of Earth System Science, New York University, New York NY 10003, USA.}

The theory that large-body impacts are the primary cause of mass extinctions of life on the Earth now has a sound theoretical and observational foundation. A convergence of evidence suggests that the biosphere may be a sensitive detector of large impact events, which result in the recorded global mass extinction pulses. The astronomically observed flux of asteroids and comets in the neighborhood of the Earth, and the threshold impact size calculated to produce a global environmental catastrophe, can be used to predict a time history of large impact events and related mass extinctions of life that agrees well with the record of $\sim 24$ extinction events in the last 540 m.y. [1] ${ }^{-2}$

The search for impact signatures at extinction boundaries in the geologic record has produced six cases of diagnostic evidence of impacts (e.g., layers with high Ir, shocked minerals, microtektites), and at least six cases of elevated Ir of the amplitude expected from collision of relatively low Ir objects, such as comets. Recent detailed studies of the extinction boundaries show evidence of biological, isotopic, and geochemical signatures of sudden environmental crisis and abrupt mass mortality similar to those seen at the KT boundary [1]. A comparison of extinction rates and severity with the record of impact events provides a straightforward relationshipthe greater the energy of the impact, the greater the mass extinction. The largest known craters have a significant correlation with the extinctions, including Manicouagan $(-100 \mathrm{~km}$ wide), close to the end-Triassic; Doulon in China $(\sim 80 \mathrm{~km})$ near the Jurassic/Cretaceous boundary; Popigai $(\sim 100 \mathrm{~km})$ near the Eocene/Oligocene transition; and Chicxulub ( $\geq 200 \mathrm{~km}$ ) at the $\mathrm{KT}$ boundary. A lower limit seems to exist, as impacts producing craters $\leq 50-60 \mathrm{~km}$ wide are not associated with global extinction pulses above back. ground levels of extinction. A newly proposed impact structures on the Falkland Plateau $(\sim 350 \mathrm{~km})$ may correlate with the end-Permian extinction ( 250 m.y.), the most severe in the last 540 m.y. [2].

The formation and subsequent breakup of supercontinents and the coming and going of ice ages are among the major events in Earth history. Furthermore, within the plate tectonic paradigm they have been closely linked through changes in ocean-floor creation rates, sea level, volcanism, and atmospheric composition $\left(\mathrm{CO}_{2}\right.$ content) [3]. These would seem to depend strictly upon intemal Earth processes (e.g., mantle convection, rising deep mantle plumes). However, recent evidence points to a possible role for asteroid and comet impacts in supercontinent breakup episodes, and in explaining several paradoxes pertaining to past ice ages.

Large impacts create magnitude $\geq 12$ earthquakes, and such quakes could result in deep fracturing near impact sites, as well as in regions at great distances from the sites, where seismic waves are focused [4]. Impact-related fracturing could lead to cracking of the lithosphere, mantle melting, vast outpourings of lava (flood basalt eruptions), and development of hotspots. These might be most likely to occur in areas where broad upwellings or plumes in the mantle produced stresses that could be released by the impact-induced fracturing [3].

Correlation and possible cause-and-effect relationships among large-body impacts, extinction events, and continental flood basalt eruptions have been suggested [5,6]. Our previous work showed an apparent correlation between the ages of rapidly erupted continental flood basalts (CFBs) and extinction boundaries over the past $250 \mathrm{~m}$.y. Use of new and more reliable ${ }^{4 \prime} \mathrm{Ar} /{ }^{39} \mathrm{Ar}$ and $\mathrm{U}-\mathrm{Pb}$ age determinations on flood basalts improves the correlation.

This correlation is significant at the $\sim 99 \%$ level [7]. We believe that these data support possible cause-and-effect relationships among impacts, extinctions, and flood basalt eruptions.

The breakup of supercontinents, such as Pangaea, are attributed to upwelling of hot plumes in the Earth's mantle, which eventually break through to the surface. The breakup events are often marked by flood basalts. The discrete ages of the flood basalt eruptions show that the breakup of Pangaea (and its southern region of Gondwanaland) occurred in a number of phases.

A clue to the possible association of supercontinent breakup and a large impact comes from events that took place at the end of the Permian Period (245-250 m.y.), a time marked by the most severe mass extinction of life in the geologic record (about $96 \%$ of species

TABLE I.

\begin{tabular}{lccc}
\hline CFBs & m.y.-* & m.y. & Extinction Boundaries \\
\hline Columbia River & $16.2 \pm 1$ & $14 \pm 3$ & Lower/mid Miocene \\
Ethiopian & $36.9 \pm 0.9$ & 36 & Eocene/Oligocene \\
North Atlantic & $60.2 \pm 2$ & $61 \pm 2.5$ & end Danian \\
Deccan & $65.5 \pm 2.5$ & $65 \pm 1$ & KT \\
Madagascar & $86.5 \pm 0.5$ (new) & $92 \pm 1$ & Cenomanian/Turonian \\
Rajmahal & $117 \pm 1$ & $110 \pm 3$ & Aptian/Albian \\
Serra Geral & 138 (new) & $137 \pm 7$ & Late Jurassic \\
Antarctic & $176 \pm 1$ (new) & $173 \pm 3$ & Bajocian/Bathonian \\
Newark & $201 \pm 1$ & $211 \pm 8$ & end Triassic \\
Siberian & $248 \pm 2.5$ & $255 \pm 3$ & Permian/Triassic \\
\hline
\end{tabular}

* Errors are lo.

+ ${ }^{4} \mathrm{Ar} /{ }^{34} \mathrm{Ar}$ age determinations or average of geological timescales were used for ertors. 
TABLE 2.

\begin{tabular}{ll}
\hline Continental Flood Basalts & Event \\
\hline Columbia River(U.S.) & Failed break (?) \\
Ethiopian & Red Sea break \\
North Atlantic & Europe-Greenland break \\
Deccan (India) & India-Seychelles \\
Madagascar & Madagascar-Seychelles/India \\
Rajmahal(India) & India-Antarctica break \\
Serra Geral (South America) & South America-Africa break \\
Antarctic & Tranantarctic rifting \\
Karoo(SouthAfrica) & South Africa-Antarctica break \\
EasternU.S. & North America-Africa break \\
Siberian & Failed Siberian break (?) \\
\hline
\end{tabular}

became extinct). A large, roughly circular region of anomalous crustal deformation occurred around the present Falkland Plateau at the same time (248 m.y.). Geophysical and geological information allow the identification of one and possibly two circular basins (about 350 and $200 \mathrm{~km}$ in diameter) of possible Late Permian age on the Falkland Plateau-suggesting impacts of planetesimals 10 $20 \mathrm{~km}$ in diameter [2]. The great impact may have provided a locus for the subsequent breakup of Gondwanaland, providing radial and concentric lines of weakness in the lithosphere, and possibly localizing the development of mantle convection pattems. This model may explain the similarity in timing of impactor showers, flood basalt enuptions, extinctions, hotspot outbreaks, and reorganizations of plate motion [3].

Major episodes of glaciation are recorded by diamictites interpreted as tillites in the Early Proterozoic (about 2.3 b.y.), Late Proterozoic ( $\sim 850-600 \mathrm{~m} . \mathrm{y}$.), Late Ordovician ( $435 \mathrm{~m} . \mathrm{y}$.), Late Devonian ( $\sim 370$ m.y.), and Late Paleozoic ( 320 to $\sim 250$ m.y.). This leads to several climatic paradoxes: Late Proterozoic glacial deposits are found at all paleolatitudes, the early glaciations occur at times when atmospheric $\mathrm{pCO}_{2}$ is predicted to have been high, and some glacial deposits are associated with warm climate indicators $[8,9]$.

Numerous published studies have revealed that many recognized tillite sequences were actually the products of massive debris flows and large-scale "rainout" of coarse sediment. As a result, the tillites are now generally reinterpreted as glaciomarine debris-flow deposits, but this interpretation does not readily explain the scale and textures of the diamictites [8,9]. Recently, three groups have presented evidence that some inferred glacial sequences have many of the essential characteristics of ballistic debris-flow ejecta created by large impacts $[8-10]$ and may contain evidence of shock [9]. Might some deposits interpreted as glacial in origin be ejecta of large impact events? If so, significant revisions in the long-term climate history of the Earth will be required.

References: [1] Rampino M. R. and Haggerty B. M. (1994) in Hazards Due to Comets and Asteroids, Univ. of Arizona, in press. [2] Rampino M. R. (1992) Eos, 73, 336. [3] Rampino M. R. and Caldeira K. (1993) EPSL, 1/4, 215-227. [4] Rampino M. R. and Caldeira K. (1992) GRL, 19, 2011-2014. [5] Rampino M. R. and Stothers R. B. (1988) Science, 241, 663-668. [6] Stothers R. B. and Rampino M. R. (1990) GSA Spec. Paper 247, 9-18. [7] Stothers R. B. (1993) GRL, 20, 1399-1402. [8] Oberbeck V. R. et al. (1993) J. Geol., 101, 1-19. 19] Rampino M. R., (1994) J. Geol., in press. [10] Sears J. W. and Alt D. (1992) Intern. Basement Tect. Assoc. Pub., 5, 385-392.

\section{CMTT TO P.IO}

HYDROTHERMAL WITWATERSRAND GOLDMINERAL. IZATION CAUSED BY THE VREDEFORT MEGA-IMPACT EVENT? W. U. Reimold, Economic Geology Research Unit, University of the Witwatersrand, Private Bag 3, Johannesburg 2050, RSA.

Masaitis [1] recently reviewed many geological and morphological aspects that might render impact structures interesting and sometimes important economic geological targets. However, the role of hydrothermal processes that might be triggered by impact events and that, in connection with the effects of structural geological modification in and around an impact crater, might lead to mineralization of economic magnitudes has not yet been explored. Considering the enormous energies released on impact of even small projectiles [e.g., 2,3], this aspect should clearly be emphasized.

Dressler and Reimold [4] drew attention to the particular setting of the Vredefort Dome near the geographic center of the preserved Witwatersrand Basin (South Africa) with its exceptional Au and $\mathrm{U}$ deposits. An impact origin for the Vredefort structure was first suggested by Daly [5], and since the recognition of, particularly, shatter cones [6] and coesite and stishovite [7] this view has been accepted by the majority of geologists. However, this hypothesis has not remained unchallenged, and the discovery of stnuctural complexities and of temporal relationships between the various deformation phenomena and geological events in the area of the Vredefort Dome led to critique of the impact model for this structure [8,9]. Modeling the size of the $2-\mathrm{Ga}[10]$ Vredefort structure on the basis of radial distribution of shock effects, such as shatter cones or planar microdeformations in quartz [11], resulted in diameter estimates ranging from 180 to $300 \mathrm{~km}$, with preference given to the upper limit. This places the Vredefort structure in the same size range as the buried Chicxulub Crater structure, for which a $300-\mathrm{km}$ diameter has just been determined [12]. Clearly the lack of any other impact structure of such size (the next largest would be the deeply eroded (similar to Vredefor) Sudbury structure that probably originally measured $<200 \mathrm{~km}$ in diameter [13]) implies that continued detailed study of the exposed remnants of the Vredefort structure is of utmost importance for the understanding of large impact cratering events and the resulting formations.

Various groups have studied the role of hydrothermal alteration in impact structures [e.g., 14-17]. It was suggested that within the confines of an impact structure extensive circulation of impactheated fluids could take place [18]. Such effects are not only known from large impact structures [e.g., 15], but were noted in very small structures as well [e.g., 16]. Like the origin of the Vredefort structure by either endogenic or exogenic processes, the formation of the Witwatersrand ores has been controversial. An avidly conducted argument between those workers favoring a detrital origin of the Witwatersrand gold and a second school of "hydrothermalists" has been carried out [19]. To date many geologists studying the Witwatersrand Basin support the so-called "Modified Placer Hypothesis" for the formation of these ores, by partial remobilization of primary detrital deposits. However, source and nature of the fluids that caused large-scale remobilization of gold and other base metals throughout the $\sim 40,000 \mathrm{~km}^{2}$ of the Witwatersrand Basin have not yet been identified or resolved. Some workers believe that these fluids were liberated during the extrusion of the $2.7-\mathrm{Ga}$ Ventersdorp lavas, while others have related a basin-wide $250^{\circ}$ $400^{\circ} \mathrm{C}$ metamorphic phase of post-Ventersdorp age with base metal 
remobilization [20] and suggested an association with either the Bushveld magmatic phase at about $2.065 \mathrm{Ga}$ or with the Vredefort event [e.g., 21].

It has been known for several years that extensive pseudotachylite occurrences are not restricted to the area of the Vredefort Dome, but also occur at multiple stratigraphic levels within the surrounding Witwatersrand Basin $[22,23]$. These occurences are mainly linked to bedding-plane parallel faults or to normal faults. Some of the former occurences are closely related to important reefs. Like in Vredefort, several generations of pseudotachylites and other fault rocks were identified in the Witwatersrand Basin. Planar microdeformation features in quartz are observed in Witwatersrand pseudotachylites, too, but are less abundant than in Vredefon lithologies. Recently several bedding-fault-related occurrences of pseudotachylite and their respective host rocks were studied in petrographic and chemical detail [24-26] and dated with the ${ }^{41} \mathrm{Ar}$ ${ }^{39} \mathrm{Ar}$ stepheating technique $[25,27]$. We could demonstrate that pseudotachylites associated with, but younger than, various reef horizons can be highly enriched in Au and other base metals (e.g., $\mathrm{Zn}, \mathrm{Pb}, \mathrm{Cu}$ ). Distinct alteration zones mark the contacts between pseudotachylite-bearing fault zones and the country rocks (e.g., at the Ventersdorp Contact Reef, VCR $[25,26])$. Pseudotachylites also contain hydrothermally deposited mineral phases, such as sericite, chlorite, and various sulfides and oxides, in the form of vesicle fillings or matrix minerals. They contain Au either as primary detrital grains that obviously are derived from the precursor rocks, or as tiny, secondary crystallites in the matrix. Detailed fluid inclusion analysis of all lithologies in the VCR fault zone [26] relates the alteration and deposition of secondary Au to a $250^{\circ}-350^{\circ} \mathrm{C}$ metamorphic event. The fluids were clearly not of magmatic, but of sedimentary-metamorphic origin. ${ }^{40} \mathrm{Ar}-{ }^{34} \mathrm{Ar}$ chronology on seven pseudotachylite specimens from the VCR fault zone [27] from geographically well-separated locations in the West Rand and Central Rand gold fields consistently yielded 2.0-Ga ages. These results separate the pseudotachylite-forming event from the Bushveld magmatic phase at $2.065 \mathrm{Ga}$ ago. The fact that pseudotachylites with hydrothermal mineral phases also yielded well-defined 2-Ga ages is regarded as evidence for autometasomatism at that time. Because the Vredefort event is believed to have occurred at just about $2 \mathrm{Ga}$ ago [10], it is currently debated whether this widespread hydrothermal alteration, associated with basin-wide, large-scale remobilization of Au and other base metals, is a direct consequence of the Vredefon impact event at that time. It is proposed that a series of beddingparallel faults, dipping at shallow angles toward the Vredefort Dome [e.g., 23], acted as channels for fluids that originated nearer the center of the structure. No evidence for significant lateral movements, nor for distal accumulations of Au and base metals, have been observed to date. It is therefore thought that, while these processes affected a major part of the Witwatersrand Basin, actual chemical transport did not exceed distances wider than individual faulv/alteration zones (several meters at maximum). Further fluid studies on Vredefort lithologies and other Witwatersrand reefs and fault rocks, as well as metamorphic and chronological studies, are in progress and will be applied to test this model. Should it be proven correct this model would have significant consequences both for the understanding of hydrothermal systems associated with impact structures (are they really confined to the interior of crater structures, or do these effects further extend into crater floor and crater environs?) and for the geological and geochemical exploration in and around large impact structures.
In this context it should be recalled that Duane and Reimold $[28,29]$ proposed an impact origin for the $\sim 800-\mathrm{km}$-diameter Simpson Desert depression in Central Australia. This region is surrounded by a belt comprising a host of ore deposits of mainly hydrothermal origin and of vast economic importance.

References: [1] Masaitis V. L. (1992) Meleoritics, 27, 21-27. [2] Melosh H. J. (1989) Impact Cratering: A Geologic Process, Oxford, 245 pp. [3] Dence M. R. et al. (1977) in Impact and Explosion Cratering, 247-275, Pergamon. [4] Dressler B. O. and Reimold W. U. (1988) in International Conference on Global Catastrophes in Earth History, 42-43, LPI Contrib. No. 673. [5] Daly R. A. (1947) J. Geol., 55, 125-145. [6] Hargraves R. B. (1961) Trans. Geol. Soc. S. Afr., 64, 147-154. [7] Martini J. E. J. (1978) Nature, 272, 715-717. [8] Nicolaysen L. O. (1972) GSA, 132, 605-620. [9] Reimold W. U. (1992) in Large Meteorite Impacts and Planetary Evolution, 59-60, LPI Contrib. No. 790. [10] Walraven F. et al. (1990) Tectonophys., 171, 23-48. [11] Therriault A. M. et al. (1993) LPS XXIV, 1419-1420. [12] Sharpton V. L. et al. (1993) Science, 261, 1564-1567. [13] Grieve R. A. F. etal. (1991) JGR, 96, 22753-22764. [14] Stöffler D. et al. (1977) Geol. Bavar., 75, 163-189. [15] Newsom H. E. (1980) Icarus, 44, 207-216. [16] Newsom H. E. et al. (1987) Proc. LPSC I7th in JGR, 9I, E239-E251. [17] Komor S. C. et al. (1988) Geology, 16, 711-715. [18] Koeberl C. et al. (1989)GCA, 53, 21132118. [19] Pretorius D. A. (1991) Econ. Geol. Mon., 8, 139-163. [20] Phillips G. N. and Myers R. E. (1988) Econ. Geol. Mon., 6, 598-608. [21] Frimmel H. E. et al. (1993) Econ. Geol., 88, 249265. [22] Killick A. M. and Reimold W. U. (1990) S. Afr. J. Geol., 93, 350-365. [23] Fletcher P. and Reimold W. U. (1989) S. Afr. J. Geol., 92, 223-234. [24] Reimold W. U. and Koeberl C. (1991) Terra Abstracts, 3, 386. [25] Reimold W. U. et al. (1993) The VCR Revisited, GSSA, Western Transvaal Br., 55-58. [26] Boer R. H. el al. (1993) The VCR Revisiled, GSSA, Wesiern Transvaal Br., 9294. [27] Trieloff M. et al. (1992) in Large Meteorite Impacts and Planetary Evolution, 75-77, LPI Contrib. No. 790. [28] Duane M. J. and Reimold W. U. (1989) LPS XX, 252-253. [29] Duane M. J. and Reimold W. U. (1990) LPS XXI, 301-302.

CAN AN EXTRATERRESTRIAL IMPACT EVENT EXPLAIN THE PATTERN OF BIOTIC CRISIS NEAR THE KT BOUNDARY? J. K. Rigby Jr. ${ }^{\text {, G. P. Landis }}{ }^{2}$, and R. A. Hengst ${ }^{3}$, 'Department of Civil Engineering and Geological Sciences, University of Notre Dame, Notre Dame IN 46556-0767, USA, ${ }^{2}$ Mail Stop 905, U.S. Geological Survey, Denver Federal Center, Denver CO 80225 , USA, ${ }^{3}$ Biological Sciences, Purdue University North Central, Westville IN 46391 , USA.

There are three basic questions regarding the KT boundary: (1) Was there an extraterrestrial impact event at or near a stratigraphic interval that preserves one of the Earth's largest recorded biotic crises? (2) Did that extraterrestrial impact event cause the biotic crisis? (3) Are there other processes, not related to the extraterrestrial impact, that are more robust in their explanation of sequence, scope, and selectivity of KT extinctions?

While the first question remains an open issue in some circles, progress is being made in answering questions (2) and (3). Any extinction event will have to be substantiated on the basis of the preserved geologic record, whatever its weaknesses, because it is the only available data and is the only means by which our ideas 
regarding extinction can be tested. Even reworking of older materials into younger rocks has been used to explain some of the record inequities. Discoveries made during the 1993 field season in Montana's continental section may not totally resolve the reworked issue but they definitely place the bulk of the circumstantial evidence on the side of limited, if any, reworking of fossils. Rock record constraints now demand that several biologic trends associated with KT boundary deposits must be answered in order to sustain a viable extinction hypothesis. These constraints fall into two general categories: (1) faunal and floral selectivity of extinction and (2) conditions that anticipate the boundary event and wam of crisis.

Extinction selectivity is difficult to explain by a single event; here are some examples of such selectivity: (1) Dinosaurs are said to become extinct at the KT boundary, yet those species most closely related to living reptiles and amphibians that would have the most difficulty surviving the cold conditions specified by the impact model survive and do well, (2) Oceanic siliceous and carbonate photosynthetic plankton, inhabiting the same cubic meter of water, suffer widely different extinction rates. (3) Mammals, in the process of radiating, continue more-or-less uninterrupted and increase diversity across the boundary. (4) Ammonites appear to suffer extinction before the KT boundary in some geologic sections, yet apparently continue across the boundary in others, showing variation in extinction pressures with respect to latitude.

Several groups of organisms appear to anticipate the biotic crisis. Rudist clams blossom in the Cretaceous, yet suffer extinction before the boundary as do inoceramid clams. In North America, twothirds of dinosaur lineages become extinct between the time of maximum diversity 10 m.y. before the KT and the KT boundary; only 12-13 species of the approximately 40 species (depending upon taxonomic preference) remain prior to the KT event. We are approaching consensus regarding the magnitude of KT boundary extinctions, but it is virtually impossible to explain long-term declines and selective extinction with sudden cataclysmic scenarios. Perhaps there are more robust explanations that do a better job of explaining what is no longer a "knife edge" but a less-well-defined and protracted extinction.

The Pele Hypothesis [1] provides a unique model that relates a number of well-established geological events to mantle processes. Among these are $\mathrm{O}$ blooms predicted from increased photosynthetic activities made possible by increased levels of $\mathrm{CO}_{2}$ from mantle activity. Cerling [2] shows that Cretaceous atmospheric $\mathrm{CO}_{2}$ was considerably more abundant than at present, with concentrations reaching 10-12x modern abundance during much of the Cretaceous and importantly near the KT boundary. Berner [3] shows that such $\mathrm{CO}_{2}$ may be sufficient to create the Cretaceous greenhouse effect. Changes in $\mathrm{CO}_{2}$ concentrations rapidly and profoundly affect organic material accumulation rates, which were also affected during episodes of eustatic adjustment. These factors may have led to $\mathrm{C}$ sequestering in the form of coal and oil deposits, which in tum produced an increase in atmospheric $O$.

Consider the effects of increased $O$ levels on the biosphere. Landis and others [1] have shown atmospheric $\mathrm{O}_{2}$ concentrations in excess of $30 \%$ during the Cretaceous. $\mathrm{O}_{2}$ concentrations ranged from a high of $35 \%$ to a low of $28 \%$, considerably higher than at present. Oxygen is integral to the process of energy production in both plant and animal species [4]. It is logical to seek verification of these unique atmospheric conditions in organisms that evolved to survive in these conditions. Terrestrial vertebrates of the Cretaceous are reasonably well known. The sauropod dinosaur,
Apatosaurus, is one such animal and analysis of its bone-constrained anatomy provides a number of obvious physiological limitations [5]. These include an elongated neck with considerable dead air space, extremely small nostrils for the size of the animal, a large bulk with attendant demands for $\mathrm{O}$, and no obvious mechanism for efficient, and deep, ventilation mechanics. Hengst et al. [6] estimated tidal volumes at slightly over $100 \mathrm{I}$ with dead space conservatively estimated at $30 \mathrm{I}$. Ventilation was probably achieved by rib movements alone with maximal capabilities approximately $4 x$ that of tidal volumes. Thus, 30 breaths were needed to refresh the lung. This implies that sauropods had a high potential for $\mathrm{CO}_{2}$ retention and consequent acidosis. They probably had limited exercise capabilities that were further limited by crocodilian-type lung areas and low $\mathbf{0}$-carrying capacities of the blood [7]. It was concluded that although minimal effort would have been possible in $21 \% \mathrm{O}_{2}$ concentrations there was insufficient reserve for stressful conditions. High $O$ concentrations create increased $O$ pressures sufficient to allow a respectable range of activity intensities.

Our research has indicated that the low tolerance to $O$ stress may well explain the progressive decline in species variety as the $\mathrm{KT}$ boundary is approached. It is also important to consider the effect that limited $O$ transpon might have had on other, vigorous activities. For instance, the $\mathrm{O}$ available in migration over mountainous areas would cause considerably larger problems than a similar migration near sea level.

References: [1] Landis G. P. et al. (1993) GSA, 25, 362. [2] Cerling T. E. (1991)AJS, 291, 377-400. [3] Bemer R. A. (1991) AJS, 291, 339-376. [4] McAlester A. L. (1970) J. Paleontology, 44, 405-409. [5] Spotilla J. R. et al. (1991) Mod. Geol., 16, 203-227. [6] Hengst R. A. et al. (1993) GSA, 25, 297. [7] Jones J. H. et al. (1989) FASEB J., 3, A234.

CHARACTERISTICS AND ORIGIN OF SPINEL-BEARING SPHEROIDS AT THE KT BOUNDARY. E. Robin, L. Froget, J. Gayraud, R. Rocchia, and L. Turpin, Centre des Faibles Radioactivités, CEA/CNRS, 91190 Gif-sur-Yvette, France.

Introduction: Spinel-bearing spheroids have been reported at several KT boundary sites throughout the world [1]. Although the origin of these spheroids is not clearly established, they are interpreted as condensed products derived from the cloud of vaporized projectile and target material produced by a large asteroid impact [1-5]. The occurrence of numerous meteoric spinels in these spheroids shows that at least some of them could be derived from meteoritic debris heated and oxidized in the atmosphere [6]. Here we report on the mineralogical and chemical features of the spinelbearing particles at the KT boundary and we discuss their possible $\operatorname{origin}(\mathbf{s})$.

Samples and Procedure: From the $18 \mathrm{KT}$ sites we have investigaled so far [7], only DSDP site 577 still contains wellpreserved spinel-bearing spheroids. At the other sites, the spheroids have experienced intensive alteration and in most cases only spinels have survived. However, a few spheroids from Beloc (Haiti), Petriccio (Italy), El Kef (Tunisia), and Caravaca (Spain) have also been recovered and studied. At site 577 about 100 particles were analyzed for $\mathrm{Ir}, \mathrm{Ni}, \mathrm{Co}, \mathrm{Cr}, \mathrm{Sc}$, and REE with a high-purity $\mathrm{Ge} \gamma$ ray detector [8]. At other sites, particles were analyzed only for Ir. Debye-Scherrer and X-ray diffraction analyses have been performed on a set of particles in order to characterize mineralogical phases. 
Individual particles were then mounted in epoxy and polished for detailed scanning electron microscopy and electron microprobe analysis.

Results: DSDP site 577 (North Pacific Ocean). Two distinct populations of well-preserved spinel-bearing particles have been found right at the boundary [8]: spheroids with dendritic spinel textures uniformly dispersed in the whole particle and irregularly shaped fragments with tiny spinels essentially confined to the rim. Chemical analyses of spinels contained in the particles are consistent with those previously reported [4]: they have high $\mathrm{Ni}(>1 \%)$ contents, low Ti contents $(<1 \%)$, and a high Fe oxidation state $\left(\mathrm{Fe}^{3+1}\right.$ $\mathrm{Fe}_{\text {total }} \approx 96$ atom $\%$, see [7]). In addition to spinel, augite crystals are observed and pure augite spherules, some of them containing spinels, are found. Although most of the minerals originally present in the particles are now replaced by smectite, their morphology and composition have been preserved. In 86 analyzed spheroids, Ir contents range from less than $2 \mathrm{ng} / \mathrm{g}$ up to $610 \mathrm{ng} / \mathrm{g}$, consistent with the range of Ir contents observed in cosmic ablation spheres [8]. In fragments (1) particles analyzed as yet), Ir contents range from $95 \mathrm{ng} / \mathrm{g}$ to 1200 $\mathrm{ng} / \mathrm{g}$, with an average value of $530 \mathrm{ng} / \mathrm{g}$, very close to the $\mathrm{Ir}$ abundance of meteorites. We also found systematic $\mathrm{Cr}, \mathrm{Co}$, and $\mathrm{Ni}$ enrichments in spheroids and fragments as well, with abundances sometimes approaching those in meteorites, and low REE contents, with a relatively flat pattern (Fig. 1), which excludes a mixing with more than $10 \%$ of terrestrial material. The small Ce anomaly may be attributed to postdepositional contamination by the surrounding REE-rich sediment.

Beloc (Haiti). Only spheroids are found. Spinel are embedded in a smectitic matrix enriched in iron oxide (goethite). The spinel composition differs from the one measured at site 577 [7]. No augite crystals are observed. Iridium analyses of 10 spheroids reveal concentrations ranging from less than $2 \mathrm{ng} / \mathrm{g}$ up to $100 \mathrm{ng} / \mathrm{g}$.

Petriccio (Iraly) and El Kef (Tunisia). At both sections, many flattened spheroids are found but few of them contain spinels. At Petriccio, the particles are altered and filled with glauconite, $\mathrm{K}$ feldspaths, and iron hydroxide. At El Kef they are mainly composed of goethite and smectite. Rare kaolinite and $\mathrm{K}$-feldspaths are present. No augite crystals are observed. Iridium analysis on a set of spheroids from Petriccio gives an average content of $40 \mathrm{ng} / \mathrm{g}$, slightly

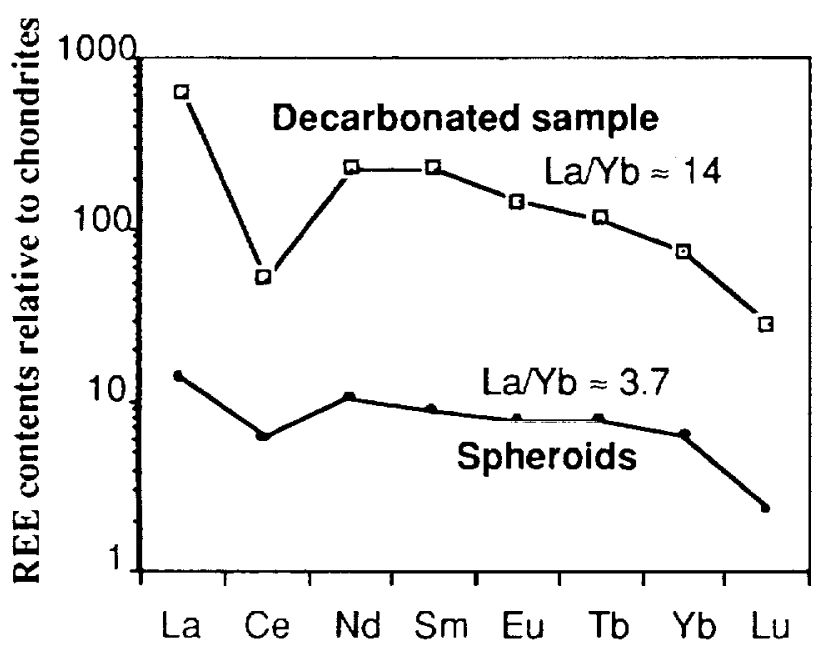

Fig. 1.
TABLE I. Elemental contents determined by INAA for 97 spinel-bearing debris samples ( 86 spherules and 11 fragments) from site 577.

\begin{tabular}{|c|c|c|c|c|}
\hline & \multirow{2}{*}{\multicolumn{2}{|c|}{$\frac{\text { Population } 1}{\text { Spheroids }}$}} & \multirow{2}{*}{\multicolumn{2}{|c|}{$\frac{\text { Population } 2}{\text { Fragments }}$}} \\
\hline & & & & \\
\hline & Average & Range & Average & Range \\
\hline Sc & 21.2 & $9.4-32.6$ & 20.0 & $13.1-39.4$ \\
\hline $\mathrm{Cr}$ & 920 & $30-4200$ & 1600 & $600-3600$ \\
\hline $\mathrm{Fe} \%$ & 22.0 & $15.0-39.0$ & 18.8 & $13.4-32.9$ \\
\hline Co & 167 & $2-500$ & 140 & $30-340$ \\
\hline $\mathrm{Ni}$ & 2100 & $60-9000$ & 3200 & $500-11,000$ \\
\hline La & 4.4 & $<2.0-8.5$ & 3.6 & $1.1-3.2$ \\
\hline $\mathrm{Ce}$ & 4.9 & $1.1-13.4$ & 8.4 & $<6-8.4$ \\
\hline Nd & 6.1 & $<2.0-20$ & $<12.0$ & - \\
\hline $\mathrm{Sm}$ & 1.6 & $<0.6-3.3$ & 1.7 & $0.65-2.8$ \\
\hline Eu & 0.54 & $0.15-1.60$ & 1.3 & $0.85-1.70$ \\
\hline $\mathbf{T b}$ & 0.38 & $0.08-0.96$ & $<0.75$ & - \\
\hline $\mathrm{Yb}$ & 1.20 & $<0.36-3.5$ & $<1.45$ & - \\
\hline Lu & 0.08 & $0.03-0.16$ & $<0.15$ & - \\
\hline Ir ppb & 84 & $<1.5-610$ & 530 & $95-1200$ \\
\hline
\end{tabular}

From [8]. Concentrations are in $\mu \mathrm{g} / \mathrm{g}$. except Ir which is in $\mathrm{ng} / \mathrm{g}$. Typical 10 standard deviation is $<5 \%$ for $\mathrm{Cr}$. Sc. Co, and $\mathrm{Ir} ; 5-25 \%$ for $\mathrm{Ni}$ and REE.

lower than previously measured [2]. Spinel composition at these sites still differs from that observed at site $\mathbf{5 7 7}$ and at Beloc and also differs between them [7].

Caravaca (Spain). K-feldspath spheroids are abundant [2], but none of them contain spinels and their Ir content is lower than in the surrounding matrix. Numerous lenses almost entirely made of spinels are present and their Ir content is comparable to that in the surrounding matrix $(\approx 70 \mathrm{ng} / \mathrm{g}$ ).

Discussion and Conclusions: From the study of the spinelbearing particles at site 577 we can draw the following conclusions: (1) Morphological, mineralogical, and chemical evidences show that spinel-bearing particles at the KT boundary derive from nearly pure meteoritic debris. If KT spheroids are formed in the cloud of vaporized projectile and target material, then the target contribution is negligible. (2) The occurrence of partially melted meteoritic debris is inconsistent with a condensation process.

This rules out some proposed mechanisms for the origin of spinel-bearing spheroids at the KT boundary. Formation during a cratering event on land is unlikely, as no meteoritic material survived in such an event. In addition, the contribution of the target is always high in impact on land and the amount of meteoritic material in impact-melt rocks is in general $<1 \%$ relative to $\mathrm{Cl}$ chondrites and still lower in the long-range ejecta. Last but not least, impact products, i.e., tektites and microtektites, are extremely reduced objects free of any crystalline inclusion. Condensation from the bolide itself is also unlikely, as spinel crystallization requires high $O$ fugacities [9] and there is no available $O$ in meteorites.

Considering the formation conditions of spinels [9] we can envisage two possible origins for KT spheroids: (1) ablation and oxidation of meteoritic debris in the atmosphere [6]. which implies that several objects resulting either from an oblique impact or from a fragmented comet are involved [7]; and (2) oxidation of meteoritic debris in the water vapor cloud produced by an impact in the ocean; in such an event pure meteoritic debris can be recovered and highly oxidized spine] can be formed [10]. 
References: [1] Smit J. and Romein A. J. T. (1985) EPSL, 74, 155-170. [2] Montanari A. et al. (1983) Geology. II, 668-67l. [3] Smit J. and Kyte F. T. (1984) Nalure, 310, 403-405. [4] Kyte F. T. and Smit J. [1986] Geology, 14, 485-487. [5] Bohor B. F. et al. (1986) EPSL, 81, 57-66. [6] Robin E. et al. (1992) EPSL, 108, 181-190. [7] Robin E. et al., this volume. [8] Robin E. et al. (1993) Nature, 363, 615-617. [9] Gayraud J. et al., this volume. [10] Margolis S. V. et al. (1991) Science, 25I, 1594-1597.

ON THE ORIGIN OF THE REGIONAL VARIATIONS IN SPINEL COMPOSITIONS AT THE KT BOUNDARY. E. Robin, J. Gayraud, L. Froget, and R. Rocchia, Centre des Faibles Radioactivités CEA/CNRS, 91198 Gif-sur-Yvette, France.

Introduction: Spinels with morphologies and compositions quite similar to meteoric spinels (the term "meteoric" that we use here is defined in [1]) have been found throughout the world at the KT boundary. Their presence and their high abundance is a strong argument in favor of a major extraterrestrial accretion event at the end of the Cretaceous. These minerals display a wide variety of morphology (octahedral, dendritic, skeletal, cruciform, etc.) and composition [2] that likely reflects differences in their formation conditions [1-4]. Here we discuss the cause of the regional variations in spinel compositions and the implications for understanding the KT event.

Samples and Procedure: We have searched for meteoric spinels at $18 \mathrm{KT}$ sites: Sopelana and Caravaca in Spain, Bidart in France, Stevns Klint in Denmark, Gosau in Austria, Petriccio and Nago in Italy, El Kef in Tunisia, Brazos River in Texas, Beloc in Haiti, Mimbral in Mexico, DSDP site 536 in the Gulf of Mexico, DSDP sites 577 and 465 respectively in North and South Pacific Ocean, DSDP sites 524 and 527 in South Atlantic Ocean, and ODP sites $761 \mathrm{C}$ and 752 in the Indian Ocean. Spinels were extracted from sediment samples with a magnetic separator and recovered on a 0.4- $\mu \mathrm{m}$ nuclepore filter (see [5] for a description of the method). The filters were then mounted in epoxy and polished for detailed scanning electron microscopy and electron microprobe analysis of individual spinels $(>2 \mu \mathrm{m})$.
Results and Discussion: Meteoric spinels are found at nearly all sites except at Stevns Klint, Brazos River, and DSDP site 465, where the ir concentrations are below detection limit $(<0.1 / \mathrm{mg})$. At other sites, the abundance of spinels varies from $\approx 0.3 / \mathrm{mg}$ at Mimbral up to $3000 / \mathrm{mg}$ at ODP site $761 \mathrm{C}$. Their occurrence is generally associated with the maximum Ir anomaly, in coincidence with a sharp decrease of the carbonate fraction. Results of the average composition of KT spinels are given in the Table I except for ODP site 752 and DSDP sites 524 and 527, for which spinels were not analyzed so far. Several conclusions can be drawn from these results considering the formation conditions of meteoric spinels [1]:

$\mathrm{KT}$ spinels have high $\mathrm{Ni}$ content $(>1 \%)$ and high $\mathrm{Fe}^{3+} / \mathrm{Fe}_{\text {Iolal }}$ ratio $(>70 \%)$, showing that they were formed from undifferentiated material in a very oxidizing environment $[1,3]$. These formation conditions are very constraining and allow us to rule out some possible sources for KT spinels. They cannot be derived from terrestrial magmas, which are strongly depleted in $\mathrm{Ni}$ and evolve under extremely low oxygen fugacity $[1,3]$. Direct condensation of spinel crystals during continental cratering events is very unlikely because of the reducing conditions that prevailed in the impact vapor cloud [4]. The only process known to form spinels with such a composition is ablation and oxidation of meteoritic debris in the atmosphere [3]. Spinels from Pacific and Indian Oceans have an $\mathrm{Fe}^{3+} / \mathrm{Fe}_{\text {total }}$ ratio $>90 \%$, which requires an $O$ fugacity $>0.21$ atm or higher than the one existing at sea level [I] for their crystallization. Although no definitive explanation exists today [1], such highly oxidized spinels could be indicative of oceanic impacts $[4,6]$.

Large variations in spinel compositions are observed from site to site, even for nearby sites. For example, there is virtually no overlap in the $\mathrm{Cr}$ content of spinels between Italian sites (Petriccio, Nago) and the Tunisian site (E] Kef) (see Fig. 1). Variation in the $\mathrm{Cr}$ content of spinels is also observed between Sopelana (Spain) and Bidart (France), which are only $200 \mathrm{~km}$ apart. It implies that very heterogeneous formation conditions prevailed on a local geographical scale. On the other hand, numerous cosmic debris containing Alrich spinels of quite homogeneous composition are found over at least $2 \times 10^{7} \mathrm{~km}^{2}$ in the Pacific Ocean [7]. This suggests that more than one object struck the Earth at the end of the Cretaceous. The largest ones in the Pacific account for the wide dispersion area of Al-rich spinels and smaller ones over Europe and North Africa

TABLE I. Average composition of KT spinels (number of analyses in brackets).

\begin{tabular}{|c|c|c|c|c|c|c|c|c|c|c|c|c|c|}
\hline & & Sopel. & Carav. & Bidart & Gosau & Petric. & Nago & Mimb. & Beloc & H5.36 & $\mathrm{H} 76 \mathrm{IC}$ & & $\mathrm{B}^{*}$ \\
\hline & [151] & {$[224]$} & [138] & {$[97]$} & [157] & {$[213]$} & [42] & {$[45]$} & [318] & [31] & [80] & [46] & [10] \\
\hline $\mathrm{MgO}$ & 9.8 & 7.7 & 9.0 & 10.3 & 9.3 & 9.2 & 11.1 & 10.3 & 12.7 & 15.6 & 15.6 & 16.4 & 19.5 \\
\hline $\mathrm{Al}_{2} \mathrm{O}_{3}$ & 5.7 & 5.1 & 5.2 & 3.7 & 4.5 & 3.4 & 2.4 & 4.6 & 4.7 & 5.9 & 4.4 & 6.6 & 22.8 \\
\hline $\mathrm{TiO}_{2}$ & 0.2 & 0.5 & 0.4 & 0.3 & 0.5 & 0.2 & 0.2 & 0.2 & 0.4 & 0.4 & 0.1 & 0.2 & 0.3 \\
\hline $\mathrm{Cr}_{2} \mathrm{O}_{3}$ & 16.9 & 8.0 & 9.0 & 5.3 & 6.2 & 2.7 & 1.5 & 7.1 & 5.7 & 1.7 & 1.8 & 1.3 & 0.2 \\
\hline $\mathrm{MnO}$ & 0.5 & 0.6 & 0.5 & 0.5 & 0.5 & 1.0 & 0.2 & 0.1 & 0.5 & 0.6 & 0.5 & 0.3 & 0.4 \\
\hline $\mathrm{FeO}^{+}$ & 12.0 & 14.8 & 12.7 & 10.9 & 11.9 & 11.2 & 10.6 & 12.0 & 7.5 & 5.8 & 3.5 & 4.5 & 3.9 \\
\hline $\mathrm{Fe}_{2} \mathrm{O}_{3}$ & 48.7 & 57.3 & 57.3 & 62.8 & 60.6 & 65.4 & 68.5 & 60.1 & 63.6 & 68.0 & 69.7 & 67.9 & 51.4 \\
\hline $\mathrm{NiO}$ & 4.6 & 4.8 & 5.2 & 4.3 & 5.2 & 4.9 & 3.0 & 3.5 & 5.0 & 2.6 & 4.4 & 2.9 & 1.5 \\
\hline Total & 98.8 & 98.8 & 99.2 & 98.1 & 98.8 & 98.1 & 97.5 & 98.1 & $100.0^{ \pm}$ & $100.0^{\ddagger}$ & $100.0^{\ddagger}$ & $100.0^{5}$ & 100.0 \\
\hline D. $0 . \$$ & 78.6 & 77.9 & 80.4 & 83.9 & 82.2 & 84.5 & 85.4 & 82.7 & 88.7 & 91.7 & 94.9 & 93.4 & 96.0 \\
\hline
\end{tabular}

* Two populations of spinels observed at OSDP site 577.

' $\mathrm{FeO}$ and $\mathrm{Fe}_{2} \mathrm{O}_{3}$ calculated assuming spinels are stoichiometric.

i Normalized analyses.

D.O. - iron oxidation state $\left(\mathrm{Fe}^{3+} / \mathrm{Fe}_{\mathrm{rotaj}]}\right.$ in atom\%). 

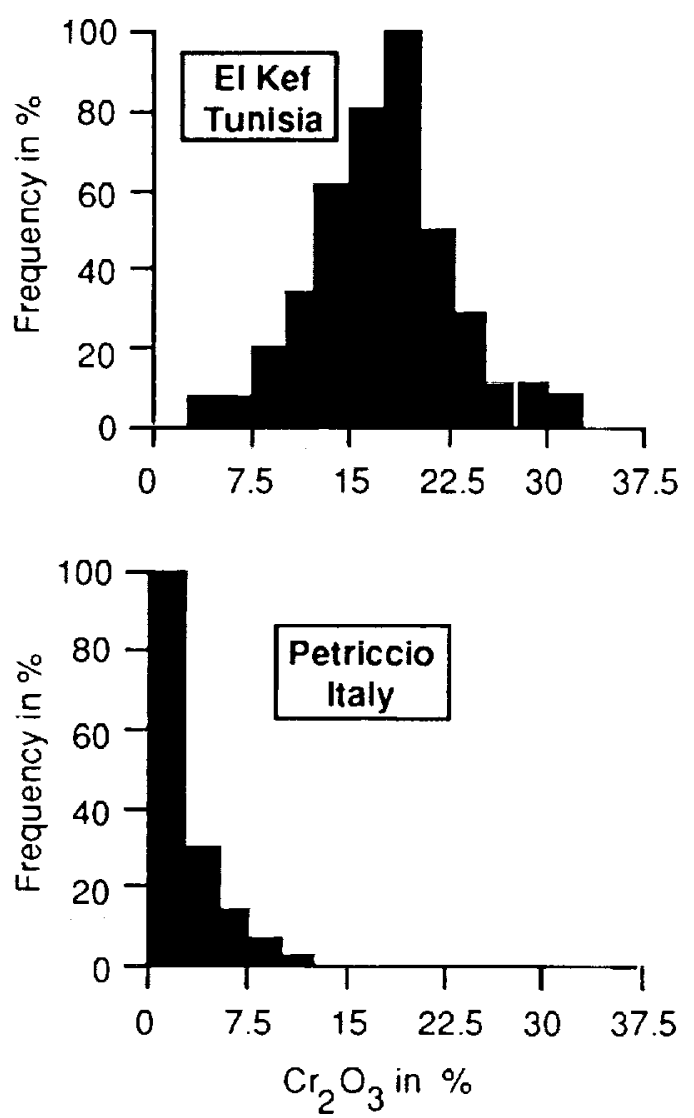

Fig. 1. A histogram showing the spinel Cr content.

account for the variation in spinel composition on a local scale.

Spinels from Pacific and Indian Oceans are always more oxidized than those from European and African sites (see Fig. 2). Spinel from the Carribean area seems to have an intermediate oxidation state though spinel from DSDP site 536 are highly oxidized. The same tendency is observed for their $\mathrm{Cr}_{\mathrm{r}}$ content: Spinels from Pacific and Indian Oceans have lower $\mathrm{Cr}$ content than those from European and African sites. Only spinels from Italy have a relatively low $\mathrm{Cr}$ content. The fact that the $\mathrm{Cr}$ content and the $\mathrm{Fe}^{3+1}$ $\mathrm{Fe}_{\text {total }}$ ratio of meteoric spinels is controlled by the O fugacity [1] suggests that spinels from Pacific and Indian Oceans were formed under higher $\mathbf{O}$ fugacities than those from European and African sites. This is consistent with the hypothesis of large objects impacting in the Pacific and Indian Oceans and smaller ones in Europe and North Africa. Indeed, large objects decelerate at low altitudes and thus at high $O$ partial pressures while small objects decelerate at higher altitudes and thus lower $O$ partial pressures. If so, it suggests a preferential arrival of cosmic bolides in the hemisphere containing the Pacific and Indian Oceans.

Conclusions: (1) The high abundance of meteoric spinels in most KT samples investigated here confirms that a major cosmic accretion event occurred at the end of the Cretaceous. (2) The wide range of spinel composition observed from site to site indicates that several objects have impacted the Earth at this epoch rather than a single one. Multiple objects could derive from a single disrupted bolide. (3) The observed variation of the $\mathrm{Fe}^{3+} / \mathrm{Fe}_{\text {total }}$ ratio of $\mathrm{KT}$ spinels from Pacific to Europe suggests that the largest objects
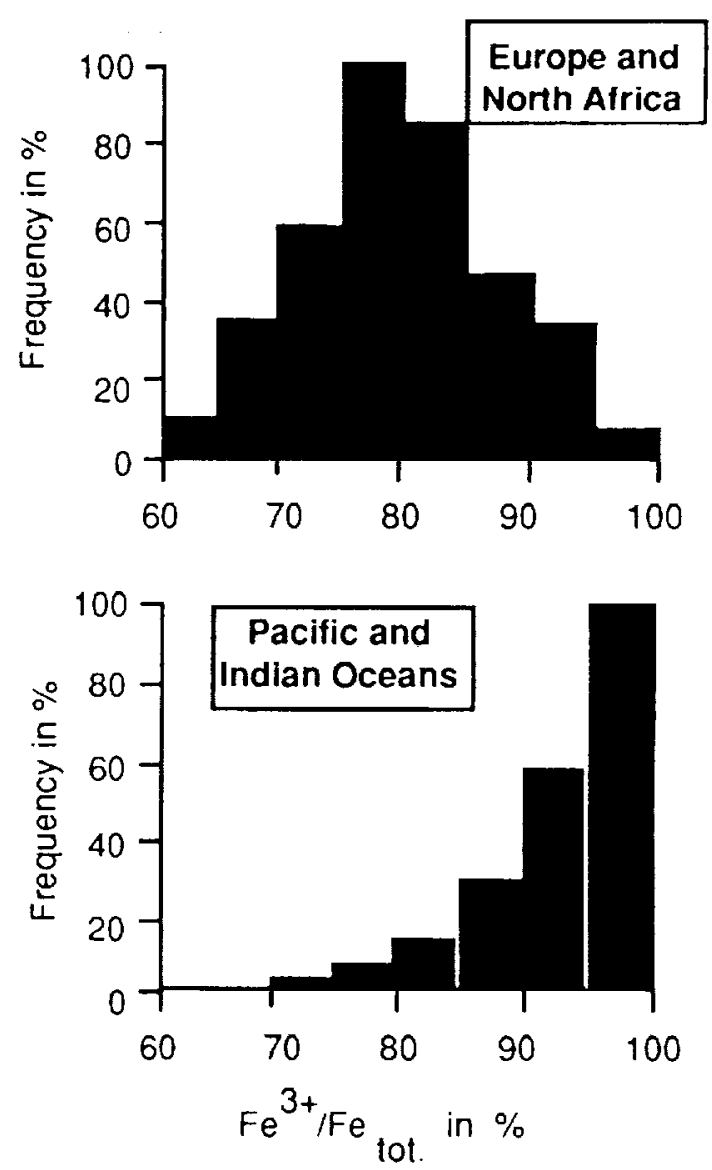

Fig. 2. A histogram showing the $\mathrm{Fe}^{3+} / \mathrm{Fe}_{\text {tol }}$ of $\mathrm{KT}$ spinels

would have impacted in the Pacific and Indian Oceans and smaller ones in Europe and North Africa. This would also explain the homogeneous spinel composition over a large area in the Pacific and the heterogeneous spinel composition on a local scale in Europe and North Africa.

References: [1] Gayraud J. et al., this volume. [2] Kyte F. T. and Smit J. (1986) Geology, 14, 485 - 487. [3] Robin E. et al. (1992) EPSL, 108, 181-190. [4] Robin E. et al. (1992) LPS XXIII, 11611162. [5] Robin E. et al. (1991) EPSL, 107, 715-721. [6] Margolis S. V. et al. (1991) Science, 251, 1594-1597. [7] Robin E. et al. (1993) Nalure, 363, 615-617.

\section{STRATIGRAPHICAL DISTRIBUTIONS OF COSMIC} MARKERS AT THE KT BOUNDARY IN THE CARIBBEAN AREA. R. Rocchia, L. Froget, E. Robin, and J. Gayraud, Centre des Faibles Radioactivités, Laboratoire mixte CEA-CNRS, Avenue de la Terrasse, 91198, Gif-sur-Yvette cedex, France.

Introduction: The KT sites of the Caribbean area are markedly distinct from the sites found in the rest of the world. In this region, the KT sedimentary sequence is rather complex and often contains lithological units that are either absent or less pronounced elsewhere. These units, located at the base of the KT sequence, are a bed of spherules or coarse globules overlain by a massive sand- 
stone bed ending as fine-grained ripple bed. Diverging explanations have been proposed for this sedimentary sequence. The sandstone layer could represent a series of turbidites over $10^{5} \mathrm{yr}$ or so without genetic link with the KT event [1]. Another explanation is that the sandstone was produced by a tsunami generated by a nearby impact [2]. In that hypothesis, the spherule bed is interpreted as the remain of a tektite layer produced by the impact, which is now supposed to have taken place in the Yucatan peninsula. Then, the entire sequence, including the ripple beds and marly layers overlying the sandstone, should represent a deposition time not exceeding a few hours or at most a few days. Clearly, the evaluation of the timing of the KT transition sequence is critical. The position of the chemical and mineralogical ingredients directly produced by the impact [PGE overabundances, Ni-rich (meteoric) spinels, and shocked quartz] are powerful tools to evaluate the formation of the sequence with a fine time resolution. We report here about meteoric spinels and Ir. Spinels are very important for timing considerations because they were originally locked in rather big bodies (up to several hundreds microns) that sedimented without delay. Therefore, they are well adapted to record a rapid event.

Sites: We report about four very distant sites located around, inside, and outside the Gulf of Mexico: Beloc (Haiti), Mimbral (Mexico), Brazos River section (Texas), and Hole 536 (Gulf of Mexico).

Iridium and Spinel Distributions: Beloc (Haiti). Results about this section have already been published [3]. In this section, formed under about $2000 \mathrm{~m}$ of water, the sandstone is missing, probably because the site is out of the Gulf of Mexico. The spherule bed $(25-30 \mathrm{~cm}$ thick) seems to be nicely size graded. Iridium and spinels appear significantly higher up section, $46-63 \mathrm{~cm}$ above the base of the spherule bed and separated from this bed by $20-30 \mathrm{~cm}$ of carbonated sediments. At Beloc, the cosmic markers and the spherules are not mixed: they are located in stratigraphically distinct layers. Moreover, the glass remains contained in the spherule bed differ significantly from tektites. Presently, on stratigraphical and chemical grounds, there is no evidence for a genetic link between spherules and the KT cosmic markers. However, the interval of time separating the sedimentation of spherules and Ir spinels is not necessarily long. The size grading observed in the spherule bed, likely due to the size-dependent transit time through $2000 \mathrm{~m}$ of water, suggests that this part of the sequence at least was deposited rapidly. The fact that spinel-bearing spheroids of the same size as the smallest spherules $(0.2 \mathrm{~mm})$ are found in well-separated layers implies a significant delay of several tens of hours or days but not necessarily more.

Mimbral (Mexico). This section is typical of the KT sequence observed in several outcrops around the Gulf of Mexico. The sandstone is a 2-3-m-thick massive bed. Here again, the cosmic markers, Ir and spinels, are stratigraphically separated from the spherule bed (contrary to what was published [2], spinels found in the spherule layer are not meteoric spinels but terrestrial alumino- and titanochromites similar to those found all over the section). They appear in the sedimentary sequence on top of the sandstone bed in the 20$30-\mathrm{cm}$-thick series of ripple beds. Both Ir and spinel concentrations (maximum values $0.5 \mathrm{ng} / \mathrm{g}$ and $300 \mathrm{spinels} / \mathrm{g}$ respectively) are low compared with other distant sections $(9-28 \mathrm{ng} / \mathrm{g}$ and $30,000 \mathrm{spinel} / \mathrm{g}$ at Beloc for instance). The integrated $\mathrm{Ir}\left(15 \mathrm{ng} / \mathrm{cm}^{2}\right)$ and spinel fluxes $\left(3 \times 10^{3}\right.$ spinels $/ \mathrm{cm}^{2}$ compared with $10^{5}$ spinels $/ \mathrm{cm}^{2}$ at Caravaca) are also very low. The maximum spinel concentration is found a few centimeters below the maximum Ir abundance. These features show that part of the cosmic infall is missing in Mimbral.

Brazos River (Site 1-Texas). In this section, we have not found any meteoric spinels. Iridium overabundances are observed only above the presumed tsunami deposit with a maximum concentration of $\mathrm{ng} / \mathrm{g} 25 \mathrm{~cm}$ above the ripple bed. In the absence of meteoric spinels the KT boundary should be placed at this level, consistent with paleontological data [4]. The time represented by this $25-\mathrm{cm}$ interval is uncertain.

ODP Hole 536 (Gulf of Mexico). In this core, the spherule and sandstone beds are missing. Iridium and spinels are found mainly in a calcareous ooze containing cretaceous fossils (section 536-9-5, $75-120 \mathrm{~cm}$ ), unit 4 of Alvarez et al. [5]. Iridium concentrations are low (maximum $0.7 \mathrm{ng} / \mathrm{g}$ ) but the integrated flux is rather elevated: $55 \mathrm{ng} / \mathrm{cm}^{2}$ and comparable with the global average. Contrary to what has been published [6], spinel concentrations (15,000 spinels/g) and flux $\left(10^{5}\right.$ spinels $\left./ \mathrm{cm}^{2}\right)$ are also high. Alvarez et al. [5] suggested that this unit represents the finest fraction of cretaceous sediments stimed up by a KT impact wave. If so, it means that most of the Ir and spinel-bearing particles sedimented at the very end of this redeposition phase. However, this deposition mode is questioned by the recent work of Keller et al. [6]. Whatever the exact explanation for this sequence could be, it remains that Ir and spinels are found isolated in the sediment and not mixed with globules. The most puzzling thing is that sediments do not contain any globule or trace of tsunami-turbidite when the record of the cosmic event (Ir and spinels) is apparently complete in reworked sediments.

Discussion and Conclusions: The four sections sludied in this report, even if they differ on some points, have in common the fact that the different markers of the KT boundary transition (smectiteglass spherules, sandstone bed, cosmic markers) are systematically found unmixed in very distinct lithological units. In particular, the spherule-glass layer is never found mixed with Ir and meteoric spinels. This is rather strange if we consider the expected effects of giant tsunami waves produced by an impact in the Yucatan peninsula.

Two possibilities can be envisaged: (1) The glass globules have a volcanic origin and are unrelated to the $K T$ boundary cosmic event. This would explain why the $\mathrm{Fe}^{3+} / \mathrm{Fe}^{2+}$ ratio of the remains of the glass is so high (0.7) compared with the ratio measured in known lektites ( $* 0.1$ ) [3] and why they do not contain lechatelierite. (2)The glass remains are relics of unusual tektites. Then, the nonmixing of globules and spinels can be explained by two distinct bolides colliding with the Earth over a rather short period of time. This has already been proposed to explain the traces of erosion that are observed at the interface between the boundary clay (kaolinite due to a first impact) layer and the fireball layer (second impact) in continental deposits of North America [8]. Some paleobotanical data could also be explained in that way [9]. However, the occurrence of two exceptional and independant events is unlikely on statistical grounds.

So, if we consider the case of a single impact, the nonmixing of globules and spinels could result from the fragmentation (not vaporization) of the bolide during the collision with injection of big fragments on rather distant orbits on which they can stay for a few days. This kind of rebound, or ricochet, is expected to occur in oblique collisions [10]. In addition, this multiple-object dispersion mode could also account for the compositional variations of spinels observed from sites 10 sites [7]. A way to understand the KT sequence in the Caribbean region is to study the distribution of shocked quartz with respect to other KT markers. 
References: [1] Stinnesbeck W. et al. (1993) Geology, 21. 797-800. [2] Smit J. et al. (1992) Geology, 20, 99-104. [3] Jéhanno C. et al. (1992) EPSL, 109, 229-241. [4] Beeson D. et al. (1993). [5] Alvarez W. et al. (1992) Geology, 20, 697-700. [6] Keller G. et al. (1993) Geology, 21, 776-780. [7] Robin E. et al., this volume. [8] Shoemaker et al. (1992) LPS XIII, 1293-1294. [9] Wolfe J. A. (1991) Nature, 352, 420-422. [10] Schultz P. H. et al. (1990) GSA Spec. Paper 247, 239-261.

Ni-RICH SPINELS (METEORIC SPINELS) AS INDICATORS OF THE KT EVENT TIMING. R. Rocchia, E. Robin, L. Froget, and J. Gayraud, Centre des Faibles Radioactivités, Laboratoire mixte CEA-CNRS, Avenue de la Terrasse, 91198, Gif-surYvette, France.

Introduction: Highly oxidized $\mathrm{Ni}$-rich spinels are minerals formed when a piece of extraterrestrial matter (rich in $\mathrm{Ni}$ ) is melted and oxidized in the Earth's atmosphere (high $O$ fugacity). Such minerals have no counterpart in terrestrial rocks but are systematically found in the fusion crust of meteorites [1,2], in cosmic spherules [2-4], in the ablation products found in a Jurassic horizon [5], and in particles associated with oceanic impact debris from late Pliocene sediments [6]. They are specific markers of meteoritic material that interacted at high temperature with the Earth's atmosphere [2,7]. Moreover, they are easily synthesized in the laboratory by simple fusion of meteoritic material [8]. Therefore, they can be labeled meteoric spinels since their formation is associated with the occurrence of meteors.

Relevance to the KT Event: $K T$ boundary spinels. In addition to high concentrations of PGEs (platinum group elements), KT boundary sediments also contain $\mathrm{Ni}$-rich spinels [9-11]. These minerals, found in nearly all KT sections, cannot be distinguished, by their morphology and composition, from meteoric spinels derived from pure meteoritic material. The appearance of these minerals in KT boundary sediments, in exact coincidence with the planktonic crisis, is a major argument supporting a cosmic origin for the KT boundary biological crisis [2].

A short catastrophic event. In all marine KT sites where the Ir anomaly has been observed, the Ir enrichments are not confined to the boundary clay layer: Overabundances are also observed on both sides of the boundary. Such extended distributions are sometimes considered as the indication of a long-duration event. This observation is used to support very different scenarios: the occurrence of a shower of comets or a period of intense volcanic activity. However, the extent of the Ir distribution is not necessarily due to a long event and can be explained in another way. It might also be due to the chemical properties of elemental Ir, which can remain for a long time in the ocean reservoir [12] and may have diffused in the sediments after deposition. KT meteoric spinels can be used to remove the ambiguity. These minerals have a quite simple behavior: they are locked in rather big spheroids, a few tens or hundreds of micrometers in size, that cannot stay for long in seawater and that, once settled, cannot move inside the lithified sediment. Therefore, the stratigraphic distribution of meteoric spinels can provide less questionable information about the duration of the KT event than Ir and other chemical markers.

In all KT sites analyzed for Ir and spinels, both markers have their maxima at the same stratigraphic level. This is a consequence of the fact that both have the same cosmic origin. However, as expected, Ir and spinel stratigraphical distributions are quite different. Iridium exhibits broad distributions, but spinel distributions are always very narrow. Data from the sites of El Kef, Caravaca, and Hole $761 \mathrm{C}$, leg 122, speak by themselves: Anomalously high Ir concentrations are found over about $1 \mathrm{~m}$ when the distribution of spinels never exceeds a few centimeters in thickness (Figs. la-c). Two sections deserve particular attention.

El Kef: This section, the stratotype of the KT boundary in the mesogean domain, is considered the most complete one for paleontological studies. Sediments of the KT transition, nearly totally deprived of coarse detrital component, appear to have been deposited under extremely quiet conditions. The section of fers the advantages of a rather low bioturbation and a high sedimentation rate permitting the study of the KT sequence with the highest resolution. Actually, this is the section where we have observed the most different Ir- and $\mathrm{Ni}$-rich distributions. The Ir anomaly is extremely dissymetric and characterized by a rather narrow (2 $\mathrm{cm}$ wide) peak followed by a low concentration tail extending in the basal Danian over about $2 \mathrm{~m}$. Overabundances are also oberved in the last tens of centimeters of the upper Maastrichtian. The integrated Ir flux, $\approx 70$ $\mathrm{ng} / \mathrm{g}$, is comparable with the world average value. The maximum concentration of $18 \mathrm{ng} / \mathrm{g}$ is found in a $1-2-\mathrm{mm}$-thick brown-reddish layer in exact coincidence with the mass extinction level (drop of carbonate). This layer contains 5-10\% of the total Ir flux. Nickelrich spinels have a quite different distribution: $95 \%$ of them are found in this millimetric layer [13]. Taking into account the sedi-

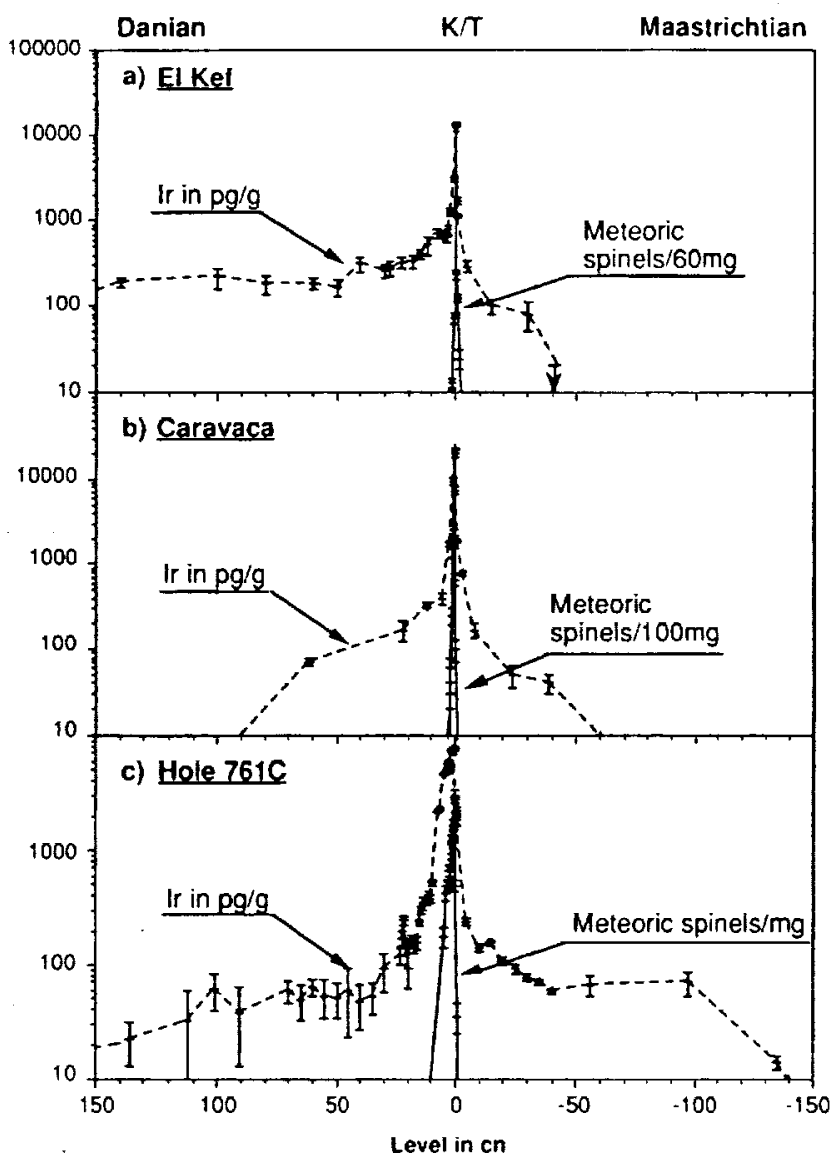

Fig. 1. 
mentation rates evaluated in the upper Cretaceous and early Danian, this pulselike distribution corresponds to a deposition time that cannot exceed $100 \mathrm{yr}$. The infall of meteoric spinels at El Kef is the result of a quasi-instant event.

Gubbio Sections (Botaccione, Gubbio): This historical site has been the subject of thorough investigations. The finding of shocked quartz and Ir secondary maxima in levels distinct from the boundary layer has pushed Crocket et al. [14] to propose that multiple events, probably explosive volcanic eruptions, occurred over a period of more than $3 \times 10^{5}$ years. These results initiated additional studies and a blind sampling investigation by different laboratories. A vailable data [15] show that secondary Ir maxima are real. However, it is not demonstrated that these maxima result from multiple Ir events or from postdepositional diffusion and dissolution. Meteoric spinels can provide conclusive information about that point. Our preliminary data show that, in the Bottacione section, these minerals are not present in secondary Ir levels; they are found only, like in other sections, in the boundary clay. The stratigraphic distribution of meteoric spinels, even if the cosmic origin of these minerals is ignored, does not suppon the volcanic hypothesis of Crocket et al. [14]. Long-duration mechanisms are excluded: All the data points to a single cosmic event occurring right at the paleontological boundary.

Conclusion: In all KT sections analyzed so far, the stratigraphic distribution of meteoric spinels is extremely narrow. This indicates that the meteoritic material, responsible for the formation of spinels and also for the Ir enrichments, was accreted during a single and extremely brief event, or series of events, that occurred in exact coincidence with the planktonic crisis. This result is inconsistent with scenarios based on continuous or repetitive long duration events. In particular it excludes the occurrence of a comet shower over several $10^{5}$ years produced by the perturbation of the Oort cloud at the time of the KT transition.

References: [1] Brownlee D. E. et al. (1975) JGR, 80, 49174924. [2] Robin E. et al. (1992) EPSL, 108, 181-190. [3] Robin E. (1988) Thesis, University of Paris XI, 131. [4] Koeberl C. et al. (1989) GCA, 53, 937-944. [5] Jéhanno C. et al. (1988) Proc. LPSC 18th, 623-630. [6] Margolis S. et al. (1991) Science, 251, 15941597. [7] Robin E. et al., this volume. [8] Gayraud J. et al., this volume. [9] Montanari A. et al. (1983) Geology, 11, 668-671. [10] Smit J. et al. (1984) Nalure, 310, 403-405. [11] Kyte F. et al. Geology, 14, 485-487. [12] Goldberg E. D. et al. (1986) Appl. Geochem., 1, 227-232. [13] Robin E. et al. (1991) EPSL, 107, 715721. [14] Crocket et al. (1988) Geology. [15] Rocchia et al. (1990) EPSL, 99, 206-219.

\section{DINOSAURS WITHIN THE HISTORY OF MULTICELLU. LAR ORGANISMS. D. A. Russell, Canadian Museum of Nature, Ottawa ON KIP 6P4, Canada.}

Since the appearance of multicellular organisms about 600 m.y. ago [1]. various descendent groups separated into temporally overlapping assemblages ("evolutionary faunas") and their diversifications often approximaled exponential functions of time [2-11]. Exponentiality suggests that the diversifications were quasi-autocatalytic or in part biologically driven. Beginning (presumably) with a single species 3800 m.y. ago, there are now about $10,000,000$ species living on our planet [12]. These points, fitted to an exponen- tial curve, imply that half the modern number of species were present on our planet during the dinosaurian era.

Although the identification of "progressive" trends in the history of life has long been controversial [13], some have argued that living systems became more complex [14] and that locomotor and feeding efficiency and activity levels have increased in animals through geologic time [15]. These "improvernents" could be linked to the relative competitive fitness of members of the more modem "evolutionary faunas" $[16,17]$ and evidently enhanced probabilities of surviving mass extinctions as well [5]. Among backboned animals, an increase in activity levels (metabolic rates) over the past $150 \mathrm{~m} . \mathrm{y}$. is reflected in the projected food requirements (per unit time and body mass) of (ypical dinosaurian and modem mammalian herbivores [18]. The mass of the central nervous system relative to that of the body in backboned animals has also increased in a quasiexponential manner through geologic time. Brain size in dinosaurs conformed to the general trend $[19,20]$.

In a dynamic sense, the relative fitness conferred by "progressive" attributes should be reflected in the competitive success of organisms possessing them. Organisms that are known to have extended their distributions are characterized by their relatively superior competitive, defensive, and reproductive performances and their origination within areas of relatively greater diversity [3,5,2]-24]. Thus, the success of Asian placental mammals in invading Australia may be facilitated by the generally lower lifetime fecundities, metabolic rates, and smaller brains of indigenous Australian mammals $[23,25,26]$. Dinosaurs would in all probability be even less able to resist modem Asian invaders than are living Australian mammals.

These pattems imply that the primitive metazoan biosphere was characterized by a low diversity of sluggish animals capable of only limited and stereotyped behavior and the modern ("advanced") biosphere by a high diversity of animals, many of which are very active and capable of a large variety of behavioral responses. The biosphere during the dinosaurian era probably lay near the midpoint of these two extremes.

Biodiversity is known to be linked to various physical variables over broad areas of the Earth's surface, including area [27-28], temperature $[29,30]$, solar radiation, atmospheric warmth, availability of water and plant fodder [28], and atmospheric $\mathrm{CO}_{2}$ levels [31]. As well as being autocatalytic, diversity trends should reflect broad-scale temporal changes in the physical environment of the planetary surface. Indeed, downward "spikes" in diversity caused by mass extinctions were immediately followed by logistic rebounds, revealing the operation of nonbiogenic factors modulating diversity $[4,7]$. When exponential curves are fitted to points at the extremes of family-group diversity trends (e.g., marine animals [8, Fig. 4], terrestrial plants [9, Fig. 6B] and terrestrial vertebrates [11, Fig. 9.4B]), it is evident that the trends often broadly departed from exponentiality (departures are larger with linear fits). Brief "hyperexponential bursts" of diversity due to biological innovation [4], and long-term compensatory interactions between a warming Sun and declining greenhouse gases [32], are probably unrelated to these departures.

In the case of marine animals, an early interval of maximal diversification coincided with the absence of polar ice, an expansion of shallow seas over the continents [33] and very high atmospheric $\mathrm{CO}_{2}$ levels [34] (the latter limit the growth of marine phytoplankton Ioday [35]). The succeeding negative trend coincided with a reduction in the area of epicontinental seas, return of high-latitude glacia- 
tion, and rapid fall in $\mathrm{CO}_{2}$ levels. It is perhaps relevant that marine organisms with calcareous skeletons, which are preserved in abundance in the fossil record, become less diverse in progressively cooler waters [36]. During the negative marine interval, complex ecosystems were becoming well established on land. Near its end, animals of terrestrial origin were invading the seas, suggesting that plant productivity and organismal diversity had become relatively greater on land, as they are today $[7,37]$.

In terrestrial environments, plant diversity stagnated over a long period during which the diversity of marine invertebrates was again increasing. This period coincided with a time when most of the land areas of the Earth were united into a giant supercontinent and arid environments were extreme and widespread [33]. Plant diversity and productivity were evidently concentrated in higher latitudes instead of the broader equatorial region [38-40]. The general pattern of diversification in terrestrial vertebrates resembled that in terrestrial plants in conformity with their dependence upon plant productivity. The most recent phase of maximal diversification, in which dinosaurs participated [41], began during the latter part of the dinosaurian era [41] and continued to the present. The trend in brain size appears to reflect diversity of terrestrial organisms, increasing little through much of the dinosaurian era [19]. It thus appears to be a function of the diversity of interorganismal reactions.

Insect diversification does not show the prominent departures from exponentiality present in the three previous cases. One relatively minor negative departure coincides with the arid interval encompassing most of the dinosaurian era, and another with the origin of small insectivorous birds [42]. Dinosaurs belonged to a biosphere that was much simpler than that of the present; similarities to relatively hyperdiverse, hyperactive, and hypercerebral modem terrestrial vertebrates should not be overemphasized. During early Mesozoic time growth in diversity in terrestrial environments appears to have been constrained by heat and aridity. However, with the retum of more mesic conditions in late Mesozoic time, dinosaurs increased in diversity, activity, and behavioral complexity and decreased in size, thereby paralleling birds and mammals. The mass extinction produced by the terminal Mesozoic bolide impact did not greatly impede the general trend toward greater diversity $[6,7]$. However, dinosaurs were apparently exterminated as a result of their dependence on living plant tissues [43]. Acid rains generated by the impact were evidently more injurious to plant growth than thermal excursions or a brief interval of darkness [44]. The relative imponance of selective pressures loward greater organismal diversification, metabolic rates, and behavioral complexity through geologic time suggests the utility of broad interests, industriousness, and thought to our own species.

References: [1] Conway M. S. (1993) Nature, 361, 219-225. [2] Cailleux A. (1979) Bull. Cent. Rech. Explor. Product. ElfAquitaine, 3, 497-504. [3] Jablonski D. and Bottjer D. J. (1991) Science, 252, 1831-1833. [4] Miller A. I. and Sepkoski J. J. (1988) Paleobiology, 14, 364-369. [5] Sepkoski J. J. (1991) Fourth International Congress of Systematic and Evolutionary Biology, 210236, Dioscorides, Portland, Oregon. [6] Sepkoski J. J. (1992) in The Proterozoic Biosphere (J. W. Schopf and C. Klein, eds.), 553-561, Cambridge Univ. [7] Sepkoski J. J. (1992) in Systematics, Ecology and the Biodiversity Crisis (N. Eldredge, ed.), 77-100, Columbia Univ., New York. [8] Sepkoski J. J. (1993) Paleobiology, 19, 4351. [9] Knoll A. H. and Niklas K. J. (1987)Rev. Palaeobot. Palynol., 50, 127-149. [10] Labandeira C. C. and Sepkoski J. J. (1993) Science, 261, 310-315. [11] Benton M. J. (1989) in Evolution and the Fossil Record (K. C. Allen and D. E. G. Briggs, eds.), 218-24I, Belhaven, London. [12] May R. M. (1992) Sci. Am., 267, 42-48. [13] Ruse M. (1993) Tree, 8, 55-59. [14] Pettersson M. (1978) J. Soc. Biol. Struct., J, 201-206. [15] Vermeij G. J. (1987) Evolusion and Escalasion, Princeton Univ. [16] Sitwell N. (1983) New Sci., 97, 161-163. [17] Aronson R. and Sues H. (1987) in Predation (W. Kerfoot and A. Sih, ed.), 355-366, Univ. Press of New England, Hanover, Massachusetts. [18] Coe M. J. et al. (1985) in The Origins of Angiosperms and Their Biological Consequences (E. M. Friis et al., eds.), 225-258, Cambridge Univ. [19] Russell D. A. (1983) Adv. Space Res., 3, 95-103. [20] Wyles J. S. et al. (1983) Proc. U.S. Narl. Acad. Sci., 80, 4394-4397. [21] Aronson R. (1990) New Sci., I27, 34-37. [22] Tunnicliffe V. (1992)Palaios, 7, 338-350. [23] Vermeij G. J. (1991) Science, 253, 1099-1104. [24] Lodge D. M. (1993) Tree, 8, 133-137. [25] Hinds D. S. and MacMillen R. E. (1984) Science, 225, 335-337. [26] Murray P. (1991) in Vertebrate Palaeontology of Ausiralasia (P. Vickers-Rich et al., eds.), 1071I 164, Pioneer Design Studio, Victoria, Australia. [27] Brown J. H. (1986) Biol. J. Linn. Soc., 28, 231-251. [28] Wylie J. L. and Currie D. J. (1992) Biol. Cons., 63, 137-144. [29] Heinrich B. (1977) Am. Nat., III, 623-640. [30] Brock T. D. (1985) Science, 230, 132-138. [31] MelilloJ. M. et al. (1993)Nature,363, 234-240. [32] Schwartzman D. W. and Volk T. (199I)Palaeogeogr. Palaeoclimatol. Palaeoecol., 90, 357-371. [33] Crowley T. and North G. R. (1991) Oxford Monogr. Geol. Geophys., 16. [34] Berner R. A. (1992) Nalure, 358, 114. [35] Riebesell U.etal. (1993)Nature, 36I, 249-25I. [36] Clarke A. (1992) Tree, 7, 286-287. [37] Rodin L. E. et al. (1975) in Productivity of World's Ecosysiems (D. E. Reichle et al., eds.), 1326, U.S. Natl. Acad. Sci., Washington, DC. [38] Tiffney B. and Niklas K. (1990) in Causes of Evolution (R. M. Ross and W. D. Allmon, eds.), 76-102, Univ. of Chicago. [39] Ziegler A. M. et al. (1987) Geol. Soc. London Spec. Publ. 32, 25-49. [40] Ziegler A. M. et al. (1993) Philos. Trans. R. Soc. London, B34I. [41] Dodson P. (1990) Proc. U.S. Natl. Acad. Sci, 87, 7608-7612. [42] Sereno P. C. and Gao C. G. (1992) Science, 255, 845-848. [43] Sheehan P. M. and Fastovsky D. E. (1992) Geology, 20, 556-560. [44] Hildebrand A. R. (1993) J. Roy. Astron. Soc. Can., 87, 77-118.

KT BOUNDARY: HISTORICAL CONTEXT, COUNTERREVOLUTIONS, AND STRAWMEN. G. Ryder, Lunar and Planetary Institute, Center for Advanced Space Studies, Houston, TX 77058-1113, USA.

Some authors have recently downplayed both the abruptness of the KT transition and its importance. Interest in the boundary is attributed to (1) extinction of dinosaurs, (2) rise of mammals, (3) controversy related to impact, and (4) closeness to the present. Thus Stanley [1] states that "... . these factors have led us to overrate the terminal Cretaceous crisis." In fact, this boundary has been recognized as major in both importance and abruptness since the early decades of the nineteenth century, well before dinosaurs or Ir were even concepts. I contend that the KT boundary extinctions represent the most clear example of a mass extinction event, more so than the Permian-Triassic extinctions, because the latter took place over a period of several millions of years and cannot even be postulated as a (single) event.

Many of those who are at best skeptical and commonly devoted opponents of the impact-extinction hypothesis for the KT boundary 
changes have set up strawmen and imputed to that hypothesis attributes neither inherent nor generally included by impact proponents. Such imputations are that nearly all of the uppermost Maastrichtian extinctions are impact caused, that virtually everything was instantaneously wiped out worldwide, and that extraterrestrial causes would produce more random extinction. Whereas some (particularly some paleontologists) have demanded exact burdens of proof of "impactors," they have not demanded them of themselves; for instance, "impactors" alone are criticized for not explaining the survival of crocodiles and turtles. I attempt first to put the KT boundary in a historical context, and then to limit what the impact hypothesis actually does demand.

The recognition of a major and abrupt change that is the KT boundary took place (under catastrophic thinking, admittedly) at about 1810 with the studies in the Paris Basin by Cuvier and Brongniart. This preceded dinosaurs, Ir, thin sections, isotopes, radioactivity, and natural selection. In 1813 D'Halloy distinguished "cretaceous" from "mastozooic" as the upper two of four divisions of rocks; no Permian-Triassic boundary was then recognized, but subsumed in the second group from the (now) Paleozoic through Jurassic (yet D'Halloy was familiar with the rocks that Murchison later included in the Permian).

Phillips, in recognizing major and significant divisions and labelling them as Paleozoic, Mesozoic, and Cenozoic around 1840 , followed D'Halloy's distinction of Permian rocks from Triassic rocks (around 1830), and recognized the critical significance of the Mesozoic-Cenozoic change. Murchison's Permian originally included rocks now recognized as Triassic, so the Permian-Triassic boundary was not obvious to everyone in the rocks of Europe at around 1840. Under the then-recently-established uniformitarian (in all its combined forms) principles, transitions were expected. Boundaries were in consequence expected to be arbitrarily assigned, and this was (and remains) the case for the Permian-Triassic. The expected passage beds for the Mesozoic-Cenozoic boundary were never found. That they did not appear seems to have been an embarassment for Lyell and perhaps even more so later for Darwin. Lyell had subdivided the Cenozoic, yet noted (under uniformitarian thought) that the change from Cretaceous to (then) Eocene was equivalent to the entire Tertiary. While the relevant strata in Britain are indeed missing (though only a few million years worth, not sixty), Lyell was familiar with European strata, where more complete successions occur. Although Darwin was familiar with this faunal change, his only mention of it concems the abrupt extinction of the ammonites. The immense faunal break without significant lithological change has been used to infer the presence of a sedimentological break even with no evidence, e.g., northeast Mexico [2], a clear demonstration of the power of uniformitarianism. Nonetheless, the geologically sudden extinctions at the end of the Mesozoic have been generally regarded as real and demonstrably more abrupt than those at the beginning [e.g., 3], even if some son of uniformitarian and terrestrial causes were sought.

There appears to have been little difficulty anywhere in pinning down the KT boundary with precision since the mid $1800 \mathrm{~s}$. An (arbitrary?) question as to whether the Danian should be included with the Cretaceous was resolved. The boundary has since become more tightly defined and recognizable, not less, particularly using microfossils. The recognition of a global Ir-rich layer (whatever origin is invoked) at the paleontologically defined boundary has led to its use as a marker bed, and the more precise correlation of some marine and nonmarine records. Terrestrial disruptions took place geologically simultaneously with marine changes, and both ammonite and dinosaur fragments persist to the boundary. Such precision and correlation is not possible for the Permian-Triassic boundary, for which correlation of marine and nonmarine sequences has proven elusive, and equivocal even among marine sequences. The KT boundary extinction is not a poor relative of the Permian-Triassic mass extinction. It was quite different, far more abrupt and clear (i.e., rate was much faster), and affected many more ecological niches, even if the total number of orders, families, or genera that became extinct was smaller. They are not really comparable. There are mass extinctions and there are mass extinctions.

The presence of an Ir-rich layer, shocked quartz, and the identification of perhaps the largest Phanerozoic impact crater with a precisely correct stratigraphic and radiometric age in the Yucatan, have convinced most workers that there was a boundary impact event. There remain considerable differences in opinion of the significance, if any, of that event in extinctions. An important historical point is that the abruptness of extinctions led to the analysis for Ir at a particular horizon, and that measurement led to the inference of an impact. The consequent hypothesis that the impact in some way caused the extinctions is not in itself dependent on a specific mechanism(s), although such were reasonably suggested. Many counter-revolutionary papers over the last decade, however, give the impression that it is those who invoke an impact who have required a particular paleontological significance. Yet it was never the case that an impact was inferred and that then there was a search for associated extinctions. It is ironical that some paleontologists chose to downplay the significance of the boundary after the impact was inferred. Rather than evaluate the record in the light of an impact, they chose to construct strawmen.

Some paleontologists have made an effort to show that (stepped) extinctions were taking place up to the boundary; they follow with the specious conclusion that the impact had no significant effect. (Identification of relevant "stepped extinction" requires exceptionally fine stratigraphic resolution, and the phrase also incorporates some significant genetic implications of its own.) The impact hypothesis, however, in no way requires that all or even most of the extinctions resulted from the impact. It does demand that those that define the change from Mesozoic to Cenozoic took place fairly rapidly as a result of (and therefore not before) the impact. This demand is fulfilled in the drastic microfaunal changes, the floral changes, and the extinction of ammonites, belemnites, dinosaurs, and probably marine reptiles right at the boundary. That inoceramids did not survive as far as the boundary, or that some foraminifera went extinct earlier, is (or may be) correct, but does not deny the catastrophic extinction. Neither does the persistence of genera, or even species, through the boundary, even if they went extinct shortly after. While there were considerable geologically immediate effects of an impact, longer-term effects seem unavoidable. Thus Hallam's [4] statement ". . . exact contemporaneity required by the impact hypothesis ..." is misleading.

Impact skeptics have also tumed to demonstrating the case for selective extinctions, particularly but not only latitude-dependent ones, and concluding that these are more compatible with a nonimpact scenario [e.g., 5,6]. Such a conclusion depends upon a knowledge of extinction mechanisms in both gradual and abrupt situations, the very things researchers are currently attempting to understand. To suggest that gradual climatic changes and sea-level changes caused abrupt extinctions is to divorce the direct mechanism from the indirect one, with the same problems of interpretation 
and association as the impact scenario. There is no reason to suggest that changes created by an impact at the end of the Cretaceous would not have affected tropical more than high-latitude environments.

The abruptness and importance of the KT boundary has been recognized from the birth of stratigraphy, and the fundamental change from Mesozoic to Cenozoic has come to be more tightly constrained over $180 \mathrm{yr}$. Its significance is not merely a product of dinosaur-fascination and impact fantasy. It is a much more abrupt boundary than that of the Paleozoic-Mesozoic. Those who are skeptical of the impact hypothesis should not demand more of it than is inherent in it; too many strawmen have led to confusion on what are the relevant issues.

References: [1] Stanley S. M. ( 1987) Extinction, 242. [2] Hay W. M. (1960) Proc. 2lst Intl. Geol. Congr., 5, 70-77. [3] Bramlette M. N. (1965) Science, 148, 1696-1699. [4] Hallam A. (1989) Great Geological Controversies, 244. [5] Keller G. et al. (1993) GSA Bull., 105, 979-997. [6] MacLeod N. and Keller G. (1993) GSA Abstr. with Progr., 25, A-296.

GEOCHEMICAL RECORD OF THE KT EVENT IN DINOSAURIAN REMAINS FROM MONGOLIA. V. S. Samoylov and Ch. Benjamini, Department of Geology, Ben Gurion University of the Negev, 84120 , Beer Sheva, Israel.

Geochemical data obtained from Cretaceous-Paleogene faunas from South Mongolia [1] have shown that geochemical features of Late Cretaceous faunal remains are preserved. We present here new investigations of reptilian remains from the Gobi Desert, a wellknown locality for vertebrate remains of Mesozoic and Cenozoic age.

Dinosaurian remains were collected in South Mongolia from sediments dated to the Early Neocomian-Aptian-Albian of the Early Cretaceous and the Cenomanian-Maastrichtian of the Late Cretaceous. Geochemical features were investigated from dinosaurian remains over a period of about $70 \mathrm{Ma}$, nearly to the time of their extinction. Maastrichtian deposits are overlain with discomformity and discordance by Late Paleocene sediments in which dinosaurian remains are absent, but other reptilian remains have been observed.

Different types of dinosaurian remains (bones, eggshell, and coprolite), including a large collection of bones from different parts of dinosaurian skeletons (vertebrae, extremities, ribs, skull, pelvis), were collecied. In parallel with dinosaurian remains, the Cretaceous sediments enclosing them were examined, as well as other Cretaceous-Paleogene faunal remains.

Dinosaurian remains were completely fossilized but are characterized by good external and morphological preservation. Moreover, the fossilized dinosaurian remains also preserved their internal textural features and the main chemical characteristics. Bone remains preserved the haversian canal texture characteristic for bone tissue of vertebrates. The haversian canals in osteons were packed by calcite aggregates, which were surrounded by thin lamellar apatite crystals.

The bone remains have carbonate-phosphate composition and were consistently enriched in $\bar{R} E E s, \mathrm{Y}, \mathrm{Sr}, \mathrm{Ba}, \mathrm{Pb}, \mathrm{U}$, and Th. REEs, $\mathrm{Y}, \mathrm{Sr}, \mathrm{Ba}$, and $\mathrm{Pb}$ are mainly concentrated in the apatite, while $\mathrm{Zn}$ is mostly accumulated in the carbonate fraction.

Considerable anisotropy was established for the distribution of fluorine and several trace elements between different parts of the skeleton (Table 1). The enrichment of bone remains in $\mathrm{Sr}, \mathrm{Ba}, \mathrm{Pb}$, REE, and $Y$ is observed in the following order: ribs-pelvis-skullextremities-vertebrae. Morphological types of dinosaurian bone remains are markedly distinguished by REE spectrum with the biggest accumulation of HREE and $Y$ and HREE relative to LREE in vertebrae.

Eggshell has an essentially calcite composition and is distinguished geochemically from bone remains by sharp depletion in $F$, $S$, and trace elements. REE spectrum of these two types of dinosaurian remains is also different. The geochemical features of eggshell is defined by the chemical composition of the calcite forming $90 \%$ and more of these remains. Calcite from eggshells was depleted in trace elements relative to calcite from the bone remains. At the same time, calcite from eggshell is also significantly distinguished from epigenetic calcite (Table 1).

Coprolite, as with bone remains, represents carbonate-phosphate fossil material with approximately the same proportion of

TABLE I. Average contents of some elements in dinosaurian remains (ppm).

\begin{tabular}{|c|c|c|c|c|c|c|c|c|}
\hline Type of Remains & $\mathrm{Sr}$ & Ba & $\mathrm{Pb}$ & REE & $\mathrm{La}$ & $\mathrm{Ce}$ & $\mathrm{Nd}$ & $\mathrm{Y}$ \\
\hline \multicolumn{9}{|l|}{ Unaltered Bones: } \\
\hline Average & 1820 & 735 & 77 & 5043 & 1000 & 1300 & 860 & 1030 \\
\hline Ventebrae* & 2810 & 1030 & 156 & 7447 & 1280 & 2650 & 1600 & 2900 \\
\hline Extremities* & 2200 & 920 & 140 & 7366 & 1860 & 2620 & 1350 & 2200 \\
\hline Skull* & 2280 & 680 & 98 & 6469 & 1740 & 2040 & 1265 & 2180 \\
\hline Ribs* & 1920 & 620 & 90 & 3755 & 1230 & 760 & 910 & 1180 \\
\hline Pelvis* & 1880 & 680 & 112 & 5423 & 980 & 1945 & 1290 & 1345 \\
\hline $\begin{array}{l}\text { Phosphate } \\
\text { fraction }\end{array}$ & 2.320 & 840 & 126 & 6775 & 1560 & 2240 & 1400 & 2200 \\
\hline Carbonate & & & & & & & & \\
\hline fraction & 1830 & 535 & 90 & 926 & 280 & 340 & 200 & 120 \\
\hline Altered Bones: & & & & & & & & \\
\hline Average & 1200 & 1150 & 39 & 1937 & 500 & 740 & 385 & 430 \\
\hline \multicolumn{9}{|l|}{ Carbonale } \\
\hline fraction & 230 & 1400 & 18 & 98 & 26 & 35 & 18 & 11 \\
\hline Eggshelis & 360 & 174 & 48 & 2.30 & 62 & 87. & 35 & 52 \\
\hline Coprolite & 3200 & 800 & 61 & 3994 & 1400 & 1900 & 480 & 300 \\
\hline
\end{tabular}

* Data for cortical and epiphyseal parts of bones. 
calcite and apatite fractions, but coprolite was markedly enriched in $F$ and $S r$, but was depleted in REE, $Y$, and $Z n$. Besides, LREE, especially $\mathrm{La}$ and $\mathrm{Ce}$, contribute more to the REE spectrum. On the average, the value of the LREE/HREE ratio is 9.8 , i.e. 4.3 times more than for dinosaurian bone remains.

The epigenetic processes causing alteration of the bone chemical composition were represented by the carbonatization and rarely by silicification and baritization. On the whole, these processes led to the depletion of bones in F, S, Sr, Pb, REE, Y. The change of the REE spectrum with the accumulation of LREE relative to HREE is characteristic for altered bones. Epigenetic processes evidently cannot cause the accumulation of some trace elements in dinosaurian bone remains. On the contrary, these processes are the cause of the depletion in these elements, apart from barium (Table 1). The progressive enrichment of bones in $\mathrm{F}, \mathrm{Sr}, \mathrm{Ba}, \mathrm{REE}, \mathrm{Y}, \mathrm{Pb}, \mathrm{Th}$, and $\mathrm{U}$ and depletion in $\mathrm{Zn}$ and LREE relatively to HREE took place during the Late Cretaceous. Analogous behavior of these elements is also established during the Maastrichtian up to KT boundary. Late Maastrichtian bone remains are especially enriched by $\mathrm{F}, \mathrm{Sr}$, $\mathrm{Ba}, \mathrm{U}, \mathrm{REE}, \mathrm{Y}, \mathrm{Pb}, \mathrm{Th}$, and HREE + Y-relative LREE. The observed distribution of elements in dinosaurian bone remains can result from the different processes.

However, it is difficult to attribute the anisotropy in distribution of elements between separate skeleton parts to geological processes. A significant pause in geotectonic and magmatic processes took place in South Mongolia in the very Late Cretaceous (from $\sim 80 \mathrm{Ma}$ ) and in the very Early Cenozoic (to $\sim 45 \mathrm{Ma}$ ). Thus, these processes cannot be involved as a cause of local dinosaurian extinc. tions at the Mesozoic-Cenozoic boundary. Moreover, at the time of Late Jurassic-Early Cretaceous intensive continental rifting and attendant magmatism, dinosaurian faunas were blooming.

Epigenetic processes cannot be also considered as the cause of trace element and volatile accumulation in dinosaurian bone remains. On the contrary, these processes led to considerable depletion of bones in trace elements.

In South Mongolia, a direct relation is noted between the type of sedimentation, usually the mudflow deposits, and the conditions that were favorable for preservation of dinosaurian remains. The excellent textural and chemical preservation of dinosaurian remains are attributed to their fast burial at the formation of mudflow deposits, presumably under aridic conditions. At the same time, it appears unlikely that sedimentation and diagenesis affect boneremain composition. There is no correlation in trace-element composition between bones and the sediment enclosing them, between bone-bearing and bone-free sediments, and even between the composition of the bone phosphate fraction and the apatite from sediments, enclosing these bone remains. The apatite from sedimentary rocks is depleted in REE and $Y$ in comparison with bone apatite and REE spectrum is obviously different for these two types of phosphate fractions. It is difficult to explain this distinction in chemical composition if both fractions had been subjected to the same diagenetic processes.

The data on distribution of some trace elements between dinosaurian skeleton fragments testify to the considerable anistropy in the distribution of some volatile and trace elements between different parts of the skeleton. It is unlikely that this distribution had been the result of epigenesis or fossilization. It is impossible to explain by these processes the difference in elemental accumulation in different parts of the skeleton, including the very different concentration of individual REEs in them. The composition of dinosaurian remains was evidently formed during their lives. Considerable anisotropy of element distribution in different dinosaurian remains and different parts of each skeleton confirms this conclusion.

Maastrichtian remains are characterized by maximum contents of $\mathrm{F}$ and some trace elements. These data reflect changes in dinosaurian life conditions in South Mongolia during the Late Cretaceous, with special peculiarities in the Mastrichtian. Data on chemical composition of Late Cretaceous and Paleocene faunal remains show special enrichment of all Maastrichtian remains, not only of dinosaurs but other fauna, some trace elements at the Mesozoic-Cenozoic boundary, and thus the special biosphere conditions of that time. It is interesting that trace elements and $F$ are especially concentrated in the dinosaurian vertebrae. Specifically, verebrae fragments were enriched in $Y$ and HREE, which are potentially very toxic. In this context, the data on the partitioning of some volatiles and trace elements between bones and coprolite is worth noting. They demonstrate that excretion failed to remove some key elements from dinosaurian organisms, most significantly HREE and $Y$, which are accumulated in dinosaurian skeletons.

Geochemical studies of dinosaurian remains from South Mongolia demonstrate that their geochemical features were determined by original biochemistry of dinosaur bone tissues. The evolutionary character of change in dinosaurian bone chemistry indirectly indicates that dinosaurian extinction in South Mongolia was not the result of an abrupt catastrophe. This extinction was evidently predetermined by changes of their living conditions during the Late Cretaceous.

References: [1] Tauson L. V. et al. (1990) Doklady Akad. Nauk SSSR, 3II, 200-204 (in Russian).

\section{VISUALIZING THE NATURE AND CONSEQUENCES OF} THE CHICXULUB IMPACTOR: CLUES FROM VENUS. P. H. Schultz, Department of Geological Sciences, Brown University, Providence RI 02912, USA.

Little doubt remains that a major impact occurred at the end of the Cretaceous and that the Chicxulub site is the smoking gun [13]. Although its outer dimension has grown from less than $200 \mathrm{~km}$ [1,2] to almost $300 \mathrm{~km} \mathrm{[4],} \mathrm{the} \mathrm{limit} \mathrm{of} \mathrm{crustal} \mathrm{disruption} \mathrm{does} \mathrm{not}$ necessarily correspond to the scale of excavation nor is it simply proportional to impactor size. Impact craters on other planets clearly document postformation crater enlargement through collapse of the rim [5] with concentric pattems of structural failure extending well beyond the excavation cavity [6,7]. The well-preserved cratering record on Venus provided by the Magellan mission provides a critically needed dataset not only to assess the effect of terrestrialscale gravity on crater formation but to appreciate both the lithospheric and atmospheric response to impact cratering [8]. On the basis of such comparisons, it is proposed that the Chicxulub Crater was formed by a 10-15-km-diameter impactor striking at an angle close $1030^{\circ}$ from the southeast. This type of collision would maximize the atmospheric and biospheric response to an impact for the northern hemisphere.

Venus Cratering Record: Radar imaging from Magellan combined with other planetary data allows testing models of crater growth and the effect of impact angle [8]. Five conclusions are relevant for understanding the Chicxulub structure. First, centralpeak morphology preserves a signature of impactor direction and 
angle as determined independently by ejecta deposit asymmetry. On Venus (and other planets), central peaks become offset uprange with decreasing impact angle (from horizontal) and typically become breached downrange. This observation is significant since it suggests that information about the impactor may not be completely lost during crater modification. Second, central peak size comprises a greater fraction of crater size with decreasing angle of impact. This result is inconsistent with models ascribing the scale of central relief solely to energy or gravity effects. For a given impactor size, however, crater size decreases as impact angle decreases. The Magellan data then can be understood if central peak size corresponds to a characteristic pressure limit indicative of the terminal deceleration of the impactor $[5,9,10]$. Hence, impactor size largely controls central peak (uplift) diameter while crater size reflects the combined effects of size and velocity (on a given planet). Third, enhanced crater enlargement occurs for craters larger than about $80 \mathrm{~km}$ on Venus. Fourth, oblique impacts result in greatest depths uprange and shallower excavation downrange. This asymmetry results in greater uprange collapse, thereby circularizing the outer crater boundanes during modification. And fifth, the atmospheric response to impacts becomes increasingly offset downrange on Venus as the dense atmosphere decelerates and captures a significant portion of the impactor and target products.

Chicxulub Impactor: Geophysical data reveal several intriguing asymmetries in the interior ring structure of Chicxulub similar to craters on Venus and other planets. First, the central Chicxulub gravity field becomes poorly expressed to the northwest $[2,4]$ yet preserves a preexisting linear gravity anomaly [4]. As a result, the central structure appears to be breached, open to the northwest. Second, two gravity lows occur to either side of the breached central anomaly about $100 \mathrm{~km}$ from the center and subtending an angle of about $30^{\circ}$ to either side of the northwest-trending axis of symmetry. Third, the center of curvature of the $180-\mathrm{km}$ semicircular break in the Bouguer gravity anomaly to the southeast is not coincident with the center of curvature of either the inner $20 \mathrm{mgal}$ central high nor the concentric gravity lows. And fourth, the central $70-\mathrm{km}$-wide magnetic anomaly is slightly elongate in a northwest-southeast direction [2].

Cratering efficiency decreases with increasing scale due to the effects of gravity $[11,12]$. At very large scales, the early compression stage during penetration comprises a significant fraction (10-20\%) of the final transient excavation cavity. Hypervelocity impacts in laboratory and computational experiments reveal that lateral detachment of the shock during penetration physically corresponds to a transition zone from downward to lateral growth. The lateral dimensions ( $x$ ) of this zone were found to be expressed by an interior pit in a wide range of nonporous media

$$
(x / 2 r)=2.2\left(v_{i} / c_{1}\right)^{2 / 3}\left(\delta_{p} / \delta_{t}\right)^{1 / 3}
$$

where impactor velocity $(v)$, radius (r), and density $\left(\delta_{p}\right)$ are scaled to target sound speed $\left(c_{1}\right)$ and density $\left(\delta_{1}\right)$. This dimension is independent of impact angle. The limit of shock damage, however, extends to much greater distances, thereby promoting collapse and enlargement, whether by residual seismic energy [13] or the continued dynamic motion of the gravity-limited flow field $[14,15]$.

This perspective on scaling combined with planetary analogs allows interpreting the geophysical data for Chicxulub in a different working hypothesis. If the $60-\mathrm{km}$-diameter central gravity anomaly defines the rebound limit established by the penetration zone $(x)$, then equation ( 1 ) indicates that the impactor dimensions range from 10 to $15 \mathrm{~km}$ for velocities of 30 and $15 \mathrm{~km} / \mathrm{s}$ respectively. The pair of offset gravity lows to the northwest closely resemble the downrange effects of projectile failure and ricochet found on the planets and in laboratory experiments. On this basis, Chicxulub appears to have been formed by an object impacting at about $30^{\circ}$ (from the horizontal) heading northwest. The well-defined southeastem boundary marks the enhanced collapse of the uprange rim. The proposed trajectory is consistent with the distribution pattem of fragments of shocked quartz [16], the size of "tektites" [17], and enhanced Ir levels [18]. Moreover, it is consistent with the paleontological record of the greatest biospheric stress occurring in the northem hemisphere [19].

Consequences: Specifying the impactor size and trajectory allows exploring possible consequences, largely preserved on Venus [8]. Images reveal spatial and temporal decoupling of the vapor/ melt cloud from the late-stage ejecta deposition around oblique impacts, consistent with phenomena observed in laboratory experiments [20]. The combined deceleration and lateral containment of the downrange-moving vapor cloud interferes with ejecta emplacement and creates a parabolic zone of turbulent deposition. Craters larger than about $40 \mathrm{~km}$ in diameter $(40-70 \mathrm{~km})$ exhibit a downrange disruption zone about $1.6 \times$ larger than the crater diameter. Allowing for the difference in atmospheric density between Venus and the Earth, the downrange vapor cloud from Chicxulub would have created a $650-\mathrm{km}$-wide firestorm engulfing and boiling upper meters of the Gulf of Mexico in its path. The unrestricted expansion in the upper atmosphere, however, eventually envelopes most of the northern hemisphere. Entrained shocked target material would be rapidly driven downrange. This mix of dispersed melt and clastic debris arrives well in advance of debris from a separate more hemisphencal cloud rising above the impact and later ballistic ejecta. If $10 \%$ of the impactor energy comprises this downrange firestorm, then scaling relations indicate that its basal limit would take about $5 \mathrm{~min}$ while the excavation crater finishes within $1 \mathrm{~min}$.

The downrange (northwest) ricochev/melt fractions from the impactor should result in low-angle hypervelocity impacts fanning out over the Gulf. Consequently, tsunamis will be generated not only by formation of the crater but also by downrange ricochet and later ejecta. At greater distances downrange, ejecta deposits should exhibit staged and complex emplacement sequences. Calculations further indicate the generation of an intense hurricane-like stom as the downrange firestorm equilibrates.

References: [1] Penfield G. T. and Camargo Z. A. A. (1981) Mtg. Soc. Explor. Geophys. Abstr., 51, 37. [2] Hildelbrand A. R. et al. (1991) Geology, 19,867-871. [3] Sharpton V. L. et al. (1992) Nature, 359, 819. [4] Sharpton V. L. et al. (1993) Science, 261, 1564-1567. [5] Schultz P. H. (1988) in Mercury (F. Vilas and C. Chapman, eds.), 274-335, Univ. Arizona, Tucson. [6] Melosh H. J. and McKinnon W. B. (1978) GRL, 5, 985-988. [7] Wichman R. and Schultz P. H. (1989) JGR, 94, 17333-17357. [8] Schultz P. H. (1992) JGR, 97, 16183-16248. [9] Schultz P. H. and Gault D. E. (1992) LPI Contrib. No. 790, 64-65. [10] Schultz P. H. and Gault D. E. (1993) LPS XXIV, 1257-1258. [11] Gault D. E. and Wedekind J. (1977) in Impact and Explosion Cratering (D. Roddy et al., eds.), 1231-1244, Pergamon, New York. [12] Holsapple K. A. and Schmidt R. M. (1982) JGR, 97, 1849-1870. [13] Melosh H. J. (1982) JGR, 87, 371-380. [14] Schultz P. H. et al. (1981) in Multi-Ring Impact Basins (P. Schultz and R. B. Merril, eds.), 181-195, Pergamon. [15] O'Keefe J. A. and Ahrens T. A. (1992) LPI Contribution 790 , 
55-56. [16] Bohor B. F. (1990) GSA Spec. Paper 247, 335-342. [17] Smit J. et al. (1992) LPS XXII, 87-100. [18] Alvarez W. et al. (1982) GSA Spec. Paper 190, 305-316. [19] Spicer R. A. (1989) Phil. Trans. R Soc. London, B325, 291-305. [20] Schultz P. H. and Gault D. E. (1990) GSA Spec. Paper 247, 239-262.

SIDEROPHILE-ELEMENT DISTRIBUTION IN CHICXULUB MELT ROCKS: FORENSIC CHEMISTRY ON THE KT SMOKING GUN. B. C. Schuraytz and V. L. Sharpton, Lunar and Planetary Institute, Houston TX 77058, USA.

The magnitude and duration of catastrophic environmental effects resulting from collision of an extraterrestrial body with Earth are, to first order, proportional to the energy released on impact. This energy can be estimated from knowledge of the characteristics of the projectile, the size and morphology of the impact structure, and the amount, distribution, and composition of the ejecta. Significant progress toward piecing together the KT puzzle has come from recent studies of distal and proximal ejecta deposits [1-7] and recognition of the $\sim 300-\mathrm{km}$-diameter Chicxulub impact basin as the KT source crater [8-13]. The character of the projectile in terms of its size and correlation with known meteorite types, however, is still uncertain [14-16]. In order to constrain better the chemical fingerprint of the projectile that may have triggered the KT extinctions, we report the results of analyses on samples of impact melt rocks from Chicxulub.

Samples of impact melt rock from drill core intervals Y6-N17, Y6-N19, and $\mathrm{Cl}-\mathrm{N} 10$ have major-element and lithophile-traceelement abundances characteristic of average continental crust $[11,17]$, and most elements fall within the compositional range of impact glasses from Haiti [3]. The crustal character of Chicxulub melt rocks and their compositional similarity to proximal KT ejecta are supponed by $\mathrm{S}, \mathrm{Nd}$, and $\mathrm{O}$ isotopic analyses [6].

Instrumental neutron activation analyses (INAA) reveal that several melt rock fragments from $\mathrm{Cl}-\mathrm{N} 10$ and $\mathrm{Y} 6-\mathrm{N} 19$ have $\mathrm{Ir}$ abundances well above those typical of continental crust [11]. Measured Ir abundances in five samples range from $2.5 \pm 0.5 \mathrm{ppb}$ to $13.5 \pm 0.9 \mathrm{ppb}$. These anomalous concentrations are within the range of Ir enrichments in melt rocks from other terrestrial impact structures [15,18], and suggest that the Ir is of extraterrestrial origin. Iridium was below our detection limit in six other samples, with 20 upper limits ranging from $<1.5 \mathrm{ppb}$ to $<2.9 \mathrm{ppb}$. No measurable Ir was found in our sample of Y6-N17 (20 upper limit <15 ppb Ir; $8.1 \pm 1.8 \mathrm{ppb} \mathrm{Au})$, confimed by results of [19] for their analyses of samples from the same core interval. While some variation in Ir concentration among melt rocks is not unusual, it has been sug. gested that if Ir is detected in one sample, Ir enrichments are generally found in all samples within a single melt sheet [15]. Consequently, it is possible that all our samples contain enhanced levels of $\mathrm{Ir}$, albeit below our detection limit of $\sim 1 \mathrm{ppb}$. In addition, the Ir variations we observe reflect sampling on a relatively small scale, and although the differences in measured Ir abundances are significant analytically, they may not be representative of variations among larger samples integrated over the entire melt sheet.

Iridium variations among the different samples of Y6-N19 may reflect in part the heterogeneous lithologic character of this melt rock breccia [11]. The nine centimeler-sized fragments were taken from an $18-\mathrm{cm}$ length of core to sample specifically the variety of melt clasts and melt matrix types. However, significant Ir variations were also observed between $\sim 100$-mg and $\sim 60-\mathrm{mg}$ splits of finely ground powder from a single fragment of Y6-N $19-\mathrm{R}(8.5 \pm 0.5 \mathrm{ppb}$ and $13.5 \pm 0.9 \mathrm{ppb}$ respectively). In contrast to the lithological heterogeneity of Y6-N19, two samples taken from different biscuits within the $\mathrm{C} 1-\mathrm{N} 10$ core interval exhibit similar, uniform intergranular textures, virtually free of unmelted clasts. Thus, the difference in Ir abundance between C1-N10-1 $(6.0 \pm 0.7 \mathrm{ppb})$ and two splits of the same powder from $\mathrm{Cl}-\mathrm{N} 10-2(<2.2 \mathrm{ppb}$ and $<1.7 \mathrm{ppb})$ cannot be attributed to macroscopic lithologic differences. Furthermore, a split of our $\mathrm{Cl}-\mathrm{N} 10-1$ powder analyzed by a different laboratory yielded an Ir concentration of $15 \mathrm{ppb}$ [17]. Additional evidence for the heterogeneous distribution of an extraterrestrial component in $\mathrm{Cl}-\mathrm{N} 10$ is indicated by significant variations in $\mathrm{Os}$ abundance and Re-Os isotopic ratios [17].

Chromium and the siderophile elements $\mathrm{Co}$ and $\mathrm{Au}$ also show variations within and among some of the melt rock fragments; however, interelement correlations are not clear-cut for the limited number that also contain Ir. There appears to be a crude positive correlation of Co with $\mathrm{Ir}$, and inverse correlations of $\mathrm{Cr}$ with $\mathrm{Co}$ and Ir, but these trends are not consistently maintained for all samples. The analytical uncertainties for $\mathrm{Ni}, \mathrm{As}$, and $\mathrm{Sb}$ are too large to resolve differences among the samples for these elements.

Figure 1 shows the $\mathrm{Cr}$ and siderophile-element distribution pattems relative to $\mathrm{CI}$ chondrites based on average measured abundances within the $\mathrm{C} 1-\mathrm{N} 10$ and $\mathrm{Y} 6-\mathrm{N} 19$ core intervals. Common to both intervals is the depletion in $\mathrm{Ni}$ relative to the more refractory siderophiles, and progressive enrichment of the more volatile elements with chalcophilic tendencies. Although different in detail, these melt rock pattems bear an overall resemblance to that of the KT boundary fish clay at Stevns Klint [14], providing additional constraints on impactor type and the partitioning of projectile material between the target and the ejecta. For example, arguments against a chondritic projectile stem mainly from the low $\mathrm{N} / \mathrm{I}$ r ratio observed at Stevns Klint [14-16]. The KT boundary layer in the Raton Basin also appears to have a subchondritic Ni/lr ratio [20]. If

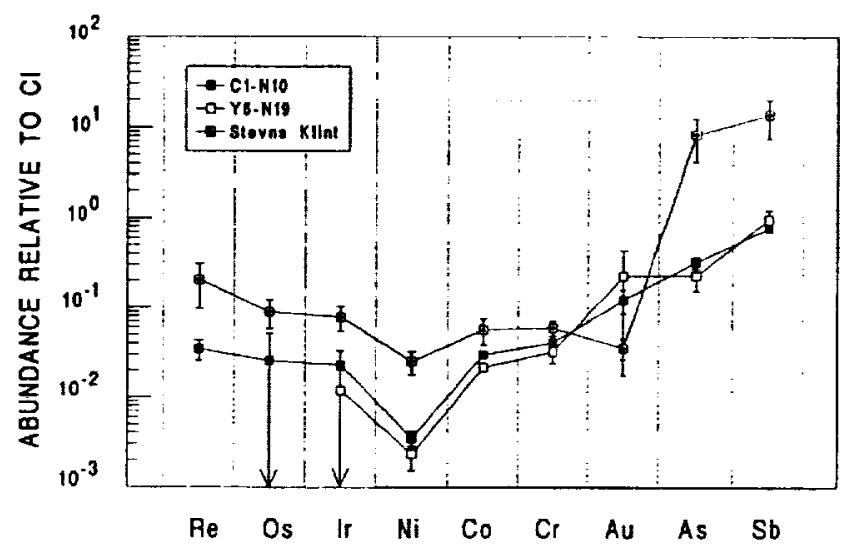

Fig. 1. Siderophile-element and $\mathrm{Cr}$ abundance ratios in Chicxulub melt rock samples relative to $\mathrm{Cl}$ chondrites [26]. Elements along the abscissa are arranged in order of decreasing nebular condensation temperature [27]. Shown are the average and range of two samples from $\mathrm{Cl}-\mathrm{NIO}$, and the mean and standard deviation of nine samples from $\mathrm{Y} 6-\mathrm{N} 19$. Rhenium and $\mathrm{Os}$ data for $\mathrm{Cl}-\mathrm{N} / \mathrm{O}$ are from [ 17]. Also shown are the mean and standard deviation of six samples of the KT boundary fish clay at Stevns Klint [14]. 
the low $\mathrm{Ni} / \mathrm{Ir}$ ratio common to Chicxulub melt rocks and both continental and marine KT sections is also characteristic of the projectile, then arguments favoring an Fe or ureilite meteorite might be strengthened [15]. However, indications of hydrothermal alteration and the potential for fractionation in the melt rocks [21], possible postdepositional mobility of Ir in sediments [22], as well as evidence for fractionation of siderophile elements in impact melt specimens relative to the projectile where the projectile composition is known [23], suggest that attempts to characterize the impactor at this juncture would be premature.

Small-scale variations, particularly between aliquots of a single powdered sample, suggest that the Ir is concentrated in a trace phase that is not uniformly disseminated in the melt rock. Our initial report on the discovery of Ir in the Chicxulub melt rocks noted that the higher Ir concentrations seemed to correlate with the abundance of opaque, highly reflective phases [11]. No metal grains have yet been identified in the melt rock. The dominant opaque mineral is magnetite; however, petrographic examination of thin sections from $\mathrm{Cl}$ N 10 and Y6-N19 reveal the presence of $<1 \%$ sulfides, ranging in size from $10-300 \mu \mathrm{m}$ and distributed irregularly in the melt matrix. Significant enrichments of siderophile elements have been found in association with $\mathrm{Ni}$-Fe sulfide particles in melt rocks at the East Clearwater impact structure [24,25]. In the absence of discrete metal, sulfides would seem to be likely carrier phases for Ir and other siderophile elements.

Work is in progress to separate the sulfides and other phases to search for the Ir by INAA. Preliminary characterization of the sulfides by electron microprobe indicates that most of the grains are pyrite, with subordinate chalcopyrite. Random analyses of the pyrite revealed significant enrichments in $\mathrm{Co}$ and $\mathrm{Ni}$, with Co concentrations up to $6 \mathrm{wt} \%$. Figure 2 shows an example of pyrite from $\mathrm{Cl}$ $\mathrm{NIO}$, which suggests that the $\mathrm{Co}$ and $\mathrm{Ni}$ were enriched by oscillatory growth zoning. Although both siderophiles appear to be enriched in the same general regions, close inspection reveals that the zones of highest $\mathrm{Ni}$ concentration (1.1 wt\%) are relatively depleted in $\mathrm{Co}$ $(0.6 \mathrm{wt} \%)$, whereas the highest $\mathrm{Co}(3.9 \mathrm{wt} \%)$ corresponds to $0.2 \mathrm{wt} \%$ $\mathrm{Ni}$. The best estimates of the average concentrations in this pyrite are $0.7 \mathrm{wt} \% \mathrm{Co}$ and $0.5 \mathrm{wt} \% \mathrm{Ni}$. These results confirm the concentration of siderophile elements in a heterogeneously disseminated trace phase, and indicate that some siderophile-element fractionation has occurred. The paragenesis of the pyrite, and whether or not this phase contains Ir, requires further investigation. Clearly, more evidence must be gathered before the composition and caliber of the $\mathrm{KT}$ bullet can be ascertained.

References: [1] Sigurdsson H. et al. (1991) Nature, 353, 839-842. [2] Izett G. A. et al. (1991) Science, 252,1539-1542. [3] Koeberl C. and Sigurdsson H. (1992) GCA, 56, 2113-2129. [4] Smit J. et al. (1992) Geology, 20, 99-103. [5] Alvarez W. et al. (1992) Geology, 20, 697-700. [6] Blum J. D. et al. (1993) Nature, 364, 325-327. [7] Krogh T. E. et al. (1993) EPSL, 119, 425-429. [8] Hildebrand A. R. et al. (1991) Geology, 19, 867-871. [9] Kring D. A. and Boynton W. V. (1992)Nature, 358,141-144. [10] Swisher C. C. et al. (1992) Science, 257, 954-958. [11] Sharpton V. L. et al. (1992) Nature, 359, 819-821. [12] Sharpton V. L. et al. (1993) Science, 26I, 1564-1567. [13] Sharplon V. L. et al., this volume. [14] Kyte F. T. et al. (1980) Nature, 288, 651-656. [15] Palme H. (1982) GSA Spec. Paper 190, 223-234. [16] Kyte F. T. and Wasson J. T. (1982) GSA Spec. Paper 190, 235-242. [17] Koeberl C. et al. (1993) GCA, in press. [18] Grieve R. A. F. (1982) GSA Spec. Paper
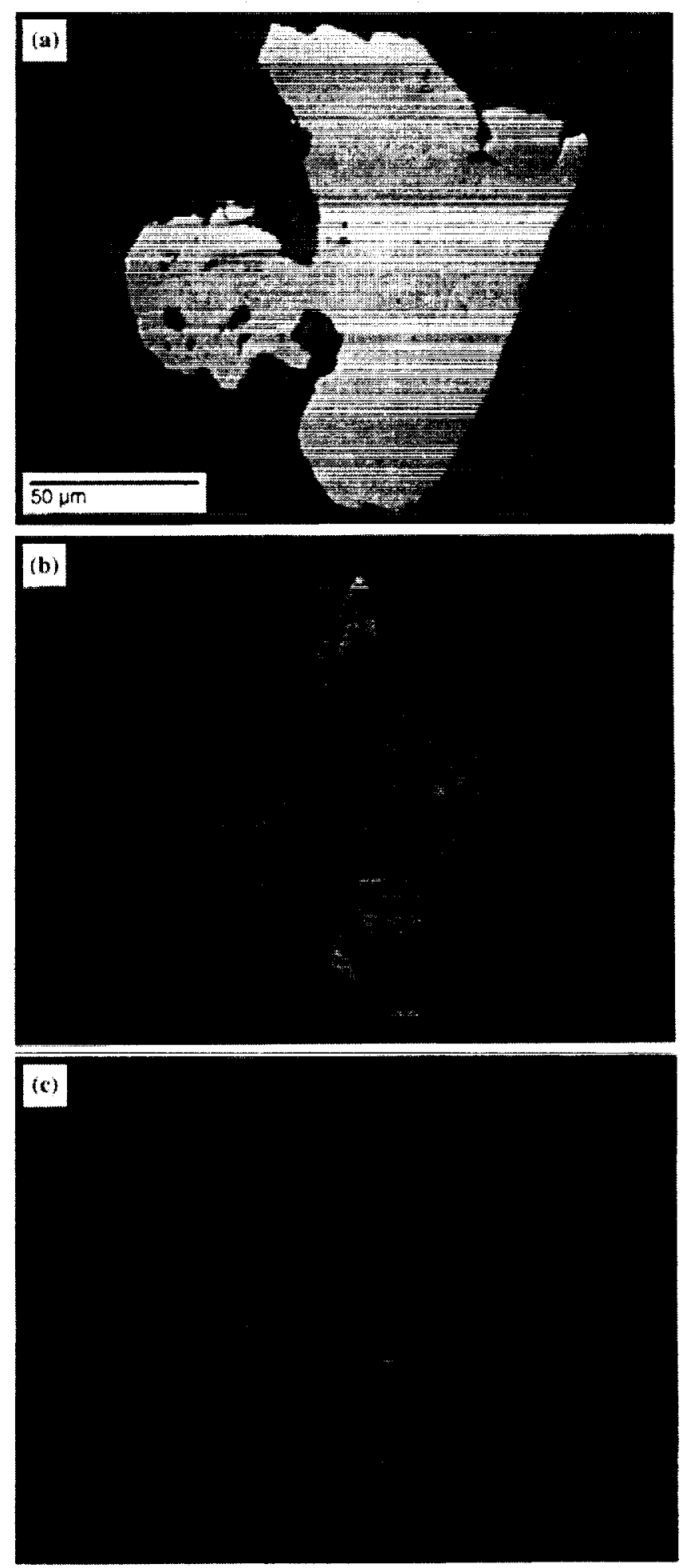

Fig. 2. Photomicrographs of pyrite grain in thin section from $\mathrm{Cl}-\mathrm{N} 10$. (a) Backscatter electron image of pyrite with minor silicate inclusions surrounded by porous matrix of quarz and feldspar. Slightly darker-gray grain in saddle along the upper right margin of the pyrite is magnetite. (b) X-ray map of Co. (c) X-ray map of $\mathrm{Ni}$. 
J90, 25-37. [19] Hildebrand A. R. et al. (1993) LPS XXIV, 657-658. [20] Izett G. A. (1990) GSA Spec. Paper 249, 100. [21] Schuraytz B. C. and Sharpton V. L. (1993) Nature, 362, 503504. [22] Colodner D. C. et al. (1992) Nature, 358, 402-404. [23] Mittlefehldt D. W. et al. (1992) Meteoritics, 27, 361-370. [24] Palme H.etal. (1979)Proc.LPSC 10th, 2465-2492. [25] Grieve R. A. F. et al. (1980) Contrib. Mineral. Petrol., 75, 187-198. [26] Wasson J. T. and Kallemeyn G. W. (1988) Phil. Trans. R. Soc. London, A325, 535-544. [27] Wasson J. T. (1985)Meteorites, W. H. Freeman and Co., New York, 267 pp.

THE CHICXULUB MULTIRING IMPACT BASIN: EVALUATION OF GEOPHYSICAL DATA, WELL LOGS, AND DRILL CORE SAMPLES. V. L. Sharpton', L. E. Marín'2, and B. C. Schuraytz', 'Lunar and Planetary Institute, 3600 Bay Area Boulevard, Houston TX 77058, USA, 'Instituto de Geofísica, Universidad Nacional Autónoma de México, Cd. Universitaria, Mexico City, CP 04510 , Mexico.

In 1981, Penfield and Camargo [1] reported concentric gravity and magnetic anomalies over a region in northernmost Yucatan where unusual occurrences of crystalline rocks had been reported from wells drilled into the carbonate platform, and they proposed that these observations could signal a buried impact structure. Over the last few years, as eyes tumed toward the Gulf of Mexico region in search of the KT impact site, support has mounted for this Yucatan crater, now known as the Chicxulub structure [2-9]. Al. though uncertainties still exist as to its exact size and how it affected the global biosphere, it is now clear that the Chicxulub impact crater is the source of the worldwide ejecta layer associated with the KT extinction event $[2,6,8,10,11]$. Here we present observations from geophysical data, well logs, and drill core samples that indicate the Chicxulub structure is a multiring impact basin $\sim 300 \mathrm{~km}$ diameter, and propose that it is the sole source of the impact debris laid down at KT boundary layer.

Lithologic Evidence of Impact: Three Petroleos Mexicanos exploratory wells are located near the center of the concentric gravity anomalies over the Chicxulub structure (Fig. 1) and all intercepted breccias and crystalline silicate rocks at depths of $\sim 1 \mathrm{~km}$ below sea level [e.g., 12, 13]. Samples from the Yucatan 6 and Sacapuc I wells include suevite, a polymict, clastic-matrix breccia (Fig. 2) analogous to impact-produced breccias observed at other terrestrial craters such as the Ries Crater in Germany. The Chicxulub suevite contains clasts of silicate basement and platform rocks showing abundant and unequivocal evidence of shock metamorphism [6], including (1) planar deformation features in quartz, feldspar, and zircons, indicating dynamic pressures up to $23 \mathrm{GPa}$; (2) shock mosaicism in quartz and feldspar grains; (3) diaplectic glasses such as maskelynite ( $30-45 \mathrm{GPa}$ ); (4) fused mineral glasses, particularly of alkali feldspar, indicating shock pressures above 45 $\mathrm{GPa}$, and (5) impact melts of whole-rock composition (>60 GPa).

Below the deposits of suevite (Fig. 2) are thick sequences of impact-melt and melt-matrix breccia [6], similar to the clast-free and clast-rich melt zones observed at other meteorite impact craters such as Manicouagan, Quebec. Melt samples show ubiquitous evidence of chemical and thermal disequilibrium and superheating as is characteristic of impact-melt rocks. Undigested basement clasts retain indications of shock metamorphism but are usually overprinted with subsequent thermal effects such as recrystallization

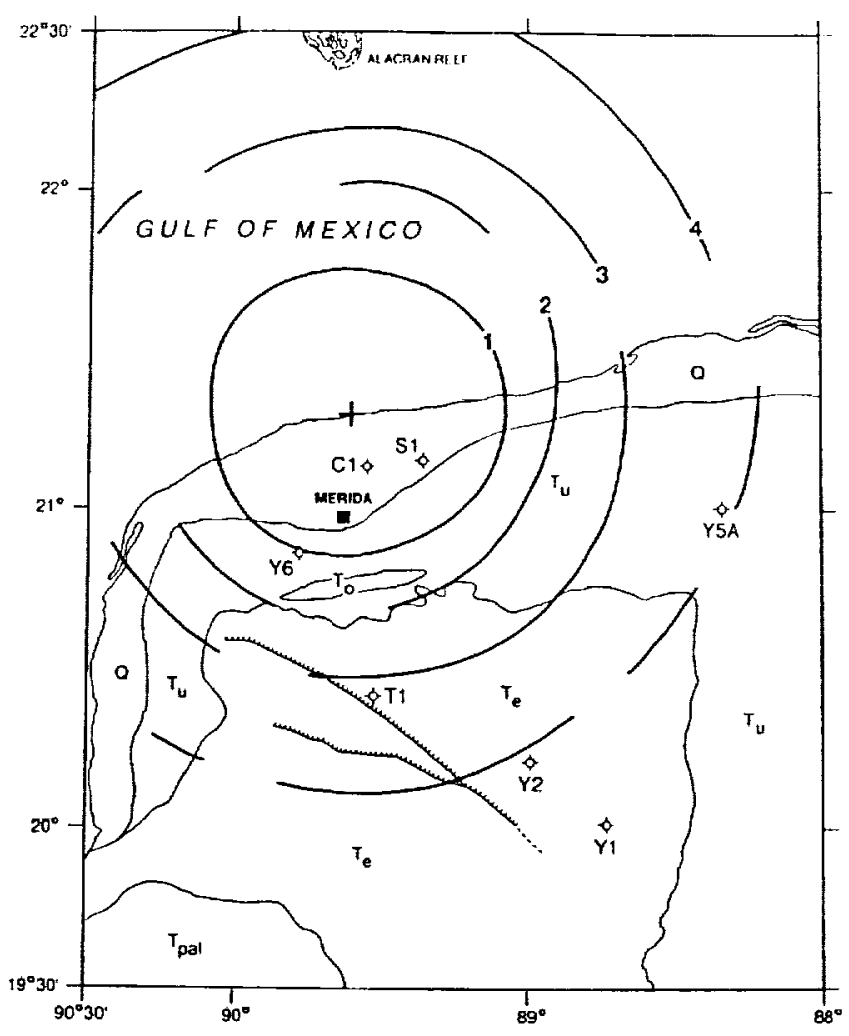

Fig. 1. Surface units, ring locations, and wells in the vicinity of the Chic xulub multiring impact basin. See Sharpton et al. [6] for details.

and annealing. Elevated siderophile-element abundances in some melt-rock samples $[6,7,9]$ we have studied indicate a meteoritic component nonuniformly distributed throughout the melt sheet.

Outside the central region of buried crystalline rocks in the Chicxulub structure (Fig. 2) wells intercepted thick sequences of breccia composed mainly of anhydrite and carbonate clasts from the Mesozoic platform sequence. These breccia deposits are similar to the Bunte Breccia at the Ries Crater in that they represent primarily the uppermost target lithologies and show modest evidence for shock metamorphism.

Size and Morphology of the Chicxulub Impact Basin: Penfield and Camargo [1] originally recognized two concentric zones in gravity anomaly and aeromagnetic data: an inner zone of $\sim 60 \mathrm{~km}$ diameter characterized by a gravity high and high-frequency magnetic anomalies approaching $1000 \mathrm{nT}$, and an outer gravity trough with low-amplitude (5-20 nT) magnetic anomalies. Primarily on the basis of these patterns Hildebrand et al. [2] proposed that the Chicxulub Crater was a double-ring or peak-ring basin with a rim diameter of $\sim 180 \mathrm{~km}$.

More recently, however, the gravity data over the northem Yucatan have been reprocessed [14] and additional concentric patterns outside the original two have been identified (Figs. I and 3). The outermost ring is located at a diameter of $\sim 300 \mathrm{~km}$. Several arguments have been presented, suggesting that this ring corresponds to the modified rim of the Chicxulub multiring basin [14]. Of particular importance is the observation that gravity values increase abruptly and significantly at the inner flank of the $-200-\mathrm{km}$-diameter ring (ring 3 in Figs. $I$ and 3), previously interpreted as the rim 


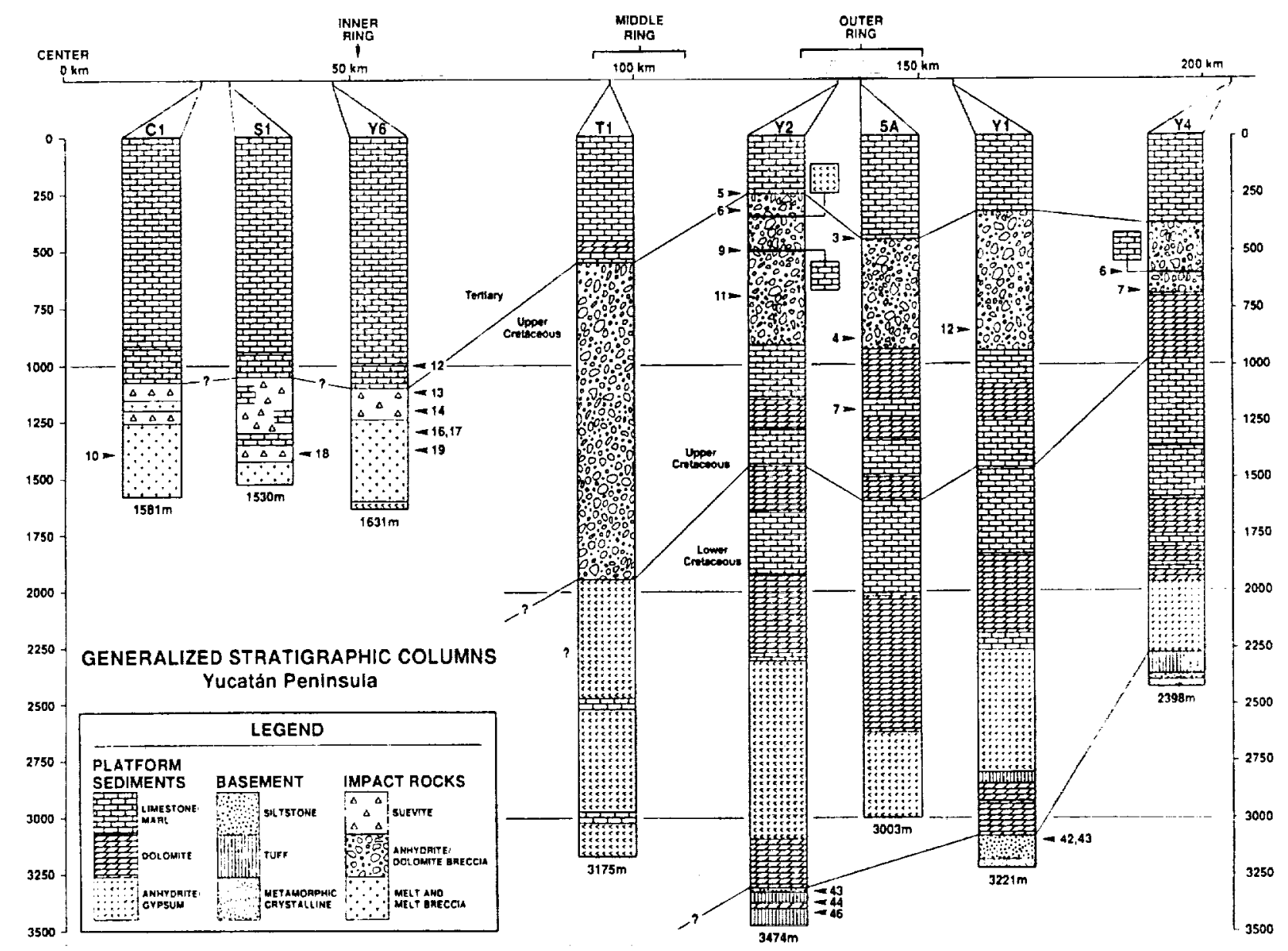

Fig. 2. Stratigraphic correlations across the Chicxulub basin based on well logs and sample analysis. Wells are arranged in distance from the basin center. The samples we have studied are identified by the numbered arrows. Other lithological assignments are based on visual inspection of cores updating previous published and unpublished reports. Ring designations refer to the three most prominent rings in the gravity analysis of Sharplon et al. [6].

crest. Such steep gradients define the edge of a major mass deficiency in the basin center. We believe that this is more consistent with the deep transient crater boundary than with the rim crest, which is the outer edge of a broad zone of modest and shallow deformation located well outside the deep transient crater. The fourth ring is probably not an exterior ring (i.e., located outside the topographic rim), as observed at some large multiring basins on other planets, because it has a detectable gravity expression and because of its association with the edge of the basin's circular gravity low.

There are additional observations that also indicate that Chicxulub may be $-300 \mathrm{~km}$ in diameter. Well-log and sample-analysis data have been used to compile the stratigraphic correlations in the vicinity of the Chic xulub Basin shown in Fig. 2. These data indicate that the boundary between the platform sediments and the crystalline basement is depressed $\sim 750 \mathrm{~m}$ in wells within $150 \mathrm{~km}$ of the basin center. Other major stratigraphic boundaries are depressed as well. In addition, thick sequences of breccia are observed in each of these wells. The Ticul 1 well, closest to the intermediate ring (ring 3 in Figs. 1 and 3) contains the thickest breccia unit, even though previously published reports based only on drill cultings show no breccias at all [e.g., 12,13].
Major-element chemistry $[2,5,6]$ and isotope analysis [11] indicate that the Haitian impact glass spherules and the Chicxulub melt rocks are identical and could be formed by a mixture of $94 \%$ silicate basement and $6 \%$ platform carbonate rocks [11]. Given an average thickness of $\sim 2 \mathrm{~km}$ for the platform cover in this region [12], and allowing for vaporization of carbonates near the impact point, silicate basement would have to be melted to a minimum depth of 15$20 \mathrm{~km}$ to provide these proportions. To the degree that depth of melting constrains the minimum depth of the excavation cavity $d_{c x c}$ then the transient crater diameter $D_{1}$ can be estimated [15] from the equation $d_{c x c} \cong 0,1 D_{1}$ or, for Chicxulub, $D_{1} \equiv 150-200 \mathrm{~km}$. The final crater diameter $D$ resulting from the collapse of the transient cavity follows from the relationship $D_{1} \cong 0.5-0.65 \mathrm{D}$ [15]. This predicts $\mathrm{D} \cong 300 \mathrm{~km}$ for the Chicxulub Crater, in good agreement with the stratigraphic data from well logs and the geophysical data.

Finally, crater studies show that even at the smallest possible final rim crest diameter of $170 \mathrm{~km}$, the Chicxulub basin would not likely be a peak ring basin. Planetary datasets show a clear progression in the morphological classes of large craters with increasing size and that the transition diameter from one class (such as peakring basin) to the next (multiring basin) depends strongly on surface gravity. The planet whose surface gravity and other properties are 


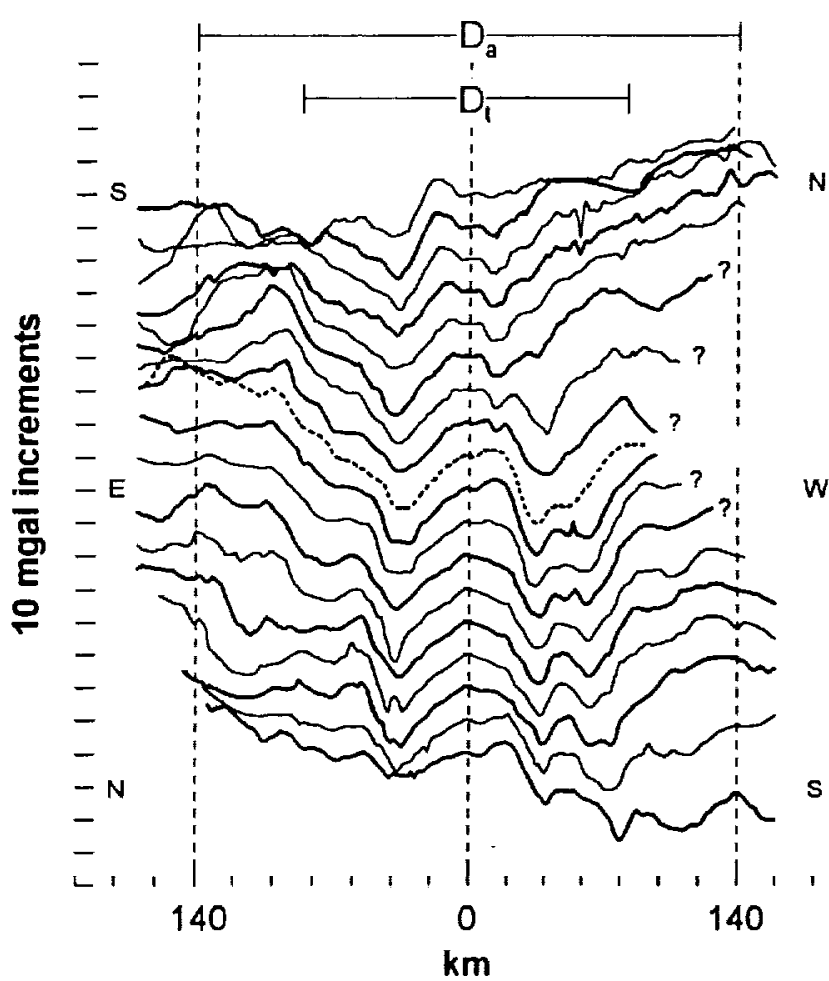

Fig. 3. Gravity profiles taken across the Chicxulub basin at $10^{\circ}$ intervals of azimuth. $D_{1}$ and $D_{a}$ refer to the transient crater diameler and final or apparent crater diameter resulting from this analysis. Profiles are offset vertically by $10 \mathrm{mgal}$; the annotated vertical axis shows the $0 \mathrm{mgal}$ value for the designated profiles, beginning from the boltom with north to south. Dashed profile is due east to west. The value of the center point of each gravity profile is $10.4 \mathrm{mgal}$.

most similar to Earth is Venus. Evaluation of over 1000 impact craters detected by the Magellan spacecraft reveal that double-ring, or peak-ring basins are constrained to diameters between $40 \mathrm{~km}$ and $110 \mathrm{~km}$ [16]. All larger craters are multiring basins, i.e., basins characterized by three or more concentric rings. This, coupled with the evidence above, suggests that the previous model of Chicxulub as a $\sim 180-\mathrm{km}$-diameter peak-ring basin is incorrect.

Consequently, we believe the interpretation most consistent with all available information is that the Chicxulub structure is a $\sim 300-\mathrm{km}$-diameter multiring basin (Fig. 4) similar to the largest impact landforms observed on the Moon, Mercury, and Venus [14]. Such events are extremely rare; there is only one other impact basin of comparable size produced in the inner solar system within the last billion or so years: the $280-\mathrm{km}$ Mead Basin on Venus.

Chicxulub Multiring Basin and the KT Boundary: Melt rocks within the Chic xulub Crater have experienced varying levels of hydrothermal alteration and albitization [17]; however, ${ }^{41} \mathrm{Ar}-$ ${ }^{39} \mathrm{Ar}$ determinations on relatively pristine melt rock samples from the center of the basin indicate a crystallization age at or very near the KT boundary $[6,10]$. Evaluation of the magnetization of these and other samples show that they cooled during an episode of reversed geomagnetic polarity, consistent with a KT boundary age $[6,18]$. Analysis of the $\mathrm{Rb}-\mathrm{Sr}, \mathrm{O}$, and $\mathrm{Nd}-\mathrm{Sm}$ isotopic systems confirm a chemical link between the Chicxulub melt rocks and the impact glasses contained in the KT boundary deposits at Beloc, Haiti [11]. Unmelted breccia clasts, representing the silicate base-

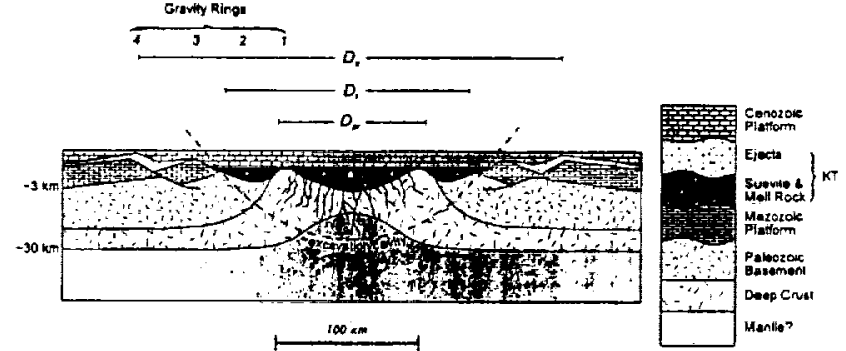

Fig.4. A schematic model of the Chic xulub impact basin that we derive from this analysis. This simplified cross section shows the general configuration of the crater but does not consider erosion; erosion at the time of impact could rearrange the upper crater units significantly and reduce crater topography. Faults and unit boundaries are simplified

ment impacted by the Chicxulub basin forming event, are mediumto high-grade continental crust similar to the lithic clasts observed within KT boundary sediments from around the world $[6,19]$.

Krogh et al. [8] recently determined that U-Pb ages of zircon xenocrysts from a Chicxulub breccia sample are $-545 \mathrm{Ma}$, with a small percentage showing a 418-Ma age. These 545-Ma-old zircons match the crystallization age of those within the upper member (magic layer, fireball layer, etc.) of the KT doublet in the Raton Basin of New Mexico. This provides compelling evidence that the Chicxulub impact event is responsible for both the shocked minerals observed in the upper member of the KT boundary sequence and the glass-rich lower member. Consequently, all evidence to date points to a singular, extremely energetic, and deadly impact event at the KT boundary.

References: [1] Penfield G. T. and Camargo-Z A. (1981) Tech. Prog. 37. [2] Hildebrand A. R. et al. (1991) Geology, 19, 867. [3] Pope K.O. et al. (1991) Nalure, 35I, 105. [4] Quezada-M. J. M. et al. (1992) LPS XXIII, 1121. [5] Kring D. A. and Boynton W. V. (1992) Nature, 358, 141. [6] Sharpton V. L. et al. (1992) Nature, 359, 819. [7] Koeberl C. et al. (1993) Geochim. Cosmochim. Acta, submitted. [8] Krogh T.et al.(1993)Nalure, submitted. [9] Schuraytz B. C. and Sharpton V. L., this volume. [10] Swisher C. C. et al. (1992) Science, 257, 954. [11] Blum J. D. et al. (1993) Nature, 364, 325. [12] Lopez-Ramos E. (1993) Geologia de Mexico, UNAM. [13] Weidie A. E. (1985) in Geology and Hydrogeology of the Yucatan (W. C. Ward et al., eds.), NOGS Publications. [14] Sharpton V. L. et al. (1993) Science, 259, 1564. [15] Melosh H. J. (1989) Impact Cratering, Oxford. [16] Schaber G. C. and Sharpton V. L. (1993) Nature, 362, 503. [18] Urrutia-Fucugauchi J. et al. (1993) Testononhurirs. submitled. I191 Sharpton V. L. et al. (1990) GSA s. $\mathbf{N} 94-28311$

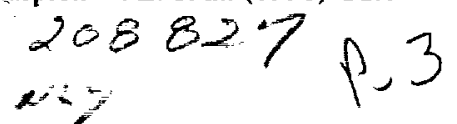

WERE ALL EXTINCTION EVENTS CAUSED BY IMPACTS? P.M. Sheehan and P. J. Coorough, Department of Geology, Milwaukee Public Museum, 800 W. Wells Street, Milwaukee WI 53233, USA.

Extraterrestrial impacts are firmly implicated in several of the five major Phanerozoic extinction events. A critical issue now is whether extraterrestrial events have been the only mechanism that produced physical changes of sufficient magnitude to cause major extinction events $[1,2]$. 
While we believe the evidence is overwhelming that the KT extinction event was caused by an impact $[3,4]$, we also find that an event of similar or larger size [5] near the end of the Ordovician is best explained by terrestrial causes [6-9].

The Ordovician extinction event (End-O extinction event) occurred near the end of the Ordovician, but the interval of extinction was completed prior to the newly established Ordovician-Silurian boundary [6]. In spite of extensive field studies, a convincing signature of an associated impact has not been found [10-13]. However, a prominent glaciation does coincide with the End-O extinction event.

Late Ordovician Glaciation and Extinction: During the Late Ordovician sea level was high, and broad epicontinental seas covered most continental plates. The Baltic, Laurentian, and Siberian plates were isolated and inhabited by zoogeographically discrete faunas. Extensive glacial features in North Africa document a Late Ordovician glaciation that lasted for 2-3 m.y. [14,6,8]. Sea level declined as water was transferred to the ice caps, and the epicontinental seas were drained. River drainage systems were incised into the carbonate platforms. Albedo changes caused by progressive exposure of the sea floor may have intensified the glaciation [15]. Drop-stones from icebergs were present in high-latitude oceans [16]. The glaciation ended abruptly, as evidenced by rapid eustatic rise in global sea level. Oxygen and $C$ isotopic studies are consistent with ocean chemistry changes expected during the glaciation [1719].

The End-O extinction event tracked the glacial epoch. Epicontinental sea faunas were decimated by the regression that marked the beginning of the glaciation $[20,8]$. Around the margins of many continents a new fauna called the Hirnantia fauna appeared and replaced older stocks. Many elements of the Hirnantia fauna originated in high latitudes. The appearance of the Hirnantia fauna commonly corresponds with a change from warm-water, carbonate rocks to cool-water, siliceous rocks.

As the glaciation intensified, planktonic groups, such as graptolites, progressively became restricted to the tropics [20]. The glaciation increased oceanic circulation, which in tum oxygenated previously anoxic areas of the oceans, reducing the habitat of some planktic organisms including graptolites [21], but providing new habitat for other benthic organisms [8]. A pulse of extinction during an interglacial event may have eliminated some benthic animals [6]. At the end of the glacial epoch climatic warming, sea level rise, and the return of anoxic waters dealt the final blow to the ecosystem [6].

Ecologic patterns changed significantly during the extinction interval. Long-standing communities of animals were decimated. New communities evolved during the glacial interval, but these communities were eliminated when the glaciation ended. A third set of communities was established in the Silurian, and recovery of the ecosystem required several million years [22].

Zoogeographic pattems were also disrupted. In the Late Ordovician highly endemic faunas formed distinct zoogeographic provinces in the epicontinental seas on each of the isolated continental plates. These provinces were eliminated by the extinction and survivors were dominated by animals with wide geographic distribution. The postextinction interval was characterized by the some of the most cosmopolitan faunas in the geologic record [7]. Tens of millions of years of evolution in isolated seaways were required before prior levels of provincialism were attained.

Study of a Non-Impact-Related Extinction Event: Study of the End-O extinction event is more difficult than studying the $\mathrm{KT}$ event because añ impact clay is missing, so there is no worldwide event horizon to which phenomena can be tied. Correlation in the Ordovician relies primarily on fossil data and the extinction reduced the number of species that were available for correlation. Graptolites and conodonts, the two groups most useful for correlation, were especially hard hit. Postextinction species tended to have exceptionally long geologic ranges, making correlation following the extinction difficult. Some events, such as the appearance of the Hirnantia fauna in two different areas, may be mistakenly taken to be synchronous. The Hirnantia fauna was a cold-water fauna that apparently moved toward the tropics as the glaciation intensified. Thus, the first appearance of the Hirnantia fauna probably happened at different times in different places. Eustatic sea level rise and fall may prove to be the most accurate method of correlation during this interval.

Comparison of Impact and Nonimpact Extinction Events: Even though the End-O extinction event had a terrestrial cause, it was still catastrophic. The physical perturbation of the environment was beyond the ability of the ecosystem to adapt through normal evolutionary processes.

The primary difference between the KT and End-O extinction events was the duration of the events. The KT event was instantaneous on a geologic timescale, and postimpact perturbation of the physical environment lasted less than a million years. The End-O event had an extinction interval of 2-3 m.y. with several pulses as the ice caps advanced and retreated.

In spite of these differences, the effect on the Cretaceous and Ordovician biotas was quite similar. An impact and a glaciation are capable of producing similar levels of extinction at family and generic levels $[5,22]$. In both cases long intervals of ecologic stability were disrupted, and new ecologic communities and provinces were established [23].

There is currently a paradigm shift underway in paleontology from one that views evolution as pervasively gradual to a paradigm of gradual evolution punctuated by occasional catastrophic events that are accompanied by restructuring of the entire ecologic landscape. Determining whether or not these catastrophic events include both terrestrial and extraterrestrial events is imperative.

If some extinction events are not caused by impacts, there is a wild card in the current search for periodicity of extinction events. If one of the five major Phanerozoic extinction events had a terrestrial cause, many smaller events also may have had terrestrial causes. The history of life might include a group of extinction events caused by periodic impacts and another group of extinction events with non-periodic, terrestrial causes.

Acknowledgments: Work was supported by N.S.F.grant EAR9004589.

References: [1] McL aren D. J. and Goodfellow W. D. (1990) Annu. Rev. Earth Planet. Sci., 18, 123-171. [2] Raup D. M. (1990) GSA Spec. Paper 247, 27-32. [3] Sheehan P. M. et al. (1991) Science, 254, 835-839. [4] Sheehan P. M. and Fastovsky D. E. (1992) Geology, 20, 556-560. [5] Sepkoski J. J. (1986) in Patterns and Process in the History of Life (D. M. Raup and D. Jablonski, eds.), 277-296, Springer-Verlag, Berlin. [6] Brenchley P. (1989) in Mass Extinctions Processes and Evidence (S. K. Donovan, ed.), 104-132, Columbia. [7] Sheehan P. M. and Coorough P. J. (1990) Geol. Soc. London Mem. 12, 181-187. [8] Sheehan P. M. (1988) New Mex. Bur. Mines. Mem. 44, 405-415. [9] Owen A. W. et al. (1991) Geol. Surv. Canada Paper 90-9, 179-190. [10] Orth C. J. et al. (1986) Geology, 14, 433-436. [11] Wilde P. et al. (1986) Sci- 
ence, 233, 339-341. [12] Orth C. J. et al. (1990) GSA Spec. Paper 247, 45-59. [13] Wang K. et al. (1992) Geology, 20, 39-42. [14] Bennacef A. (1971) Am. Assoc. Petrol. Geol. Bull., 55, 22252245. [15] Gildner R. F. and Cisne J. L. (1987) Paleoceanography, 2, 177-183. [16] Robardet M. and Dore F. (1988) Palaeogeog. Climar. Ecol., 66, 19-31. [17] Marshall J. D. and Middleton P. D. (1990) J. Geol. Soc. London, 147, 1-4. [18] Middleton P. D. et al. (1991) Geol. Surv. Canada Paper 90-9, 313-323. [19] Wilde P. and Berry W. B. N. (1986) in Global Bio-Events (O. Walliser, ed.), 7591, Springer-Verlag, Berlin. [20] Skevington D. (1978) Alcheringa, 2, 21 -26. [21] Melchin M. J. and Mitchell C. E. (1991) Geol. Surv. Canada Paper 90-9, 143-154. [22] Sepkoski J. J. (1990) J. Geol. Soc. London, 146, 7-19. [23] Sheehan P. M. (1991) in The Unity of Evolutionary Biology (E. C. Dudley, ed.), 103-118, Discorides, Pontland

\section{N94- 28312}

5

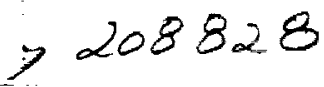

OZONE CONTROL OF BIOLOGICAL ACTIVITY DURING EARTH'S HISTORY, INCLUDING THE KT CATASTRO-

PHE. W. R. Sheldon, University of Houston, Houston TX 77204 5506, USA.

There have been brief periods since the beginning of the Cambrian some $600 \mathrm{~m}$.y. ago when mass extinctions destroyed a significant fraction of living species. The most widely studied of these events is the catastrophe at the KT boundary that ended the long dominance of the dinosaurs. In addition to mass extinctions there is another profound discontinuity in the history of Earh's biota, the explosion of life at the end of the Precambrian era, an episode that is not explained well at all. For some 3 b.y. before the Cambrian, life had been present on Earth, but maintained a low level of activity, an aspect of the biota that is puzzling, especially during the last twothirds of that period. During the last 2 b.y. before the Cambrian, conditions at the Earth's surface were suitable for a burgeoning of the biota, according to most criteria: The oceans neither boiled nor were frozen solid during this time, and the atmosphere contained sufficient $\mathbf{O}$ for the development of animals. The purpose of this paper is to suggest that mass extinctions and the lackluster behavior of the Precambrian biota share a common cause: an inadequate amount of ozone in the atmosphere.

Calculations of atmospheric ozone $\mathrm{O}_{3}$ have been made with the concentration of $\mathrm{O}_{2}$ in the atmosphere as a variable parameter $[1,2]$, but with the solar spectrum at the top of the atmosphere assumed to be that observed at present. On the basis of these calculations it is of interest to note that the present ozone atmosphere is only some $30 \%$ above the critical value of $7 \times 10^{18} \mathrm{O}_{3} \mathrm{~cm}^{-2}$, a level that provides a "full screen" for the biota; however, an $\mathrm{O}_{2}$ concentration only $10 \%$ of the present atmospheric level (PAL) creates an ozone atmosphere only $20 \%$ below the critical value. Consequently it has been assumed that when the $\mathrm{O}_{2}$ concentration reached the neighborhood of $10^{-1}$ PAL, the biota found an environment on the Earth's surface relatively free of degradation from solar ultraviolet (UV) radiation. Here that concept is questioned and a scenario is described in which a robust $\mathrm{O}_{2}$ atmosphere could be present, but an $\mathrm{O}_{3}$ atmosphere anywhere near the critical value would not be formed.

Present concem for the Earth's ozone layer is focused on chemical processes in the atmosphere that destroy $\mathrm{O}_{3}$; the ozone production rate is constant and not considered to be a potential problem. In the geologic past such was certainly not the case and the main point of this paper is that during the Earth's history the $\mathrm{O}_{3}$ production rate has been the controlling factor for the biota. Specifically, it is suggested that cometary activity during the Precambrian and comet showers during mass extinction events provided a supply of volatile material to the inner solar system that selectively absorbed UV photons capable of photolyzing the $\mathrm{O}_{2}$ molecule (and thus precluded $\mathrm{O}_{3}$ production); at the same time the solar flux at near-UV wavelengths arrived at Earth unattenuated, resulting in an extremely harsh environment for the biota at the Earth's surface and at ocean depths down to several tens of meters.

The comets under consideration consisted of volatile material that accumulated in the region of the nebular disk beyond Jupiter's orbit. Then gravitational perturbations by the four giant planets redistributed a portion of these cometary bodies to form the Oort comet cloud at the outer boundary of the solar system [3]. At the same time a much larger number of these bodies were expelled from the solar system, or were disrupted and vaporized by passing in the vicinity of the Sun $[4,5]$.

In order to estimate the amount of cometary volatile material that is required to have a critical effect on $\mathrm{O}_{3}$ production in the atmosphere it is assumed that the rate of $\mathrm{O}$ photolysis $\left(\mathrm{O}_{2}+\mathrm{hv} \rightarrow \mathrm{O}+\right.$ $\mathrm{O})$ required for $\mathrm{O}_{3}$ production is proportional to the flux of photons in the extreme UV that drive the reaction; further it is assumed that a reduction of the $\mathrm{O}_{3}$ production rate of $\frac{1}{\mathrm{c}}$ of its present value would result in an environment sufficiently harsh at the Earth's surface to account for the Precambrian biota or mass extinctions. In the present atmosphere the flux of $200-n m$ photons is reduced to $\frac{1}{c}$ of its value at the top of the atmosphere by $\sim 10^{23} \mathrm{O}_{2}$ molecules per $\mathrm{cm}^{2}$. However, the cometary volatile material would consist of water $\left(\mathrm{H}_{2} \mathrm{O}\right)$ and ammonia $\left(\mathrm{NH}_{3}\right)$, molecules with $\mathrm{UV}$ absorption cross sections greater than that of $\mathrm{O}_{2}$ by factors of 10 and $10^{\circ}$, respectively [2]. Thus an average concentration of $\sim 7 \times 10^{8} \mathrm{~cm}^{-3}$ of $\mathrm{H}_{2} \mathrm{O}$, or $\sim 7 \times$ $10^{3} \mathrm{~cm}^{-3}$ of $\mathrm{NH}_{3}$, would be required along the path connecting the Earth and the Sun. If the cometary material is constrained to a disk 0.1 AU thick the total amount of $\mathrm{H}_{2} \mathrm{O}$ would be $2 \times 10^{25} \mathrm{~g}$, or $10^{20} \mathrm{~g}$ of $\mathrm{NH}_{3}$. Comparing the collision cross sections of the Earth and the disk (a factor of $5 \times 10^{7}$ ), it is concluded that during the same period of time cometary transport would deposit $4 \times 10^{17} \mathrm{~g} \mathrm{H}_{2} \mathrm{O}$ on Earth, or $2 \times 10^{12} \mathrm{~g} \mathrm{NH}_{3}$. Assuming a residence time of one year for vaporized material in the disk (corresponding to an average velocity of $50 \mathrm{~km} \mathrm{~s}^{-1}$ for the outward transpon of the vapor), during the $3 \times$ $10^{9}$ years of cometary activity in the Precambrian $1.2 \times 10^{27} \mathrm{~g} \mathrm{H}_{2} \mathrm{O}$, or $6 \times 10^{21} \mathrm{~g} \mathrm{NH}_{3}$, would have been deposited on Earth.

It is appropriate to consider two aspects of this proposed scenario for the effect of comets on the history of Earth's biota: whether it is possible and what, if any, further conclusions would result. The most direct quantitative comparison involves the total amounts of $\mathrm{H}_{2} \mathrm{O}$ or $\mathrm{NH}_{3}$ predicted to have been deposited on Earth by cometary activity [6,7]. The amount of $\mathrm{H}_{2} \mathrm{O}$ alone that would be required exceeds the amount on Earth by more than 2 orders of magnitude, but the amount of $\mathrm{NH}_{3}$ required is about equal to the mass of Earth's atmosphere. Thus the proposed scenario seems to meet the zeroth order test, epsecially where $\mathrm{NH}_{3}$ is concemed. However, it should be noted that the required amount of volatile material could be an overestimate, since the absence of an $\mathrm{O}_{3}$ atmosphere for perhaps only $1 \%$ of the time during the Precambrian could suffice to suppress the development of the biota on the Earth's surface. Another consideration is the fact that solar luminosity was less during the 
Precambrian era. Also, the amount of cometary volatile material that has been deposited on Earth may be more than is found at present, since some of the volatile material may have been removed by impact erosion. In addition, the UV absorption cross sections of cometary $\mathrm{H}_{2} \mathrm{O}$ and $\mathrm{NH}_{3}$ may be larger than the values measured in the laboratory, since in comets they could be in the form of cluster molecules [8]. Finally, the continuous introduction of $\mathrm{H}_{2} \mathrm{O}$ and $\mathrm{NH}_{3}$ at the top of the atmosphere would not only supress $\mathrm{O}_{3}$ production by UV absorption, but the photolyzed products would catalytically destroy $\mathrm{O}_{3}$ by the well-known reactions al work in the stratosphere at present [9].

Since suppression of the $\mathrm{O}_{3}$ atmosphere by comets in the inner solar system appears to be possible, it is of interest to note that the same mechanism would resolve two other current problems involving the history of Earth and Mars. The likelihood of $\mathrm{NH}_{3}$ in the Precambrian atmosphere was suggested [10] in order to provide the necessary greenhouse effect when solar luminosity was less than its present value, and thus reconcile calculated ocean temperatures with the observation that the oceans had not frozen. However, calculation of $\mathrm{NH}_{3}$ photolysis [11] indicated a lifetime for $\mathrm{NH}_{3}$ in the atmosphere that was significantly less than that which was required. The presence of $\mathrm{NH}_{3}$ and $\mathrm{H}_{2} \mathrm{O}$ in the inner solar system according to the scenario presented here could reduce the rate of $\mathrm{NH}_{3}$ photolysis in the Earth's atmosphere to a level that would permit the small amount of $\mathrm{NH}_{3}$ that had been suggested [10]. In a similar way the efficient greenhouse nature of $\mathrm{NH}_{3}$, in conjunction with its shielding from solar UV radiation by cometary outgassing in the inner solar system, could account for the warmer temperatures on Mars that are needed to explain the fluvial features that have been observed there.

To summarize the main suggestion proposed here: Discontinuities in the history of Earth's biota can be explained by the single unifying suggestion that low levels of $\mathrm{O}_{3}$ production are controlled by cometary activity. Precambrian biological activity is explained along with mass extinctions. Where mass extinctions since the Cambrian are concerned, comet showers from the remnants of the nebular disk lasting for thousands to millions of years provide a model consistent with the paleontological record, which shows biological degradation lasting for similar periods and becoming increasingly destructive with time until the event suddenly ends. Since the model proposed here appears to answer some outstanding questions it should be investigated further.

Acknowledgments: This work was supported by NSF grant ATM-9206417.

References: [1] Ratner M. I. and Walker J. C. G. (1972) J. Atmos. Sci., 29, 803. [2] Levine J. S. (1982) J. Molec. Evol,, 18, 161. [3] Oon J. H. (1950) Bull. Inst. Neth., M, 91. [4] Hills J. G. (1981) Ap. J., 86, 1730. [5] Fernandez J. A. (1980) lcarus, 42, 406. [6] Oro J. et al. (1990) Annu. Rev. Earih Planet. Sci., 18, 317. [7] Delsemme A. H. (1992) Origins of Life and Evolution of the Biosphere, 2I, 279. [8] Frank L. A. and Sigworth J. B. (1993) Rev. Geophys., 31, 1. [9] Turco R. P. (1985) The Photochemistry of Almosphere (J. S. Levine, ed.), 77, Academic. [10] Sagan C. and Mullen_G. (1972) Science, 177, 52. [11] Kuhn W. R. and Atreya S. K. (1979) Icarus, 37, 207.

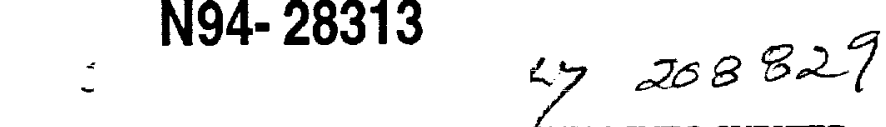

THE CRASH OF PSHOEMAKER-LEVY 9 INTO JUPITER AND ITS IMPLICATIONS FOR COMET BOMBARDMENT

ON EARTH. E. M. Shoemaker and C. S. Shoemaker, Lowell Observatory, 1400 West Mars Hill Road, Flagstaff AZ 86001, USA.

Periodic Comet Shoemaker/Levy 9 will impact Jupiter in late July $1994[1,2]$. The comet, which broke into more than 20 telescopically detectable fragments [ 3 ] when it passed within the Roche lobe of Jupiter on July 8, 1992, is captured in a highly eccentric orbit about Jupiter. The 21 recognized nuclei will be spread out in a train of the order $7 \times 10^{6} \mathrm{~km}$ long at the time of impact, and the impacts will be spread in time over about $51 / 2$ days centered on about July 21.2 UT [4]. In addition to the train of recognized bright nuclei, the comet consists of "wings" of unresolved bodies that are the source of a very broad composite dust tail. The linear extent of the wings is about an order of magnitude greater than that of the train of recognized discrete nuclei. Collision of the wings will be spread in time over several months. Thus the impact of P/S-L 9 with Jupiter will be an event of appreciable duration.

Sizes of the recognized nuclear fragments of P/S-L 9 are not yet firmly established. Photometry from high-resolution images acquired by the Hubble Space Telescope suggests that the 11 largest nuclear fragments range from 2.5 to about $4.3 \mathrm{~km}$ in diameter, and that the precursor body, before breakup, was about $8 \mathrm{~km}$ in diameter or larger [5]. A preliminary dynamical solution for the development of the observed train of nuclei by Scotti and Melosh [6] suggests that the precursor body was only about $2 \mathrm{~km}$ in diameter. However, a later solution by Chodas and Yeomans [4], based on orbits of the individual nuclei, indicates that the precursor body was about $9 \mathrm{~km}$ in diameter. We conclude that the precursor of $\mathrm{P} / \mathrm{S}-\mathrm{L} 9$ was of the order $9 \mathrm{~km}$ diameter and that the total impact energy will be of the order $10^{*}$ megatons TNT.

Observations of comets discovered shortly after escape from jovicentric orbit, plus the discovery of P/S-L 9, indicate that the frequency of collision of objects orbiting Jupiter with the estimated impact energy of P/S-L 9 is of the order once per millenium [7]. Collisions with Jupiter of comets on free heliocentric orbits are several times more frequent. These collision rates are an order of magnitude higher than those predicted with the use of Opik's equations, which fail for very-low-velocity encounters with Jupiter.

The development of a train of cometary debris by tidal breakup leading to multiple impacts on a planet has direct relevance to the impact history of Earth. Both periodic and long-period Sun-grazing comets are subject to tidal disruption. A catastrophically disrupted periodic comet on a free heliocentric orbit can be expected to form a compact debris stream somewhat similar to but much narrower than an ordinary meteoroid stream. If such a stream intersects Earth's orbit at one of the nodes, Earth will be subject to repeated impacts as a result of its annual passage through the stream $[8-10]$. High-inclination periodic comets tend to be driven to Sun-grazing orbits [11], and the formation of compact debris streams should occur fairly frequently. Breakup of very large (several hundred kilometers in diameter) periodic comet nuclei should have occurred occasionally during the last $0.5 \mathrm{Ga}$, leading to comet showers with durations of the order of $10^{5} \mathrm{yr}$. If one such breakup occurred when the distance to a node was near I $\mathrm{AU}$, an intense pulse of bombardment lasting a few decades may have occurred. We postulate that just such an event happened at $\mathrm{K} / \mathrm{T}$ boundary time. 
References: [1] Carusi A. et al. (1993) IAU Symposium I60, 9. [2] Chodas P. W. and Yeomans D. K. (1993) Bull. A.A.S., 25, 1042. [3] Jewitt D. et al. (1993) Bull. A.A.S., 25, 1042. [4] Chodas P. W. and Yeomans D. K. (1993) Bull. A.A.S., 25, 1042. [5] Weaver H. A. et al. (1993) Science, in press. [6] Scotti J. V. and Melosh H. J. (1993) Nature, in press. [7] Shoemaker E. M. et al. (1993) Bull. A.A.S., 25, 1042. [8] Shoemaker E. M. (1991) ACM '91, 194, [9] Shoemaker E. M. and Izett G. A. (1992) LPS XXIII, 1293-1294. [10] Shoemaker E. M. and Izett G. A. (1992) LPI Contrib. No. 790, 66-68. [11] Bailey M. E. et al. (1992) Astron. Astrophys., 257, 315-322.

\section{Ornet $\rightarrow 0 \% 127$}

\section{CRYSTALS, LITHICS, AND GLASSY EJECTA AT THE KT} BOUNDARY: IMPLICATIONS FOR LITHOLOGY OF THE CRUST AT THE IMPACT SITE. H. Sigurdsson', S. Smith', S. D'Hondt', S. Carey', and J.-M. Espindola? , 'Graduate School of Oceanography, University of Rhode Island, Narragansett RI 02882 , USA, Instituto de Geofísica, Universidad Nacional Autónoma de México, Cd. Universitaria, Mexico City 04510, Mexico.

Ejecta from bolide impact may contain melt quenched to glass droplets as well as rock fragments and fractured mineral grains from the impact terrane. In distal sections of the ejecta deposit, an impact origin for glass and shocked minerals may generally be established, whereas the origin of lithics and unshocked crystal fragments found in association with impact glass is uncertain, due to possible contamination from other sources. In addition to 1-8-mm-diameter glassy ejecta spherules, the $0.5-1-\mathrm{m}$-thick KT boundary impact

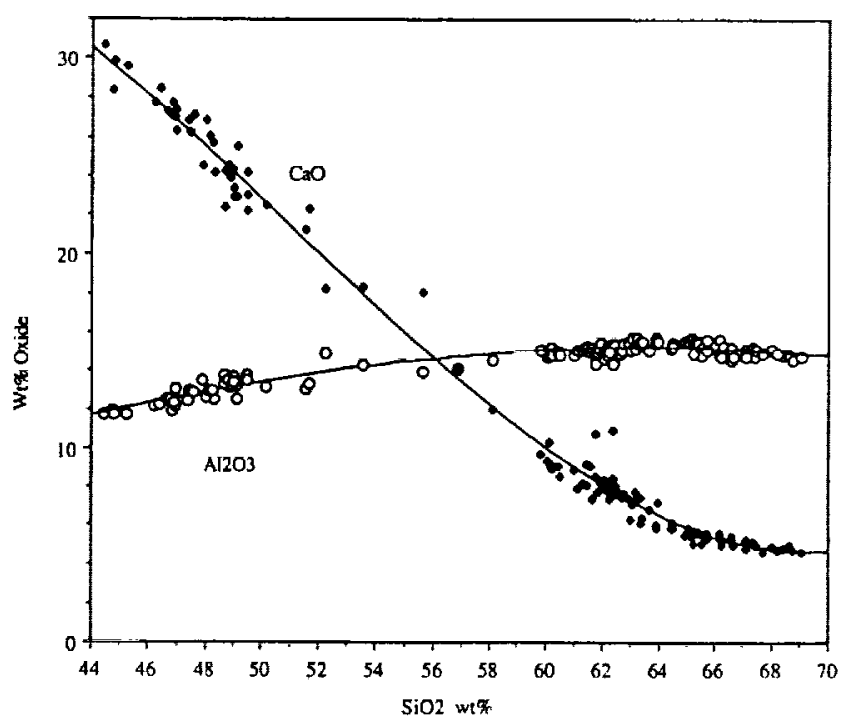

Fig. 1. Compositional trends in KT boundary glassy ejecta spherules, illustrating the smooth compositional trends of $\mathrm{Al}_{2} \mathrm{O}_{3}$ and $\mathrm{CaO}$, from high-Ca yellow glasses to the more abundant high-silica glasses. In total, the dataset represents analyses of 140 spherules. The compositional range from 44$62 \mathrm{wt} \% \mathrm{SiO}_{2}$ can be modeled as a simple binary mixing trend [1], whereas the high-silica glasses reflect a more heterogenous source. Curves define bestfit regression lines through the data, with correlation coefficient of 0.992 for $\mathrm{CaO}$ and 0.91 for $\mathrm{Al}_{2} \mathrm{O}_{3}$.

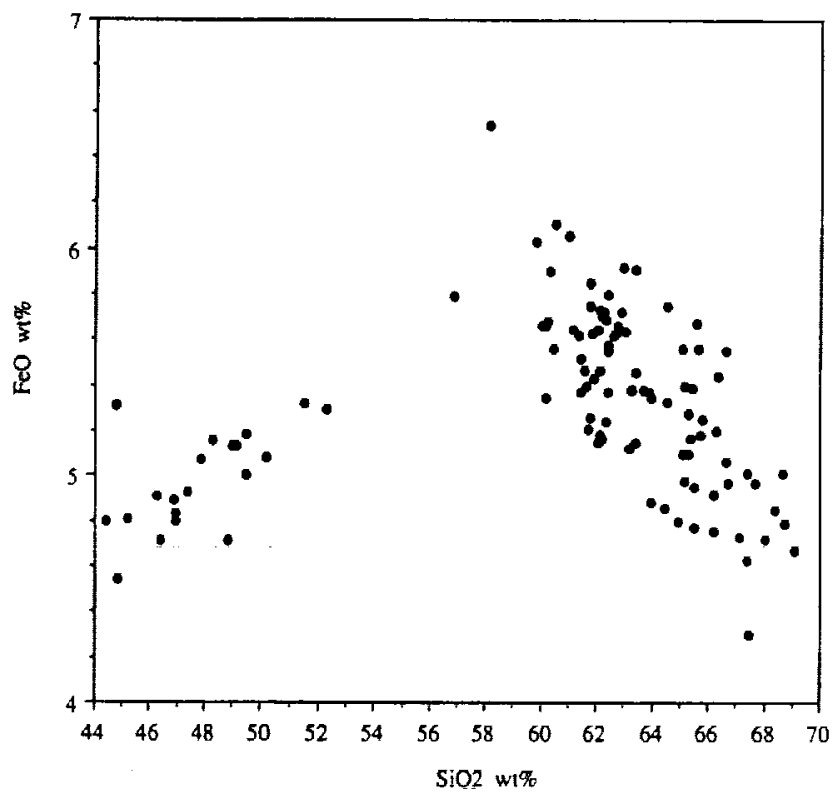

Fig. 2. Two distinct trends of FeO content in KT boundary impact glasses. The trend of decreasing Fe content with increasing silica in the high-silica glasses may reflect heterogeneity in the source region, whereas the trend be tween high-Ca glasses ( $44-54 \mathrm{wt}_{\mathrm{t}} \mathrm{SiO}_{2}$ ) and high-silica glasses can be modeled as a mixing trend.

ejecta layer in the Beloc pelagic carbonate sediment formation in Haiti contains silicate mineral fragments and rock fragments that may provide clues about the nature of the Earth's crust at the impact site. Because of the monotonous and relatively pure lithology of the enclosing upper Createceous and lower Tertiary carbonate sediments, the Haiti exposures of the KT boundary layer provide an opportunity to detect mineral ejecta present in only trace amounts,

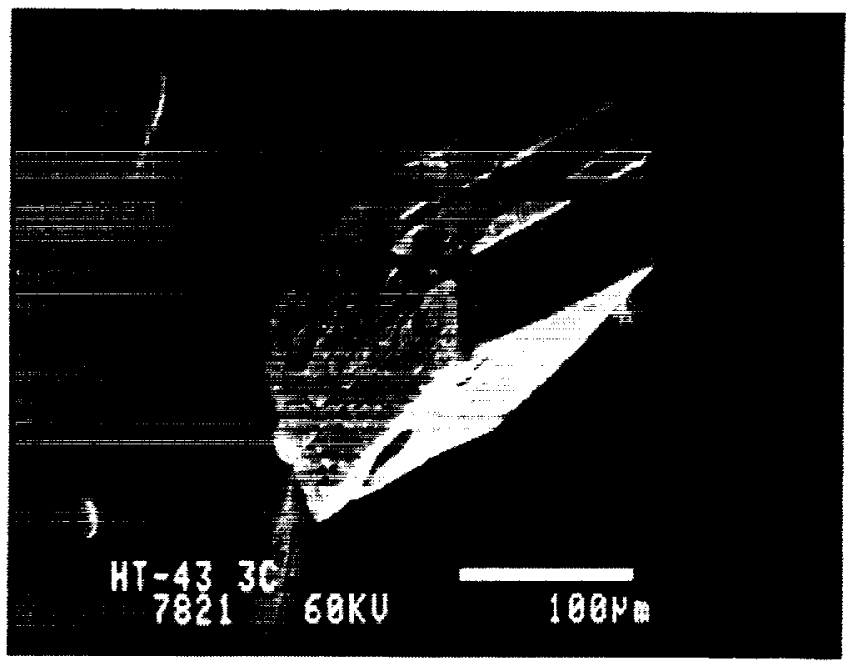

Fig. 3. Scanning electron micrograph of a crystal of amphibole from the KT boundary ejecta layer. The 400 - $\mu$ meuhedral crystal is entirely defined by $(110\}$ cleavage planes and formed by breakage. Mineral chemistry is consistent with derivation from $9-12 \mathrm{~km}$ depth in the crust. 
TABLE 1. Silicate minerals and glass in the KT boundary ejecta layer.

\begin{tabular}{lrccrccc}
\hline & Amph. & Plag-1 & Plag-2 & \multicolumn{1}{c}{ Cpx. } & Glass Incl. & Glass-Cpx. & Haiti Glass \\
\hline $\mathrm{SiO}_{2}$ & 45.78 & 56.55 & 56.66 & 51.96 & 68.69 & 65.51 & 65.47 \\
$\mathrm{Al}_{2} \mathrm{O}_{3}$ & 8.02 & 27.69 & 27.28 & 1.71 & 13.82 & 15.08 & 15.49 \\
$\mathrm{FeO}$ & 8.44 & - & - & 7.85 & 2.93 & 4.07 & 4.95 \\
$\mathrm{Fe}_{2} \mathrm{O}_{3}$ & 5.35 & 0.29 & 0.48 & 1.86 & - & - & - \\
$\mathrm{MgO}_{2}$ & 15.68 & n.d. & n.d. & 14.88 & 0.50 & 2.51 & 2.49 \\
$\mathrm{CaO}$ & 11.52 & 9.71 & 9.29 & 20.81 & 1.86 & 5.79 & 5.61 \\
$\mathrm{Na}_{2} \mathrm{O}$ & 1.33 & 5.13 & 5.61 & 0.37 & 5.01 & 4.19 & 3.83 \\
$\mathrm{~K}_{2} \mathrm{O}$ & 0.50 & 0.38 & 0.20 & n.a. & 2.41 & 2.02 & 1.67 \\
$\mathrm{TiO}_{2}$ & 1.35 & n.a. & n.a. & 0.48 & 0.53 & 0.61 & 0.62 \\
$\mathrm{MnO}$ & 0.41 & n.a. & n.a. & 0.65 & 0.15 & 0.22 & 0.05 \\
$\mathrm{Sum}$ & 98.38 & 99.75 & 99.52 & 100.57 & 95.90 & & 100.27 \\
\hline
\end{tabular}

in addition to the abundant impact glass $[1,2]$. New studies of the chemistry of glass spherules from the Haiti deposit (Fig. 1) further define the mixing trend already documented between high-Ca yellow glass and high-silica black glass spherules $[1,3]$. The high-silica glasses with $\mathrm{SiO}_{2}>62$ wt\% define a separate trend in terms of most oxides, such as FeO (Fig. 2), which may reflect chemical range in the crustal source region. New analyses show that $S$ content of yellow high-Ca glasses ranges up to $1.25 \% \mathrm{SO}_{3}[4]$.

Isolated mineral fragments in the ejecta layer include amphibole, quartz, clinopyroxene, and plagioclase. Amphibole is a relatively common and well-preserved crystal component in the ejecta layer, and is present at all levels, except in the interval $1-30 \mathrm{~cm}$ above the base. The amphiboles are up to $0.5 \mathrm{~mm}$ in size, and occur exclusively as angular, euhedral crystals whose shape is defined by $\{110\}$ cleavage planes (Fig. 3 ). These amphiboles are magnesiohomblendes to tschermakitic hornblendes, and define a coherent compositional trend, with a relatively narrow range from $(\mathrm{Mg}$ / $\mathrm{Mg}+\mathrm{Fe})=0.70-0.80$ (Amph. in table). Variation or zoning within individual crystals is small, in the range $(\mathrm{Mg} / \mathrm{Mg}+\mathrm{Fe})=0.02-0.07$. The amphiboles are relatively high in $\mathrm{AI}_{2} \mathrm{O}_{3}(7-12 \mathrm{wt} \%)$; with total Al cations in the range 1.3-1.45 in the structural formula, these amphiboles could have equilibrated at total pressure of 3-4 kbar (9-12 km [5]). Shocked quartz crystals up to $0.55 \mathrm{~mm}$ in size have already been documented from the Haiti KT section [6,7]. Fractured plagioclase is very rare and occurs as solitary and angular crystal fragments. The crystals are of andesine-labradorite $\mathrm{An}_{50} \mathrm{Ab}_{48} \mathrm{Or}_{2}$ and are relatively unzoned (Plag-1 in table; $A n_{47-52}$ ). Biotite crystal flakes are very rare.

Solitary clinopyroxene and plagioclase crystals with a reticulate glass coating are also present. The euhedral clinopyroxene has the composition $\mathrm{Wo}_{44} \mathrm{En}_{44} \mathrm{Fs}_{12}$ (Cpx. in table), is $0.7 \mathrm{~mm}$ in length, and is coated with glass. It contains a rhyodacite glass inclusion (Glass Incl. in table), indicating a magmatic or volcanic origin of the mineral. However, the glass coating on the exterior of the crystal (Glass-Cpx. in table) is dacitic in composition and virtually identical to the common impact glass spherules found at the KT boundary in Haiti (Haiti glass in table). The subhedral to euhedral $0.7-\mathrm{mm}$ plagioclase is of $\mathrm{An}_{47.2} \mathrm{Ab}_{51.6} \mathrm{Or}_{1.2}$ mean composition (Plag-2 in table), zoned from $\mathrm{An}_{51}$ core to $\mathrm{An}_{44}$ rim, and also coaled with dacitic glass. A single 1.3-mm highly vesicular pumice fragment is also present. In addition, the KT boundary deposit in Haiti contains minerals that are authigenic in origin. They include common crys- tals of euhedral to subhedral barite, up to $1 \mathrm{~mm}$ in diameter, euhedral and bipyramidal crystals of perfectly formed clear quartz, and high-Ca-K phillipsite zeolites. Lithic fragments of graywacke are present but rare in the ejecta deposit, up to $1.5 \mathrm{~mm}$ in size. They consist dominantly of relatively poorly sorted sedimentary rock, containing large $(0.5 \mathrm{~mm})$ and rounded quartz grains in a silty to clayey matrix.

Studies of mineralogy of upper Cretaceous and lower Tertiary sediments from DSDP Legs 4 and 15 at 10 sites in the Caribbean provide information on sedimentation of silicate minerals elsewhere in the region at KT boundary time $[8,9]$. In addition to authigenic minerals in the latest Mastrichtian-early Paleocene central Caribbean carbonate sediments, such as cher, clinoptilolite, and barite, these studies also record grains of homblende, plagioclase, and clinopyroxene.

If the silicate mineral assemblage in the Haiti deposit is of ejecta origin, as indicated by impact glass coating on clinopyroxene, then it may indicate a crustal section including both calcalkaline volcanics and possibly mid- to upper-crustal amphibolites, overlain by greywacke, evaporites, and carbonate sediments. In terms of comparison with geologic terrane in the Yucatan region, the greywacke lithic fragments in the Haiti deposit may correlate with the Jurassic Todos Santos Formation, which is over $400 \mathrm{~m}$ thick in well Y-I $[10,11]$. Similarly, the silicate mineral assemblage in the Haiti deposit may be derived from the Yucatan crystalline basement rocks of Paleozoic age, which in the same well include felsic metaporphyry, crystalloblastic quartz chlorite schist, and rhyolite [10-12].

References: [1] Sigurdsson H. et al. (1991) Nature, 349 , 482-487. [2] Sigurdsson H. et al. (1991) Nature, 353, 839-842. [3] Sigurdsson H. et al. (1992) EPSL, 109, 543-560. [4] Chaussidon M. et al., this volume. [5] Johnson M. C. and Rutherford M. J. (1989) Geology, 17, 837-841. [6] Hildebrand A. R. and Boynton W. V. (1990) Science, 248, 843-847. [7] Izett G. A. (1991)JGR, 96, 20879-20905. [8] Donnelly T. W. and Nalli G. (1973) Init. Rept. DSDP XV, 929-961. [9] Donnelly T. W. (1973) Init. Rept. DSDP XV, 969-987. [10] Bass M. N. and Zartman R. E. (1969) Eos, 50 , 313. [11] Viniegra O. F. (1971) Am. Assoc. Petrol. Geol, Bull., 55, 478-494. [12] Donnelly T. W. et al. (1990) Geology of North America, Vol. $H, 37-76$. 
MISUNDERSTANDINGS REGARDING THE KT BOUNDARY DEPOSITS IN THE GULF OF MEXICO. J. Smit', W. Alvarez ${ }^{2}$, P. Claeys ${ }^{2}$, S. Montanari ${ }^{3}$, and Th. B. Roep', 'Institute of Earth Sciences, Vrije Universiteit, de Boelelaan 1085, 1081 HV Amsterdam, Netherlands, ${ }^{2}$ Department of Geology and Geophysics, University of Califomia, Berkeley CA 94720 , USA, ${ }^{3}$ Osservatorio Geologico, Coldigoco, Apiro di Frontale, Umbria, Italy.

Some recent papers [ 1,2$]$ suggest that ( 1 ) the KT boundary in the Gulf of Mexico is not marked by unusual tsunami-generated clastic deposits, (2) clastic deposits, where present, predate the KT boundary, and (3) nomnal debris-flow or turbidite deposits represent an extended amount of time, not related to impact. These suggestions, however, are based on a few misconceptions, which seriously hamper a clear view on the KT boundary problem.

The definition of the KT boundary used in the literature [3] is often not unequivocal. In [3] the KT boundary is said to be at either (1) the first occurrence of Paleocene (planktic) species or (2) at the mass extinction of Cretaceous biota. I will demonstrate below that these two definitions are not synchronous and may differ by as much as $50,000 \mathrm{yr}$. In practice, in studies other than those with extremely high resolution, that is not a problem, but in particular in KT boundary sections around the Gulf coast, with up to 12 -m-thick rapidly deposited clastic beds at the KT boundary, the ambiguous definition leads to misplacement of the KT boundary $[2,4]$.
The KT boundary Stratotype and Point (GSSP) is located in the Kef section in Tunisia, and is defined at the base of the so-called boundary clay, which includes a thin (red) clay layer rich in Ir, spherules, and shocked quartz. This decision of the KT working group of the International Commission of Stratigraphy has formally been ratified by IUGS [5]. The KT boundary in Kef is at a sharp lithologic discontinuity, between hemipelagic Upper Cretaceous marls and a clay layer. The discontinuity coincides with an abrupt decrease in abundance of planktic foraminifera and a relative increase of survivor species (e.g., G. cretacea). The KT boundary is, however, not coincident with the first appearance of new Paleocene species. These appear between 10 and $25 \mathrm{~cm}$ (representing $>5000 \mathrm{yr}$ ) higher up in the section, at the transition of the so-called boundary clay and hemipelagic marl. This clay interval is also coincident with the P0 zone, a biozone that is defined [6] as the zone between the mass disappearance of Cretaceous foraminifera and the first appearance of new Paleocene species. Subsequent redefinition [7] of $\mathrm{PO}$, including first appearance of $G$. fringa, $G$. minutula ( $G$. conusa) in an upper POb zone, further confuses the stratigraphy, and should be rejected.

Correlation of KT boundary strata from Kef to the Gulf coast can be problematic, when the sedimentology of the KT (clastic) beds is not correctly interpreted. Biostratigraphic correlation is also hampered by the frequent use of relative abundance plots. These plots do not discriminate between in situ and reworked species if they are

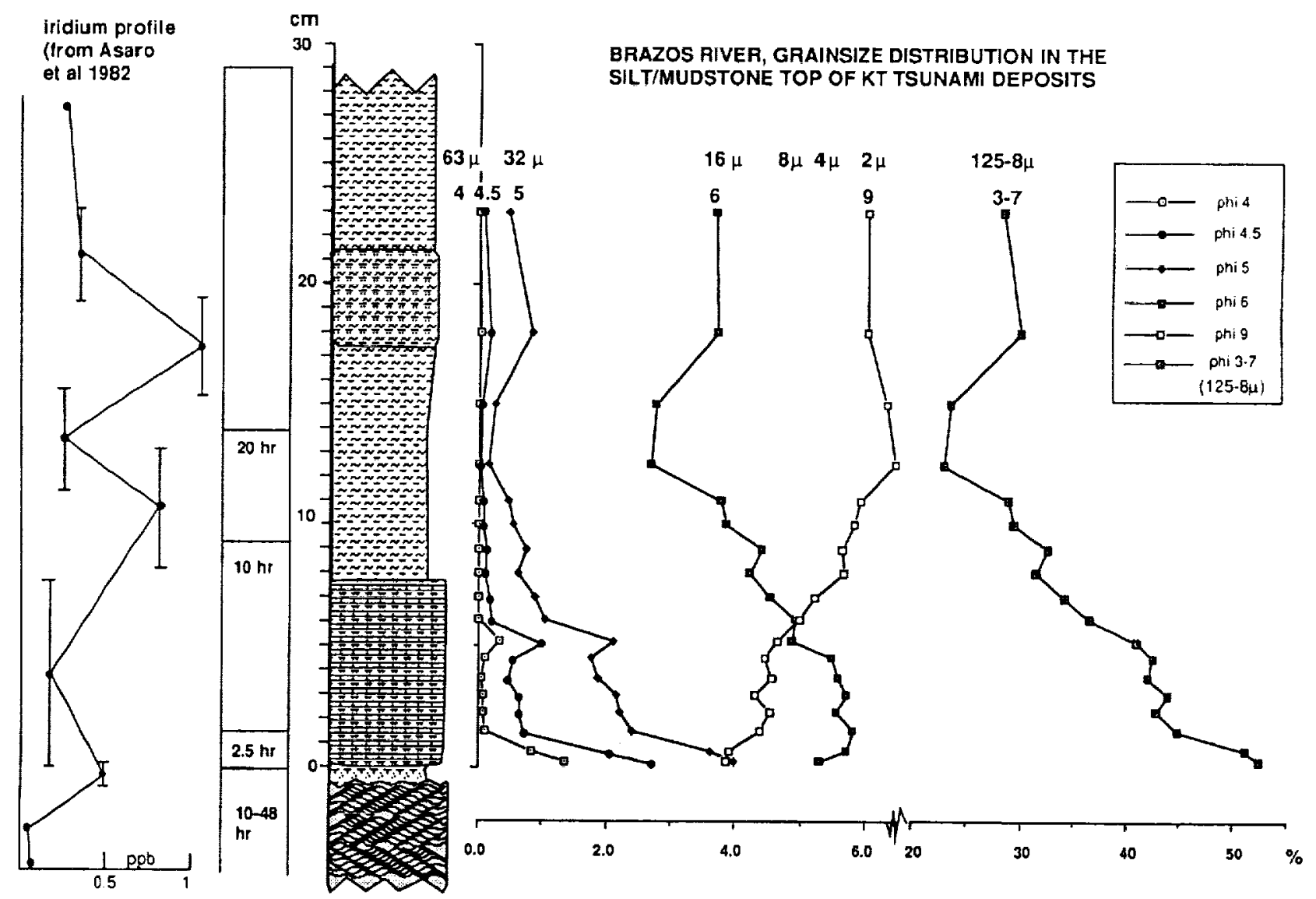

Fig. 1. 
TABLE 1. Settling of tsunami mudstone tail at Brazos, computed for different thicknesses of suspension cloud layer.

\begin{tabular}{|c|c|c|c|c|c|c|c|c|c|}
\hline $\begin{array}{l}\text { Grain } \\
\text { phi }\end{array}$ & $\begin{array}{l}\text { Size } \\
\mu\end{array}$ & $\begin{array}{l}\text { Settling } \\
\text { Velocity } \\
\mathrm{cm} / \mathrm{s}\end{array}$ & $\begin{array}{c}\text { Settling } \\
\text { Velocity } \\
\mathrm{m} / \mathrm{hr}\end{array}$ & $\begin{array}{c}2 \mathrm{~m} \\
\text { Time }(\mathrm{hr})\end{array}$ & $\begin{array}{c}5 \mathrm{~m} \\
\text { Time (hr) }\end{array}$ & $\begin{array}{c}10 \mathrm{~m} \\
\text { Time (hr) }\end{array}$ & $\begin{array}{c}25 \mathrm{~m} \\
\text { Time (hr) }\end{array}$ & $\begin{array}{c}50 \mathrm{~m} \\
\text { Time }(\mathrm{hr})\end{array}$ & $\begin{array}{c}500 \mathrm{~m} \\
\text { Time (hr) }\end{array}$ \\
\hline 3 & 125 & 1.6 & 57.60 & 0.03 & 0.09 & 0.17 & 0.43 & 0.87 & 8.68 \\
\hline 4 & 64 & 0.53 & 19.08 & 0.10 & 0.26 & 0.52 & 1.31 & 2.62 & 26.21 \\
\hline 4.5 & 40 & 0.1 & 3.60 & 0.56 & 1.39 & 2.78 & 6.94 & 13.89 & 138.89 \\
\hline 5 & 32 & 0.07 & 2.52 & 0.79 & 1.98 & 3.97 & 9.92 & 19.84 & 198.41 \\
\hline 6 & 16 & 0.017 & 0.61 & 3.27 & 8.17 & 16.34 & 40.85 & 81.70 & 816.99 \\
\hline 7 & 8 & 0.005 & 0.18 & 11.11 & 27.78 & 55.56 & 138.89 & 277.78 & 2777.78 \\
\hline
\end{tabular}

not corrected (normalized) for the abundance of foraminifera and sedimentation rates [3]. These plots create the illusion of large-scale survivorship, the illusion of thriving planktic populations surviving the KT event, while in reality planktic populations decrease by orders of magnitude. Correlation can also be achieved by means of using the Ir anomaly, spherules, and shocked quartz, all three present in both the Kef and the Gulf coast KT sections. The red layer in Kef (and elsewhere) is easiest to explain as the distal ejecta of a large impact event (presumably Chicxulub). Using this assumption, everything in the red clay should be equivalent to entire ejecta sequences in Gulf coast sections, including the basal tektites in the clastic beds, which have been found now in all the $\mathrm{KT}$ sections around the Gulf coast (Moscow Landing, Snow Creek, and Lynn Creek in Alabama, Darting Minnows Creek [8] in Brazos, and all the clastic bed sequences in Mexico, including the new KT section in La Ceiba, near Poza Rica). Because the KT boundary is defined below the ejecta sequence in Kef, it should be defined below the ejecta-rich clastic beds in the Gulf coast.

The Brazos River sections illustrate this dilemma best because there is abundant literature on these sections. Sometimes the KT boundary is placed above, and sometimes at the base of the clastic beds. Recently, we found abundant tektitelike spherules in the basal coarse-grained channels of the clastic beds in the Darting Minnows Creek outcrop, which also contains glauconite and shell hash. The coarse basal channels grade into fine sandstone with climbing ripples (not wave ripples) with bidirectional current indications. The grading may repeat $2-3 \times$. At Brazos and in all other Gulf coast clastic $K T$ beds these sequences were deposited in one sedimentary event, estimated to last between several hours to a few days. The top sandstone ripples are overlain by $2 \mathrm{~cm}$ silt, $8 \mathrm{~cm}$ limestone, and $20 \mathrm{~cm}$ mudstone respectively. The first new Paleocene biota appear at the top of the mudstone. We have analyzed the grain-size distribution of the insoluble residue of the lime-mudstone interval with a Fritsch A-22 high-resolution laser particle sizer, and the gradual grain-size decrease (Fig. 1) clearly shows that the lime-mudstone is the result of settling out of silt and clay from a thick suspension cloud, apparently settling together with the Ir from the vaporized bolide. Assuming a suspension cloud thickness (Table 1 ) of $50 \mathrm{~m}$, this means that the first $20 \mathrm{~cm}$ of the mudstone has been deposited in a few days at most, and the remainder presumably in a few weeks. The clastic bed and graded mudstone top belong to one sedimentary event, lasting between one and four days. This duration is compatible with tsunami wave travel times from Chicxulub Crater to Gulf coast outcrops $(C=\sqrt{g} \times$ depth, or $=3.13 \times 3000 \mathrm{~m}$, or $\sim 600 \mathrm{~km} / \mathrm{hr})$ and, including refraction and reflection, leading to estimates from one to a few days for the duration of tsunami-wave and seiche activity in the Gulf. Estimates of prolonged deposition [2] of the clastic beds of Gulf coast KT outcrops are based on the assumption of hemipelagic beds within the clastic deposits and burrowing in the clastic beds. However, thin sections show that these so-called hemipelagic beds are extremely silty/fine sandy, and fundamentally differ from Mendez shales below and Velasco shales above the clastic bed. Another argument [2] for prolonged deposition is the occurrence of burrows. The Penon (Mexico) outcrop shows that the burrows postdate the deposition of the latest rippled sandstone. All foraminifera in the clastic beds and mudstone tail are necessarily reworked and cannot be used for biostrigraphic analysis. However, in the first demonstrably hemipelagic strata above the clastic beds, the abundance of Cretaceous foraminifera has already sharply decreased, testifying to the direct relationship between the Chicxulub impact and the extinctions at the KT boundary.

References: [1] Keller G. et al. (1993) Geology, 21, 776-780. [2] Stinnesbeck W. et al. (1993) Geology, 21, 797-300. [3] Keller G. (1989) GSA Bull., 101, 1408-1419. [4] Olsson R. K. and Liu C. (1993) Palaios. [5] Cowie J. W. et al. (1989) Episodes, 112, 79-83. [6] Smit J. (1982) GSA Spec. Paper 190, 329-352. [7] Keller G. (1988) Marine Micropaleoniol., 13, 239-263. [8] Bourgeois J. et al. (1988) Science, 24I, 567-570.

IMPACT-TSUNAMI-GENERATED CLASTIC BEDS AT THE KT BOUNDARY OF THE GULF COASTAL PLAIN: A SYNTHESIS OF OLD AND NEW OUTCROPS. J. Smit ${ }^{4}$, Th. B. Roep ${ }^{1}$, W. Alvarez ${ }^{2}$, P. Claeys ${ }^{2}$, S. Montanari ${ }^{3}$, and M. Grajales ${ }^{4}$, 'Institute of Earth Sciences, Vrije Universiteit, de Boelelaan 1085, 1081 HV Amsterdam, Netherlands, 'Department of Geology and Geophysics, University of California, Berkeley CA 94720, USA, ${ }^{3}$ Osservatorio Geologico, Coldigoco, Apiro di Frontale, Umbria Italy, ${ }^{4}$ Institute Mexicano del Petroleo, Apartado Postal 14 805, 07730 Mexico.

The KT boundary is marked in Gulf coastal plain outcrops, from Alabama to Guatamala [1], by unusual clastic deposits. These clastic deposits are interpreted as tsunami deposits [2-4] probably generated by the Chicxulub impact. These beds have also been interpreted as storm beds, lowstand sands [5], and turbidite or debris flows [6]. Sedimentologic analysis of the clastic beds at Moscow Landing, Alabama, Brazos, Texas, and Los Ramones, Rancho Nuevo, Sierrita-Las Rusias, Penon, Porvenir, MulatoBruselas, La Lajilla, Mesa de Llera, Mimbral, La Ceiba, and possibly Bochil, all in eastern Mexico, show that the buildup of the 
clastic beds follows a consistent pattem, well recognizable all over the Gulf, but modified by local variables, such as waterdepth, distance from shoreline, and eustatic sealevel changes. In all oulcrops, we can discem four distinct, successive, energy-decreasing sedimentary units, each representing a successive phase in the course of the tsunami activity in the Gulf of Mexico.

The basal unit 1 consists of shallow channels, filled laterally with bubbly spherules, all similar to the spherules containing impact glass in Mimbral and Lajilla and in Beloc (Haiti). New localities with bubbly tektitelike spherules are in Darting Minnows Creek [2], Moscow Landing (Alabama), and La Ceiba, Poza Rica (Mexico). Preliminary analysis did not yield glass from these spherules. Those localities also contain similarly sized platform limestone clasts. These were first found in Mimbral, and are not locally derived material, but are non- or partially molten ejecta. $A^{87} \mathrm{Sr} /{ }^{86} \mathrm{Sr}$ ratio of $0.707502 \pm 0.000008$ (K. Beets, personal communication) of the limestone clasts is compatible with a Campanian age of these clasts. The ejecta are mixed with locally derived material from the seafloor, such as soft upper Cretaceous chalk and marl clasts, fossils, and washed-out foraminifera. The unit 1 sediments are relatively poor in detrital sand, in comparison with the overlying units [2-4]. Commonly (Moscow Landing, Ramones, Rancho Nuevo, Sierrita, Mimbral), due to the weight of the channel-filling, the channels themselves sink down into the soft chalky and marly oozes of the seafloor, pushing oozes away from the channel centers to the edges, where they form "mud diapirs." Diapirism continues also during the fill of unit 2 channels, showing that diagenetic lithification of cerain beds in unit 1 postdates the deposition of the clastic beds. Possibly preceding, and continuing through, the deposition of unit 1 are slumping and sliding movements, probably induced by seismic waves arriving from the impact site. These slides are observed in outcrop in Moscow Landing (Alabama), but in Guatamala large slides must also have occurred, as the carbonate platform limestones underlying the clastic beds are followed in the earliest Danian P0 and Pla zones by pelagic deposits [I]. The loading of unit 1 or the seismic shaking also causes "injections" of spherule-rich material down into the soft Mendez oozes (Lajilla, Sierrita, Mimbral). Paleocurrent direction measurements are seldom possible, but in Mimbral we observe lateral infilling of different channels from different directions.

Unit 2 overlies unit 1 channels with a sharp contact, which mark a transition to detrital-rich sands, often mixed with water-saturated wood fragments. At Mimbral (Fig. I) we observe at least six successive channels in unit 2 , each with a coarse basal part scouring in the top of the preceding channel. The coarse layers of all these channels contain tektitelike spherules, obviously reworked from unit 1 channels. Preliminary sediment petrologic analysis shows interesting differences between the unit $\mathbf{2}$ channels, not obvious in the outcrop. The upper channels are better washed out (contain less mud) than the basal ones. Overall, unit 2 is grading upward, with coarse rounded and armoured clayballs mainly at the base. Burrows do not occur in any of the unit 1 and 2 sedimentary layers, which might have indicated an extended amount of time between the sediment layers. Sedimentary structures are of a wide variety, owing to the variations in current strength and suspension load in different localities. The most conspicuous structures are parallel laminations with primary current lineation, climbing ripples, and small-scale trough cross bedding. Note that unequivocal wave ripples have not been observed in any of the outcrops and that all cross bedding is caused by currents.

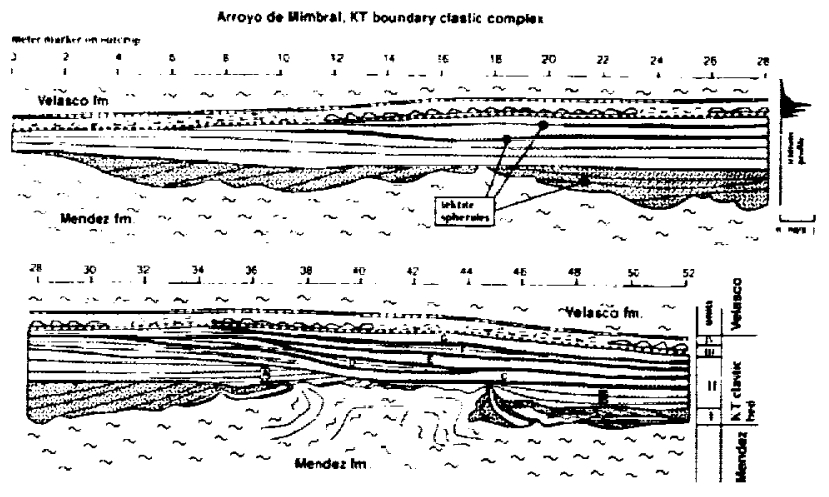

Fig. 1. Mimbral, Mexico. Simplified cross section through the outcrop. showing the different channellized units. Iridium abundances from [3]. The soft Mendez oozes were squeezed away by loading of the unit I channels into diapiric structures between the channels. The top ripples are more continuous than the lower channels and drape over every outcrop in eastem Mexico, even at:those sites where the lower two units are not deposited, like at the Mesa de Llera, $30 \mathrm{~km}$ northwest of Mimbral. These ripples could be due lo contour currents generated by the developing seiche in the Gulf of Mexico.

Unit 2 sedimentary structures in almost all sections contain a wealth of indications for paleocurrent directions, but most were found in the Lajilla section (Fig. 2). Current directions were measured on flutecasts, ripple migration, primary current lineations, and three-dimensional analysis of crossbedding forests. The measured current directions are bidirectional, different by $180^{\circ}$; interestingly, those directions point toward and away from Chicxulub. The currents switch direction at least 12 times in ascending order in Lajilla, showing at least 6 passages of giant waves. The Brazos River, Ramones, Rancho Nuevo, Penon, Mulato, Mimbral, and La Ceiba outcrops also show these opposite current directions in unit 2 , demonstrating that this is not a local phenomenon, but a common characteristic of the KT clastic beds, invalidating a mass-flow or turbidite origin.

Unit 3 rests conformably on unit 2 at the first thin laterally continuous silt layer. Several of such silt layers are intercalated in between fine sandstone ripples. The fine sandstone ripples decrease in thickness, while the silt layers increase in thickness upsection. The first silt layer is also the first with significant Ir enrichment and is an indication that more time (minutes to hours) becomes available for settling of fine sediment in between the amival of weakening tsunami or seiche waves. Burrows abound in the topmost sandstone layer and some can be observed to penetrate into lower silt layers. At Penon, spectacular unknown burrow structures can be observed, penetrating up $1060 \mathrm{~cm}$ down into unit 3 and then spreading radially in dichotomizing $1-\mathrm{cm}$ tubes of over $2 \mathrm{~m}$ length. All the bioturbation demonstrably postdates the deposition of the unit 3 sandstone ripples. The last unit 3 sandstone flaserbeds are often only a few millimeters thick.

The top unit 4 consists of micritic limestone and mudstone, seemingly homogeneous in outcrop, but showing a gradual decrease in grain size. The mudstone is interpreted as the settling out of the suspension cloud in seawater, stirred up by the passing tsunami waves. Iridium abundances are still high and multipeaked in this interval, and thus apparently the fine-grained Ir carrier simultaneously settled out from the atmosphere and seawater column. The transition from unit 4 to the overlying hemipelagic oozes is often 


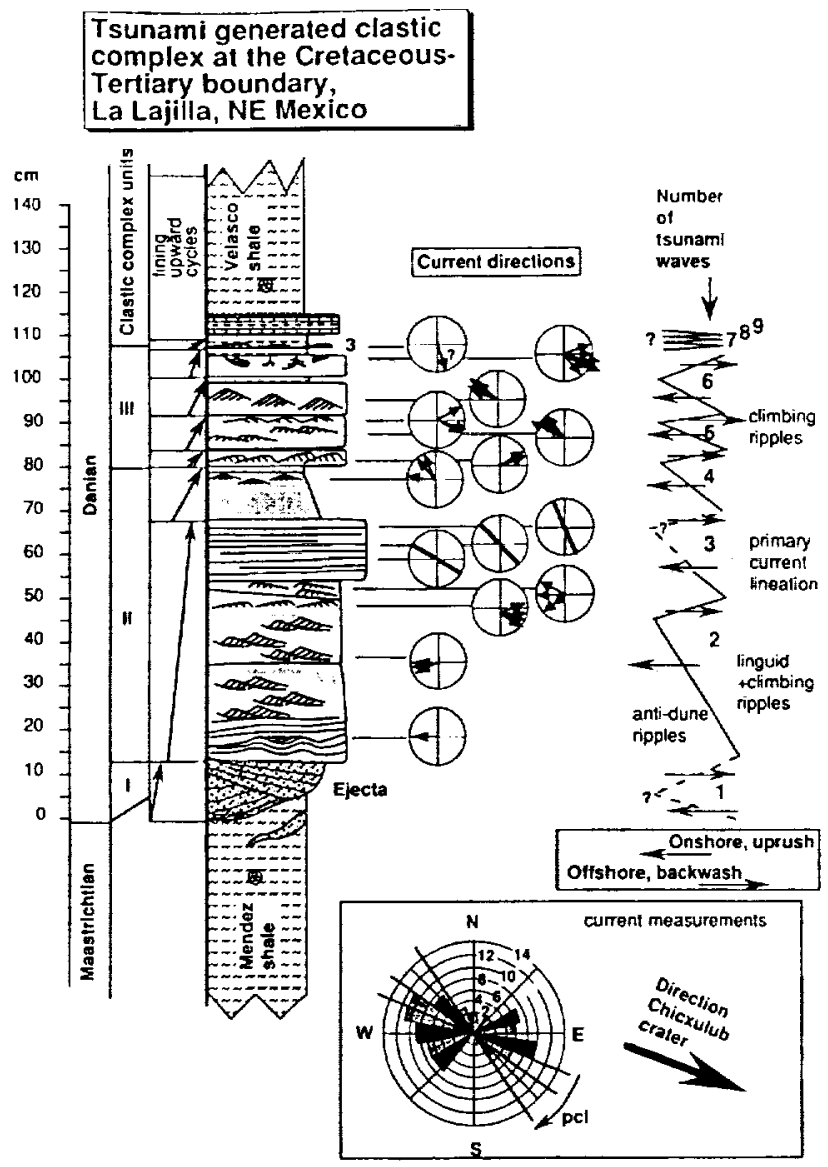

Fig. 2. La Lajilla, Mexico, $40 \mathrm{~km}$ east of Ciudad Victoria. Measured paleocurrent directions contain two dominant $180^{\circ}$ different directions: one toward and one away from the Chicxulub Crater. Those two directions alternate successively stratigraphically upward, showing both up-surge and backwash surges of at least six individual tsunami waves.

imperceptible in the field, but varies from $9 \mathrm{~cm}$ at Mimbral to $25 \mathrm{~cm}$ at Brazos River. The rich foraminiferal faunas of the Cretaceous have then already disappeared in all sections, showing the immediate response of the biosphere to the consequences of the Chicxulub impact. Maybe these are not the final extinctions, but at least there is the initial dramatic reduction of foraminiferal populations.

Nature has played a number of postdepositional tricks on the clastic deposits, often obscuring our view on the KT events. Weathering of spherules to smectite and of fine sandstone laminae to clay or zeolites has led to ambiguous interpretations. In a number of outcrops in the U.S., where the depositional depth of KT deposits is much less than in Mexico, an early Danian sea-level fall has often removed evidence of the tsunami deposits (Littig Pit and Walker Creek, Texas; Braggs, Alabama). The lowstand deposits may superficially resemble the tsunami deposits, because at the lowstand the backwash sands of the tsunami waves are re-reworked into the lowstand and succeeding transgressive sands. Clastic KT deposits in sections like Brazos River and Moscow Landing barely survived the sea-level fall, and in Moscow Landing units 3 and 4 are stripped off. At even shallower depths (above wavebase) like in the La Popa Basin in northeastern Mexico, where subsidence apparently keeps up with the sea-level drop, all tsunami-wave deposits have been destroyed and are incorporated in normal sediments with hummocky cross bedding and other wave-ripple structures.

In conclusion analysis of the KT clastic beds in Gulf coastal plains shows that the entire complex of clastic beds has been deposited in one pulsating event, lasting for several days. Deposition by a series of giant tsunami or seiche waves is the most likely explanation, and that hypothesis has been confimed by the bidirectional paleocurrent directions and variable current strengths.

References: [1] Hildebrand A. R. et al. (1991) Geology, 19, 867-871. [2] Bourgeois J. et al. (1988) Science, 241, 567-570. [3] Smit J. et al. (1992) Geology, 20, 99-103. [4] Smit J. and Romein A. J. T. (1985) EPSL, 74, 155-170. [5] Mancini E. A. et al. (1989) J. Res., 19, 93-104. [6] Stinnesbeck W. et al. (1993) Geology, 2I, 797-300.

STRATIGRAPHY AND SEDIMENTOLOGY OF KT CLAS. TIC BEDS IN THE MOSCOW LANDING (ALABAMA) OUTCROP: EVIDENCE FOR IMPACT-RELATEDEARTHQUAKES AND TSUNAMIS. J.Smit ${ }^{1}$, Th. B. Roep ${ }^{1}$, W. Alvarez ${ }^{2}$, S. Montanari ${ }^{3}$, and P. Claeys ${ }^{2}$, 'Institute of Earth Sciences, Vrije Universiteit, de Boelelaan 1085, 1081 HV Amsterdam, Netherlands, ${ }^{2}$ Department of Geology and Geophysics, University of Califomia, Berkeley CA 94720, USA, ${ }^{3}$ Osservatorio Geologico, Coldigoco, Apiro di Frontale, Umbria, Italy.

Around the Gulf of Mexico, over $>2500 \mathrm{~km}$ from Alabama to Guatamala, the KT boundary is marked by highly unusual clastic beds. These beds have earlier been interpreted as tsunami-generated deposits [1,2], storm deposits, turbidites and debris flows [3], fluvial conglomerates, or sea-level low-stand deposits [4].

Sedimentologic analysis of the clastic beds at Moscow Landing, Alabama, Brazos, Texas, and Los Ramones, Rancho Nuevo, SierritaLas Rusias, Penon, Porvenir, Mulato-Bruselas, La Lajilla, Mesa de Llera, Mimbral, La Ceiba, and possibly Bochil, all in eastem Mexico, shows that the buildup of the clastic beds follows a consistent pattern, well recognizable all over the Gulf, but modified by local variables, such as water depth, distance from shoreline, and eustatic sea-level changes. The depositional pattern comprises a first unit 1, consisting of ejecta reworked with local material in shallow channels, which usually sink down into the soft seafloor. Unit 2 is an upward-grading complex series of pulses of coarse sands, containing distinctly more quartz sand, repeatedly backwashed from nearshore areas. Unit 3 consists of fine sandstone ripples, altemating with fine silts, grading into a siltstone/mudstone top (unit 4). The grain-size decrease in the top mudstone [2] at Brazos River, containing the Ir-rich dust, shows that the settling of the mudstone on the seafloor takes a few hours to days, depending on the assumed thickness of the suspension cloud.

The easternmost outcrop studied is Moscow Landing, Alabama. The KT clastic beds here are known as Clayton basal sands and interpreted [4] as early Danian lowstand channel deposits, topped by a transgressive surface in sequence stratigraphy terms, as evidenced by a bored hardground. However, the situation is clearly more complex. In some sections the transgressive surface erodes down to the Cretaceous Praitie bluff chalk (Braggs). It is possible that a few lowstand channels are preserved (Mussel Creek) and filled with Clayton sands but most of the basal Clayton channels should be reinterpreted as tsunami-generated deposits, preceding 
the early Danian lowstand, because of the presence of altered tektites identical to the tektites at other Gulfcoast KT sections. The Moscow Landing outcrops combine all three (near) KT phenomena. Over most of the outcrop, the bored transgressive surface lies disconformably on the Prairie bluff chalk. We interpret most "channels" (actually triangular wedges) to be filled with tsunami-generated deposits. (Fig, I). Large blocks $(>800 \mathrm{~m}$ ) of the Prairie Bluff chalk bounded by small faults are tilted to the south. However, most of these faults do not offset the early Danian transgressive surface. The top of the Prairie Bluff chalk is liquified and slumped but only near the faults. The fault movements also plastically deform bedding planes of the basalmost Clayton sediments thus before they were lithified. In some of the faults Clayton sands have been injected. A second coarse (backwash) infilling cuts the tilted bedding planes.

Thus fault movements (listric faulting) just precede and continue through deposition of the basal pan of the clastic beds. Initially, a triangular seafloor depression is created by the listric faulting on the downthrown side (the southern end) of the tilted blocks. The first sediment to fill the depression is a conglomeratic mixture of locally derived chalk clasts, shells from the seafloor, tektite like spherules, and relatively little coarse sand. These con-

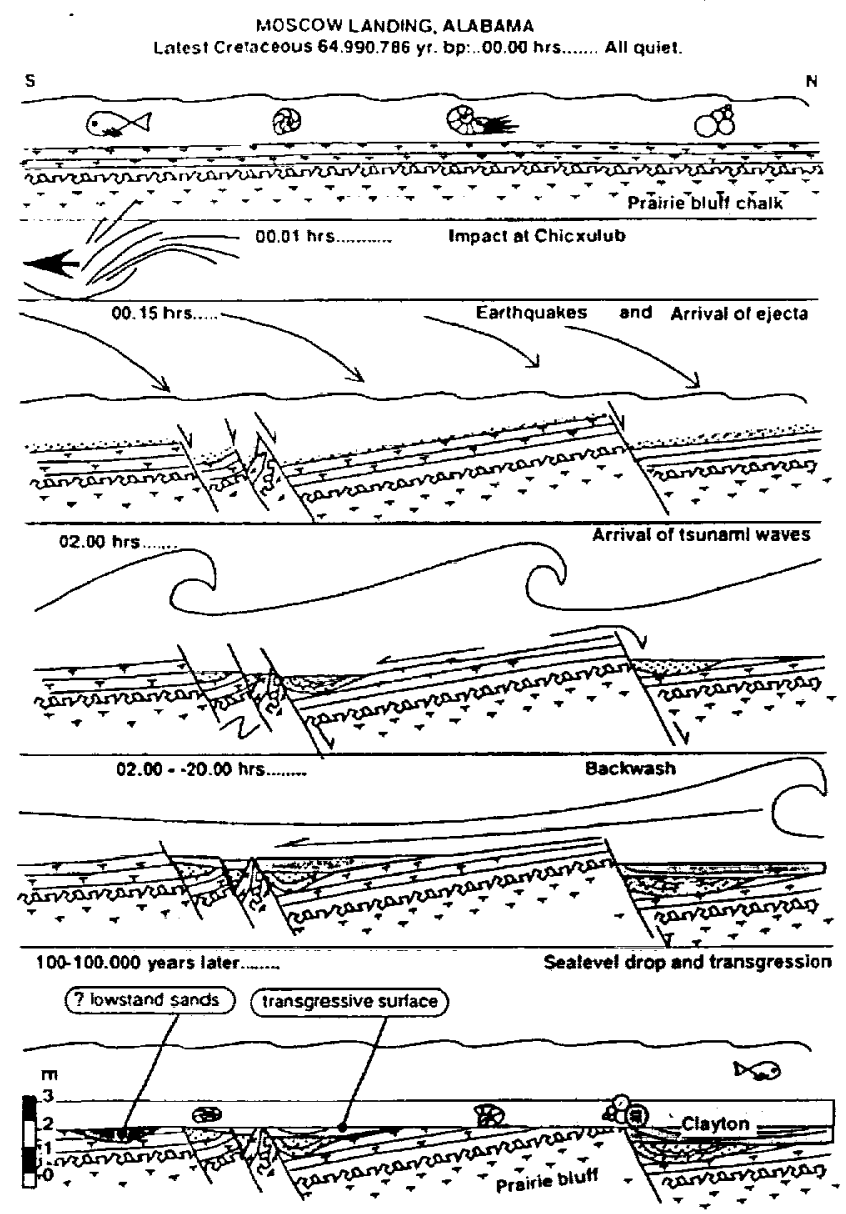

Fig. 1. Interpretation of sequence of events at KT boundary time at Moscow Landing, A labama. The wrinkled line is a phosphatic hardground, $1-2 \mathrm{mbelow}$ the KT boundary, that has not been liquified. Vertical depthexaggerated. Depth of sea not to scale. glomerates sink down into the soft seafloor oozes. We interpret these basal sequences in the light of the arrival of impact-induced seismic waves causing sliding and slumping (like in Guatamala) and simultaneous (or shortly followed by) arrival of ejecta. A few hours later the first tsunami waves arrive, eroding the seafloor and reworking the ejecta and fossils from the seafloor into the triangular depressions (unit 1). The next sediments to arrive are pulses of fossiliferous conglomeratic and coarse sands, still deformed near the faults. Similar sand pulses continue and erode the (oversteepened) first sands. These (unit 2) conglomeratic sands are probably backwashed from near-shore areas and we think it even possible that all the sands from the basal Clayton are repeatedly reworked backwash sands.

At Moscow Landing the finer clastic topbeds (units 3-4), as known from Brazos River and Mexico, are lacking due to truncation by the bored transgressive surface with the first Danian fossils. This transgressive surface erodes and truncates the Prairie Bluff chalks, the faults, and the above (units land 2) sequences in the channels. A few symmetric channels may belong to the lowstand phase preceding the transgressive surface. This awaits biostratigraphic testing because they might contain Danian fossils, while tsunamigenerated sediment should contain exclusively reworked Cretaceous biota.

References: [1] Smit J. and Romein A. J. T. (1985) EPSL, 74, 155-170. [2] Bourgeois et al. (1988) Science, 24I, 567-570. [3] Stinnesbeck W. et al. (1993) Geology, 21, 797-300. [4] Mancini E. A. et al. (1989) J. Foram. Res., 19, 93-104.

\section{KT BOUNDARY SECTIONS IN SOUTHERN MEXICO (CHIAPAS): IMPLICATIONS FOR THE PROPOSED} CHICXULUB IMPACT SITE. W. Stinnesbeck', T. Adatte? and G. Keller ${ }^{3}$, 'Facultad de Ciencias de la Tierra, Universidad Autonoma de Nuevo Leon, Ap. Postal 104, 67700 Linares, Nuevo Leon, Mexico, 2Institute Geologie, 11 rue Emile Argand, 2007 Neuchâtel, Switzerland, ${ }^{3}$ Department of Geological and Geophysical Sciences, Princeton University, Princeton NJ 08544, USA.

It has been proposed that the circular gravity structure in the subsurface of Yucatan, Mexico, represents the crater of the KT boundary bolide impact. We studied the nearby surface exposures of Bochil and Chilil in the Mexican state of Chiapas in order to search for evidence, such as impact ejecta or exotic sedimentation, that would support the proposed Yucatan impact scenario.

The Chilil section is located $20 \mathrm{~km}$ northeast of San Cristobal de las Casas and represents a transition between the Angostura Formation of Late Cretaceous age and the Soyalo Formation of the Paleocene. The Angostura Formation consists of thin- to medium-bedded bioclastic limestones with corals, echinoderms, large benthic foraminifera, and rudists. This sequence is capped by $15 \mathrm{~cm}$ of bioturbated marly limestones with abundant early late Maastrichtian (G. gansseri zone) plankic foraminifera. Crusts and nodules of $\mathrm{Fe}$ and $\mathrm{Mn}$ oxides characterize the lithological contact to the overlying rhythmically bedded pelagic marls and shales of the Soyalo Formation, which contains abundant Late Paleocene (zone P2) foraminifera. Thus, both the lithology and fossil assemblages indicate an extended hiatus spanning the Upper Maastrichtian, the KT boundary, and the Lower Paleocene. This also appears to be the case in the $\mathrm{KT}$ boundary sections of the Peten area in nearby Guatemala where platform limestones with rudists discontinuously underlie flysch- 
like sediments of the Paleocene. Moreover, similar sedimentation and hiatus pattems are observed in deep sea sections throughout the Caribbean and Gulf of Mexico [1].

The Bochil section is located $30 \mathrm{~km}$ northeast of Tuxtla Gutierrez and seems to present a record of the $\mathrm{KT}$ boundary that is more complete. In this area, flysch deposition of the Xochitlan Formation began in the Late Campanian and continued into the Lower Tertiary, with many hundreds of meters of rhythmically bedded shales, silts, and sandstones. Debris flows of well-rounded conglomerates of possibly fluviatile origin are intercalated in the lower part of the sequence and indicate uplifting of the Chiapas Block and erosion. Up-section occurrences of thick breccia beds of platform carbonates and isolated olistolithic limestone blocks suggest further tilting and collapse of the nearby carbonate platforms. This "wildflysch" type of sedimentation persists during most of the Maastrichtian and Paleocene. Across the KT boundary, we observed no lithological or sedimentological changes, other than this "wildflysch" sedimentation, and no proximal impact ejecta or other exotics.

Our field investigations of KT boundary sections in southem Mexico have so far revealed no evidence of a tsunami deposit or proximal impact ejecta related to the proposed bolide impact on nearby Yucatan. Investigation of KT boundary age deep-sea cores in the Caribbean and Gulf of Mexico has also yielded no evidence of impact-derived sediments [1]. Although such sediments have been earlier interpreted to be present in DSDP sites 536 and 540 [2], these sites were subsequently found to contain a hiatus spanning from the Lower Danian ( $P$. engubina zone) through the Upper Maastrichtian [1]. A KT boundary hiatus spanning from the Danian through the Upper Maastrichtian appears to be present throughout the Caribbean and Gulf of Mexico and is probably related to the latest Maastrichtian sea-level lowstand and subsequent sediment starvation during rising sea levels. The absence of KT boundary age deposits in deep-sea sections in general [3] and in the Caribbean region in particular [1] imdicates that the search for $\mathrm{KT}$ complete sections should continue in shallow marine deposits.

References: [1] Keller G. et al. (1993) Geology, 21, 776-780. [2] Alvarez W. et al. (1992) Geology, 20,679-700. [3] MacLeod N. and Keller G. (1991) Geology, 19, 497-50I.

KT BOUNDARY DEPOSITS IN NORTHEASTERN MEXICO: BOLIDE IMPACT OR SEA-LEVEL LOWSTAND? W. Stinnesbeck', G. Keller ${ }^{2}$, and T. Adatte ${ }^{3}$, 'Facultad de Ciencias de la Tierra, Universidad Antónoma de Nuevo León, 67700 Linares, Nuevo León, Mexico, 2Department of Geological and Geophysical Sciences, Princeton University, Princelon NJ 08544, USA, ${ }^{3}$ Institute of Geology, University of Neuchâtel, 2007 Neuchâtel, Switzerland.

In northeastem Mexico, channelized clastic deposits of near KT boundary age occur over a distance of $300 \mathrm{~km}$ in a north-northwest south-southeast direction. We report here on the stratigraphy, lithology, and depositional environment of these deposits at El Mimbral, La Lajilla, El Peñon, El Mulato, La Sierrita, La Parida, and Los Ramones, in the Mexican States of Tamaulipas and Nuevo Leon (Fig. 1) in order to evaluate impact-generated tsunami [ 1] vs. nomal deposition during sea-level lowstands [2].

In all sections examined, the clastic member discontinuously truncates the Maastrichtian Mendez. Formation, which consists of rhythmically bedded sandstones, shales, marls, and marly limestones. Foraminiferal assemblages suggest that sediment deposi-

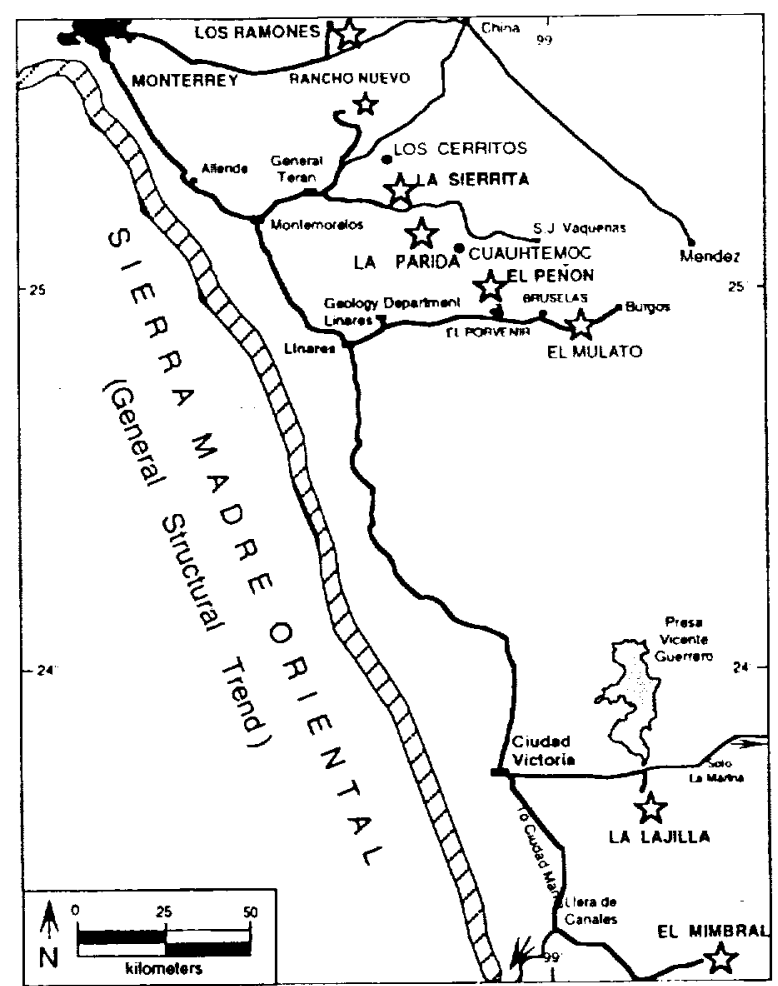

Fig. 1. Location map of near-KT boundary clastic depasits in norheastern Mexico.

tion occurred in upper slope to outer neritic environments during the late Maastrichtian. This is indicated by the presence of planktic foraminiferal assemblages characteristic of the $A$. mayaroensis zone, including the index taxon, in the Mendez Formation. as well as throughout the clastic deposit [1-3]. A thin layer of Maastrichtian marl containing the $A$. mayaroensis-zone fauna also caps the clastic deposit at El Mulato and La Lajilla [4]. This also indicates that deposition of this clastic member occurred during the latest Maastrichtian. The first Tertiary planktic foraminifera are present in the shales and marls directly overlying the clastic deposit at Mimbral [1-3] and La Parida or overlying the thin Maastrichtian marl layer at La Lajilla and El Mulato [4]. In all sections examined, except El Mimbral, this fauna belongs to the early Paleocene Pla $(P$. eugubina) zone. At El Mimbral the basal Tertiary zone P0 is present in a 4-cm clay layer at the edge of the clastic channel deposit [3].

We have subdivided the end-Maastrichtian channel fills of northeastern Mexico into three units, which are defined by lithology, sedimentology, and mineralogy [2,5].

Unit 1-Spherule-rich Layer: The basal unit 1 is characterized by abundant poorly cemented calcareous spherules, chlorite, quartz, and glauconite. Glauconite commonly fills chambers of foraminifera. A well cemented discrete sandy limestone layer (SLL) with convolute surface is present within this unit and contains only few graded spherules (El Mimbral, outcrop I and El Peñon, outcrop I) (Fig. 2). At El Mimbral the convolute laminated bedding surface of this limestone is draped by the overlying spherule-rich sediments. Moreover, the SLL is in contact locally with the overlying massive sanstone of unit 2 (outcrop near meter mark 36), which also drapes around it. This suggests that the SLL was at least semilithified prior 


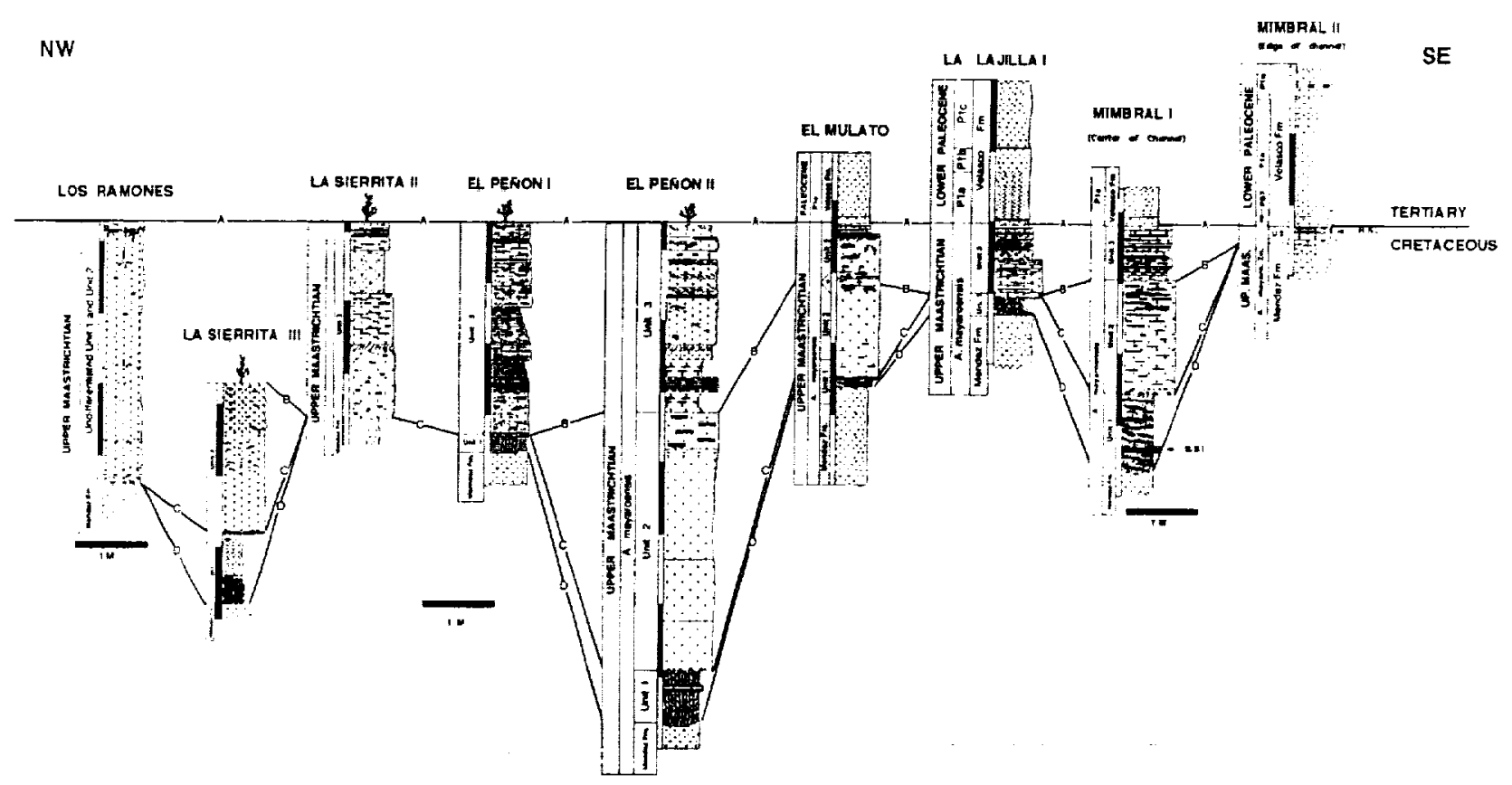

Fig. 2. Lithostratigraphic correlation of clastic near-KT boundary channel-filldeposits of northeastem Mexico.

to Iater deposition. At La Lajilla and El Penon II this SLL is at the top of unit I due to an erosional disconformity. The spherules of unit I are of multiple origins including organic, volcanic, and oolitic. They are transported from shallow neritic environments, as also indicated by the common presence of benthic foraminifera and glauconite. No glassy spherules have been observed and glass fragments are extremely rare. They are similar in composition to those of Beloc, Haiti, which have been variously interpreted as of impact or volcanic origins [1,2,7-9].

Unit 2-Massive Sandstone: This unit consists of a massive, commonly laminated sandstone with mudclasts at its base. At Mimbral, distinct layers of wood and leaf debris are present near the bottom of this unit. If deposition occurred in a few hours to days, this plant debris could not have settled in distinct layers at the base of unit 2 prior to deposition of coarse sands.

Unit 3-Interlayered Sand-Silt Beds: Unit 3 consists of interlayered sand, shale, and siltstone beds with diverse sedimentological features such as horizontal laminations, ripple marks, small scale cross-bedding, flaser bedding, and convolute lamination. Thin layers with nornal hemipelagic sedimentation and distinct layers containing zeolites [5] were detected within this unit. It is generally topped by resistant rippled sandy limestone (RSL) layers containing bioturbation, most commonly Chondrites, Zoophycos, and $\mathrm{Y}$-shaped Thalassinoides burrow networks.

This three-par depositional sequence is surprisingly constant and allows comelation not only of the three units, but also of individual beds such as the sandy limestone layer of unit 1, the rippled sandy limestone of unit 3 [2] (Fig. 2), or the zeolite-enriched layers of unit 3 [5]. Variable thickness or absence of the three units depends largely on which part of the channel is exposed. Sections are most expanded in the center of the channel where usually all three units are present. Toward the edges, first unit 2 disappears followed by unit 1 and finally unit 3. The RSL at the top of unit 3 is laterally most continuous (Fig. 3 ). We propose that the channelized near-KT-boundary clastic deposits of northeastem Mexico were deposited over an extended time period, rather than hours or days, and by normal sedimentary processes that include gravity flows and turbidity currents, rather than impact-generated tsunami waves. Our interpretation is based on: (1) Lithologically, sedimentologically, and mineralogically distinct units, subunits, and individual zeolite-enriched layers that can be correlated over more than $300 \mathrm{~km}$. Such systematic correlatability is not compatible with a catastrophic event and chaotic sediment deposition. (2) Semilithification of the sandy limestone within the spherule-rich unit I prior to deposition of the upper spherule-rich sediments and prior to the deposition of unit 2 sandstones. (3) Multiple origins of the spherules, including volcanic, organic, and oolitic; these spherules also indicate transport from a shallow neritic environment rich in glauconite. (4) Presence of plant debris in discrete horizons at the base of the sandstone of unit 2 that could not have settled within hours or days and prior to the coarse sand grains of this unit. (5) Discrete layers with hemipelagic foraminifera in unit 3. (6) Bioturbation in unit 3 which is of Maastrichtian and not Teriary origin. Al least part of these benthic communities lived during deposition of the rippled sandy limestone, and burrows are usually infilled with the same sediment. (7) Deposition of the clastic deposit occurred prior to the KT boundary as indicated by the presence of thin marls on top of the sequences in La Lajilla and El Mulato, which contain A. mayaroensiszone foraminifera and no Tertiary elements.

We interprete the channelized clastic beds of northeastern Mexico as fan deposits, which accumulated during the major eustatic sealevel lowstand near the end of the Maastrichtian [10]. In our scenario, the top of the clastic member marks the end of this regressive cycle followed by a sea-level transgression that began a few thou- 


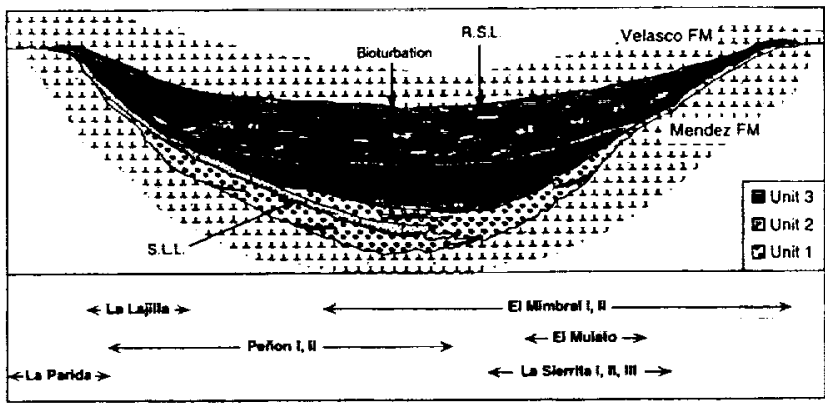

Fig. 3. Sketch of idealized channel deposit showing thinning out of units 1,2 , and 3 toward the edges of the channel. SLL: sandy limestone layer within unit 1; RSL: rippled sandy limestone layer that caps unit 3.

sand years below the KT boundary as indicated by the Maastrichtian bioturbation and subsequent deposition of the thin marl layer present at La Lajilla and El Mulato. In northeastem Mexico as elsewhere, the trans-KT interval is marked by a sea-level transgression, sediment starvation, and a shor hiatus [11,12].

References: [1] Smit J. et al. (1992) Geology, 20, 99-104. [2] Stinnesbeck W. et al. (1993) Geology, 21, 797-800. [3] Keller G. et al. (1994), Palaios, in press . [4] Lopez Oliva J. G. and Keller G., this volume. [5] Adate T. et al., this volume. [6] Bohor B. F. and Betterton W. T. (1993) LPSXXII. [7] Jéhanno C. et al. (1992)EPSL, 109, 229-241. [8] Lyons J. B. and Officer C. B. (1992) EPSL, 109. 205-224. [9] Izett G. A. (1991) JGR, 96, 20879-20905. [10] Haq B. U. et al. (1987) Science, 235, 1156-1166. [11] MacLeod N. and Keller G. (1991) Geology, 19, 497-501. [12] Keller G. et al. (1993) GSA Bull., I05, 979-997.

\section{NORTHERN METEORITIC IMPACTS AND SOUTHERN} VOLCANIC MANTLE PLUMES: THEIR ROLES IN GENERATING SOME DIFFERENTIAL KT BOUNDARY EXTINCTION ENVIRONMENTS. F. L. Sutherland, Division of Earth and Environmental Sciences, The Australian Museum, 68 College Street, Sydney, NSW, 2000, Australia.

The long, vigorous debate [1,2] for impact [3] or volcanic [4] causes in KT extinctions [5] has established both processes as viable events $[6,7]$.

Impact Views: Precise dating links the Chicxulub Crater, Yucatan, with proposed "tektite" deposits in Haiti and Mexico [8,9] and also correlates them with the Manson Crater, U.S.A. [10], and other minor craters [11]. These are considered impact features by most workers, although some prefer volcanic origins [12]. The nature and correlation of glasses [13-18] and proposed tsunami deposits $[19,20]$ from the the Caribbean-Mexico impact are also under debate. Interpretations of KT boundary impact deposits in relation to Chicxulub and Manson events differ $[21,22]$, but favor a Chicxulub link [23]. KT boundary beds vary in global trace-element signatures [24]. The impact school considers a large chondritic (?) impactor accounts for the Ir anomaly [25], high-pressure or hightemperature minerals (shocked quartz [26], stishovite [27], diamond [28], Ni spinels [29]) and extraterrestrial amino acids [30].
Volcanic Views: This school contends that voluminous flood basalt episodes, e.g., Deccan plume [31] and large explosive eruptions [32], explain Ir anomalies, shocked minerals, and boundary clay characters [33]. The Ir argument uses Ir detected in hotspot volcanos, e.g., present Deccan plume site [34], and in volcanic horizons in Antarctic ice [35].

Combined Views: One scenario triggers flood volcanism by meteorite impact [36] (and more specifically at KT time [37]). Another considers impact and volcanism as coincidental but unrelated events [7].

Palaeontological Views: KT mass extinctions caused by impact and/or volcanism also rely on precise palaeontological correlations [38,39]. Northem terrestrial $[40,41]$ and shallow marine [42] palaeobotanical records support some catastrophic KT extinctions. Northern dinosaur records seem sharply truncated, with Teriary

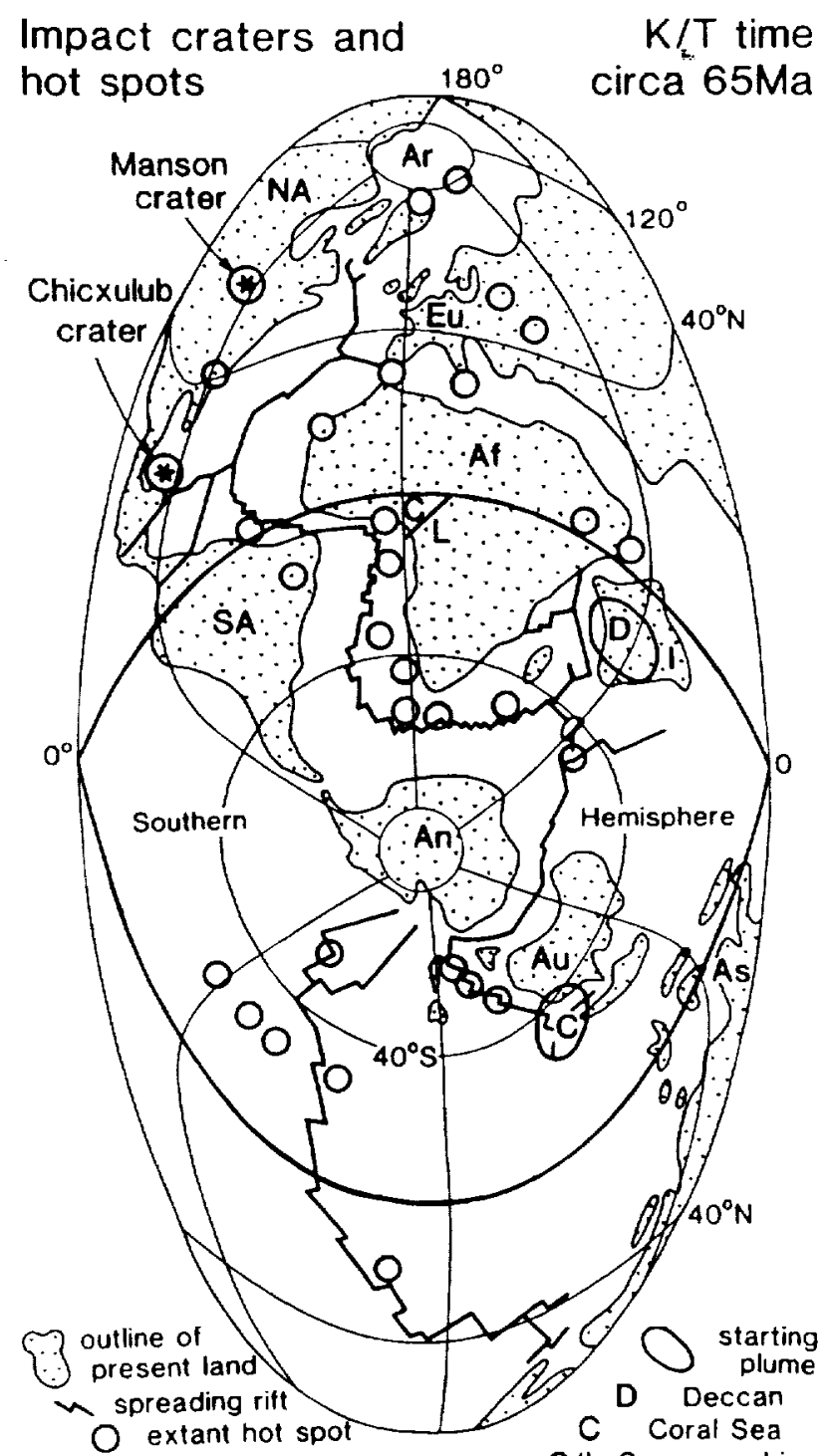

* impact crater

$\mathrm{C} / \mathrm{L}$ Cameroon Line

Fig.1. Suggested meteorite impacts and hotspot volcanism at KT time. 


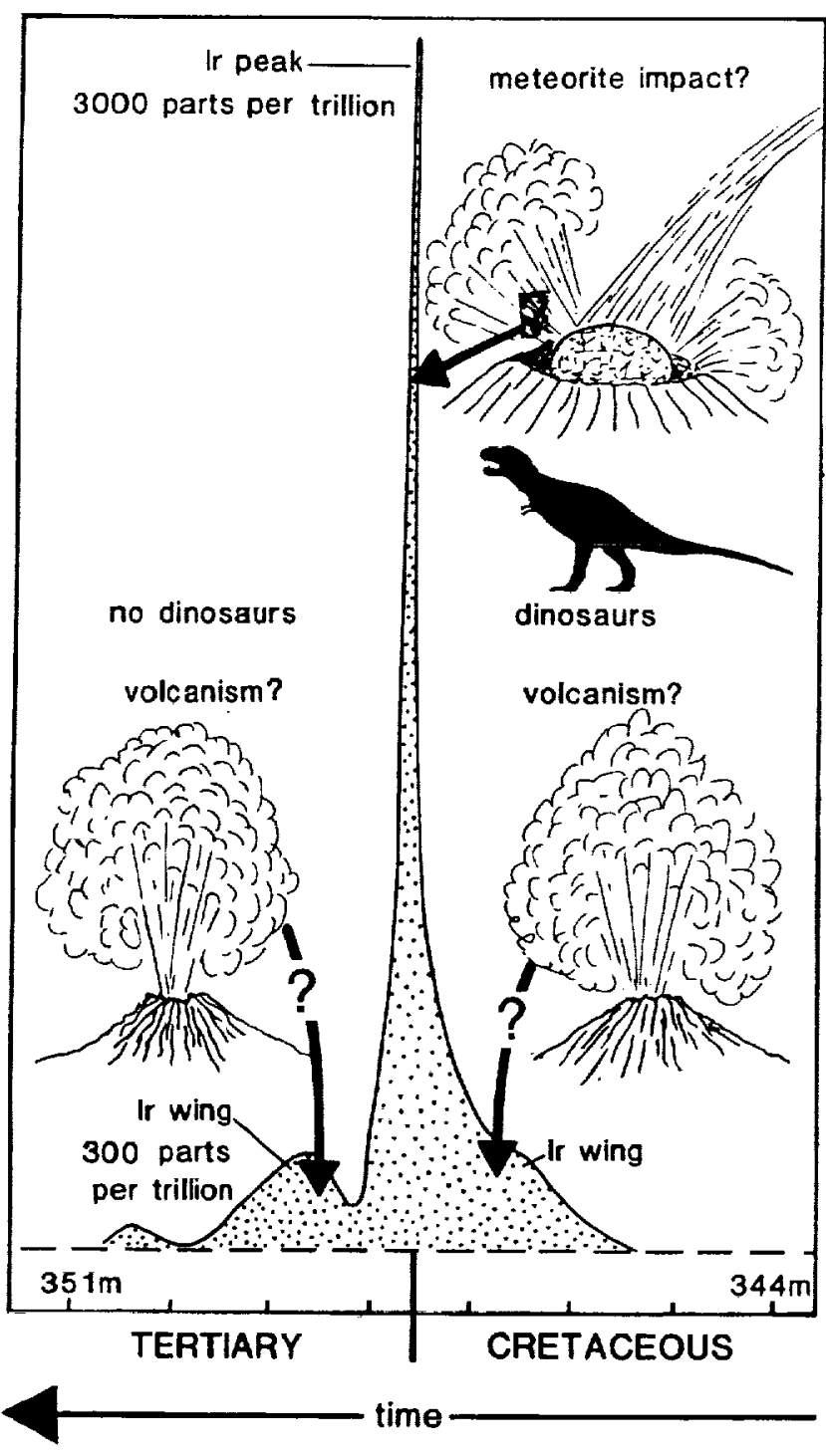

Fig. 2. Interpretation of Ir anomaly across KT boundary.

remains being reworked [43] and some ambiguous sections proving Cretaceous [44]. Dinosaur eggs (France, China) show abnormal increases of Se [45] and pathological protein structure [46] in egg shells toward the KT boundary. The extinction of the dinosaurs contrasts with the survival of most large vertebrate groups [47]. The "classic" KT extinction of planktonic foraminifera differentially selected the large, ornamented, deeper-dwelling tropical forms, suggesting extended rather than a sharp general extinction [48]. Absence of "wildfire" soot [4l], reduced floral extinctions [49], transitional extinctions in some southern KT sections [50], and the presence of surviving animal groups in Australia [51] suggest some possible differential extinctions.

Hemispherical Views: Available evidence suggests multiple northern meteorite impacts (Fig. 1), with a Chicxulub impact giving KT Ir anomalies and extinctions [52] and a Pacific impact (?) giving Ni spinel fallout [53]. The KT deposits suggest fractionation of Pt group elements after impact [25] and a lethal thermal pulse from reentering ejecta from a Chicxulub impact was probably regional rather than global [54]. The southem hemisphere in contrast shows more starting plume and extant hotspot activity around $K T$ time (Fig. 1). The main northern plumes (Hawaii, Greenland) started well in the Cretaceous [7]. Initial Deccan volcanism probably predates and overlaps the KT boundary by 1-3 Ma [55].

Synthesis: The KT Ir anomaly includes lower level (300 ppl) wings and a sharp higher level ( $3000 \mathrm{ppt}$ ) peak [56]. The extended basal wings accommodate the estimated Deccan Ir budget and the central peak requires sudden Ir input (Fig. 2). This suggests a late Cretaceous biota already exposed to abnormal volcanism, when subjected to sudden impact effects. Environmental perturbations from Greenland-North Atlantic rift margin volcanism continued into the early Tertiary [57]. Coincidence of major meteorite impact during flood volcanism can be expected in geological time [58]. The $\mathrm{KT}$ event shows distinct differences to the even larger PermoTriassic extinction event [59], which coincided with voluminous $\left(1.5 \times 10^{6} \mathrm{~km}^{3}\right)$ Siberian plume lavas [60]

Conclusion: Predominant northem impacts imposed on dominant southem volcanism gave unevenly disturbed KT environments. This led to geographically modified extinctions in some $[47,61]$ but not all $[42,62]$ groups.

Acknowledgments: I would like to thank the Royal Society of New South Wales for adapted figures.

References: [1] Glen W. (1990) Am. Sci., 78, 354-370. [2] McClaren D. J. and Goodfellow W. D. (1990) Annu. Rev. Earth Planet. Sci., 18, 123-171. [3] Alvarez W. and Asaro F. (1993) New Sci., 263, 44-52. [4] Officer C. (1993) New Sci., I37, 34-38. [5] Hallam A. (1987) Science, 238, 1237-1242. [6] Sutherland F. L. (1989) J. Proc. R. Soc. NSW, 121, 123-164. [7] Sutherland F. L. (1993) J. Proc. R. Soc. NSW, I26, 1-25. [8] Swisher C. C. et al. (1992) Science, 257, 954-958. [9] Sharpton V. L. et al. (1992) Nature, 359, 819-821. [10] Kunk et al. (1989) Science, 244, 15651568. [11] Grieve R. A.F. (1991)Meteoritics, 26, 175-194. [12] Officer C. B. and Carter N. L. (1991) ESR, 30, 1-49. [13] Sigurdsson H. et al. (1992) EPSL, 109, 543-559. [14] Lyons J. B. and Officer C. B. (1992) EPSL, 109, 207-220. [15] Kring D. A. and Boyton W. V. (1992) Nature, 358, 141-144. [16] Blum J. D. and Chamberlain C. P. (1992) Science, 257, 1104-1107. [17] Schuraytz B. C. and Sharpton V. L. (1993) Nature, 362, 503-504. [18] Koeber] C. (1992) GCA, 56, 4329-4332. [19] Florentin J. M. et al. (1991) Science, 252, 1690-1693. [20] Montgomery H. et al. (1992) EPSL, 109, 593-600. [21] Bohor B. F. (1992) LPI Contrib. 890, 8-9. [22] Shoemaker E. M. and Izett G. A. (1992) LPI Contrib. 890, 6768. [23] Blum J. D. et al. (1993) Narure, 364, 325-327. (24] Tredoux M. et al. (1989) J. Geol., 97, 585-605. [25] Evans N. J. et al. (1993) GCA, 57, 3737-3748. [26] Owen M. R. et al. (1990) GSA Spec. Paper 247, 343-347. [27] McHone J. F. et al. (1989) Science, 243. 1182-1184. [28] Gilmour I. et al. (1992) Science, 258, 1624-1626. [29] Robin E. et al. (1992) EPSL, 99, 206-219. [30] Zahnle K. and Grinspoon C. (1990) Nature, 348, 157-160. [31] Courtillol V. E. (1990) Sci. Am., 263, 53-60. [32] Rice A. (1990) GSA Spec. Paper 244, 39-56. [33] Premovi P. I. et al. (1993) GCA, 57, 1433-1466. [34] Tontain J. P. and Meyer G. (1989) GRL, 16, 1391-1394. [35] Koeberl C. (1989) EPSL, 92, 317-322. [36] Rampino M. R. and Calderia K. (1993) EPSL, 1/4, 215-227. [37] Alt D. et al. (1988) J. Geol., 96, 647-662. [38] Upchurch G. R. (1989) in Mass Extinctions: Processes and Evidence (S. K. Donovan, ed.), 195216, Belhaven. [39] Hansen H. J. et al. (1992) Meteoritics, 27, 30. [40] Johnson K. R. et al. (1989) Nature, 340, 708-711. [41] Wolfe J. A. (1991) Nature, 352, 420-423. [42] Gartner S. (1993) GACl 
MAC Prog. and Abstr., Edmonton. [43] Kerr R. A. (1992) Science, 243, 479. [44] Conrad J. E. et al. (1992) USGS Bull., N 1990-C. [45] Hansen H. J. (1990) GSA Spec. Paper 247, 417-423. [46] Zhao Z. et al. (1992) $28 \mathrm{th} I G C$, Kyoto, Abstr., I, 237. [47] Archibald J. D. (1993) New Sci., 137, 24-27. [48] MacLeod N. and Keller G. (1993) GAC/MAC Prog. and Abstr. [49] Kirk R. J. (1993) GAC/ MAC Prog. and Absir. [50] Zinmister W. J. (1993) GAC/MAC Prog. and Abstr., Edmonton. [51] Deighton L. (1991) New Sci., 13I, 14. [52] Sharpton V. L. et al. (1993)Science, 26I, 1564-1567. [53] Robin E. et al. (1993) Nature, 363, 615-617. [54] Hildebrand A. R. (1993) GAC/MAC Prog. and Abstr. [55] Venkatesan T. R. et al. (1993) EPSL, 119, 181-189. [56] Rocchia R. et al. (1992) EPSL, 99, 206219. [57] Eldholm O. and Thomas E. (1993) EPSL, 117, 319-329. [58] Hsu K. J. (1989) J.Geol. Soc. London, 146, 749-754. [59] Holser W. T. and Margaritz M. (1993) GCA, 56, 3297-3309. [60]Campbell I. H. et al. (1992) Science, 258, 1760-1762. [61] Emiliani C. et al. (1981) EPSL, 55, 317-334. [62] Raup D. M. and Jablonski D. (1993) Science, 260, 971-973.

\section{NUMERICAL SIMULATION OF IMPACT CRATERING AT} CHICXULUB AND THE POSSIBLE CAUSES OF KT CATASTROPHE. T. Takata and T. J. Ahrens, Division of Geological and Planetary Sciences, California Institute of Technology, Pasadena CA 9 I125, USA.

The Chicxulub Crater, located on the Yucatan peninsula, is considered as the most likely site of the impact crater, which was formed by an extraterrestrial object that appeared to have caused the catastrophic extinction at the KT boundary [1]. Recent investigations of the gravity field in this area extended the possible diameter of the crater from $180 \mathrm{~km}$, which had been previously estimated in Hildebrand et al. [1] to $260-340 \mathrm{~km}$ [2]. In order to create a 260 $340-\mathrm{km}$-diameter crater, the impacting object diameter required is $20-30 \mathrm{~km}$, if the meteorite impacted at a velocity of $20 \mathrm{~km} / \mathrm{s}$. The impact of the meteorite of this diameter, that is $2-4 \times$ scale height of the Earth atmosphere, could result in global effects on the ecology, environment, and trigger climate changes that may last $\sim 10^{4}$ years.

Geological investigations indicate that the Chicxulub Crater was inferred to have been excavated shallow sea platform containing 2-4-km-thick carbonate and evaporitic rocks (mainly limestone, dolomite, and gypsum) overlying the basement rock of andesite at KT time (65 m.y.) [3]. This topographical and geological environment for the Chicxulub Crater is expected to be a typical feature of $\mathrm{KT}$ impact craters. This is because of the high ratio of sea surface to the continental surface, and the warmer climate of Cretaceous age. These will result in thick carbonate rock sequences. The production and release of the water vapor and $\mathrm{CO}_{2}$ from the terrestrial surface to the atmosphere is expected during an impact event. The increase of the water vapor and $\mathrm{CO}_{2}$ in the atmosphere may have resulted in increasing the global temperature of the atmosphere via the greenhouse effect [4,5].

Moreover, the enomous amount of fine dust ejected from the crater into the atmosphere and its subsequent global dispersal in the stratosphere could have possibly decreased solar insolation, inducing a short-duration decrease in global temperalure as first proposed by Alvarez et al. [6]. Partial destruction of the ozone layer in the upper atmosphere may have also been a factor in extinction of some species. Possible scenarios, including breakdown of the usual an- nual hemispheric climate cycle due to the combination of the above mechanisms, have been discussed for a decade. What mechanisms caused extinction of what organisms have not been conclusively demonstrated. One approach to this complex problem is to examine the mechanics of impact cratering in the Chicxulub Crater lithology and estimate the possible environmental or climatic consequences.

The impact cratering process on the lithology of the Chicxulub impact site was investigated by a numerical simulation. We used the Smoothed Particle Hydrodynamics (SPH) numerical technique [7]. The SPH method is a free lagrangian method, and suitable for the highly distorted motion of materials. All the materials are expressed by particles that satisfy the hydrodynamic equations and are treated like $\mathrm{N}$-body problems. In our simulations, axisymmetric geometry is applied in order to expand the region taken into account in the calculations.

In order to simulate the response of the lithology at KT time around the Chicxulub Crater site in our code, we assumed a target with basement rock of andesite, overlaid by a $3-\mathrm{km}$-thick carbonate rock layer, and an atmosphere. A Tillotson equation of state for limestone is applied for carbonate, and an ideal gas with constant specific heat ratio is used for the atmosphere. All the target materials including atmosphere is initially stabilized and is in hydrostatic equilibrium. The radius of meteorite is assumed to be $12.5 \mathrm{~km}$. The advantage of the SPH method is that it can represent the transfer

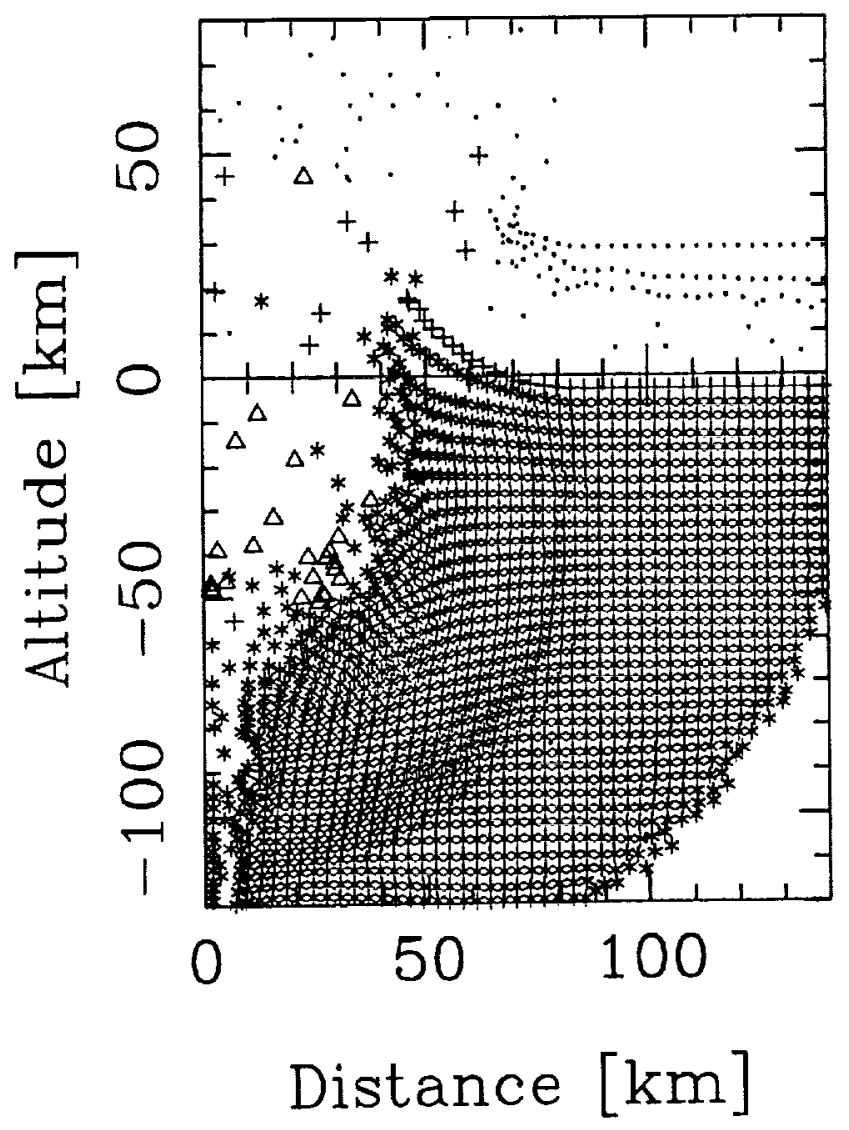

Fig. 1. Particle position during impact at Chicxulub at $\mathrm{t}-16$ (s) after.the impact. The symbols of the particles $\cdot, \Delta_{,}+$, and $x$ represent impactor. basement rock, carbonate rock, and atmospheric particles respectively. The impactor size is $25 \mathrm{~km}$ and the impact velocity is $20 \mathrm{~km} / \mathrm{s}$. 


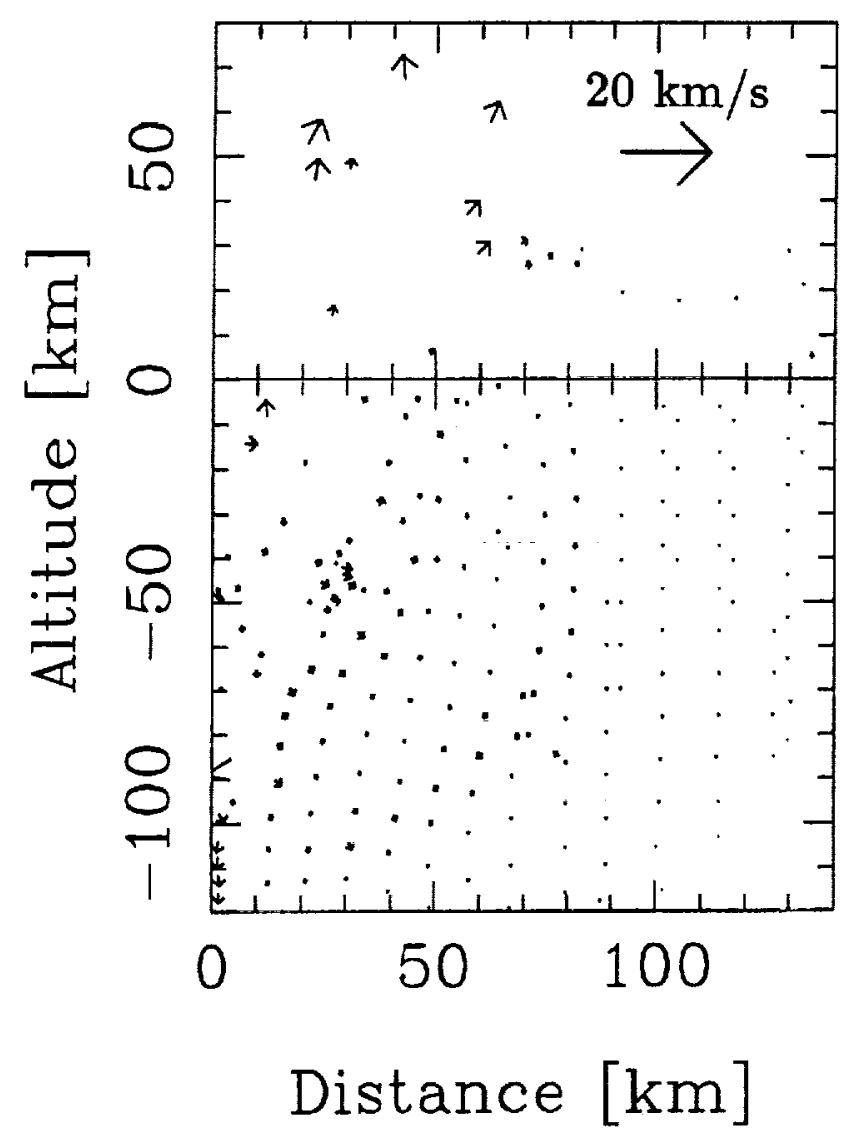

Fig. 2. The velocity field of the impact cratering at the same time as Fig. 1

of energy and interaction of materials among impacting meteorite, the surface materials, and the atmosphere. Numerical simulations have been employed since publication of Alvarez's hypothesis $[8,9]$, however, the uniqueness of our calculation is that we include an atmosphere in addition to the carbonate systems.

Figures 1 and 2 show position of materials and particle velocity at $16 \mathrm{~s}$ after the impact. We can observe that the ejecta curtain extends to more than one scale height of the atmosphere and the mixing of carbonate, basement rocks, and impactor in the ejecta within the atmosphere. Drilling data from the center of Chicxulub Crater demonstrated the melt sheet was observed beneath a 200 400-m-thick breccia layer. The results of the calculation show that approximately $10 \mathrm{~km}$-thick-melt sheet is produced. The total mass of melt is approximately $20 \times$ the impactor mass.

The energy transfer to the atmosphere takes place via two mechanisms: (I) Direct impact of the bolide on the atmosphere accounts for very few percent of the atmospheric heating. (2) The work done on the atmosphere by the moving ejecta curtain transfers the bolide energy to the atmosphere. When the ejecta curtain of target materials starts to develop after the impact of meteorite, the total amount of energy transfered to the atmosphere is less than $0.5 \%$, that is, $\sim 20^{22} \mathrm{~J}$. However, the ejecta transfers an enormous amount of energy into the atmosphere due to the gas drag [8]. As a result of the impact, carbonate rock takes up approximately $10 \%$ of the impact energy, $5 \%$ of the initial energy was left in the meteorite as the internal heating, and the rest of the energy is transfered to the basement rock.
The amount of $\mathrm{CO}_{2}$ production by the shock-induced decarbonation of the carbonate rocks is also estimated. The decarbonation of calcite was observed experimentally to occur at $20 \mathrm{GPa}$ [10]. Young carbonate rocks should have had a certain degree of porosity because they were recently deposited. In the laboratory, shock experiments using $50 \%$ porous chalk induces devolatilization of $90 \%$ of the available $\mathrm{CO}_{2}$ at $10 \mathrm{GPa}$ [11]. Therefore, we assumed that all the carbonate pressurized to more than $10 \mathrm{GPa}$ devolatilizes. By determining the mass of carbonate exposed to $>10 \mathrm{GPa}$, the production of $\mathrm{CO}_{2}$ by Chicxulub cratering is found to be $10^{16}-10^{17} \mathrm{~kg}$. This mass of $\mathrm{CO}_{2}$ is $10-100 \times$ the $\mathrm{CO}_{2}$ inventory in the present atmosphere. This is a greater increase in $\mathrm{CO}_{2}$ than obtained previously by O'Keefe and Ahrens [5].

The mixing ratio of impact to target material ejected into the atmosphere is approximately $0.01-0.02$. This value agrees with this ratio $(0.01-0.1)$ found in the worldwide $P$-rich element ratio at the KT boundary [8]. We calculate that all the meteorite material ejected to the atmosphere is melted or vaporized.

In conclusion, the production of the enormous amount of $\mathrm{CO}_{2}$ dust of terrestrial and extraterrestrial origin was confimed in our numerical simulation of Chicxulub Crater. The climate system should have been affected by the impact-induced $\mathrm{H}_{2} \mathrm{O}$ and $\mathrm{CO}_{2}$ and dust on various time scales. Heating of the atmosphere probably produces higher water and $\mathrm{CO}_{2}$ vapor pressures [4,5]. If a water cloud expanded globally this may have increased the albedo of the Earth on a timescale of several months. These albedo-temperature feedback systems may have been disordered by abrupt changes of constituents of atmosphere.

Acknowledgments: We appreciate the use of the CRAY YMP at JPL for these calculations.

References: [1] Hildebrand A. R. et al. (1991) Geology, 19 , 867-872. [2] Sharpton V. L. et al. (1993) Science, 261, 1564-1567. [3] Swisher et al. (1992) Science, 257, 954-958. [4] Emiliani C. et al. (1981) EPSL, 55, 317-334, [5] O'Keefe J. D. and Ahrens T. J. (1989) Nature, 228, 247-249. [6] Alvarez et al. (1980) Science, 208, 1095-1 108. [7] Gingold R. A. and Monaghan J. J. (1977) Mon. Not. Astron. Soc., I81, 375. [8] O'Keefe J. D. and Ahrens T. J. (1982) GSA Spec. Paper 190, 103-120. [9] Roddy D. J. et al. (1987) J. Impact. Eng., 5, 525-541. [10] Lange M. A. and Ahrens T. J. (1983) LPS XIV, 419-420. [11] Tyburczy J. A. and Ahrens T. J. (1986) JGR, 9I, 4730-4744.

$$
\text { On, T }
$$

REVERSE-POLARITY MAGNETIZED MELT ROCKS FROM THE KT CHICXULUB STRUCTURE, YUCATAN PENINSULA, MEXICO. J. Urrutia-Fucugauchi', L. Marín', and V. L. Sharpton', 'Laboratorio de Paleomagnetismo y Geofísica Nuclear, Instituto de Geofisica, Universidad Nacional Autonoma de México, Del. Coyoacan 04510 D.F., Mexico, ${ }^{2}$ Lunar and Planetary Institute, 3600 Bay Area Boulevard, Houston TX 77058, USA.

We report paleomagnetic results for core samples of the breccia and andesitic rocks recovered from the Yucatan 6 Petroleos Mexicanos exploratory well within the Chicxulub structure (about $60 \mathrm{~km}$ south-southwest from its center), northern Yucatan, Mexico. A previous study has shown that the rocks studied contain high Ir levels and shocked breccia clasts and an $\mathrm{Ar} / \mathrm{Ar}$ date of $65.2 \pm 0.4 \mathrm{Ma}$ (Sharpton et al., 1992). Andesitic rocks are characterized by stable single-component magnetizations with a mean inclination of $\mathbf{- 4 3}$. Breccias present a complex paleomagnetic record characterized by 
multivectorial magnetizations with widely different initial NRM inclinations. However, after alternating field demagnetization, welldefined characteristic components with upward inclinations are defined.

IRM acquisition experiments, comparison of IRM and NRM coercivity spectra, and the single-component magnetization of the andesitic rocks indicate the occurrence of Fe-rich titanomagnetites of single or pseudosingle domain states as the dominant magnetic carriers. Mean inclinations from the andesitic rocks and most of the breccia samples give a mean inclination of about -40 to -45 , indicating a reverse polarity for the characteristic magnetization that is consistent with geomagnetic chron $29 \mathrm{R}$, which spans the KT boundary. The inclination is also consistent with the expected value (and corresponding paleolatitude) for the site estimated from the reference polar wander curve for North America. We suggest that the characteristic magnetizations for the andesitic and breccia rocks are the result of shock heating at the time of formation of the impact structure and that the age, polarity, and paleolatitude are consistent with a time at the KT boundary.

Recently, we have acquired samples from well Yucatan 6 from three different intervals [(N9, N17 (depth: 1295.5-1299 m), and N19 (depth: $1377-1379.5 \mathrm{~m}$ )]. We are currently determining their paleomagnetic signature.

\section{N94- 28314}

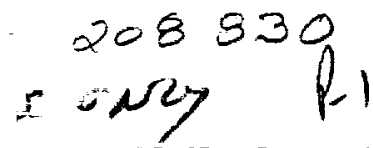

SUPERNOVAE AND MASS EXTINCTIÓNS. S. van den Bergh, Dominion Astrophysical Observatory, National Research Council, 507 I West Saanich Road, Victoria BC V8X 4M6, Canada.

Shklovsky [1] and others have suggested that some of the major extinctions in the geological record might have been triggered by explosions of nearby supernovae. The frequency of such extinction events will depend on the galactic supemova frequency and on the distance up to which a supernova explosion will produce lethal effects upon terrestrial life. In the present note it will be assumed [2] that a killer supernova has to occur so close to Earth that it will be embedded in a young, active, supemova remnant. Such young remnants typically have radii $\leq 3 \mathrm{pc}\left(1 \times 10^{19} \mathrm{~cm}\right)$.

Larger (more pessimistic?) killer radii have been adopted by Ruderman [3], Romig [4], and by Ellis and Schramm [5]. From observations of historical supemovae, van den Bergh [6] finds that core-collapse (types Ib and II) supernovae occur within $4 \mathrm{kpc}$ of the Sun at a rate of $0.2 \pm 0.1$ per century. Adopting a layer thickness of $0.3 \mathrm{kpc}$ for the galactic disk, this corresponds to a rate of $\sim 1.3 \times$ $10^{-4}$ supemovae $\mathrm{pc}^{-3} \mathrm{~g} . \mathrm{y} .^{-1}$. Including supemovae of type la will increase the total supermova rate to $\sim 1.5 \times 10^{-4}$ supernovae $\mathrm{pc}^{-3}$ g.y. ${ }^{-1}$. For a lethal radius of $R$ pc the rate of killer events will therefore be $1.7(R / 3)^{3} \times 10^{-2}$ supemovae per g.y. However, a frequency of a few extinctions per g.y. is required to account for the extinctions observed during the phanerozoic. With $\mathrm{R}$ (extinction) $-3 \mathrm{pc}$, the galactic supemova frequency is therefore too low by 2 orders of magnitude to account for the major extinctions in the geological record.

References:- [I] Shklovsky I. S. (1969) Supernovae, 15. [2] Seward F. D. (1978) J. Brit. Interplanet. Soc., 31, 83-92. [3] Ruderman M. A. (1974) Science, 184, 1079-1081. [4] Romig J. H. (1975) Ph.D. dissertation, Univ. of Colorado. [5] Ellis J. and Schramm D. N. (1993). [6] van den Bergh S. (1993) Comments Astrophy., in press.
DISSECTING THE KT EXTINCTION: COMPONENTS AND COMPARISONS WITH THE PERMO-TRIASSIC AND "MODERN" MASS EXTINCTIONS. P. D. Ward, Mail Code AJ-20, Department of Geological Sciences, University of Washington, Seattle WA 98195, USA.

The KT extinction can now be differentiated into a number of separate components, or phases, equivalent in some ways to the steps of Earl Kauffman (1988). The initial phase commenced in the marine realm at the base of the $A$. mayaroensis zone in equatorial regions, and perhaps later in high latitudes. The major taxa affected were inoceramid bivalves, the reef facies, and other benthic mollusks. This phase coincided with (and was probably caused by) oceanographic changes including differences in ocean water oxygenation and a sea-level drop of great magnitude. The second pulse occurred at the KT boundary, and was far greater in magnitude, producing the extinction of all ammonites and a majority of planktonic foram and nannofossil species. The final phase was a benthonic foram extinction during the Paleocene. On land, the initial pulse was evidenced by floral and perhaps terrestrial vertebrate extinctions, with a greater pulse coinciding with the KT boundary. It is not known if the precursor pulses on land and in the oceans were synchronous.

The Permo-Triassic extinctions also show pulses of extinction. New work in the Karoo Series of South Africa shows three major pulses of extinction among land vertebrates, which, like KT, may or may not coincide with extinctions in the marine realm.

Finally, many workers now believe that we have entered a new period of mass extinction. This extinction began 2 m.y. ago with marine mollusk extinctions. Its second phase occurred during the last 50,000 yr with mammalian and avian extinctions. Its major pulse can be expected to occur within the next $500 \mathrm{yr}$, coincident with human population maxima.

\section{Crant $70 \angle 2 D$}

CATASTROPHIC A LAMO BRECCIA, UPPER DEVONIAN, SOUTHEASTERN NEVADA. J. E. Warme, Department of Geology and Geological Engineering, Colorado School of Mines, Golden CO 80401, USA.

An anomalous sedimentary deposit, informally named the Alamo Breccia after the local settlement of Alamo in southeastern Nevada, occurs as a single bed in the Upper Devonian. It is interpreted as a gigantic debris flow and turbidite generated by a shallow-water landslide. It is anomalous because it formed upon the surface of a long-lived carbonate platform and not just at the platform edge.

To date, the Alamo Breccia has been identified in seven mountain ranges, covering an area of about $50 \times 150 \mathrm{~km}\left(7500 \mathrm{~km}^{2}\right)$. Before tectonic shortening by thrust faulting, the area may originally have been greater. Thickness of the Alamo Breccia ranges from $\sim 30-130 \mathrm{~m}$, averaging $80 \mathrm{~m}$; a conservative volume estimate is $600 \mathrm{~km}^{3}$.

All evidence indicates that the Breccia was deposited as a single event, probably within a day. It is dated by conodonts as early Frasnian, or the early part of the early Late Devonian, approximately 375 m.y. ago (Sandberg and Warme, 1993). The composition of the Alamo Breccia is almost entirely platform limestone and dolomite, except in some locations where it is secondarily partially or completely dolomitized. Fragments represent the spectrum of carbonate 
lithologies present on the Devonian platform; no clasts of deepwater derivation have been recognized.

Lower and upper contacts are sharp. The lower contact is erosive but usually follows approximately the same underlying stratum for hundreds of meters. The upper contact is usually sharp, but appears gradational with overlying mudstones at some localities. Internally the Alamo $B$ reccia is a graded bed. It has been zoned into four zones, two $(A, B)$ of which are always present and two others $(C, D)$ that are common but not universal (Warme et al., 1993). From the top downward, zone $A$ is an exquisitely graded bed, two to several meters thick. Clasts range from 2-3 dm or more in diameter at the base, becoming gradually smaller upward to the capping sand or mud. Downward zone A merges with zone B of larger clasts, ranging up to $10 \mathrm{~m}$ or more in largest dimension, with relatively finer matrix. zone B may extend to the base of the Breccia, but in most localities is interrupted downward by one or more huge clasts (zone C) commonly hundreds of meters long and ten or more meters thick. Zone $C$ clasts are generally parallel or subparallel to regional bedding surfaces. Zone $\mathrm{D}$, a detachment horizon showing bedrock dilation and fluidization, may or may not be present between zone $C$ clasts and underlying intact bedrock.

Breccia fabric is characterized by overall rough grading, superb grading in zone $A$, and general (sub)parallel orientation of tabular clasts (including those in zone C). Imbrication of clasts is rare, and shows no consistent paleocurrent direction.

The Alamo Breccia is anomalous, suggesting unusual derivation, for several reasons: (1) It occurs within the framework of a carbonate platform. Underlying and overlying beds represent shallowing-upward platform cycles of the Guilmette Formation, commonly capped by exposure surfaces (desiccation cracks, karst). Only at its thickest $(130 \mathrm{~m}$ ) and westemmost (westem Timpiute Range) exposure is it bracketed by beds representing deeper-water, off-platform paleoenvironments, which are the normal milieu of such mass flows. (2) Its lower boundary, an eroded surface of detachment, represents an apparently horizontal surface over a distance of at least $30 \mathrm{~km}$ land ward from the seaward platform edge and over an area of several thousand square kilometers. (3) The Alamo Breccia is the only such intraplatform mass flow recognized from Cambrian to Mississippian time.

A working hypothesis for the origin of the Alamo Breccia is that it was triggered by an earthquake, perhaps spawned by a nearby bolide. Circumstantial evidence for such an impact is (1) the singular occurrence of such a deposit; (2) the presence of numerous unique quartz grains, found in conodont-sample residues only from within the Breccia and not from adjoining beds (these anomalous grains have blotchy extinction under cross-polarized light and are peripherally studded with metallic oxide crystals; they may represent altered tektites or other impact debris); (3) a weak Ir anomaly that exists near the top of the Breccia in one locality; and (4) conodonts representing deeper-water biofacies that occur only in the Breccia, not in confining beds (C. Sandberg, personal communication, 1993).

The anomalous conodont occurrence is consistent with physical evidence that the detachment and debris flow creating the Alamo Breccia were concurrent with, or immediately followed by, a isunami or similar wave that uprushed landward far beyond the detachment headwall. Other evidence for such a wave includes the observation that the Alamo Breccia fills the entire vertical space left by the slide; the slide scar is brim full of debris swept into it, from the adjoining platform as a single graded bed. In addition, three locali- ties, tens of kilometers beyond the distribution of the thick Alamo Breccia, show a single thinner (1-5-m) graded bed that was apparently deposited by the uprush, stranded above sea level, and then karsted before subsequent flooding by the next sea level cycle.

Whether or not the Alamo Breccia was triggered by extraterestrial impact, it represents a local but significant event in the Devonian history of Nevada and perhaps more distant regions.

\section{WHERE ARE THE CHICXULUB COARSE-GRAINED,} IGNEOUSLY LAYERED IMPACT MELT ROCKS ANALOGOUS TO THOSE AT SUDBURY? P. H. Warren', P. Claeys', and E. Cedillo-Pardo2, 'Institute of Geophysics, University of Califomia, Los Angeles CA 90024-1567, USA, 2Instituto Mexicano del Petróleo, Eje Central Lazaro Cardenas 152, 07739 México DF, Mexico.

The Chicxulub basin is an impact structure with circular gravity anomalies that suggest as many as four rings, the most prominent one having a diameter (D) of roughly $170 \mathrm{~km}$, and the biggest (marginally significant) having D $300 \mathrm{~km}$ (if real, this implies the $170-\mathrm{km}$ ring is close to the rim of the transient crater) [1]. Hildebrand et al. [2] advocate a structural $D$ of $\sim 170 \mathrm{~km}$ and a transient crater D of $\sim 90 \mathrm{~km}$. Even if the structure's D is "only" $170 \mathrm{~km}$, it must have had catastrophic effects, and its age of $65.01 \pm 0.08 \mathrm{Ma}$ [3] coincides with the KT boundary.

Impacts this large should produce enormous volumes of impact melt. Figure I shows impact melt volume as a function of transient crater size, estimated by two methods: (1) a power-law relationship [4] and (2) application of equation 7.10.2 of Melosh [5] along with an unnumbered equation (for estimating volume displaced as a function of transient crater D) [5, p. 119]. Method (2) consistently gives roughly $40 \%$ higher melt volumes than method (I), and the absolute value of any such estimation is probably uncertain by at least a factor of 2 . However, comparison with observed craters [4]

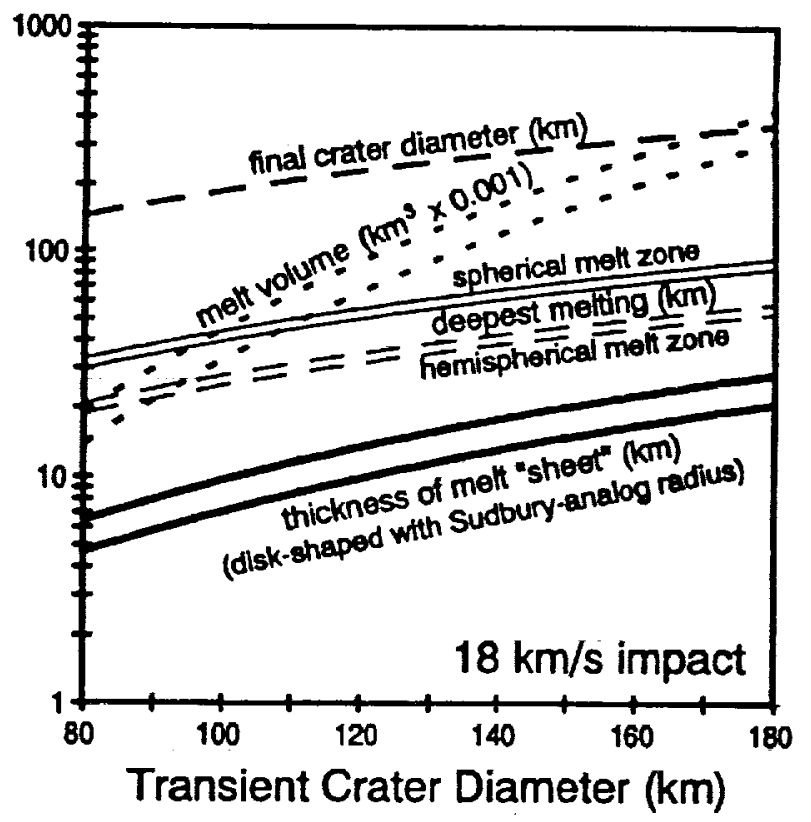

Fig. 1. Model predictions for scale of impacı melting. 
confirms the slope of the (melt volume)/D relationship. An additional area of uncertainty is the impact velocity; a range of $12-70 \mathrm{~km} / \mathrm{s}$ (encompassing nearly all conceivable major impacts) would shift the estimated melt volumes by a factor of $0.9-1.5$. The velocity used in Fig. 1 is slightly greater than the estimated average terrestrial impact velocity of $17 \mathrm{~km} / \mathrm{s}$ [6]. The nominal "crater diameter" implied by a given transient crater D $[6,7]$ is also shown, albeit the "crater diameter" concept is hardly applicable to a multiring basin. Figure I also shows curves for melt volume translated into depth of deepest melting, by modeling the initial melt distribution as confined to volumes of either spherical or hemispherical shape, and for idealized thickness of an impact melt "sheet," modeled as a total aggregation of the melt into a volume of shallow-cylinder shape, with the cylinder's diameter equal to the transient crater $D$.

Of course, impact melt will hardly aggregate into a near-surface sheet with $100 \%$ efficiency, but a melt compositionally similar to average Chicxulub melt [8] will have a much lower density than any plausible country rock, and thus should tend to efficiently rise to near the surface. The only comparable Earth structure, in terms of size and melt composition, is Sudbury. The Sudbury Igneous Complex was once widely assumed to represent mainly endogenous melt, formed only indirectly in response to the impact. Many recent studies [e.g., 9] suggest that the Sudbury structure is larger than previously supposed (its transient crater $\mathrm{D}$ is now estimated at roughly $100 \mathrm{~km}$ ), and also that virtually the entire igneous complex represents impact melt. By this view, the original thickness of the aggregated Sudbury melt sheet was roughly $2.5-4 \mathrm{~km}$ [10], i.e., lower, but only by a factor of 2-3, compared to the idealized melt sheet thickness (Fig. 1).

The Sudbury Igneous Complex [10] is a mass of medium-grained rocks with strong vertical compositional layering. Thus, it is often likened to layered igneous intrusions of the Skaergaard-Stillwaler variety, even though fine-scale igneous layering is absent at Sudbury. The Sudbury rocks range from a mafic norite with pyroxenes that have $\mathrm{Mg} /(\mathrm{Mg}+\mathrm{Fe})$ as high as $78 \mathrm{~mol} \%$, to a thick capping granophyre (roughly half of the total complex), consisting of $-90 \%$ quartz + feldspar with only $10 \%$ mafic minerals, including pyroxenes with $\mathrm{Mg} /(\mathrm{Mg}+\mathrm{Fe})$ as low as $25 \mathrm{~mol} \%$.

All the Chicxulub impact melt rocks described thus far appear more fine grained than any significant portion of the Sudbury Igneous Complex. From the $\mathrm{Cl}$ core near the center of the structure, the only impact melt-like rocks are described as "glass" or "microcrystalline" [1] ], or else "fine- to medium-grained coherent crystalline" [8]. Core SI, roughly $26 \mathrm{~km}$ from the center of the structure, yielded "thick units of andesitic glass" [11]. From core Y6, roughly $50 \mathrm{~km}$ from the center of the structure, impact melt-like rocks have been described as either microcrystalline $(\mathrm{N} / 4, \mathrm{~N} 17)$, or (N19) finegrained to glassy melt rock clasts set in a "medium-to coarsegrained" melt rock matrix [11,12].

We have studied three Chicxulub thin sections: one from C1/N9, immediately ( $\leq 4 \mathrm{~m}$ ) above the N 10 sample of Sharpton et al. [8], and two from $\mathrm{Y} 6 / \mathrm{N} 19$, the same position (to within $2.5 \mathrm{~m}$ ) as a sample described as medium-coarse-grained by Sharpton et al. [8]. The impact melt portions of all our samples are fine grained. Grains in $\mathrm{Cl} / \mathrm{N} 9$ are mainly $-0.3 \mathrm{~mm}$ in maximum dimension (the largest, possibly a relict from a target lithology, is $1.6 \mathrm{~mm}$ ), and the section includes at least six clasts of very fine-grained $(-20 \mu \mathrm{m})$ material (Fig. 2a). The melt rock portions of the two $\mathrm{Y} 6 / \mathrm{N} 19$ sections are dominated $(80$ vol\%) by grains $<10 \mu \mathrm{m}$ across (Fig. $2 \mathrm{~b}$ ). The extraordinarily wide range of feldspar compositions (Fig. 3) sug- (a) Chicxulub Y $6 / \mathrm{N} 19-1$ $5.6 x$

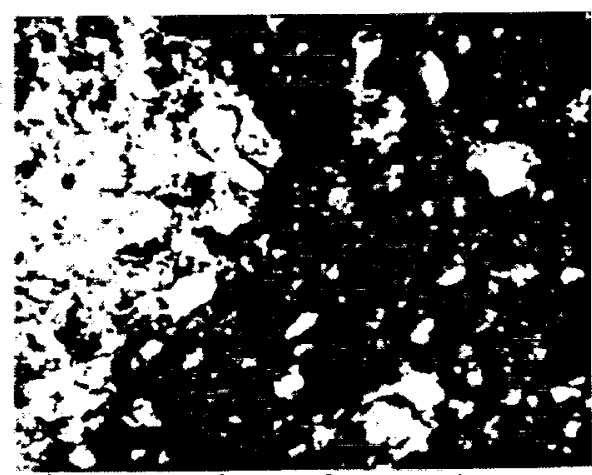

(b) Sudbury, 150 $\mathrm{m}$ from edge $5 \times$

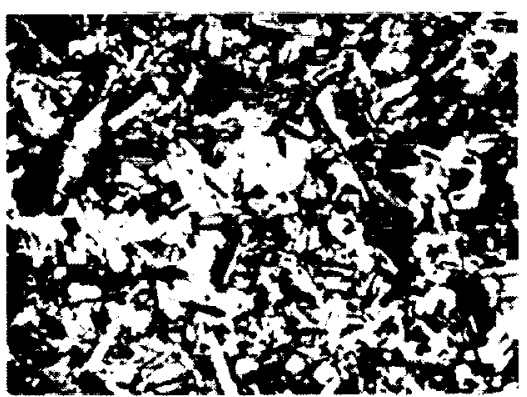

(c)

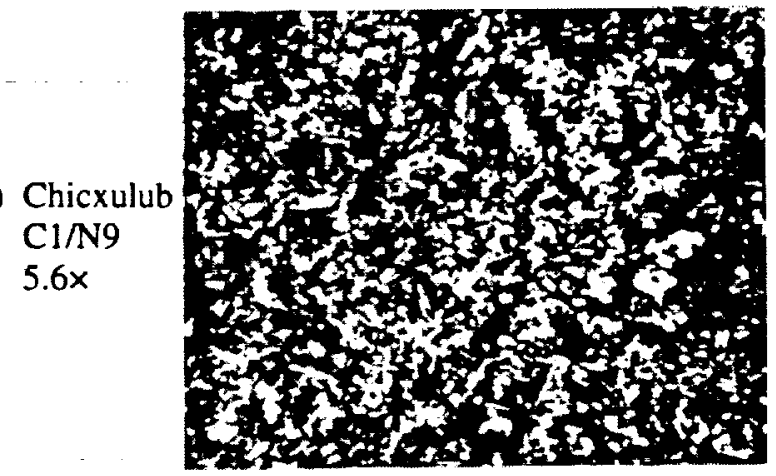

Fig. 2. Thin-section views of Chicxulub impact melts and a peripheral Sudbury IC rock [after 10]. all at similar scale. Left third of (a) shows part of the anhydrite-rich granophyre.

gests a clast-rich impact melt origin [13]. Even if elsewhere in Y6/ N19 the texture is medium-coarse-grained [8], this can hardly represent an igneous cumulate rock, $\dot{a}$ la customary interpretations of the Sudbury Complex. For comparison, Fig. 2c shows the texture of a Sudbury rock only $150 \mathrm{~m}$ from the edge of the complex, in which grain sizè (max. dimension) averages $\sim 0.75 \mathrm{~mm}$ [10]. Interior Sudbury rocks are twice this coarse, and uniformly lack perceptible clasts. Moreover, the uppermost Sudbury IC rocks are far more granitic than any Chicxulub melt rock yet described.

Comprising approximately half of thin section $\mathrm{Y} 6 / \mathrm{N} 19-11$ is a large fragment of a granophyric or mymekitic rock of extraordinary mineralogy: the only major minerals are quartz + feldspar (Fig. 3) and $\sim 8 \%$ anhedral, locally vermicular, anhydrite. Origin of the anhydrite by a late-stage reaction process appears unlikely, on grounds of texture and mass balance. Apart from the predominance of anhydrite in place of more "normal" minor phases, this fragment is similar to the granophyre layer than comprises the upper half of 


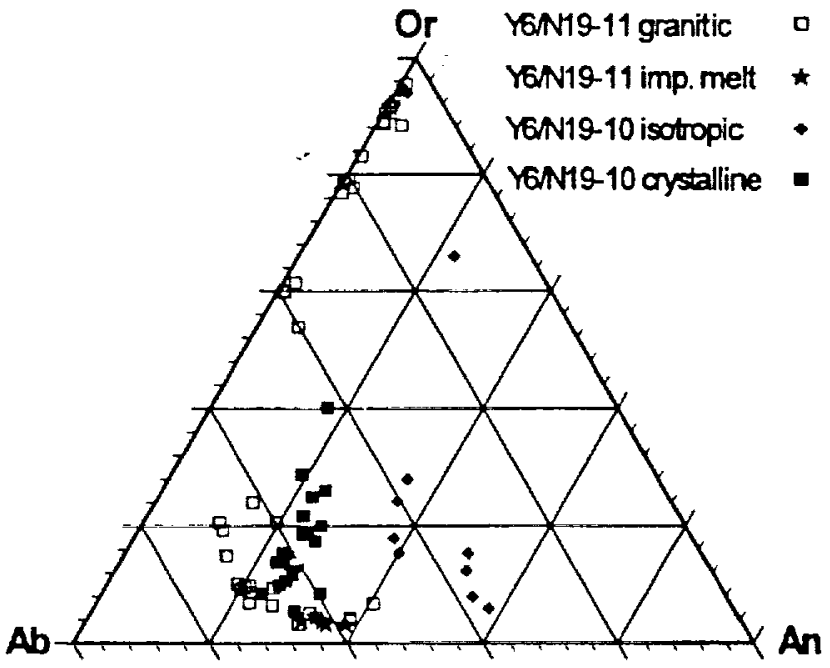

Fig.3. An-Ab-Orproportions in feldspars and feldspathic glasses.

the Sudbury Complex. The fragment is definitely not analogous, however, because it contains quartz. with multiple sets of planar elements indicative of shock metamorphism. Thus, this material was part of the basement at the time of the impact.

Atop the igneous complex at Sudbury is a thick (up to $1.6 \mathrm{~km}$ ) breccia layer, the Onaping Formation, interpreted [14,9] as a welded mass of back-fallen ejecta mixed with subordinate, heterogeneously distributed impact melt. Microbreccias with textures roughly similar to the Chicxulub impact melts are fairly common in the Onaping formation, but only as thin "veinlets" or subrounded fragments no more than "a few meters" across [14]. The Onaping also contains many fine-grained, often fluidal-textured "melt bodies" with typical dimensions of the order $100 \mathrm{~m}$. Possibly the available samples of Chicxulub impact melt are all from an Onaping analog. If so, deeper drilling may eventually reveal a much coarser and more differentiated igneous complex. The great heterogeneity in siderophile (Ir) concentrations found by Sharpton et al. [8] would be less surprising for a suite of Onaping-like samples than for samples of the main mass of impact melt. Weighing against this Onaping analogy, however, are the large vertical dimensions of apparently uniformly finegrained, little-differentiated impact melt rocks in cores $\mathrm{Cl}$ and especially Y6 (where the "microcrystalline andesite" is $\sim 380 \mathrm{~m}$ thick) [11].

If indeed the Chicxulub impact melt is nowhere as coarsegrained and compositionally layered as the Sudbury Complex, the simplest explanation would be that the total yield of impact melt was much greater at Sudbury. Yet the Sudbury structure appears, based on evidence that is in many respects more direct, to be similar in size, if not smaller, than Chicxulub. Perhaps the Chicxulub structure is actually smaller than Sudbury. Or perhaps recent interpretations of the Sudbury Complex as nearly pure impact melt have gone too far-a complicating factor is that the Sudbury impact hit a region already warmed by the Penokean Orogeny [14].

Future deep drilling near the center of the Chicxulub structure can be expected to clearly indicate which of these two models accurately describes the distribution and end state of the Chicxulub impact melt, thus helping to clarify the role of impact melting in early planetary differentiation [9], as well as the key question of the magnitude of the Chicxulub impact.
Acknowledgment: We thank J. Christie for petrographic advice.

References: [1] Sharpton V. L. et al. (1993) Science, 26I, 1564-1567. [2] Hildebrand A. R. et al. (1993) SOMEXPAL Conf. (abstract), Mexico City. [3] Swisher C. C. et al. (1993) Science, 257, 954-958. [4] Grieve R. A. F. and Cintala M. J. (1992) Mereoritics, 27, 526-538. [5] Melosh H. J. (1989) Impact Cratering. [6] Chyba C. F. (1991)/carus, 92, 217-233. [7] Croft S. K. (1985) Proc. LPSC I5th, in JGR, 90, C828-C842. [8] Sharpton V. L. et al. (1992) Nature, 359, 819-821. [9] Grieve R. A. F. et al. (1991) JGR, 96, 22753-22764. [101 Naldrett A. J. and Hewins R. H. (1984) in The Geology and Ore Deposits of the Sudbury Structure, 235-251. [11] Hildebrand A. R. et al. (1991)Geology, 19,867-871. [12] Kring D. A. and Boynton W. V. (1992) Nature, 358, 141-144. [13] Cedillo P. E. (1992)GSA Absir. wish Progr., A333. [14] Peredery W. V. and Morrison G. G. (1984) in The Geology and Ore Deposits of the Sudbury Struciure, 491-511.

A SEARCH FOR SHOCKED GRAINS IN THE KT BOUNDARY AT BRAGGS, ALABAMA. S. Y. Wdowiak', T. J. Wdowiak', D. C. Gillis ${ }^{3}$, and M. Dudley4, 'Analytical Technologies Inc., Pensacola FL 32514, USA, 2University of Alabama at Birmingham, Birmingham AL 35294, USA, ${ }^{3}$ Marshall Space Flight Center, Huntsville AL 35812, USA, ${ }^{4}$ State University of New York at Stony Brook, Stony Brook NY 11794, USA.

We have searched the KT boundary that is exposed at Braggs, Alabama, for grains that exhibit evidence for having a shock history. The transitional section has been described previously by others [1-3] and shown to have small multiple Ir anomalies in the tens of parts per trillion (ppt) range [4]. The location of the Ir anomalies in the Braggs section at the bottom of anomaly 29 rormal paleomagnetic zone (single Ir peak) and in anomaly 29 reversed paleomagnetic zone (multiple Ir peaks) guided our search to Bed 10. The combination of the Braggs, Alabama, and Brazos River, Texas [5], KT boundary sites is interesting from the standpoint of their

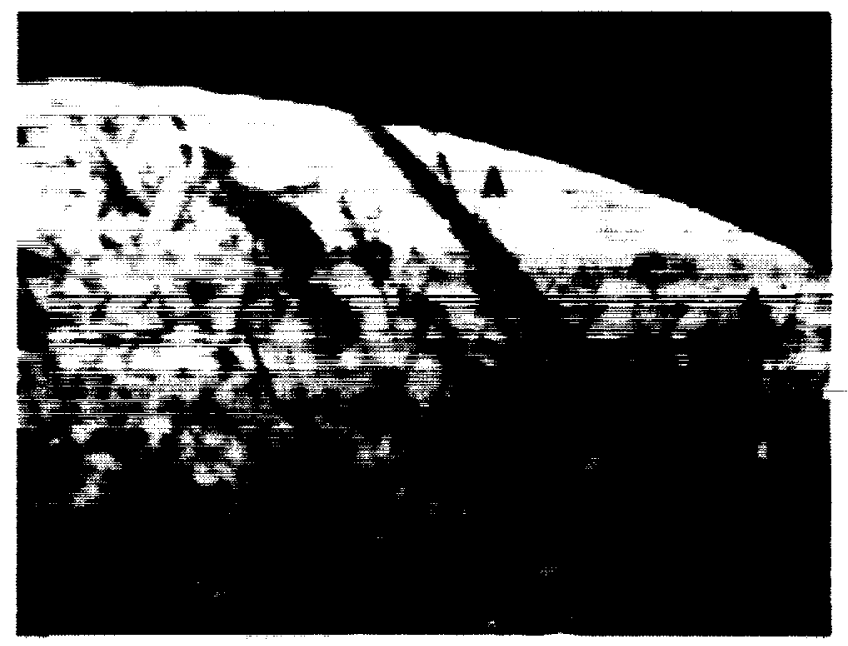

Fig. 1. An optical image using a video microscope of a grain from bed 10 showing multiple (chevron) lamellae suggesting it has been shocked. The long dimension of the image is $380 \mu \mathrm{m}$. 

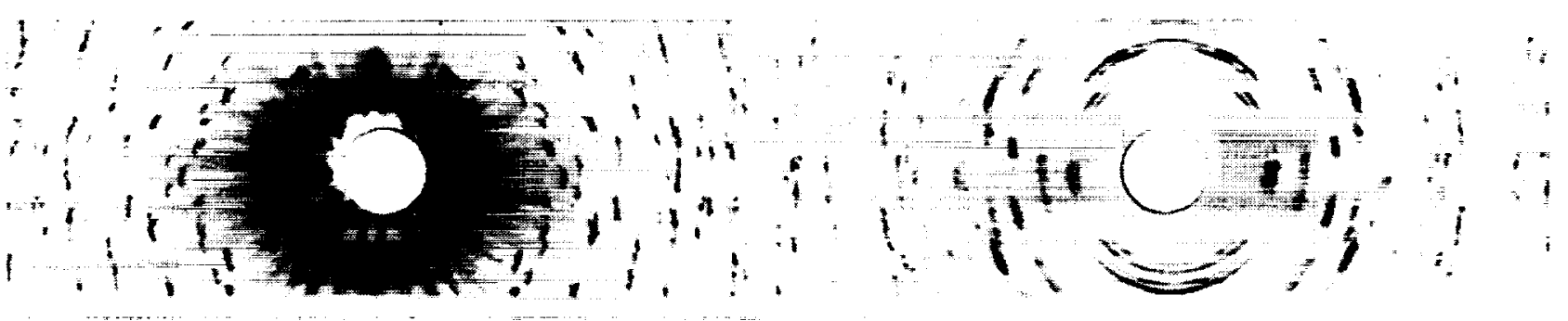

Fig. 2. Debye-Scherrer X-ray diffraction pattem of the grain shown in Fig. I. The asterism (streaking) of the pattem is characteristic of shocked grains.

being approximately equidistant $(\sim 1000 \mathrm{~km})$ from the proposed $\mathrm{KT}$ impact feature at Chicxulub, Yucatan, but placed on opposite sides of the inland sea that existed at that period.

The Braggs KT outcrop was located using Copeland and Mancini's paper [2]. Beds were identified from the locations and lithological descriptions that are stated in the document. All the samples were collected using steel geology picks, chisels, and spades. Descending vertical trenches were excavated for the purpose of obtaining samples from beds $2,4,6$, and 10 . Trenching allowed the sampling of the beds from top to bottom. The samples were stored in plastic bags until they could be transferred into glass jars. Depending upon the type and amount of available sample, $10-300 \mathrm{~g}$ were extracted from the bulk mix of each specimen for examination. Approximately $20 \mathrm{ml}$ of $\mathrm{HCl}$ acid was added to the samples to dissolve carbonate material. Afterward the samples were rinsed with deionized water and air dried. The samples were wet sieved using a 125 - $\mu m$-sized sieve (no. 230). The $>125 . \mu \mathrm{m}$ particulate was air dried and dry sieved with the following sieve sizes: I $\mathrm{m}, 500 \mu \mathrm{m}, 250 \mu \mathrm{m}$, and $125 \mu \mathrm{m}$.

During the first stage of grain selection, a stereomicroscope was used to view the sample in a petri dish that was placed between crossed polarizers. For samples $2-\mathrm{H}$ and $2-\mathrm{G}$ and beds 3 through 5 , the stereoscope functioned well. Quartz grains from the $>1-\mathrm{m}$ - and $>500-\mu \mathrm{m}$-sized samples were easily seen and easy to remove. However, the increased amount of glauconite-filled foraminifera that is present in higher beds such as bed 10, $>250-\mu \mathrm{m}$ samples, affected the locating and extraction of quartz grains. An Olympus $\mathrm{CH}$ polarizing light microscope was used to view the $>250-\mu \mathrm{m}$-sized particulates spread across a wide, flat glass slide. The $20 \times$ objective was beneficial in observing details of small grains as well as assisting in the removal of specific grains. Even with the increased magnification, the amount of glauconite, usually $50 \%$ of the processed sample, and the particulate size prevented, easy observation and isolation of quartz grains in the $>125-\mu \mathrm{m}$ material.

While selecting possible shocked grains, those exhibiting obvious albite and polysynthetic twinning were avoided since they are characteristics of feldspar. Grains containing inclusions, suspected planar elements, and unusual features were isolated and mounted in refractive index oil, 1.544. They were examined with the Olympus $\mathrm{CH}$, and petrological characteristics such as Beckie lines, sign of elongation, interference figure, and morphology were noted. Next, details of the grains were observed with a video camera attached to an optical microscope and coupled to a television monitor. Use of a video system allowed contrast to be manipulated when viewing the grains. A stage micrometer was used to establish a scale for the $10 x$ and $43 \times$ microscope objectives. Grains were photographed from the monitor using a Polaroid camera.
Optical signatures of individual grains that had experienced a shock environment were searched for. These signatures included lamellar features, decorated planar elements, and, in particular, multiple occurrences of these features in a grain. Those grains found by optical microscopy to have characteristics suggesting candidacy for having been shocked were rare $(<0.1 \%$ ) among all grains examined. None of these candidate grains exhibited immediately evident features such as those often pictured in the literature [e.g., 6]. Rather, they usually presented an impression of decorated multiple planar elements and in one case multiple lamellae in conjunction with decorated planar elements (Fig. 1). The paucity of readily evident shocked grains in our samples from the Braggs, Alabama, site is similar to the experience of others who have searched for such grains at the Brazos River, Texas, locations [7].
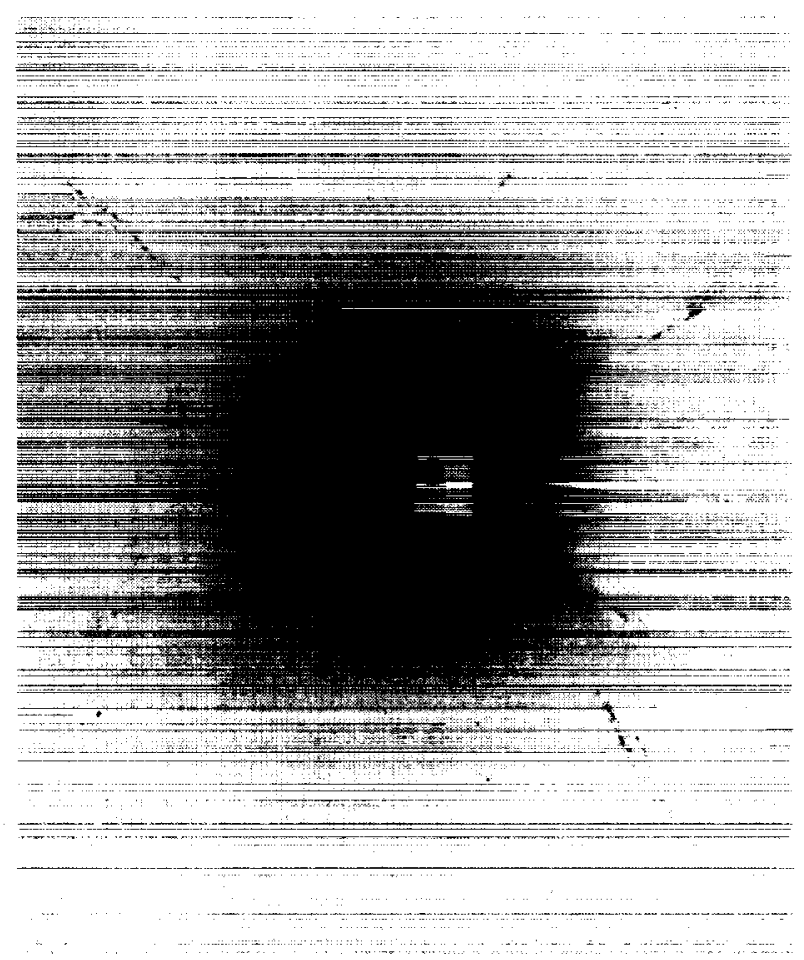

Fig. 3. Synchrotron Laue $X$-ray diffraction pattem of the grain shown in Fig. I. The asterism can be seen to be caused by a multiplicity of diffraction spots that in turm are the product of a disturbed lattice structure in a single grain. 
We have utilized $X$-ray diffraction to examine some of the most provocative grains for evidence of shock metamorphism as has been done by others [6]. This includes Laue and Debye-Scherrer techniques with a $\mathrm{Cu}$ target source, and Laue diffraction using a synchrotron source. Figure 2 shows the Debye-Scherrer pattern, while Fig. 3 is a synchrotron Laue pattem of the grain considered to be our best candidate for exhibiting multiple lamellae most like those seen in the literature. This is the grain also shown in Fig. 1. These diffraction pattems indicate the grain does not have the ordered structure of a grain of quartz that has not been shocked. In the DebyeScherrer pattern there is apparent asterism similar to that shown for KT grains by others [6]. The synchrotron Laue pattem shows clearly what the Debye-Scherrer pattern suggests, i.e., the asterism is composed of a multiplicity of diffraction spots. Our X-ray diffraction pattems of this grain, as well as another candidate grain, indicate them to be highly disordered, which is consistent with their optical appearance, and possible shock metamorphism.

References: [1] Worsley T. (1974) Soc. Econ Paleontol. Mineral. Spec. Publ. 20, 94-125. [2] Copeland C. W. and Mancini E. A. (1986) in GSA Centennial Field Guide, 6, 369-372. [3] Jones D. et al. (1987) Geology, 15, 311-315. [4] Asaro F. (1991) personal communication. [5] Bourgeois J. et al. (1988) Science, 24l, 567570. [6] Bohor B. F. et al. (1987) Science, 236, 705-709. [7] Bohor B. F. (1992) personal communication.

THE FRASNIAN-FAMENNIAN EXTINCTION EVENT: DOMINANCE OF EXTRINSIC OVER INTRINSIC FACTORS IN THE RECOVERY OF REEF COMMUNITIES. G. E. Webb, Paleoecology Research Program and Department of Geology, Texas A \& M University, College Station TX 77843, USA.

Extinction events are recognized in many different ways and may be seen as short-term biotic diversity minima, numerous coincidental extinctions, or decreases in originations. Amounts of community-ecological disruption and resulting lag time before ecosystem recovery have also been important in shaping our perceptions of an event. The Late Devonian Frasnian-Famennian (FF) extinction event provides an example for which the cause, or causes, and duration of the event are controversial [1]. Less controversial is the imponance of an abrupt change in global reef communities at the boundary. Microbes, corals, and stromatoporoids constructed Frasnian shelf edge reefs. It is widely accepted that reef-building corals and stromatoporoids perished during the FF event and that comparable reef communities, and hence, reefs, were not abundant again until the Permian. The intervening, impoverished record of Carboniferous reefs is considered lag time during which reef communities gradually recovered as new constructors and ecological relationships evolved after the FF event $[2,3]$. This intrinsic, evolutionary community recovery was termed erathemic succession [4] and its length, following the FF event, has been used to imply that the event was particularly severe. However, the extended length of upper Paleozoic reef recovery has been attributed partly to subsequent ecologic perturbations caused by external agents [5]. Recent research $[6,7]$ supports this hypothesis and, further, suggests that intrinsic erathemic succession played only a small role in upper Paleozoic temporal reef distribution. Postextinction lag times are inappropriate proxy indicators of extinction severity because they can be subject to subsequent, unrelated, extrinsic controls.
Shelf-edge reefs were globally abundant in the Frasnian but the majority were terminated well before the end of the stage. The remainder were terminated at the FF boundary except for a few reefs with stromatoporoids and corals that survived for a short time into the Famennian [8]. Other reefs survived longer without stromatoporoids and corals [9], and those on the Russian Platform apparently were not affected by the FF event [10]. Hence, the effect of the FF event on global reef communities has been overstated [11]. Additional stromatoporoid-bearing reefs were initiated in the Famennian of Canada [12]. All reefs, except for those on the Russian Platform, ceased growth by the Devonian-Carboniferous (DC) boundary. The DC boundary may be a more important marker for global reef communities than the FF boundary. Lower Toumaisian reefs are known only from Russia [10]. By the middle Toumaisian, deepwater bioherms (Waulsortian mounds) were abundant on ramps, which were the dominant carbonate setting [13,14], and shallow water reefs were known only in eastem Australia [7] and Russia [10]. By the Visean, shallow-water reefs wcre abundant globally on numerous shallow carbonate shelves. Reefs declined dramatically by the early Namurian, however, owing toclastic influ xes onto many shelves and tectonic uplift and regression of epeiric seas. Early Namurian reefs were rare and few reefs, with the notable exception of the Akiyoshi atoll complex of Japan, survived past the Mississippian-Pennsylvanian boundary [7].

Reef communities were clearly set back by events in the Late Devonian, but slow recovery in the Carboniferous was not caused by slow, intrinsic, erathemic succession. Important reef-building microbes, such as those that built Frasnian and Famennian reefs in the Canning and Bonaparte Basins of Western Australia, were available to build reefs as late as the late Visean. New reef-building corals were developing by the middle Toumaisian in eastern Australia. The implication that reef communities did not exist because of the lack or scarcity of preserved reefs is unfounded. Lower Carboniferous bioherm communities, although largely endemic, were not limited by the lack of constructors. Rather, their distribution was tightly constrained by proximate factors, such as local tectono-stratigraphic settings and sea-level sedimentation histories [7]. The global pattern of temporal reef distribution represents a composite of these individual, local histories. However, global ultimate causes are probably responsible for many of the proximate factors, thus lending a global pattern to the composite. The following global factors affected Late Devonian-Lower Carboniferous reef distribution: (1) Abundant, anoxic black shales have been linked with the FF event [15] and imply relative instability of oceanic stratification that may have led to periodic poisoning of shallowwater habitats from the Frasnian to Toumaisian. (2) The development of deeper-rooting trees in the Late Devonian may have increased the rate and depth of soil formation and hence the influx of terrigenous sediment and nutrients to shallow waters [16]. Clastic sediments smother reefs and abundant nutrients favor nonskeletonized fleshy algae over reef-building organisms. (3) The long-term regressional trend toward greater continentality [17] had several adverse affects on reefs. Shallow carbonate shelves were lost through exposure and the influx of terrigenous sediments increased owing to the lowered base level and enlarged area for subaerial erosion. The associated relative change in shallow bathymetric profiles and increased production of mobile, especially oolitic, shoaling sands [18], also adversely affected reefs. (4) Climatic changes associated with the global shift from the Devonian "greenhouse" climate to the mid-Carboniferous "icehouse" climate [17] 
also may have been important because most reef builders appear to have preferred tropical climates. Rapid glacio-eustatic sea-level Nuctuations also may have disturbed some reef communities. (5) The accretion of Pangaea, with resulting tectonism and loss of continental margins, limited reef development in some areas and may have changed global oceanic circulation patterns [19]. (6) Major changes in ocean chemistry, such as the shift from calciteto aragonite-favoring seas at the Mississippian-Pennsylvanian boundary [20], also may have caused perturbations in reef communities.

In conclusion, there is no doubt that a major change took place in global reef communities during the Late Devonian. However, it may be preferable to attribute the change to multiple events rather than to a single FF event. Furthermore, the apparent long recovery time for global reef communities resulted not from the severity of the disruption of the community at the FF boundary, but from a multitude of subsequent, local disruptions. These local disruptions were driven by an extended period of profound, global changes in tectonics, sea level, climate, ocean chemistry, and even the terrestrial biosphere. The intrinsic, evolutionary recovery rate of post-Frasnian reef- and bioherm-building organisms appears to have played only a limited role in the length of recovery. Therefore, extrinsic, environmental factors played a more important role in the recovery and distribution of post-Frasnian reefs than did intrinsic, erathemic succession. The apparent "lag time" before recovery of upper Paleozoic reefs is a poor indicator of the severity of an FF extinction event.

References: [1] McGhee G. R. Jr. (1989) Mass ExtinctionsProcesses and Evidence (S. K. Donovan, ed.), 133-151. [2] Sheehan P. M. (1985) Geology, 13, 46-49. [3] West R. R. (1988) Palaios, 3. 152-169. [4] Copper P. (1989) Mem. Ass. Australas. Palaeonis., 8, 371-385. [5] Copper P. (1988) Palaios, 3, 136-151. [6] Horbury A. D. (1992) Sed. Geol., 79, 117-137. [7] Webb G. E. (1993) Carb. Jur. Pangea, Prog. and Absir., 329. [8] Burchette T. P. (1981) SEPM Spec. Publ., 30, 85-142. [9] Mory A. J. and Beere G. M. (1989) Bull. Geol. Surv. W. Austral., 134, 1-184. [10] Ulmishek G. F. (1988) Can. Soc. Pesrol. Geol. Mem. 14/l, 527-549. [11] Steam C. W. (1987) Geology, 15, 677-679. [12] Steam C. W. et al. (1987) Palaios, 2, 560-570. [13] Ahr W. M. (1989) SEPM Spec. Publ. 44, 203-212. [14] Wright V. P. and Faulkner T. J. (1990) Geol. J., 25, 139-144. [15] Goodfellow W. D. et al. (1988) Can. Ass. Petrol. Geol. Mem. 14/3, 9-21. [16] Algeo T. J. and Maynard J. B. (1993) GSA Absir. with Progr., A-83. [17] Fischer A. G. (1984) Biotic Crises in Ecological and Evolutionary Time (M. M. Nitecki, ed.), 103-131. [18] Wilkinson B. H. et al. (1985) J. Sed. Petrol., 55, 171-183. [19] Stanley S. M. (1988) Palaios, 3, 228-232. [20] Sandberg P. A. (1983) Nature, 305, 19-22.

THE PERMIAN-TRIASSIC OF THE GARTNERKOFEL-1 CORE (CARNIC ALPS, AUSTRIA): ORGANIC CARBON ISOTOPE VARIATION. W. S. Wolbach', D. R. Roegge' , and I. Gilmour'2, 'Department of Chemistry, Illinois Wesleyan University, Bloomington IL 61702, USA, 'Department of Earth Sciences, The Open University, Milton Keynes MK7 6AA, UK.

The extensive study of the Permian-Triassic (P/Tr) boundary sequence of the Gartnerkofel-1 Core, Carnic Alps, Austria, has included detailed descriptions of its stratigraphy [1], mineralogy [2,3], geochemistry of common and trace elements [4-6], and stable $C$ and $O$ isotopes in carbonates $[4,7,8]$. The results of these studies are consistent with gradual sea-level regression, leading to in- creased erosion of organic material and metals $[4,8]$. Oxidation of organic $\mathrm{C}$ in the ocean would lead to oceanic anoxia. A reducing ocean would allow increased accumulation of organic $\mathrm{C}$ and precipitation of metallic sulfides [8]. While organic $C$ abundances have been measured [4], until now no study of organic $C$ stable isotopes has been conducted across the $\mathrm{P} / \mathrm{Tr}$ sequence.

Procedures: Bulk $C$ residues were isolated from a suite of $P /$ Tr sequence samples from the Gartnerkofel-1 Core, Camic Alps, Austria, using the $\mathrm{HCl}$ and $\mathrm{HF}-\mathrm{HCl}$ procedures of Wolbach and Anders [9]. An attempt was made to separate organic from any elemental $\mathrm{C}$ using extended acid dichromate oxidation [9]. The residues were combusted to $\mathrm{CO}_{2}$ for mass-spectrometric analysis, yielding isotopic data, and weights for organic $\mathrm{C}$. Carbon isotope measurements were made on a VG SIRA 24 mass spectrometer using sealed-tube combustion.

Organic C Abundance: The brown color of all carbonaceous residues, the total and rapid disappearance of residue aliquots upon dichromate oxidation, and their $\mathrm{C}$ content ( $1100 \%$ ) were consistent with these residues being composed completely of organic $\mathrm{C}$, with no elemental $\mathrm{C}$ component. Thus all carbonaceous residues from the suite of $\mathrm{P} / \mathrm{Tr}$ samples studied are assumed to be $100 \%$ organic.

Organic $C$ concentration increases sharply $15 \times$ to $4600 \mathrm{ppm}$ in the Triassic (Tr), $8.5 \mathrm{~m}$ above the top of the 6.5 - $\mathrm{m}$-thick Tesero Horizon (TH), thought to contain the P/Tr boundary (Fig. 1a). The organic concentration remains elevated for $1.5 \mathrm{~m}$, then drops back to baseline values. At first glance, the increase in organic $C$ concentration seems to parallel a similarly sharp increase in $S$ concentration ( $S$ data from [5]) (Fig. Ib). Expanded depth scales over the

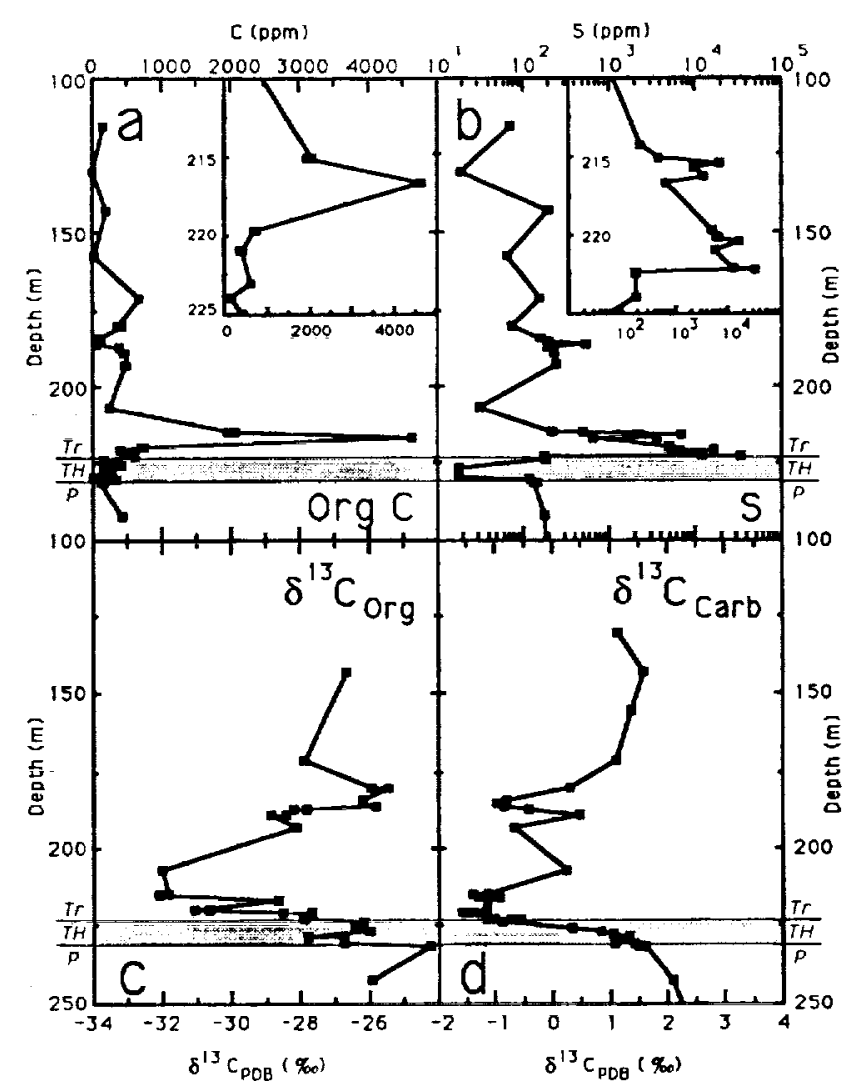

Fig. 1. 
regions of increase (insets in Figs. la, b), however, show that the $\mathrm{C}$ increase actually occurs $5 \mathrm{~m}$ above the first of two $S$ peaks.

The sequence of rocks from $\sim 245$ to $\sim 170 \mathrm{~m}$ represents roughly $3 \mathrm{Ma}$, or $\sim 40,000 \mathrm{yr} / \mathrm{m}$ [8]. Thus the first increase in $S$ occurred $\sim 200,000$ yr before the $C$ increase, assuming constant sedimentation rates. This implies that although more $S$-rich sediments were being deposited, any $C$ that was also being eroded as a result of the regression was being oxidized in the water column and not being accumulated in sediments. The destruction of $\mathrm{C}$ would gradually deplete the ocean of $\mathrm{O}_{2}$, leading to anoxia, elevated precipitation of metallic (and other) sulfides, and the observed increase in preserved oceanic $\mathrm{C}$. That the $\mathrm{C}$ enrichment is likely to be oceanic in origin is supported by the observation that the carbonaceous residues were easily oxidized by dichromate; residual organic matter from land is generally much more difficult to destroy [9]. The second increase in $S$ overlaps the $C$ peak, and thus might represent increased $S$ in organic matter from sulfate reducing bacteria.

Organic $\mathbf{C}$ Isotopes: The isotopic composition of organic $\mathbf{C}$ $\left(\delta^{13} \mathrm{C}_{\text {Org }}\right)$ decreases by $6-8 \%$ in the Triassic, beginning $12 \mathrm{~m}$ above the TH and persisting for nearly $45 \mathrm{~m}$ before retuming to baseline values (Fig. 1c). This isotopic shift falls well within a negative $\sim 4 \%$ shift over a similar stratigraphic interval observed for $\delta^{13} \mathrm{C}$ of carbonate $\mathrm{C}\left(\delta^{13} \mathrm{C}_{\mathrm{Carb}}\right.$; carbonate data from [7]) (Fig. Id). This interval represents $\sim 2 \mathrm{Ma}$.

The start of the negative shifts for $\delta^{13} \mathrm{C}_{\mathrm{Org}}$ and $\delta^{13} \mathrm{C}_{\text {Carb }}$ coincide with the first increase in $S$, corresponding to increased erosion. $\delta^{13} \mathrm{C}$ of organic $C$ is on average $\sim 25 \%$ lighter than that for carbonate $C$. Thus, incorporation of light $\mathrm{CO}_{2}$ from eroded, oxidized $\mathrm{C}$ into forming carbonates and photosynthetic marine species would cause both to become isotopically lighter. Increasing anoxia of the ocean would eventually result in increased preservation of marine organic $\mathrm{C}$ and $\mathrm{S}$. Increased abundances would be expected after the initial isotopic shifts, which is observed.

The increased preservation of marine organic $\mathrm{C}$ would preferentially tie up ${ }^{12} \mathrm{C}$, increasing $\delta^{13} \mathrm{C}$ of carbonates. In fact, the shift of $\delta^{13} \mathrm{C}_{\text {Carb }}$ back to heavier values begins immediately after the organic $\mathrm{C}$ abundance peak. As erosion slows, the supply of eroded $\mathrm{C}$ would decrease and anoxia would diminish. With no light $\mathrm{CO}_{2}$ source, $\delta^{13} \mathrm{C}_{\text {Carb }}$ and $\delta^{13} \mathrm{C}_{\mathrm{Org}}$ would retum to normal.

Recent measurements on the age and duration of the Siberian Traps flood basalts have placed them synchronous with the Permian-Triassic Boundary $[10,11]$ and determined that they were erupted over an extremely short time interval $(900,000+800,000$ yr [ $[10])$. Such large-scale volcanism would have led to substantial quantities of dust and $\mathrm{SO}_{2}$ in the atmosphere with subsequent climate changes that may have caused the global regression and subsequent changes in erosion rates.

To summarize, organic $C$ abundances and $\delta^{13} C_{O_{r g}}$ across the P/Tr boundary seem consistent with the occurrence of sea-level regression leading to erosion, oceanic anoxia, and increased precipitation, events that have been suggested as the cause of other geochemical changes taking place at that time [8].

Acknowledgments: We want to thank R. Schmitt for donating the samples and $\mathbf{J}$. Gibson for making the $\mathrm{C}$ isotope measurements.

References: [1] Boeckelmann K. (1991)Abh.Geol. B.-A., 45 , 17-36. [2] Fenninger A. (1991) Abh. Geol. B.-A., 45, 53-60. [3] Boeckelmann K. and Magaritz M. (1991) Abh. Geol. B.-A., 45, 61-68. [4] Holser W. T. et al. (1989) Nature, 337, 39-44. [5] Klein P. (1991) Abh. Geol. B.-A., 45, 109-121. [6] Attrep M. Jr. et al.
(1991) Abh. Geol. B.-A., 45, 123-137. [7] Magaritz M. and Holser W. T. (1991) Abh. Geol. B.-A., 46, 149-163. [8] Holser W. T. et al. (1991) Abh. Geol. B.A., 45, 213-232. [9] Wolbach W. S. and Anders E. (1989) GCA, 53, 1637-1647. [10] Renne P. R. and Basu A. R. (199I) Science, 253, 176-179. [11] Campbell I. H. et al. (1992) Science, 258, 1760-1763.

\section{ANTARCTICA, THEFORGOTTENSTEPCHILD: A VIEW} OF KT EXTINCTION FROM THE HIGH SOUTHERN LATITUDES. W. J. Zinsmeister ${ }^{1}$ and R. M. Feldmann ${ }^{2}$, 'Department of Earth and Atmospheric Sciences, Purdue University, West Lafayette IN 47907 USA, ${ }^{2}$ Department of Geology, Kent State University, Kent $\mathrm{OH} 44242$, USA.

Considerable hyperbole has been published during the last decade about the great terminal Cretaceous extinction event. With the publication of the impact hypothesis in 1980, a vocal segment of the scientific community and the media has accepted as factual the impact scenario as the primary cause for the extinction at the end of the Cretaceous, and for the dinosaurs, in particular. It is quite evident that a major biotic crisis occurred 64 m.y. ago; but, for many in the geologic community, the cause is far from clear. The discovery of an impact crater that may have formed at the end of the Cretaceous proves only that there was an impact at the end of the Cretaceous. The crater in itself does not provide the final piece of evidence to explain the demise of the dinosaurs or the wholesale loss of life at the end of the Cretaceous.

If the KT extinction event resulted from a cataclysmic impact. the fossil record provides little positive evidence to support this mode of extinction. Virtually all the paleontologic arguments used by proponents of the impact hypothesis are based on either negative evidence, apparent abrupt species disappearance, or untestable models. The scientific method demands that a hypothesis be testable. Thus far, impact proponents have provided little direct evidence that can be tested to support an impact-driven extinction. Where is the layer of burnt and twisted dinosaurs bones? Not one burnt stump has been offered in support of the global forest fires that are alleged to have swept across the Earth, consuming the last of the dinosaurs. For that matter, if a faint Ir enrichment layer can be preserved in marine rocks, where is the associated extirpation layer of ammonite shells and marine reptile bones? If the impact was as catastrophic and as pervasive as portrayed by the impact community, where are the bodies?

Another paleontologic observation that demands to be addressed, but has been ignored, is the well-documented decline in biotic diversity during the Campanian and Maastrichtian. The extinction event has been portrayed by some as though the world simply had a"very bad day."The long decline in diversity during the Campanian' Maastrichtian has been considered to be unimportant or has been ignored. If biotic diversity had remained unchanged until the KT extinction event, the impact scenario would be very appealing; however, the Earth's biota did decline during the Late Cretaceous. To suggest that the decline in diversity is distinct and unrelated to the extinction event verges on special-pleading. Was the Late Cretaceous diversity decline a harbinger of impending global catastrophe? If we are to resolve the cause of one of nature's great catastrophes, we must integrate all available physical and biological data. 
The KT section on Seymour Island, Antarctica, has one of the best, if not the best, marine KT boundary sections known in terms of exposures as well as the occurrence, distribution, and preservation of megafossil faunas and microfloras. The KT sequence exposed in the Seymour Island region provides the only record of shelf and nearshore environments from the continent of Antarctica and data from these deposits provide a unique insight into the effect of events at the end of the Cretaceous on the biota from the high southem latitudes.

Seymour Island is one of several islands in the James Ross Island region on the northeast tip of the Antarctic Peninsula. The sequence on Seymour Island consists of continuous shallow shelf sandstones and sandy siltstones of the Lopez de Bertodano Formation and ranges in age from late Campanian through the Maastrichtian into the Paleocene. Well-exposed sections on the nearby James Ross and Vega islands have increased the Late Cretaceous record in Antarctica back through the Campanian into the Santonian. Although the Seymour Island region was first studied by Otto Nordenskjold's Swedish South Polar Expedition at the beginning of the century, it was not until the mid 1970s that the region began to be systematically studied by scientists from several nations. Although geologists from Argentina and the United Kingdom have been active in the James Ross Island region, only the Americans have focused their efforts exclusively on Seymour Island. Four major stratigraphic and paleontologic field programs were conducted during the 1980s. In 1989, the results documenting the stratigraphic and faunal changes across the KT boundary were published [1]. Although there is a marked change in diversity and composition across the KT boundary, the change is not abrupt, but occurred over a stratigraphic interval of approximately $30 \mathrm{~m}$ and is referred to as the "KT transitional interval." While a number of taxa with stratigraphic ranges extending back to the Campanian disappeared within this interval, other species passed through completely unaffected. No single horizon within the measure section could be termed an extirpation horizon. Microfloral studies from Seymour Island also show a comparable transition across the boundary. Although these data are well documented and important to the understanding of events at the end of the Cretaceous in the southem hemisphere, they have not been addressed.

Of equal interest to the biotic changes at the KT boundary are the longer-term faunal changes during the Late Cretaceous from the high southem latitudes. The Earth's high-latitudes regions are very sensitive to global climatic perturbations. Changes in the diversity and composition of high-latitude faunas and floras may be viewed as the harbinger of impending global events. The Late Cretaceous record of several major widespread groups of marine invertebrates from the James Ross Island region differs significantly from the lower latitudes. The bivalve inoceramids, which were common elements of the late Mesozoic marine community up to the very end of the Cretaceous in the lower latitudes, disappeared in Antarctica during the late Campanian. Belemnites also show a similar pattern, disappearing in the latest Campanian or earliest Maastrichtian in Antarctica while surviving until the end of the Cretaceous in the lower latitudes. The ammonite faunas display what can only be termed a "diversity crash" in the Late Cretaceous of Antarctica. The ammonite fauna is particularly diverse in the middle Campanian with 35 species being reported from the middle part of the Santa Marta Formation. By the Late Campanian the diversity fell to fewer than five species in the lower part of the Lopez de Bertodano Formation, followed by a slight increase in diversity to about 10 species by the middle Maastrichtian, only to decline to 5 species just prior to the KT transition interval. It is important to note that a number of contemporaneous Campanian/Maastrichtian benthic invertebrates do not show comparable diversity changes, suggesting that the ammonite diversity decline was not a result of local environmental changes in the James Ross Island region.

Although the Late Cretaceous paleontologic record from Antarctica is one of the most complete records known, it has been largely ignored. The significant differences in the record from southem high latitudes, such as the transitional nature of the faunas at the KT boundary and absence of an extirpation horizon, indicate that the extinction event at the end of the Cretaceous was not a globally instantaneous event, but occurred over a finite period of time. The diachronous disappearance of several major marine invertebrate groups in the high southern latitudes suggests that the terminal Cretaceous biotic crisis may represent the culmination of a terrestrial event, such as a longer-term period of volcanism, and not to an impact event. Although a major impact event at the end of the Cretaceous was not the primary cause of the Terminal Cretaceous Extinction Event, it may have had a significant effect regionally.

References: [1] Zinsmeister et al. (1989) $J P, 64,731-738$. 


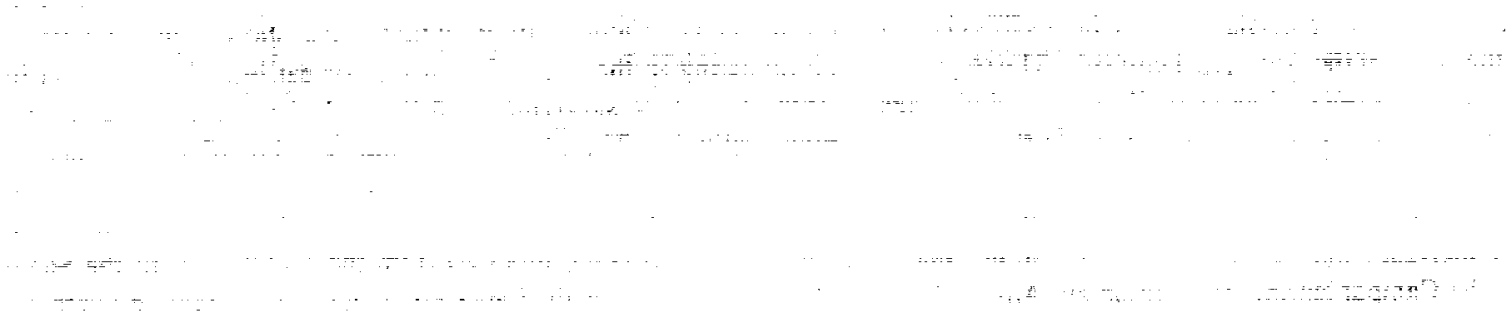




\section{Author Index}

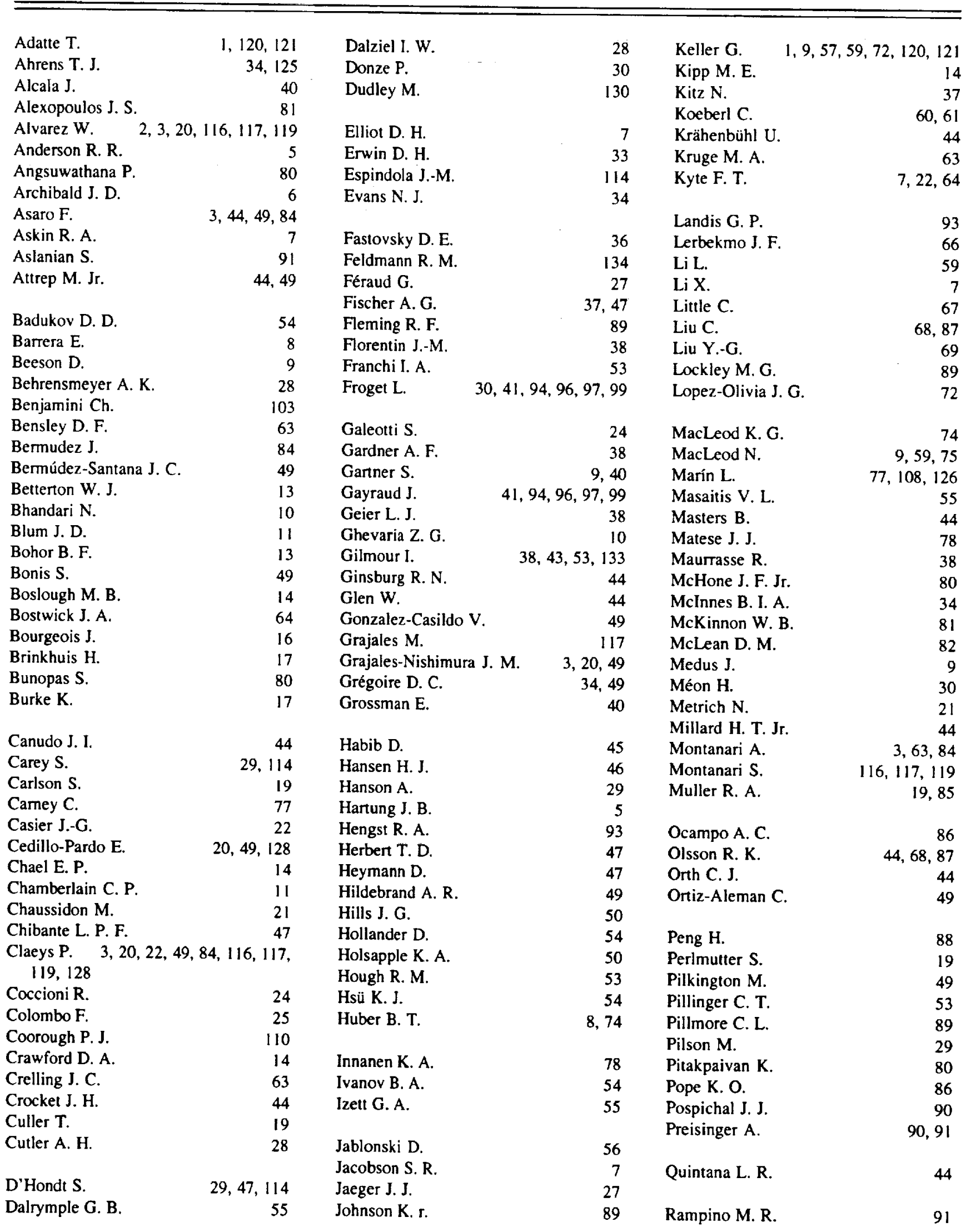




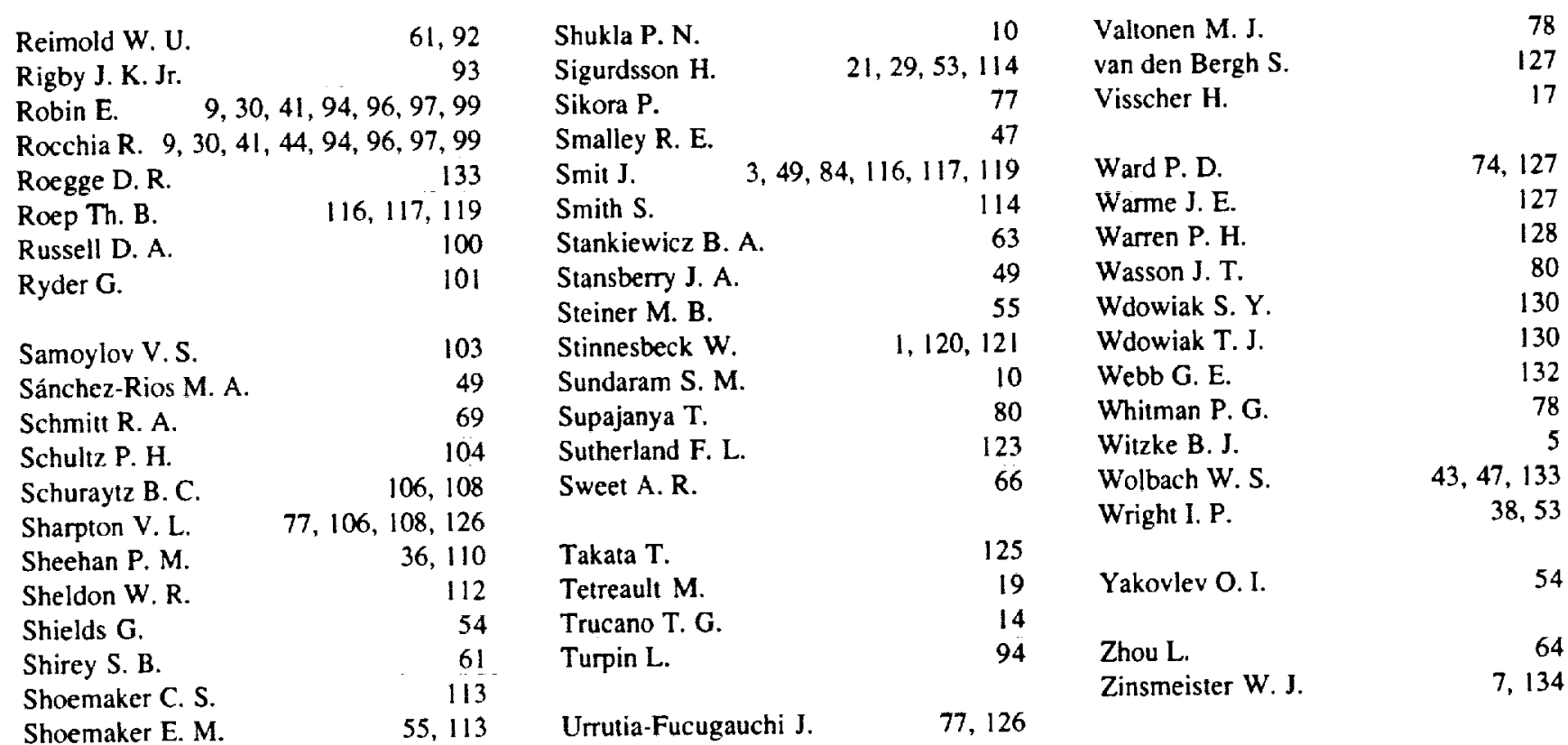

